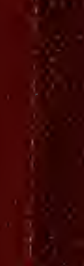




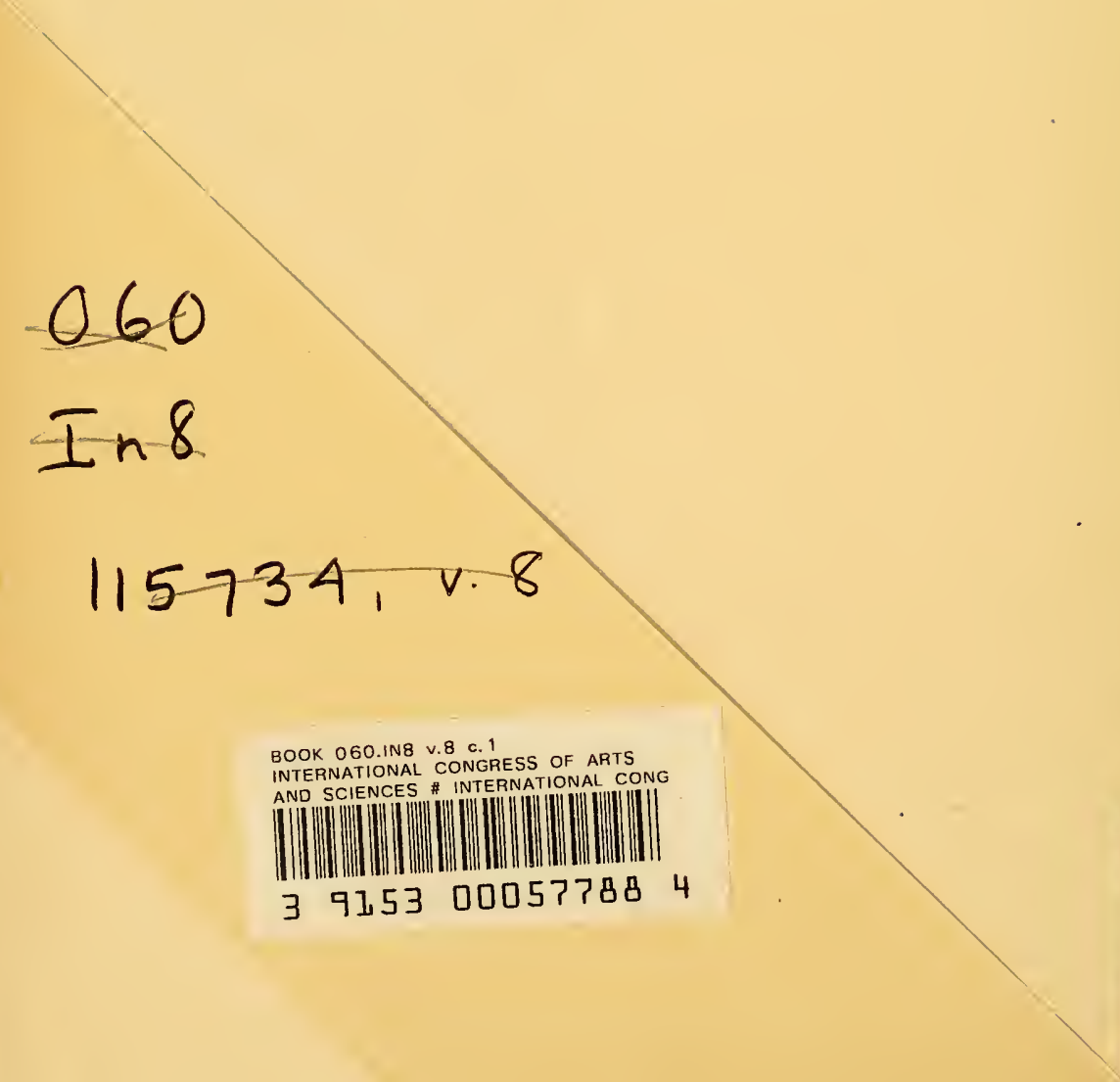





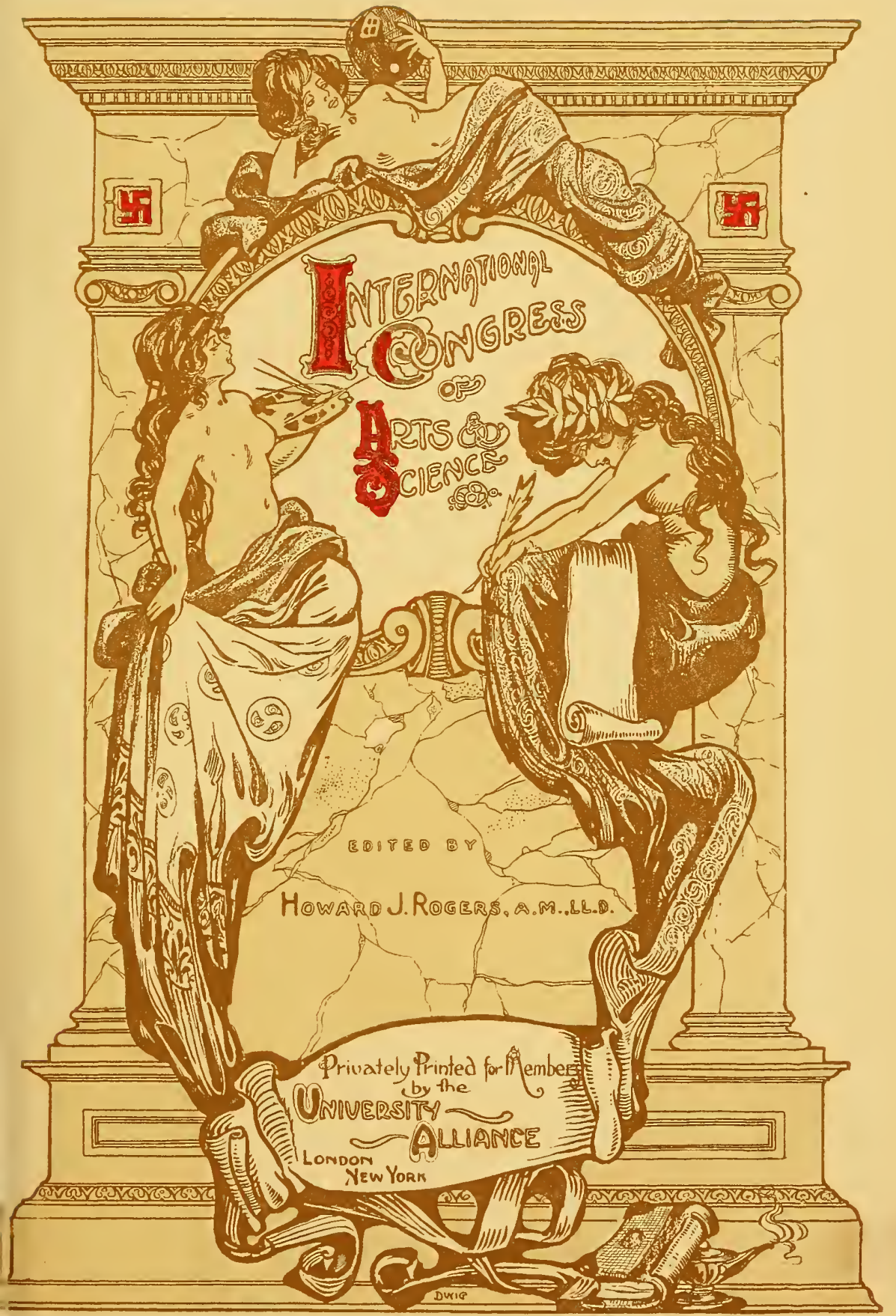



THIS FIRST EDITION DE LUXE, printed from type, is limited to five hundred sets, of which this is copy

$$
\text { No..... }
$$

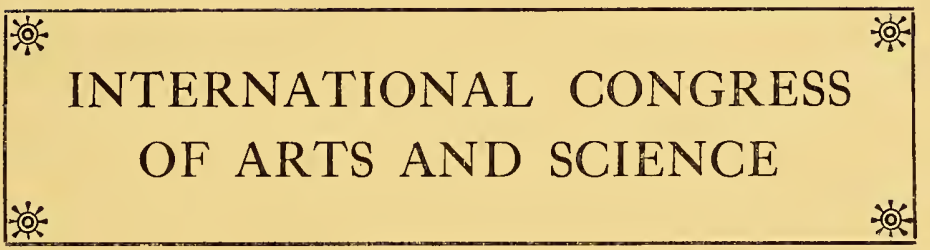


Digitized by the Internet Archive in 2010 with funding from Boston Library Consortium Member Libraries 



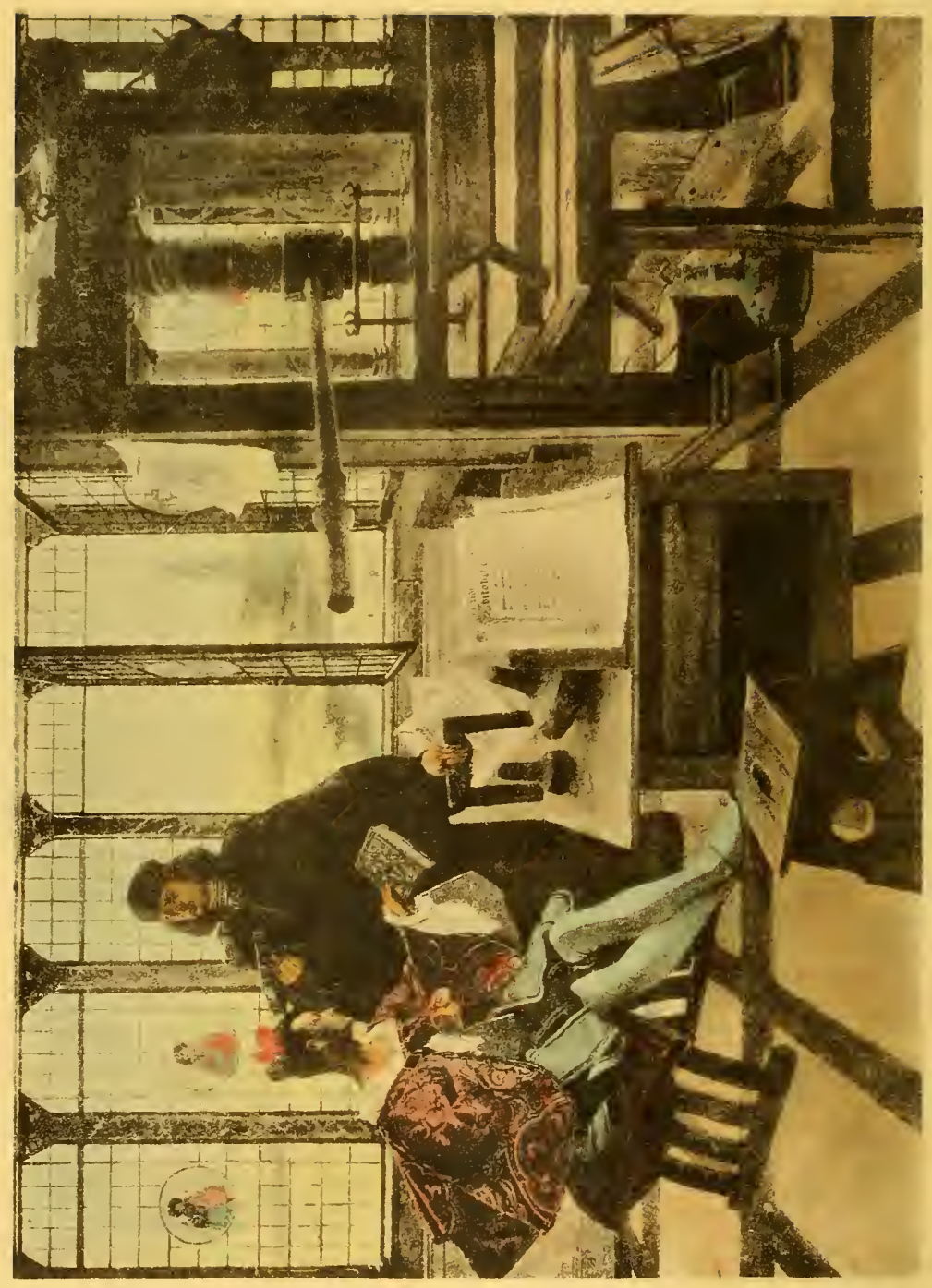




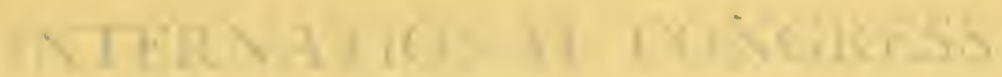

\section{AHTS AN11 GCHACE}

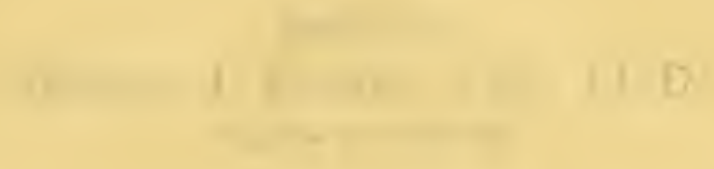

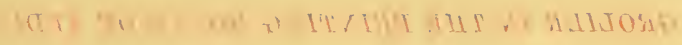

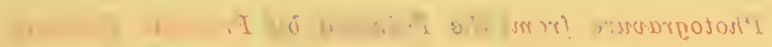

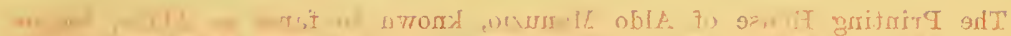

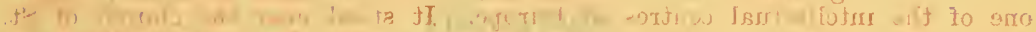

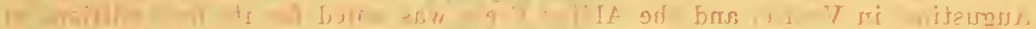

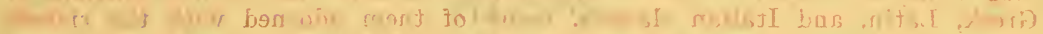

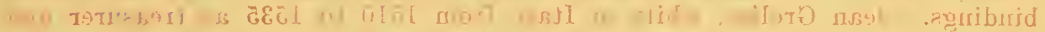

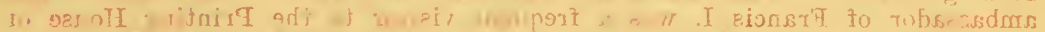

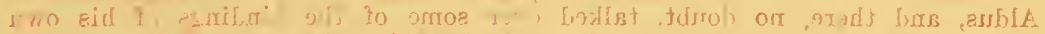

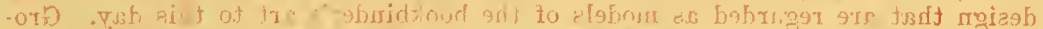

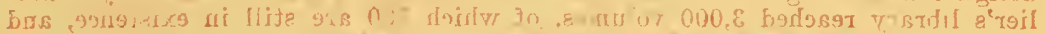

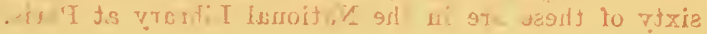

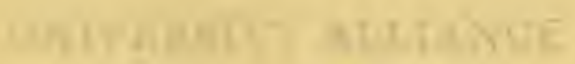 W1 1}




\section{GROLIER IN THE PRINTING HOUSE OF ALDUS}

\section{Photogravure from the Painting by Francois Flameng}

The Printing House of Aldo Manuzio, known to fame as Aldus, became one of the intellectual centres of Europe. It stood near the church of St. Augustine, in Venice, and the Aldine Press was noted for its first editions of Greek, Latin, and Italian classics, many of them adorned with the richest bindings. Jean Grolier, while in Italy from 1510 to 1535 as treasurer and ambassador of Francis I, was a frequent visitor to the Printing House of Aldus, and there, no doubt, talked over some of the bindings of his own design that are regarded as models of the bookbinder's art to this day. Grolier's library reached 3,000 volumes, of which 300 are still in existence, and sixty of these are in the National Library at Paris. 


\title{
INTERNATIONAL CONGRESS OF ARTS AND SCIENCE
}

\author{
EDITED $B Y$ \\ Howard J. Rogers, A.M., LL.D. \\ DIRECTOR OF CONGRESSES
}

VOLUME VIII

EDUCATION

RELIGION

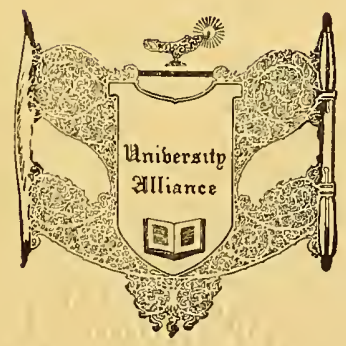

UNIVERSITY ALLIANCE LONDON NEW YORK 


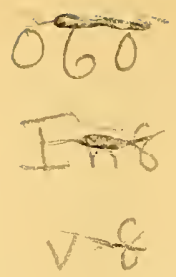

COpyright 1906 by Hovghton, Mifflin \& Co. AJ,L RIGHTS RESERVED

COPYRISHT 1908 BY UNIVERSITY ALLIANCE 


\section{ILLUSTRATIONS}

VOLUME VIII

FACING

PAGE

Grolier in the Printing House of Aldus . . . Frontispiece

Photogravure from the painting by F. FLAMENG

Mental Education of a Greek Youth

Photogravure from the painting by OTto KNILLE

Dr. Arthur T. Hadley . . . . . . . . . 16

Photogravure from a photograph

UNIVERSITY OF EDINBURGH

Photogravure from a photograph

Taking the Doctor's Degre 



\section{ORGANIZATION OF THE CONGRESS}

PRESIDENT OF THE EXPOSITION:

HON. DAVID R. FRANCIS, A.M., LL.D.

DIRECTOR OF CONGRESSES:

HOWARD J. ROGERS, A.M., LL.D.

Universal Exposition, 1904.

\section{ADMINISTRATIVE BOARD}

NICHOLAS MURRAY BUTLER, Pн.D., LL.D.

President of Columbia University, Chairman.

WILLIAM R. HARPER, Ph.D., LL.D.

President of the University of Chicago.

R. H. JESSE, Pн.D., LL.D.

President of the University of Missouri.

HENRY S. PRITCHETT, Pн.D., LL.D.

President of the Massachusetts Institute of Technology.

HERBERT PUTNAM, Litt.D., LL.D.

Librarian of Congress.

FREDERICK J. V. SKIFF, A.M.

Director of the Field Columbian Museum.

\section{OFFICERS OF THE CONGRESS}

\section{PRESIDENT:}

SIMON NEWCOMB, Pн.D., LL.D.

Retired Professor U.S. N.

VICE-PRESIDENTS:

HUGo MÜNSTERBERG, Ph.D., LL.D.

Professor of Psychology in Harvard University.

ALBION W. SMALL, Ph.D., LL.D.

Professor of Sociology in the University of Chicago. 



\section{TABLE OF CONTENTS}

\section{DIVISION G - SOCIAL CULTURE}

Social Culture in the Form of Education and Religion . . . . . . 1

WILlIAM TORREY HaRRIS

\section{DEPARTMENT XXIII - EDUCATION}

Educational Methods and Principles of the Nineteenth Century .

Arthur Twining Hadley

The Development of Educational Ideas in the Nineteenth Century $\quad$. $\quad ~ 27$ John Lancaster Spalding

Section A - Educatronal Theory.

The Place and Office of Pedagogy in the University

WrLhelM REIN

Present Problems in the Theory of Education

Elmer ElLsworth Brown

Short Paper

Section B - The Schoor.

The School in its Relation to Social Organization and to National Life Mrchael Ernest Sadler

Present Problems of the School

Wirliam H. Maxwell

Section C - The College.

The College

Wrlliam De Witt Hyde

The College

M. Carey Thomas

Short Papers 
Section D - The University.

Present Problems of the University 159

Edward Delatan Perry

The Professional Training of Teachers in France 176

Charles Chabot

Section E - The Library.

The Library in Relation to Knowledge and Life

William Edward Armytage Axon

The Library - Its Past and Future.

Guido Biagi

Works of Reference for the Department of Education . . . . . 230

Works of Reference relating to the Section of Educational Theory . $\quad 234$

Works of Reference relating to the Section of the School • • • . 235

Special Works of Reference for the Section of the School . • • . 236

Special Works of Rejerence relating to the Section of the College • • 237

Works of Reference relating to the Section of the Library. . . . . 238

\section{DEPARTMENT XXIV - RELIGION}

The Fundamental Nature of Religion

Henry Churchill King

The Expansion of Religion

Francis Greenwood Peabody

Section A - General Religious Education.

The Reason and the Functions of General Religious Education . 271 George Albert Coe

How may the Teaching of Religion be made potent for Morality? 282

Walter L. Hervey

Short Papers

Section B - Professional Religious Education.

The Teaching of Theology Charles Cuthbert Hall

Professional Religious Education: the Trained Layman .

Frank Knight Sanders

Short Papers . 


\title{
CONTENTS
}

Section C-Religious Agencies'.

Re!igious Agencies.

Washington Gladden

The Press as a Religious Agency

James Monroe Buckley

Short Paper

Section D - Religious Work.

Religious Work

Floyd Williams Tomkins

Elements in Christianity which adapt it to be the Universal and Absolute Religion

\author{
Henry C. Mabie
}

Section E-Religious Influence: Personal.

Religious Influence: Personal

\section{HugH BLACK}

Personal Religious Influence

John Edgar McFadyen

Religious Infuence.

SAMUEl AtKins Eliot

Religion and Personality .

Edward Bagby Pollard

Section F-Religious Influence: Social.

The Educated Man and Social Problems . . . . . . . 430

Joseph SwaIN

The Social Aspect of Religion .

Emil G. Hirsch

The'Secular Life as the Expression of the Religious Spirit

Edward Caldwell Moore

Social Religious Infuence JosiaH StRonG

Worles of Reference for Department of Religion

Works of Reference for the Section of General Religious Education 469

Additional Works of Reference for the Section of General Religious Education 
Works of Reference for the Section of Religious Work _ . . . . 471

Additional Works of Reference for the Section of Religious Work . . . . 472

Works of Reference for the Section of Religious Influence: Personal . . 473 $\operatorname{INDEX}$ • • • • • . . . . . . . 475

CONTENTS OF THE SERIES . . . . . . . . . . . 495 
DIVISION G -SOCIAL CULTURE. 




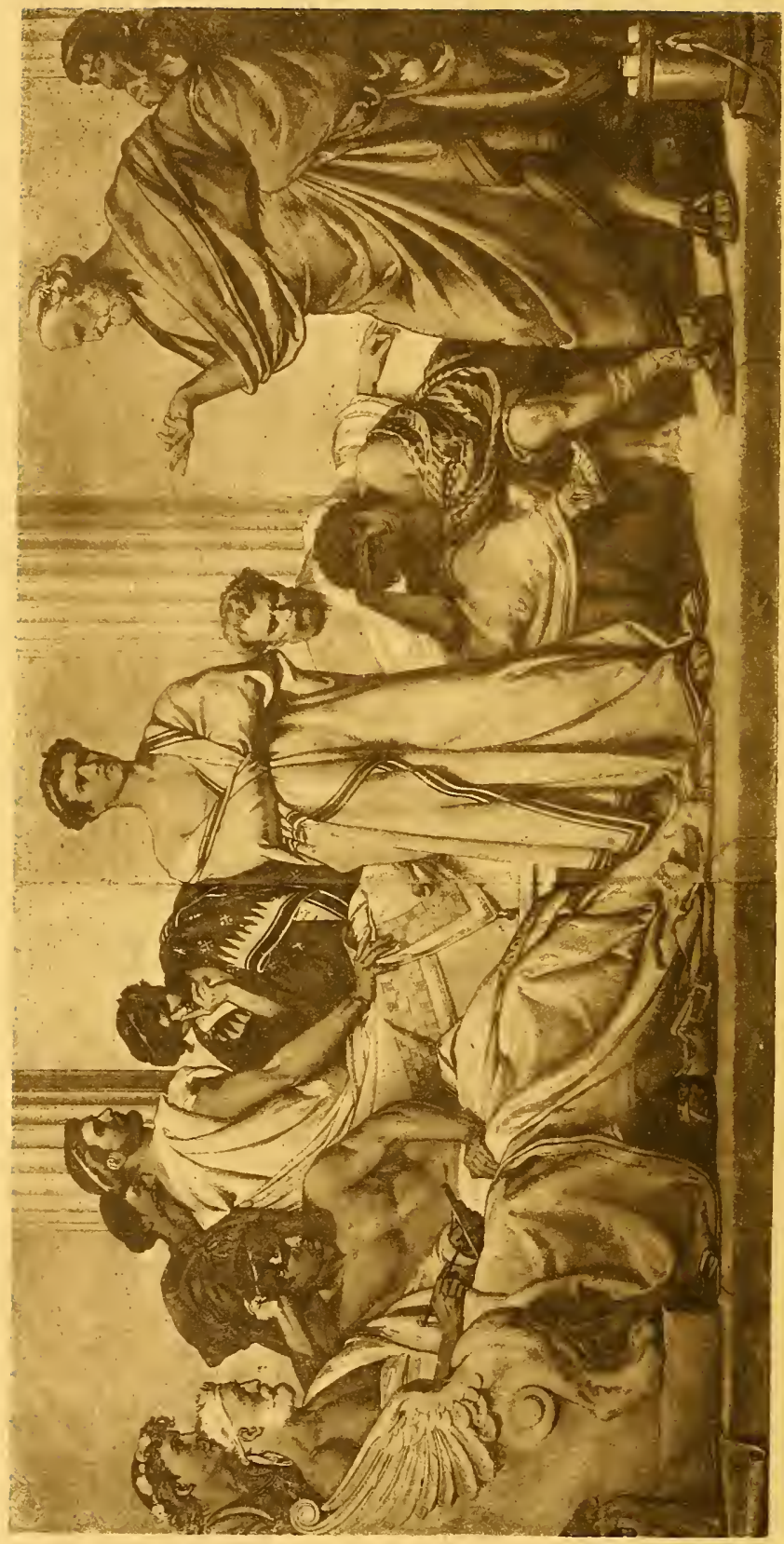





\section{MENTAL EDUCATION OF A GREEK YOUTH}

\section{Photogravure from the Painting by Otto Knille}

Greek youths were carefully trained by educators who gave equal attention to the physical and the mental needs of their charges, severity of ordeal being characteristic of both. The picture opposite is a reproduction of a section of a frieze painted by Knille for the library of the Berlin University, in which by a series of four pictures the artist very admirably depicted the prime features that distinguished the process of Greek education. 


\section{DIVISION G-SOCIAL CULTURE}

(Hall 5, September 20, 10 a.m.)

Speaker: Honorable William T. Harris, United States Commissioner of Education.

\section{SOCIAL CULTURE IN THE FORM OF EDUCATION AND RELIGION}

\section{BY WILLIAM TORREY HARRIS}

[William Torrey Harris, Educator and Commissioner of Education of the United States, since 1889. b. North Killingly, Connecticut, September 10, 1835. A.M. Yale, 1869; LL.D. University of Missouri, 1870; Ph.D. Brown, 1893; LL.D. Pennsylvania, 1894; ibid. Yale, 1895; ibid. Princeton, 1896; Ph.D. Jena, 1899. Teacher, Principal, Assistant Superintendent of Public Schools, St. Louis, 1857-67 ; Superintendent, ibid. 1867-1879. At Paris Exposition, 1878, was tendered honorary title of "Officier de l'Académie ;" represented United States Bureau of Education at International Congress of Educators, Brussels, 1880, and at Paris Exposition, 1889; received from French Government, 1889, title, "Officier de l'Instruction Publique." Member of Washington Academy of Sciences; American Social Science Association; American Philosophical Association. Author of Introduction to the Study of Philosophy; The Spiritual Sense of Dante's Divina Commedia; Hegel's Logic: a book on the Genesis of the Categories of the Mind; Psychologic Foundations of Education. Editor in chief of numerous compilations, notable among which being Webster's International Dictionary of the English Language and International Education Series (55 volumes).]

ACCORDING to the ingenious and suggestive scheme of classification of Arts and Science adopted by the Director and Administrative Board of this International Congress, social regulation forms the sixth division and social culture the seventh division of the entire programme. Social regulation is made to include as sub-topics, politics, jurisprudence, and social science, while social culture includes education and religion. Politics and jurisprudence have to do with the state, while social science is conceived as including for its objects the civil community in its industrial, municipal, and family groups, and in its providential and protective aspects.

Social culture, on the other hand, is the common name or title for the two branches of theory and practice that deal with the selfdevelopment of the individual under the direction of the church and the school.

This is our division, - the seventh and last in the entire scheme of classification, - and it is the topic of this hour's discussion to consider the unity of education and religion. 
I shall announce as my thesis, that: Social culture is the training of the individual for social institutions.

Man by his social institutions secures the adjustment of the individual to the social whole, the social unit. The person or individual comes into such harmony and coöperation with human society as a whole that he may receive a share of all the production of his fellow men, be protected against violence by their united strength, given the privilege of accumulating property and of enjoying it in peace and security in such a manner as to escape from sudden approaches of famine and penury by reason of seasonal extremes or by reason of the vicissitudes of infancy, old age, disease, or of the perturbations affecting the community. And finally, there is participation in the wisdom of the race, the opportunity of sharing in the knowledge that comes from the scientific inventory of nature in all its kingdoms, and of human life on the globe in all its varied experiments, successful and unsuccessful; the opportunity of gaining an insight into the higher results of science in the field of discovery of laws and principles, the permanent forms of existence under the variable conditions of time and place. Finally we may share through our membership in the social unity in the moral insights that have resulted from the discipline of pain, the defeat and discomfitures arising from the choice of mistaken careers on the part of individuals and entire communities. The sin and error of men have vicariously helped the race by great object-lessons which have taught mankind through all the ages, and now teach the present generation of men all the more effectively because of the devices of our civilization, which not only make the records of the past accessible to each and every individual, but institute a present means of intercommunication by and through which each people, each individual, may see from day to day the unfolding of the drama of human history.

The good of this unity of the individual with the social whole by means of institutions may be summed up by saying that it reënforces the individual by the labor of all, the thought of all, and the good fortune of all. It takes from him only his trifling contribution from his trade or vocation and gives in return a share in the gigantic aggregate of productions of all mankind. It receives from him the experience of his little life and gives him in return the experience of the race, a myriad of myriads strong, and working through millenniums.

What Thomas Hobbes said of the blessings of the political whole, the state, is true when applied to civilization as an international combination of states. 
"Outside of the state," said he, "is found only the dominion of the passions, war, fear, poverty, filth, isolation, barbarism, ignorance, and savagery; while in the state is found the dominion of reason, peace, security, riches, ornament, sociability, elegance, science, and good will."

With this point of view we see at a glance the potency of the arts of social culture, fitting as they do the individual for a coöperative life with his fellow men in the institutions of civilization.

\section{III}

My thesis proceeds from this insight to lay down the doctrine that the first social culture is religion and that religion is the foundation of social life in so far as that social life belongs to the history of civilization. Religion in the first place is not merely the process of an individual mind, but it is a great social process of intellect and will and heart. Its ideas are not the unaided thoughts of individual scholars, but the aggregate results of a social activity of intellect, so to speak, each thought of the individual being modified by the thought of his community, so that it comes back to the individual with the substantial impress of authority.

There is a religious social process, the most serious of all social activity. In it the religious view of the world is shaped and delivered to the individual by authority such as cannot be resisted by him except with martyrdom. Each modification in the body of religious doctrine has come through individual innovation, but at the expense of disaster to his life. He had to sacrifice his life so far as his ordinary prosperity was concerned, and his doctrine had to be taken up by his fellow men acting as a social whole, and translated into their mode of viewing divine revelation before it effected a modification in the popular faith. It was a process of social assimilation of the product of the individual comparable to the physiologic process by which the organs of the body take up a portion of food and convert it into a blood-corpuscle before adding it to the bodily structure.

So in the living church of a people goes on forever the great process of receiving new views from its members, and its members include not only the Saint Bernards, but also the Voltaires. The church receives the new views, but does not by any means adopt them until it has submitted them to the negative process of criticism and elimination, and finally to the transforming process that selects the available portions for assimilation and nutriment. This is certainly the slowest and most conservative spiritual process that goes on in civilization. But it is by all means the most salutary. The individuals that suggest the most radical modifications are swiftly 
set aside, and their result is scarcely visible in the body of faith transmitted to the next generation.

It is clear this conservatism is necessary. Any new modification of doctrine gets adopted only by the readjustment of individuals within the communion or church. All the inertia of the institution is against it. Again, it is not only necessary but desirable, because it is a purification process, the transmutation of what is individual and tainted with idiosyncrasy, into what is universal and well adapted for all members within the communion. The church must prove all things and hold fast to that which can stand the test. The test is furnished by what is old, by what is already firmly fixed in the body of religious faith. If its foundations could be uprooted so that religion gave up the body of its faith, all authority would go at once to the ground, and with it the relation of the institutional whole to the individuals within it. Such an event can scarcely be conceived in a realizing sense, but a study of the Reign of Terror in the French Revolution aids one to gain a point of view. When a citizen finds himself in a social whole in which all the principles that have governed the community have become shaky, he gets to be unable to count on any particular set of social reactions in his neighbors from day to day, or to calculate what motives they may entertain in their minds in the presence of any practical situation. He is forced into an attitude of universal suspicion of the intentions of his fellow men, and he is in his turn a general object of suspicion himself. The solution forced on the community is the adoption, by the committee of safety, of death for all suspected ones. But the more deaths the more suspicion. For the relatives of the slain, those who yesterday were with us, but who endeavored to dissuade us from guillotining their parents, brothers, or cousins, - as to those we are warranted in suspecting that they to-day are planning a new revolution and to-morrow may put us to death.

We may by this, after a sort, realize the situation when the foundations of religious belief are utterly broken up.

Fortunately for us our civilization carries with it even under varying creeds, sects, and denominations, the great body of religious belief unquestioned. Only the Nihilists offer a radical denial to this body of Christian doctrine, and we can see how easily we might come to a Reign of Terror if it were possible to spread this Nihilistic doctrine widely among any considerable class of our people. For the Nihilistic view would extend its death-remedy after the destruction of its enemies, to its own ranks, and guillotine its own Robespierres by reason of suspicion and distrust entertained toward one's accomplices.

The substantiality of the view of religion is the basis of civilization. It holds conservatively to elementary notions of an affirmative 
character, such as the monogamic marriage, the protection of helpless infancy in certain fundamental rights, the protection of women, the care for the aged and the weaklings of society, private ownership of property, including under property land and franchises as well as movable chattels. The church includes in its fundamentals the security of life against violence, and makes murder the most heinous of crimes. It insists on respect for established law and for the magistrates themselves. It even goes so far as to protect the heretic and to insure the private right of the individual to dissent from the established or prevalent religious creed so far as church worship or dogmas of theology are concerned. It is obvious that the community as a social whole would be obliged to limit its toleration of private creeds were there a great extension of Nihilism possible or were there to arise sects that attacked the sacredness of the family institution by polygamy, for example, or by the abolition of marriage; or sects that attacked civil society by attempting practically to abolish the ownership of property (Proudhon said: "All property is robbery "); or by the denial of the right of laborers to contract with employers for their labor.

When we study these fundamental ideas common to the different confessions of our composite church, we see at once how powerful is the established doctrine of the prevailing religious ideal in our civilization in exerting an authoritative control over individuals as to belief and practice.

\section{IV}

Many people have come to believe, in this age of greatly extended religious toleration, that the church as an institution is moribund and that its authority is about to disappear wholly from the earth in an age of science, of the ballot-box, and of universal secular education at public expense. It would seem to them that public opinion is sufficient or about to become sufficient by means of the newspaper and the book to secure life, personal liberty, and the peaceful pursuit of happiness without the necessity for a religious provision for social culture. Only the culture that comes from the secular school is adjudged to be necessary for all.

For the proper consideration of this question it is necessary to take up more fundamentally the origin and real function of religion. We shall find two fundamental views of nature and man the foundation of two opposite religious movements in the world's historythe Christian and the Oriental. According to one of these views our free secular life, our science and the arts, our literature and our productive industry and our commerce, are utterly perverse and not to be tolerated on any terms. 
A year ago or more there was published a letter written by an Arab sheik of Bagdad to the editor of a Paris newspaper (La Revue, for March, 1902), in which he expressed admiration for certain external characteristics of European civilization, but found no words bitter enough for his detestation of the Christian religion professed by all European nations. To him it was all a horrible blasphemy. The pure One as preached in the Koran is sovereign and transcendent, and to speak of it as divine-human, or as triune in the Christian sense, is to the Mohammedan an act of unspeakable sacrilege. Therefore, if our triumphs in science and art flow from our religion, the worshiper of Islam must regard them as his mortal foe. ${ }^{1}$ And yet the Arab sheik is much nearer to the Christian view than is the Buddhist or the Brahmin. The East Indian view holds a first principle that repudiates or shuts out from its attributes consciousness and will and feeling - all the elements of personality. But the Allah of the Koran is personal and in an important sense ethical, having the attributes of righteousness and goodness borrowed from the Old Testament by the Hanyf preachers of the Ebionitic sect of Old Testament Christians who proselyted Mohammed, as shown by Sprenger. ${ }^{2}$ But Brahma is above the ethical distinctions of good and evil, and goodness and righteousness are as naught to him and to the Yogi who seeks by mortification to get rid of his selfhood.

'Le Dernier mot de l'Islam à l'Europe, par le Sheikh Abdul Hagk de Bagdad, Paris, La Revue, no. 5, March 1, 1902. Passage translated from the beginning:

"Christian Peoples: The hatred of Islam against Europe is implacable. After ages of effort to effect a reconciliation between us, the only result to-day is that we detest you more than ever. This civilization of yours and its marvels of progress which have rendered you so rich and so powerful, be it known to you, that we hate them and we spurn them with our very souls. ... The Mohammedan religion is to-day in open hostility against your world of progress. ... We explain how it is that we spurn with horror not only your religious doctrines but all your science, all your arts, and everything that comes from Christian Europe. ... I, the humble Sheik Abdul Hagk, member of the holy Panislamistic league, come with a special mission to explain clearly how this comes to be. . . . Our creed is this: There is in the universe one sole being, God, source of all power, of all light, of all truth, of all justice, and of all goodness; He has not been generated; He has not generated any one. He is single, infinite, eternal; alone, He wished to be known; He made the universe, He created man. He surrounded man with the splendors of creation and imposed on him the sacred duty of worshiping Him alone. To worship cbntinually this only God is man's only mission on earth. Man's soul is immortal; his life on earth only a probation; . . . the supreme duty of man to worship the only God and to sacrifice himself to Him without reserve; the sum of all iniquity to renounce the only God and to worship a false God. . . . For us Mussulmans there is a world containing only two kinds of human beings, believers and infidels (mécréants); love, charity, brotherhood to the believers; contempt, disgust, hatred, and war for the infidels. Among the infidels the most hated and the most criminal are those who worship God but ascribe to Him earthly parents, or fatherhood, or a human mother. Such monstrous blindness seems to us to surpass all measure of iniquity; the presence among us of infidels of this kind is the plague of our life; their doctrine is a direct menace to the purity of our faith; contact with them is defilement, and any relation with them whatever a torment to our souls."

${ }_{2}^{2}$ Das Leben und die Lehre des Mohammed, Berlin, 1869, chapter I, pp. 16-27, $37-47,60,69,70-77,101-107$. 
Let us endeavor to find, by the well-known road taken by the philosophy of history, the twofold root of all human experience which gives rise to the religious insights which in their first form of external authority govern human life before the advent of the stage of reflection and individual free thought - religion before secular education.

\section{V}

Examine life and human experience as we may, we find our attention drawn to two aspects, or opposite poles, so to speak, of each object presented to us.

The first aspect includes all that is directly perceivable by the five senses, sight, sound, smell, taste, and touch. This is the aspect of immediate existence.

But experience begins at once to go beyond the immediate aspect and to find that it is a product or effect of outlying causes. We are not satisfied with it as an immediate existence; it now comes to be for us an effect or mediated existence.

If we call the first aspect an effect, we shall call this second aspect a causal process.

Each immediate object, whether it be thing or event, is an effect, and beyond it we seek the causes that explain it. The first pole of existence is, therefore, immediate existence, and the second is the causal chain in which the object, whether it be considered as thing or as event, is found.

Since the causal process contains the explanation of immediate existence, the knowledge which is of most importance is that knowledge which includes the completest chain of causation. It is the knowledge of primal cause which contains the fullness of explanation. And the mind of the human race has devoted itself chiefly to the question of first cause.

In this search, as already suggested, it has been the mind of the social whole of a people that has done the thinking rather than the minds of mere individuals. Even the most enlightened individuals and the most original and capable ones have borrowed the main body of their ideas from the religious tradition of their people, and their success in effecting modifications and new features in the existing creed has been due to the coöperation of like-minded contemporaries which assisted the utterance of the new idea so far as to make it prevail. Again the collisions of peoples settled by war and conquest have brought about new syntheses of religious doctrine, which have resulted in deeper religious insight and more consistent views of the divine nature.

It has been the long-continued process of pondering on the second 
aspect of things and events, the second pole of experience, that has reached the religious dogmas of the greater and greatest religions of human history - a process of social units in which whole peoples have merged.

This process has been a study of the question how the perfect One can be conceived as making a world of imperfect beings. For imperfect or derivative beings demand another order of being, an originating source, as a logical condition of existence. But this source must explain not only the efficient cause of the imperfect, but also the motive of purpose, the final cause or end of the creation of the imperfect being.

There are two great steps which religion takes after it leaves ancestor-worship and other forms of animism, in which disembodied individuals as good or evil demons reign as personal causes in an order above the natural order of things and events which are immediately present to our senses.

As the intellect of man became developed, socially and individually, the great step was taken above all secondary causes to a First Cause transcending nature and also transcending time and space, the logical conditions of finitude and multiplicity.

The transcendent unity, in which all things and events lost their individual being and mingled in one chaotic confusion, is conceived as a great void into which all things and events are resolved when traced to their first principle.

Transcendence was in the first stage of religious contemplation the important attribute to be kept in mind when thinking of the First Cause.

To halt in this thought of mere transcendence of the world meant pantheism in the sense that the One is conceived to possess all being and to be devoid of finitude. It exists apart in an order above all finitude as found in our experience. To deny all relation to finitude comes as a result from this abstract thought of the infinite. It is the nothing of the world of experience and is to be thought of as its dissolution. The philosophy of Kapila in the Sankhya Karika, the religion of both the Yoga doctrines, the Yoga of complete asceticism (of Patanjali) as well as the Karma Yoga expounded in the Bhagavad Gîtâ, reach a One not only above things and events and above a world-order, but also elevated even above creatorship, and above intellect and will, a pure being that is as empty as it is pure, having no distinctions within itself nor for others - light and darkness, the widest distinction in nature, are all the same to Brahma, and so also are good and evil, sin and virtue, "shame and fame," as Emerson names these ethical distinctions in his poem of Brahma, - they are all one to Brahma. 


\section{Theism}

When the social mind had reached this insight of the transcendence of the great First Cause we see that it lost the world of things and events and had annulled one of the two poles of experience which it was attempting to explain. And it had left in its thought only a great negative abstraction, pure being or pure naught, with no positive distinctions, not even consciousness nor the moral idea of ethics, goodness, and righteousness or mercy and justice. It was obliged to deny the creation altogether and conceive the world as a vast dream, a maya.

Asia's chief thought is this idea of transcendence of the one First Cause, above the world and above creation and creative activity. But in the Old Testament we have the last word of Asia; it reveals an insight which reacts against the thought of this abstract oneness as transcendental Being and sets in its place the idea of a creator.

God as creator makes the world, but does not lose his sovereignty by this act. He also retains consciousness, inward distinction; he is personal, having intellect and will and also feeling.

The pantheistic idea which conceived God only as the transcendent One followed its thought out to the denial of all creative activity and even to the denial of all inward distinction of subject and object. It ended its search for a First Cause (following out the causal line which it began with) by denying causality altogether and finding only a quiet, empty being devoid of finitude within itself and annihilating objective finitude altogether. Hence its search ended with the denial of true being to the world and to man.

But this self-contradiction was corrected by the Israelitic people, who felt an inward necessity - a logical necessity - of conceiving the First Cause as active, both as intellect making internal distinctions of subject and object, and also as a free will creating a world of finite reality in which it could reveal itself as goodness. The essence of goodness, in the Old Testament sense of the idea, consists in imparting true being to that which has it not. God creates real beings. Goodness not only makes others but gives them rights; that is to say, gives them claims on its consideration.

While Orientalism with the single idea of transcendence or sovereignty arrived at the idea of a One without the many, and at a consequent destruction of what it set out to explain, theism found a First Cause that could explain the world as created by an ethical being, a personal One that possessed what we call "character," namely, a fixed self-determination of will, of which the two elements were goodness and righteousness. This doctrine conceived ethics as a fundamental element in the character of the Absolute, a primordial form of being belonging to the First Cause. 
Time and space according to the first form of religion - that is to say, according to the first completed thought arrived at by the social intelligence of the race - are illusions and producers of illusions. All illusions arise in the primordial distinction of subject and object which constitutes the lapse into consciousness out of primeval unity which is not subject and object. ${ }^{1}$ This thought of Kapila becomes the basis of the religion of Buddhism, the religion founded on the simple idea of transcendence of the one First Cause above all causality. This is opposite to the religion of the Bible, which reveals the divine as a One that is goodness. Goodness is so gracious as to create and give independent reality to nature and man, in short, to make man able to sin and to defy the First Cause his Creator. Here emerges for the first time the idea of sin. Man, as maya or illusion, is not created nor is he a creator of things or events; his deeds are only seeming, for he does not possess true reality himself. But with the doctrine of theism, man has an eternal selfhood given him and is responsible for the acts of his will; he can sin and repent.

He can choose the ethical and form in himself the image of God, or on the other hand he can resist the divine and create an Inferno.

While theism commands man to renounce selfishness, pantheism commands to renounce selfhood.

Theism contains in it as a special prerogative the possibility of meeting difficulties insoluble to pantheism. It has solved the great difficulty of conceiving a First Cause so transcendent that it is no cause of the world and man. For theism sees the necessity of goodness and righteousness in the First Cause, and hence finds the world and man in the divine mind. But it, too, sees divine sovereignty and does not lose that thought in its theory of man and nature. Nature is full of beings that perish, notwithstanding the fact that they come from a perfect Creator. The history of man is full of sin and rebellion against goodness and righteousness. But our theistic insight knows that God is holy; that he possesses perfect goodness and righteousness. The exclusive contemplation of the imperfections of man and even of his best works leads to the pantheistic denial of the world and to despair as to man's salvation before the sovereign First Cause. The religion of theism often lapses towards Orientalism in its condemnation of nature and history as empty of all good. Whenever it has gone so far that it blasphemes the First Cause by limiting divine goodness, the church has given a check to this tendency and ushered in an epoch of missionary effort, wherein the true believer leaves off his excessive practice of self-mortification and devotes himself, like St. Francis, to the work of carrying salvation to the lost. It goes out like St. Dominic to save the intellect and to have not only pious hearts but pious intellects that devote their lives

${ }^{1}$ Memorial verses of the Sankhya Karika, nos. xxi, xxii, xxiv, lxii, lxiv. 
to the study of the creation, trying to see how God works in his goodness, giving true being to his creatures, and lifting them up into rational souls able to see the vision of God. ${ }^{1}$

\section{VII}

The piety of the intellect contains in it also another possibility of lapse into impiety of intellect, namely, through lack of power to hold to the sovereignty of God. It may go astray from the search of the First Cause and set up secondary causes in place of a First Cause. This is the opposite danger to pantheism, which gets so much intoxicated with the divine unity that it neglects nature and history and discourages intellectual piety and loses the insight into the revelation of God's goodness and righteousness in the creation of the world.

There are two kinds of intellectual impiety, one kind that goes astray after a secondary cause in place of a First Cause, and the other that passes by secondary causes as something unworthy of the true First Cause, not seeing that the true First Cause makes the world with its three orders of being: the lower ministering to the higher and the higher to the lower, - an inorganic below an organic realm, and within the organic realm creating the animal below the man, and among the races of man making savages below civilized peoples. It does not see that in all these divine goodness has its own great purpose - to make the world of time and space an infinite cradle for the development of spiritual individuality. The Christian God is not an abstract One, delighting only in abstract ones, but a Creator delighting in creators, commanding true believers to engage in the eternal work of the First Cause, namely, by multiplying his creative and educative work.

Thus from one or another form of impiety of the intellect there arise collisions with the church from age to age.

A closer and closer definition of the dogma arises out of the struggle.

One of the greatest epochs of struggle in the church arose in the time of the importation of Arabian pantheism into Spain, and thence into the other parts of Europe by reason of resort of Christian youth to the medical schools established by the Arabs.

The great commentators on Aristotle, Avicenna and Averrhoës, came to notice and caused great anxiety by their interpretation of

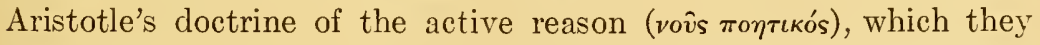
held to exist only in God; and upon the death of the individual, the passive soul or reason (voûs $\pi a \theta \eta \tau \iota \kappa o ́ s$ ), which is conceived by them as a temporary manifestation of the active reason, withdrew, and was absorbed into the deity, losing its individual being.

${ }^{1}$ See Goethe's Faust, "Scene in Heaven" (part II, act v, scene 7), Pater Profundus and Pater Seraphicus. 
To Christianity the doctrine of individual immortality is vital. Without it the world-view of the church would suffer dissolution.

The publication of the pantheistic version of Aristotle forced Christian scholars to study seriously the Greek philosophy. Piety of the heart and piety of the will did not suffice. Piety of the intellect was needed, and it came in a series of thinkers who wrote the expositions of Christian theology of which the Summa theologiae of Thomas Aquinas is the great exemplar. Piety of the intellect overcame the dangers of religious heresy.

After an epoch of rapid philosophical development - a period of a too exclusive devotion to the piety of the intellect - there came a decadence in the piety of the will and the piety of the heart, and when this began to have its visible effects in the neglect of the secular interests of the church a reaction set in, which culminated in the triumph of the pestilent doctrine of nominalism through the dialectic skill of William of Occam, and as a consequence the great philosophy of Saint Thomas of Aquino fell into neglect. But this gave an opportunity for the triumph of the study of secondary causes. Natural science began new inventories of nature and new studies of mind which set forth theories almost mechanical in their results.

With nominalism no speculative investigations into the nature of a First Cause are permissible. All that is left is an empirical study of things and events, - an inventory and a classification, - theories of forces, mechanical composition and decomposition of bodies, the transformation of sensations into ideas. Ideas were regarded as of the nature of mere opinions and of less truth than the sensations which furnish the only vivid certainty esteemed to be of real worth.

There is bound to arise a reaction against religious authority whenever the church itself neglects the exposition of the intellectual insights which are the most vital part of its contribution to civilization. For if the Christian world-view is rendered untenable, the piety of the will and the piety of the heart will soon decay.

A series of skeptical reactions not only against the church, but against the authority of the state, have taken place as a result of this movement away from theology and towards an exclusive study of secondary causes.

The German word Aufklärung, or clearing-up of the mind, has become more or less familiar to us as including the phases of this revolt against authority. It holds to the study of secondary causes and the neglect of the First Cause.

\section{VIII}

There has been only one great Aufklürung, the French Revolution, which swept together all the negative tendencies into one movement of destruction to church and state. But there are numerous, 
very numerous minor movements. In every department its influence is felt:

In the last half of the nineteenth century Herbert Spencer occupied, and still occupies, much attention. It is interesting to note that in his generalizations of science he adopted the agnostic view of his system from Hamilton and Mansell. Back of that view is Hume's skepticism especially with regard to the category of causality, and it would not be difficult to trace his extreme nominalism to the stream of influence that William of Occam set flowing within the church.

Herbert Spencer's theory of the world resembles in a marked manner the doctrine of the Oriental mind that the world-process finally comes to nothing. One after another, things and events appear and then vanish again and all remains as at first. ${ }^{1}$ It is a Sisyphus movement with no permanent outcome and no worthy result. It begins with the homogeneous, undifferentiated condition of matter and moves towards heterogeneity, individuality, and complexity of function. Evolution is this process of individualization. But all evolution is to be followed by dissolution, a return to the chaotic and unindividualized state of the homogeneous which Spencer considered to be unstable and, so to speak, impelled to evolution, but which in the end becomes unstable again and seeks its equilibrium in chaos.

One of the chief leaders of the Aufklärung has thus returned to Orientalism, and his infinite and eternal is only an unknown and unknowable power - he calls it "unknown and unknowable," though he lets us clearly see that there is a shuttle motion produced

1 " Evolution," says Spencer, in that concise statement of his system found in his Autobiography, vol. I, pp. 650-652, "Evolution . . . is a movement (6) not simply from homogeneity to heterogencity, but from an indefinite homogeneity to a definite heterogeneity; and this trait of increasing definiteness, which accompanies the trait of increasing heterogeneity, is, like it, exhibited in the totality of things and in all its divisions and subdivisions down to the minutest. (7) Along with this redistribution of the matter composing an evolving aggregate, there goes on a redistribution of the retained motion of its components in relation to one another; this also becomes, step by step, more definitely heterogeneous. . . . (13) Dissolution is the counter-change which sooner or later every evolved aggregate undergoes. Remaining exposed to surrounding forces that are unequilibriated, each aggregate is ever liable to be dissipated by the in crease, gradual or sudden, of its contained motion; and its dissipation, quickly undergone by bodies lately animate, and slowly undergone by inanimate masses, remains to be undergone at an indefinitely remote period by each planetary and stellar mass, which since an indefinitely distant period in the past has been slowly evolving, the cycle of its transformations being thus completed. (14) This rhythm of evolution and dissolution, completing itself during short periods in small aggregates, and in the vast aggregates distributed through space completing itself in periods which are immeasurable by human thought, is, so far as we can see, universal and eternal each alternating phase of the process predominating, now in this region of space and now in that, as local conditions determine. . . (16) That which persists, unchanging in quantity but ever changing in form, under these sensible appearances which the Universe presents to us, transcends human knowledge and conception, - is an unknown and unknowable Power, which we are obliged to recognize as without limit in space and without beginning or end in time." 
by it out of chaos into individuality and from individuality back again into chaos.

A creative goodness which lifts into being an infinity of other selves of animals and men, only to swallow them up again by a jealous reaction, drawing them down into the homogeneous ocean of chaotic matter, deserves rather to be called, as Plato in the Timaeus and Aristotle in his Metaphysics called it, envy and jealousy ( $\psi \theta 0$ ós), a quality of mind which they thought not possible to find in the idea of God as Creator.

The only effective counter-movement against the Aufklärung is the return to a study of the First Cause.

This does not mean the neglect of secondary causes, but their proper adjustment. It is an application of the great results of religious thought - a social institutional kind of thinking that should be gone over by every individual for his enlightenment. The church should elaborate its application of the thought of the First Cause to all secondary causes, showing in each case how the divine goodness connects and explains the entire movement from the mechanical to the chemical, and from these to the crystal, the plant, the animal, and to man.

\section{IX}

I review, in concluding my paper, the line of argument based on the second or causal aspect of experience:

(1) The first religious step is taken when all secondary causes are aggregated into one group and included in the world-order, in what we have called the first pole of experience. Ancestor-worship with its infinite series of finite spirits belongs only to a world-order. A true originating causality, a first cause, belongs to a second and higher order, to a self-determining or originating order of being which transcends the world of things and events; all things and events depending upon a being derived from beyond, and not in themselves possessing self-existence; and the true second order possessing independence, self-existence, and the power to produce duality by consciousness, will, or some other form of self-determination.

(2) The first thinking of this transcendent being becomes absorbed in the contemplation of its transcendence, or its sovereignty over the first order. While the first order is dependent and must derive its support, all that it has, from a higher order of being; the second order is independent and can exist by itself. The religious contemplation is absorbed in this fact of independence or transcendence; it searches the origin of the dependent order in the sovereignty of the independent order; but it does not find at first, in the independent, the motive for the dependent. It halts in the thought of transcend- 
ence and denies reality to the world of things and events; it becomes pantheism or Orientalism; it denies creatorship in the first principle.

(3) The result of the first insight into the presupposition of dependent being has reached an independent being which is devoid of true causality and which does not impart its true being to a derived world; this is pantheism. But, again, this result contradicts the presupposition on which the insight into the second order is based. For unless there is presupposed a true originating causality, a selfdetermining One, the higher order of being exists only in itself and not for itself; its causality is not real to itself; if its causality produces only a world of phenomenality and illusion, then the result of its causality is only to reveal to the independent being its own inefficiency as a cause; it is a cause which cannot produce anything real, hence it is not a true cause.

(4) The history of the religions of Asia is a history of the discovery of the self-contradictions of pantheism - of a true causal being which does not truly cause. It is also a series of attempted solutions to introduce true causality without destroying the transcendence or sovereignty of the First Cause. For to introduce any finite motive, that is to say, any motive depending upon another underived being, would destroy the perfection of the first original cause and reduce it to a secondary cause and thus throw back the entire investigation to the stage of ancestor-worship. The escape from this dilemma, which offers a choice between the destruction of the imperfect world and the destruction of the perfect world, $i$. e., its renunciation by philosophic thought, is found in the doctrine of the Logos and its complete exposition in the Christian doctrine of the Trinity.

(5) True causality is the self-revelation of the highest order of being. But it does not in its pure self-determination reach secondary causes. Its action in itself is the revelation of a perfect in a perfect; this is the doctrine of the Logos. Perfect self-determination results in perfect revelation in another, an eternal object becomes an eternal subject whose thinking and willing are one, and hence goodness and righteousness. Through this thought it is explained how the primary causality in the Logos becomes secondary causality through the contemplation of goodness and righteousness as the inner essence of causality.

(6) The Christian view of the world, therefore, does not compromise its idea of the transcendency or sovereignty of the First Cause, but preserves it perfectly and at the same time introduces transcendency into the world-order by the doctrine of the immortality, freedom, and responsibility of the human soul who, through religious insight, interprets the entire world-order as a process of creation and salvation; the process of creating souls with inde- 
pendent individuality and infinite powers of self-development in will and intellect, in goodness and righteousness. Consciousness proceeds through science and philosophy and theology everlastingly towards a completer comprehension of the divine method of creation of real being, that is to say, of moral beings through the inorganic and the organic processes in time and space and through the discipline of moral beings by means of their historic experience of life. This development of consciousness makes possible the coöperation of the human will with the divine will. This is the ultimate cause presupposed by secondary causation. It is the second aspect of experience in its fullness and perfection.

(7) This view of the world elevates it into the highest significance, not through its secondary causes, but through its first cause as the divine self-activity in its goodness and righteousness. It is infinite grace.

(8) This view of the world makes secondary causes significant in the light of the First Cause. It makes the history of nature thus interpreted a part of the book of divine revelation.

(9) With the pantheistic interpretation the divine purpose disappears from the realm of secondary causes, and with this there vanishes all true causality and high significance to science. For the objects of science, namely, material nature and human history, when separated from the divine and devoid of a share in the causal activity of a transcendent being who is a real cause, become a chaos or illusion, the East Indian maya.

(10) In the ruder forms of religion, the varieties of ancestorworship and fetichism, science has no place, because all secondary causes become capricious activities of spiritual beings not subordinated to a first principle of goodness and righteousness.

(11) It follows from these considerations that social culture in the form of the church and the school as independent institutions becomes possible only on the basis of the religious world-view of Christianity; and that the perennial continuance of the world-view of Christianity through the special form of social culture which belongs to the church is a necessary condition presupposed by the forms of social culture intrusted to the school. 



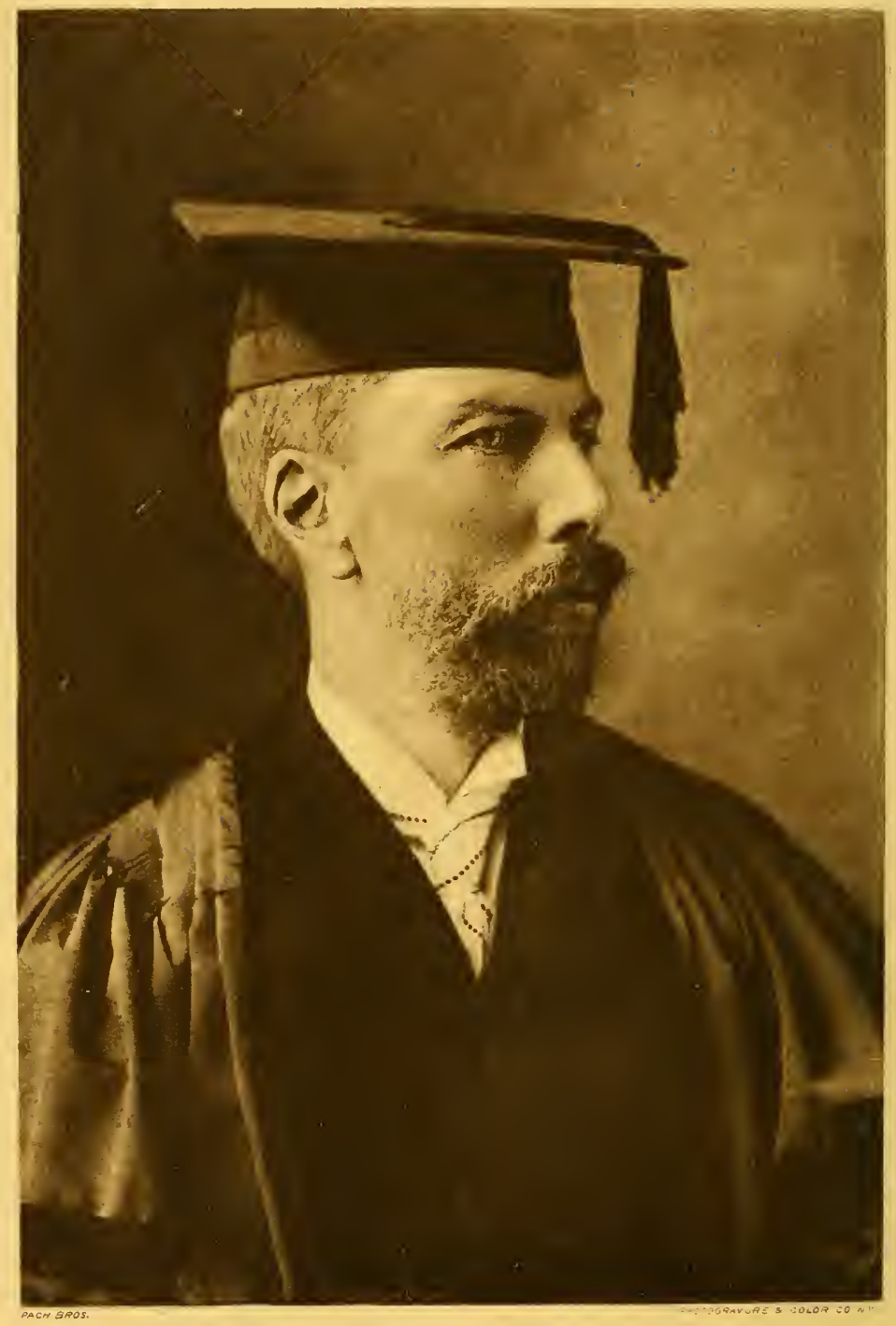




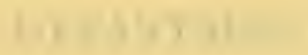

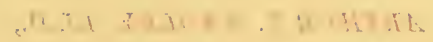

H.

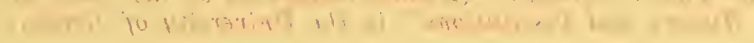


ARTHUR T. HADLEY, LL.D.,

President of Yale University. (Second incumbent of the Chair of "American History and Institutions" in the University of Berlin.) 
DEPARTMENT XXIII-EDUCATION 



\title{
DEPARTMENT XXIII - EDUCATION
}

\author{
(Hall 2, September 20, 4.15 p.m.)
}

Speakers: President Arthur T. Hadley, Yale University.

The Right Rev. John L. Spalding, Bishop of Peoria.

\section{EDUCATIONAL METHODS AND PRINCIPLES OF THE NINETEENTH CENTURY}

\section{BY ARTHUR TWINING HADLEY}

[Arthur Twining Hadley, President of Yale University. b. New Haven, Connecticut, April 23, 1856. B.A.Yale, 1876; LL.D. Harvard, Johns Hopkins, Columbia, et al.; Post-graduate, Berlin, 1878-79. Commissioner of Labor Statistics of Connecticut, 1885-87; Professor of Political Science, Yale, 1886-99; one of the original members of the International Institute of Statistics; lately President of the American Economic Association. Author of Railroad Transportation; Economics; Education of the American Citizen; Freedom and Responsibility. American Editor-in-chief of Encyclopcedia Britannica.

THIs is hardly the time or the place for a discussion of the general theory of education. The subject is too broad to be handled in forty minutes, too abstruse to be made the theme of a popular address. It will, I think, serve our purpose better if in place of any such general discussion of educational principles and methods we content ourselves with seeing what has been most distinctively characteristic in the principles and methods of the nineteenth century as contrasted with those of the ages which have preceded.

A feature that has distinguished that century, in almost every department of human affairs, has been its emphasis on the rights and powers of the individual. We have seen a growth of individual liberty in politics and economics. We have witnessed a development of individual methods in science and in art. In all the varying fields of human activity we have tried to give each man the chance to form his own conceptions of happiness and success and pursue them in his own way. It was inevitable that the same tendency should have shown itself in our educational ideals and methods. Where earlier centuries strove to establish types of character or of thought or of conduct, and make individual boys and girls conform to these preconceived types, we have tried rather to take actual boys and girls, actual men and women, and make the most of their several capacities. Psychologists, with methods as diverse as Froebel on the one hand and Spencer on the other hand, had agreed in this cardinal principle of educational theory. Practical organizers 
the world over, from Horace Mann at one end of the century to Levasseur at the other, however different the problems with which they had to deal, shaped them toward this common end. We came to regard the development of the individual as the goal of education. Some of us have even come to regard it as an axiomatic and selfevident goal; to be surprised that people in other times or countries could have sought other ends than this; to misjudge the educational systems of the past on account of their failure to conform to nineteenth-century standards. Many a writer on education is prone to treat the schools of previous ages as though they represented a very bad attempt to do what we are doing to-day, instead of a tolerably good attempt to do something totally different.

Let us see, if we can, how this pursuit of individual development manifests itself in different kinds of schools at the present time. We may well begin with the matter of professional training. This is the field of education where the aim is plainest. This is where the variety of the problems is least. This is, therefore, the point where we can see the distinctive features of the school system of any age or country most sharply exemplified.

The first difference that strikes us in the new professional training as compared with the old is the vastly greater amount of time which is accorded to it and of emphasis which is placed on its importance. In earlier ages there was no well-developed system of technical schools except for the three so-called learned professions - clerical, legal, and medical; and even in these callings the student obtained most of his real training in the actual experience of the office or the forum rather than in the preliminary work of the classroom. To-day all this has changed. In the learned professions what was formerly a brief and somewhat profitless course of study has been greatly extended in length and animated by new life and new methods. Preparation for medicine, for instance, involves not only a longer course of study in the medical school than it once did, but a time of combined study and work in the hospital, which is now recognized as an essential element in thorough training. In other professions, like the different departments of engineering or technology, special schools of a character hardly known at the end of the eighteenth century have multiplied themselves during the nineteenth until they have become more numerous and more largely attended than the old schools of theology or law or medicine. The soldier has learned that he cannot despise the theory of his trade; and this has led to the establishment, first in France and then in other countries, of military or naval academies of a high order. The success of these schools in training military engineers has led to the establishment of other colleges of engineering for men who intended to apply mathematical science to the arts of peace rather than of war. From these 
engineering colleges it was but a step toward the establishment of technological instruction in every line where a profound knowledge of physies or chemistry is necessary to fit a man for the most successful prosecution of his work. We have seen the establisnment of schools of art in its various forms. We have in more recent years witnessed the extension of the principle of professional education so as to afford training for the more purely mechanical pursuits which involve no profound knowledge of mathematics or chemistry and no long-continued or exhaustive study such as is necessary for the pursuit of art or letters; schools which take people who are under the necessity of earning a living and have little time to spare in education, in order to give them, in this little time, the opportunity to earn that living more honorably and more successfully.

And this brings us to another point which distinguishes the professional education of the nineteenth century from that which preceded it. I refer to the character of the modern technical school as a place where the individual learns to achieve success. The earlier professional colleges were occupiad with the creation and maintenance of standards of thought and of conduct rather than with the practical end of fitting the student for his lifework. The old-fashioned school of theology was chiefly concerned to uphold orthodox traditions and to maintain a spiritual atmosphere favorable to the perpetuation of such traditions. Nor was the old-fashioned school of law or medicine very different from this. The student was brought under the influence of a code of professional ethics which helped to uphold the dignity of his calling. If the teacher could inspire the pupil with this class spirit and these special standards of honor inherited from past ages, it was regarded as somewhat immaterial whether he taught him anything else. Not a few of the scientific teachers of past centuries have made it their boast that they never did anything so commonplace as a dissection or an experiment in their classrooms. To-day the case is far different. We no longer seek to maintain standards; we seek to accomplish results. We try to fit the pupil to do something. If our ideals are high, we wish to enable him to do something to benefit his fellow men. If they are a little lower, we teach him to do something which will increase his reputation. If they are on that low plane which always characterizes a certain proportion of our professional teaching, we are chiefly concerned to prepare him to make money. But whether its purpose be high or low, the nineteenth-century technical school, whether for learned professions or unlearned, is occupied to an overwhelmingly large extent with the teaching of things which will lead each man to accomplish tangible success for himself; and most of them have let the duty of maintaining public standards sink somewhat into the background. 
Less definitely perhaps, but still quite clearly, we see the same change of character in our colleges and secondary schools. In the place of a common course of study adapted to meet real or supposed public needs, we have witnessed the gradual development of elective courses intended to meet individual wishes at the moment or individual necessities for the future. We no longer lay our emphasis on developing that general attitude of mind toward intellectual questions which made the gentlemen or the scholars of the past. We are concerned rather with developing many kinds of education to suit the needs of many types of intellect and calling. The oldfashioned idea of scholarship as an end of secondary education has given place to the modern idea of science. Where the old-fashioned course made masters of arts, the modern course looks upon doctors of philosophy as its bright consummate flowers. We try to educate our college students as intellectual producers and not as intellectual consumers. I hold no brief for the old system. I shall not undertake to consider how far the great and unquestioned gain in private efficiency which has attended this change is offset by any loss in public advantage. It is sufficient to point out the difference of point of view which the change connotes, a difference which has manifested itself not in America alone, but in England and France and Germany and in every country where the old traditions of university and college life are being modified under the influence of modern theory and practice.

At the beginning of the nineteenth century a boy's course of study in the high school or the college was not determined by his individual aptitudes; it was determined almost entirely by his social standing and social aspirations. If he belonged to the trading class, he received one sort of education; if he belonged to the military class, he received another sort; if he belonged to the professional class, he received a third sort. The collegiate education one hundred years ago was based chiefly upon the supposed needs of this professional class. Whether it was obtained in the Lycée of France or the gymnasium of Germany, the public school of England, or the college of America, it gave the student a large amount of training in Latin and Greek, a somewhat smaller amount of training in mathematics and moral science, and practically no training at all in modern languages or natural and physical science. Save for the fact that it involved a good deal of hard work and enabled the teacher to know whether the pupil was really doing his work or not, this course had little practical bearing on the needs of the individual. It served rather as an initiation into the learned society of which that individual was to be a member. It stamped the professional man, or the gentleman who expected to associate with professional men, as a scholar; as one who had gone through those distinetive rites which allowed a man 
to enter the mysterious portals of learning. The degrees or certificates which were obtained in the prosecution of this course of study were, as a French critic well says, social rather than pedagogical institutions.

To-day all this has changed. This change has gone further in America than in Germany, and further in Germany than in England or France; but in every one of these countries, in greater or less degree, there has been an alteration in the underlying principle and object of college training. When class lines in business broke down, as they did at the close of the eighteenth century, it was no longer possible to maintain in their former rigidity class lines in matters of education. When careers were thrown open to ability instead of being determined by birth, each man was anxious to have the ability of his children developed instead of remaining content with those traditional studies which had once seemed a birthright and a class privilege. So long as one parent had to send his son to a college and another to a military school or else let them go altogether without education, each perforce took whatever the college or school chose to give. But as soon as he had the opportunity to select the kind of education which seemed best fitted for his son's needs, each group of schools was in a measure brought into competition with the others, and was compelled to arrange its course of study to meet the desires of the parents. We find in the progress of the nineteenth century a growing interaction and mutual influence exercised by schools and colleges of different classes upon one another. The German gymnasium and the German Realschule have not preserved the sharp distinctions which characterized them of old, but modifications and combinations have been introduced into their courses of study which make the line of demarcation between them gradual instead of sharp. The American college has borrowed so much from the American technical school, and the American technical school has borrowed so much from the American college, that it is impossible to say where one class of institutions ends and the other begins. In England and France the change has not gone so far, but there is quite sufficient evidence to show that the same tendency exists for breaking down class lines and adapting college courses to individual needs. The time is past when a high school was but a high school, an academy an academy, a classical school a classical school. Almost every institution now has alternative courses of study, calculated to develop the powers of the individual pupil rather than to promote a common school life and school discipline.

Nor does this change stop short with college and high school. It makes itself felt in common school and in kindergarten. It transforms our whole understanding of the purpose of public education. In old days we taught reading and arithmetic because without 
reading and arithmetic the pupil could not perform his duties as a citizen. We taught obedience and respect for authority because we thought that obedience was a good habit, authority a good thing to recognize. Even in this free country of America we were content to teach pupils to spell in the accredited way, simply because it uas the accredited way. To-day we have departed from all this. We have tried to see what the child wants or supposes it wants rather than what the community needs or supposes it needs. We have substituted nature study and observation for arithmetic and deportment. We have trained up a generation of children which has been brought in contact with many things, useful and otherwise, of which our children of previous ages never dreamed. But they have lost that respect for standards which is seen in accurate writing or ciphering. We need not go so far as did that pessimist who said reflectively, "School-children are not beaten so much as they were when I was a boy, but neither are they taught so much, so that what they gain at one end they lose at the other." But we may all express concerning modern school-children as a class that regret with which Artemus Ward qualified his otherwise favorable criticism of Chaucer: "Mr. C. had talent, but he could n't spell."

To-day more than ever we need to insist on the importance of this work of maintaining public standards, as compared with that of developing individual tastes and powers. This is especially true where schools are supported with public money instead of being maintained by the tuition-fees of the pupils. If a boy pays for his education, it is logical and right to give him the kind of education that he himself wants; but if the public pays for his education, it seems logical and right to give principal emphasis to the things the public wants. The public end of education is to teach the pupil to do his duty as a member of a free community. It is a purely private end to teach him to make as much as he can out of his fellow members in that community. If we use public money for private as distinct from public ends, we are adopting educational measures and principles which are socialistic in the bad sense; measures which use collective effort for the benefit of individuals instead of trying to enlist individual effort for the benefit of the community.

I do not wish to seem like a pessimist. That great good has resulted from our nineteenth-century emphasis on individual rightsand individual activities in education I firmly believe. But I also believe that in the pursuit of this good we have lost sight of some other ends which past systems of education subserved; and that in trying to provide the rising generation with the fullest capacity for enjoyment we have fallen somewhat short of giving them that capacity for discipline on which the educational systems of earlier periods laid too exclusive stress. It is an excellent thing to develop indi- 
vidual powers of work and means of happiness as fully as we can; but it is a bad thing to encourage the individual to think that his success and his happiness are the ultimate ends for which he is to work. We do not exactly teach this in so many words; but we teach it in deeds whenever we make it a principle to regard the thing which is agreeable and playful to the pupil as presumably useful, and the thing which is disagreeable or fatiguing to the pupil as presumably useless.

We are not far enough away from the nineteenth century itself to get it into right historic perspective or judge how the good and the evil of its educational movements may balance. But I will venture the prediction that the educational principles and methods of the nineteenth century will have the same kind of fate which befell the political and economic principles of that century. The introduction of the idea of liberty in polities and in economics did great and overwhelming good. The Declaration of Independence, with its emphasis on man's rights where older documents had spoken exclusively of man's duties, with its assertion of the claim of liberty where others had spoken only of the claim of authority, and with its glorification of the pursuit of happiness where previous writers had preached nothing but self-subordination, marked the opening of a great era of political development and was the starting-point for the success and prosperity of almost every nation that adopted its principles. In like manner the publication of Adam Smith's Wealth of Nations, with its cardinal principle that self-interest in trade, instead of being wicked or obnoxious, might be made an unrivaled means of public service, marked the opening of a new era of industrial efficiency and physical welfare. But there came a point when people thought so much of their rights that they forgot the existence of such things as duty, a point when the pursuit of liberty resulted in anarchy, a point when men sought to obtain their own happiness at the sacrifice of the happiness of others. There came also a point when industrial self-interest could not be made a means to the public welfare, and when those who preached its universal beneficence found their previsions unfulfilled. We have so many of these instances before our eyes that we no longer rely with the childlike optimism of our fathers on the universal beneficence of liberty in politics or in industry. We have learned that the ideals of the nineteenth century, though far better than those of the eighteenth, could not be regarded as goals of all effort or postulates of all thinking; that there was yet a word for the twentieth century to speak in a different sense from that of the nineteenth, and perhaps in a language different from that which those who had most to do in accomplishing nineteenth-century progress would have understood. So I believe it will be in matters of education. I believe that our present-day emphasis on the develop- 
ment of the individual represents an incident in educational progress rather than a fundamental principle which will underlie and control all the intellectual activity of the future. Without in the least detracting from the great and untold value of educational liberty, we may yet feel that the present moment is one for caution in applying this principle rather than for emphasizing its universal beneficence; and for laying our chief stress on the teaching of those ideas and methods, the training of those habits and emotions, which are essential to the well-being of the body politic. 


\title{
THE DEVELOPMENT OF EDUCATIONAL IDEAS IN THE NINETEENTH CENTURY
}

\author{
BY JOHN LANCASTER SPALDING
}

[John Lancaster Spalding, Roman Catholic Bishop of Peoria since 1877, Peoria, Illinois. b. Lebanon, Kentucky, June 2, 1840. B.A. Mt. St. Mary's College, 1859; S.T.L. University of Louvain, 1864; LL.D. Columbia University; ibid. Western Reserve University. Author of Life of Archbishop Spalding; Essays and Reviews; Lectures and Discourses; Education and Higher Life; Means and Ends of Education; Opportunity; Religion and Agnosicism; Things of the Mind; God and the Soul; and many noted works on religion.]

THE history of the education of a people or an age is the history of its civilization, of its intellectual, moral, and religious life, its material progress being incidental and subordinate.

Intelligence; virtue, and industry give man power over himself and all things; and it is education that makes him intelligent, virtuous, and industrious. The riches of nature and the wealth of human life are inexhaustible, but only those whom education stimulates to persevering self-activity make them their own. The controlling idea of the nineteenth century in philosophy and science is that of organic unity, implying a world-wide process of development. Hence the point of view is that of history. To understand what anything is, it is necessary to know how it has come to be what it is; for whatever exists is the outcome of an evolution which reaches back indefinitely to ultimate origins. To perceive all the facts in this process is to see things as they are. This principle is of universal validity, and its application to all the subjects and interests to which the mind can turn made possible the marvelous achievements of the last century, during which mankind grew in knowledge and in power more than in the whole historic past. The secret and the law of progress had been discovered. Heaven and earth have become what they are. All things are interdependent, and God reveals himself as his work is unfolded in the mind of man and in nature.

In learning to know how things have become what they are, we have gained insight into methods by which they may be made better than they are. In our hands a key has been placed which opens doors that from the beginning had shut man out of Nature's most richly stored treasure-house. The subconscious efforts to advance, determined by the instinctive love of life, by a still increasing craving for the sensation of life, became, in the nineteenth century, the deliberate purpose, not of individuals merely, but of whole peoples. What the multitudes had for ages felt, they now became able to think. The self-activity which in earlier times had manifested itself in exceptional minds and in isolated groups now stirred the masses. 
Education was seen to be a human need and a human right; the one means whereby a man, whether as an individual or as a citizen of an earthly or a heavenly kingdom, may fit himself to lead a noble and helpful life. It is, therefore, the need and the right not of a class nor of a sex, nor of a profession merely, but of all. Belief in the equality and kinship of men became a passion; and whatever laws or institutions are a denial of this faith were to be abrogated and abolished. Old things must pass away or re-live in the new spirit. It is the advent of the whole people, coming with mad riot and battle and celebrating its triumph in the glare of burning palaces, amidst the ruins of a falling world.

Universal education is a postulate of democracy which now first becomes self-conscious and understands that its rule is incompatible with privilege, slavery, and every kind of oppression and injustice. The people are the whole mass of men and women and, if they are to rule, they must have the knowledge and wisdom which nothing but education can impart. As all have the same divine origin and end, all must be permitted to drink at the same eternal fountain-head of truth, goodness, and love. Hence it is the duty of individuals, families, states, and churches to bend their thoughts and energies to open ways and to provide opportunities for the education of all, that all may become intelligent, free, strong, and self-controlled. Social organizations are for the sake of men, and only the virtuous and enlightened can properly cherish and maintain the domestic, political, and religious institutions. which consecrate and protect equal rights and liberties. The sense of the need of universal education was awakened by the growing consciousness that henceforth government was to be controlled more and more by the popular will, which, to be beneficent, must be enlightened. As the ideal of life became more comprehensive, the idea of education widened until it embraced the whole people and every interest. The aim is first of all practical, the formation of individuals and citizens, whose character and intelligence shall fit them to do well, each in his own sphere, the thousand things which civil society implies and requires. But if education is to be made universal, it must be organized and supported by the state through a system of free schools brought within the reach of all, which it alone has the means to establish and maintain. The belief that education should be universal and the recognition of the fact that it can be made so only through a system of public schools, for which all are taxed, have given the impulse to the most characteristic developments of educational ideas during the nineteenth century. The ancient ideals of intellectual culture and moral discipline it did not transcend, but sought to give them general application; and the success with which this has been accomplished is largely due to the influence which those ideals have exercised on the modern mind. 
What higher wisdom on this subject have we than Plato's when he says that the training which aims at the acquisition of wealth or bodily strength or mere cleverness, apart from intelligence and justice, is mean and illiberal and not worthy to be called education? But the pagan ideal was aristocratic; it was that of the freeborn dominating slaves, whose nature was supposed to be servile and incapable of true culture. It considered but a class and ignored humanity. Christ is the first humanitarian, and from Him and His followers the world has received its faith in the brotherhood of men and in the right of all to liberty and opportunity; and hence we call our civilization not Grecian or Roman, but Christian. It has sprung from the enthusiasm for humanity, the fire which Christ kindled, to burn the dividing and imprisoning walls, that all men and women might have unimpeded access to the truth and freedom which make right life possible. It is to Him, and not to the philosophers of Greece, nor to the calculating moralists of Rome, that we owe our faith in the Father in heaven and in the divine rights of man; His child, which is the master light of all our seeing, and the fundamental principle of our life, individual and social. This principle lies at the core of modern consciousness, even in the minds of those who doubt or deny; and from it our civilization, if it is to advance and endure, must develop, as of it belief in democracy and in the need of popular education is born.

The unprecedented expansion and diffusion of life and knowledge which took place in the last century are not a creation, but a clevelopment. That past still keeps us company, and what has been makes what is. He who first lit a fire, he who first used it to cook food or to render metal malleable, made a forward step with which all the advancing races have kept and still keep pace. We do not owe to the nineteenth century the alphabet or Arabic numerals, or architecture or painting, or sculpture or music, or poetry or eloquence; we do not owe to it the mariner's compass or the telescope, or the Copernican astronomy or the printing-press, or gunpowder or the circumnavigation of the Cape of Good Hope, or the discovery of America or the steam-engine. We do not owe to it philosophy or science or true religion, or the doctrine of political liberty or of equal rights; nor do we owe to it the principles of the theory and practice of education. It was an era of culmination, in which the tree of life flowered and bore more bountiful fruit; but it could not have flourished at all had not its roots been struck deep into the soil of the past which the labors of countless generations had tilled and made fertile. It was an age of progress because there had been progress from the beginning.

It did not create the home or civil society, or the state, or the church, or the school, or any of the institutions that educate. It was 
an era in which mankind came to fuller self-consciousness, an era of more rapid expansion and diffusion of the powers which make for life, in which the passion for freedom and knowledge that is inborn found an environment exceptionally favorable to its exercise. Men became aware of the universal applicability of the forces they had inherited. They invented new and more perfect machinery, and by their aid attained a marvelous power, enabling them to fly rapidly over continents and oceans, to write their thoughts with a pen that reaches thousands of miles, to talk to one another despite forbidding space, to make the lightning illumine their homes and cities with a steady glow, the sun to impress the images of all things on solid matter, and types quickly to multiply the printed page in millions of copies.

It was an epoch in which the human mind applied itself with irresistible energy to the intelligible universe. Nothing escaped observation. It measured the velocity of light, it weighed the suns and determined the elements of which they are composed, it deciphered the story of the earth's evolution from a molten mass till it became the dwelling-place of man, it established the theory of organic evolution, the germ theory of the zymotic diseases, the molecular theory of gases, the theory of the conservation of energy and of the uniformity of nature. It was a century in which not single minds alone, but whole peoples, were stirred to a higher and more persistent self-activity. The marvelous advance in science, in the arts, in control over the forces of nature, enlarged the thoughts and aspirations of men, giving them a self-confidence which made them quick to believe and be certain that what had been achieved was but a token and promise of the infinite possibilities which the persistent intelligent efforts of multitudes striving for truth, liberty, and power should and would make real. Its victories were victories of mind over matter, triumphs of enlightened nations over the ignorant; and the whole course of events tended to confirm popular faith in the might and worth of education, which ceases to be the concern of scholars merely, and becomes the chief interest of governments and states. The democratic spirit, compelling faith in equal opportunities for all, brought about a general recognition of the truth that the first and greatest of opportunities is opportunity to educate one's self; that the most effectual help a man can render his fellows is to teach them to become intelligent, self-controlled, and self-sufficient. They are mockers who will talk of the brotherhood of men and yet consent that any should remain in ignorance. It is God's will that his children know and love, and they are not Christians who refuse to coöperate to make his will prevail. The mightiest powers which manifest themselves in his universe are intellect and will, and it is a law that to act rightly they must be educated to act rightly. Work 
is a blessing, but to be condemned to work ignorantly and stupidly is misery and degradation. A man walks securely and does well only where the light of the mind shines along his path; and if he walks by faith, he still walks in the light of the mind.

Imagination, which so largely controls human life, is a will o' the wisp unless it be illuminated and directed by the educated intellect. All genuine popular movements are inspired by sympathy, by a desire to go to the help of those who suffer, who are wronged, whose burdens are too heavy, to whom opportunity is denied. It is this that has provoked and sustained the revolutions which have liberated, which have given new hope and courage to the oppressed. It is this that impressed on the nineteenth century its most distinctive feature.

It was an era of emancipation, of enlargement of the life of the whole people. Faith in the worth of liberty, of equality of rights, of universal enlightenment, became a passion. New insight was gained into the truth that ignorance is slavery, and that where the masses are permitted to remain ignorant, tyranny and oppression are inevitable. Hence the faith in liberty and in equal rights grew to be an enthusiasm for the spread of knowledge. As the beneficence of science, its power to prevent or cure disease, to develop the treasures of nature, to minister to human needs in a thousand ways, became more and more manifest, public opinion turned with increasing force to the advocacy, establishment, and maintenance of systems of free schools in which the minds of all might be prepared to adjust themselves to an environment created by widening thought and more accurate knowledge. The recognition of the indispensable need and paramount worth of universal education led to a higher appreciation of the dignity of the teacher's office. He is no longer a pedagogue, but a coöperator with God for the regeneration of the world. Teaching evolves into a learned profession, is seen to be the supreme function of all learned professions through which, if it were rightly performed, there would be little litigation or disease or sin or ignorance. When men came to understand that the teacher is the school, their love for the school issued in respect and reverence for the teacher; and he who through the ages had been a slave, or treated as one, is now honored of all the wise and good. The best things - religion and culture, morality and art - are propagated, and they can be propagated only by those in whom they are a vital power. Hence the teacher should have a liberal education, should make his own the highest faith, the truest knowledge, the purest and most generous love that have thrilled a human brain and heart, and then acquaint himself with the theoretical and practical details of his work. The first requisite is to be a genuine, fair, brave, intelligent man or woman. It is his business to further 
life, to heighten its power and quality, and he can do this only when he himself is what he would help others become.

A message of the nienteenth to the twentieth century is this: "So mold public opinion that it shall lead the best men and women to choose teaching as a vocation." Let the buildings be full of light and pure air, let the classes be small, let the hours of study be few, let the pupils gain knowledge as industriously as bees gather honey. Let the atmosphere be that which only cheerful, strong, and loving souls can create. There is nothing beautiful or fair but the mind makes it so; and where there are luminous minds there will be willing hearts, there will be interest, self-activity, and effort. The young grow stupid with the dull, tired with the weary, heedless with the indifferent. Their chief faculty is that of imitation and, if we would educate, we must place in the midst of them those into whose likeness they will find it a delight and a blessing to grow. There is not a pebble lying on unvisited shores but is held by indissoluble bonds to the universe of matter and of spirit too; and there is no subject so seemingly remote from human need but the right teacher will show it to be near and akin to us. He will take the empty forms of thought and fill them with truth as gracious as the presence of friends. To know how to interest is the teacher's great secret. It is an open one. If he himself is interesting, he will easily show that he is so, will hold his pupils to his words and to their work.

All our wisdom comes of experience, and our most fruitful experience is of noble personalities, whether in life or in literature; and since the end of education is the acquirement of wisdom, its method must be contact with teachers, acquaintance with whom is experience of virtue and culture as bodied forth in men and women we may rightly admire and love.

The most important development of educational thought in the nineteenth century was the fuller recognition of the principle that education is a universal right, that consequently it is the duty of society to provide the means of education for all, and that the one indispensable and sufficient means is the personal influence of enlightened and loving teachers. From this sprang the irresistible impulse to diffuse knowledge, to suffer none who might be taught to $\mathrm{know}$, to live and die in ignorance; from this arose systems of free schools, made accessible to all; of this was born a truer appreciation of the worth of the teacher's office, an increasing desire to induce the ablest and the most sympathetic to assume it, to procure for them the best culture, together with the discipline and training needed to give them tact and skill in the performance of their work. If the greatest minds of the nineteenth century gave most serious thought to the subject of education, considering it from the points of view of philosophy, of history, and of science, it was because the 
world had come to perceive that education, which is conscious evolution, is the method the Eternal employs to produce and perfect all that is brought forth in space and time. In developing whatever is potential in human endowment man coöperates with God to raise life to higher and higher efficiency and quality.

The value of all things was seen to lie in their power to educate, for mind is the creator of values. Strength is good only when it is controlled by the rational will; obedience is a virtue only when it is enlightened and free. The young are compelled to obey that they may learn that liberty is obedience to law. It is education that makes man strong and reasonable, obedient to law, which is the expression of the mind and authority of the Creator of all things. To assert that education is for freedom and not for authority is to wish to separate things which are inseparable. They who recognize not the authority of reason and conscience, and of the institutions in which they are embodied, live in worlds where there is no right or wrong, and are necessarily slaves. The more the subject of education was studied, the more all-inclusive it was seen to be. The evolution of the material universe had meaning, because it was the preparation of a dwelling-place wherein beings capable of knowledge and love might live and educate themselves. In this lies the significance of history, which is valuable chiefly as a record of the education of the human race. By this standard the worth of work, of religion, of science, of art, of literature, of political and civil institutions, is measured. If criminals are to be reformed, if the blind and deaf and dumb are to be enabled to enter into intelligent communion with Nature and their fellows, if a more wholesome, rational, and moral life is to be fostered in communities and in individuals, the processes and methods of education give the surest hope of success. Faith in education is faith that reason and conscience are the mightiest forces; it is faith in God.

This deeper insight into the significance and value of education led not merely to its general diffusion throughout the civilized world, it led to more humane and just views in all that relates to the nurture and discipline of the young or to the improvement and correction of the unfortunate or perverse. Love guided by wisdom was perceived to be the supreme educational force.

Socrates has said: "We can teach only those who trust and love us;" and He who lifted the race of man to higher levels and diviner aims and hopes made love the test of discipleship. The only fear which is salutary is that which springs from love. To make the young unhappy is to arrest or pervert their spiritual growth. From the joys of childhood well the waters which make life's deserts bloom, which refresh and strengthen the heart in the midst of the trials and struggles that none can escape. The house which children approach 
unwillingly and with dread is neither a home nor a school. For the criminal even the chief hope is in the power of those to whom they are committed to inspire them with respect, admiration, and love. The glory of the nineteenth century was its greater capacity for sympathy with the poor, the wronged, and the disinherited; and if the history of the twentieth is to be a record of progress, it will be due to a still greater capacity for sympathy with those who need it most. The meaning and end of civilization is the conversion of Nature's struggle for existence into man's coöperation for higher and holier life. Here, and not in devices, methods, and policies, we touch the fountain-head of educational wisdom and inspiration. Struggle is born of brutish instinct and appetite; coöperation, of reason and conscience; and the great aim of education is to establish the supremacy of reason and conscience over appetite and instinct. The domination of the animal in man had kept woman in subjection, had made her a slave, a drudge, or a plaything, but faith in education as a human need and right revealed to the nineteenth century the duty of providing for the education of women as of men. Opportunity should be given them to upbuild their being, to become all that their endowments permit, to do whatever thing is worth doing, to make of themselves not merely wives and mothers, but individual souls clothed with the liberty and the strength of the children of God. In nothing is the present age superior to all others more than in the intelligence and influence of its women; and this distinction it owes to its readiness to accept and apply educational truth in its fullness, not giving heed to those who doubt or deny or tremble for the safety of a world in which all women are invited to acquaint themselves with the best that is known and to take part in whatever concerns human welfare.

In developing educational ideas in the nineteenth century the Germans were the leaders, but the Americans were the first to perceive and welcome the truth that there cannot be an enlightened, free, and high-minded people where the women are not enlightened, free, and high-minded. We have accepted this as a principle, and our action has done more to further progress in education than all the speculations of all the philosophers. It is an implication of all our democratic faith. It is folly to imagine that the people will be wise and virtuous if the wives and mothers are not wise and virtuous. The family is the true social unit. Upon it both the state and the church must rely for the inculcation and preservation of the truth which makes man social and religious. In the family the father is the head, the mother the heart; and great thoughts, true inspirations, and generous deeds spring from the heart. Shall we put our trust in the calculating intellect, and suffer the fountain-head of life's waters to be choked by noisome weeds? 
If right education is a sovereign thing, its highest efficacy shall be shown in developing woman's power of love, sympathy, and selfdevotion, giving her at the same time a wider outlook on the world of human achievement and a firmer grasp of intellectual truth.

In the nineteenth century the business of school-teaching was largely intrusted to women, and it was the willingness of the most intelligent to undertake this task that made the rapid spread of popular instruction possible. When it was found that as teachers women were the equals of men, it was not difficult to believe that they might compete with them in other fields of activity, and so it came to be understood that for woman, not less than for man, America means opportunity, inviting to larger, freer, and worthier life. She who had been the world's all-suffering drudge, who even as wife and mother had been held in subjection and denied the joys of awakened souls, stood forth self-conscious and thinking, to do her part to make truth and love, which is God's will, prevail.

In a century in which the mind and heart of the people had been more powerfully stirred by noble passions than ever before, progress was intensive as well as diffusive. While there was among the civilized portion of mankind a general advance toward greater liberty and intelligence, there was developed in exceptional minds an unquenchable thirst for knowledge. While for the multitude the means of information were provided, the more serious and far-seeing spirits were busy seeking to throw a purer intellectual light on all the thoughts and ways of men. Standing on the vantage-ground prepared by the discoveries, inventions, and wisdom of the past, they moved forward, permitting nothing in the heavens or on the earth to escape their keen and inquiring gaze. Philosophy, religion, history, language, law, government, with whatever else may be the concern of man, were reëxamined and submitted to the test of the most searching criticism. Whatever the line of research, all felt that by increasing the store of knowledge they were enriching the race and creating opportunities for the progressive prevalence of mind over matter, of reason over instinct, and of free will over passion. At the bottom of all the feverish, persistent activity of the nineteenth century there lay a deep enthusiasm for human progress; a passionate belief that truer and wider knowledge cannot but lead to more intelligent, larger, and freer life; that it is the tendency not merely of vital religious truth, but of all truth, to emancipate. As the field of man's activity was made more fertile by more skillful culture and yielded more and more precious and abundant harvests, new hope of making the world glad, beautiful, and wholesome beyond the dream of past ages sprang within the heart. It was joy to be alive and bliss to be young. A spirit of optimism which refused to see, or at the least to be discouraged by the darker side of things, 
blew like a creative breath on the face of the people awakening to self-consciousness. The meaning of earthly existence seemed to grow deeper and more glorious. The past faded from view and the future glowed like the sky of dawn. The marvels of material progress became a symbol and a promise of a coming race illumined by science, strengthened by a higher faith, and purified by a diviner love. As everything was investigated, the study of man could not be neglected. The light which science threw upon his physical constitution but made it plainer that his true being and world is the mind, that by the soul alone can he be great and free and strong. Hence thinkers were drawn to investigate the instrument of thought, to inquire into the nature of mind, to analyze its faculties, and to determine the order and method of their development. Anthropology became psychology, the practical value of which was found to consist in its application to pedagogy; and so the most subtle and the most energetic spirits were compelled by the intellectual evolution of the age to a more thorough study of the meaning and methods of education, which became a vital concern of philosophers, theologians, poets, statesmen, and philanthropists.

Pedagogy is not a science or an art which the nineteenth century created. The word is Greek, and the earliest thinkers understood that man's educability is his most characteristic distinction. Pedagogical problems preoccupied Socrates, Plato, Xenophon, Aristotle, Cicero, Seneca, Epictetus, Mareus Aurelius, Plutarch, and Quintilian. They received consideration from Gerson and Vives; from Erasmus, Montaigne, and Charron; from Descartes, Bacon, and Locke; from Comenius, Leibnitz, and Lessing; from Thomas Reid, Dugald Stewart, and Rousseau.

But in the nineteenth century education became a matter of social interest, engaging the thought of statesmen as well as the meditations of philosophers. Kant draws up a system of pedagogy, and when Germany lay prostrate beneath the victorious armies of Napoleon, Fichte proclaims in words of burning eloquence that, if it is to rise again, recourse must be had to a more genuine and thorough education of the people. From the enthusiasm and devotion of Pestalozzi modern popular education received a powerful and enduring impulse. He breathed a new spirit into the school and enlarged its scope. He believed and made many believe that educaticn is the chief means by which the masses may be redeemed from degradation, misery, and vice. He insisted that all should be educated; that the methods should be gentle and kindly; that the affection, the conscience, and the will naed cultivation not less than the intellect; that the young should be taught not only to think but to do, and that the school should be a workshop as well as a classroom. He had a profound love for ehildren, and held that to teach 
rightly one must have the mother heart. His aim was to educate for freedom; but he failed to see with sufficient clearness that liberty involves authority, though as men become more enlightened they grow more critical and appeal with increasing emphasis from authoritative organizations to the aboriginal seat of conscience in the individual soul. Hence the school, where the people are free and intelligent, strives to make its pupils self-reliant, self-controlled, and rationally obedient.

Herbart was influenced by Pestalozzi, and though his philosophy is unsound he applied psychology to the theory and practice of teaching with true insight. He made it plain that the mind does not gain strength and wisdom by seeing or perceiving, but by reacting on the impressions received through the senses, and by relating apparently separate objects to the whole of experience, until each is understood to be part of all, made what it is by causes that reach back to eternity, itself a cause whose effects shall in turn become causes in an unending process. This is Herbart's doctrine of apperception which the teacher cannot meditate too attentively. It is a process, not merely of identification or classification, but one in which the mind sees things becoming and follows them in an endless course of evolution, until the interrelation of all things is perceived, and within and beyond all, the Supreme Spirit who makes, guides, controls, and harmonizes all. The teacher's effort must be to make his pupils understand rather than to see and remember.

Herbart's doctrine of interest and of educational values is suggestive and has compelled attention to questions which contributed to the development of educational ideas during the last century. Not less helpful is his recognition of moral life as the end of all education, and of the dependence of character on thoughts and dispositions which it should be the purpose of education to make habitual. Froebel's doctrine that education is conscious evolution, to promote which the whole environment, spiritual and physical, should be made to contribute, has had a wholesome influence on pedagogical thought. His kindergarten idea, however, while it springs from a real view, easily leads to the employment of methods which stimulate precociousness, make genuine work distasteful, and by confining the attention of children to the things immediately about them, enfeeble the imagination. There is also danger of impoverishing the sources of life by too early and too persistent appeals to self-consciousness.

The democratic movement which gave to the nineteenth century its most distinctive feature sprang from an increasing sense of the worth of the individual and led to more comprehensive notions of his rights and duties. Individualism in the matter of education found its completest expression in the writings of Goethe. Nature 
lays the foundation, and it is each one's duty to erect upon it the noblest possible structure.

Education is not merely or chiefly a scholastic affair, it is a lifework, to be carried on with unwearying patience until death bids us cease or introduces us into a world of diviner opportunities. The wise and the good are they who grow old still learning many things, entering day by day into more vital communion with truth, beauty, and righteousness, gaining more and more complete initiation into the life of the purest, noblest, and strongest who have thought, loved, and accomplished. Self-education, as a life-duty, rests on the idea that personal worth is the measure of all values and the indispensable condition of genuine success; on the conviction that whatever a man may think or do or suffer is to be considered good or evil as it increases or diminishes his personal worth. It is indeed the ideal of philosophers and saints rather than that of men engaged in the ordinary business of the world. It may, nevertheless, and doubtless does help to raise the thoughts and aspirations of many above the ordinary demands of their occupations or professions, and so to stimulate them to strive not merely to gain a livelihood or a reputation, but to live in the mind, in the conscience, in the heart, and in the imagination. It may lead them to reflect on the common ways of men and to gain insight into the fact that their failure to continue to cultivate and improve themselves, when they have quit school, is due not so much to want of time and"opportunity as to lack of will and energy. It is the result of the natural disinclination to make effort, to foster interest in knowledge and virtue simply because it is good to know and to be true and strong; of the tediousness of ceaselessly trying to surpass one's self, to know one's self, to refine taste, to purify affection, to control desire, to see things as they are, to judge not by opinion, but by evidence; to turn from present enjoyment in the hope of winning higher capacity to enjoy, to prefer the society of the immortal minds who live in books to games and gossip.

It is so much easier to run after pleasure, to labor to get riches or position than to devote one's self first to the upbuilding of one's own being, not doubting but whatever else may be needful shall be had, that it is hardly to be expected that the ideal of culture and pure religion shall strongly appeal to the many. A man's real world, nevertheless, the world in which he lives nobly or miserably, is not that which lies round about him, but that which he creates and fashions within his soul. He may wear a beggar's rags, be a slave, an outcast, a prisoner, and yet, in virtue of the truth and love which are the substance of his being, excel in worth and dignity, as in the affection and reverence of the wisest and best, the favorites of fortune and the children of success; and it is this ideal that must be made to gleam along the path of the young, to throw its heavenly light about 
the home and the school, if there is hope for better things, if we are to have not merely improved machines, but godlike men and women. The individual is at once an end and a means. He exists first for God and himself and then for his fellow men, and he becomes valuable to the society by which he is so largely formed and fashioned in the degree in which he makes his own life complete and perfect. $\mathrm{He}$ is a whole and a part of the whole, and he must continue to improve himself, if he is rightly to perform his functions as a social being. This principle applies universally and determines the end and aim of all true education. It must underlie the theory of elective studies, or the result will be fragments of men; fine parts of men rather than great and noble personalities. The young will be encouraged to move along the lines of least resistance, and the heroic temper and the divine spirit which convert obstacles into opportunities will be wanting. They will become impatient and strenuous, eager and reckless, but they will not be made capable of knowing and loving the highest truth and beauty. We shall have experts, but no philosophers, poets, and saints. If the purpose be to train for freedom, we must understand that they alone are freemen who free themselves from within; if for social efficiency, we must recognize that the vital, not the mechanical, individual is able to render the best service; if progress and the improvement of the race be the object, it is evident that success is to be hoped for from men rather than from measures.

The development of educational thought in the nineteenth century has made plain the absolute worth of the individual, and at the same time the vital union of the individual with the social organism, and his consequent duty to labor for the general welfare. It has also brought into fuller evidence the fundamental truth that human values are moral values, that character, which is the aim and end, is the result of right doing far more than of correct thinking. The world each one should labor to fashion within himself is primarily and essentially a world of righteousness. To educate, therefore, is not merely or chiefly to inform the mind; it is to strengthen, direct, and confirm the will; to foster habits of conduct, to fashion to the practice of virtue, to accustom the young to take delight in all that is good and beautiful, to feel the joy and happiness there is in overcoming passion and appetite, in triumphing over the inborn love of ease and idleness; to taste the sense of power there is in the play of the higher faculties, in the self-activity which illumines the mind, purifies the heart, and raises the imagination; to win them to believe and to know that the best and most useful things are not material but spiritual, - justice, honor, magnanimity, truthfulness, purity, gentleness, and love. Moral culture should dominate, direct, and control the whole process of education. Whatever the pupil does 
should make him wiser and better. His increasing knowledge should become the basis of larger and nobler life. Each new truth he comes to understand should teach him respect for all truth. As he gains deeper insight into science, literature, and art his reverence and admiration for the mind of man should grow profounder and more real. The triumphs and sufferings of heroes and saints should give him higher aims and nobler ambitions.

Whatever, in a word, be the subject of his study, the end and result should be increase of moral worth, improvement of character. As he will make little progress unless he be a lover of knowledge, knowledge will render him poor service unless he be a lover of virtue.

But he cannot be a true lover of virtue unless he believes and feels that to be virtuous is the greatest possible good of man, whatever may be his temporal environment. "The end of a liberal education," says Plato, "should be to enchant the soul of children, while it is yet tender und innocent, with the frequent repetition of beautiful maxims. And to embrace them all in a single one, let us say to them that the life which is the most just is also the most happy in the judgment of God; and not only shall we speak truth, but what we say will enter more easily than aught else into the minds of those whom it is important that we should persuade."

"The insight," says Dr. Harris, "that God is a free person and essentially righteous and gracious is the arrival of man at absolute knowledge. For so soon as one discovers that absolute being must be self-active or personal and that to be absolute person it must be just and gracious, he has arrived at the highest possible insight a knowing which must at the same time be true objectively."

Since ideas of education are ideas of life, they neither emerge nor become effective as isolated thoughts or fragmentary theories, but they spring from a world-view and are involved in philosophic systems which are spiritual or material, theistic or pantheistic, Christian or pagan, secular or religious. Since education is for life, notions of life determine its processes and methods. What kind of man is the highest? What kind of effort is most worthy of encouragement? What is each one's first and most urgent business? Is the individual a means, or an end, or both? Shall the chief stress be laid on the present or on the future? Does man exist for this world alone or is it his duty to look beyond and labor to fit himself for the diviner existence to which faith, hope, and love point? Is the true ideal that of pleasure, or that of virtue and power? These are questions which whoever is interested in education must strive to answer if he wishes to go deeper than its devices and technicalities and to gain insight into the fundamental truth that human values are moral values, and that success or failure is not a matter of profit and loss, but of inner growth or decay. 
The school is for the sake of a higher, richer, better life, for the sake of conduct, and conduct is inspired and nourished, not so much by knowledge as by feeling, by faith, and love, by the habitual contemplation and performance, not of what is pleasant or profitable, but of what is right and holy. Hence, if the school is to promote a higher life it must appeal to the consciousness of God's living, loving presence within the soul. It must enable the pupil to look beyond the brutal fact and present advaritage to truth and final results, to project his efforts and longings into the future in which alone he can hope to make his ideal real. In all progressive novements man is impelled to lay stress not on what is, but on what ought and is to be. The future dominates the present, as the infinite the finite, the eternal the temporal; and the future for which we hope and strive, whether consciously or not, is not a condition of body, but a disposition of soul - the ideal being not abundance of possessions, but a heavenly kingdom in which truth, justice, and love shall prevail; in which men shall be godlike, free, wise, and blessed. It is not economic and social, but spiritual and personal; not the complete exploitation and distribution of material things, but illumination of mind and elevation of soul. The supreme interests are those of the spirit, for the loss of which a universe of matter could not compensate. This is a fundamental principle of life and, therefore, of education. Could some mighty genius reduce all knowledge to a system and firmly grasp the whole, for him, as for the common man, the question of wital and infinite moment would still be matters of faith and hope, not of knowledge. The highest human good, therefore, is not intellectual but moral - a disposition of soul in which a divine faith and hope beget perfect love, manifesting itself in the fulfillment of righteousness.

It is the purpose of education to make able men, to develop capacity to see true and do right, to educe faculty from endowment, will from impulse, intelligence from instinct, but the ideal and end must be sought not in the doctrines of materialism, commercialism, or secularism, but in faith in God and in the absolute worth of life when illumined and controlled by the truth and love which are his being. In vain shall we seek to prepare a more and more favorable environment and to give opportunity to increasing numbers, if man himself be a creature of circumstance, an excrescence on a dead universe, a disease, a phantom, with nothing at the core of things to correspond with his highest thoughts and deepest yearning; if his end is as the end of a dream and all that made him is senseless and void. If the religious view of his life is not true, nothing is worth while, and whether he take for his guide utility or worldly wisdom or appetite, it matters little. Religious consciousness lies at the heart of all human consciousness, and to it we owe the deepest insights 
and the divinest efforts of the race, as by it the evolution of civilization has been inspired and controlled. The predominant influences in history have been and are religious and economic, and whenever conflict has risen between economic welfare and that of loyalty to God and the soul, the highest, the noblest, and the mightiest have preferred truth and right to temporal success, and in doing so have become pioneers in the cause of freedom and progress. As it is a chief purpose of the school to acquaint the individual with the profoundest experience and the purest wisdom of the race, religion and the conduct it inspires must continue to be its central theme. The great human interests are maintained, protected, and furthered by institutions, by the family, the state, the church, and the school, and subordinate to these and in coöperation with them, by innumerable forms of association which the ever-increasing specialization of civilized life calls into existence. The home of the modern world is the outgrowth of Christian ideals and principles. It has been fashioned and safeguarded by the church, whose teachings establish its rights, its sacredness, and its mission to form citizens capable of freedom and self-devotion, who, while striving to build here a kingdom of heaven, live for a higher world which shall not pass away.

It is only in such homes that the true children of God are bred and reared; and they need to be reinforced by the school not less than by the state and the church. If the school ignore the principles which inform the home, the state, and the church, these institutions are undermined. As the modern state is conscious that without the school it cannot have intelligent, capable, and patriotic citizens, so the church in the modern age understands that it requires the cooperation of the school, if the spirit of religion, which is faith, reverence, obedience, self-sacrifice, purity, righteousness, and love, is to remain vital. As it is the tendency of the free school to weaken the sense of responsibility in parents, it is the tendency of the religiously neutral school to suffer faith, reverence, self-devotion, purity, and love to perish of atrophy; and a church which is severed from the school loses its influence on the home and ends by becoming a club for ethical culture or social advantage, as a state which is content to exist without and apart from the school condemns itself to weakness and inferiority. It would be as reasonable to maintain that the state has no need of the school as to hold that the church does not need the school. Without the assistance of the home and the school neither the state nor the church can prosper.

To a life of virtue, freedom, and progress the church is as indispensable as the state.

"The church," says Dr. Harris, " announces the divine plan of the universe, the fundamental ideal by which all things are to be 
understood, the final standard by which all things and events are to be measured. This is the most educative of all institutions, because the person who harbors a religious ideal puts himself into the process of applying its standard to every experience of life."

This standard must be applied to the school, which furnishes to all who pass through it an experience that shapes and colors the subsequent course of their lives. The Christian religion is education, - the deepest and most far-reaching educational force in the world, - the power which more than all else originates and sustains the impulse to conduct, which is three fourths of life. "The first condition of responsiveness to religious influence," says Professor Peabody, "is the recognition that in their fundamental method and final aim, religion and education are essentially consistent, coördinate, mutually confirmatory, fundamentally one." If education means, as President Butler affirms it does, a gradual adjustment to the spiritual possessions of the race, is there doubt that the wealth of truth and love revealed in Christ is the most precious and the most vital of these possessions? Does He not furnish the highest incentive and the most effective aid to all who would grow into completeness of life, into the perfect image of God? If intimate acquaintance with the noblest who have lived, with their spirit and work, be a chief aim of education, shall we exclude Him who more than all heroes, philosophers, and poets has stirred the minds, raised the thoughts, and purified the affections of mankind? If in our democratic world all the institutions that educate are impelled by the force of public opinion to train to social service, to emphasize the truth that no one can be wise or good or great or happy for himself but only in loving, helpful association with his fellows, where shall we find an example so high or an incentive so strong as in the life of Him who came not to be ministered to but to serve; who made the love of others the test and proof of spiritual kinship with himself? If our sympathy for children, for the multitudes who are still condemned to drudgery, to sacrifice the sweetness and joy of life that the few may be surfeited with luxuries, is genuine, how is it possible that in the formative and decisive period of human existence we should deliberately shut them out, in any of the processes of education, from the mind and heart of Him who is the world's great lover of children and of the poor?

Shall we in our schools set aside days to commemorate some mediocre patriot, poet, or orator, and make it an offense there to do homage to Him who has given His name to our civilization, who has uplighted morality with an unexampled splendor, who has inspired a sympathy and love for man which has transformed the life of the race, who has made childhood sacred, and raised woman to a throne whereon the noblest must forever do her reverence, in whom great. 
ness of thought was wedded to greatness of soul in a supreme degree, who in Himself more than in the doctrines He teaches is truth and goodness and beauty?

Education is the soul's response to God's appeal to make itself like unto Him, self-active, knowing, wise, strong, loving, and fair; and the permanent example of the most complete hearkening to this appeal is the life and teaching of Christ. He moves on the plane on which the lot of the lowliest is cast, and He lives on heights to which saints and philosophers can attain but at momentary intervals.

The infinite power of the brave and the good to dare and to suffer reveals God to us more than the unimaginable force and splendor of millions of suns; it manifests to us that the spirit of man is of higher quality and greater worth than a universe of atoms. It is forgetfulness of this that makes us victims of schemes and devices, gliders over the surfaces of things, incapable of thinking or loving or doing what has everlasting value, become as traders for whom the market fixes the standard of worth, for whom success is more than the soul, who lack the spiritual mind which is the highest educational force and influence. Teachers who fail to see all things in the light of eternity and in the omnipresence of God are but servants of idols. They drift toward mechanical methods, appeal chiefly to the arithmetical and calculating understanding, leaving the faculty for divine thoughts and infinite hopes to perish of atrophy. They form tradesmen, artisans, schemers, and politicians, not men who live in the inner sanctuary of conscience and draw sustenance from the eternal unseen world of truth and love, where commercial standards have no significance or application.

To educate is to labor for the greatest happiness of each and of all in the sense in which happiness is indistinguishable from wisdom, holiness, and love. It is to accustom to think, to meditate, to give heed to the voice of reason and conscience, to withdraw from the noise of life and the tumult of passion, that this voice may be heard in all its depth and purity. It is to store the mind with true principles of conduct and to create habits of right thought and action. It is first of all a work of religion and morality, of intelligence and wisdom, of sympathy and love.

The ideal of utility certainly is applicable to human life in a thousand beneficent ways, and may illumine the path of the noblest. It adds a general principle to knowledge and is of advantage to the whole world. But it is only an aspect of the truth. All things exist for those who know how to make use of them, and their true and highest use is to minister not to appetite but to reason, not to instinct but to conscience, to the human, not to the animal. Right is higher than might, goodness than success, love than lust. There is no more doubt that falsehood, dishonesty, and impurity are wrong than 
that bodies are controlled by the law of gravitation, or that moral truth is of infinitely greater import to the spirit which is a man's self than is the physical fact. No one really believes that a bad man can be happy here or hereafter, and the higher our view of life the less we think of our pleasures and interests.

It is only when he walks in the light of this ideal that the teacher is uplifted by a profound and abiding enthusiasm for his work, which he feels to be a coöperation with God for the salvation of men. The greatest of educational problems is how to induce the best men and women to make teaching their life-calling; and it is the most difficult.

If considered merely as a career many more inviting ways open before the eager eyes of the young who have brave hearts and lofty aims. For the most part the teacher's task begins and ends with drudgery. It is monotonous, wearisome, ungrateful, and obscure. He must himself create the taste and the ability in those he instructs to appreciate the good he does them; and when appreciation comes it is like hope deferred. He is tired and outworn and no longer cares. His very soul has become subdued to the crude brains he has so long labored to suffuse with light and to open to all the glories of heaven and earth. How shall he persevere, how shall he become daily self-surpassed, how shall he retain the freshness and elasticity of youth in the dull air and routine of the schoolroom? Will it be possible for him to keep alive faith in the potency and beneficence of education? Will not the power to vivify, to create life unde: the ribs of death, depart from him, and he be degraded to the function of an attendant upon a machine?

Surely this will be the result if freedom of the soul is denied to him, if he is forbidden to impart the fruits of his holiest and most helpful experience, the thoughts he most loves, the hopes he most cherishes, the very life which is his strength and joy.

The great educators have not striven to make earth a lubberland, but to found here a kingdom of heaven wherein truth, justice, and love should prevail; wherein men should do the will of God, as in unseen worlds it is done by higher beings unhindered and untempted by human weaknesses and passions. They are the world's guides, the saviors, the inspirers of the multitude, the leaders out of captivity and bondage.

An infinite hope has descended upon the world, undreamed of by the philosophy of Greece, and like the memory of most blessed days, or like remorse, it cannot die. Individuals may become atheists and materialists, but the mind and heart of Christendom can never abandon faith in God who knows and loves and is good, and in the immortal soul of man. The wisest and the best will not cease to yearn and to labor for the coming of His kingdom on earth. In the growth of science, in the spread of knowledge, in the increase of 
liberty and opportunity they will see the fuller manifestation of the divine purpose. But as the life of the individual would be empty and meaningless if this world were all, so the race itself becomes insignificant, if beginning on a cooling spall it is to be extinguished utterly on a frozen rock. It is in the power of individuals, and of classes of people even, to smother the soul in sensual indulgence, or to stifle the voice of conscience in the mad struggle for gain, but the summit on which Christ lived and died and re-lived, once having been attained, mankind can never again in contentment and tranquillity satisfy themselves with lower things. This faith lies at the root of modern civilization. It is the vital principle of the Christian home and the Christian church; and if the state and the school organize themselves on a purely secular or utilitarian basis, our social and political life will undergo a radical change. We may increase our commercial efficiency; may so manipulate the natural resources of our continent that the markets of the world shall pay tribute to us; we may heighten the level of intelligence and raise the standard of living for the multitude, but little by little we shall lose the power to believe in the absolute worth of truth and goodness and beauty, of justice and purity and love. We shall become the richest of nations, but shall have no supreme men and women. The poet's vision, the saint's rapture, and the patriot's lofty mind shall be made impossible. Existence will cease for us to have a spiritual content, and we shall come to hold that a man's life consists in the abundance of the things he possesses, and not in the faith, hope, and righteousness which make him a child of God and a dweller in eternal worlds. 


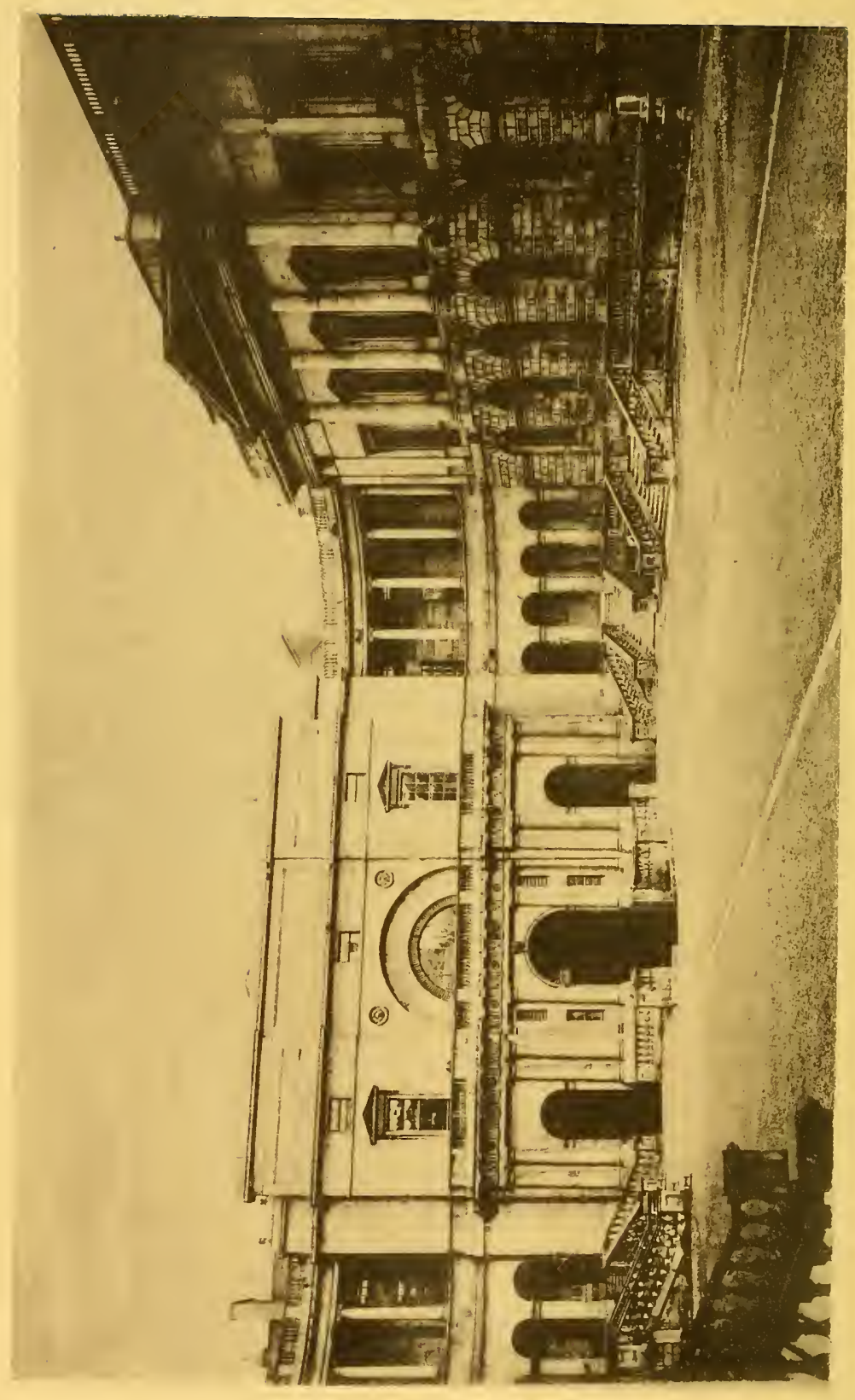




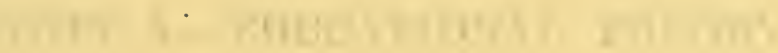

1) 9 J

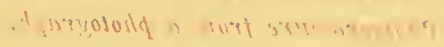


THE UNIVERSITY OF EDINBURGH Photogravure from a photograph. 
SECTION A-EDUCATIONAL THEORY 



\title{
SECTION A-EDUCATIONAL THEORY
}

\author{
(Hall 12, September 24, 3 p. m.)
}

Chatrman: Professor Charles DeGarmo, Cornell University.

Speakers: Professor Wilheim Rein, University of Jena.

Professor Elmer E. Brown, University of California.

Secretary: Dr. G. M. Whipple, Cornell University.

\section{THE PLACE AND OFFICE OF PEDAGOGY IN THE UNIVERSITY}

BY WILHELM REIN

\section{(Translated by Dr. Percy Hughes, of Columbia University)}

[Wilhelm Rein, Professor of Pedagogy, University of Jena, since 1886. b. Eisenach (Thüringen), August 10, 1847. Graduated, University of Eisenach, 1866; student, Jena, Heidelberg, and Leipzig; Ph.D. University of Rostock; Litt.D. Victoria University, Manchester, England. Teacher, Real-gymnasium, Barmen, 1871-72; Professor and Director of Normal at Eisenach, 1872-86. Author of Theory and Practice of Teaching in Primary Schools; Encyclopedic Handbook of Pedagogy; System of Pedagogy; and other works on pedagogy.]

Centuries have passed since Bacon, in inspired words, foretold the empire of philosophy and of scientific knowledge. In these days that empire has been realized. It has spread over all civilized peoples, binding them together with some invisible power. And hand in hand with this growth there has gone on, as in a tree, an inner development that has knit ring to ring, while it has produced also continually new extensions of the roots, so that the gold of scientific knowledge might be won even from the most secret veins.

Within this immense empire, which the mind of any one man no more can comprehend, pedogogy, to the present time, has lacked recognition as one link of the great chain of interconnected sciences. Only in isolated instances has it won for itself a place. Is its fate, then, that of the poet in Schiller's Teilung der Erde, who appeared on the scene only when Jove had assigned every seat to the dwellers of Olympus? If so, why fared it thus?

This result is the effect of several causes, which on closer inspection must be adjudged the work of mere prejudice.

In the first place it is often urged that pedagogy is not a science but an art. Perhaps the thought here is that expressed by Gregory of Nazianz: "The education of man is the art of arts; of all creative activities it has the greatest variety of aspects, and is the richest in problems." Or perhaps the thought is that of Melancthon's 
epigram: "The training of youth is a task greater than the conquest of Troy."

Then, too, we often hear it said that the power to teach cannot be imparted, resting as it does on natural endowment; for all educational efficiency turns on personality, which is dispensed by God alone; it is a matter rather of inspiration than of knowledge. Now no one is so foolish as to deny the power of personality in education; but neither can we question that everywhere true talent must be sustained by definite knowledge. Great artists, whether poets or musicians, painters or sculptors, never have despised knowledge, but rather have felt the necessity of devoting themselves to the scientific foundations of their art. Why should this be less true of the artist in education?

Art as a sum of capacities, combined for the attainment of a definite result, is judged by the performance. But artistic activity would ground itself on scientific principles; true power seeks the support of precise knowledge. The art of education, in like manner, points to the science of education. This is the meaning of Kant's dictum: "If education is to achieve consistent practice it must transform its routine methods into science."

This transformation has been effected by sciences more ancient than pedagogy, the practice of an art having led to systematic research and to the scientific formulation of its results. Thus in the domain of theology the art of preaching and of religious instruction is sustained by the sciences of homiletics and catechetics; in that of medicine, the art of surgery rests on the sciences of anatomy and physiology; in husbandry, the practice of agriculture as an art rests on chemistry and mineralogy, etc. Every type of activity that would be rational and that would keep in touch with the active life of the nation seeks secure foundations in science. Here let us recall a saying of Cicero: "To insist that in matters of most weight there is no science, though no trivial matter can dispense with it, is to speak with little reflection, and to spread error in things of the greatest importance."

But how could this error creep in with regard to the education of man? It is likely enough that it occurred through paying too exclusive attention to the efficiency of particular educators. In so doing each observer received the general impression that native endowment is the chief requisite for productive effort. Then the wellknown proverb came to mind, Poeta non fit, nascitur; and so it came about that very little value was assigned to what can be acquired through scientific, systematic methods.

This conclusion is the result of a twofold error. In the first place, men ignored the fact that natural endowment, to achieve its full perfection, stands in need of clarification and deepening by means 
of knowledge acquired concerning the highest aims of human progress and the best ways of securing them. The artist needs such training no less than the educator; indeed, the latter needs it the more in that he has to do, not with formless matter, but with a natural organism, which furnishes the laws of its own development. This organism the artist-educator must examine scientifically if he would enter on its development with a definite plan, and not follow vague impressions. The thoughtful educator will systematically seek to determine how far a certain result is attainable, when it is best sought, and how it is best secured. He assumes responsibility as to whither he would lead his pupil. On this point, too, he must get his bearings scientifically, both as to the alternatives present and as to the choice between them. In this way he is impelled irresistibly to scientific investigations.

In the second place we must remember that in considering the special problems that confront any one educator we touch on but a small section of the wide domain of pedagogy. The great and important field of the educational system, - school organization, administration, inspection, the training of teachers, etc., - all this has nothing to do with the art of education; but it is just here that the purely scientific problem comes to the front, that consists in deriving from the economic and political eonditions of the country, as well as from the religious, the moral, the scientific, and the artistic tendencies of the people, the organization of the general scheme of education appropriate to it, and the formulation of its underlying principles. When it has gained an insight into the past, pedagogy can turn its gaze upon the future of the people, not yielding of course to mere prejudice or fancy, but standing on the basis of scientific conviction.

When we thus study the educational system, our attention turns from the individuals that are to be educated to the society to which they belong. This forces on our notice the conception of the process of civilization. To this great process the rising generation must be conformed, so that it may in due course carry on the work, clearly conceiving the tasks that the future shall present, and bringing them to completion.

In this connection we must remember that the future of a people is not dependent on its wealth, but on its productive energy. That is the pillar (Kapital) on which rests the political, scientific, economic, and artistic greatness of a people. So long as a people retains undiminished its productive energy, so long will it hold an independent position in the family of the nations. The greater the productive capacity it can develop, the greater the portion it will win in cultural development. For this reason all who hold dear the welfare and the progress of their race will direct their efforts towards 
the strengthening and the increase of this national "capital" on which the permanence and extension of the people depends.

Now this productive energy of a people is active in many fields. On the one hand it is directed towards the preservation and the increase of our spiritual possessions, towards art, and science, morality and religion. On the other it turns to the exploitation of the riches of the earth, to their preparation and distribution as raw products, to manufacturers also and to commerce.

To what extent fundamental principles can here be laid down it is the task of the science of political economy to establish. This may be defined as the science of the proper organization of the material possessions of a people. At its side stands pedagogy as the science of the organization of the spiritual possessions. Both, moreover, are in the service of the science of statecraft, which is devoted to setting forth along well-marked lines the aim and mission, the ways and means for the people's advance toward civilization. Above all, that science would prepare the future progress of the people, bringing influence to bear on the generation that is now coming to maturity, whereby the march of civilization may be led always to still nobler ends.

Thus the work of education and of culture is part of a great system. It is an important factor in the life of a people. It stands out from an impressive background. Hence it is of great importance to organize it in the right way and so to carry out its design that the bodily and spiritual health of the people shall be preserved and augmented, and thereby its productive efficiency.

It is this task that the science of pedagogy adopts as its own. Therefore the same place is to be accorded it among the sciences as to the science of political economy.

The further objection has been raised that pedagogy stands on uncertain ground, that its results are so questionable that we cannot assign it a place among the sciences. But this objection also must be abandoned. In addition to uncertain and disputable results there are to be found in pedagogy assured possessions, just as is the case in other sciences, for example, political economy. Here, too, one lights on opposed points of view, and often wanders in a maze of contradictions and unverifiable statements; yet no one denies that political economy possesses the character of a science.

The lot of pedagogy is closely connected with the development of ethics and psychology, just as the science of medicine is closely connected with those of physiology and anatomy. To the extent in which uncertainties appear in those fundamental sciences they will appear also in the science of education. So, too, just so far as verified mateilal that has survived the purifying fires of scientific investigation is to be found in these sciences, to the same extent pedagogy may boast of fixed foundations. 
Let us now consider more closely the relation of pedagogy to these two sciences, and at the same time its relations to physiology. At the close, moreover, let us consider the thread that binds together the science of pedagogy with the sciences of politics and theology and with the philosophy of religion.

(1) The relation of pedagogy to ethics. While theoretical philosophy treats of the standards of knowledge, practical philosophy or ethics investigates the standards of human action. It explains not what is, but what should be. It establishes criteria for the evaluation of things; it embraces the appreciation of all that is.

No one can tell whence we came or whither we go. But here we are, and since we are here we try to give our presence significance. This we effect in so far as we do not spend our days without purpose, but rather set ourselves goals to strive for. Practical philosophy would point out the supreme end of human existence, that in which supreme contentment may be found. For this reason, it is urged, it takes the lead among philosophic disciplines. In it every Weltanschauung finds its centre of gravity, inasmuch as it determines the rational basis of human conduct.

Moreover, since we men are essentially volitional, we cannot cease from the delineation of some such supreme goal. We seek to produce through toil a condition of things in conformity with man's noblest purposes. We would direct the life of man towards its proper end in accordance with its nature. Only thereby do we attain the solution of the riddle of our existence here.

As the result of speculation concerning the purpose of human existence practical philosophy now submits to us a scheme of moral ideals, to the level of which we must rise if we would comprehend our problem. In these ideals are to be found the exemplars both for the individual and for the social will. They form a system of precepts which, as precipitate of the flow of moral development, can claim an independent and an absolute value.

Ethics presents to us such a scheme, but it cares not how much or how little its ideals can be realized. It is not at all concerned with the difficulties, small or great, that attend the introduction of those ideals into daily life. Therefore ethics needs supplementation by a science whose province it is to show how the demands of the ideal can be brought near to daily life, and be firmly established therein. This is the work of pedagogy, since it investigates how, through the proper education of youth, we may make ready the way for the dominion of moral ideals. Thus ethics inevitably leads to pedagogy, which is applied ethics, in that it brings ethics into the actual life of man, bridges the gap between the ideal and the real, and makes theoretical ethics a force in civilization. For the realization of moral ideals meets many obstacles, both from without and 
from within, due to the nature of our daily life and to the course of the world's routine, obstacles that can be overcome only by strenuous activity. To this end that education is efficient which proceeds on rational lines in accordance with the dictates of pedagogical science.

It is concerned with the molding of the race that is now coming to maturity, and therefore prepares the way for a state policy which shall, in like manner, seek to apply the principles of ethics to its modes of influencing the immature. Though educational activity is in the first place directed toward the minds of individual youths, yet it turns its glance at the same time toward the social conditions amid which those individuals later must move. Therefore it is always carried on in connection with investigations into social phenomena.

Because of this close connection between ethics and pedagogy it is necessary for the latter to consider with care what ethical standpoint it should adopt. For the character of a pedagogical system is determined by its ethical foundation. This raises the question, what ethical system should serve as the foundation for pedagogy: Only a brief consideration can be given to the difficulties involved.

The well-known skeptical attitude of Schleiermacher, who refused allegiance to any particular ethical system on the ground that there is none that all accept, has recently been revived, e. g., in Dilthey's essay published by the Akademie der Wissenschaften: it is urged that ethics cannot define an end of life that shall be valid for all, for such ends always appear under historical conditions that make them of only relative validity. They vary with the successive epochs of civilization; and the educational purpose that depends on such life purposes must in consequence suffer from the same historical conditions.

This skeptical ethics is without doubt right in urging that an end which is conditioned historically cannot claim to be universally valid; but no less certainly is it wrong in failing to mark amid the transient ideals of education the elements that persist through all. And it is just those elements that evolution presents to us with a character of inner necessity, that a positive ethics must bring to light, sharply distinguishing between the absolute and the merely relative. Throughout the several historical epochs relativity has clung to the changing ideals of education, to the several applications within the actual world of those values that ever remain the same. But the absolute is to be found in those successive evaluations which have maintained their fundamentally identical character throughout the past, - in the decalogue, for example, and in the moral teachings of Jesus.

From such constituent elements ethics constructs a system of all that is valid for morality. To appreciate that system we must listen to the inner voice, whereby we may appreciate the truly good, 
the crown of our spiritual life, where dwells the real self. If we attain this knowledge, we must also have the courage and the steadfast will to esteem these spiritual goods the very essence of existence, and to direct our lives accordingly, with firm faith in the unending, upward evolution of spirit.

An ethical system that sets forth these supreme moral standards, both for reflection and for action, that presents them as a system of moral ideals, must serve as the spiritual basis of educational doctrine. As in the progress of mankind these ideals are brought forward with increasing clearness, they should also with increasing clearness count as decisive factors in that individual development which education effects.

(2) The relation of pedagogy to psychology. Essentially different is the relation of pedagogy to psychology. When we have determined the purpose that pedagogy has to achieve there still remains the difficult question how those ends are to be attained. Ethics contributes the goal for which education should strive, but it has nothing to say either concerning the relation this task sustains to the individual that is to be educated, or concerning its feasibility. These matters are to be decided by what psychology shall teach us about the possibilities of mental development. So we turn now to consider the means which the educator employs to attain his ends.

And let us note that it is not a question of what means in general lead to that end, but it is of the first importance to know in what order, in what combinations, under what circumstances, with what intensity we must employ those means to attain the given end. To these questions the only science that can offer a solution is that which treats of the laws that govern the inner life of man, - psychology. This science, then, decides what methods shall be employed, and what their efficiency is. It informs us of the mental character of the individual; for it is the individual that is the material on which the artist in education has to work. This material is never laid bare in all its peculiar features, nor does it admit of a priori construction. Rather we have to search for it in the heart of each individual, and, also, in the environment that is natural to him. This is to be done with the help of psychology. Every artist must have a minute acquaintance with his material if he would produce a work of art. In like manner the educator will achieve nothing with his pupil unless he knows those psychical laws that govern his inner life.

This is of the greatest significance. For in education we are concerned with the excitation and the fashioning of psychical life as a result of external influences. These influences are only possible in so far as there are invariable laws controlling our inner life. A theory of education is conceivable only on the assumption that our psychical activities and states follow universal laws determined by 
man's inner nature. We start from the assumption that in the constitution of the psychical process there can exist no cause that acts one way at one time, and another at another time. The laws according to which ideas enter into varied associations in our consciousness, developing in those associations all the remarkable phenomena of our widely ramifying soul-life, are natural laws, as rigid and unvarying as those under which the heavenly bodies describe their mighty or bits. But, while the latter continually unfold their secrets to the inquiring eye of man, the peculiarities of human personality still veil themselves in mystery.

Psychology would bring the light of knowledge into this obscurity. It would reveal within the rise and the development of psychical life those uniform processes from which result the inner life of the individual, as each moment it is manifested, - a unity characteristic of him alone.

Psychology, then, is conceived as a theory of self-knowledge. But not in the sense that man brings to light therein, out of peaceful seclusion, his most secret thoughts and desires, in order to line them up before the judgment-seat of conscience; rather in the sense that he turns his eye upon the course of his inner life, upon its pregnant, manifold, and interwoven complexity, that he considers the play of forces, their contending influence, their strife for mastery, that he seeks for those laws that govern the rise of psychical states and their disappearance.

Now the more clearly psychology apprehends the uniform character of the mental life, and the more manifest its expositions of particular occurrences become, the more precise and the more certain are those measures which pedagogy can adopt for its ends. Therefore, the bond between psychology and pedagogy is so close that progress in the latter depends upon the advances made by the former. The fate of pedagogy is bound up with that of psychology. Pedagogy is, in respect of the means it employs; applied psychology. Every advance in psychology must have its effects on the progress of pedagogy.

In Herbart we have a good example of this. His reform in psychology originated in the pedagogical necessity of treating ideas like forces, and of deducing the phenomena of mental life from the uniform relations of these forces to each other. Since that time pedagogy has preserved its close connection with psychology; but it is in our own times that this connection has become still closer owing to the discovery of new methods in the field of physiological psychology and in the study of the infant mind.

It is from psychology that pedagogy learns how particular events in mental life affect one another. In consequence we are enabled to influence that causal nexus through precise methods which have a 
definite educational end in view, even though we cannot expect that every mental state of the pupil will become so well known that we can predetermine every possible influence.

(3) The relation of pedagogy to medicine, physiology, and hygiene. Special importance should also be attached to the relation between pedagogy and medicine, for from the latter pedagogy receives the basis on which rest the measures and the laws that pertain to the foundations of the mental life, to the material organism, $i$. e., of the pupil, to his bodily growth and well-being. As to the intimate relationship between mind and body we have the oft-quoted and illuminating saying of Juvenal, mens sana in corpore sano. The continual interaction between soul and body makes itself manifest in the impeding of the mind whenever the body gets into bad condition, and in the mental advance that takes place immediately proper attention is paid to bodily welfare. Under no circumstances can bodily and mental development continue in disregard of each other. Therefore education must always keep in mind the physical well-being of the child. And in this matter education not only does not proceed independently, but it cannot do so without grievous error. On the contrary, it has to recognize the right of physiology and hygiene to dictate the proper course. Hence we see that these sciences are auxiliary to pedagogy, inasmuch as the correct and natural nurture of the child, from the physical aspect, can be undertaken only through their contributions to the subject. But, after all, they are only auxiliary and not constituent sciences, as are ethics and psychology. For pedagogy deals with mental training. To adopt a physiological instead of an ethical and psychological basis would be to lay aside its real character. The ends and the means of mental culture maintain an independent existence; educational theory and the ideal of an intellectual life have an independent development coördinate with that of physiology and hygiene. The latter lend their aid to the educator, but they cannot define for him the fundamental principles of his occupation. No doubt for psychological materialism physiology would be a constituent science; for the reason, however, that the former does not recognize the independent existence of the soul.

But, so long as we must needs cling to a definite distinction between the mental and the physical, - and this is the thesis of the parallelism of physical and psychical states, - just so long pedagogy will take its basal principles from ethics and from psychology. It can and should accept from physiology and hygiene only certain practical maxims to be followed by those who would earry on the intellectual life.

Pedagogy, therefore, must avoid claiming to be a branch of natural science. We cannot speak of a physiological pedagogy until natural 
science is in a position to lay down ethical maxims. And that is a task which its very nature forbids it to attempt; for no empirical investigation of what is can inform us what should be. When we speak of physiological pedagogy all we can really mean is that one science suggests certain methods to the other.

In all matters of proper care and nourishment pedagogy must turn to medicine. In cases of disordered nervous systems, or where the mind seems to be overburdened, there medicine offers a helping hand. Wherever we are concerned with the provision of all those external conditions, both in the home and in the school, that make for physical well-being, there we wait on the physician's word. A wide and important field in education belongs to medicine, but with that it must remain content. No more than theology can it claim all education for its province.

At this point let us briefly consider.

(4) The relation of pedagogy to politics, theology, and to the philosophy of religion. (a) Referring to the close relations between pedagogy and politics, Kant used these words: "Two human inventions there are that one may well esteem the most difficult of all, the art of government, and the art of education." In this saying he referred undoubtedly only to domestic politics, not to external politics or diplomacy. With regard to this latter it is a doubtful and much-contested point how great a part ethical principles can and should play in it. There is no such question as regards domestic statecraft. And it is just that fact that discloses the inner relationship that subsists between pedagogy and domestic politics, namely, that they pursue a common purpose. They form as it were a circle, the radii of which have morality for their centre. In both cases the end is indicated by practical philosophy, and psychology informs us of the aids and obstacles. Without practical philosophy and psychology, both are nothing but guesswork; and though even then great artists of exceptional genius might practice them, yet they could never aspire to the rank of scientific knowledge. Both pursue an ideal, a certain type of social ideal. The art of education is handmaid to the art of politics. It is the most important instrument of domestic politics, which could achieve no permanent results without its aid. For these reasons the education of the people has the important claim on the statesman that we have already indicated.

Politics and pedagogy have the same field. For an important part of the province of politics, which may be called state pedagogy, is to cultivate the idealistic tendencies in the life of the people and to provide for the dissemination of the treasures of civilization among those approaching maturity, while so confirming them in the practice of virtue that the work of civilization may continue. State pedagogy, therefore, extends not only to the world of adults, but 
also to the sphere of the immature. The physical and the moral health of both is its constant employment. And in the sphere of adult life this includes: the direction and inspiration of the press, since that influences the range of thought among the citizens; the nurture and maintenance of art, which molds the taste; the supervision of all those public performances that affect the manners. But though the actual range of the activities of state pedagogy may be very great in this direction, yet its effect will naturally be proportionately less, since adults are not easily moved from their settled course of thinking by the educational activity of the state. On the contrary, among those still approaching maturity state pedagogy can work with great effect. And this it has done in Germany to a very considerable extent. A great host of officials direct the course of the educational and scholastic administration, leading the youth onwards, step by step, from one examination to another, until they stand on the threshold of some life vocation, entering thereby the society of adults.

This course has assumed, during the nineteenth century, an ever more rigid and more definite form. State pedagogy has not been satisfied with organizing the system of schools and the general character of instruction, but has also taken active charge of the schools and of the instruction even to the point of sketching the lesson-plans and the methods. It superintends the execution of an effective body of statutes, and issues volumes of printed instructions.

Is there room, then, for a scientific pedagogy at the side of this state pedagogy? From the standpoint of the latter one might be disposed to contest the validity of the former, indeed even to regard it as a menace to the state, inasmuch as it might set up in opposition to the traditional usage and to the powers that be a scheme of ideal education, judged by which the existing conditions are grievously backward. And this might lead to the further conclusion that from this relation there could arise nothing but discontent, while a false conception of educational conditions might prevail. Every error in educational theory would be a menace to the state system of education.

This view of the matter, however, is untenable. History is far from testifying to the destructive effects of systems of educational theory. Certainly Rousseau's pedagogy was radical enough, but in the several nations the educational world has taken no great interest in it. The conservatism of the existing order offers sufficient resistance to insure society against hasty innovations. It is far truer that scientific pedagogy has in its relations to state pedagogy a great and splendid mission to perform. For it may render most real service by keeping state pedagogy from becoming inert, and in bringing to its attention new ideas and purposes, so that it may be neither text-ridden nor 
dominated by red-tape. Hence scientific pedagogy plays the rôle of contributor, state pedagogy that of recipient. It remains entirely free to take just as much as it pleases of the results scientific pedagogy has achieved.

It is obvious that a more real peril lies in the fact that state pedagogy is too much influenced by political considerations, since it has the actual power to carry out its purposes. Pedagogy can wield only an ideal power, through the conclusiveness, $i . e$, and the consecutiveness of its reasoning. It is only too easy for the political point of view to obscure the comprehension of the social character of education, since it partly overlooks and partly underestimates other elements that coöperate with the state in education, - the family, i.e., the district and the church. Hence pedagogy can serve as umpire here, and indeed; not merely in the matter of the educational system, but also as regards the actual work of instruction. At this point freedom must preside over scientific activity; here is to be found the peculiar task of pedagogy, which state pedagogy cannot take away. In school legislature, in superintendence, and in the general plan of education where they coöperate, politics is all too disposed to claim the whole field for herself. But in hodegetics and in didactics pedagogy finds its immediate problem, into which politics neither can nor wills to enter.

Pedagogy, however, is placed in an entirely false position when it is regarded as in the service of politics in the sense that education is forced into the service of a particular clique or policy that is but a part of the entire fabric of the state, so that that particular policy demands the support of pedagogy. Compliance with such a demand is the surrender of dignity, of all self-respect; it means the renunciation of principles universally valid in favor of the varying points of view of successive governments. On the contrary, philosophical pedagogy maintains in the face of such influences its own independence, rendering thereby to the state as a whole far greater service than if it sought always to point the way of the prevailing political breeze. Pedagogy is only too susceptible to political corruption. Hence the necessity of developing a pedagogy that is coördinate with politics, independent of it, objective and impartial, so that it may be the source of purification and rejuvenation wherever politics has become debased. It were prudent, therefore, for the state to take good heed lest scientific pedagogy suffer from restricted growth, to the end that in the higher institutions of learning, the centre, that is, of mental life, its importance may be appreciated and its development furthered.

(b) Relation of pedagogy to theology. Finally, let us consider the relation of pedagogy to theology and to the philosophy of religion. It is possible to approach pedagogy either from the standpoint of 
philosophy or from that of theology. One is not to be preferred to the other; and to meet the situation we must approach the field from both sides.

Between them there is a profound and permanent dissimilarity. As regards the theological starting-point we meet a restriction in the fact that there we must needs adopt as our basal science and as our point of departure a definite religious system, which includes also an ethical system; thereby pedagogy takes a definite imprint which holds only for a particular religious society. On the other hand, philosophical pedagogy has a surer basis, since it starts out from such common ethical and psychological tenets as the civilized nations feel to be essential to the maintenance of their character.

It may be suggested, however, that there is a tendency to turn away from those religious associations that come down to us from the past, and to adopt as a basis a common religion for all men, the product of the philosophy of religion. And then one can ask, as indeed it is asked, whether to the above-mentioned constituent sciences, ethics and psychology, we must not add a third, that of the philosophy of religion. Just as the theory of ethical ideals would set up a standard by which different peoples and different epochs may judge their dispositions and their actions, in order to learn what has moral value and what has not, so, it is thought, the universal theory of religion may systematize and establish as ideas of universal validity what presents itself to the religious needs of human nature as the deepest religious conviction.

But where shall we find this universal religion? Where shall we discover the totality of religious truths - which are accepted by all cultured peoples - so systematically arranged that they can serve as the proper foundation for an educational system? Or where is that philosophy of religion which, on account of its ideal value as the supreme product of the historical development of religion, can, in its own province, direct the minds of men? And would it have the power to assimilate those convictions that live in religious communities; in which, too, our children are reared?

So long as these difficulties exist it will be well for pedagogy to confine itself to ethical principles. In carrying out its educational designs it will find itself compelled to start from the basis of some established religion, unless it would build in the air. In the face of any philosophy of religion with its subjective construction, pedagogy must ever bear in mind that it has to deal with a complex product of evolution which involves many and varied ethical outlooks. These ethical implications can be unraveled and receive systematic and independent treatment. By this means pedagogy acquires an essential foundation for its system, - in ethics, that is,- - a foundation well able to support the superstructure. 
In closing, let us consider the relations in which pedagogy stands to other sciences. It clearly is indebted to several constituent and auxiliary sciences, the results of which it makes effective in a manner adapted to its own sphere of investigation. Hence we must describe it as an applied science, classing it with medicine, with agricultural science, etc.; it is erected on the basis of ethics and psychology. It has close relations also with medicine, and points of contact with politics and theology.

As an applied science it also has many opportunities to enrich the disciplines on which it is founded. Not only can it suggest new lines of investigation to ethics and psychology; it can also make independent contributions thereto; for example, in research that seeks the foundations of morality as they are revealed in the development of children, or in investigations into the physical and psychical growth of children. It can offer valuable assistance to theology in a practical way, in so far as it provides a method of instruction that is based on psychology, one that should give new interest to catechetics.

Because of this close relation between pedagogy and several other sciences it has been denied that it itself has an independent existence, and its field has been split up in the following fashion. The history of education is assigned to the history of civilization; educational organization is a matter of politics; the determination of the ends of education is the concern of ethics, since that would establish the end of human existence in general; the investigation of the human mind, of its knowledge, and of its activities, - that is the work of psychology; hygiene deals with the care of the body; while the method of instruction in the several sciences is best left to the several sciences themselves, since they are most competent to point the way in the field of knowledge with which they deal.

No doubt it is practicable thus to apportion the field. But no one acquainted with the subject will maintain that it would aid the educational progress of the nation. Through such a division we necessarily should lose sight of the mental unity which embraces the several factors that are associated in education, and which so regulates their reciprocal influence that they do not hinder each other. It is just because the field of education is so full and extensive, and because in it there cross so many of the threads of individual and social life, that there is pressing need for a philosophical reflection upon it, so that we may secure unity in so much multiplicity, and coöperation amid so much opposition.

When we consider that the subject of pedagogical science is man as a being susceptible to consciously directed influences, we find the requisite material in his physical and psychical constitution. When we consider the end for which man must strive we must turn to men 
in their ethical and social connection. Thus is revealed precisely the limits of pedagogical activity: it is the broad field that extends from the point of departure - the child with all its educational needsto the goal, the trained man grown to individual and social independence. This is beyond dispute its field. I present, in closing, this comprehensive outline:

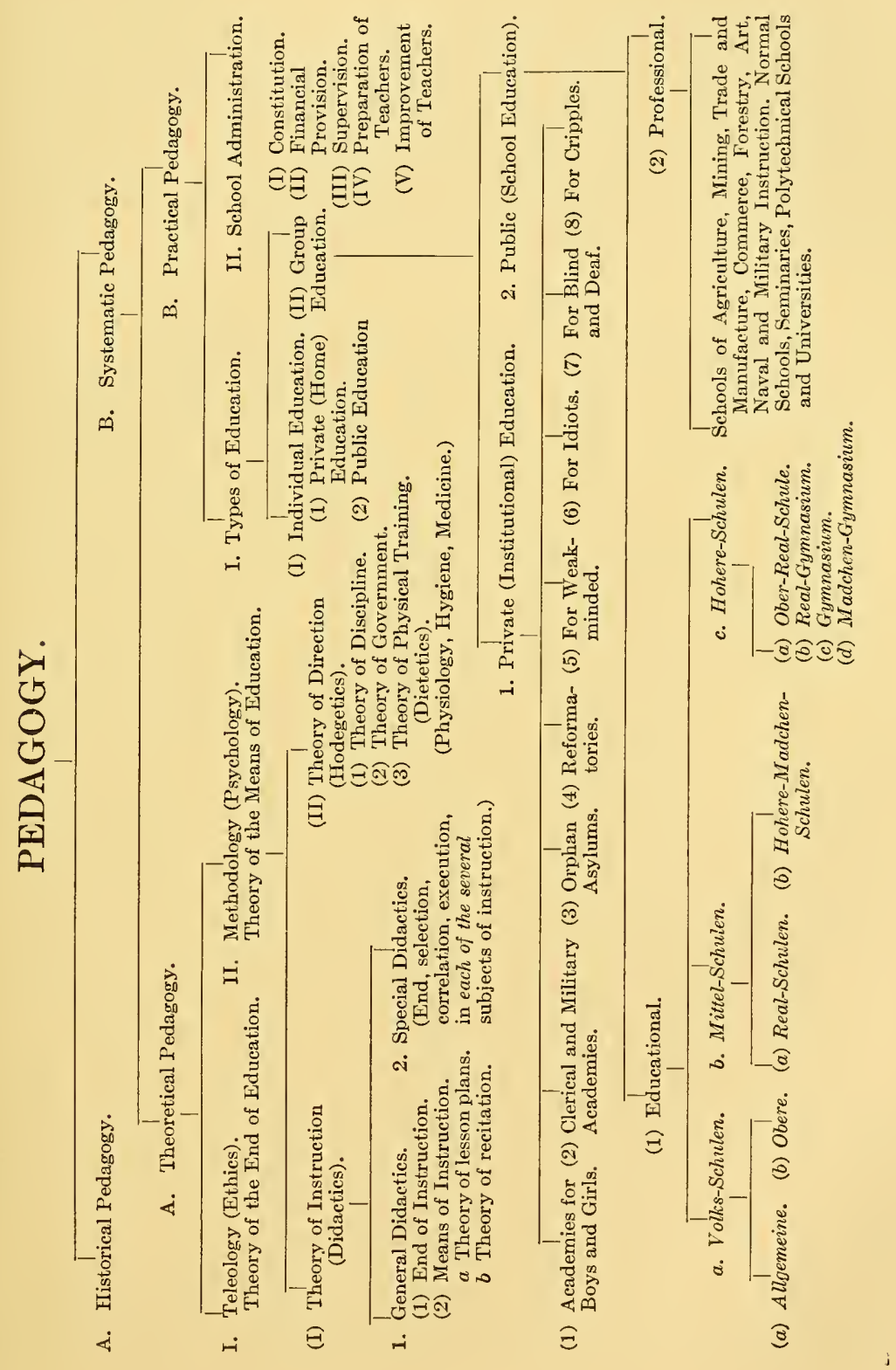




\title{
PRESENT PROBLEMS IN THE THEORY OF EDUCATION
}

\author{
BY ELMER ELLSWORTH BROWN
}

[Elmer Ellsworth Brown, Commissioner of Education, United States, 1906; Professor of Theory and Practice of Education, University of California, 18981906. b. Kiantone, Chautauqua County, New York, August 28, 1861. Graduated, Illinois State Normal University, 1881; University of Michigan, 1889; Ph.D. Halle-Wittenberg, Prussia. Principal of public schools, Belvidere, Illinois, 1881-84; Asst. State Secretary, Young Men's Christian Associations, Illinois, 1884-87; Principal High School, Jackson, Michigan, 1890-91; Acting Assistant Professor, Science and Art of Teaching, University of Michigan, 1891-92; Associate Professor, University of California, 1892-93; Professor, ibid. 1893- . Author of Notes on Children's Drawings; Making of Our Middle Schools; Origin of American State Universities; and other various addresses and articles.]

IT would be gratifying if we might speak of educational theory as the system of positive knowledge in the domain of education. But if we limited the term to things known and the sure interpretation thereof, there would be little to tell in any account of what that theory covers. We must extend our use of the word to include not only established truths, but also hypotheses which have been worked out with a good degree of care, on the basis of some knowledge of the facts involved, - hypotheses which may accordingly be regarded as fairly started on the way to a place in the body of established truth. It is better, however, that we should stop here and not include, under the term theory, the whole body of unsifted educational suggestion and sudden educational sentiment which men commonly have in mind when they speak of educational theories.

Any well-rounded theory of education must include an orderly survey of the results of educational experience and the interpretation of that experience in terms of philosophical system. The empirical and the philosophical elements are both indispensable. It is impossible, however, to devote equal consideration to both elements in so brief a paper as this, and the emphasis will accordingly be thrown on the empirical side, with only occasional reference to the ultimate conceptions of philosophy.

Because of its instrumental relation to the solution of all other problems, the methodology of educational inquiry may be regarded as the first of present problems in the theory of education. It seems advisable, accordingly; to begin our examination of problems with some consideration of this preliminary problem. ${ }^{1}$

${ }^{1}$ It is hardly to be supposed that any one will confuse the methodology of research, here referred to, with the methodology of training and instruction, which receives much more attention in pedagogical treatises. There is, in fact, a real and highly significant connection between the two. 


\section{The Method of Educational Research}

Roughly speaking, we find at least four methods of educational theorizing already in use: The philosophical, the historical, the natural-scientific, and that proceeding directly from experience in the art of education. So complex a subject must necessarily employ somewhat different methods in its different branches. Even within a fairly homogeneous science this is the case. Much more must it be so in a subject which is not a well-marked-off science, but rather the congeries of knowledge with which an institution, a profession, is concerned. It may be that a wholly new method will not be needed; but there is urgent need of a sharpening of the several methods already employed, each of them highly diversified within itself. There is need, too, of a closer application of those methods to the specific facts which they are to collect and explain, and of an adequate correlation of those methods and of the results arrived at through their use. And new developments of method which promise actual increase of knowledge are to be sought and welcomed and employed. A few notes on these several modes of procedure should be added.

Historical research has a highly elaborated method of its own. Any adequate history of education must stand the severe tests of this method. Only such educational history can offer lasting contributions to our educational theory. We must seek in historical facts, as interpreted with historical insight, a knowledge of those social ideals, convictions, purposes, which determine the direction and the content of the education which any people will provide for its young. In democratic countries, in particular, this historical knowledge leads up to an understanding of public opinion, by which public education is fashioned and inspired. These things reveal the informing spirit of education. The knowledge of what is and has been in human institutions cannot, like a knowledge of natural laws, enable us to forecast future events with anything like certainty. Nor can it alone give guidance in the choices of the future. It does not of itself furnish us with any adequate theory of education, but it does contribute much that is indispensable in the framing of such theory. Classical examples will occur to every one, such as may be found in the writings of Aristotle and of Montesquieu. In their widely different ways, such men as Letourneau, Rashdall, Lexis, Balfour, have, in recent years, been making notable contributions to this side of educational theory. And vast collections of material for future work of this kind are made by the English Education Department, the Gesellschaft für deutsche Er:iehungs- und Schulgeschichte at Berlin, and other agencies. 
The extension of the methods of the natural sciences into several sciences contiguous to education offers a hope of measured and objective certainty in wide reaches of educational territory. For educational purposes the representative natural science is psychology. That indeterminate science has spread over new fields, employing a variety of methods, and in many instances its problems are such as are of vital concern to education. Here, again, it should be remarked that no psychology can permanently serve the purposes of educational theory which does not satisfy the severest standards of psychological research. So long as "educational psychology" is less than psychology, it is less than educational. Even among stanch friends of educational research there is still a disposition to accept as "pedagogical" some forms of psychological study which are not sufficiently scientific to be called "psychological." It is not to be forgotten, on the other hand, that the results of pure psychological study are not ready-made and finished materials of educational theory. There is undoubtedly much intermediate work to be done in order that psychological methods may render their full service to education; but such work should be intermediate in its scientific position only, and not in the excellence of its quality. It would be easy to find examples of good work in the psychology of education, but difficult to pick out any few examples for special mention. Numerous studies in the several aspects of fatigue have provided matter for educational application which has not as yet been fully utilized. Studies in memory, along lines made classic by Ebbinghaus, are of considerable educational significance, chiefly as showing the limitations of training in this field. The studies of James and Baldwin in the subtle workings of the mind on the side of its motor activities, overlap the field of education, and the treatment by Dewey of problems immediately educational gives striking illustration of the relation of psychological to educational method.

So far, the contributions of historical and natural science. But this is not all; and when we have surveyed what history and natural history have to offer at the present time, we are left with the sense that a vital centre of educational theory still has not been covered. Education is an art which addresses itself to the attainment of social ideals, subject to conditions discovered by natural science. It is precisely in the formation of correct and comprehensive judgments relative to this art that our educational theory finds its place and use.

How, then, are such judgments formed? As a matter of fact, in this as in other arts, they commonly arise out of individual taste and opinion; and that in turn is an outcome of individual experience thrown on a background of traditional doctrine. The vexing question is how to sift and correct that opinion, how to elevate that taste 
into something having universal validity; how, in a word, to make educational judgments conformable to truth. Such sifting and correction have not been wholly wanting in the past. The traditional background of individual opinion itself has served in some rough fashion as a corrective; for that which it has offered has already survived more tests than the ordinary experience of one lifetime can apply, and is likely accordingly to be wiser than the independent wisdom of most individuals. But the more wise among writers on education have supplied their own corrective of individual caprice, in their broad knowledge of contemporary life, as well as of contemporary education, in their judicial temper, their wide sympathies, their moral elevation and sense of the fitness of things. The opinion of some unusually gifted individual has now and again rallied about it many followers, making a school of educational thought. The varied judgment and experience of the members of such a group, coöperating, comparing views and results, criticising one another, have led to conceptions which are presumably nearer to truth than those even of the leader himself. In recent years, governments and educational bodies have sought systematically to correct the judgment of individuals through conferences of many individuals, chosen from different schools of thought, with reference to their recognized and varied abilities. In this way there have been added to our educational literature such valuable papers as the reports of the Dezember Konferenz and of our own Committee of Ten.

This enumeration of correctives is not exhaustive, but it is sufficient to show that in the past a serious endeavor has been made to render empirical judgments relative to the art of education more free from the caprice of individual opinion, more nearly universal, more accordant with the truth of things. But such procedure at the best has left much to be desired. The resulting doctrines have been full of assumptions the correctness of which is doubtful; assumptions which, at the same time, are capable of being tested as to their correctness by psychological, historical, or other scientific research. The more the scientific spirit comes abroad in the field of education, the more clear becomes the demand that, wherever possible, the results of such research shall replace the naïve pronouncements of even the finest unscientific insight.

So far as we can foresee, education must continue to offer free play to the creative spirit of teaching, without which the teaching art cannot be true art; and at the core of educational theory must still be that personal sense of personal and social values, that discriminating appreciation of excellence in things done, which is needed to guide, interpret, and criticise the finer products and processes of the human spirit. The offerings of sociology, psychology, and the physical sciences are not contributions to our knowledge of educa- 
tion till they have been appropriated and organized at this vital centre of educational doctrine, where we are immediately concerned with the processes, products, and ideals of education as an art.

In this attempt to get at the characteristic methods of educational theory we find that we are dealing with processes closely related to those employed in the science of politics. But it may now be added that both political judgments and educational judgments are very vitally related to judgments in the field of esthetics. ${ }^{1}$ The methods which we have been considering are paralleled by some of those with which, for example, modern movements in literary criticism have made us familiar. We find here the same endeavor to correct subjective opinion by every means which may give it a wider validity: by the appeal to the findings of broad experience and slow-sifting time; by the appeal to history, to anthropology, to psychology and sociology. In education as in literary criticism it is impossible, by any amassing of exact scientific data, to dispense with the large-minded discrimination of men whose cultivated taste and moral sense are weighted with full knowledge of their kind and of their time.

We may make use at this point of the distinction made by De Quincey between the literature of knowledge and the literature of power. Placing the line of demarkation where De Quincey did not place it, but where the development of natural science since his time might suggest that it now be drawn, we may say that much of the better literature of education, as we have it now, is literature of power rather than of knowledge. Writers of genius - publicists, moralists, and teachers - have contributed works of undoubted influence and value to our body of educational doctrine. Even when a lack of fully ascertained fact is apparent in such writings, and when the lack of scientific system and completeness is equally noticeable, they often go straight to the heart of education as a problem of contemporary life. Some of the educational writings of Matthew Arnold, of M. Fouillée, of President Eliot, of Sir Joshua Fitch, may be mentioned as widely different examples of the literature here referred to. In these instances we have a literature of power, weighted with much of accurate knowledge. It must be the aim of improved method in our educational theory to make the literature of power in education increasingly a literature of knowledge and power.

Having in mind such considerations and examples as have been brought forward, we may now partially describe this central, characteristic, correlating method of educational knowledge as the method of educational criticism. The term is not a happy one, and one more adequate can doubtless be found. If used, it should be under-

${ }^{1}$ The treatment of ethics by Herbart as a division of esthetics will be recalled. 
stood as meaning criticism in the larger and more vital sense appreciative, constructive, creative criticism. However closely affiliated with esthetic criticism on the one hand or with political science on the other, it can draw nothing finished for its purposes from these or any other sources. It must make its own way, determine its differentiæ, establish its peculiar canons, with all patience and persistence. The distinct need of the immediate future is that by all possible means the literature of power in education, including the literature of educational experience, be rendered more scientific. ${ }^{1}$

In the foregoing discussion several different methods of educational research have been mentioned. It should be noted that no sharp distinctions are drawn between them. They are overlapping and coöperating methods, and to render their coöperation effective, to prevent the waste of a working at cross-purposes, is a prime consideration in educational theory. Certain elements of good method reappear wherever we go. The method of comparison is one of these. Another, overlapping this, is the statistical method so satisfying in the sense of exactness and finality which it brings, and so misleading oftentimes with the appearance of explanation where it has merely arranged materials preparatory to a possible explanation. These are modes of procedure which cannot be dispensed with in our educational research, and must be employed in their most perfectly developed modern forms. Quite as important are the objective observation and accurate description of phenomena, which must always be a first consideration in any method which aims at being scientific. ${ }^{2}$

It should now be added that no educational theory can be fully scientific till it has been made to take its place in the ordered system of philosophy. The principles of psychology and the related sciences, the social purposes revealed in history, and the standards of excellence in the art of teaching, are to be brought within the scrutiny of philosophical method, and made to show the ultimate grounds of their scheme of values and of personal influences. The tendency of some students to approach educational theory as a branch of a philosophic system, while neglecting any close examination of the facts of education with which it has to do, is certainly at fault. But equally faulty and inadequate is the procedure which is content with the mere generalization of educational facts, and fails to see those facts and generalizations in just perspective in the organic whole of human

${ }^{1}$ It may be found that the theory of other professional and institutional subjects shares, along with that of education, in this character of art criticism; and as the sciences and the arts become more intimately bound together, the methodology of the sciences even may be in a measure influenced from this side.

2 Something of this sort is, I think, what Professor Hanus has in view in his papers on the formulation of educational doctrine; and in a different way, what Dr. J. M. Rice has in view in his recent articles in The Forum. 
knowledge. Empirical judgments, as they become clarified and organized, reveal implications which can be adequately explained only in the full light of philosophy. The approach may be from the one side or the other, according to the student's predilection, and the emphasis of attention be placed at one point or another, but no partial view of the relations of education can wholly satisfy. Still further it should be clear that no philosophy of education is worthy of the name which is not an integral part of a rounded philosophical system; and no lower grade of philosophizing will serve for the problems of education than that which is demanded for the solution of the other capital problems of philosophic speculation. In other words, a philosophy of education must be the work of a philosopher. Notable examples of such work are at hand. To say nothing of ancient masterpieces, it is sufficient to refer to the pedagogical writings of Herbart, the Pädagogite als System of Rosenkranz, and the work by Commissioner Harris entitled Psychologic Foundations of Education. In a rather more fragmentary way, the educational implications of the doctrine of organic evolution have been worked out by Herbert Spencer, by M. J. Guyau, and by numerous other writers, and in one form or another that doctrine has influenced very profoundly the most of recent studies in this field.

Coming now to a consideration of problems calling for solution in the near future, we are embarrassed by the fact that such problems crop up everywhere, and choice among them for the purposes of this brief paper is extremely difficult. For many reasons, however, which need not be enumerated, the part which education has to play in bringing up men and women fitted for coöperative freedom in our modern societies, seems to offer the most significant and interesting themes. We proceed accordingly to take account of some of the problems of this group, viewing them as central to the present educational situation and immediately bound up with present-day practice of the art of education.

They are problems that must be attacked by such methods as we have at hand or can make available for use. We shall very soon find that the solution of these central problems depends upon the solution of certain related problems in contiguous fields, to which various special methods, already fairly well ascertained, may be applied. The small group of problems with which we begin determines then the choice of subjects for consideration in those related fields; and the whole set of questions here proposed, in their relations one with another and in the various handling which their varied character suggests, may serve to illustrate the composite method of educational research which has been roughly sketched in the preceding paragraphs. 


\section{The Central Group of Problems: Relating immediately to the} Art of Education.

In this group we may note three problems, all of which are living questions in the education of different peoples to-day, all of which are, moreover, intimately interwoven one with another. They are those of:

(1) The relation of election to prescription in studies;

(2) The relation of studies for general culture to vocational studies;

(3) The relation of guidance to spontaneity in the methods of instruction.

The elective system, under some very broad limitations, has long held sway in the German universities. During the past half-century and more it has been making steady progress in the colleges and universities of America. In the higher institutions of other lands its influence is present, and it is working itself out in a great variety of forms. By degrees it has made its way downward into the secondary schools, and we have even seen something of it in the higher grades of the elementary schools.

This is a movement in the direction of a larger freedom for the personal development of the individual and of every individual who rises to the higher stages of education. According to different points of view it tends, on the one hand, to the dissolution of some of the best of social bonds; or, on the other hand, to the fitting of men for a higher service of society.

Closely connected with the problem of electivism is the problem of the relation of general to vocational training. The principle of election has always been recognized, where permanent castes, have not been established, to this extent at least, that a man's vocation has been chosen by him or for him from the several which may have been open; and that some part of his training has been specialized in accordance with this choice. A current tendency runs toward a stronger emphasis on the importance of vocational training, of training for arts and trades as well as for the "learned "professions, and toward the demand that the profession shall be chosen to fit the man even if choices made in earlier years be freely changed as the learner's character and aptitudes become better known. With the growth of election in studies pursued for general culture, the distinction between culture courses and vocational courses has become obscured. In their spirit and methods and subjects of study, general and technical schools have become in a measure assimilated to each other. The implications of this tendency, its advantages and dangers, present a large problem for theoretical solution.

The emphasis on individuality and freedom in the choice of course and of studies is accompanied, especially in Anglo-Saxon lands, by 
a like regard for individual choice and initiative in the processes of instruction and of training. Our schools tend to become institutions of coöperative self-education. The implications and limitations of this movement and its permanent relations with the organic whole of educational thought and practice, furnish another important range for theoretical inquiry.

The current discussion of these questions, in so far as it rises above the mere iteration of commonplaces, belongs mainly to the literature of power rather than that of knowledge. It embodies the opinion of many large and forceful personalities, with their differing estimates of educational tradition, of personal and social values, of the changing needs of our time. It shows various degrees or creative daring on the part of men who are the makers as well as the apologists of our modern education. In a word, it is literary art, reflecting and interpreting the art of education. As such it is of very great significance. It is not at all the business of educational theory to brush aside such discussion, if that were possible. This literature of the art of education may serve rather as a base for the movement toward making this part of our theory of education more thoroughly scientific.

This is far from saying that nothing has yet been done toward a scientific examination of such subjects. It must be admitted that adequate objective and critical treatment of them is generally lacking or has appeared only in fragments and beginnings; yet one who appreciates the positive excellence of some of the art-literature of these questions, with its occasional appeal to scientific and philosophical knowledge, will venture only with extreme diffidence to offer his suggestions of improvement.

The chief improvements to be suggested are a more adequate definition of the questions at issue, which shall take account of their place in the historical tendency and development to which they belong; and the substitution, wherever possible, of accurate statement of facts, objectively determined, for easy assumptions and mere personal opinions. The actual working and results of different systems should be examined with greater thoroughness, and more than superficial comparisons should be instituted among them. Where such facts admit of it, they should be subjected to statistical treatment, and all care should be taken to see that the things enumerated and compared are of the same denomination - are comparable - the attendant circumstances which give to every fact its full significance being taken fully into the account. It is not unlikely that ways may be devised of adding systematic experiment to our observation of that which comes to pass under ordinary conditions, and so of reducing. somewhat the number of distracting variable elements and defining more exactly the play of calculable influences. 
It is evident, however, that there can be no adequate solution of any of these problems without adequate related knowledge of psychological fact and historical tendency; and the ultimate insight of philosophy is equally indispensable, if interpretation is indeed to interpret.

\section{The Second Group : Institutional Problems}

The problems which have been brought forward as constituting a central group are elustered about thetideal of individual freedom in education, the ideal of Lernfreiheit. But this Lernfreiheit is conditioned by Lehrfreiheit. To understand the present significance of such academic freedom, it is necessary to know somewhat intimately the history of educational institutions, and particularly to know the history of their relations with the other great institutions of human society since the latter half of the eighteenth century, that is, since the time of the American and French revolutions.

Studies in this field should lead to an understanding of:

(1) The institutional relations of the modern school;

(2) The educational significance of modern democracy; and

(3) The internal relations of modern educational systems, and particularly the relation of institutions of higher education to institutions for the education of the people.

These are very broad questions, but they are such as admit of objective investigation. Such investigation should make clear the meaning and tendency of that individualism which has so deeply affected our modern schools by making clear the dominant ideals of modern civilization and the related bearings of the modern conception of academic freedom.

It will be seen at once that these problems are interwoven with one another as well as with those designated as the central problems of this discussion. The great change through which the institutions of education have passed in coming under the general control of the civil power after long domination by the church has not been by any means a simple process, which could be set forth in a formula. It has been, instead, an extremely complicated movement, and one well worthy of such painstaking historical inquiry as has been devoted to other relations of church and state. Out of this shifting and conflict has arisen a somewhat clearer consciousness of the functions of the school. In changing from an organ primarily of ecclesiastical propaganda to an organ of political propaganda, the school has tended to throw relatively greater emphasis on those parts of instruction which are not in the nature of propaganda at all - those parts in which it works directly for the betterment of human life instead of working to that end mediately, through the inculcation of principles 
peculiar to any other institution. What effect on this movement the rising power of industrial organization will have is problematical. It is not unlikely that in some ways the educational demands of industrial institutions may be thrust in between those of church and state. Knowledge of industrial and commercial history is increasingly needed for an understanding of educational movements, now barely begun, which loom large in our future.

In the mean time, the institutions of education have been passing through a notable internal development. Education has come to be regarded as itself a centre of manifold but unified interests; it has become conscious of a far-reaching mission; already it has its own highly-developed ideals, traditions, and loyalties. Such sentiments were abroad in the early universities. With the upgrowth of provision for universal elementary instruction, educational systems commonly appeared in two grades or divisions, pursuing somewhat diverse ends, and with a considerable rift between them. More recently this divergence has been disappearing. Universities and lower schools have drawn nearer to each other; university ideals have come to animate schools of every kind and grade; the ideals of popular and technical education in turn have influenced the universities; the manifold institutions of education have, in a word, become knit together in spiritual unity, making in effect one great worldinstitution. And this has ceased to be a merely subordinate and tributary institution. It has virtually taken its place alongside of the other great human institutions as one of the cardinal concerns of human society.

No one could hope to characterize in a paragraph the informing spirit and ideals of this great institution of education in its modern development. But some brief indication of its nature should be attempted. Its first principle would seem to be that of free service of the commonwealth. This is the familiar principle of "academic freedom; " only it is now seen that such freedom cannot permanently be the prerogative of a single and separate division of our educational system, as of a university, but must inhere in educational institutions as such. This free school is closely allied with a free press, free science, and free art; its rise is closely connected with the wide dissemination of modern vernacular literatures and the wide acceptance of modern natural science, and it is coming in halting and uncertain fashion to show some connection with modern art other than literary art. In its relations with modern science it tends to spread abroad some measure of that spirit of suspended judgment and impartial acquiescence in the teachings of objective evidence which belong to that science at its best. In its relations with art it tends to promote that self-restraint which belongs to the truly artistic achievement of every age. In some degree it furthers, 
too, that finer realism which modern art shares with modern aspirations in the field of morals, a realism which aims at essential rather than merely conventional truth and righteousness. Even where most secular it is mildly religious, with that pervasive religion which is an overflow from creeds and rituals. It enjoys a fine catholicity of human interest, a neighborliness to which no man is a foreigner nor a Samaritan. It disengages itself from the partisanship of the sects and sections of other institutions; for even where most bound by ecclesiastical or other dependence, it is influenced by that rising respect for the personality of the learner which in our day restrains those who would do violence to the honest convictions of even a little child.

The great movement in education here referred to has gone forward in unison with the other great movements in human culture which have made our civilization what it is to-day. Only patient and critical and clear-sighted historical research can reveal the real trend and significance of these movements, but they are plainly connected with those views of human life which in the eighteenth century were ushered in with the doctrine of the rights of man, and with a democratic conception of social relations. Education in modern schools seems to tend toward democracy everywhere, even in lands where every effort is put forth to prevent such an outcome. It accents the tendency toward democracy which it finds already at hand a tendency not necessarily toward a democratic as opposed to a monarchical form of government, but toward the democracy of fair opportunity for every man. It is out of this play of currents, strivings, and ideals that the individualism of our time has arisen an individualism more sharply conscious of itself because of its interplay with a new spirit of collectivism which has arisen along with it. It has come to pass that as our education has become less narrowly institutional, more widely universal, it has come to lay new emphasis on the responsibility of individuals, each of whom is to render his peculiar service to society. It seeks to discover in each his best aptitude for such service, and to raise that aptitude to its highest efficiency through training. The fine adjustment of individualism to collectivism, in a school intended to perpetuate and promote the best things of our time, is a problem of educational theory as well as of educational practice, and calls for a much more searching inquiry into the place and meaning of modern scholastic freedom than any that has yet been made.

The growth of such freedom, in making way for the individual in the training of the schools, has made way also for a psychological treatment of educational problems. In the modern school such approach to educational doctrine from the side of psychology is an indispensable accompaniment of the attempt to make education 
real for every person educated. Because the art of education is making in plain honesty this attempt to find the real pupil and to address the appeal of education to his real possibilities and make it serve his real needs, it must have, in common with those other arts with which it is allied, - with the arts of government, of guidance, of persuasion, - the help of science, and the help, particularly, of psychology.

We pass now to a consideration of certain psychological aspects of the questions that have already been reviewed.

\section{The Third Group: Psychological Problems}

The psychological problems most obviously involved in the problems of Lehrfreiheit and Lernfreiheit which have thus far been considered, are those entering into the problem of psychological or educational diagnosis, which stands in intimate connection with certain forms of physiological diagnosis. By such diagnosis is meant a determination of the normal and typical human characteristics and characters with which education has to do, the ranges of normal variation among them, and the demarkation of their pathological accompaniments. A little more definitely, this may be considered under the three divisions of:

(1) The determination of the successive stages of normal human development, with especial reference to the ripening of instincts and to manifestations of accelerated and arrested development;

(2) The relation of the generic to the specific in mental development, with especial reference to possibilities of general or " formal " culture; and

(3) The relation of motor tendencies to general culture and to the processes of development, particularly under the forms of imitation and suggestion.

In discussions of prescription and election, frequent reference is made to the cultural or disciplinary value of studies. It is held that the intellectual and moral gain from any single bit of instruction spreads, as it were, over a considerable area of the mental life - over the whole of that life in all of its aspects, it may be; or over all manifestations of one or more "faculties," as it is more commonly stated. This assumption, if not wholly incorrect, is very greatly overdrawn, yet it has persisted in educational discussions long after psychologists have abandoned the doctrine on which it is seen to rest. Recent psychology has shown that mental traits and activities which are so related that they may conveniently be grouped under a single designation are not commonly found to be so related that the improvement by training of one member of the group bearing the common name results in equal improvement of all members of that 
group. An improvement in "memory" or " discrimination" or " attention," for example, usually turns out on examination to be improvement in memory or discrimination or attention as applied to some single class of impressions or some particular set of ideas, with much less evidence, or none at all, of improvement in the same function as directed toward different objects. This fact has led numerous theorists in education to an opposite extreme. They have concluded that no general improvement of the mind through training is possible - that any such improvement which may be apparent is simply the reappearance in new situations of some elements of a situation in which an educative process was originally carried on. According to this view, general culture, except in so far as it consists of habits and conceptions that are in general use, is a delusion and nothing more, and all discipline and training must be narrowly specific.

Some recent studies, however, seem to point to relationships among mental traits and functions which would call for a more moderate statement than this. It seems clear enough that the spreading or transference in the mind of the good effects of any course of training is much more narrowly circumscribed than has commonly been supposed, but it may still be doubted whether such spreading influence is altogether wanting or is limited to the transference of definite ideas. Moreover, it seems not improbable that the freedom with which the gains of culture circulate among our mental functions and contents may differ greatly in different individuals and may increase in the same individual as he matures in life and advances in his course of training. So the psychological determination of the possibility and the range of formal discipline is necessary to render the discussion of elective studies more precise and true to fact, and the scientific study of this question may even yet yield vital and unexpected results.

Very much has been done already in the more general blocking-out of the stages of our mental development. Such investigations, of which we have notable examples in the work of Preyer and Hall and Sully and Miss Shinn, have provided working hypotheses that are of extreme interest, but these, for the most part, have not been critically and adequately tested, and have not been organized into a complete system of developmental psychology. When we have more definite knowledge of the relation of different functions one to another, not only in cross-section, but also in their successive unfolding, we shall be able to replace many of the subjective opinions expressed in discussions of prescription and election, with ascertained facts set in their rightful relations. To this end it is extremely desirable, as Thorndike has pointed out, that the cases studied be adequately representative; that the actual development of individuals be directly studied in- 
stead of being inferred from the showing of different individuals of different ages at one given time; and that the whole range of variation be noted, whereas common practice neglects the extremes and concentrates attention on the median line.

The motor-psychology, if the term may be permitted, or let us say the situation-psychology, of which we have heard so much in recent years, is highly significant in the theory of education. Its bearing on the relation of general to vocational studies in particular is farreaching and intimate. Still more significant in its bearings on such problems as are here proposed is the special study of imitation and suggestion, which we associate with the names of M. Tarde and Professor Baldwin, and which other psychologists have carried far in other directions. Further researches in this fascinating field are needed for the clearing-up of our problem of studies and the method of dealing with studies. To what extent is the real and permanent result of studies and methods, in the mind of many a learner, obscured by the very fact that as an imitator he seems to share in the good that his fellows get from them? Can we not, in the spirit of our finer scientific and ethical realism, separate the actual from that which arises through conscious or unconscious mimicry? Yet it is to be remembered that pupils in the schools not only live under a constant play of suggestion-influences, but are preparing for a life which is to be lived under similar influences. Such influences are to be reckoned with accordingly as a constant factor in human life, but incalculably variable in kind, direction, and amount. These facts eall for further psychological study in order that we may know more accurately how they enter into the problem of school-training, and particularly what bearing they have on the momentous transition which the learner sooner or later must make from the little life and much training of the school to the larger life and more diffused culture of the great world beyond the school.

If the solution of these psychological problems one by one will do much toward the clearing-up of the problems of education with which we have set out, much more will the organization of the results of such psychological studies in a system of psychological or educational diagnosis. For it will give us a vastly better understanding of the common nature and the individual characteristics of pupils, and of the relation of these one to another. It is such an understanding that we need in order to deal wisely, on the psychological side, with the questions under discussion.

And the study of these psychological doctrines not only has a direct bearing on our doctrine of education, but affects it indirectly through its bearing on the study of institutions. For our history and social science are undoubtedly becoming more psychological. A study of the mental processes of individuals reveals in new guise 
the fact that every man becomes what he is in great measure through his social relations. In unexpected and immensely significant ways psychology is illustrating and amplifying the saying of Aristotle that man is a political animal. The meaning of the individual in his relation to institutions receives accordingly a psychological interpretation. We may not say simply that the history of the individual is a history of progress from status to contract. We see it as a history of individuals who constantly realize their individuality in institutions, but with this progressive change greatly accented in our day, that institutions are becoming much more plastic and individuals more conscious of a power and right and duty to react upon their institutional environment. Modern institutions are safe from violent and revolutionary change not through their rigidity, but through a certain fluidity of their constitution - through capacity for continuous change and betterment under the varied influence of many individuals who live their lives and make their characters in new and more vital relations with society. These things must be taken into the account when we frame our educational doctrine with reference to individual aspects of instruction.

\section{The Central Group of Problems : Further Consideration}

It has been the business of this paper to formulate some of the more urgent present problems in the empirical theory of education. The topic assigned to me seems to call for the statement rather than the solution of such problems. Moreover, the solutions are not ready and could not be given even if they were called for. Yet it may not be amiss to indicate the general character of the solutions to which the methods we have discussed seem likely to lead us.

Summarily stated, they seem to lead to a demand for the further extension downward of the elective system, of vocational pursuits, and of the methods of spontaneous self-education, together with an extension upward of organizing prescription in some of its forms. This statement is not simply paradox. It presupposes an organic view of educational institutions, which in their ideal connection one with another serve coöperatively the aims of modern education. At every stage, and in every one of its members, this great educational system is seeking to prepare its pupils for real participation in the civilized life of their time. Every one is to participate in that life as giver and recipient, as learner and maker; and his learning and his making should be all of one piece. He is to participate as under forms and laws and authorities, yet as contributing in a larger or less measure to the shaping of laws and forms and as exercising some share of social authority. So in all parts of education, though in widely varied proportions, the coördinate elements 
of direction and self-direction must be present. That each person may participate in the same civilization is the aim of prescription, of uniformity; that each may participate in the way that is most real for him, that is the care of the elective system and the methods of spontaneity. The two procedures are correlated in thought, and are to be correlated in practice.

To be a little more specific, let us note the bearing of some such general solution of these problems upon the conduct of instruction in colleges and universities. Such studies of the actual working of the elective system as have thus far been reported, very fragmentary at best, seem to indicate that student choices are made for the most part with serious purpose, but, except under some sort of group system, with too little coherence and with far too much of hit and miss. If these choices are to be of the sort contemplated in this paper, they must represent as nearly as possible the student's own way of getting into right relations with his world. Many different lines of approach may lead to this desired end. But mere random election of studies is hardly a mode of approach; it is rather a skirting about the edge of things. The question arises whether student choices can be made a real way to the heart of things, and it seems reasonable to conclude that this can be done. It is more likely to be accomplished if the students shall have been brought up under a system of education in which their spontaneous choices shall have been all along in active and progressive coöperation with the directive leadership of their teachers. The system under which there is a sharp break between secondary school and university - the former being under close prescription, the latter offering sudden and unqualifiedf reedom - is unfavorable to the making of real power of choice in either one of its members. Then, the mere election of incoherent courses in a variety of subjects at the university is vicious and misleading. The group system, by massing the work of any one student on, courses relating to different aspects of one subject, yields a better result, for the value of the group is much greater than the sum of the values of its several parts. But the group system, too, is liable to abuse; for even a large group of courses, all of them pretty much the same in kind, all on about the same level, may not carry the student very far into the heart of things. What is to be desired is that as the student adds course to course in any given subject, he shall steadily rise to more adequate conceptions, to the mastery of more searching and rigorous methods. The danger-points in education are those plateaux where the student spreads out and ceases to rise. The elective system presents peculiar dangers of this sort, and calls accordingly for special precautions.

Under such administration as has been proposed and under the guidance of philosophic teachers, the student who enters the world 
of knowledge from any side is carried forward toward the centre and heart of things. The further he goes the more evident becomes the connection between his principal subject and other subjects, some of which are instrumental to the higher pursuit of his own special studies and some of which carry him on to more comprehensive views.

The guidance and prescription which predominates in earlier years must be mixed with spontaneity and freedom; and the larger election of later years calls for the personal direction and assistance of more than formal teachers. On the whole the system proposed calls for more of real teaching. If it requires fewer set lectures and class lessons, and leaves the learners rather more to themselves than the practice we are familiar with, it makes such personal help and guidance as are given more real and vital and indispensable. It calls, too, for a much wider differentiation of the processes of education in our edueational systems.

The elective system, in fact, presents the double danger of scattering superficiality and of intense narrowness. A little more should be said concerning the second of these. Here again a safeguard is to be found in the better handling of the lower grades of instruction. If adequate attention is paid in those grades to the successive rise of a variety of instincts and interests on the part of different pupils, if against a background of prescription there is free play permitted to the individual change and difference manifested in these things, the pupils will have been warmed to many kinds of scholastic pursuit, each undertaken at the most favorable moment for happy and lasting impressions. Such procedure must go far toward preventing narrowness in later years.

The conception of the nature of general discipline to which we are coming emphasizes this view; for if we can count on but little of undistributed and universally transferable mental power, it is so much the more important that in his earlier years the pupil should have been introduced to many and varied special pursuits, and that each of them should have been pursued at such time and in such manner as might join to it the full energy of spontaneous activity.

The vital integration of things learned with things done should reënforce the several stages of this process. It should do more: for, by uniting the art impulse with the interest of knowledge, it should tend to liberalize the later pursuit of a vocation, as well as any later pursuit of special studies.

We may not pursue the subject further at this time. I have tried to indicate, with the utmost brevity, one probable outcome of the study of the small group of problems proposed, by such methods as have been indicated. It all comes to this, in short, that these problems cannot be solved for the college or the university, nor for a school of any other grade, without reference to the comprehensive view of

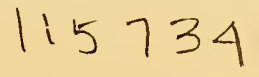


education as a whole; prescription and the freedom of the learner should be regarded as concomitants in education of every grade; they should work together in varying combinations to insure the highest participation of the learner in the life of his people, in the civilization of his time; and only through such combination may education hope to prepare men for activity guided by real, personal choice and inspired by the full sense of individual responsibility. Such activity alone is moral; and by promoting such activity in the coöperative life of this age education makes its contribution to brotherhood, the supreme end, for this world, of human endeavor.

But such education as is here contemplated is possible only in the hands of better teachers - better selected, better trained, better supported - of many teachers as good as the few, the best, who are already found in the schools. If society would attain, through education, such high ends as have been pointed out, it must seek and find such teachers and make them the high stewards of its will.

\section{BIBLIOGRAPHICAL NOTE}

The works to which reference has been had in the preparation of this paper do not form any compact group but are scattered over many fields. Accordingly no attempt has been made to list them in the form of a bibliography. The following are mentioned as among the more recent publications dealing specifically with the subject of present-day problems and tendencies in education:

Dewer, J., The situation as regards the course of study. In Educational Review, vol. xxir, pp. 26-49, June, 1901.

Eliot, C. W., Educational reform; essays and addresses. New York: The Century Company, 1898 , pp. $9+418$.

Hughes, R. E., The making of citizens; a study in comparative education. New York: Charles Scribner's Sons, 1905, pp. 405.

MüNch, W., Zukunftspädagogik, Utopien, Ideale, Möglichkeiten. Berlin, 1904, pp. $4+269$.

Payne, Bruce Ryburn. Public elementary school curricula. New York: Silver, Burdett and Company, 1905, pp. 200.

Riвот, A. F. J., La réforme de l'enseignement secondaire. Paris, 1900, pp. $12+$ 308.

Young, E. F., Some types of modern educational theory. (Contributions to education, no. 6.) Chicago: 'The University of Chicago Press, 1902, pp. 70. 


\section{SHORT PAPER}

Professor H. H. Horne, of Dartmouth College, presented the following interesting paper on "A Science of Education."

It is the purpose of this brief paper to reach a conception of the nature and method of a science of education, if indeed such a science is possible.

The term science means, in this connection, as usual, organized and verifiable knowledge. Such a body of knowledge may be one of two kinds, either a description of what is, or a prescription of what ought to be.

The term education in this connection means the school processes whereby human individuals are developed into the maturity of their powers.

Is a science of education possible? There can be no question that a descriptive science of education is possible. Careful students of education can gather, classify, and verify knowledge of the school processes. There can be scientific knowledge of existing educational agencies. The unorganized data for such a descriptive science are already largely at hand in all the various school reports of each country. Such a descriptive science of American education was really partially attained in the volumes entitled Education in the United States, prepared for the Paris Exposition. ${ }^{1}$ Still more exact and comprehensive knowledge of the nature of educational experience may be confidently expected; indeed, it is already being gathered. And such descriptive knowledge of past and present educational methods and results may be our best preparation for the answer to the next question.

A prescriptive or normative science of education, is it possible? Is it possible to say at all how men ought to be educated? If so, is such knowledge organizable and verifiable?

Here we may turn profitably to the history of educational theory. Every educational reformer from Socrates to Eliot has known something about how youth ought to be educated. That their ideas differed from each other was but natural uncler the changing conditions of their age. Each generation has always known something about how the next generation ought to be educated. Such knowledge it has always derived from its own experience and from its conception of what man himself is and ought to become. The history of educational theory, then, presents not a static but a developing normative science of education. Since education became an object of serious study in Plato, there has always been a relatively valid, but never a universally valid, pedagogy. And it may further be observed that, so long as life grows and society changes, we have no need for an absolute pedagogy. Sufficient unto the educational generation is its own theory.

The impossibility of a universally valid pedagogy, clearly shown by history, was also clearly announced by Professor Dilthey of the University of Berlin in 1888, before the Berlin Academy of Sciences. Such a declaration was doubtless necessary to limit the overleaping ambition of young scientific pedagogues. It would misconstrue this real service to suppose that Professor Dilthey has shown the impossibility of a relative and growing science of education.

When the Educational Review was established in America, Professor Royce found himself in agreement with Professor Dilthey, as thus expressed: "There is no universally valid science of pedagogy that is capable of any complete formulation and of direct application to individual pupils and teachers. Nor will there

${ }^{1}$ Under the editorship of Dr. N. M. Butler. 
ever be one so long as human nature develops, through cross-breeding in each new generation, individual types that never were there before; so long as history furnishes, in every age, novel social environments, new forms of faith, new ideals, a new industrial organization, and thus new problems for the educator. ${ }^{1}$

Here is needful warning that no abstract formula in itself is adequate to the new pupil come to school. All old principles of education must ever be newly interpreted and newly applied; old formulas must grow or become outgrown. They must not master, but obey, the teacher's spirit.

It would again be to misunderstand the real service of Professor Royce's contribution to suppose he had denied the possibility, or even the desirability, of formulating into principles our present knowledge of how education ought to proceed. It would be a self-contradictory extreme of pedagogic skepticism to say that nobody knows anything about what education ought to be. The organization of present knowledge concerning normative educational procedure is analogous to the manuals of practice in medicine, law, and the ministry. Out of their general medical, legal, and theological knowledge, the physician, lawyer, and minister meet the needs of the individual cases. So out of what general knowledge of right educational method he may possess, the teacher is enabled more efficiently to forward the individual pupil's growth. The lack of a universal science of pedagogy is no more crippling to the art of teaching than the lack of universal therapeutic prescriptions to the practice of medicine, but the presence of a relative, adjustable, modifiable science is serviceable in both cases. In short, all principles of all sciences that apply to live organisms are subject to continual modification in the application, and the lot of pedagogy is the lot of all the organic normative sciences. We cannot deny the foundations of the youngest of the learned professions without similarly involving the foundations of the three oldest.

Concerning the effect on a science of education of its changing data, which is the real problem of Professors Dilthey and Royce, I find in a valuable recent discussion of Professor O'Shea the following: "The social environment to be dealt with changes in character with the evolution of the race, and varies with the different races; the physical environment is modified by the locality, and so on. But our general principle, as a type of educational propositions, is none the less scientific because it has not just the same application in all instances, though it may be less mathematical, less perspicacious, more complex and indeterminate on this account." 3

The looseness now evident in our conception of a normative pedagogical science is, of course, due to the hitherto rather haphazard methods of observing and collecting educational experience, as well as to the indefinite variety of human individuals to whom the general maxims must be applied. This looseness is considerably tightened in Thorndike's new book on Educational Psychology. This is perhaps the largest attempt so far to apply the methods of exact science, measurement, and statistics, to educational problems, and will do more than volumes of opinion to bring pedagogy into good repute among scientists. Professor Thorndike writes in his concluding chapter, concerning "The Problem of Education as a Science," the following: "The true general theory must be the helpless one that there can be no general theory, or be made up of such extremely vague conclusions as the features common to all human natures and the changes everywhere desirable allow. ... A true educational science must be inductive, must be made up from the study of the particular facts in answer to thousands of different questions. . . . The science of education when it develops will, like other sciences, rest upon direct observations of and experiments on the influence

${ }^{1}$ Educational Review, vol. I, "Is There a Science of Education,' p. 24.

${ }^{2}$ Education as Adjustment, p. 13. 
of educational institutions and methods made and reported with quantitative precision. Since groups of variable facts will be the material it studies, statistics will everywhere be its handmaid. The chief duty of serious students of the theory of education to-day is to form the habit of inductive study and learn the logic of statistics." 1

The time is ripe now for this inductive study; the " psychological moment" has arrived. As well-wishers to the science of education, we must welcome the child and adolescent study movement, the pedagogical experiment institution, the work of the committees for " the organization of educational experience," and the methods of exact science in educational study.

But we cannot agree that the inductive method alone, even supplemented by exact measurements, is adequate for a science of education. We know too much about men already through biology, physiology, psychology, logic, esthetics, ethics, sociology, and anthropology, to neglect it all for the sake of new observations. We must not fail to enter into the deductive labors of the educational thinkers of the race, and particularly of the modern men like Alexander Bain, the English and American Payne, Hinsdale, and others. Deduction must still conserve what induction discovers. Only, I would say, in our deductions we must look to all the sciences of man, and not, as we are too prone, to psychology alone. Educational science is no longer applied psychology. For example, " anthropologists have discovered that, in human childhood, whether of race or individual, the hand leads the mind, so that the seat of intelligence is best reached through manual training." "

Without recapitulating, here then briefly is our conception of the nature and method of a science of education: a body of growing and adjustable knowledge concerning how education ought to proceed, continuously derived deductively from all the sciences of man and inductively from all the experience of the school. Of such a science of society's chief undertaking, men will some day say with Mackay:
"Blessings on Science! When the earth seemed old, When Faith grew doting, and our reason cold, 'Twas she discovered that the world was young, And taught a language to its lisping tongue."

${ }^{1}$ Educational Psychology, pp. 163-164.

${ }^{2}$ W J McGee, "Strange Races of Men," World's Work, August, 1904, p. 5188. 

SECTION B-THE SCHOOL 



\section{SECTION B - THE SCHOOL}

(Hall 12, September 23, 10 a. m.)

Chatrman: Dr. F. Louis Soldan, Superintendent of Public Schools, St. Louis. Speakers: Dr. Michael E. Sadler, University of Manchester.

Dr. William H. Maxweld, Superintendent of Public Schools, New York City.

Secretary: Professor A. S. Langsdorf, Washington University.

\section{THE SCHOOL IN ITS RELATION TO SOCIAL ORGANIZATION AND TO NATIONAL LIFE}

\section{BY MICHAEL ERNEST SADLER}

[Michael Ernest Sadler, Professor of the History and Administration of Education, Victoria University of Manchester. b. Barnsley, Yorkshire, England, 1861. M.A. Oxford (Trinity College and Christ Church); Post-graduate, University of Jena, 1895; LL.D.; Columbia University. Officier de l'Instruction Publique; Secretary of the Oxford University Extension Delegacy, 1885-95; Student and Steward of Christ Church, Oxford, 1886-95; Director of Special Inquiries and Reports to the Board of Education for England and Wales, 18951904. Author of special reports on educational subjects; reports on secondary and higher education.]

WERE it possible for some eighteenth-century observer of men and manners - say, for Addison or Bishop Butler or Dr. Johnson - to return to life in order to study the educational principles and practice of the more democratic communities of the present day, he would probably dwell on six things as being (apart from those changes in courses of instruction which are due to the progress of physical and historical science) the most conspicuous points of difference between the old order as he knew it and that which now prevails. He would note, first of all, that the public schools open up for the children of the masses of the people a range of individual opportunity which in extent and in stimulating variety goes beyond any precedent in history. Secondly, he would observe, with surprise though not necessarily with approval, that school discipline, especially on its physical side, has lost its former severity of application. Thirdly, he would stand amazed at the effective recognition which has been given to the claims of women to intellectual self-development. Fourthly, he would find, in all grades of education from the kindergarten to the university, the teacher's calling regarded with greatly increased honor and consideration. Fifthly, he would be impressed by the successful assertion by the secular state of the right to impress an ideal of life upon the consciousness of the rising generation. And 
sixthly, he wou'd justly conclude from the amount of our educational discussion and from the scale of public educational expenditure that the present gene:ation attaches to the school, as a factor in social eulture, an importance which was foreign to the habitual thought of his own time.

In bringing about this great change of opinion four nations have borne an especially brilliant part - France, Germany, Switzerland, and the United States of America. Without Rousseau and the ethical and social ferment of the Revolution; without Kant, Fichte, and Humboldt, not to speak of Froebel and of Herbart; without the genius of Pestalozzi and his self-sacrifice at Stanz; without the high Puritan tradition of New England; without the illumination of Franklin's common sense; without the logical audacity of Jefferson; without Washington's measured warning; without Horace Mann's missionary enthusiasm; without Emerson's profound insight into the deeper obligations of democracy, the world would have won its way far more slowly to the modern conception of the public school. The value of these confluent forces and the subtle outcome of their interaction upon one another impress themselves upon the mind of the student of the history of educational ideals, and of the struggle of those ideals to get themselves realized in institutional life and in public administration. Not least is this so when the work of the student lies, as does my own, in a country which is under heavy obligation alike to French, to German, to Swiss, and to American educational effort, and which nevertheless has found in no one of them singly the precise formula of a remedy for its own special educational needs.

Is there not often a delusive simplicity in too highly generalized discussions of the worth of the elementary school? The elementaryschool problem in the modern state is not one problem, but a conglomerate of problems. Nay we not say that educational progress will lie in the direction of differentiation of schools with definite regard to different types of future calling in the body politic, and to different kinds of social need, rather than in the assimilation of all the public elementary schools in a community to one general form, whether in respect to discipline (some schools need a stricter discipline than others), to balance of studies or to internal organization? Differentiation of schools within a general framework of administrative unity seems necessary if the elementary schools are to grapple with the complex needs of modern and especially with those of city communities. (This view is confirmed by the fact that in the sphere of high-school education there is a similar tendency towards differentiation of aims.)

Another obstacle to educational progress has lain in the too common habit of regarding the school as if it were almost an end in itself, 
and in artificially separating our study of the specifically school problems from the study of the other sociological and economic questions which are in fact intimately connected with it.

The study of educational science stands in very close relationship to sociology, to biology, to physiology, to the science of public health, to economics, and to politics, as well as to psychology, ethics, and religion. Nor can it dispense with the aid of political and economic history as throwing light upon the course of the development of various forms of corporate life, while the comparative study of racial characteristics is needed in order to a judgment concerning the type of education which is likely to be more appropriate to the particular group or people under review.

But school problems have been too rarely regarded in relation to their social context. Different branches of social effort and of social administration have been kept too often in an unfruitful and unscientific separation from one another. There has been a false kind of specialization of thought and of practical treatment in the common handling of school problems. Too little synthetic thought has been devoted to the relationship between specifically school problems and the general social welfare of the community, including the life-needs, other than individualistically economic, of the different categories of pupils in the schools. The result is that in educational investigation we have failed to make the most profitable use of much already accessible social experience, and many workers in other parts of the sociological field have, in their turn, omitted to give the necessary special study to the technical problems of the school. There has bren too much undiscriminating generalization and too little scientifically planned analysis of the diverse problems which lie concealed under the apparent unity of the elementary-school question. Specialization within arbitrary limits has defeated its own object and has held us back from the course of conjoint investigation over the whole field of action which must precede successful synthesis and which alone can lead us to the attainment of more precise social aims in administrative and educational reform. Happily, there is now noticeable all over the world a distinct movement towards less separatism in our treatment of the school problem. We observe everywhere, and not least in America, an effort in the direction of more synthetic inquiry into the relationship between school work and other departments of social activity. But so little has yet been done to bring our knowledge of educational history into its true relation to the history of economic and social development, and we are still so far from having brought into the common stock our educational experience and observations and the experience and observations gained in other departments of sociological inquiry, that we are not yet in possession of the materials upon which alone we 
could venture to build up a consistent and accurately classified theory of educational aims and practice, adjusted to the diverse and perplexing needs of modern life. Hence it is prudent to regard much of our present practice as provisional and as likely to require considerable revision when more has been done to coördinate the experience already gained in our own and other related branches of social effort, and when the time has come to draw confident conclusions from a wide range of skillfully planned educational experiments.

From this point of view, the highest significance of the current modern conception of the public school seems to lie less in what it has already achieved, great though that achievement has been, than in the certainty of the further changes to which it promises to lead. In few parts of the field of social regulation must the studentadministrator feel himself further from his final conclusions than in the matter of public education. The subject of his study is vast, iridescent with incessant change, and still largely unexplored. Some of the factors are hidden in their operation, elusive of exact analysis, and necessarily slow in producing their effects. The sciences from which he must derive some of his guiding principles are themselves germinating afresh. Moreover, education, in any full sense of the word, involves a social ideal. It postulates a stable social structure. It operates through a variety of influences, only some of which are, or can be, concentrated in the work of the school. But at the present time we are but feeling our way toward some firmer and less fluctuating form of social organization. It is impossible to predict the outcome of the stupendous forces, economic and emotional, which are now stirring the world to its depths. Educational organization follows great intellectual and social movements after an interval, and attempts to carry out their main idea. It was so at the time of the Renaissance and at the Reformation. At the present time educational thought faithfully reflects the welter of conflicting ideas in which we live.

During the past half century the most characteristic achievement of the public elementary school, in its best democratic form, has been its work of social liberation and of social encouragement. It has opened new avenues of hope, new opportunities of self-realization. Its economic service to the world, at a period when individual buoyancy and initiative were especially needed, has been immense.

But still greater has been its service in stimulating a belief in ideals among great multitudes of people, who would otherwise have been in grave danger of falling into a state of intellectual indifference bordering upon materialism. At a period of rapid intellectual and social transition it has furnished new motives of action, new hopes for the future. It has helped forward those who were economically and morally strong enough to avail themselves of the new opportun- 
ities to which it opened the door. It has scoured away many prejudices and obsolete distinctions. It has cleared the ground for new foundations. But its work has been least successful among the morally weak and among those lacking vigor of personal initiative. Its influence has been first assimilative and then selective, but not in the highest sense socially coördinating. It has drawn forth from the masses the most vigorous individuals and given them an entirely new start toward personal independence and prosperity. But it has left a great residuum, and for the educational treatment of that residual social deposit it seems desirable that measures should be taken very different from those which have proved themselves appropriate to the needs of the more vigorous. In dealing with the residual deposit which consists of the physically or mentally deteriorate, the time seems to have come, especially in the great centres of population, for a more deliberate or far-reaching attempt to reconstruct for them a new social order upon the basis of a more scientific organization and of a more provident discipline planned in the interests of collective, or at least of corporate, well-being. In our educational policy we seem to have reached the point at which it is necessary to discriminate between the needs of the vigorous and of the deteriorate. For the former it is sufficient and prudent to provide an educational system which postulates a good home environment, adequate nutrition, and a healthy physique, and which, therefore, relies with confidence upon methods which stimulate individuality and open the windows of new and varied opportunity. But for the residuum of deteriorates a very different and more comprehensive course of treatment seems necessary.

One danger of the situation is lest there should now begin in some countries a too sweeping reaction against the individualizing tendency of the best democratic elementary education and lest, with the needs of the deteriorates too exclusively in their mind, some administrators should attempt to curtail the freedom and intellectual activities of the elementary schools as a whole (eminently well suited as they are to help forward those children who are fitted by natural endowment and other circumstances to take advantage of them), in order to impress upon the whole elementary-school system a form more appropriate to the needs of the physically and intellectually deteriorate. This danger is increased by the fact that many earnest social workers have, in the nature of things, been absorbed in their labors among the deteriorates, and have been impressed by the frequent failure of the present school system to supply the kind of moral and physical discipline which the deteriorates require. Such workers, while speaking with just authority about the needs of that section of the population with which their labors have been concerned, have often had comparatively little time to observe with equal thorough- 
ness the very different effects of the schools upon the numerically larger aggregate of vigorous children and families. Hence it is possible that some devoted and high-minded philanthropists might,

- with the best intentions, favor a change in educational policy which would be hurtful to the interests of the community as a whole, though well calculated to supply a more formative discipline for the physically and intellectually deteriorate. Is there not need for the most careful discrimination between the educational needs of different classes of the community, which are sometimes spoken of too much in the lump? Equally careful should be the discrimination exercised in judging the different educational needs of members of the same family. It is perilous to allow a great mass of deteriorates to form itself in our modern cities, but in the long run it would be far more perilous to deprive the whole elementary-school system of its strong individualizing power. Let us deal with the deteriorates as a problem which, though appalling in its magnitude, is nevertheless the problem of a minority. For the non-deteriorate that system of public elementary education will, in the long run, continue to produce the best results, which stimulates individuality and which, while laying great stress upon the inculcation of social duty, relies in the last resort upon the moral and intellectual vigor of the child itself. The highest aim of a great system of popular education is not to mold multitudes of men to one pattern. Its ideal is not blind submission to rules imposed from without, but willing and intelligent obedience to a noble and self-chosen way of human life. From this point of view an ideal of educational uniformity, in any stratum of national instruction, is (I would submit) a wrong ideal, whether it be set up by an ecclesiastical organization or by the secular state. Within the broad framework of allegiance to the state we need abundant variety of educational tradition and experiment. The chief task of the school is, surely, to bring about, through the quickening of individual powers, a greater readiness to give each his best to the common good, and yet so to shape for each the ideal of public welfare as to enhance men's reverence for the rights of the individual conscience and to give them a clearer understanding of the worth of sturdy personal character, of stability of moral principle, and of brave initiative. From this point of view the course of training which popular education should endeavor to provide is one which would jealously guard the exercise of the individual judgment without which no real progress is permanently possible, while at the same time insisting on due obedience to the teacher's authority and fostering a desire to subordinate selfish aims to public interests and to corporate needs. All true education is thus a combination of opposites. It seeks neither to absorb men's minds in mundane or material things, nor yet to shut them out from bearing a vigorous part in the practical 
activities of the modern world. It would teach men to be true to both sides of the truth. If it fosters an untempered and arrogant individualism, it is false to its trust, but not less false if, rushing to the other extreme, it were to seek to inculcate passive obedience to some social or intellectual theory, imposed dogmatically by rulers who, however scientific, yet denied the right of criticism, of protest, and of practical dissent.

The enormous difficulty of accomplishing this educational task in the circumstances in which the work has to be done, and with the instruments available for the purpose, must fill every student of the subject with some misgiving and concern. Nor is the difficulty materially lessened when we take into account the fact that all that the school in its specific sense can at best be expected to accomplish is to set its pupils on the road to getting for themselves intellectual and moral benefit from the much longer course of education which awaits them, when school days are over, in the real tasks of life. Yet at the very time when the student of education has come to realize more vividly than ever before the intricacy and incalculable difficulty of the higher work of the school, the great mass of every free people is evincing to a degree hitherto unparalleled its belief in the value of popular education and its readiness to make large sacrifices for its extension and improvement. Such confidence as this has not been lightly won. That it should be thus displayed with evident sincerity, and on so vast a scale, is in itself a pronf that popular education has already achieved a colossal work. At a period of unexampled economic development it has furnished to the strong and energetic (to take the matter as it should be taken, at its best) with a keener perception of personal opportunity, with some of the means of seizing those opportunities, and (what is of high economic and often of moral worth) with self-confidence and bright hopes for the future. To have done this, at such a crisis and on so vast a scale, is an epochmaking work and one of which the benefits far transcend the accompanying disadvantages. To many thousand humble homes on either side of the Atlantic there has come after long and bitter discouragement a ray of bright hope from the American public school.

But this quickening sense of new economic opportunity does not alone explain the modern belief in the virtues of public education freely open to the masses of the people. Does there not also lie behind that belief a more subtle cause? Shall we be wrong in tracing it back in part to something not less fundamental than eagerness for new economic opportunities, namely, to an instinctive sense of need of something which may fill the place of those traditional and less conscious processes of social education now in swift decay? 
The critical movement in thought and the revolution in economic processes have profoundly shaken the old order of ideas, and with them the various established traditions of social conduct which in considerable measure rested upon them and had grown out of them. To the great majority of human beings the firmest kind of education is that which results from the impalpable but steady influence of a stable social environment. The silent pressure of such an environment molds the thoughts, directs the sympathies, shapes the purpose, upholds the will, and fixes the way of life. Such an environment embodies a long tradition. It is venerable with precedent and tough with habit. At its best it is consecrated by a thousand pictures, and means brotherhood, loyalty to a beloved tradition, and memories hallowed by death. But much of this educational inheritance the stress and changes of our modern life have weathered away. The disappearance of the old order in its thousand different forms and implications was inevitable. Often its disappearance was a boon, but sometimes an incalculable loss. And much of the great development of popular education from the time of Pestalozzi onwards has been due to an effort, often conscious, sometimes instinctive, to repair, if it be possible, this loss of the old upholding environment by the more deliberate efforts of the school. The relative importance of the school has grown through the decay of other forms of virtually educational tradition. If the aim of education is to prepare a child for the life which he will have to live, increase of schools does not necessarily mean a proportionate increase of real education. What existed before may have been in a true sense education, though less intellectual in form and less organized in its presentation.

\section{III}

If we examine the great educational traditions or school systems of the medieval and modern world, we find that they fall into six main groups according to their dominant purpose.

(1) The chief design of some of them has been to initiate their pupils into the manners, the tone of thought, and the point of view, as well as into the necessary accomplishments, of some fairly welldefined class or profession. Such, for example, was the business of the knightly education of the Middle Ages. Such, again, was the aim of Madame de Maintenon's school at St. Cyr, and a similar, though not precisely formulated purpose has influenced the educational tradition of great schools like Eton. (2) A second group is formed by those schools which were intended to maintain the tenets and the intellectual presuppositions of some great section of the community. Such, for example, were the schools founded under the influence of Luther and Melancthon, the schools of the Jesuits, Calvin's school at Geneva, Sturm's at Strasburg, the schools of the 
Puritans in Massachusetts and Connecticut, and the Nonconformist academies in England. Such, too, are the schools under the control of the Holy Synod in Russia. Such school systems are, in the nature of things, rarely coterminous with the whole area of national life. In some cases the range of this influence extends over parts of more nations than one. (3) A third group has had for the dominant purpose the training of competent recruits for the service of church or state, whether as administrators, secretaries, officials, diplomatists, or members of the clerical and other learned professions. When church and state have been in close alliance, this group has been virtually identical with that just mentioned. This training of competent recruits for the church or public service was the aim of the clerkly education of the Middle Ages - the educational ladder up which climbed so many brilliant boys of humble birth. This was William of Wykeham's intention when, after the depletion of the ranks of the English clergy by the Black Death, he founded St. Mary's College at Winchester. Such was the far-seeing purpose of the makers of New England in their policy with regard to secondary and higher education, and such, too, was, in great measure, the motive for the reorganization, under the influence of Humboldt and his successors, of the higher schools which have ever since been one of the institutional glories of Germany. (4) A fourth group of school systems has aimed at what may be called rescue-work, at saving the neglected classes from moral and educational destitution. Such was the intention of the schools for poor children instituted by Catholic piety in France in the seventeenth century; and of the schools of industry established by benevolent social reformers in England during the reign of Queen Anne, a movement which drew part of its inspiration from the work of Francke at Halle. Such, too, was the first aim of Pestalozzi and the purpose of the most distinguished supporters of Lancaster and of Bell in England in the early years of the nineteenth century.

(5) The dominant aim of a fifth group has been the opening up of new social and economical opportunities for the children of all classes, in the belief that it is to the interest of the whole community to multiply opportunities of self-advancement for strenuous individuals possessing intellectual grit and persistence of purpose. This has been the most characteristic note of the democratic educational movement which draws its philosophy and inspiration from the more individualistic theories of the eighteenth and nineteenth centuries. (6) The sixth group aims more definitely at the consolidation of the national life by impregnating the masses with national feelings. Such, rather than the more individualistic aim, was advocated by Mazzini, and such has been the chief purpose of those who have developed the state primary school system in France under the Third Republic. In 
more than one country at the present time we can watch, within the compass of what is technically a single school system, a conflict between the dominantly individualistic and the dominantly nationalizing aim.

Now may we not say that each of these six motives may reasonably be expected to persist, though with different degrees of intensity, according to circumstances, throughout the course of educational development of a great people? Is it not expedient to take account of each of them and, with due guarantees for national unity, to permit each of them to have its influence and to find its characteristic expression?

As against this view and its administrative implications, it may be urged that the essential thing is to secure at any cost national unity of means as a practically homogeneous school system. But, while fully admitting the indispensable importance of national unity, I would raise the doubt whether after all national unity in any true and permanent sense is to be secured by the elimination of differences in the educational traditions through which the rising generation is permitted to pass. National unity is the outcome of a complex variety of causes and is not the mechanical outcome of a school system. To believe that school-teaching by itself can secure it is an exaggeration of the actual power of the school. To eliminate, in pursuance of such a belief, fruitful varieties of school tradition seems likely to cause an educational injury which would far exceed any benefit that might reasonably be expected to follow from the administrative convenience of greater uniformity.

The ground upon which I would chiefly support this view (and in advancing it I readily admit that in certain circumstances it may be necessary to suspend educational freedom as an act of political necessity) is that in the case of great numbers of children the moralizing, character-forming, and socializing influences of a school are most effective in their operation when the school is intimately associated with the life and tradition of some homogeneous social group. As illustrations of this point I would cite the Little Schools of Port Royal, and the schools connected with the Society of Friends. It seems to me to be the true interest of the nation to recognize the educational possibilities of these various group-connections, and instead of attempting to give an educational monopoly to a uniform system of state institutions, to permit a part of the work of national education to be done through different social groups, provided that the efficiency of their work is periodically tested by methods of inspection approved by the state. In some cases the municipality or township would form such a group. In other cases the unit would be a group of families or of individuals, voluntarily united on a basis of intellectual or religious agreement. 
By way of practical comment upon some of the points submitted for your consideration in this paper I will venture to conclude with a brief reference to the present educational situation in England. At no earlier time in her history has England been so deeply stirred on the subject of national education as she is to-day. No one can yet foresee the final outcome of the movement which is now in progress; but it is already clear that in future the organized work of the school will play a much more important part in English life than, in spite of the immense advances which have been made since the passing of Mr. Forster's Act in 1870, has yet been the case. There is a widespread conviction that greater efficiency in the intellectual side of school training is vitally important to the civic well-being of the nation as well as to its industrial and commercial interests. The history of popular education in England has been at bottom (class selfishness and ecclesiastical prejudice apart) the history of a conflict between two ideals, the ideal of the education of the people mainly through a public school system, and the ideal of education mainly through the influences of an established social environment and through the faithful discharge of appointed duties in life; or in other words, the ideal of education mainly through free scholastic opportunity and the ideal of education mainly through social discipline. Each ideal had its share of truth. But the one side believed that the school could do more than schools alone can ever do. The other side greatly underrated the service which efficient schools can render to a nation, and at the same time failed to see how far the actual social environment was from furnishing the kind of training which their argument presupposed. But the new trend of educational thought is bringing these two ideals into union. The conception of the school organized in close relationship to an improved social environment combines the thoughts for which each side contended. Those who really care for educational progress in England are thus, in respect of essentials, less divided than they have ever been before. There has never been so good a chance of their uniting their forces in order to overcome the widespread indifference which still exists, and to thrust aside the actual opposition to popular education which still lingers here and there, but is no longer a serious obstacle to reform. The fact that, to a degree unprecedented in England, the value of an efficient school system is now so widely appreciated among us is due in no small measure to our study of the educational methods and organization of Germany, Switzerland, and America. In this connection I would ask to be allowed to pay a tribute of gratitude to the labors of Commissioner Harris and of his colleagues in the Bureau of Education at Washington. While it is generally understood that each 
nation must develop its educational system on its own lines and with due regard to its own history and special needs, there is a hearty admiration for the great educational work which has been done elsewhere and a desire to attain, though perhaps in different ways, to a corresponding excellence.

What is most needed among us, in order to overcome inertia, is a strong movement of national feeling and a motive to make our schools less sectional in temper and more definitely part of the national life. The problem will be how to combine such a strong national feeling with the preservation of fruitful variety of educational traditions.

In respect of the elementary schools there is every sign that our progress will be in the direction of greater differentiation of type. The great increase of well-being in England among the artisan population has virtually produced a new class. For this class a superior type of elementary school is necessary, and is, in fact, already being provided. The English artisans are steadily pressing for elementary schools of a high order, with smaller classes, highly-trained teachers, well-equipped buildings, and spacious playgrounds, and supplemented by further courses of continuative instruction. ' Their requirements are in the way of being met, though very much still remains to be done. It is perhaps in this grade of English education that the example of America has been most potent, though the influence of our class distinctions is too strong for the parallel to be complete.

But the economic changes which have raised the artisan class to so high a point of well-being have also had the effect of stratifying the population and of concentrating in the slums masses of people who are poor, ill-nourished, ignorant, badly housed, and only to a small extent benefited by our present methods of training. In respect of this part of the social problem, ameliorative action on a comprehensive scale is urgently required. Palliatives and patchwork are inadequate to the urgency of the need. If the conditions in which these slum populations live were drastically reformed, and if the state, acting in coöperation with local authorities, took charge, in labor colonies, of the lives of those adults who showed themselves incapable of independent existence up to the standard of decency which it might impose, the welfare of the children of the slum districts could be effectively provided for; their enfeebled constitutions might be reëstablished through suitable and regular feeding; their self-respect might be established through the enforcement of cleanliness; and they might be given a course of school training based to some extent on that which has been successful in our industrial schools. In elementary schools of this differentiated type very careful attention would be given to physical training, and manual instruction, inculcating a respect for the dignity of thorough work, would form an important feature of the curriculum. Were com- 
prehensive measures of this kind adopted, there is reason to believe that in one or two generations all the ground which has been lost would be recovered. ${ }^{1}$ What, in short, is wanted is a resolve to attack this slum problem under scientific guidance, on a well-considered plan, with the help of great resources, and with the thoroughness, energy, and persistence which are displayed in great works of modern engineering. And in such a plan the labors of the school-teachers and the educational influence of a new type of elementary school would play an important part.

Our third great educational need is a better system of secondary day-schools. It is almost impossible to exaggerate the social and economic value of the service which will be rendered to the nation by such schools when they are made more generally accessible and more intellectually efficient. The cost will be great; it will be necessary to raise the salaries of the teachers, which are now too often on a quite inadequate scale, if we are to draw in sufficient numbers into the service of the schools men possessing the attainments, the skill, and the personal influence which are necessary for the efficient discharge of the duties of a secondary schoolmaster. It would seem desirable that the course should begin at latest at twelve years of age and extend till fifteen at earliest. Pupils of exceptional capacity should be drafted into these schools from the public elementary schools at not later than twelve years of age, with scholarships covering the cost of the fees, and, when necessary, maintenance allowance should be granted in addition. The curricula of the schools should be of different types, but it is probable that the study of English, Latin, and mathematics would, in a considerable proportion of them, form the backbone of the course of studies. Their aim would be to give a thorough and searching intellectual discipline, to develop through the corporate life of the school a healthy sense of comradeship and of public duty, and also to turn the thought of the pupils toward intelligent reflection on social problems, and to arouse in their minds a desire to throw themselves with vigor, when the time should come, into tasks of public usefulness and of social amelioration. In all this reorganization of our English schools I trust that we shall refrain from going to extremes in pressing sudden changes of aim and practice. Our best hope for educational progress lies not through contention but through conciliation and mutual agreement. Richard Baxter's words may be cited as applicable to the present educational situation in England: "Greater light and stronger judgment are usually with the reconcilers than with either of the contending parties."

\footnotetext{
${ }^{1}$ See report of Committee on Physical Deterioration. London, Eyre \& Spottiswoode, 1904.
} 


\title{
PRESENT PROBLEMS OF THE SCHOOL
}

\author{
BY WILLIAM H. MAXWELL
}

[William H. Maxwell, City Superintendent of Schools, New York City. b. March 5, 1852, Stewartstown, County Tyrone, Ireland. B.A. Queens University, Ireland, 1872; M.A. 1874; Hon. Ph.D. Saint Lawrence University; Hon. LL.D. Columbia University. Associate Superintendent of Public Instruction, Brooklyn, New York, 1882-87; Superintendent of Public Instruction, 1887-98. Fellow of Brooklyn Institute of Arts and Sciences; President of National Educational Association. Author of Introductory and Advanced Lessons in English Grammar.]

BeCAuse parents do not in all cases desire education for their children, or, desiring it, do not know what good education is, or, knowing what it is, cannot afford to procure it for their children, the state is compelled, as a measure of self-preservation and a means of progress, to assume the responsibility of establishing and maintaining schools. A despotic government may establish schools for the purpose of developing a particular type of subject, - the soldier, for example, - as was the case in Sparta. In a democratic society, however, the object is, not to develop a particular type of citizen, but to develop the fullest efficiency, individual and social, of each citizen. In the light of this fundamental truth, the following propositions regarding the functions of the state and the functions of the school in providing education will, I believe, be generally accepted.

(1) The public schools should provide such an education that the opportunities of all citizens to make a living and to lead happy and prosperous lives shall be equal, as far as education can make them equal.

(2) The public schools should provide the highest quality of education, not only for the purpose of equalizing the opportunities of all, but in order that there may be a "perpetual succession of superior minds, by whom knowledge is advanced, and the community urged forward in civilization." 1 Even if comparatively few can avail themselves fully of such education, it is still invaluable to the many by supplying intelligent leadership and expert counsel. The field of human activity is so enormous that, in the more complicated affairs of life, each man, outside a necessarily limited field of experience, needs and should learn to accept the guidance of experts - the specialists in the various departments of law, medicine, surgery, sanitation, engineering, agriculture, and the like. Moreover, as Professor Marshall has pointed out, at least one half of the best natural genius born into a country belongs to the manual-labor classes. Without opportunities for the higher culture the greater

${ }^{1}$ John Stuart Mill, Principles of Political Economy, book v, chap. xi, sec. 8. 
part of this " best natural genius" would be fruitless. Communities that do not provide facilities for the training of genius born in obscurity are on the high road to decadence. These are the reasons why in all states of the Union high schools, and in many states colleges and universities, are maintained at the expense of the taxpayers.

(3) The school, as distinguished from the college, provides training for childhood and youth. The period of childhood, from the point of view of the school, extends from the third or fourth year to the twelfth; and the period of youth from the thirteenth to the eighteenth.

(4) The state should require that the primary elements and means of knowledge should be taught to all children.

(5) The school should provide training for the body as well as for the mind, because the physical nature is the foundation of all life, including the mental; because for good or ill the condition of the body influences the mind, and the condition of the mind influences the body; because without due coördination between the mind and the body, no person is thoroughly equipped for the battle of life; and because a race of men and women capable of enduring the labors of peace and the hardships of war is necessary to the safety of society.

(6) The intellectual training given in the schools involves, in the first place, the adjustment of the mind to its spiritual environment through gaining some knowledge of the intellectual inheritances of the race, and, in the second place, the development of the qualities of industry, energy, helpfulness, and devotion to duty - qualities necessary both to individual and to social progress.

These six propositions are, I think, fundamental. They give rise, however, to a host of most difficult problems in practical administration. The limit of this paper permits me to discuss briefly only a few of the most important.

First among these problems is the problem of physical education.

For the purposes of training the body directly and the mind indirectly four agencies are more or less employed in some schools and should be extensively employed in all schools: play, gymnastics, athletics, and manual training. Play has been defined as "the spontaneous physical expression of individuality;" ${ }^{1}$ it is " nature's way of preparation for later serious living." In the school its use is imperative as affording relaxation and reaction from work and as preserving the individuality of the pupil by affording him an opportunity to follow his own bent. Gymnastics is exercise directed to curing physical defects and to making the body strong and graceful. Athletics consists of organized play involving feats of strength, skill, and agility, performed by several persons in competition. In addition to the physical qualities developed by gymnastics, athletics

\footnotetext{
'Horne, The Philosophy of Education, p. 74.
} 
develops the intellectual qualities of alertness, self-knowledge, executive ability, and "presence of mind," or the ability to think effectively in a crisis; and the moral qualities of self-control, selfreliance, courage, endurance, humility in victory, fortitude in defeat, and loyalty to one's fellows through working together for a common end. Manual training specifically trains the hand as the executive of the mind; it gives opportunity for self-expression in material forms - raffia, paper, pasteboard, cloth, wood, and metal; it gives facility in the manipulation of the simplest and most generally used tools that have aided man in his ascent from savagery; it cultivates the mental and moral habits of accuracy and truthfulness, and it induces a realization of the dignity of labor.

Without these four forms of physical culture - play, gymnastics, athletics, and manual training - no school is doing its perfect work.

Only in very recent years has the conception of physical education as an essential part of a child's training found its way into educational theory and practice. Hence the people's schools in our large cities are, as a rule, very inadequately equipped for any of the forms of physical education.

A most serious difficulty in the way of providing such equipment is raised by the congestion of population in our large cities, caused partly by the ever-increasing immigration and partly by the continuous movement of population from rural to urban life. The result is a deplorable lack of space in which children may play. This condition exists in nearly all our large cities, and particularly in New York, where the huge tenement, crowded to suffocation, full of nerve-racking noises, abominable stenches, and woeful sights, is the home, if home it may be called, of hundreds of thousands of children. With no place to play but the streets, boys, so deep-seated is the instinct for play, form organizations of their own for street games. The organization is the gang, and the games are gambling, stealing, fighting, and sometimes even stabbing or shooting. With no comfort or privacy in the rooms they call home, girls show a constant tendency to degenerate both physically and morally. Moreover, the poorer classes are in these days invariably the most prolific. If, as Prime Minister Balfour recently pointed out, the chief burden of perpetuating the race falls upon the poor in urban communities, then it is essential to the well-being of society that the school should labor incessantly for their physical improvement.

The physical-education problem of the school is, therefore, twofold: To secure equipment for gymnastics and manual training in school buildings, and to provide space for athletics and free play, in which the child's individuality may have scope to develop amid pleasant and healthful surroundings. 
A partial solution of the problem is to open the school buildings and yards in the afternoon and evening throughout the school year and during the summer vacation for purposes of manual training, gymnastics, athletics, and free play. The New York educational authorities are using the school buildings in this way. The result is that thousands of children find rest, recreation, and improvement in the school buildings; that the "little mothers" find peace and quiet for their infant charges; and that hundreds of street gangs are converted into boys' clubs earnestly seeking self-improvement.

Even, however, if every school-house in the city were used at all reasonable hours for purposes of recreation and improvement, the measure would still fall short of counteracting the tenement-house evil. The tenement-house destroys the home; and without the well-ordered home and its influences the school can accomplish comparatively little. Nothing short of a revolution in the existing tenement-house system will restore the life of the poor in the city of New York to something like normal conditions. And how is this to be accomplished? I answer unhesitatingly that the tenement-house, as it has been known in New York City, must be eradicated.

University and other social settlements are doing good, small parks afford some relief, and the public schools are doing a good deal and may do much more, but none of these instrumentalities goes to the root of the matter. The central evil of the crowded tenement is that it destroys home and family life, and no cure will be complete except a cure which restores to the poor man in cities the possibility of making a home for his wife and children. To this end the municipality should lay down strict rules, determined by experts, as to the height, floor-space, air-space, and number of families to be accommodated, according to which all tenements built by private owners shall be constructed. New York took a considerable stride in this direction by its tenement-house law of 1901, but the remedy is farfrom being sufficient. The municipality should employ its credit to purchase tracts of unoccupied land upon which to erect model homes for workingmen amid pleasant and sanitary surroundings, and rent, or sell them, at a moderate profit.

To such a scheme the objection will be made that it is rank paternalism. I answer that paternalism is justified when private initiative fails to root out an evil that is sapping the vitality of the nation at its root - the home life of the people. Again, it will be objected that municipal management is often, if not generally, characterized by carelessness, extravagance, and fraud. The all-sufficient answer is, first, that no amount of plundering and blundering on the part of municipal authorities could equal in its bad effects the evil wrought by the heartlessness and rapacity of tenement landlords; and, in the second place, that the experience of municipal authorities amply 
demonstrates that committees of citizens, serving without remuneration, through salaried experts, manage vast undertakings and enormous properties with economy and efficiency. The essential condition is that the undertaking should be large enough to warrant the employment of experts of first-class ability.

The school should and must at all waking hours do all that its resources permit to supply what the home, even under the most favorable conditions, loses by moving from agricultural to urban life; but if the home and its wholesome influences are not to be obliterated among the city poor, the city must see to it that the so-called working classes are enabled to live in homes where homely virtues have a chance to flourish and where children have space to play.

But there is still another aspect of physical education. Education, whether physical or mental, is seriously retarded, if not practically impossible, when the body is improperly or imperfectly nourished. The child of poverty, with body emaciated, blood thin, and nerves on edge, because he has not enough to eat, grows up stunted in body and in mind. What a farce it is to talk of the schools providing equal opportunities for all when there are hundreds of thousands of children in our city schools who cannot learn because they are always hungry! The schools of Paris provide a simple, wholesome midday meal for their hungry children. In many places in the British Islands the same thing is being done. Should we do less in the cities of democratic America? In no other way can we be sure that the schools will, as far as education may, provide equal opportunities for all.

Another of the very serious problems of school administration confronting us at present is the division of time as between the elementary school and the high school. The customary division assigns two years, from the ages of four to six, to the kindergarten; eight years, from six to fourteen, to the elementary school; and four years, from fourteen to eighteen, to the high or secondary school. If it is true, as is now generally believed, that the period of childhood closes at twelve, that the period of youth begins at thirteen, and that the child and the youth need different subject-matter and different methods of teaching, it is obvious that a distribution of time which requires two years of the period of youth to be spent under school conditions fit only for the child, is open to most serious objections. Specifically stated, these objections are as follows:

First, the present arrangement causes the loss of valuable time by prolonging for two years a method of teaching that is fitted only for children; second, it unduly defers and therefore unjustly abbreviates the time devoted to foreign languages, to the higher mathematics, and to science; and third, in cities where school accommodations are limited in proportion to the number of children, it is wasteful because, 
while the classrooms occupied by grades of the first six years are crowded, those devoted to the seventh and eighth years are often partially empty.

In order to obviate the waste of effort, of time, and of space involved in the present organization of schools, I suggest the following arrangement:

(1) School life, above the kindergarten age, should be divided into two equal periods - the elementary, corresponding to the epoch of childhood; and the secondary, corresponding to the epoch of youth. Each period would provide for six years of school work - the elementary, from six to twelve; the secondary, from thirteen to eighteen.

(2) For economic reasons, inasmuch as children leave school rapidly after they are of age to go to work, the secondary schools should be of two kinds, which might be called the pre-academic and the academic. The pre-academic schools would provide three years of work, from thirteen to fifteen, and would be established at convenient points selected with a view to accommodate the children promoted from the elementary schools. The academic schools, which would be comparatively few in number and established only in crowded centres, would provide another three years of work for youths from sixteen to eighteen. In this way space would be economized, much more work would be accomplished, and it may be reasonably anticipated that our young men and young women, before leaving the high school or academy, would have covered most, if not all, of the work that is now accomplished by the end of the sophomore year in the average college. A beginning of this plan has been made in several cities by the enrichment of the last two years of the elementary course of study, through the introduction of a foreign language, algebra, and elementary physics. The gradually extending use of the departmental system of teaching, by which one teacher, instead of teaching all subjects for a year or half a year, teaches one subject through two years, is also contributing to the same result. Teachers who teach subjects for which they have special talent and preparation, and in which they are interested, to pupils thirteen and fourteen years of age, are almost certain to adopt methods suitable to the period of youth rather than to the period of childhood.

After the problem of the distribution of time comes the problem of the elementary curriculum. What studies shall be pursued by children between the ages of six and thirteen? The answer to this question is found in the fundamental assumption that mental education is the gradual adjustment of the child to his spiritual environment.

President Butler was probably the first to advance this view of education as a development of Mr. John Fiske's discovery that the 
prolonged period of infancy in the human race lies at the foundation of family life. President Butler defines our spiritual environment as "the spiritual possessions or inheritances of the race." 1 These spiritual inheritances he classifies as our scientific inheritance, our literary inheritance, our artistic inheritance, our institutional inheritance, and our religious inheritance. As education is the work of the school, it is obviously, then, its function to introduce the child to his spiritual inheritances. As a recent writer has well expressed the thought: "This production from within the mind of its own world in response to the stimulating effects of the world without is education as a process, as an activity.... What his race has produced he (the youth) reproduces, and thus universalizes his individual nature and socializes his private impulses." 2

This philosophic view of education which calls, as far as may be, for the reproduction in the individual of what has been produced by the race, is responsible for large additions to the elementary curriculum. At the same time, and in entire harmony with the philosophic view, there has been a constantly growing demand on the part of the people for the teaching of such subjects as carpentry, sewing, and cooking. Hence there has arisen the problem of the curriculum. Since we can teach but a small fraction of our spiritual inheritances, on what principle shall we make the selections? How shall we avoid giving teachers more to teach than they can teach well, and pupils more to learn than they can learn well? How shall we prevent what is popularly known as the "overcrowding " of the elementary curriculum?

Twenty-five years ago the average elementary school in America taught reading, writing, spelling, grammar, geography, arithmetic, United States history, and what was called civics. In order to fill in the time, arithmetical rules of no possible use in life were taught, and the children's wits were exercised or blunted by outlandish mathematical puzzles; a manual of United States history and the Constitution of the United States were learned by heart; long lists of meaningless names were memorized in geography; parsing with the utmost detail was continuous; drawing, where drawing was taught, was exclusively from flat copies; and the crowning glory of the school was held to be the ability to spell sesquipedalian words whose signification had never dawned upon the childish intellect. The lack of intelligence in this work is to be accounted for by two facts: first, that teachers were not as well educated or trained as they are to-day; and second, that in the absence of interesting subjectmatter they required their pupils to commit to memory dry and useless details in order to fill up the prescribed time. The additions

'Butler, The Meaning of Education, p. 17.

${ }^{2}$ Horne, The Philosophy of Education, p. 100. 
that have been gradually made are nature-study, which is intended to train what President Eliot calls "capacities for productiveness and enjoyment "through the progressive acquisition of an elementary knowledge of the outside world; algebra, chiefly as an aid, through the equation, to the solution of arithmetical problems; inventional geometry; literature, studied as such, distinct from the ordinary reading-lesson; language and composition, as the art of expression; drawing from objects; and manual training and other physical exercises. This seems a long list of subjects, and yet every subject is justified and required by the fundamental assumption that the school exists for the progressive adaptation of the child's mind to its spiritual environment. In other words, each child has a right to the acquisition not only of the tools of knowledge, but at least to the beginnings of a knowledge of literature, of science, of art, of institutions, and of ethics, so that when he leaves school he may be able to continue along the road on which he has started. Educators throughout the United States are now practically agreed that each of these great divisions of knowledge should be represented in some way in each year of the course.

How, then, has room been made, or may room be made, for the new subject-matter and the new activities? In the first place, through the correlation of studies, the reinforcing of one study through other studies, as the correlation of history with geography, and of composition with literature. In the second place, through improved methods of teaching, so that more work is accomplished in a given time. The early introduction of the idea of ratio in arithmetic, and the use of the phonetic method in teaching reading, are cases in point. It is safe to say that when reading is scientifically taught the average child reads better at the end of the first year in school than twenty-five years ago he could read at the end of the third year and that he actually reads five times as much matter during the first three school years as he read during the same period a quarter of a century ago. In the third place, time may be saved by lopping off useless and wearisome detail in all subjects. To a considerable extent this pruning process has been applied in the best schools.

That the memorizing of unnecessary details has not altogether gone out of fashion, however, is shown by the recent exposure of methods of teaching history in the high schools of one of our most enlightened states. One hundred students who entered a state normal school were asked to write answers to the question: "How were you taught history in the public school?" Of the one hundred, sixty-two answered that they had "memorized the text-book and recited it word for word as nearly as possible." 1 But history is not the only subject in which children's time is wasted and their interest 
destroyed by memoriter methods. In geography, in grammar, in arithmetic, even in nature-study, it is still not unusual to find teachers consuming their pupils' time in memorizing unessential details and a vast redundancy of technical terms. Mr. Frank McMurry lays down the following plain rules for the rejection of superfluous subjectmatter in teaching:

"(1) Whatever cannot be shown to have a plain relation to some real need of life, whether it be esthetic, ethical, or utilitarian in the narrow sense, must be dropped.

" (2) Whatever is not reasonably within the child's comprehension, likewise.

"(3) Whatever is unlikely to appeal to his interest; unless it is positively demanded for the first very weighty reason.

"(4) Whatever topics and details are so isolated or irrelevant that they fail to be a part of any series or chain of ideas, and therefore fail to be necessary for the appreciation of any large point. 'This standard, however, not to apply to the three R's and spelling." I

The intelligent application by teachers of these four rules, together with the more general dissemination of improved methods of teaching, will gradually solve the problem of the "overcrowding of the elementary curriculum."

The elective system, which has obtained so firm a footing in American colleges and universities, has spread to the secondary schools, while there are not wanting those who argue in favor of introducing it into the elementary schools. Some would go so far as to say that a youth of fourteen should be permitted, while in high school, to pursue as many studies or as few studies, for as long a time or for as short a time, as he pleases. Though there are few who take this extreme view, yet the elective principle has found a firm lodgment in the secondary school. For the most part it takes the form of a choice between a college preparatory course, a commercial course, and a manual-training course, or a choice between two or more related subjects of study. If we assume, as I think we must, that the principle of election has been firmly established in the secondary schools, the problem which at once arises is: How shall the student be guided to a wise choice of courses and of subjects? Obviously, when he enters, the teachers of the secondary schools cannot advise him, because when he presents himself at their doors they know nothing of his special aptitudes and little of his previous studies. In the great majority of cases parents are quite as incompetent as his new teachers to give him useful counsel. How is the boy, at the age of fourteen, to determine whether he shall take the college preparatory course, or the commercial course, or the manual-training course? Here is a problem of the first importance. It is of the first import-

${ }^{1}$ Educational Review, May, 1904. 
ance to the boy himself, because his future happiness and success in life depend in no small measure on the prudence with which he makes his selection. It is of the first importance to society, because there is no economic waste comparable in its proportions to that occasioned by setting people to work for which they have no natural aptitude. How, then, is the problem to be solved? I fear we must lay the burden in the first instance on the elementary school - a burden which that institution has hitherto made but little effort to assume. That the elementary school has not done more to guide the future academic work of its pupils is generally attributed to one or other of two causes, neither of which I believe to be tenable. In the first place it is claimed that the elementary school presents the same subject-matter and the same activities to all pupils and therefore turns out a machine-made - I believe that is the term generally employed - a machine-made product that is alike in all its parts. The answer is that the elementary school must of necessity present the same subjects and the same activities to all its pupils, because these subjects and these activities constitute the necessary food and the necessary training of the child mind; that the use of the same studies and the same exercises does not result in producing the same type of mind and disposition, because different minds, according to inherent capacities, react in different ways upon the same stimuli; and, finally, that the intellectual capacities, dispositions, and tendencies of the graduates of the elementary schools are actually not alike, but as various as there are individuals. The second criticism. is that the bright pupil is made to keep step with the dull pupil. "Marking time" is the phrase used in the educational cant of the day. To properly administered schools this criticism does not apply. Even if it did, however, the pity lavished on the particularly bright pupil is largely wasted. He can generally take care of himself. Our sympathy is needed, not for the bright, precocious pupil, but for his duller, though not on that account less able, associate. The problem really is, not how to drive the bright pupil through the grades at railroad speed, but how to give the slower pupil the assistance - but little will be needed in the majority of cases - that will help him over obstacles and enable him to keep up with his more brilliant companions. Any school which lavishes the time and energy of its ablest teachers on the more brilliant, to the neglect of the duller pupils, falls far short of its duty.

The fault, then, lies neither in the sameness of the curriculum nor in the retardation of bright pupils, but in the failure of elementaryschool principals and teachers to realize their responsibility for the future welfare of their pupils. Where, on the other hand, all pupils have equal opportunity and equal advantages, there the teachers, if they take an interest, may note the different reactions produced by 
identical stimuli on different minds, and advise the boy of literary ability to take the college preparatory course, the one with business instincts to take the commercial course, and the one with a turn for mechanics to pursue the manual-training or mechanic-arts course. In this way the elementary school may become of much greater benefit to society than it is at present.

The elementary school can, however, guide only the first steps of the student. After he has fully entered upon the work of the secondary school it becomes one of the chief duties of that institution to train him to make intelligent selection among courses and subjects of study.

There remain to be considered three problems of the highest importance in the administration of the American school - the problem of compulsory attendance, the problem of the supply of teachers, and the problem of finance.

Most of the Northern States of the Union have enacted compulsory-education laws, more or less stringent in their nature. These laws are not, however, strictly enforced. In the South there is not even a pretense made of compulsory school attendance. Several reasons may be assigned for the laxity that undoubtedly exists in the enforcement of compulsory-education laws: a widespread repugnance to state interference with the supposed liberties of parents; the opposition of the employers of child labor, such as the cotton manufacturers of the South, the coal-mine owners of Pennsylvania, the glass-makers of New Jersey, the sweat-shops of New York, and the small traders in all large cities; the opposition of private schools which dread a diversion of their children to the public school; the opposition of some foreign-born, non-English-speaking communities, founded on the fear that their children would, in the public school, lose the use of their native tongue; and, lastly, the lack of adequate administrative machinery for the enforcement of existing laws.

Gradually to overcome this widespread opposition to compulsory school attendance the following measures are suggested:

(1) Governmental registration and inspection of all private and parochial schools, to the end that no school may be permitted to exist which does not teach its pupils the English language and the elementary duties of citizenship. There should be no interference public opinion in America would not tolerate any interferencewith endowed, proprietary, or sectarian schools, if such interference would in any way limit the liberty of teaching or the rights of parents to determine the schools in which their children shall be trained. Such interference on the part of the state should be forbidden for educational as well as political reasons, because the competition of private schools is essential to the well-being and the growth of public 
schools. On the other hand, the state owes it to society, and society owes it to itself, to see to it that all its future citizens, either in public or in private schools, are taught the English language and at least an elementary knowledge of American history and institutions, and that they are taught by persons who are qualified to teach.

(2) The registration of all children in large cities. If such a measure is necessary in the comparatively stable population of Paris, in order to secure a strict enforcement of a compulsory-education law, how much more necessary is it in a city like New York or Chicago, in which population is constantly shifting over a widely extended urban territory, and to which is added annually an enormous influx of non-English-speaking foreigners?

(3) The education of society to a realizing sense of the necessity on social grounds of a strict enforcement of a reasonable compulsoryeducation law. The great truth must be brought home to all that the man who fails to educate his children commits a twofold sin a sin against his children, whom he deprives, as far as his power goes, of the ability to live happy and prosperous lives; and a sin against society, which suffers and deteriorates in proportion as its members fail to participate in the spiritual inheritances of the race and fail to receive that training for citizenship which springs from association in the exercises of the school. On the other hand, I may justly claim for my country that there is no other in which education is more generally appreciated, or in which it is pursued with greater zeal. The enthusiasm of the many will not, however, atone for the indifference of the few.

The problem of the supply of teachers presents three principal phases:

(1) How shall teachers be trained?

(2) How shall teachers be appointed?

(3) Shall women teachers continue in the vast majority in American schools?

There are two prevailing types of method in training teachers, whether in the university, the normal school, or the city trainingschool: that which regards the study of the science and art of teaching as incidental to the acquisition of scholarship, and that which looks upon it as a pursuit requiring the undivided attention of the student. Just as the professions of medicine, law, theology, and engineering now require that the intending licentiate shall devote some years to the exclusive study of the technique of his future work, so it may be confidently predicted that in the not distant future every person who is to teach our children shall be required not only to reach a high standard in scholarship, but to devote from two to four years to special preparation for the most delicate and difficult of all arts - the art of training children. 
Up to forty years ago the conception was widely prevalent throughout the United States that any one who knew enough to keep ahead of his pupils in their lessons was sufficiently well instructed to be appointed a teacher. The natural result of this generally accepted view was the appointing of teachers by citizen committees who were too often swayed by prejudice, favor, or political and religious considerations. As a higher conception of the school and its functions and of the teacher and his duties has gained ground, we are slowly, but surely, realizing the necessity of a method of appointment and promotion that will relieve the teacher from humiliation and the schools from the incubus of political management. Two plans have been somewhat widely tried: appointment by a single expert, supervisor, or superintendent, and appointment as the result of competitive examination. Appointment by a superintendent has been known to lead to the displacement of an honest and fearless official and the substitution of one who is subservient to political control, and is not likely to be extended. Appointment by competitive examination, on the other hand, while it may not always attract the right persons to the right places, is slowly, but surely, gaining ground. It has raised the standard of scholarship and professional equipment among teachers. As a general rule it selects the best from among a mass of applicants for a given position; and it preserves the self-respect of the individual teacher, because it frees him from the necessity of begging or cringing for a position and enables him to feel that he obtains appointment or promotion solely upon his own merits. As communities awake to the necessity of delivering their schools from the abhorrent influences of political and ecclesiastical patronage, we may look to see a more rapid spread of this method of appointing and promoting teachers.

Attention has recently been attracted by the report of the Mosely Commission to what has been called the feminization of American schools, because the great majority of public school teachers are women. It was an economic reason, in the first instance, - the fact that women work for smaller wages than men, - that led to the present preponderance of the feminine element in the teaching force. It is more than doubtful, however, whether American schools and American education have deteriorated in consequence. It is quite certain that the refined woman of to-day who has been thoroughly trained is a much better teacher than the coarse, ignorant, pedantic schoolmaster of fifty years ago, who excited no feeling but contempt, hatred, or terror in the breasts of his pupils. We all believe in the salutary influence of the masculine mind in teaching, particularly in the case of older pupils, but we also believe that the influence of a strong woman is better than that of a weak man; and that a woman teacher of ability who is devoting her life to educational 
work is apt to be a better teacher than the male fledgeling who takes up teaching as a makeshift, and whose mind is set, not upon education as a career, but upon law or medicine. In short, to increase the efficiency of the public school-teaching force by increasing the number of efficient men teachers - men who would devote their lives to the work - would involve a largely increased expenditure of money in order to induce such men to make teaching their life-work. And this brings me to my last problem - the problem of finance.

If we are to have school-houses properly equipped for the training of the body as well as the mind - for manual training, play, gymnastics, and athletics; if all children are to enjoy their God-given right to education; if schools are to be equipped for scientific as well as literary studies; if salaries are to be paid to teachers that will attract men and women of breeding and refinement to the teaching profession; and if all the teachers are to be thoroughly trained, so that they will be models to imitate and persons capable of arousing interest and inspiring effort - if all these things are to be accomplished, it is evident that the sums devoted to education in America, enormous as they are, must be very greatly increased. For effective purposes, the revenue of a public school system ought to possess two characteristics: first, it should be ample; and second, it should be stable. It should be sufficiently ample in each community to provide schooling for all children in classes not to exceed forty to a teacher, and in adequately equipped buildings; to pay teachers reasonable salaries, so that they may be able to live in refined surroundings and take advantage of opportunities for self-improvement; and to provide pensions after retirement, so that while in active service they may be relieved of anxiety regarding provision for old age. It should be stable, so that the educational authorities may be able to carry out a consistent and progressive policy. It should not be subject to the whims and caprices of the politicians who control the municipal administration of our large cities. It should not be fluctuating from year to year, and thus lead to the establishment of activities one year which must be abandoned for lack of funds the next.

I have selected from among the innumerable problems in school administration which now confront the people of the United States those that seem most important and most urgent, and I have ventured in each case to suggest a solution. Every solution proposed involves an increased expenditure of money. Immeasurably more effective, however, than money - vital though money is - to uplift the school, are the love and skill of the devoted teacher. Love for children and teaching skill are the greatest things in the school. 

SECTION C - THE COLLEGE 
1 


\title{
SECTION C - THE COLLEGE
}

(Hall 12, September 23, 3 p. m.)

\begin{abstract}
Chatrman: Chancellor W. S. Chaplin, Washington University.
Speakers: President William De Witt Hyde, Bowdoin College. President M. Carey Thomas, Bryn Mawr College.

Secretary: Professor H. H. Horne, Dartmouth College.
\end{abstract}

\section{THE COLLEGE}

\section{BY WILLIAM DE WITT HYDE}

[William De Witt Hyde, President of Bowdoin College and Professor of Mental and Moral Philosophy. b. September 23, 1858, Winchendon, Massachusetts. A.B. Harvard University, 1579; DD. and LL.D. Pastor of Congregational Church, Paterson, New Jersey, 1883-85. President of Bowdoin College, 1885. Author of Practical Ethics; Practical Idealism; God's Education of Man; From Epicurus to Christ; The College Man and the College Woman; and other works.]

THe best approach to a definition of the college is by closing in upon it from the two sides of the institutions between which it stands: the school and the university. And as in the mariner's compass not only is there a northeast between north and east, but several intervening points, so we shall find between the school and the college a school-college, and between the university and the college a university-college, which for our more accurate purposes we shall have to take into account. Before defining the college, let us define in the order the school, the university, the school-college, and the university-college.

The school imposes the symbols of communication, together with the rudiments of science, literature, and art, on the more or less unwilling child. I know the words "impose" and "unwilling" sound hard and harsh, and will evoke a protest from the advocates of the sugar-coated education. But with all due respect for what kindergarten devices, child-study, and pedagogical predigestion can do to make learning attractive, the school must be essentially a grind on facts and principles, the full significance of which the child cannot appreciate, and which consequently must appear hard, dry, and dull. The world is so big and complex, the mind of the child is so small and simple, that the process of the application of the one to the other can scarcely be effective without considerable pain. Consequently in the school there must be rigid discipline, judicious appeal to extraneous motives, and a firm background of unquestioned authority. I appreciate most highly all that has been done in the 
ways above referred to in the direction of mollifying this discipline. But in a brief definition of a great institution the essential, not the accidental, elements - the enduring features, not the latest phases of it - must be emphasized.

The university, including in that comprehensive term graduate, professional, and technical training, is the exact opposite of the school. The school brings together the large world and the child's small mind, involving the pain of mental stretching to take in materials of which there is no conscious want. The university presupposes the enlarged mind, which it applies to some small section of truth, such as law, medicine, architecture, engineering, dentistry, forestry, Latin, history, astronomy, or chemistry. This, too, is a somewhat painful process, but its pains are of the opposite nature, due to confining the enlarged mind, full of varied human interests, to the minute details of a narrow specialty. Of discipline the university has practically nothing. It requires only intellectual results. Such moral and spiritual influences as it affords are offered as opportunities rather than imposed as requirements. Its atmosphere is absolutely free. Its professors are specialists. Its students are supposed to be men.

Having briefly defined the two institutions on either side, it might seem the proper time to present the definition of the college. But on both sides intermediary types have been evolved, which must be carefully distinguished from the college proper, - the school-college, and the university-college.

The school-college admits its students poorly prepared, and gives them in the school-college the work they ought to have done in the school. Its professors are schoolmasters, teaching several subjects, mainly by the school method of recitation from the book or repetition of dictated lectures. Laboratory work is confined chiefly to prearranged illustrative material. The conduct of the students is minutely supervised by the faculty. Little or nothing inside or outside of the recitation-rooms is left to the initiative of the students. A considerable proportion of the so-called colleges of the United States are of this school-college type. They are inexpensive; and curiously enough, the less endowment they have, the less it costs to attend them. Their graduates, unless by virtue of native wit, hardly have the breadth and initiative necessary for leadership in commercial, professional, and public life.

By the university-college I do not mean necessarily one connected with a university. A college connected with a university may be a real college, and a university-college may be connected with no university. Its distinctive mark is the application to immature students of methods of instruction and discipline which are adapted only to the mature. Its instruction is given in large lecture courses, 
with little or no personal interest in his students on the part of the lecturer, or required reaction on the part of the hearer. This personal contact is sometimes supplied vicariously in the person of a graduate student, or recently fledged doctor of philosophy, who quizzes fractions of the mass at stated intervals. The information imparted is the best and most advanced. The fame of the lecturers is unsurpassed. But the appropriation of the material presented is largely optional. As the personal element in teaching is largely vicarious, learning in turn tends to become vicarious also. Printed notes, expert coaches, improvised "seminars," reduce to comparatively few hours the labor of those who register themselves as students. Affording splendid and unequaled opportunities for the earnest and studious few, these university-colleges afford the wealthy idler the elegant leisure that he craves.

For the great majority of the students in a university-college, even athletics becomes likewise vicarious, the exertions of the elegant idler in this direction being confined mainly to the lungs and the pocketbook. In so vast a body the opportunity for social leadership and prominence in college affairs is confined to the exceptional few; impossible for the average many. The average boy of eighteen or twenty soon drifts into the irresponsibility of an unnoticed unit in the preponderating mass. Discipline in the university-college becomes practically limited to the requirement that the student shall exercise sufficient control over his animal and social instincts to maintain intense intellectual activity for two periods of two or three weeks in each college year.

By thus closing in upon the college from both sides, and marking off the institutions which come so close to it that they are often confounded with it, we have made the definition of the real college comparatively easy. We are now ready to describe its characteristic marks.

It requires as a condition of admission that the work of the school shall have been thoroughly done. Either by examination before entering, or by elimination at the first opportunity afterward, it strictly limits its students to those who have had a thorough school training. It does this because it is impossible to give a college education to an untrained mind. It is even more essential that a student shall have done hard work before coming to college than that he shall do hard work while in college. The previously trained mind can get a great deal out of college with comparatively little work. The mind that has not been previously well trained can get very little out of college, even by hard work. This may be a stumblingblock to the school man, and foolishness to the university man; but the college man knows that in spite of these criticisms from below and from above, an amount of leisure can be well afforded in college 
which would be fatal in either academy or university. In order to be profitable, however, it must be the leisure of a mind previously subjected to prolonged and thorough discipline.

The method of teaching in the college is on the whole different from that of either school or university. In the school the abstract facts and principles, as laid down in approved and authoritative books, are transmitted by the teacher to the student. The individual reconstruction of those principles and facts in the mind of teacher and student, though important, is relatively less essential. If by gift of genius you get this element of individuality in either teacher or student, you are profoundly grateful; but the school can, and in a vast majority of cases must, get on without the interpreting individuality of the teacher and the reconstructive unification of the student. I am speaking not of ideals, but of facts.

Now there is room for the schoolmaster in the college, but his sphere is very limited. In formal studies like mathematics, and the elements of such languages as have not been previously acquired, every college ought to have two or three thorough drillmasters on its faculty. There is nothing about a college atmosphere that can make analytical geometry easy, or the irregular French verb fascinating, or German prose sentences intelligible without grammar. Such school work as our requirements for admission permitted to be postponed until after admission to college must be done there in the hard, exacting school way.

In the university it is the individuality of the student that counts. Not the facts in the text-books; not the insight and interpretation of the professor; but the initiative of the individual student is what the university is after. The college in the more advanced courses must introduce also a moderate degree of this university element. Most of our colleges, by the group system, or by the requirement of major and minor subjects as a condition of taking the bachelor's degree, insist that something like a fourth or a third of a student's courses shall lead up to and culminate in such comparatively independent work. In this way we give every college student a taste of real scholarly work; and discover the comparatively few who are fitted to prosecute it to advantage in the university.

The college professor, the type to which the majority of the college faculty should belong, is very different from either the schoolmaster or the university specialist. He is a man who grasps his subject as a whole; deals with each aspect of it in its relation to the whole; is able to make the subject as a whole unfold from day to day, and grow in the mind of the student into the same splendid proportions that it has assumed in his own; and who can put it to the test of practical application in matters of current interest. If he is a chemist he is able to give expert testimony in court. If a geologist, 
he is able to take part in government surveys, or lead in exploration. If an economist, he is able to contribute something to the settlement of labor troubles. If an historian or professor of government, he must be able to bring ancient precedent and remote experience to bear on current complications. If a professor of the classics, he must love the masters of English prose and verse all the better for his familiarity with the ancient models; and show how much more the modern things mean when thrown on the ancient background. College students despise a professor who is so lost in his subject that he cannot get out of it, prove its worth by some concrete application, and make life as a whole the larger and richer by the contribution he makes from his special department. He must be human; intensely interested in individuals; eager to see his favorite authors, his beloved pursuits, kindle into enthusiasm the minds he introduces to them. The college professor must know his subject; he must be a competent investigator in it, and a thorough master of it. If as a badge of such mastery and aptitude for investigation he has the degree of Ph.D., all the better. But this is not essential. He must know men and the large movements and interests of the world outside. He must present his subject, lit up with the enthusiasm of a great personality; an enthusiasm so contagious that the students cannot help catching it from him, and regarding his subject for the time being as the most compelling interest in life. He must be genial, meeting students in informal, friendly ways outside of lecture rooms, either in general social intercourse or in little clubs for the prosecution of interests related to his subject. He must have high standards of personal character and conduct, and broad charity for those who fall below them. In short, he must be first of all a man whom young men would respect, admire, and imitate, and love, and then in addition he must know the subject he professes in the broad, vital, practical, contagious way described above.

The course of study in a college covers in a broad way the main departments of language and literature, science and art, history, economics, and philosophy. At least four languages besides English: Latin, Greek, French, and German; mathematics; at least four sciences: physics, chemistry, biology, and geology or astronomy; history, both ancient and modern, both American and European; both orthodox economic theory and current economic heresy, together with special study of such subjects as banking, taxation, transportation, trust and labor problems; the principles and problems of government, both national and municipal; literature studied as literature and not merely the corpse of it, in the shroud of grammar and coffin of philology; philosophy as the attempted answer to the perpetual problems of ontology, cosmology, conduct, and human aspiration; enough of fine art to make one at home in the great 
buildings and galleries of the world - these are the essentials of the college curriculum.

Each of the leading subjects should be presented in at least three consecutive courses extending over a year each: one elementary; one or more broad, general, interesting, practical; at least one specific, intensive, involving research, initiative, and a chance for originality. These broad middle courses are the distinctive feature of the college, and they are the hardest to get well taught. For one man who can teach a college course of this nature well, you can find ten who can teach a university specialty, and a hundred who can teach the elementary-school course. But if you dare to leave out these broad, comprehensive college courses, or if you fail to get men who are broad and human enough to teach them, you miss the distinctively college teaching altogether; you have in place of the college one or another of the four institutions previously described.

These real college professors, - these men who can make truth kindle and glow through the dead cold facts of science; who can reveal the throbbing heart of humanity through either ancient or modern worlds; who can communicate the shock of clashing wills and the struggle of elemental forces through historic periods and economic schedules; who can make philosophy the revelation of God, and ethics the gateway of heaven, - these men are hard to find, infinitely harder to find than schoolmasters on the one hand, and specialists on the other. Yet unless you can get together at least half a dozen men of this type you must not pretend to call your aggregation of professors a college faculty; you cannot give your students the distinctive value of a college course.

The discipline of a college is different from that of either a school or a university. The true college maintains a firm authority; and will close its doors rather than yield any essential point of moral character or intellectual efficiency to student clamor and caprice. Yet this authority is kept well in the background, delegated perhaps to some form of student government, and is used only as a last resort when all the arts of persuasion and all the influences of reason fail. Not more than once or twice in a college generation of four years will it ever be necessary to draw the lines sharply and fight out some carefully chosen issue on grounds of sheer authority.

On the other hand, the college has much of the liberty of the university; yet in such wise that it cannot be perverted into license to do whatever may seem for the time being right in the eyes of immature and inexperienced youth. Spies and threats, and petty artificial penalties are as foreign to a true college as to a university. Yet the college does make the way of the transgressor hard - much harder than the university even attempts to do. 
What, then, is the secret, what is the method of true college discipline, which avoids both these extremes, yet secures the advantages at which both school and university aim? It is personal friendliness, intelligent sympathy, appealing to what is best in the heart of the college student. By intimate appreciation of all worthy student interests, ambitions, and enthusiasm the college officer comes to understand by way of contrast whatever is base, corrupt, and wanton in the life of the little community, and to know by intuition the men who are caught in the toils of these temptations. Any competent college officer can give you, if not offhand, certainly after a half-hour's consultation, an accurate account of the character of any student in his institution; his haunts, his habits, his companions, his ways of spending time and money, and all that these involve. Where it seems to be needed, either some professor or the president has a friendly conference with the student, bringing him face to face with the facts and their natural consequences, but making no threats, imposing no penalties, simply calling the student's attention to principles with which he is already perfectly familiar, and offering him whatever help and encouragement toward amendment friendly interest and sympathy can give. Usually the whole matter is strictly confidential between officer and student, though when this proves inadequate the aid of students likely to have influence is secured, and in extreme cases the coöperation of parents and friends at home is invoked. Information that is directly or indirectly acquired through this close sympathy with student life is never made the basis of any formal discipline whatever. A student may persist in evil ways, and be known to persist in them, and be treated by the college in no other way than he would be treated in similar circumstances by his father and mother at home. If he performs his work and avoids scandal he may go on and graduate, precisely as he might continue to live under his father's roof. If his evil courses lead to failure in his work, or if they bring scandal upon the college through overt acts, or obviously injurious influence, then he is asked to withdraw.

Such, in brief, is the spirit of college discipline. It fits neither the immature nor the mature, but youth who are passing from immaturity into maturity. It appeals to the highest and best motives, and scorns to deal with any others. It brings to bear the strongest personal influences it can summon, but deigns to use no others. It sometimes fails, but is usually in the long run successful. It presupposes absolute sincerity, perfect frankness, endless patience, infinite kindliness on the part of the college officer. It is sure to be misunderstood by the general public. It takes the average student about half his college course to come to an understanding of it. It lays those who employ it open to the charge of all manner of partiality, 
weakness, inefficiency, from those who look at the outside facts and do not comprehend the inner spirit. But it is the only discipline that fits the college stage of development; it does its work on the whole effectively; it turns out as a rule loyal alumni, moral citizens, Christian men.

In its religious life the college should be as little as possible denominational. The narrowness of sectarianism and the breadth of the college outlook are utterly incompatible. Denominations may lay the eggs of colleges; indeed, most of our colleges owe their inception to such denominational zeal. But as soon as the college develops strength it passes inevitably beyond mere denominational control. Church schools are often conspicuous successes. Church colleges are usually conspicuous failures. A church university is a contradiction in terms.

It is equally necessary that the college should be intensely Christian. The administrative officer should believe in the power of the best motives over the worst men and the application of great principles to little things. He should know that persons are more than the acts that they do. He should believe what most people practically deny, - that a sinner can be saved and that he is worth saving. It is only on such a profoundly Christian basis that a college can be successfully conducted. A college which is not Christian is no college at all. For the faithful, hopeful, loving treatment of persons as free beings of boundless capacity and infinite worth is at once the essence of Christianity and the distinguishing mark of the true college.

Christianity in the college, as everywhere else in the world, presents the two aspects which Jesus contrasted in the parable of the two sons whom the father asked to work in his vineyard. There is the conscious, professed, organized Christianity, which joins the church and the association, attends and takes part in meetings, and casts about to find or invent ways to make both the world and one's self better than they otherwise would be. Sometimes, unfortunately, the Christian of this type neglects that devotion of himself to such forms of good as are already established, - the intellectual tasks, the athletic interests, the social life, of the institution. In that case the result is that, good as it means to be, good as in many respects it is, this type of Christianity fails to be appreciated by the majority of the students; the leadership of all forms of college life passes into other hands, and this avowed, expressed, organized Christianity lives at a poor dying rate, by faculty assistance and student toleration. People who forget the lesson of the parable that there are two types of Christianity, and confound this type with the whole of Christianity, sometimes take a very discouraged view of the condition of Christianity in our colleges. 
What, then, is the other, the relatively unconscious, unprofessing type? Who is the Christian who, as Jesus says, in the judgment day will be surprised to find that he ẉas a Christian at all? He is the man who lives for something bigger and better, loses himself in something wider and higher than himself. He does his work with a sense of responsibility for the honest improvement of his powers and opportunities; or, better still, with devotion to some aspect of scientific truth or human welfare that has gotten hold of him. He enters heartily into the sports and enthusiasms of his fellows, sacrificing comfort and convenience to the promotion of these common ends. He shares his time and property with his friends, and supports generously their common undertakings. He stands up for what is right, yet always has a helping hand for the fellow who has fallen down. He looks forward to life as a sphere where he is going to serve public interests and promote social welfare, at the same time that he supports himself and his family.

Now, if this is Christianity, if the cultivation of these traits and aims is growing in Christian character, then our colleges are mighty agencies for the spread of Christianity. No man can go through one of them and catch its spirit without becoming a better Christian for the remainder of his days.

Of course it is highly desirable that these two types of Christianity should understand and appreciate each other. Especially fortunate is the college where these two types coincide; where the most prominent members of church and association are at the same time the best fellows, and where the best fellows give their influence and support as officers and workers in distinctively Christian organizations. In some men's colleges, and in most women's colleges, this is happily the case. If, however, we can have but one of the two types, as often happens, we must agree with Jesus that good work and good fellowship on a basis unconsciously Christian are better than a conscious profession which remains self-centred and self-satisfied, outside the more genial and generous current of the life of the community.

The last feature of the college, but by no means the least significant, is this genial, generous, social life. Even if nothing were learned save by absorption through the pores, the intimate association with picked men of trained minds for the most impressionable years of one's life would almost be worth while. To take one's place in such a community, to bear one's share in its common interests and common. endeavor, to take the social consequences of one's attitude and actions in a community which sees clearly and speaks frankly, rewards generously, and punishes unmercifully, is the best school of character and conduct ever yet devised.

This is the leading consideration in determining the desirable size of a college. As Plato says of the state, we may say of the 
college, - it should be as large as is consistent with organic unity. If some types of life and character, the rich or the poor, the independent or the conservative, the high scholar or the good fellow, the athlete or the man of artistic temperament, are left out, then it is too small. If, on the other hand, a man can be a mere unit in a mass toward which he feels little or no definite responsibility; if his specific contribution is not needed and his individual opinion does not count; if the games are played, and the papers are edited, and the societies are managed, and things generally are conducted by experts whom he merely knows by sight and reputation; then that college is too large for him; he will probably come out of it as small as he went in.

For the most enjoyable and profitable social life the college community inevitably breaks up into little groups, - fraternities, musical associations, athletic teams, and clubs for scientific, literary, historical and philosophical study. Extension and intensity are inversely proportional; and a man who misses the closer contact and warmer fellowship of these smaller groups misses much that is most valuable in college life. Athletics are carried to excess, as is everything else in which youth take a leading part. But the incidental excesses of a few individuals are much more than counterbalanced by the increased physical health, moral tone, and freedom from asceticism and effeminacy in the college community as a whole. Cut off as they are from the natural outdoor tasks and sports, from chores and workshops, from hunting and fishing, from sailing and riding, some artificial outlet for physical vigor is absolutely essential. Some object for community enthusiasm, community loyalty, and community sacrifice is equally a moral and social necessity. The worst evil of athletics is not the effort put forth by the athletes themselves, but the extent to which these interests absorb the time and conversation, the thought and aspiration, of both combatants and non-combatants. Even this evil, great as it is, is small in comparison to the moral evils which would infest a group of vigorous young men from whom some such outlet was withheld.

The fraternities and societies likewise have slight possibilities of evil, but accomplish an overwhelming preponderance of good. It is through them, directly or indirectly, that the most effective personal and social influence can be brought to bear on those who need it. Occasionally a fraternity drops to the level of making mere good-fellowship an exclusive end, to which scholarship, morality, efficiency, are merely incidental. A college is fortunate which at any given time does not have one or two fraternities that are tending in this direction. But the contempt of their rivals, the influence of their graduates, the self-respect of the better members themselves, together with direct or indirect faculty remonstrance, serve to bring a fraternity to its senses in a quarter of the time it would take to 
straighten out an equal number of isolated individuals. Isolated good and isolated evil are more nearly on an equality. But good influence can be organized and mobilized a hundred times as quickly and effectively as evil influence; and where the moral forces in faculty and students are alert, the fraternities serve as rallyingpoints for the concentration of the good and the dispersion of the evil.

Departmental clubs, in which one or two members of the faculty meet informally with a few of the more interested students for conference on some phase of their subject, are perhaps the consummation of the college spirit. Modern methods of instruction, however, make contact in the laboratory over experiments and in the library in research so close that many of the regular classes assume more the aspect of a club than a class. The newest and best college libraries provide small rooms for the use of books by professors and students together in each literary and historical department; and regard such rooms quite as indispensable as the room where books alone are stored.

There is one serious danger, and only one, that besets the college. The ordinary objections, hazing, excessive athletics, dissipation, lawlessness, idleness, are due either to exaggeration of exceptional cases, or the unwarranted expectation that large aggregations of youth will conduct themselves with the decorum that is becoming where two or three mature saints are gathered together for conference and prayer. I grant that a man who cherishes this expectation will be disappointed; and if he chances to be a college officer, and undertakes to realize this expectation, he will be deservedly miserable. With all its incidental follies and excesses, college conduct is more orderly, college judgment is more reasonable, college character is more earnest and upright, than are the judgment, conduct, and character of youth of the same age in factories, offices, and stores, or on farms or on shipboard. As far as these matteris go, college is physically, mentally, and morally the safest place in the world for a young man.

The one serious danger is so subtle that the public has never suspected its existence; and even to many a college officer the statement of it will come as a surprise. It is the danger of missing that solitude which is the soil of individuality and the fertilizer of genius. College life is excessively gregarious. Men herd together so closely and constantly that they are in danger of becoming too much alike. The pursuit of four or five subjects at the same time tends to destroy that concentration of attention to one thing on which great achievement rests. The same feverish interest in athletics, the same level of gossip, the same attitude toward politics and religion, tend to pass by contagion from the mass to the individual, and supersede independ- 
ent reflection. The attractiveness and charm of this intense life of the college group tends to become an end in itself; so that the very power which wholesomely takes the student out of himself into the group invites him to stop in the group instead of going on into those intellectual and social interests which the college is supposed to serve. This devotion to college rather than to learning; to the fellows rather than to humanity; to fraternities and teams rather than to church and state, is a real danger to all students, and a very serious danger to the exceptional individuals who have the spark of originality hidden within their souls. The same forces that expand small, and even average men, may tend to repress and stunt these souls of larger endowment. To guard against this; to make sure that the man of latent genius is protected against this deadening influence of social compulsion toward mediocrity, is one of the great duties of the wise college professor. He must show the student of unusual gifts that he is appreciated and understood; and encourage him to live in the college atmosphere as one who is at the same time apart from it and above it. The formation of little groups, temporary or permanent, among the more earnest students for mutual recognition and support, groups which actually do for a student while in college what Phi Beta Kappa attempts to do in a merely formal and honorary way afterwards, may help these choice minds to stem this tide of gregarious mediocrity. Wherever the faculty is alert to detect its presence, even genius can thrive and flourish in a college atmosphere.

Such is the college. It is an institution where young men and young women study great subjects, under broad teachers, in a liberty which is not license, and a leisure which is not idleness; with unselfish participation in a common life and intense devotion to minor groups within the larger body and special interests inside the general aim; conscious that they are eritically watched by friendly eyes; too kind ever to take unfair advantage of their weaknesses and errors, yet too keen ever to be deceived.

The function of the college follows so obviously from the concept that it requires but a word to draw the inference. It makes its graduates the heirs of all the wisdom and experience of the ages; placing, if not within their actual memories, at least within the reach of their developed powers and trained methods any great aspect of nature or humanity they may hereafter wish to acquire. It gives each one of them a sense of achievement and mastery in some one subject of his choice, giving him, in that one department at least, the impulse to read its books and study its problems as long as he shall live. It places its alumnus on a plane of social equality with the best people he will ever meet, and gives him a spirit of helpfulness toward the lowliest with whom he will ever come in contact. It makes him the servant of the state in wise counsel and effective leadership. It 
gives to the church ministers who can do more than turn the cranks of ecclesiastical machinery and repeat ritualized tradition - prophets who gain first-hand contact with the purposes of God. It prepares men who will bring to the study and practice of law ability to apply eternal principles and ancient precedents to the latest phases of our complex civilization. It trains its graduates who practice medicine to give every patient the benefit of whatever science is developing of healing efficacy for his particular case. It trains men who are to be engineers, bankers, manufacturers, merchants, to put the solidity and integrity of natural law into the structures that they rear, the institutions they control, the fabrics they produce, and the transactions they direct. It trains men and women who will give to domestic and social life that unselfishness and geniality which comes of having the mind lifted above the selfish, the artificial, the petty, into sincere and simple intercourse with the good, the true, and the beautiful.

The function of the college, then, is not mental training on the one hand nor specialized knowledge on the other. Incidentally it may do these things at the beginning and at the end of the course, as a completion of the unfinished work of the school, and a preparation for the future pursuits of the university. The function of the college is liberal education; the opening of the mind to the great departments of human interest; the opening of the heart to the great spiritual motives of unselfishness and social service; the opening of the will to opportunity for wise and righteous self-control. Having a different task from either school or university, it has developed a method and spirit, a life and leisure of its own. Judged by school standards it appears weak, indulgent, superficial. Judged by university standards it appears vague, general, indefinite. Judged by its true standard as an agency of liberal education; judged by its function to make men and women who have wide interests, generous aims, and high ideals, it will vindicate itself as the most efficient, the most precise means yet devised to take well-trained boys and girls from the school and send them either on to the university or out into life with a breadth of intellectual view no subsequent specialization can ever take away; a strength of moral purpose the forces of materialistic selfishness can never break down; a passion for social service neither popular superstition nor political corruption can deflect from its chosen path.

I cannot sum up the function of the college better than in words formerly used in reply to the question of a popular journal, "Does a College Education Pay?"

To be at home in all lands and all ages; to count nature a familiar acquaintance, and art an intimate friend; to gain a standard for the appreciation of other men's work and the criticism of one's own; to 
carry the keys of the world's library in one's pocket, and feel its resources behind one in whatever task one undertakes; to make hosts of friends among the men of one's own age who are to be leaders in all walks of life; to lose one's self in generous enthusiasms and cooperate with others for common ends; to learn manners from students who are gentlemen, and form character under professors who are Christians - these are the returns of a college for the best four years of one's life. 


\title{
THE COLLEGE
}

\author{
BY M. CAREY THOMAS
}

[M. Carey Thomas, President of Bryn Mawr College since 1894. b. Baltimore, January 2, 1857. A.B. Cornell University, 1877; Ph.D. University of Zürich, 1882; Johns Hopkins University, 1877-78; University of Leipzig, 1879-82; Sorbonne and Collège de France, 1883; LL.D. Western University of Pennsylvania, 1896. Dean of the Faculty of Bryn Mawr College and Professor of E.nglish, 1885-94; Alumni Trustee of Cornell University, 1895-99; Trustee of Bryn Mawr College, 1903 to present date. Author of The Association of Collegiate Alumnce in its Relation to Women's Education; College Entrance Requirements; The Future of Women in Independent Study and Research; Should the Higher Education of Women Differ from that of Men? Education of Women.]

No one of the other subjects selected for discussion in the seven divisions, twenty-four departments, and one hundred and twentyseven sections of the Congress of Arts and Science seems to me so vitally connected with the future well-being of the American people as the American college which we are to discuss to-day.

The college does indeed need eloquent defenders, such as the speaker who has preceded me, for the executioner's ax is at its throat. The school, however badly planned, taught, and administered, has an assured existence; the university, however amorphous and inchoate, is to be fostered and extended; but the college, the centre of all our culture for the past century, is sore beset, and has more to fear from the Judas-like kisses of its friends in high places than from the mob of the illiterate and sordid, who always cry "Loose us Barabbas" when the powers of evil are in the ascendant and any mighty influence for good is brought to the judgment seat. Let us this afternoon mount the tribunal and try the case. As the accused is on trial for his life, plain speaking will be in order.

We are told first of all that the prisoner cannot be identified, that his personality is all abroad, that his very age is not certain, and that even his name is not his own, but that he is often caught masquerading under the name of " university " or " high school."

It is true that his adversaries have striven mightily to destroy the character and moral stamina of the college course through the foolish dissipations of unrestricted electives, but, thanks be to the powers that make for righteousness, they have striven in vain. Everything now indicates a return to the old educational standards of strenuous intellectual discipline, and to better than the old standards. It cannot be denied that other enemies of the college, working in darkness, have insidiously set out to hew off one year of his age, the very flower of his maturity, in order to enrich the professional school; and that still other enemies, working openly in the eye of day, have 
deprived him outright of the last and supreme year of his growth; and that even now a howling pack of high schools is at his heels, snatching at the first year of his budding strength. It is too true that within the past decade two mighty university foes have come up against him - one from the greatest city of the East, and one from the greatest city of the West - menacing his life itself with whirling swords, to cut him asunder at the belt-line, leaving him a two years' torso, casting the last two years, the heart and brains of him, in part to the professional school, but in greater part to outer darkness and destruction; and yet, although all this is true, and although the combat is still raging, it is not, I think, too soon to assert that the prisoner at the bar will continue to be in the future, as he has been in the past, four years of age, four whole, happy, fruitful college years no more, no less.

Finally, as to the name of the accused. His name is " the college," the name that has come to be applied by universal consent to a four years' course of liberal, non-professional study, superimposed on the course of the high school, private school, or academy, pursued by young men (and, since 1870, by young women) from eighteen or nineteen to twenty-two or twenty-three years of age, who have, as a rule, left their homes and come to reside in the college itself, or in the town or city in which it is situated. The name and the thing are purely Anglo-Saxon, brought over by our forefathers from the mother country. The college as an institution is unknown outside the United States and Great Britain and her colonies. The name is ingrained in our thought and history and should be retained so long as the thing itself remains. It is a real obstacle to clear thinking to call a "college course " a " university course," as is constantly done in the West. There is absolutely no difference in the methods of instruction of a properly organized college, whether it be detached like Amherst or Bowdoin, or part of a group of professional and technical schools, like Michigan or Chicago. Even eminent university presidents have been betrayed by this loose terminology into assuming that the instruction in the detached college and in the college of a university should differ essentially, forgetting that the mind of the boy or girl does not change with the change of name, and that students of the immaturity of the American student between eighteen and twenty-two years of age cannot with advantage to themselves pursue college subjects by university methods. ${ }^{1}$

It seems to me vain to hope to displace the term "university," which is now so firmly established throughout the entire West, and recently also in the East as well. And, after all, is there any good reason why we should use the word in its foreign German or French,

\footnotetext{
${ }^{1}$ See, e. g., President's Report, University of Chicago, 1898-99, reprinted in the decennial publications of the University of Chicago, series I, pp. 94, 95.
} 
and not in our own English sense? Oxford and Cambridge have been composed of numerous undergraduate colleges from the beginning of their history. The Scotch and Irish universities are so organized. The new universities of Manchester and Birmingham and Liverpool correspond precisely to our state universities, with college departments and undergraduate technical and professional schools. "University," in English and American usage, means, and has always meant, a group of schools, all undergraduate, of which the undergraduate college usually is, and always should be, the most important. However low in grade is the instruction offered, a variety of technical and professional courses seems to constitute the claim to the name " university" in Anglo-Saxon countries. But if it is vain to displace the term " university," let us see to it that the word " college" is used correctly, and let us sharply distinguish by the preface of the word "graduate" the true graduate schools of medicine, law, and theology, and also the true graduate philosophical school from the ordinary low-grade non-graduate professional schools of the majority of American universities. ${ }^{1}$ Let us accustom ourselves to speak of the graduates of Harvard College, Michigan College, Chicago College, or of graduates of the college of Harvard, Michigan, or Chicago, just as we speak of graduates of the Medical School or Law School of Harvard, Michigan, and Chicago. The term university graduate is too broad, and may mean anything from a doctor of philosophy to a farmer or horse-doctor, without even a high-school education. It should not be used for college graduates. Unless this rule is followed by college and university authorities, all our detached colleges will inevitably be compelled in self-defense to call themselves universities - a real pedagogical misfortune, and a break with tradition and culture.

But let us proceed to trial. Why should the prisoner lose his head, or his feet, or be sawn asunder in the middle? Is it because, as indicated above, our American university professional schools are not university schools in the French or German sense? Already in 1884 the far-seeing president of Harvard University had begun to urge the shortening of the college course and the raising of requirements for admission to professional schools; in 1893 the Johns Hopkins University opened its school of medicine, the first graduate, or true university professional school, in the German sense, in the United States. Also in 1893 Professor Von Holst, in his oration before the first Convocation of the University of Chicago, sounded a clarion note of awakening to American universities, and in 1900 Professor Perry's lucid and admirable monograph on American Universities drove

${ }^{1}$ The only graduate professional schools in the United States are the Medical School of the Johns Hopkins University, the Medical, Law, and Theological Schools of Harvard, and the Law School of Columbia. 
home the conviction of sin. Since 1893 university presidents, like all other American scholars, have realized that our American universities are not universities in the German sense of an assemblage of graduate professional schools, and it is in order to reform this condition of affairs that many of them have joined President Eliot in endeavoring to shorten the American college course. Obviously one way to make our professional schools graduate schools (in name, if not in fact) is to lower the standard of the degree we require for admission. This is the method adopted by Harvard, which since 1902 has required the B.A. degree for admission to its schools of law, medicine, and theology, but has reduced the time requirement for its bachelor's degree from four to three years. Another and more rapid method of producing graduate professional students has been in operation at Chicago University since 1898. The college course has there been cut in half, and a certificate of what we may call "immaturity," but which Chicago calls a diploma of "University [sic] Associate," has been given at the end of the sophomore year, and it is hoped to require this certificate for admission to the professional schools of the university. ${ }^{1}$ The president of Columbia is now urging still more radical action which, if generally adopted, will, in my opinion, sound the death-knell of the college. He proposes two B.A. degrees, one to be conferred at the end of the sophomore year for those who take up professional study, and one to be conferred at the end of the present senior year for such other students as may chance to linger to receive it. ${ }^{2}$ Graduate professional schools obtained by such a sacrifice of culture and efficiency will, it seems to many of us, be graduate schools only through the quibble of a misused name.

Another and even more insidious plan for securing graduate students in professional schools is now in operation in many universities. The last year of college work is permitted to be taken in the law or medical school, and is counted double, - once as the senior year of the B.A. course, and twice as the first year of the professional course. The student himself also counts double, once as an undergraduate senior, and twice as a graduate member (which he is not) of the graduate professional school. Nothing more disastrous to honest standards of academic work can be conceived of. Yet

\footnotetext{
${ }^{1}$ See the decennial publications of the University of Chicago, series I, pp. 8.5, S6, $92,93,95,96$.

${ }^{2}$ [I greatly regret that I should have overlooked President Butler's suggestion (see President's Report, Columbia University, 1902, p. 44) that these two B.A. courses should be differently lettered, although I confess that to my mind the substitution of an $\mathrm{M}$ for a $\mathrm{B}$ in the degree conferred at the end of the present four undergraduate years will do little, or nothing, to avert the disastrous consequences to be feared. The sentence in question should have read as follows: He proposes in reality two undergraduate courses, one to be known as the B.A. course, ending with the present sophomore year for those who take up professional study, and one to be known as the M.A. course, ending with the present senior year for such other students as may chance to linger on to complete it. - AUTHOR.]
} 
Harvard, Yale, Columbia, Cornell, Pennsylvania, and many other Eastern and Western universities are now educating ministers, doctors, and lawyers under this shifty and canny arrangement.

But why, then, apart from the desire of some universities to inflate their professional schools, should the college course be shortened and its content lessened? For let us squarely face the fact that this is the issue involved. It is idle to assert, as has been asserted repeatedly in official Harvard publications (see President's Report for 1901-1902, p. 27, and many earlier reports), that the content and quality will not be lessened by a shortened college course; or, in other words, that four years' work can be done in three years' time. All practical teachers know that the professor must adapt his pace to the average of his class, and that if the majority is doing four years' work in three years' time the majority will see to it that three years' work, and not four years', is done. Harvard itself is a case in point. In 1880 twenty-one courses were required for the Harvard B.A. degree; in 1904 only seventeen and one half courses are required, of which one and one half may be passed off at entrance, or in reality only sixteen courses are required in the present three years' Harvard B.A. course as against twenty-one courses required for the former four years' Harvard B.A. course. A recent report of a "Committee on Improving Instruction in Harvard College," appointed in May, 1902, whose membership of nine included some of the best known senior professors of the Harvard faculty (see Harvard Graduates' Magazine, June, 1904, pp. 611-620), states that " the average amount of study in Harvard College is discreditably small ;" that "the average amount of work done by undergraduates (more than one half of whom have obtained the grade of $\mathrm{A}$ or $\mathrm{B}$ ) in connection with a three hours' course is less than three and one half hours a week outside of the lecture room;" and "that the difficulty of raising the standard is seriously increased by students taking six courses each" (in other words, by students taking the college course in three years). If under the unrestricted elective system the college course has lost tone and become too easy by one fourth for the ordinary student, the remedy would seem to be in stiffening up the already emasculated course, not in lopping off a year of it. ${ }^{1}$

${ }^{1}$ President Eliot (President's Report for 1902-1903, p. 24) says: "Nobody doubts that at present the degree of Bachelor of Arts can be obtained in Harvard College, or in any other [sic] American, English, or Scotch college or university by any young man of moderate parts with a small expenditure of force during not more than one half of each of the years of nominal residence."

Professor W. E. Byerly (Harvard Graduates' Magazine, December, 1902, p. 186) says: "It is commonly, and I believe correctly, asserted that a student of fair ability, entering college from a good preparatory school, choosing his courses with discretion, using borrowed or purchased lecture notes, and attending one or two coaching 'seminars' for a couple of evenings before the mid-sear and final examinations, can win our A.B. degree without spending more than half an hour a day in serious study outside of the lecture and examination rooms." 
Why should the college course be shortened? Because in France and Germany a boy completes his course in the lycée or gymnasium at twenty years of age, and enters upon his professional course at the university without anything that remotely resembles our college course. But is this a reason? How do we know that the German or French boy is better off without a college course? After sitting side by side with the German gymnasium graduate in Leipzig for three years and hearing him blunder through his pro-seminar recitations, and after listening in the Paris International Congress of 1900 to prolonged discussions of the limitations of the lycée graduate and the misfortune of his choosing a career with only the school-boy's outlook given by the lycée course, - discussions in which he was incessantly compared by Frenchmen themselves to the English and American college graduate, greatly to his disadvantage, - I have come to the conclusion that he is much worse off. If it were possible, and if possible desirable, to enforce over the whole United States two or three castiron high-school courses, so diffieult and rigid that private schools would be practically annihilated by the impossibility of reaching their standard, and to require the completion of one of these courses not only for admission to all the colleges, but also to all the law, medical, and theological schools, in the United States; and above all to every lucrative and distinguished position, whether civil or military, in the gift of the general or state governments, including, of course, the position of teacher in these same high schools, and in the primary schools as well; and if, furthermore, completion of six out of the nine years in these high schools were made the condition of escaping one year's hated service as a common soldier in the army, and the escaping of such service, furthermore, were made, as in Germany, a primary social necessity for gentlemen - if all this were possible, perhaps our American boys too would be able to learn as much by twenty years of age as German or French boys; and perhaps such tremendous financial and social bribes would buy the silence and coöperation of American parents in the German and French deliberate and unwavering sacrifice of youthful joy and sports before the Moloch of future success. Even if all these impossible conditions were to come into existence in the United States, it is at least an open question whether we should not have lost in education far more than we should have gained. In all comparisons between German and American higher education it ought never to be forgotten that the German and French universities do not profess to teach systematically and to examine the ordinary college student who is preparing himself for the life of affairs. They deal primarily with professional students, whereas the reverse is coming to be true in the United States. But it is unprofitable to contrast one country with another when educational conditions are so radically different. 
Our opponents ask us what there is sacred about the number four, and remind us that some few early American colleges had a three year's' course, as have Oxford and Cambridge to-day. But our conditions are wholly unlike those of colonial America, and Oxford and Cambridge. In England, as in Germany, the would-be honor student who goes up to Oxford and Cambridge from the great English public schools - which are in themselves residential colleges in our sense, giving the social and educational stamp of the American, college, and teaching far more of classics and mathematics than any American high school or academy - has everything to gain or lose in his aitter-life, both financially and socially, from his success or failure in the most rigid examinations the world has ever known. Perhaps if in our American colleges we could select by the most strenuous competition the best tutors and employ them at high salaries to teach our college students in small groups of two, three, and four students, and all our abiest students by themselves; and if we too could make so much depend upon the grade obtained by these students at the end of a three years' course of study in an examination so rigorous and searching as to be without parallel in our educational system, we might be able to obtain as good results in three, as in four years. But in Oxford and Cambridge, as in Germany, it is only the "honor," not the "pass," men who attain this education. The education of the average man is neglected.

There is, of ccurse, nothing sacred about a four years' course as such, except in so far as the experience of seventy years has proved it to be adapted to the needs of successive generations of college students. The college department of the Johns Hopkins University is often referred to as an example of a three years' college course, but in reality it is composed of the usual four college classes, the first-year students being known as " candidates for matriculation," and a real freshman, or preparatory, year being maintained under the name of a "class for non-matriculants." The standard of admission to the three years' college course has been set so high that since the opening of the college, in 1876, this class of non-matriculates, or freshman, has formed 21.5 per cent of the whole undergraduate body of students, and in the year 1903-1904 these non-matriculates numbered 38, and the matriculates 104; in other words, the non-matriculates were not less than the number of freshman one would naturally expect in an undergraduate college numbering 142 students. Moreover, the undergraduate department of the Johns Hopkins University is so small and unimportant as compared to its graduate school that, even if the course of study were not practically a four years' course, it could not be used to prove that a three years' college course will satisfy the needs of the community, especially as an immensely greater proportion of the graduates of the college of the Johns Hopkins Uni- 
versity (over one fourth) enter the graduate school than is the case elsewhere.

For the past nineteen years I have acted as adviser to the students who have studied at Bryn Mawr College, and I have been consulted by them in their freshman, sophomore, junior, and senior years. If my experience proves anything at all, it proves that the first two years, or the first three years, of a college course do not really count as equal in value to one half, or three fourths, of four years, because the junior and senior years are usually years of such intellectual awakening, and furthermore that the senior year has a value far greater than that of the other years. It is the culmination of the whole college course, and a student who leaves college at the end of three year's suffers, it seems to me, incalculable loss. As the entrance requirements of Bryn Mawr are at least as high as those of any college in the United States, and as its college course, organized under the group system, is really strenuous and difficult, and as girls are supposed to be more mature than boys of like age, and admittedly at present study more faithfully, my observations could not, I think, have been made under more favorable conditions for the shortened college course.

Why, then, should this priceless senior year be omitted, or taken in the law or medical school? Is it because those high in authority have told us that boys are entering college from one to two years older than in the past, and that, therefore, this lost year must be recovered? But four careful statistical studies of age on entering college have proved beyond a shadow of doubt that such statements are not supported by fact, and that for the great majority of colleges the median and average age of admission has not varied three months in the past fifty years, the median age showing a net reduction of two months in fifty years for all colleges, and the average age having fallen one and one half months in the past forty years. ${ }^{1}$

\footnotetext{
${ }^{1}$ President E. Benjamin Andrews, "Time and Age in Relation to the College Curriculum," Educational Review, February, 1891, pp. 133-146. S. C. Bartlett, "Shortening the College Course," Education, June, 1891, pp. 585-590. Professor W. Scott Thomas, "Changes in the Age of Graduation," Popular Science Monthly, June, 1903, pp. 159-171. (The arguments of above three papers are summarized by Professor Elmer C. Brown in Addresses and Proceedings of the National Educational Association, 1903, pp. 492-493.) Professor Henry P. Wright (President's Report, Yale University, 1901-1902, pp. 43-44, and 47-50) has shown that, in spite of the very great gradual increase in the amount required for admission the average age of Yale classes at graduation has increased less than four months in the forty years from 1863 to 1902 , and only nine months in the past eighty years. In studying the age of admission during the past forty or fifty years, care should be taken to consider only the statistics of those colleges which have maintained a genuine college course during this time, whose standards have developed gradually, and not colleges situated in large cities that have developed from comparatively low-grade institutions into really high-grade colleges within the past few years. For example, the age of graduation at New York University has risen thirteen months in the past fifty years (see Popular Science Monthly, June, 1903, p. 160). Since 1860 the age of graduation at Columbia, and the work done, have risen two whole years according to careful estimates, and according to actual
} 
We are told by these same special pleaders that in maturity and acquirement the college student of to-day is two years above the college student of thirty years ago. This statement does not admit of the same disproof, but as the age of the college student of to-day remains the same as thirty years ago, we may be permitted to doubt it. Maturity and acquirement are more a matter of age than we realize. Were it not for this it would be easy for American fittingschools to prepare boys and girls for the highest American collegeentrance requirements at seventeen, or even at sixteen, but the majority of colleges do not wish such young students. Immaturity of mind would make them undesirable.

We have been told repeatedly in the course of this discussion that college attendance in the United States was falling off, and that, unless our colleges were to be deserted by students, we must shorten the course in order to attract the sons of practical men. Again, statistical investigation has proved this statement also mistaken. On the contrary, practical men are sending their sons and daughters to college in such overwhelming numbers that all our best colleges are growing in students out of all proportion to the population. ${ }^{1}$

Recently a novel and equally fallacious argument has been brought forward by President Eliot. We are told that the college course must be shortened to three years because an examination of the marriage statistics of a certain college for men shows that the children of married graduates are not numerous enough (in the classes graduating from 1870 to 1879, for example, not over 1.95 children per Harvard father) to enable college men to reproduce themselves, and that the children are so few because the four years' college course has unduly delayed the beginning of professional and business life, and has thereby prevented such men from marrying until so late in life that their power of reproduction is limited - presumably by old age. It is almost needless to point out that before drawing any such farreaching conclusion in regard to the shortening of the college course it would be necessary to know many other factors in each particular

statistics the age of admission has risen one year between 1880 and 1902 (see President's Report, Columbia University, 1902, p. 39). It is only recently that colleges situated in cities have been able to maintain standards of admission and class work such as the best-known New England colleges, Harvard, Yale, Amherst, etc., have maintained for the past five decades.

1 Professor Arthur N. Comey, "The Growth of New England Colleges," Educational Review, March, 1891; and "Growth of the Colleges of the United States," Educational Review, February, 1892. Mr. Talcott Williams, "The Future of the College," Proceedings of the Association of Colleges and Preparatory Schools in the Middle States and Maryland, 1894, and also "College Entrance Examinations," Proceedings of the same association, 1896, - an admirable statistical paper, showing not only that college students have greatly increased, but that at Amherst during the last fifty years the percentage of those students graduating in each entering class has risen from 70 per cent to 72 per cent, and that at Yale during the past thirty years the percentage has risen from 63 per cent to 72 per cent. 
case, such as the average age of marriage of these college graduates, the age and other qualifications of the women they marry, and, above all, whether there is the slightest ground for supposing that the postponement of marriage one year by a man presumably in his prime could materially affect the number of children he is able to beget, if he and his wife wish for the largest attainable family. But a reference to well-known statistics will dispose of the whole argument. In the case of the alleged increase of the age of graduation, and the assumed decrease of college students, the facts themselves were incorrect; here the conclusions are wholly unjustified. The failure of Harvard students to reproduce themselves is not a peculiarity of Harvard graduates as such, but seems to be a characteristic of our American stock, and, above all, of our native Massachusetts stock, to which two thirds of Harvard graduates belong. It seems to be as true of native American factory operatives, farmers, and artisans as of Harvard graduates, and has, therefore, nothing whatever to do with the length of a college course, or, indeed, with a college education at all. ${ }^{1}$

Should, then, our college course be shortened because our professional courses are long? There were in the year 1902, according to the report of the United States Commissioner of Education, 88,879

${ }^{1}$ See President Eliot, President's Report, Harvard University, 1901-1902, pp. 31-32. For additional statisties of the marriage-rate and size of families of college graduates of Yale College see Mr. Clarence Deming, Yale Alumni Weekly, March 4, 1903. Professor Thorndike, "Decrease in Size of American Families," Popular Science Monthly, May, 1903, gives similar statistics for New York University, Middlebury, and Wesleyan. Dr. George J. Engelmann, "Education not the Cause of Race Decline," Popular Science Monthly, June, 1903, prints tables for Harvard, Yale, Princeton, Bowdoin, and Brown, and compares them (favorably for college graduates) with similar statistics for other classes of the population. President G. Stanley Hall and Dr. Theodate L. Smith, "Marriage and Fecundity of College Men and Women," Ped. Sem., vol. x, September, 1903, pp. 275-314. President Stanley Hall, Adolescence (Appleton \& Co., 1904), vol. II, pp. 590-606, discusses the question of the marriages and children of college men and women, but draws conclusions apparently unjustified by existing data in the case of men college graduates, and certainly wholly unwarranted in the case of women college graduates. These statistics may be compared with similar statistics for Massachusetts and the rest of the United States, Dr. Nathan Allen, "The New England Family," New England Magazine, 1882; F. S. Crum, "The Birth-Rate in Massachusetts" (1850-90), Quarterly Journal of Economics, April, 1897; S. W. Abbott, "Vital Statistics of Massachusetts from 1856-1895;" Dr. Ellis, " Deterioration of Puritan Stock and its Causes," privately published by author, New York, 1894; Kuczynski, "The Fecundity of the Native and Foreign-Born Population in Massachusetts" (period from 1835-1897), Quarterly Journal of Economics, November, 1901, and February, 1902; Dr. Fred. A. Bushee, American Economic Association Publications, May, 1903; Dr. John S. Billings, "The Diminishing Birth-Rate in the United States," The Forum, June, 1903; Dr. Fred. A. Bushee, "The Declining Birth-Rate and its Cause," Popular Science Monthly, August, 1903, "These statistics put the whole native population of Massachusetts in the same position as college graduates, and the question accordingly seems to be one of the upper class, or of the older part of the population, and not simply a question of the educated classes" (see p. 357); Joseph Körösi, "An Estimate of the Degree of Legitimate Vitality, Drawn from Municipal Statistics, Budapest," with comments by Francis Galton, Journal of the Royal Statistical Society, vol. 5.5, December, 1894. 
students pursuing college courses in the United States, and 49,076 students studying law, medicine, and theology, and of these only 7189 had received the bachelor's degree. Only two medical schools, the Johns Hopkins and Harvard, and only two law schools, Harvard and Columbia, now require a bachelor's degree for admission. It was estimated by a special committee of the Board of Overseers of Harvard University that in 1890 only $\&$ per cent of the medical students, 18 per cent of the law students, and 23 per cent of the theological students of the United States had received the bachelor's degree (see Report, p. 12). In the law and medical schools of Yale, Columbia, Pennsylvania, and Cornell, which, together with the purely graduate schools of the Johns Hopkins and Harvard, may be assumed to be the best-equipped and most advanced professional schools of the East, the bachelors of arts and science did not average 31 per cent of the whole body of professional students in 1902 (see President's Report, Harvard University, 1901-1902, p. 29). Only 11 per cent of college graduates of twenty-seven of the most advanced colleges in the United States study theology (see Professor Francis G. Peabody, "The Proportion of College-Trained Preachers," The Forum, September, 1894, pp. 30-41). Clearly, then, the answer is emphatically, No. The college course must not be impoverished in the interests of a few thousand holders of the bachelor's degree pursuing professional study, and forming scarcely 7 per cent of the total number of college students, and not even one third of the professional students, in the most advanced professional schools in the East. Moreover, even as it is, these college graduates in professional schools are not a year older than the non-college graduates in these same professional schools, according to the age-tables of the Harvard Law School covering twenty years (see President's Report, Harvard University, 1893-1904, p. 127). Yet most discussions on the length of the college course begin gravely with the statement: "Since it is admitted by common consent that the practice of the professions begins too late in life; therefore, the college course must be shortened." But who has admitted it? Surely a study of the whole subject affords us no reason for admitting it. Quite the reverse. Before we repeat over like parrots such phrases as this, let us investigate the actual conditions. For example, let us first find out what the non-college graduates who form two thirds of professional law students have done with the three years during which the other one third are in college, and why they are only a few months younger than college graduates in law schools. How do we know that, if we shorten the college course in the interest of this college third, they will spend the year thus saved in the professional schools? May not they also clissipate it like the two thirds who do not go to college? 
And, surely, the college course should not be shortened because of our graduate schools of philosophy. So few students are graduated from these schools that they are a negligible quantity. In the past five years, from 1898 to 1902 , only 1566 men and women have received the degree of Ph.D. from the thirty-four graduate schools of the United States, and most of these graduates have been bribed by scholarships and fellowships to take this degree. During these five years over 54,900 bachelor's degrees have been conferred. ${ }^{1}$ Also the age-tables of the Harvard Ph.D.'s, kept during the past seven years (see President's Report, Harvard University, 1902-1903, p. 139), prove that the greater number of Harvard Ph.D. graduates (and presumably other Ph.D.'s) are twenty-eight years of age and over, and do not, therefore, take up graduate study immediately on graduation, and are not directly affected by the length of the college course.

Shall we shorten the college course because the college has proved itself inefficient in the past? No, a thousand times, No! It has been the glory of our past, the source of stability and sanity, the radiant centre of all our gallant action and liberal thought. And since its integrity has been so seriously threatened, we have become aware by numerous statistical investigations that the college has also been in the past the nursing mother of statesmen and men of affairs, and the lavish bestower of fame and of all those social distinctions that we long to receive at the hands of our fellow men. It has been proved that although in the past only 1 per cent (the ratio is now over 3 per cent) of American men have received a college education, in the Fifty-fourth and Fifty-fifth Congresses, the House of Representatives contained nearly 36 per cent and the Senate over 36.3 per cent of college-bred men, or thirty-two times as many as might have been expected; that in the fifty-seven years, from 18411898, 55 per cent of the Speakers, 55 per cent of all the elected Presidents of the United States, and 54 per cent of all the Vice-Presidents have been college graduates, and that 68 per cent of members of the Supreme Court, and 85 per cent of the Chief Justices of the United States have been college-bred men. ${ }^{2}$ One out of 40 college graduates as against 1 out of 10,000 non-college graduates are mentioned in Appleton's Encylopedia of American Biography. ${ }^{3}$ In the 1900 edition of Who's Who in America, 1 in every 106 of the living graduates of the colleges mentioned in Who's Who has attained mention as against

${ }^{1}$ See reports of the United States Commissioner of Education. Science, August 19,1904 , states that in the past seven years, from 1898-1904, only 1713 Ph.D.'s have been conferred.

2 Professor John Carleton Jones, "Does College Education Pay?" The Forum, November, 1898.

${ }^{3}$ President Charles F. Thwing, "The Preëminence of the College Graduate," Within College Walls, pp. 156-181. 
1 in 600 of non-college graduates; or, in other words, a college graduate's chance of this kind of Who's Who eminence is more than 5.6 times that of the non-college-bred man. If we assume that 27 per cent of lawyers are college graduates, this 27 per cent forms 46 per cent of the eminent Who's Who lawyers. Likewise the 24.7 per cent of college-bred clergymen form 53.3 of the divines mentioned in Who's Who, and although only 7.5 per cent of physicians have received a college degree, this 7.5 per cent furnish 42 per cent of the physicians who have attained Who's Who fame. ${ }^{1}$

What does a year more or less matter in beginning professional life, even if all college graduates entered the learned professions (which they do not), if college-bred professional men have five times the chance of other men to attain wealth and eminence? Why should college graduates wish to enter business life younger than twenty-two and a half years of age, if their college education will insure them more than five times the chances of success they would have had had they begun work four years earlier? How can we be sure that this chance will be reduced only proportionately by taking away one, two, or three years from the present college course?

Why should we wish to lay rash hands on an institution so wonderfully adapted to our needs as the American college? How could we have hoped for more overwhelming proof of its efficiency and success, measured not only in the wider vision, broader intellectual sympathies, deeper personal happiness of its graduates, and in all the intangible and ineffable things of the spirit, but also, in this truly unexpected and marvelous fashion, in the ringing coin of the marketplace? I confidently believe, therefore, that the college course of the future will be four years.

Will the college course of the future be wholly elective? When President Eliot became president of Harvard College in 1869, only one half of the Harvard college course was elective, but from that day to this Harvard has led the way under his guidance toward unrestricted electives, not only in the college, but in the school. Since 1890, however, there are many indications that the pendulum is swinging back again and common sense reasserting itself. Every one believes in giving the student a wide choice in studies under certain restrictions; the question is precisely whether or not the student shall be guided in some degree by the accumulated experience of

${ }^{1}$ Professor Edwin Grant Dexter, "A Study of Twentieth-Century Success," Popular Science Monthly, July, 1902. See also his "High-grade Men: in College and Out," Popular Science Monthly, March, 1903. (Three times as many $\Phi \beta \mathrm{K}$ graduates, or high-grade graduates of twenty-two colleges, are shown to have attained mention in Who's Who as we should expect; in other words, if an ordinary college graduate has five and one half times the chance of eminence of other men, a college graduate of high academic rank has more than fifteen times the chance of eminence.) The investigation is carried farther by Professor A. Iawrence Lowell, "College Rank and Distinction in Life," Atlantic Monthly, October, 1903. 
educated men that have gone before him, as expressed in a college curriculum. Our decision as to the wisdom of unlimited freedom of electives in both school and college depends on whether subjects of study do, or do not, differ among themselves, apart from their practical value, as intellectual disciplines, that is, in training our mental powers. Everything in education depends on our answer to this question. I confess that it is to me inconceivable that all subjects, irrespective of their subject-matter, even if equally well taught, should give the same, or equal, intellectual results. The mere statement of such a proposition seems to me a reductio ad absurdum. If the proposition be true, why do college-bred students excel students that have had severe professional training, not only in afterlife, but also in the professional school itself? In the ten years from 1891 to 1902 the 37 per cent of Bachelors of Arts in the Yale Law School carried off 62 per cent of the honors and 70 per cent of the prizes, and in the Columbia Law School 94 per cent of the 237 men who have attained honor rank in the past ten years have been college graduates. ${ }^{1}$

If we believe that there is a real difference in the intellectual value of studies, it follows as a consequence of this conclusion that certain studies should be taken by every one if we have in view the development of intellectual power by the college course; and if we believe in mental discipline, the element of continuity also must be insured by the college, and, of course, by the school, and only so many electives should be permitted as are consistent with training and continuity. There is, I believe, a kind of curriculum that combines all these qualifications - the "group system " - introduced in 1876 in the three years' (now four years') undergraduate course of the Johns Hopkins University, amplified into a four years' course and named the " group system " by Bryn Mawr College at its opening in 1885, introduced into the college course of the University of Indiana in 1858 by President Jordan and Professor von Jagemann, and now adopted in slightly altered form in the West by Illinois, Northwestern, Indiana, Missouri, Wisconsin, California, and by the two most recent educational foundations of the West, Leland Stanford Junior and Chicago, and in the East by Williams, Dartmouth, Tufts, New York University, by Pennsylvania (in the strict Bryn Mawr form), and by the four women's colleges of Smith, Wellesley, Mt. Holyoke, and the Woman's College of Baltimore. Yale adopted the A B C system, or modified group system, in 1901. Clark College of Clark University opened in 1902 with the group system in full operation, and the approval thereby given to the group system by its president, the Hon. Carroll D. Wright, the well-known statistician, is very

\footnotetext{
${ }^{1}$ See President's Report, Yale University, 1902-03, p. 131; and President's Report, Columbia University, 1902, p. 125.
} 
significant. Princeton, whose president, as a graduate student of the Johns Hopkins University and a professor of Bryn Mawr College, was familiar with the true group system, puts in operation this year a modified group system, and the president of Columbia, in his report for 1902, promises an early consideration of the group system recommended by three members of the Columbia scientific faculty, two of whom became acquainted with the working of the group system as students in the Johns Hopkins University and professors at Bryn Mawr College.

It is, then, I think, clear that our four years' college course will be, not a free elective course, but that wisely ordered combination of freedom and authority known as the group system. In this respect Harvard does not, I believe, represent the most enlightened educational opinion.

The American college in its fullest perfection will be a residential college. We are coming to see that the best results of college life are only to be obtained when the college student lives an academic life among his companions. The English college for men is unique among the institutions of the world, and its finished product - the English gentleman, equipped beyond his fellows for social and political life is the admiration and despair of other nations. In the two cities of Oxford and Cambridge, isolated from the outside world, among green lawns and medieval buildings of wonderful beauty and charm, this educational process has gone forward for hundreds of years, and has given us the men of thought and action who have guided the destinies of the English-speaking races. The ineffable whole of English college life cannot be attained without semi-seclusion in academic surroundings and intimate and delightful association with other youth of the same age and with professors who are devoting themselves to scholarship and research.

There is no fear that in the future the larger colleges will absorb the smaller. Colleges will multiply in the future as in the past, and the more there are of them the better. It is impossible, and highly undesirable if it were possible, to concentrate the youth of our vast country into a few large colleges. Each college creates its own supply of students, and two thirds of the students of all our colleges, large and small, come from within a radius of one hundred miles. As each student can, as a rule, attend but one college, each such college must be educationally as perfect as possible. If we reduce our independent American colleges to glorified high schools, as has been suggested, perhaps with questionable disinterestedness, by the presidents of some of the larger universities, we thereby cut off the majority of American students from a complete college education.

It is clear to me that the college of the future will be coeduca- 
tional. There are in the United States 464 colleges for men. In 1870 one third of these colleges admitted women; in 1880, so successful had coeducation proved itself to be, one half had been opened to women, and in 1900 two thirds of all colleges for men had become coeducational. At the present time, if we omit Catholic colleges, which, in America, are mainly training-schools for priests, 80 per cent, or four fifths, of all colleges for men teach women exactly the same subjects by the same professors in the same lecture-rooms, and allow them to compete for all their degrees, prizes, and fellowships. There are in the United States also thirteen separate colleges for women. In the year 1902 there were nearly 22,507 women studying in colleges for men, and over 5549 women studying in separate women's colleges, or in all about 28,000 women college students. Although there were in the United States two million less women than men, women formed about one third of all college students. In addition to the 28,000 women students in colleges and graduate schools of philosophy, there were, in 1902, 9784 women studying engineering, mechanics, agriculture, and other technical subjects in universities and technical schools; 1177 studying medicine, 218 studying pharmacy, 162 studying dentistry, 165 studying law, and 106 studying theology, or a total of 12,614 women pursuing professional and technical courses. If we combine these two classes of students we get a total of 40,676 women studying in the colleges and professional and technical schools of the United States, and the number of college and professional women students is steadily increasing. Coeducation is the only economical method of educating all those women. It is impossible, even if it were not criminally wasteful, to duplicate in every part of the world colleges and universities for women, and not all the wealth of all the world can duplicate the few great scientific teachers that are born in any single generation. Experience proves that unless schools, and still more universities, are conveniently near, even boys go without a higher education. Unless in the future all existing colleges and universities are to become coeducational, unnumbered generations of girls must go without any education beyond that of the high school.

This is not the place to discuss whether or not the college curriculum for men and women should be the same. Women must decide this for themselves. Men cannot decide it for them. In a few years one third of all the college graduates of the United States will be women, and we may safely leave the kind of education to be given their daughters in their hands. For myself I am convinced that college and school education should train the mind and faculties, and not fit directly for practical life, and that, therefore, the question as to whether a woman is to make beds, or a man to curry horses, after leaving college, should not affect their education in college, but 
that all the more on this account should they be raised by their education above the petty routine of their after-life.

As the outcome of this discussion of the college this afternoon I have hoped that there might be some practical way suggested of uniting together, for the collection of statistical and other information in regard to college education, those of us who are interested in maintaining and enriching the college as the source of all our culture. It would not be necessary to include in such an association all of the 477 colleges of the United States. It would be entirely feasible, and eminently desirable, to adopt, for example, some such clear and definite conditions of admission as I have indicated on pages 11 and 12 of my monograph on the Education of Women. By applying four entirely impersonal and general tests I was able to select the 58 best equipped and most advanced colleges of the United States. In such an association there would be no secret rites of initiation such as seem somewhat to interfere with the influence of the Association of American universities; but each college would understand clearly why it was admitted or excluded, and these very conditions of admission would tend to raise the excluded colleges to the admission standard. The colleges thus banded together could then mutually agree upon a systematic way of keeping, collecting, and publishing educational statistics. At present our college statistics are scarcely kept at all, or, if kept, are kept by such different methods that comparison is impossible. For example, no subject has been more hotly debated than the elective system, and the debate has raged during the past thirty years. Yet we have no satisfactory records of the subjects elected by students in different colleges covering a series of years, or even last year. The Harvard Exhibit at this Exposition contains a chart of electives chosen during a series of years, but there is no indication of whether the one required course in Freshman English inflates the bloated block of English electives; nor do we know whether other required courses affected earlier blocks. Chicago University frankly states that required courses greatly influence the tables of electives published in its reports, but we are not told how great this influence is. Cornell in its tables lumps Semitics, Greek, and Latin. Some other colleges put in one elective class philosophy and education; still others bibliography and elocution!

Such a college association as I have suggested would make it impossible for any one ever again to base radical changes in college courses on mistaken facts, such as I have referred to in my brief discussion of the length of the college course. Such a statistical association would greatly lighten the labors of the overworked college president, who now has to collect his educational data as he runs, and perhaps I may be permitted to add - as my own trade is also that of college president - that it would also greatly improve the trust- 
worthiness of the statistics on which he bases his educational reforms. Even the few facts I have presented to you this afternoon. have been collected at great expenditure of time from many journals and educational magazines published during the past twenty years. They are nowhere to be found classified and arranged. Indeed, if the present chaotic conditions in education are to continue, boards of trustees ought to be required by law to provide a trained statistician as the running mate of every college or university president before letting him loose on our educational systems.

Intellectual experiments are the most costly of all conceivable experiments, for they affect the mind stuff of the next generation. The decline or advance of the race is the issue involved. It is indeed terrible to think that changes of vast importance have already been made in the constitution of the American college, based on such incorrect assumptions and misleading arguments as those which $I$ have attempted to disprove. This discussion has at least shown the need of collecting carefully and studying accurately such educational data as exist before we lay rash hands on the college which, imperfect as it may be, has yet proved itself so marvelously adapted to our needs in the past. 


\section{SHORT PAPERS}

President Henry Churchill King, D.D., of Oberlin College, presented the following paper on "The Function of College Education":

HAS the American college a real function, a logical and vital place in a comprehensive system of education? or is it the blunder of a crude time and a crude people, an illogical hybrid between the secondary school and the university, that ought to hand over a part of its work to the secondary school and the rest to the university, and to retire promptly from the scene with such grace as it can muster? or, at best, is its older function now incapable of realization?

Just because these questions concern the place of college education in a system of education, they can be answered only in the light of a comprehensive survey of the entire problem of education.

The problem of education in its broadest scope may perhaps be said to be the problem of preparation for meeting the needs of the world's life and work. Much of the training belongs necessarily to the home and to the interactions of the inevitable relations of life. Much of it, probably, can never be brought into any organized system. But organized education must do what it can to insure, first, that no men shall lack that elementary training and knowledge without which they are hardly fitted at all for ordinary human intercourse or for intelligent work of any kind in society, still less for growing and happy lives; second, that there shall be those who can carry on the various occupations demanded by our complex civilization, in the trades, in business, and in the professions; third, that there shall be investigators, scientific specialists, extenders of human knowledge, in all spheres. None of these needs are likely to be denied - not even the last; for our age has had so many demonstrations of the practical value of scientific discoveries that it is even ready to grant the value of the extension of knowledge for its own sake. That, then, every man should have the education necessary to render him a useful member of society; that the necessary occupations should be provided for; that there should be a class of scientific specialists constantly pushing out the boundaries of human knowledge, - we are all agreed. And to this extent at least, the problems, first, of the elementary schools; second, of the trade, technical, and professional schools; and third, of the university proper, are recognized and justified.

Our difficulties begin when we try to define more narrowly just what is to be included in our first group of schools. Exactly what education is indispensable that one may become a useful member of society? Virtually we seem to have decided that indispensable education is covered in our primary and grammar grades; for the majority do not go further, and compulsory education does not require more. And yet, with practical unanimity, the United States have decided that the state is justified in furnishing, and, indeed, is bound to furnish, that smaller number of its children who are willing and able to take further schooling, opportunity to continue for three or four years longer in studies of so-called "secondary" grade. The state can justify this procedure only upon the ground that such further study prepares still better for citizenship, and that it is of value to the state that even a much smaller number should have this better preparation; or, also, and perhaps more commonly, upon the practical ground that the secondary education furnishes the knowledge and training which, if not indispensable to citizenship, is indispensable to many of the higher occupations and forms of service to the state. No sharp line, certainly, can be drawn between the studies of the grammar school and those of the high school. And we all 
recognize and justify the secondary school, and unhesitatingly include it as practically indispensable to the state, if not to all its citizens, in our first group of schools, to form the unified public school system.

But it needs to be borne clearly in mind that if the true justification of elementary and secondary education is the preparation of useful members of society, it cannot be regarded as merely intellectual. The moral side of the matter is, if there is any difference, even more important - the learning of order, of obedience, of integrity in one's work, of steadfastness in spite of moods, of the democratic spirit, of a real sense of justice, and of the rightful demand of the whole upon the individual. If these are not given in some good measure, then, whatever the intellectual results, in just so far, from the point of view of the state, public school education is a failure. And yet no doubt it must be said that since in America the school children are all in homes, the American public school teacher has, quite naturally, not regarded himself as primarily charged with anything but the intellectual training of the child. Other training has been largely incidental - taken up only so far as the order of the school demanded, or as it was inevitably involved in the situation. Even so, the moral training has been by no means unimportant. But it may be doubted if there is any change in public school education so important to-day as that the teacher should plainly recognize that his real responsibility is to train his charges to be useful members of society, with all that that implies. Let the child and the parent and the teacher all alike understand that the state undertakes the free education of all its children just because it hopes thus to prepare them to be valuable members of a free people, and that whatever is necessary to that end, provided it does not violate individual consciences, is within the function of the public school. This means, of course, that it is the business of the public school to teach living as well as studies.

But with this recognition of the broader function of the public schools, with the necessary acknowledgment of a real broadening even on the intellectual side of technical and professional courses, and with the present common admission of the danger of a specialism not broadly based, is the distinct function of the college clearer, or has it rather been taken on by the other members of the educational system? To a certain extent, no doubt, the latter is true and ought to be true.

But we might well argue for college education, in line with the more practical argument already made for secondary education, that the highest success in the great occupations of the world's work, including scientific specialism, requires an education preliminary to the technical training, more extended not only, but of a broader type than secondary education can furnish. This seems commonly granted now by the technical schools themselves. And this position is no doubt correct. But is this the chief reason for college education? It is not merely for the purpose of carrying on the world's work in this external sense that college education exists, nor does this sufficiently define its function. The college does not look beyond to the technical or professional school, or to the university proper for its justification; but rather is itself the culmination of the work that at least ought to be undertaken by the public schools.

We might, therefore, argue again and more truly, probably, for college education, in line with the other argument for secondary education, that the world needs preëminently the leadership of a few of greater social efficiency than any of the other types of education by their necessary limitations are able to offer. For when all is said that can possibly be said for elementary, secondary, technical, professional, and specialized training, what still do the world's life and work need? All these are necessary, but obviously, for the highest life of society, much more, and much that is greater, is demanded. Here are instruction and discipline, technical skill and professional training, and heights of specialized knowledge. "But where shall wisdom be found, and where is the place of under- 
standing?" The elementary school saith, "It is not in me;" and the secondary school saith, "It is not with me." It cannot be gotten for technical skill, nor shall professional success be weighed for the price thereof; it cannot be valued with the gain of the specialist, with his enlarged knowledge or his discovery. "Whence then cometh wisdom, and where is the place of understanding?"

One cannot answer that question by raising small inquiries of immediately appreciable gain. Let us ask, then, the largest questions and note their generally admitted answers. Assuming that the world and life are not wholly irrational, what is the best we can say concerning the meaning of the earthly life? What is the goal of civilization? What is the danger of the American nation? What are the greatest needs of the individual man?

The wisdom of the centuries has not been able to suggest a better meaning for the earthly life than that it is a preliminary training in living itself. The goal of civilization, our sociologists tell us, is a rational, ethical democracy. Our political students insist that the foremost danger of the nation is the lack of the spirit of social service. The greatest needs of the individual man are always character, happiness, and social efficiency. If these are even approximately correct answers to our questions, then the deepest demands to be made upon an educational system are that, so far as it may, it should give wisdom in living that should insure character and happiness to the individual, and that spirit of social service that should make men efficient factors in bringing on the coming rational and ethical democracy.

This requires that somewhere in our educational system we should attack the problem of living itself and of social service in the broadest possible way, and in a way that is broader than is possible to either the elementary or secondary school, though neither of these may legitimately shirk this task. Just this, then, is the function of the college: to teach in the broadest way the fine art of living, to give the best preparation that organized education can give for entering wisely and unselfishly into the complex personal relations of life, and for furthering unselfishly and efficiently social progress. As distinguished from the other forms of education, it has no primary reference to the earning of a living, or to the performance of some specific task; it faces the problem of living in a much broader and more thoroughgoing fashion; it does not specifically aim or expect to reach all, but seeks to train a comparatively small self-selected number who shall be the social leaven of the nation.

If the task so set the college seems too large, let us remember not only that the admitted individual and social goals require no less, but also that the outcome of the maturest thinking upon man and his relation to the world indicates that the best anywhere can be attained only through such breadth of aim.

For if we seek light from psychology we are confronted at once with its insistence upon the complexity of life - the relatedness of all - and upon the unity of man. But these principles deny point-blank the wisdom of an education exclusively intellectual, and require rather that, for the sake of the intellect itself, the rest of life and the rest of man be not ignored. Positively, they call for an education that shall be broadly inclusive in its interests, and that shall appeal to the entire man.

If we turn to sociology, we meet, if possible, an even stronger emphasis upon the complexity of life, and a clear demand that, back of whatever power the individual may have, there should lie the great convictions of the social consciousness, that imply the highest moral training, and set one face to face with the widest social and political questions. No narrow education can meet the sociological test.

And if we ask for the evidence of philosophy, we have to note that its most characteristic positions to-day in metaphysics and theory of knowledge, its teleological view of essence, its insistence that the function of knowledge is 
transitional, and that the key to reality is the whole person, - all refute a purely intellectual conception of education and logically. require a broader view of education than has anywhere commonly prevailed.

And if as a Christian people, professing to find our highest ideals in the Christian religion, we seek guidance from its goal - that all men should live as obedient sons of the heavenly Father and as brothers one of another - we are face to face again with that problem of the complex world of personal relations that cannot be solved except through the training of the entire man.

In all these lines of psychological, sociological, philosophical, and Christian thinking-our theories are right; our practice in education at best lags far behind. Every line of modern thinking is a fresh insistence upon the concrete complexity of life and upon the unity of man, and demands an education broad enough to meet both. Nothing justifies the common extraordinary emphasis on the intellectual as the one aim of education.

It is not, then, by accident that we speak of the necessity of a liberal education. For let us notice that even on the intellectual side the most valuable and vital qualities cannot be given by rule or by any narrow technique. The supreme demand is for what we call sanity, judgment, common sense, adaptability - all different names, perhaps, for the same thing, namely, ability to know whether a given case is to be treated according to general precedent - by appeal to a general principle - or decided upon its individual merits; to know whether our problem is one of classification or one of more thorough acquaintance with the particular. No rules or methods of procedure can make a reasoner or an investigator; for the vital point is to pick out of a new situation, the exact element in it which is significant for the purpose in hand. The case cannot have been anticipated; the only help that education can give is through much practice in discrimination and assimilation, and through the bestowal of a wide circle of interests, esthetic and practical, even more than intellectual. Interpretative power is similarly conditioned, and calls for the richest life in the interpreter. Even the scientific spirit, then, - the most valuable gift of a scientific training, - is not merely intellectual. Still less are the historical spirit and the philosophic spirit intellectually conferred; they require at every turn the use of the key of the whole man.

And we certainly have a right to ask of education that it bring men to appreciation of the great values of life - what else does culture mean? - to esthetic taste and appreciation, to moral judgment and character, to the capacity for friendship, to religious appreciation and response.

But if we have a right to demand from an educational system in any measure these qualities - judgment, adaptability, discernment, interpretative power, the scientific, historical, and philosophical spirit, and the culture adequate to enter into the great spheres of value, - esthetic, personal, moral, and religious, - it is evident that they can be given only indirectly and through the most liberal training. Do they not lie, in the nature of the case, quite beyond the limits of elementary, secondary, professional, or specialistic training, and constitute the great aims of college education? Is there anything else likely to take the place of the college in performing this greatest educational work?

President Mary E. Wooltey, of Mt. Holyoke College, presented the following paper on "The Place of the College in the Great Educational Movement":

THE form of the subject is itself significant, indicating the new conditions in education. A twofold tendency of the age has invaded the educational world; first, a movement toward the utilitarian, and second, that toward consolidation, or what may be termed an " academic trust." It is perhaps not remarkable that tendencies so characteristic of the century in its industrial and social life should 
show themselves also in education, but the fact that they are felt there is of too great importance to be disregarded.

The increase in requirements for admission to college has meant a corresponding development in the equipment and courses offered by the secondary school, and the affiliation of some of these schools with the university presents an entirely new problem to the college. With the affiliated school leading directly to advanced standing in the university and the undergraduate course merging into the professional work, the casual observer may feel that the college is in an uncomfortable position between the upper and the nether millstone, when the new conditions in reality emphasize the important work of the college and its peculiar fitness for it.

First. The university stands for specialization, the college for liberal culture. It may be dangerous to make sweeping assertions, since they open the way for exceptions, but they also have the virtue of furnishing a starting-point for discussion. To say that the university cannot give a liberal education is as far from the truth as to maintain that highly specialized work is impossible for the college; but general culture is the forte of the college, specialization of the university, which is only another way of saying that the emphasis in the college is naturally placed upon the undergraduate work, in the university upon the graduate course. That the tendency of the university is toward making the undergraduate course an adjunct of the graduate work and the professional school is shown by the courses elected by the undergraduates; by the fact that the movement in favor of shortening the course required for the A.B. degree, that the student may more quickly enter upon his professional work, comes from the university; by the argument so often urged that it is to the advantage of the student to take his undergraduate course there, that it may play into his professional work.

The college can and should insist upon a symmetrical undergraduate course which shall send out, not specialists, but liberally educated men and women. That such a course must be flexible goes without saying, and to a certain extent each college must work out its own salvation while coöperating with others.

Liberal culture implies something different from unrestricted elective. The elective system has been responsible for a great and salutary change in education, broadening the curriculum, meeting the needs of differing types of mind, and giving opportunity for wider preparation, but even a good thing may be carried to excess. A freshman is not always ready to be thrown entirely on his own resources. The college, with its greater insistence upon a prescribed course and with certain restrictions upon the elective, emphasizes a more symmetrical development.

Second. The university is characterized by a spirit of laissez-faire, the college by attention to the individual. The university considers the subject rather than the student, the college has a better opportunity to regard the student in relation to the subject, and thus understanding his possibilities and limitations, to " educate" in the truest sense. The head of a department in the university has an important executive position, must be the man of affairs as well as the scholar, and cannot ordinarily come into as close touch with the undergraduate life as is both possible and necessary for the college professor. The old ideal of the personal influence of the instructor as a factor in education, at least partially obscured by the modern conception of him as a specialist simply, whose responsibility extends no further than the classroom, is far more easily preserved in the college.

In other ways the college has more of the personal element, for the law of compensation works in academic as well as in other relations, and the very magnitude of the university means a certain sacrifice of unity and of esprit de corps. At Oxford and Cambridge the personal feeling for the individual college, the pride of belonging to Balliol or Magdalen, to King's or Trinity, cannot be over- 
looked as a factor in the educational influence. College spirit may be carried to an extreme, but enthusiasms rightly directed are as valuable in the intellectual world as electricity in the physical realm. Education must take into consideration not only method and equipment, the opportunities for research and investigation, but also all the influences which enter into the training and development of a life. 



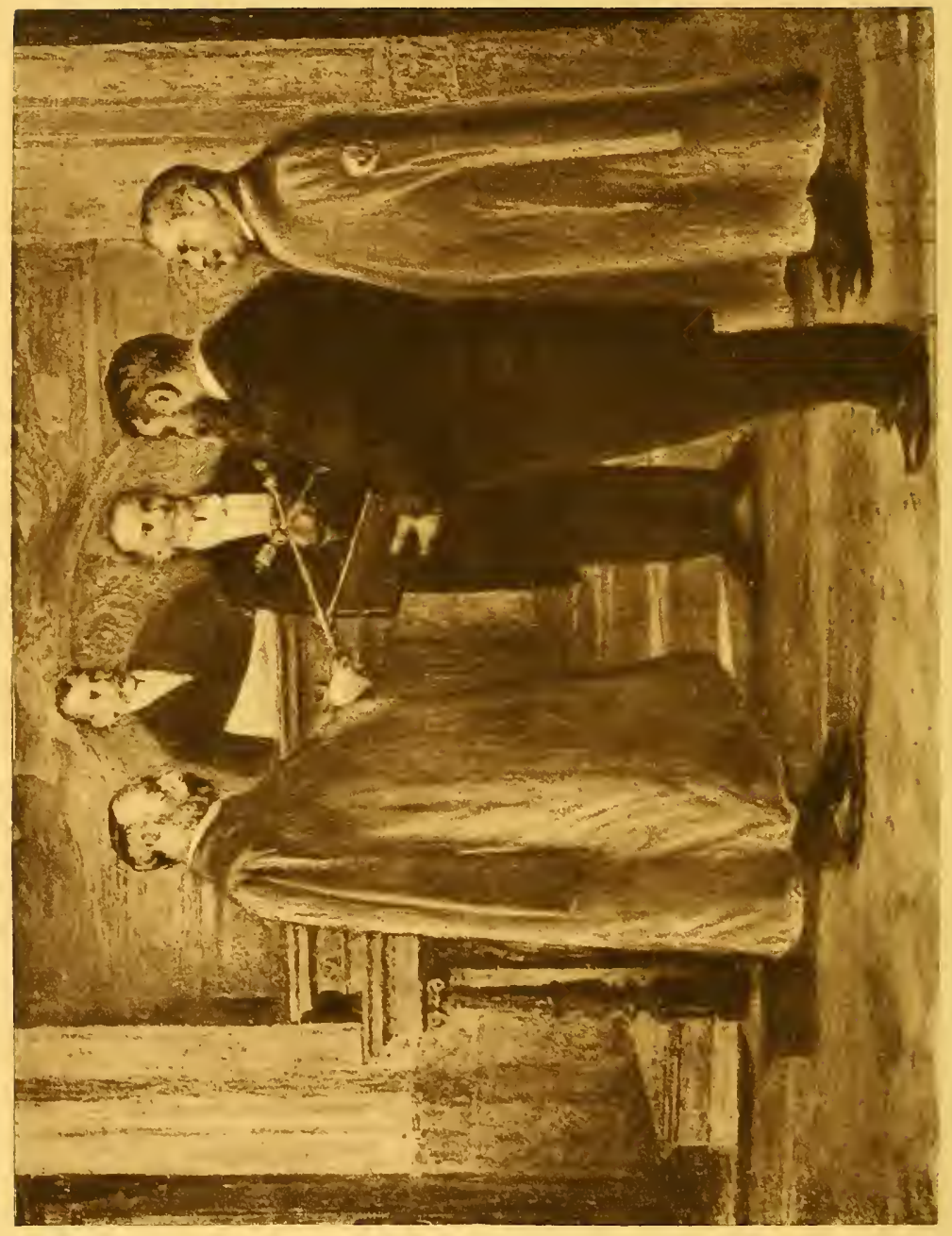




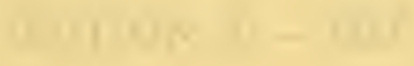

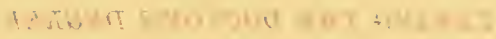 \\ in 10 त.}

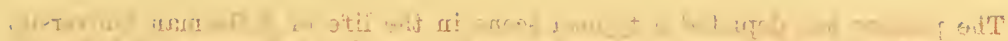

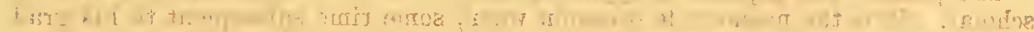

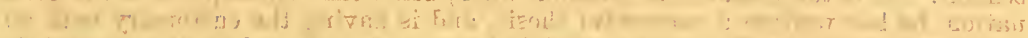

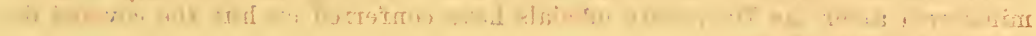




\section{TAKING THE DOCTOR'S DEGREE}

Photogravure from the Painting by $K$. Storch.

The painter has depicted a typical scene in the life of a German University scholar. It is the memorable oceasion when, some time subsequent to his graduation, he has written a successful thesis, and is having the customary oath administered after the University officials have conferred on him the coveted degree of a doctor of laws. 




\title{
SECTION D-THE UNIVERSITY
}

(Hall 12, September 24, 10 a. m.)

\begin{abstract}
Speakers: Professor Edward Delavan Perry, Columbia University. Professor Charles Chabot, University of Lyons, France.
\end{abstract}

\section{PRESENT PROBLEMS OF THE UNIVERSITY}

\section{BY EDWARD DELAVAN PERRY}

[Edward Delavan Perry, Jay Professor of Greek and Dean of the Faculty of Philosophy, Columbia University, New York. b. Troy, New York, 1854. A.B. Columbia College, 1875; Ph.D. Tübingen, 1879; LI.D. Columbia College, 1904. Postgraduate, Leipzig and Tübingen, Germany; Columbia University.]

WHEN one examines in turn the universities of the great nations which lead the world's civilization one is struck by the diversity of their history, of their aims, of their organization and operation, and by the difference in the measure of influence which they exert in the several countries which support them. Starting mostly from the model of the University of Paris, passing through endless vicissitudes of ecclesiastical, governmental, or corporate control; in turn endowed and plundered, fostered and suppressed; the centres now of ultra-conservative, now of extreme radical tendencies in religion, in politics, or in scientific theory; in one place content merely to impart to youth of still tender age a modest measure of inherited learning, altogether theoretical and unpractical, in another subordinating, even sacrificing, everything else to the development and maintenance of technical schools, in yet another unwearied in the pursuit of advanced scientific investigation of all sorts; in one age and place if not actually stationary, yet rather moved than moving in the resistless current of the world's progress with faces firmly fixed upon the past, in another eagerly peering into the gloom of the unknown which their own light shall yet illumine - do these protean institutions contain a common element that justifies us in assuming the existence of problems that affect them all alike, be they European or American or Asiatic, ancient or of yesterday, poor and struggling or proud in the rich endowments of centuries or in the more than princely benefactions of a single generation? When even the name university seems to have taken a new signification and use in every country where it occurs (and in none so many or so puzzling applications as in our own United States), what problems can there be, common to them all, that are not in equal degree problems of the secondary school, or of the college, 
or of the technical school? And if such problems can be isolated, how do they differ, as "present" problems, from those that confronted our ancestors or our immediate predecessors, or from those that continue in existence as questions still unsolved?

A starting-point for the response to these questions may perhaps best be found in this simple fact: In every country of the civilized world the institution which gives the most advanced instruction, whatever form that may take except the exclusively practical, is called a university. Such an institution may do this well or badly, may do few or many other things besides giving this kind of instruction; but the feeling is universal that this kind of organization does something which others are not expected to do, which in most cases they cannot do. Unfortunately the converse is not universally true; in our own country scores of so-called universities are no more than high schools, and poor ones at that; but in every civilized land the highest level of educational achievement is reached by a university.

It is a commonplace that every institution, to be influential and really profitable to the life of the nation as a whole, must be in harmony with the national spirit and ideals. This would seem to give us naturally as many types of universities as there are nations, and to a limited extent this is true, though it has often been pointed out that all the varieties are referable to two or three early forms. The most intensively and exclusively national forms and tendencies have their proper place in the schools; here if anywhere the seeds of patriotism must be sown and character developed in accordance with ancestral and national traditions. In the schools, therefore, in the colleges, by whatever name we choose to call the institutions whose pupils are expected merely to acquire knowledge and to develop character, we expect to find the greatest diversity in the practices and interests of different nations. Each people must here work out its own salvation, with an eye to its own profit; it should learn what it can from the experience and example of others, but its responsibility begins and ends with itself so far as the mere transmission of acquired knowledge is concerned. But when we pass on to the actual increase of human knowledge and to the training of the maturer minds to take their part in thus pushing out the boundaries of the known, we necessarily overstep the limits of the national, and enter upon ground common to all the nations of the earth. Here the interests of civilized nations can only coincide, and on this ground must meet the institutions which in each country, whether organized especially to this end or not, carry on this work as far as it is carried on at all. These are, preëminently, the universities. They may be of one form or another, with simple or complicated aims; but this responsibility is theirs, this duty and 
opportunity. If they perform this duty to the best of their ability they justify their existence, whether they do other things or not; if they neglect it, though they may turn out accomplished and wellread gentlemen, fitted to enjoy to the utmost whatever pleasure comes their way, or eminent lawyers or physicians, or brilliant engineers or chemists, they fail in the one point wherein their opportunity, and consequently their duty, are unique. And this is as true of the universities in the newest country as of those in the oldest. Service, and training for service, of our fellow men is, or should be, the keynote of modern education. But there are many forms of service, many ways in which the trained man or woman may help along the world's advance in civilization; and who is justified in saying that an occupation which to him seems profitless and a mere amusement may not contribute in the end to the sum of human welfare? Whatever else the university may do or leave undone, it cannot without being unfaithful to its highest opportunity neglect to train some persons to be contributors to the sum of human knowledge, to be investigators. It may do, and in most instances is organized to do, many things beside this, and so far as it does these well it is fulfilling more or less well its duties toward the nation in which it exists; but its duty toward the world at large is not fulfilled unless it helps in the work of actual research and uses this activity as an inspiration and model for those of younger generations who shall take up the torches that fall from the hands of their elders and carry them a little further onward.

In the obligation to service of this sort I conceive the common ground of universities the world over to lie; here is their point of contact, here their bond of union, and from this common point of view are visible many problems that concern them all alikeproblems that can be solved only by coöperation of many countries. Getrennt marschieren, vereint schlagen, is a principle that must at last prevail in the world's highest educational practice no less than in its wars; marching by way of its duty to its own country, each university must strive to pass beyond that and to reach the ultimate goal of service to the whole human race.

Is the problem thus confronting the universities of the world a modern problem exclusively or chiefly, so that the experience of our predecessors can help us but little to solve it?

It is chiefly a modern problem, because it is only in very recent years that great nations have begun to look steadily abroad in educational matters, to view themselves as reflected in the views of other nations, to profit by the experience of those others; because enormous advances in science of all sorts have been made within a century, countless new fields of investigation opened up, and old ones reëxplored. The doctrine of free investigation in all directions pos- 
sible to the mind of man as the duty of the university, of complete Lehrfreiheit, is comparatively recent, and not even yet adopted without reserve by some of the oldest, richest, and most famous universities of the world. For centuries after the beginning of universities in Europe these institutions regarded as their one duty the handing down of knowledge given to them by earlier ages; for them truth, as Paulsen puts it, "war ein Gegebenes," something " delivered," not something to be found out. "The content of instruction was provided for the medieval university; its task was to hand down the fixed body of learning." To Germany belongs the honor of having, first among nations, seen the inestimable advantage to the nation at large of so identifying the principle of research in all fields with the university that " university teacher" and "investigator," "leader of scientific thought," should become practically synonymous terms, and that the nation should look primarily to its universities and to men trained in them for counsel and guidance. This is, it seems to me, the vital point of the whole matter - the impregnation of the students of a university with the same enthusiasm for widening the bounds of human knowledge that is felt by those who guide the university, so that whatever their profession, they may practice it with an eye to this as well as to their personal success. The teacher who succeeds in doing this with a single pupil is in effect a university teacher. Herein is the fundamental difference between the university of to-day and the university of the olden time. It is to-day expected to turn out trained men and women for the professions, and thus to serve Church and State no less than was the university of old; but above and beyond this, to serve humanity at large by the insistence upon the pursuit of truth for its own sake. If the teachers of our youth feel this enthusiasm within them, it cannot fail to take root in the hearts of their pupils.

What must the universities do to exert such an influence as widely and deeply as possible in the world, along with the other functions traditionally and properly assigned to them?

Research alone, uncoupled with training in its methods, is rather the duty of such bodies as the learned "academies" existing in some countries, or of the fortunate individuals who can give their lives to it, than of the universities. This narrower view of research was the one held for generations by the great English universities, when they have held it at all, and until the most recent times " research" meant for them chiefly literary, mathematical, and, to certain extent, historical investigation. It is plain also that research, along with such training in methods, cannot be the only functions of even the ideal university. There are the professions to be provided for; the welfare of the community demands the existence of highly trained experts, both as practitioners and as teachers; and to aban- 
don the training of these to purely technical or professional schools would be suicidal for the universities, and a calamity to the state.

Our own country is much too lax in this respect, and is full of incompetent practitioners, by no means all of whom are self-taught; most have graduated from some school which has the right to bestow degrees. In some other countries, wiser than ours in this particular, the practice of a profession is made in effect impossible for those who have not been trained in a university school, and governmental control of the latter holds them rigidly to a high standard. In lands where this regulation is impossible, owing to the form of government or to deeply rooted traditions, the duty of upholding the highest standards of professional training falls upon the universities. These can, by providing the best training to be had anywhere, attract the best men to their schools, and with them leaven the whole body of practitioners.

The university, to be serviceable to the fullest extent, must be impartial in its welcome to subjects of research. It must not proscribe certain fields of research or withdraw its support from investigations therein merely because few students are attracted to them, or because such studies seem unpractical and not likely to "pay." After a long and hard struggle the natural sciences have, in many quarters, prevailed, and by reason of the countless ways in which the results of researches therein can be put to practical use, for commercial profit and for the physical welfare of man, their appeal, particularly in newer countries, drowns the voice of the advocate of the philosophical, philological, and historical sciences. Unfortunately the bitterness of controversy is not yet extinct; the scorn formerly poured out in blind wrath by the "classical men" upon studies in natural science has been returned with interest. The classical languages and literatures seem threatened with starvation by withdrawal of their nutriment. A naturalist, who will cheerfully spend his life in determining the number of recognizable variations in a species of beetles, will be heard to sneer at researches into the history of human institutions or of human speech, no less bitter and one-sided in his views than the classical scholar who sneers at him. Yet as long as man's associations are with his fellow men, as long as he remains the "political animal" of Aristotle, so long will the sciences that make for the comprehension of man, of his history, of his future, deserve at least an equal place with the sciences of the extra-human world. No knowledge, however extensive and accurate, of natural science can dispense us from the need of better knowledge than we possess of the human mind, of human passions, and human ambitions, of the history of mankind upon the earth. The person who discovers or helps to discover a law of any part of the vast complex which we call nature is a benefactor 
of the race; but so also is he who discovers a law of the human mind, whether that be manifested in language as the instrument or in literature as the form of expression, in statutes and ordinances of civilized peoples or in uncouth customs of savages, in works of painting or sculpture or architecture or music, or in the countless manifestations of man's religious emotions, beliefs, and practices. "We make the world a better place to live in," say the " practical " men. "Yes," say the " theoretical " men, " and we, by making men better fitted to live in it, also make it a better place to live in; for it is made up of human beings no less than of inanimate things." Each is fully justified in his pride, and the latter is performing as noble and permanent a service as the former; each is contributing to the progress of the race.

But the mere limitations of endowment, not to mention others, make it in most cases impossible for any one university to provide courses of research in all fields of human knowledge. Such instruction is very costly, sometimes almost prohibitively so, and the other needs which the university must meet are more immediate and pressing. Here is where intelligent and unselfish coöperation, to a.far greater extent than has yet been seen in the world of higher education, is imperatively called for. In how many parts of the world we see within the compass of a few miles two or more universities attempting the same work with insufficient endowments, inadequate faculties, and a discouragingly small number of students, while mere local pride and a mistaken kind of loyalty prevent consolidation or partition of the fields to be covered. Such partition of work of course implies the right of the student to migrate freely from one university to another, without sacrifice of his standing or loss of time or credit. In the first period of development of European universities this migratoriness of students, even beyond national limits, was very marked; then a reaction set in, owing to the growing bitterness of feeling between neighboring states, or even districts, intensified by confessional differences; for example, in the eighteenth century the subjects of certain German states were actually forbidclen to attend the universities of certain others. But since the end of the eighteenth century migration of students among the German, Austrian, and Swiss universities is commoner than persistence of residence at one university. The benefits of the custom have been too often set forth to need discussion here. But there is need of still further progress; not only must the migration from country to country, already in fashion in certain directions, be encouraged, but currents must be made to flow in both, nay, in many directions. Inestimable benefits have already accrued to American education in all its stages from acquaintance with the ideals and methods of other countries. On all sides tre have seen, of late years, educational commissions sent 
from one country to another to observe and report. Probably there are few states of the civilized world that have not some lessons to teach the others; the thoroughness of German scholarship, the elegance and precision of the French and English, are reciprocally needful. America, for generations viewed as merely a learner by the nations of Europe, and still needing much light, has at last become recognized as a possible teacher, and seems in a fair way to repay at least a part of her educational debt to older countries. It has recently been well said that while in America much time is wasted in the schools, in Germany an equal amount is wasted in the universities. We may still learn from Germany how to correct the one evil, even though the conditions in the two countries differ so greatly; and Germany may perhaps learn from our practice how to correct the other. There are already encouraging beginnings of reciprocal action in the interchange of students. The French Government several years ago entered into relations with one or more American universities for such an interchange, on fellowship stipends. Only last spring some eminent professors of German universities, while on a visit to the United States, expressed the hope that it might soon be made possible for Germans to spend a part of their time of study at American universities, with full credit at home for the time thus occupied, just as some of our universities allow time spent at a foreign university to be counted toward their own degrees. A movement in this direction has already been made by the Philosophical Faculty of Berlin. As the other states of the Empire are apt to follow Prussia's lead in educational matters, we may hope to see this privilege extended to the Saxon, the Bavarian, and the Badensian student as well.

The Rhodes Scholarships, in some respects a curiously one-sided benefaction, may yet serve indirectly a wider purpose than their founder foresaw; they may yet lead to reciprocal provision for foreign study on the part of Englishmen, and so find their own usefulness doubled.

The university must be democratic. It must not serve directly or indirectly the exclusive interests of one part or class of the community, whether that part be the social aristocracy, or the church, or the technical practitioners, or the adherents of one or another form of political theory or religious belief. This does not mean, however, that it should admit to its work or lectures every person that chooses to apply. On the contrary, admission to research and professional training must be restricted, and closely; but the restriction must be merely one of qualification for work of the character which the university is called upon to do. Restriction because of lack of residential accommodation is, for the university as such, 
most unwise, for often those excluded are better fitted for its work than those admitted, who may be admitted for other reasons family or political or religious connections, ability to pay the prices demanded, and so on. Nor does restriction on account of sex seem to me possible of retention for many years longer. One has only to compare the situation of to-day with that of twenty-five years ago to understand how irresistible is the tendency toward equality of the sexes in respect to opportunities of education. The desire for large numbers of "graduates" and professional students, merely from satisfaction in the contemplation of large numbers, is a serious danger to which American universities are peculiarly exposed. In advanced work not a very great number of students can be properly handled at one time; for mere lectures it makes perhaps little difference whether the instructor addresses twenty-five or two hundred students, but the more modern methods of laboratory and seminar have brought with them a necessary restriction in the size of classes, and the personal relations borne by the most successful teachers towards their advanced students cannot, in the nature of things, be extended to very many at once. A selection must always be made. In the first instance only those thoroughly qualified by previous training to profit by the courses should be admitted to them - except in certain cases as "hearers" or "auditors" - and only the most promising of the whole number to the advanced work. It is in my opinion a very grave though a widespread error to suppose that the university which admits the most students does the greatest service to the community. That greatest service is done by the institution which holds its standards high and firm; not so high indeed that only the exceptional student can hope to reach them, but so high that its certificate of approval, its degree, shall be accepted at a premium all over the educational world. This view is often decried as " undemocratic," particularly in America, and when applied to the professional schools of our universities. But democracy can here logically imply no more than the lack of restrictions arising from birth, class, belief, or sex; no democratic spirit can insure the making of a competent scholar out of poor material, or justify hampering the man of good endowment and training by yoking him with others who can never maintain his pace. The welfare of the country demands that there be some who can push on far in advance of their fellows, and it is the worst spirit of trades-unionism which would hinder them under pretense of giving all others an equal chance with them. The welfare of the country is greater than the apparent collective welfare of all the units that compose it; in things spiritual the whole is often greater than the apparent sum of its parts, because some of the most important parts cannot be estimated alone, but only in their effect upon others, as quickening and inspiring influences. 
The number of persons admitted to the universities, in any country, who are fitted by nature to become exclusively investigator's, is very small. Here it is particularly true that many are called but few chosen; but any one who is fitted by nature to become a good practitioner ought to be able to learn how to investigate for himself, and so to add something to the sum of human knowledge, in connection with the exercise of his profession. This is the kind of professional man that the university should expect to turn out; not the physician who is content with merely curing his patients; nor the mining or the civil or the electrical engineer who is content merely with making his creations pay dividends; nor the lawyer who is content merely with winning his cases; but men of all these professions who look beyond practice to actual enlightenment of places that are still dark, though it be given to each one to shed only a tiny gleam of light which reveals a minute speck of truth hitherto unknown. This is one form of the ideality for which the university as such must strive; not only the ideality of the poet, the painter, or the musician, but also an ideality which may inhere in geology as well as in Greek, in anatomy as well as in the history of literature an ideality which transfigures all study, and fills the pursuit of even the most practical profession with the noble passion for the things beyond and above mere "success in life." By this the university makes of its children an aristocracy within a democracy, not hostile to that democracy, but preservative of it; an aristocracy that is not a " close corporation," but open to every one competent to reach it; not reproducing itself from within, but replenishing itself from without. "Aristocracy" is a noble word, though often dragged in the mire by those who should hold it free from taint; and the aristocracy of mind and education can imperil the liberties of no community. The university, and these men and women its offspring, must lead public opinion and not follow it; nor must they sit aloof from the national life nursing their superior culture in a fine sense of detachment. The university graduate who does not feel that he owes service to the community as his $\gamma \in v^{\prime} \epsilon \theta_{\iota a}$, as the thank-offering: for his spiritual birth, is an unworthy son of his alma mater, and the university that has not made him feel this duty is an unworthy spiritual parent; but his service, so far as lies within his powers, should be one that can be performed by none in the community so well as by himself. The millions of money annually spent upon universities are wasted if their "output" does not show itself able to do what the rest of the community cannot do.

I have dwelt at length upon these general phases of the whole duty of the university because this seems to me greater than all other problems of the university, and greater now than in any previous age because of the profound changes already taking place or imminent 
in every civilized community. The problem is: How can the university make of itself the most efficient instrument for giving, with or without professional training (in which latter I include of course the profession of teacher) the enthusiasm and proper training for research, the latter being recognized as the most important of all, the sine qua non of university training? The injection of the transfiguring ideality of which I have spoken above into university teaching in all its ramifications is a process necessary in every country that maintains a complete system of education, and must be carried out by each country in its own way. In some it is practically accomplished already, in others hardly begun. The many other specific problems which confront the universities are, in my opinion, all subsidiary to this, and the solution of each of them but a different way to this end.

I have spoken thus far as though but one type of university existed, a type more closely resembling the German than any other, yet not German because of the inclusion in it of the technical schools, which in Germany are separate from the " universities," with their time-honored "four faculties" of theology, law, medicine, and philosophy (though in some German universities we find, as is well known, a subdivision of one or another faculty). This I have done to avoid confusion; and it seems necessary now to explain that so far as I know no university of exactly this type exists anywhere in the world. Certainly not in the United States, because those few which include the "four faculties" include also "undergraduate colleges," the aim of which, while not contrary to the ideal of the university, is not coincident with it, but rather preparatory and conducive to it. Not in England, where the "university" is either a group of colleges which do almost all the teaching, or merely an examining body, or as yet merely an incomplete institution consisting chiefly of technical schools; and not on the Continent of Europe, because there the technical schools are still separate institutions. Yet the ideal which I have tried to formulate is pursued in England, in the United States, and on the Continent of Europe, and in other parts of the world. By " university" in the United States I mean so much of one of our complex and heterogeneous institutions as trains for the work of research of an advanced character, whether coupled or not with professional instruction, to which training are admitted only those who have had a previous training roughly to be estimated, in accordance with American custom, by the baccalaureate degree or its equivalent. This part of such an institution has to solve " university problems;" or rather, the institution as a whole has to solve them for that much of itself, along with many others which affect other portions of its complex organism. These questions are thus made much more difficult of solution for American 
institutions than for those of older countries. The American "university" is tending to become a huge magasin, an emporium of learning, a sort of Ministry or Department of Education. In its desire to be all things unto all men it is apt to lose sight of the logical distinctions between different stages and fields of education, and to assume that everything it does is exactly as important as everything else done by it, or by any other institution.

The first problem that presents itself is naturally that of money. Probably no university exists which has all the money it needs; such a one would be an absurdity in the world of education. A university which has all the money it needs does not deserve all that it has; it condemns itself out of its own mouth, by confessing that it can think of no new paths in which to strike out, or does not care to enter upon them. A school, even a college, may conceivably have money enough; not so a university. Instruction in methods of research is well known to be the most expensive of all kinds. The great specialists in medicine and law and engineering and chemistry command, as practitioners, fees far in excess of anything that a university could afford to pay them as salaries if it demanded all of their time and activity. It is fortunate for the universities that the profitableness of actual practice often does not appeal at all to the men best fitted to instruct, and that in other cases men eminent in practice, satisfied with the income produced by devoting part of their time to it, use the rest in lecturing or conducting courses of research in a university or professional school. It is plain to every one that large and commodious laboratories are needed for even a few advanced students, although fine laboratories and equipment do not of themselves make investigators, any more than fine art schools necessarily turn out great painters or sculptors, or fine conservatories of music great composers - the right kind of men must be there to use them. The scientific spirit and insight and patience and training which make discoveries would doubtless make them anyway with the merely necessary materials at hand; but good equipment makes for good work. The danger here lies in the temptation to mere splendor. The need of well-equipped libraries is less evident to the outsider - sometimes least evident to the Maecenas from whom donations are fondly expected (I speak as an American) yet it is not less great than that of laboratories. It is probably not too much to say that the need least well supplied, in all universities but a very few exceptionally favored ones, is that of proper endowments for the constant purchase of books. Other equipments too are requisite: museums and collections; and for the history of art, casts, photographs, engravings, models, at least in universities where there is not ready access to good public museums. The rapidity with which large sums disappear when applied to such objects is only 
too familiar to those who are charged with the duty of providing and administering such collections. Another temptation, particularly hard to resist, is that of devoting the endowments chiefly to things that bring in an immediate return - the " things that pay," as the phrase is. How to touch the generous impulses of the men of wealth, or convince the rulers of the state of the university's needs, and to do this without sacrificing the ideal of the university to please the whim or vanity of the one or the other - this is one of the greatest and most insistent problems, and it grows greater and more insistent with every year, because of the constant advance and ramification of human knowledge.

The question of the best organization for the work that the university has determined to do is no sooner apparently settled than it again raises its head. Of course in the United States, where new organization and reorganization are constant, this problem is particularly pressing. It here presents itself in different aspects to East and West. To the older East, with its great institutions of learning built up on a collegiate foundation, for generations undergraduate colleges, on which have been grafted from time to time professional schools with little or no organic relation to each other or to the central stem, the problem has been largely one of favoring the new without sacrificing the old, of bringing to the institution as a whole that feeling of solidarity which naturally inheres in an "undergraduate" college. In the West, in the state universities, where the professional and technical schools have from the first held the more important place, the conditions are almost reversed. In Europe the technical schools have from their first establishment stood on altogether different ground, as something apart from the university, requiring a different preparation of candidates for admission, and in most cases possessing decidedly inferior social prestige. But this condition is passing away in Europe; it is coming to be seen, for example, that medicine and law are quite as truly technical professions as engineering and architecture, and the latter quite as well entitled to be called "learned professions" as the former. Germany has begun to wipe out the invidious distinctions between Hochschulen pure and simple, i.e., universities, and technische Hochschulen, formerly called Polytechnica. In Prussia the technische Hochschulen have had, since 1899, the right of giving the doctor's degree in engineering, and the other states of the Empire have followed suit. This has naturally reacted upon the secondary schools which are feeders to these institutions - a point to be touched upon presently.

What is to be the attitude taken toward technical schools by the university which includes them in its corporate membership? For the United States this is indeed a burning question. Are the tech- 
nical and professional schools to be viewed and treated as undergraduate or as graduate schools? That is to say, shall they or not admit students who have not had a preliminary training indicated by the possession of a bachelor's degree? Hardly any two institutions in America are answering that question in the same way. Some of the Eastern institutions have made the schools of medicine and law "graduate" schools in that sense, but none has yet had the courage to take the same step with regard to the technical schools - of chemistry, engineering in its many forms, and architecture. Here is, it seems to me, an exceedingly great opportunity for the larger and more powerful institutions of the United States to serve the ultimate welfare of the country, by putting all their technical and professional schools on a graduate basis. Probably no one now alive will see the abolition in this country of technical and professional schools unconnected with any university. These, so far as not controlled by the state, will go their own way, for the most part (of course there are honorable exceptions) aiming to " fit for practice" in the shortest possible time, and taking little or no account of the ideal emphasized above, - the ideal of research, of training in methods of research, of encouragement and inspiration to research, as the proper ideal of the university, whether that be done in connection or out of connection with training for professional practice. The university's technical and professional schools should be put and maintained on a higher plane. If in the course of time they drive the others out of existence, so much the better - the fittest will have survived; if not, it will surely be better for us to have the higher ideal and its partial realization before the eyes of the country and the world than to see the lower one everywhere prevailing. For here is the point of contact with other lands and other civilizations, and we shall be measured by the best of what we have accomplished. The professions are steadily assuming a more and more important and commanding position in the world. The universities, to keep their hold on the nation, to be the leaders which their duty calls them to be, must, identify themselves with the professions as never before, but with only the very highest forms of professional education. For them to lose their traditional hold on the older professions, or to fail to secure a firm hold on the newer ones, would be for them to lay the ax to their own roots. To keep and secure this hold they must make themselves everywhere in the world recognized as the centres of research. Paulsen said, some years ago, that some of England's greatest lights in science would be inconceivable as members of an English university. That is a terrible indictment to bring against a university; fortunately it is less true now than in 1893, when he said it; and it is becoming less true every year. 
I have said little or nothing, in this connection, of that part of the university, whether it be an American or a European university, which is not commonly considered professional or technical: the part called "philosophical faculty" in Germany and most countries of Continental Europe, and including the parts devoted to political science and economics, and to mathematical and natural science, which in some places are organized as separate faculties; in others included in the faculty of philosophy or elsewhere. Some of our American universities comprehend all these parts under the collective name of "graduate" schools - an insufficient designation in those institutions which have made one or more of the professional schools also into graduate schools. The history of this part of the university body has been singularly varied. At first, in Europe, subordinated to the other faculties, it has there been raised to perfect equality with them, and in general has maintained the ideal of theoretical research far more completely than the other faculties; yet in Germany it has become almost as much of a professional faculty as the others, having been made the pathway to the profession of teaching in the schools of higher rank. In the United States also the tendency is strong in the same direction; the majority of those who, as graduate students, pursue courses leading to the degrees of master of arts and doctor of philosophy do so with a view to becoming teachers. Here, too, almost without exception, are found those students who, without thought of active professional practice, pursue their work for the sake of study and research alone as far as the university can guide them. This is naturally the most " theoretical" part of the university, the least exclusively professional and technical; there is nothing like it to be found outside of university organization, whereas the work of the theological, the legal, and the technical faculties is almost everywhere duplicated outside. In fact, taking the Christian countries as a whole, theological training is given much more outside of universities than in them, and the same is true of technical training. This "philosophical" part of the university (I use the name without prejudice to the others - not as if they were necessarily unphilosophical, and not in the narrower sense of the term) - this part is preëminently called upon to maintain the ideal of research. It has no raison d'être if it does not maintain it; but it is not called upon to maintain it single-handed. It is important that the philosophical faculty, in the wider sense, be a large part numerically of every university, and that it be not subdivided in any such way as to weaken its solidarity. The task of fitting teachers for the higher school work, and, of course, those who look forward to giving instruction in non-professional subjects in colleges and universities, will always be peculiarly its own, and these teachers must be imbued with the idealism which shall protect them from degeneration 
into mere teaching-machines - Unterrichtstechniker, to quote again from Paulsen.

In America the relations of this part of the university to the rest offer many problems peculiarly pressing, because the individuals who compose these faculties almost without exception form part of others as well - a condition entirely different from that existing in European universities. They generally have quite as much to do in an undergraduate as in the graduate school, and so are in a position analogous to that of the Gymnasiallehrer who also lectures in the university. The situation is, of course, largely, if not exclusively, the result of insufficient funds. No good "graduate school" could possibly be self-supporting, and the institutions of which these schools form parts have naturally many other demands to meet. The burden of double teaching weighs very heavily upon the American professor, making exceedingly difficult the necessary concentration of mind upon the higher work. To regulate these conditions is certainly one of the most important problems before the American university organizer.

To do this chosen work with the best result the universities must have well-prepared material. The need of this has been met by different nations in different ways. Least care has hitherto been taken in the United States, where until very recent years almost any one was thought well enough trained for admission to a school of medicine or law or technology. Germany has been the most careful, demanding until not long ago a gymnasial training for all faculties of the universities, and a full course in the Realschule for admission to the technische Hochschule. But even here, some years ago, a reaction set in against the exclusive privileges of the gymnasium, and now certain parts of the university are open to the graduates of Realschulen and Realgymnasien. The end of the extension of privileges is not yet reached; the natural sciences will doubtless receive still greater concessions. But the principle is still firmly maintained that admission to professional training is to be denied to those who have not a rigid and thorough preliminary training. The kind of training may vary, but its amount and thoroughness may not be diminished. This is still an urgent need in America: not how the universities may get the largest numbers of students, or fill up the schools that "pay" the best, but to get a reasonable number of the best-prepared students, who will push on beyond their masters. Much has been written of late years about the undue prolongation of university, especially professional, study; and from this point of view what seems only a school question becomes.a burning university question as well, for the university can build only upon the foundation of the school, or of the school and the college.

The best form of instruction for the university to follow is still 
a matter of discussion. Everywhere it is recognized that mere school methods do not suffice; the lesson to be learned, the pensum, the "recitation," to use an American term, has no proper place in university work. Even where a new subject is taken up, for example, an Oriental language, this method is felt to be out of place. The lecture, on the other hand, which up to a few years ago held chief sway in the Continental universities of Europe and was thence imported into American colleges and universities, has been vigorously assailed. Why should students take down from the lips of a lecturer, the objectors say, things which they could find more quickly and satisfactorily in books? There is much force in the objection, and the lecture has lost much of its prestige. The seminar, and laboratory, and elinical work, under the direct guidance of an instructor, have largely taken its place. Yet its usefulness is by no means gone. As a means of informing a number of students quickly of the latest developments of science its place cannot be taken by books, for purely practical reasons; the books cannot be printed quickly enough, nor could publishers be found to issue new editions every year, nor could the students be expected to buy as many books as this method would imply. Again, the personality of the teacher would be largely lost - and the personality of a really good teacher, his visible and communicable enthusiasm, are potent factors in the production of a satisfactory pupil. Undoubtedly much time can be saved by judicious use of printed bibliographical and other lists, and the lectures should be kept in close connection with seminar and laboratory work; but to abolish them entirely would mean an immense loss to university instruction. There is a certain freedom and flexibility in the lecture which make it particularly useful. It is thus eminently suited to advanced instruction, where a number of mature students have to be guided. It meets the needs which they have in common. On the other hand, the individuality of the advanced student must be maintained to the utmost; he must be shown how to work, but left to himself to apply the principles, with such criticism from his instructor as his application calls for, which is properly done in seminar, laboratory, or clinic. His selection of work must not be too closely limited, and he must be encouraged to strike out for himself. His Lernfreiheit must be guaranteed him.

It is manifestly impossible, within the limits here set, even to touch upon all the university problems of to-day. I have, therefore, attempted merely to indicate what seemed to me the all-important ones. In the prospectus of this Congress we read: "The central purpose is the unification of knowledge, an effort toward which seems appropriate on an occasion when the nations bring together an 
exhibit of their arts and industries." There is no field of human physical activity which might not find illustration among the exhibits, and no field of mental activity not provided for in the deliberations of this Congress; but more than this, there is nothing represented in either the Exposition or the Congress which may not properly be made the subject of university study.

Not only do the architect and the legislator build wiser, but also the poet often speaks truer, than he knows. Terence's

homo sum: humani nil a me alienum puto

has gained in the course of ages a deeper and truer meaning, probably far deeper than the poet ever intended it to bear, but a meaning and a truth from which mankind ean never recede. So too the very word " university," which as originally used had no reference to the universality of human interest, but denoted merely the whole body of teachers and scholars of the studium generale, has earned the right to the wider sense now attached to it; it is becoming, and it is our duty to help it to become, a panepistemion, as the Greeks of to-day call it. Nothing that man can possibly find out is alien to him; not only to increase knowledge, but to multiply the fields of knowledge, is the peculiar province of the universities, which might well take as their motto that famous line. They are peculiarly called upon to take all research under their protection, to train for it, and to encourage its practice. 


\title{
THE PROFESSIONAL TRAINING OF TEACHERS IN FRANCE
}

\author{
BY CHARLES CHABOT
}

\section{(Translated from the French by Professor Charles B. Goold, Albany Academy)}

[Charles Chabot, Professor of the Science of Education at the University of Lyons since 1891. b. Villette (Ain), 1857. Elève de l'Ecole Normale Supérieure, 1876; Licencié ès lettres, 1877; Agrégé de philosophie, 1879; Docteur ès lettres, 1897. Professeır de Philosophie aux Lycées de Saint Ouen (1879), Moulins (1881), Besançon (1889), Lyons (1891). Author of Nature et Moralité; Rollin et la Discipline des Collèges; L'Enseignement Secondaire dans le Rhône (collaborateur); La Pédagogie au Lycée; Collaborateur de la Revue Pedagogique et de l'Aimée Psychologique.]

THE question of the professional training of teachers in France is one of the vital problems of the day. As a result of the study and experiment we are spending in its solution is to arise, let us hope, a new and better state of affairs in the matter of both primary and secondary education. In achieving this reform which, in the matter of secondary education, will amount to the introduction and establishment of a system, we may look for model and suggestion to the educational systems in vogue in other countries than our own. So widely divergent and conflicting, however, are such models that we can use them only by adapting them to the needs of our own national character and temperament. How shall our country solve this important problem by combining, along the lines of these needs, its own traditions with the suggestions coming from abroad? It seemed to me that this question is of interest not only to French teachers, but also to the international congress of teachers which I have the honor to address.

It is my purpose in this paper to present but few of my own views and to deal chiefly with facts. I shall mention, briefly, the history and present status of our system; first, in regard to primary education; second, in regard to secondary education; then I shall suggest some plans for reform.

\section{Primary Education}

It is to the Revolution that we are indebted, if not for the idea of a professional training for teachers, at least for a plan of general organization corresponding to that idea. The Convention passed, October 31,1794 , an act establishing " a normal school in which should be gathered, from all parts of the Republic, citizens already instructed in the useful sciences, for the purpose of learning under'the tuition of the ablest professors in every department of knowledge, the art of teaching." This school, established in Paris, was to become a sort 
of nursery for the propagation of normal schools; for its 1400 pupils taken from the provinces, were to return, after four months of study, to their respective districts and establish in them similar schools. This institution lasted only four months and came to an untimely end in the political turmoil. Moreover, under this form, it seemed hardly suited to its purpose. But the idea, together with the name of normal school, survived, and in 1808 the school was reëstablished, or established on a different basis, for the training: of teachers of secondary instruction. So far, however, as primary teaching is concerned, we owe it to private, or at least local, initiative that the idea of a normal school was again taken up and realized under a decidedly practical form. Normal schools were established first in the eastern departments of France; then in other localities, with ever-increasing success. There were thirty of them in 1833 when Minister Guizot incorporated in the famous enactment which bears his name a clause compelling " each department to support, either by itself or in conjunction with other departments, a normal school for primary teachers." This provision was not carried out strictly; but if the institution could be jeopardized it conld no longer be destroyed. As a matter of fact it was in peril when the normal schools, apparently dangerous on account of their liberal views, were attacked, threatened, almost wiped out. But they soon regained their popularity, and, thanks to the efforts of Minister Duruy, toward the end of the Second Empire continued to flourish. In 1870 nearly every department had a normal school for male teachers, but nineteen only had one for female teachers, while the normal courses annexed in the others to the primary schools were quite inadequate. Since 1879, owing to the efforts of Jules Ferry, the provisions of the law have been actually enforced in all the departments, and we now have eighty-seven normal schools for male teachers, eightyfive for female teachers, with a total of 7736 pupils, maintained, according to the statisties of 1900 , at a cost of $8,000,000$ francs.

Admission to the normal schools is by competitive examination. As a rule candidates come from the higher primary schools and must pass written and oral examinations, the scope of which, however, embraces nothing of a purely professional nature. In the school itself the professional training is as follows:

(1) There is, to begin with, instruction in the theory of teaching. This is given by the principal and deals with the application of psychology to education, the practice or history of pedagogy, and school administration. The instruction in science and literature is, as a rule, excellent; but the professors do not touch the question of pedagogy, or at least are not obliged to do so. Some few, however, test their pupils' ability actually to conduct a recitation, supplementing such efforts with criticism and advice. 
(2) There is, on the other hand, some practical work. This is done in the practice or experimental school, which is an ordinary primary school, associated or not, as the case may be, with the normal. Its organization is not everywhere the same. On the average, every normal student spends thirty days in the practice school, divided into several periods according to a system of rotation. In certain schools these days are subdivided into four weekly periods, during each of which the pupil-teacher discontinues his studies and devotes his entire time to the school of practice. In other schools he spends only his afternoon in the practice school, devoting the morning to the normal. Moreover, his period of apprenticeship is not always organized in the same way: in some cases he will have charge of all the recitations; in others he will be present in certain classes and will personally conduct only a few. In every instance, however, he has the same duties as his instructor; he must instruct his class, keep a notebook of his preparation, correct his pupils' exercise-books, etc.

In this apprenticeship he has, as teacher and guide, not his professors, who, with few exceptions, do not enter the training-school, but the principal of this school, under the authority and control of the head of the normal. This teacher shows his apprentice in the first place by example how to manage a class and conduct a recitation; then assists him by direction, criticism, and advice, in the actual work of teaching.

These are the essential features of the system. Doubtless the results obtained depending, as is always the case, on the efficiency of the men, are as satisfactory as we have a right to expect. But the question may fairly be raised whether the organization itself leaves nothing to be desired, and we shall see that a reform must be thought out.

The examinations for the elementary and higher licenses, which all normal students have to pass, are not of a professional nature, for at this stage an examination on the application of psychology to education cannot be reckoned as a pedagogical test and the elementary license, which is all that is required of a public or private school teacher, does not demand any such test. But no one can be appointed full teacher in an ordinary public school unless he has obtained a certificate of proficiency in pedagogy. Before attempting an examination to gain this certificate a preliminary course of two years' teaching is required. The examination embraces a thesis on some educational subject, a criticism of the exercise-books containing a month's work, questions on pedagogy, and, above all, as a practical test, the conducting of a class by the candidate in a primary public school. The candidate is now duly qualified to teach. His professional training is continued by actual practice, by a course of reading, especially by the reading of some journal devoted to peda- 
gogy, and lastly by discussions on teaching, held in his school district, which he is expected to attend. These discussions, the subjects for which are prearranged by mutual agreement, are held under the direction of an inspector and treat of practical questions in regard to teaching. Often, too, in schools in which there are several teachers, the principal calls a meeting of his assistants every month or fortnight, and discusses with them questions arising from the life and routine work of the school.

To teach in the higher grade primary and normal schools a special certificate is requisite, calling for substantial literary or scientific attainments. The professional part consists of a thesis on some questions of ethics or psychology as applied to education; as a matter of fact, this is not always satisfactory. ${ }^{1}$ The oral tests, consisting of the correction of a task, assignment of lessons, comments upon a text, and preparation of material, may be of a very professional nature, but that depends on the views of the examining board, and the candidate does not submit to these tests in a class before his pupils.

Professors for our normal schools, as you know, are especially prepared for the discharge of their duties and for gaining this certificate, in the advanced normal schools for primary teachers at St. Cloud and Fontenay. These are genuine professional schools, intended expressly to train men and women teachers. As a matter of fact their training is excellent; and, speaking only of the past, the inspiring personality of M. Pecaut at Fontenay and that of M. Jacoulet at St. Cloud are reproduced in the character and earnest zeal of those who have been their pupils. However, pedagogy, in the proper sense of that term, occupies only a subordinate place as compared with general instruction or culture. Both of these schools require a thesis as a part of their entrance examination, and there are one or two discussions a week on ethics and psychology, not, however, especially pedagogic. The course of study is, then, not at all professional in its scope, and the special training of the pupils for their future work is dependent on such private conferences as they can have with the director or the professors. Moreover, the latter, who come either from the university or the high schools of Paris, are not always interested or well posted in pedagogy, nor are they anxious to teach it. However, since 1898, each of the pupils from Fontenay serves a fortnight apprenticeship as teacher in a primary school, where she receives some instruction in school matters and herself conducts a few recitations.

All certificates of fitness for the various special branches (singing, drawing, sewing, bookkeeping, etc.) require a test of ability to teach

${ }^{1}$ More professional perhaps is the thesis required for a certificate of fitness to teach modern languages, involving the question of methods of teaching. 
these subjects, but there is seldom any organized work of preparation for this test.

Finally, the examination which the inspectors of primary schools or directors of normal schools are obliged to pass is more particularly or even wholly pedagogic and professional. It embraces theses and lessons in pedagogy and in school administration; comment on a passage from a pedagogical writer; the inspection of a school in the presence of an examining board. Preparation for this examination is systematically organized in some universities and by groups of private teachers.

Such is the actual state of affairs. The theory and practice of teaching play some part, variable indeed, but still positive and effective, in the education received by teachers of various grades. In this fact is to be found the chief reason for the remarkable progress in our primary instruction during the past twenty years. Can we make still further improvement if we broaden and strengthen this education and secure for it the benefit to be derived from new scientific truths and from recent pedagogic experiences? This is the thought of very many educators. Let me outline their criticisms and their proposed reforms.

\section{A. Criticisms}

In this professional training of teachers actual pedagogy and the sciences or studies inseparable therefrom do not, generally speaking, receive the place which is due them. The instruction given is neither sufficiently scientific nor sufficiently concrete and practical. Psychology as applied to education is, with some exceptions, quite general in its scope; it is the psychology of the adult, not that of the child, which has yet made progress of late. Only in a few normal schools is any effort made to accustom the pupils to undertake a systematic study of the children in the training-school. So, too, the general principles of hygiene are taught, not those of school hygiene. The history of theories is dwelt upon, but too little attention is given to the history of teaching and of the school, even less to the methods employed in foreign countries. All this is left to the chance of individual reading, that is to say, often reduced to a matter of slight importance or, in the case of many teachers, to a matter of no importance at all. One can become director of a school without any additional qualifications and without thereby being any better informed than a mere beginner. It is true that in large cities the better teachers are first appointed directors' substitute, which gives opportunity of judging them by their actual work. This is an excellent guaranty of their fitness when such estimate is fair and impartial. But whatever be the value of this precaution and period of apprentice- 
ship, their knowledge of teaching often remains limited to the meager qualifications required for a certificate of fitness. They have more practice but no more professional knowledge than their assistants. This is an argument which the opponents of directors and the principle of supervision never fail to urge against it.

In like manner the professors in the normal school rest contented, or at least may do so, with the inadequate knowledge of pedagogy required to pass their examinations. If many of their number are solicitous about the progress of pedagogical studies there is nothing obligatory about the matter, nothing even to inspire interest in it. They teach literature and science to our future instructors without being obliged to keep in touch with new methods of instruction. If they are not ambitious of becoming primary inspectors they may lose all interest in the science of teaching. The director, on whom devolves the teaching of pedagogy, has shown his ability by passing an examination for his position, but the practical part of this instruction belongs also to the director of the training-school, and he is under no obligation to devote himself to any special study of the art of teaching.

Finally, is it not clear that our primary inspectors, and even our normal school directors, are too deeply engrossed in their administrative duties, too fully occupied by the purely practical part of their work, to devote to the study of pedagogy the attention which it deserves, or which they might be willing to give it? How many of them have the time or the means to keep informed on what is going on in other countries?

\section{B. Plans for Reform}

It seems then necessary in certain cases, useful in all, to broaden the professional training of our primary teachers. The influence of some would be better assured thereby, the initiative of all quickened and made productive. What is it expedient to do, and how shall it be done, without overstepping the bounds of moderation, without falling into the pedantry of pedagogy? Place must be found at the same time for the philosophy of education and for some positive knowledge of school hygiene, child psychology, the history of pedagogy, and its development in other countries. The interest and critical spirit of teachers of every grade must be aroused on educational questions. A plan looking to the reorganization of our normal schools, presented by the Minister of Education to the Parliamentary Education Commission, has already been tried in a score of schools, at Lyons in particular. Its general adoption seems to be in the not distant future. Its essential features are as follows: General training and professional training are clearly distinguished, almost 
divorced. The former, with better chosen, simplified, and more interesting courses of study, fills in the first two years. At the end of this period the pupil receives a certificate of fitness as a primary teacher. This takes the place of the two licenses to teach and is to be required from now on of every teacher in either a public or private school. The third year is devoted, first, to a complementary and more independent work of general culture, a sort of philosophy of the teaching done in the first two years; second, above all, to professional training. At the end of this third year the pupil receives a certificate of pedagogic fitness. The course of study in preparation for the acquirement of this certificate is henceforth clearly mapped out. All those who, without having been admitted to the normal school, may wish to become public school teachers, will have to spend a year at the school in preparation for their work. Up to the present time the certificate of pedagogic fitness has not been required of instructors in private schools. Even now during the first two years of their course the normal students have studied psychology as applied to education, have made frequent visits to the school of practice, have made their psychological investigations by a systematic study of the minds and characters of children. This work is continued during the third year, but pedagogical training takes the foremost place. The course of study ${ }^{1}$ for this (third) year is, it will be seen, extremely interesting. It embraces lessons in pedagogy and school government; reading and analysis of classical authors; studies in the application of methods to various subjects of the course; practical application in the primary school of the lessons learned in the normal; a period of earneșt apprenticeship either in the training-school or in the neighboring schools; visits to rural schools; finally, critical estimates and discussions in regard to all of these various tests.

The results already obtained from this reform are, if we may believe its partisans, decisive, at any rate very encouraging. But even the most optimistic express the hope that in the future the practical examination for the certificate of pedagogic fitness may be placed at least toward the close of the first year of teaching and passed by the young instructor in the presence of his class.

Whatever may be the outcome of this new plan, instruction in psychology, ethics, and pedagogy is destined to assume a character really concrete. Ideas about text-books or courses of study are not sufficient. The educator of the future must learn to know the child by studying children, must learn methods by applying in the school for practice what he has been taught in the normal. Indeed, all

${ }^{1}$ I am indebted to M. Mironneau, Director of the Lyons Normal School for Teachers, for documents giving this course. They form, moreover, a part of our exhibit in this Exposition. 
this is contemplated in the proposed plan. It is to be hoped too that room may be found for the philosophy of education, for school hygiene, and for some ideas of the pedagogy of other countries than our own.

Finally, would it not be well to open the university to teachers with a view to broadening their general or professional training? This question is being more and more persistently raised in Germany. In France, in certain university towns, normal students of the third or fourth year pursue either public courses or a few of the private courses in the departments of literature or science. In other cities free lectures are given for the normal schools themselves by university professors. Doubtless it would be sufficient to make these attempts more general, to strengthen them and extend their advantages to the other normal schools. I have no doubt the university professors would gladly lend their aid to such an attempt. At any rate, if a department of pedagogy were established in all of our universities, it would be easy to connect it with the normal schools of that part of the country. The normal director or professors would continue to give instruction in practical pedagogy, but the university professor would be a member of the examining board to pass judgment on the students' pedagogic dissertations. It would be his further duty to lecture each year on such questions of vital importance as might call for discussion.

Another reform which has been suggested raises even greater difficulties, for it threatens the very existence of the normal schools at St. Cloud and Fontenay. Their pupils, it is claimed, are students in the department of higher education. Should we not be justified in turning them over to the universities? Is it not useless and expensive to assemble and confine them in special schools, the cost of whose establishment and maintenance must be met, when the same instruction could be given, in some instances, by the same professors, in.the University of Paris or the universities in other parts of France? To the examination for a professorship sit not only the pupils of these special schools, but also candidates who have pursued their studies in a department of the university, and it is clear that the universities could offer to these young teachers every opportunity necessary for preparation for their future work. Ought we then to abolish the schools at St. Cloud and Fontenay? The idea suggests itself readily enough, but its practical application is by no means an easy matter. These two schools have traditions that are of real value. Thanks to the very unity of management and to the maintenance in them of the pedagogic spirit these institutions are in a position to render still greater services. But they can urge no greater claims for support than could the normal school of Paris; moreover, the decentralization would have advantages unnecessary 
to enumerate in America. If the schools at St. Cloud and Fontenay are to be abolished, we must fully replace all their excellent qualities by creating in the universities something of the same spirit that has animated these two institutions. This solution of the question is quite possible, even desirable, provided pedagogical institutions are organized into which would be brought together, without loss of individuality, however, all of our students of pedagogy, as well as all of our future teachers of primary or secondary schools. On this condition the new organization would be quite superior to the present system.

In any event it is indispensable that in the future our teachers should receive, in schools or elsewhere, better instruction in the art of teaching, in accordance with the programme which I have indicated, and that they should have more practice in the actual work of teaching. This is the underlying idea of a new plan, still under discussion, to separate, as in the normal schools, general culture and professional training. The former would be intrusted to the various universities; the latter, covering a period of a year, would be given to St. Cloud and Fontenay, which would become exclusively pedagogical. Under the new scheme normal school professors will play an important part in the management of teaching. Under the present system they have no preparation for this duty. In the case of the students of St. Cloud at least, they may never have taught in a primary school. Their professional preparation should evidently be adapted to their future work.

In regard to primary school principals, the question has already been agitated of requiring of them a new certificate of fitness and professional skill. ${ }^{1}$ This would constitute a sort of teacher's degree similar to that granted by the University of Chicago; it might consist of the diploma established by the Lyons Faculty of Letters for advanced pedagogical study, or perhaps better still of a similar diploma cut down in its requirements and adapted to the purposes of the primary school. The general principle of an increase in the number of examinations is undesirable and burdensome, but this examination has come to be a necessity. The requirements for such a diploma as I have described allot a generous share to individual and original work. In fact, in addition to practical exercises and an examination on various pedagogical subjects, it calls for the writing of a dissertation on some topic left, subject to his professor's approval, to the candidate's own choice. In this way there would be some certainty that a principal would be able to show his assistants how the most elementary question of practice is the concrete expression of some general theory, and, conversely, how theoretical ideas find their expression in familiar processes.

${ }^{1}$ In Paris, already, by reason of the large number of candidates for such positions, an examination has just been instituted. 
Finally, the practical value of this organization will depend on the action of the normal school principals and primary inspectors. How shall they be prepared for these important duties? It has been proposed in various quarters that all examinations for these positions be abolished. The primary inspectors, from among whose number are subsequently taken without further examination the normal school principals, would be chosen by the administration from among the best of the professors or instructors and in accordance with the capacities of which they may have given proof. But this very choice from among two hundred candidates, all of whom are not known by the same heads of departments, would be constantly subject to mistake and unintentional injustice, to suspicion of favoritism, and in many cases would be determined simply by the success of the students. It would take only accidental account of the general pedagogical studies so necessary for one who is to act as a guide for future teachers. It is then neither probable nor desirable that the examination be abolished. Ought it to be reformed? Yes, undoubtedly, in some points; but there should be no radical transformation, for it has proved its usefulness; it is really pedagogic and professional.

(1) In regard to the written examinations which eonsist of a thesis on some subject connected with teaching or on school management, I suggest that there are too few. Trifling accidents may cause the rejection of really able candidates, while permitting those of inferior ability to pass. In too many cases mental capacity is judged by a single pedagogical examination, so that the power of memory of the least desirable candidate enables him to gain, if not a good mark, at least one sufficient to pass. The element of chance would be eliminated if we required two or even three written examinations in the theory, practice, and history of pedagogy.

(2) In the matter of oral examinations, the actual conducting of recitations is indispensable. The practical test of an inspection of his school by the examining board is excellent. The test of interpreting some author is a difficult one and vigorously opposed by some. It is perfectly fair and convineing, however, by reason of its very difficulty. It permits the examiner to form a fair judgment, not merely of the candidate's power of discrimination and clearness of mental vision, but also of his professional fitness. An inspector, even on seientific subjects, ought to be able to explain to his teachers a good page from some work on pedagogy or to discuss intelligently the contents of a printed cireular of directions.

With these limitations, it is simply necessary to make the examination as accessible to candidates on the scientifie side as to those on the literary. This would be an easy matter if the subjects for theses and oral work or the text required for reading were chosen 
with a due regard to the teaching of science. Lastly, some place should be found on the programme for the art of teaching as developed abroad. I would suggest for each period of three years the study of some country in which this art has reached a high standard of excellence.

With these guaranties the primary inspectors, already a choice body of men, would really be adequate to the discharge of their duties, capable of directing the most intelligent and the best-trained of their subordinates, able to arouse and sustain in others something of their own zeal and interest in teaching. If it should seem wise finally to demand some additional title from such of their number as might be placed at the head of the normal schools, evidence of further professional study of a more independent and personal kind should be required. In token of such study the university might grant a sort of doctor's degree.

\section{Secondary Education}

It will not take long to describe what has been, and is even to-day in France the professional preparation of our teachers in secondary public education. There has been none; there is hardly any now. Our professors supply this deficiency in part by a knowledge, talent, and superiority which raise them above their task. But they are for the most part indifferent, if not hostile, to pedagogy, as though it were a kind of professional apprenticeship. And yet they are provided with degrees or professional titles, while many of them have passed through the higher ${ }^{1}$ normal school. But there is no true professional training required either of the professor or of the instructor. The normal school founded in 1808 for the future teachers of secondary education soon abandoned, if indeed it ever fulfilled, its pedagogic rôle. Its destiny and crowning distinction consisted in the fact that during the whole of the nineteenth century it was to be the real school for higher education. It took the place of the universities which failed in the performance of their duty. But it became increasingly disloyal to the purposes for which it was established. Although occasional unsuccessful attempts were made to remind it of its duty, these efforts were put forth for the most part during the progress of some political reaction with a view to discrediting the institution, all of which was by no means calculated to restore any of its lost prestige to pedagogy. So that the higher normal school became a sort of rallying-point for the opposition to all normal school instruction. "It is useless to learn to teach," said one of its directors; and one of its most distinguished teachers recently ridi-

${ }^{1}$ This title (higher) was given to the school in 1849 , when an unsuccessful attempt was made to establish normal schools for secondary education throughout France. 
culed the study of the mental processes of children, declaring that the young graduates of twenty-two know infinitely more of child nature than the specialists who devote their time to its investigation.

It should be added, however, that a period of apprenticeship in teaching, either before or after graduation, has been repeatedly prescribed. The period which followed graduation embraced nothing in the way of pedagogy and was a mere matter of form. The other was required of normal students, then extended ten years ago to all students receiving scholarships. This is the whole extent of their professional preparation, which has been cut down to the necessity of teaching one or two weeks in a high school.

Even until recently the professor who received the apprentice, while he did not refuse him his advice, was charged with the duty of merely judging his work, not of directing it; in many eases he was present only at the last recitation. Moreover, this period of apprenticeship was not, and is not yet, generally accepted with good grace, either by the apprentice himself, by his university teachers, or by the high-school professor. Each of them sees in it merely a hindrance to his ordinary work and an interruption of his daily habits. It is easy to see that any idea of a betterment of the system was thwarted by the very burdensomeness of the system itself. The progress in pedagogical ideas, an acquaintance with the methods in vogue abroad, our own primary and normal school system, the crisis in secondary education itself - all these factors have served to make more necessary some change for the better in our secondary school system. The Paris International Congress of 1900 demanded it. The parliamentary investigation which preceded the reforms of 1902 reached the same conclusion in the matter. It was decided, announced, proclaimed, that we were to have an organized system of professional preparation for our teachers of secondary education; that the higher normal school, restored to its original purpose, was to become an institution devoted to pedagogy. So much for what has thus far been accomplished. The question has not yet been raised in reference to teachers in academies and to the master of arts degree nor in regard to teachers in the high schools for girls. As for requirements, as an agrégé, after an inquiry and various plans for reform, we have continued to think that pedagogy had nothing to do with the matter, and that a professor had no need of knowing the philosophy of education or the psychology of the child, or the theory and history of methods, or the methods employed abroad. There has been merely an extension to all agrégé requirements of the rules adopted in reference to history. These provide for "two kinds of examinations: first, examinations covering the general principles of the subject, undergone before the several university faculties and the normal 
school; second, professional examinations undergone before examining boards appointed by the Minister of Education." But the programme of these tests embraces nothing of a professional nature. Doubtless the questions selected for discussion are taken from the high-school courses, but there is nothing to indicate that they will be treated as in a high-school recitation and that there will be any change in the established traditions. Meanwhile everything of a professional nature that can be positively counted upon is the provision that candidates must have passed a period of apprenticeship in the high school " under the conditions laid down by the regulations." These regulations, and this entire organization, are still in the future, and it remains to be seen whether the apprenticeship will have practically any positive sanction. In the matter of modern languages professors in the Paris high schools have been requested to deliver some lectures before their apprentices on pedagogical subjects. The inspectors general of modern languages and physics have likewise explained in similar lectures to the teachers already engaged in actual work the new methods which they desire to have employed. Finally, some few universities for some years past have begun to attach a little more importance to the apprenticeship of their students on a scholarship in the high schools and have tried to organize a system of coöperation on the part of the high school and university.

Interesting as such attempts may be, they are, after all, unsubstantial in character, vague and shadowy in outline. Half-hearted plans that may amount to nothing, they look forward to clearly defined, adequate courses of study to render them successful. They take no positive ground either for or against systematic preparation for teaching. I may then be allowed in this connection to show briefly what seems to be possible and desirable in the way of realization in our own country of that reform which has already been accomplished elsewhere. If we are backward, at least we may profit by the experience of others and construct anew. The underlying principle I shall not attempt to discuss. To those who still believe that our future professors have nothing to learn of the theory or practice of teaching, that they will discover everything by their own genius and without injury to the pupils intrusted to their training, that one can always impart successfully to whomsoever he pleases the knowledge that he himself has acquired - to such misinformed and belated opponents of pedagogy there is nothing further to be said after all that has been said.

If the State competitive examination (agrégation) and the master of arts degree (licence) should be evidence of fitness to fill a position in our secondary schools, they naturally demand tests, both equally necessary, in the theory and practice of teaching. Without theory 
practice becomes routine; without practice theory remains a barren abstraction. The function of the university is to impart instruction in the theory and science of teaching; but it can do nothing on the practical side, for it lacks proper experimental material in the way of pupils. On the other hand, the high school, on which devolves the duty of providing the practical apprenticeship, is not adapted to working-out the theory of teaching. Equally inadequate, it seems to me, would be the introduction either into our high schools or universities of the German seminar system. Theory and practice both have their proper functions; there should be no confusion or conflict between them. With which then should we begin? With the theory? But students take little or no interest in the solution of purely theoretical questions unless they have already had to do with the practical side, the side which presents concrete examples and illustrations and suggests problems. In medicine one is interested in medical courses only after some actual experience in the sick-room. Shall we then commence with the practical side? But the apprentice will fail to derive from his apprenticeship all the advantage which he should if he lack the theoretical knowledge requisite to understand its meaning, its value, its very insufficiency. There is but one solution of the problem: theory and practice, instead of following one after the other, must go hand in hand, working on parallel lines, each vitalizing or enlightening the other. This is the plan suggested by the faculty of letters in the University of Lyons. ${ }^{1}$

Candidates for positions as teachers would pass a period of apprenticeship during the year preceding their entrance on the actual duties of their profession. Theoretically it would be advisable that this period should last one year, and that it be placed after the requirements for agrégation, or for the licence in the case of those who do not wish to go further. Practically, however, we should have to be satisfied at least temporarily with one semester of apprenticeship, to be combined with the last year's study, as a requisite either for agrégation or, in the case of those who have decided not to attempt agrégation, as a requirement for a licence. All these candidates would then be brought together for their apprenticeship in the high school, where the agrégés and holders of a licence could be taught separately. This arrangement would certainly be feasible for the university courses in pedagogy, some of which would fortunately foster a closer relationship with the students preparing for primary work. The work might be mapped out like this.

First, in the University. Here all candidates would receive instruc-

${ }^{1}$ There is no difficulty in applying this principle in the universities outside of Paris equally as well as in that city. The University of Paris has its normal school - the old higher normal. It is fair that the other universities should have theirs as well, in each of which might be gathered all candidates for instruction in the art of teaching. 
tion in the general science of teaching. One lecture a week would be sufficient to cover the ground. The subject-matter of the lectures would embrace a discussion of these topies: general philosophy of education, psychology of the child; general methods of teaching, education, and discipline; outline of the history of pedagogy and the methods employed abroad. Moreover, it is to be hoped that in each particular department some professor will undertake to deliver a course of lectures setting forth, if not the present approved methods of instruction, at least what they have been in the past and what is their status abroad. There might also be an elementary course in school hygiene, and finally a few lectures on the rights and duties of the officials, charged with the superintendence of secondary education. The professor of pedagogy might also arrange for a series of visits to primary or normal schools. The completion of this university course would best be marked by granting a diploma for pedagogical studies, the requirements for which would embrace first, an essay on some question connected with the course of study; second, an oral discussion and examination on the same topic. In place of these tests, however, might be advantageously substituted a short period of residence in some foreign country, to be devoted to a study of its educational system and a formal report thereon.

Second, in the High School. Here the apprentices would be intrusted, according to the special branch that each was studying, to the particular care of professors who would receive for their extra work of supervision a fair compensation. Each professor could supervise the work of from four to, at most, six students, who would be handed over to him by one of his colleagues in the university. He would be free to map out as he pleased the work of this group of students, but would not fail to have them conduct a certain number of classes and do similar practical work. The coöperation between university and high school in the theory and practice of teaching would be more complete and effective if the university professor should happen to hear two or three of the classes intrusted to his students. From time to time the apprentice might be present at the classes and in departments of instruction other than those in which he was specializing and might even inspect some of their recitations. The carrying out of this part of the programme would naturally devolve upon the principal, who also would give instruction on the organization and general direction of studies and discipline. In a word, our future professors would learn to know the life of the school and to take an interest in it before participating themselves in the common work. The results of this practical apprenticeship would be attested by a series of reports submitted by the principal, by the high-school professor, by the university professor, 
and finally, by the apprentice himself, whose views would not fail to be of interest. ${ }^{1}$

Thus will be fostered in a perfectly natural way among our high school and academy professors, by the scientific study of pedagogy, and by practical initiation into the art of teaching, that pedagogic spirit without which the best regulations and printed rules must remain useless and which would dispense with the necessity of many such rules and regulations.

\section{Conclusion}

Important, indeed, then, in its bearing upon our primary education, especially so for our secondary education, is the reform in question. Its underlying principle is the necessity of giving to pedagogy its proper place in the training of teachers and educators. In and of itself it will not be sufficient; it will never take the place of genius nor do away with the necessity of talent on the part of the teacher, but it will render both fruitful in results, and eliminate many a mistake and error. For the type of pedagogy to which we refer must be at once scientific and inspiring, suited to the instruction and upbuilding of enlightened minds, not dogmatic, mechanical, slavish.

In all this programme that I have attempted to outline nothing seems to me a more essential feature than the study of the organization and methods in vogue in foreign schools. Among the innovations that I hope to see adopted, none seems to me more fruitful of good results than the creation of scholarships for travel and residence abroad for pedagogic purposes. It is well for our future educators to broaden their mental horizon by seeing other countries than their own, not with a view to forgetting it, but the better to understand and to serve it by bringing to its aid the benefit of what they may have learned elsewhere. Is not this the thought that has brought here such a goodly number of educators, and is not this the firm conviction which this Congress is destined to leave in the minds of all who have had the pleasure of attending its sessions?

1 This system was adopted this year at Lyons by the University and by the High School. 

SECTION E-THE LIBRARY 



\title{
SECTION E-THE LIBRARY
}

\author{
(Hall 12, September 22, 3 p.m.)
}

Chairman: Mr. Frederick M. Crunden, Librarian, St. Louis Public Library.

Speakers: Mr. William E. A. Axon, Manchester, England. Professor Guido Biagi, Royal Librarian, Florence.

Secretary: Mr. C. P. Pettus, Washington University.

IN opening the Section of The Library, Mr. Frederick M. Crunden, Librarian of the St. Louis Public Library, and Chairman of the Section, spoke as follows:

"The Louisiana Purchase Exposition is an epitome of "the life and the activity of the world - from the naked Negrito to the grande dame with her elaborate Paris costume; from the rude wigwam of the red Indian to the World's Fair palace filled with the finest furniture, rugs, and tapestries, sculpture and painting and decorations that the highest taste and finest technique can produce; from the monotonous din of the savage tom-tom to the uplifting and enthralling strains of a great symphony orchestra; from fire by friction, the first step of man beyond the beast, to the grand electric illumination that makes of these grounds and buildings the most beautiful art-created spectacle that ever met the human eye. And to all this magnificent appeal to the senses are superadded the marvels of modern science and its applications; the wonders of the telescope, the microscope, and the spectroscope; the telegraph in its latest wireless extension; the electric motor and electric light; the telephone and the phonograph; the Roentgen ray, and the newfound radium.

"And now after this vision of wondrous beauty, this triumph of the grand arts of architecture and sculpture and landscape - of all the arts, fine and useful - has for six months enraptured the senses of people from all quarters of the globe, the learned men of the world have gathered here to set forth and discuss the fundamental principles that underlie the sciences, their correlations, and the methods of their application to the arts of life, - to summarize the progress of the past, to discuss the condition of the present, and attempt, perhaps, a forecast of the future.

"In the scheme of classification, so comprehensive and wellordered as to be in itself an achievement, our subject appears in the last department that concerns itself with man's purely mundane affairs, and is the last section in that department. It thus appears properly as a climax and summary of the arts and sciences intelligible to man in his present stage of existence; and if the problem of 
the future life is ever solved this side of the grave, the knowledge conserved and disseminated by the library will be the starting-point and the inspiration of the advance, as it has been of all progress since the art of written speech was invented. "The library is the reservoir of the common social life of the race. It is at once the accumulator and the transmitter of social energy.' Without the library the highest social culture is impossible; and a most moderate degree could be achieved by very few.

" Under the main division, 'Social Culture,' the Library is one of the five sections in the Department of Education. In education are summed up all the achievements of the past and the possibilities of the future. In the words of Wendell Phillips: 'Education is the one thing worthy the deep, controlling anxiety of the thoughtful man.' 'Education,' exclaims Mazzini, ' and my whole doctrine is included and summed up in this grand word.' It is practically a truism that Jules Simon utters when he says, 'Le peuple qui a les meilleures écoles est le premier peuple; s'il ne l'est pas aujourd'hui il le sera demain.'

"Under this Department of Education, with its grades, the School, the College, and the University, the Library is assigned the last section. It belongs there in chronological order of development as an active factor in popular instruction and enlightenment; and furthermore, the presentation of its claims and functions comes naturally after those of the other factors in education, because it is an essential coadjutor and supplement to each and all. It is a summary and a climax. There have always been libraries, and they have always been a factor in education; but the public, free, taxsupported library is but just a half-century old, and could hardly be considered out of the long clothes of infancy till the year 1876, while its general acceptance as an essential supplement to the public school and a coördinate factor with the college and university may be considered the accomplishment of the last decade. This acceptance, however, is not yet universal. There are still teachers who look on general reading as an interierence with school work and an extra burden on their shoulders.

"We start, then, with the axiomatic proposition that all human progress depends on education; and no elaborate demonstration is necessary to show that the library is an essential factor in every grade of education.

"Higher education, certainly, cannot dispense with the library. The well-known dictum of Carlyle- 'The true university of modern times is a collection of books ' - was accepted as a striking statement of a man with the rhetorical habit, without, perhaps, a realization of its full significance. It has been recently expanded into a more express and specific tribute to the importance of the library in 
university education. In an address delivered in St. Louis and afterwards published in the North American Review, President Harper said:

" "The place occupied by libraries and laboratories in the educational work of to-day, as compared with that of the past, is one of commanding importance. Indeed, the library and the laboratory have already practically revolutionized the methods of higher education. In the really modern institution the chief building is the library. It is the centre of the institutional activity. . . That factor of college work, the library, fifty years ago almost unknown, to-day already the centre of the institution's intellectual activity, half a century hence, with its sister, the laboratory, almost equally unknown fifty years ago, will have absorbed all else and will have become the institution itself.'

"As to the value of the library in elementary education, Doctor Harris says:

" What there is good in our American system points toward this preparation of the pupil for the independent study of the book by himself. It points toward acquiring the ability of self-education by means of the library.'

"I might quote similar utterances from many other eminent educators as to the value - the necessity - of the library in early education; but I can think of no stronger summing-up of the subject, nor from higher authority, than this statement from President Eliot: 'From the total training during childhood there should result in the child a taste for interesting and improving reading, which should direct and inspire its subsequent intellectual life. That schooling which results in this taste for good reading, however unsystematic or eccentric the schooling may have been, has achieved a main end of elementary education; and that schooling which does not result in implanting this permanent taste has failed. . . The uplifting of the democratic masses depends on this implanting at school of the taste for good reading.'

"To persons who have given little thought to educational questions these utterances will have the weight that attaches to the highest authority; but we need no university president nor national commissioner to tell us these facts. We have learned them from our own experience; and enlightened as we now are, it seems to us strange that question could ever have been raised as to the essential character of the library in elementary education. Yet there are some of us, I am sure, who can recall painful consequences from putting into practice an educational theory not generally accepted by the pedagogues of our childhood days.

"We know that higher education is impossible without a library, for the library is the storehouse of the world's knowledge, the record 
of humanity's achievements, the history of mankind's trials and sorrows and sufferings, of its victories and defeats, and of its gradual progress upwards in spite of frequent fluctuation and failure. In this chronicle of the past lie lessons for the present and the future; from the lives of storied heroes comes the inspiration that leads the race onward and upward. A university without a library would of necessity have a very small and weak faculty - only the few professors who could be induced to go where the most important instrumentality of their work was lacking; the university that has an adequate library includes in its faculty the professors of all other universities and all the great teachers of all countries and ages.

"But is it worth while to consider a university without a library? Can there be such an institution?

"In higher education, then, the library is a necessity. In elementary and secondary education it is no less essential, if the most is to be made of the few years that the average child spends in school and if he is to be started on a path of self-culture. On this point Stanley Jevons says: 'In omitting that small expenditure in a universal system of libraries which would enable young men and women to keep up the three $R$ 's and continue their education, we spend $£ 97$ and stingily decline the $£ 3$ really needed to make the rest of the $£ 100$ effective.'

" At the International Library Conference in London, in 1897, one of the most distinguished American librarians, who has been an administrator in a large educational field outside of the library, expressed his view of the supreme importance of the library in a scheme of popular education by saying that if he had to choose between the public school and the public library - if he could have only one (though the alternative is one that never will nor can be presented), he would keep the library and let the school go. For, he argued, every child would learn to read somehow, and, with a free library that actively sought him, he would be better off than if he had a school to teach him to read, but no books to read after he had learned. But however divergent might be opinions regarding this impossible alternative, there is no doubt that the public library, with enlarged functions and activities, has at least equal potentialities with the school. Whether the formal instruction of the school or the broader education of the library is of greater value, depends on what is the chief aim. If it is merely to make breadwinners, the school may be the more useful, though in this, too, the library is an efficient coadjutor; but if our purpose is to make men and women, citizens of a progressive nation, active members of an aspiring society, the library may fairly claim at least equal rank with the school. For the school wields its direct influence over the average child but a few years; the library is an active influence through life. 
"Again, more than ninety-five children out of every hundred leave school before they are sufficiently mature to comprehend those studies which open their eyes to the universe, which bear upon their relations to their fellow men, upon their duties as citizens of a state, as members of organized society. These are the studies that deal with the most important problems that mankind has to solve. They cannot be taught to children; they cannot be taught, dogmatically, at all. They involve the consideration of burning questions, subjects of bitter controversy - the world-old battle between conservatism and innovation, which, as Emerson says, 'is the subject of civil history.' They cannot be taught by any teacher; they cannot be taught by any text-book or by any one book. Their adequate consideration calls for the reading of many books - books of the present and the future as well as of the past. The electrician. who allowed himself to be guided by the treatises of twenty years ago would have no standing; neither has the economist or sociologist who has not kept up with the literature of the last thirty years or the last three years. It would be of no particular advantage for all of us to be electricians. We can safely trust that field to experts; but it is extremely desirable that every man should comprehend the great issues of economics and politics. The school cannot even present the important problems of sociology; the university cannot adequately do so without the library. On no other subject is the wide reading that Matthew Arnold enjoins so necessary. And no other subject is of such momentous importance to mankind; for the betterment of social conditions is a necessary forerunner and foundation of moral and religious progress. And that cannot be true religion which does not lead to social betterment. In that noblest aspiration ever put into the mouth and mind and heart (too often, alas, only the mouth!) of man we are taught to pray not that we may be transplanted to a better world, but that God's kingdom may come and his will be done in this world.

"We are not likely to abate our eagerness in the pursuit of knowledge of physical science, for the zeal of the scientist is stimulated by the spur of commercialism; and, though it seems impossible, the twentieth century may bring forth as wonderful discoveries and inventions as the nineteenth. But, to take the advance just now most sought, can any one raise the question as to which would be of greater benefit to St. Louis, to reach Chicago in an hour by air-ship or to take six or ten hours for the trip and find there - and everywhere - a contented body of workmen supplying us with the necessities of life and a set of managers carrying on the transportation system that we already have on equal terms to all people? What the world's progress most needs is 'evening up.' The advancing column presents a very ragged front, with physical science 
and its applications so far ahead that they have almost lost sight of social science in the rear. It would be no great disadvantage to the world - to the progress of mankind as a whole - if the swiftfooted legion of applied science would merely mark time for a period, while attention should be given to a better organization of the vast human army. The objective point would be reached as soon, for a nation is like a railway train, it can go no faster than its hindmost car. But this is not likely to happen at present. Applied science has every stimulus from within and without, every reward intrinsic and extrinsic; while progress in the social and political sciences must carry the dead weight of the inertia of conservatism and also meet the active and intense opposition of vested interests, which have ever the single purpose of preserving the status quo, no matter how unjust or maleficent.

"The solution of these all-important problems cannot be found in the school, where immature minds are taught merely how to use the tools of knowledge; these questions cannot be settled by the small number of university students; they must be solved by the social education of the masses, by instilling in them in their early school years a desire for knowledge and a love for good reading, which will lead them to continue their education by means of the library. The education of the mass of the voters, who determine the character of a democratic government, must not be left to the party organ or the stump-speaker. The great social and political questions should be studied and pondered in the quiet of the closet and not decided, without previous thought, amid the hurrahs of the hustings.

"To make the public library realize fully its possibilities as the People's University calls for more than the opportunity which every public library now offers; it requires active effort to reach out and bring the people to the library by the fullest coöperation with the school and by means of attractive lecture courses, which shall stimulate reading and guide it in profitable channels. But the beginning of this work - the inculcation of a taste for good reading lies with the school, with the library's coöperation, especially during the years from six to ten or twelve, those years when nearly all the children come under the school's influence and when the habit of reading can be most easily formed.

"If charged with placing undue stress on the value of the library, I might urge its comparative newness and its consequent lack of recognition; and as an evidence of the latter I might point to the fact that in this great educational exposition, while one vast palace is given up to exhibits of the school, the library has with difficulty secured, through the courtesy of the Missouri Commission, a part of a room in the State Building for an exhibit of its activities in the great work of education, in which, as I am trying to show, its poten- 
tialities are as great as those of the school. As our Board of Directors said, in its appeal to the Exposition Directors for a separate library building: "The library, besides being the most efficient and most economical agency for popular education, represents all the Fair will have to show. It stands for the sum total of human knowledge. It is the instrumentality through which knowledge has been conserved and cumulated. Only through the library can civilization continue to advance. Books are the most potent factors in progress. Without books we should have had no powerful locomotives to show, no wireless telegraphy, no wonder-working machinery, no beautiful buildings, no impressive statuary, no paintings to arouse wonder and yield delight, no World's Fair to draw distinguished scientists and educators from all over the world.'

"By way of introduction to the comprehensive addresses of the two distinguished delegates who have traveled four or five thousand miles to lay before this section, and, through publication, before

- the world, the past history and the present problems of the library, it has seemed to me appropriate that, as chairman, I should present a brief plea for the consideration of the library as one of the greatest factors in human progress. It has existed, though not in its present form or with its present functions, from the dawn of recorded civilization. It is itself the record of civilization, and without it there can be no records and no civilization. It is the repository, the custodian, the preserver of all the arts and sciences, and the principal means of disseminating all knowledge. With the school and the church it forms the tripod necessary to the stable equilibrium of society. Let me briefly summarize the functions of the public library.

" (1) It doubles the value of the public school instruction, on which is expended more than ten times the cost of the library.

" (2) It enables the children who leave school at an early age (an overwhelming majority) to continue their education while earning their living. It provides for the education of adults who have lacked, or failed to utilize, early opportunities. This is of special importance in a country like the United States, where one of the greatest political problems is the assimilation of a vast influx of ignorant foreigners of all races and languages.

" (3) It supplies books and periodicals needed for the instruction of artisans, mechanics, manufacturers, engineers, and all others whose work requires technical knowledge ${ }^{1}$ - all persons on whom depends the industrial progress of the community.

"(4) It furnishes information and inspiration to ministers, teachers, journalists, authors, physicians, legislators - all persons on

\footnotetext{
${ }^{2}$ The information furnished by a book in the Cincinnati Public Library once saved that city a quarter of a million dollars. This, in numerous instances, but on a smaller scale, is a part of the every-day work of every library.
} 
whose work depends the intellectual, moral, sanitary, political, and religious welfare and advancement of the people.

" (5) It is the stimulus and the reliance of the literary and study clubs which, especially among women, have done so much not only for individual self-culture but also for civic enlightenment and social betterment. This represents its numerous post-graduate courses, which are taken by constantly increasing numbers.

" (6) It has philosophers and theologians to explain and expound and to exhort those who are willing to listen; but, far better, it has poets and dramatists and novelists, who compel a hearing and impress on heart as well as mind the fundamental truths of morality and religion.

" (7) It is also a school of manners, which have been well defined as minor morals. The child learns by example and by the silent influence of his surroundings; and every visit to a library is a lesson in propriety and refinement. The roughest boy or the rudest man cannot fail to be impressed by the library atmosphere and by that courtesy which is the chief element in the 'library spirit.'

" (8) It imparts, as the school cannot, knowledge of one's self and of one's relations to one's fellow man, and thus prepares the individual for citizenship and fellowship in organized society and leads him to be an active force in social advancement.

" (9) It elevates the standard of general intelligence throughout the community, on which depends its material prosperity as well as its moral and political well-being.

“(10) But not last, if an exhaustive list were aimed at, - nor least, it supplies a universal and urgent craving of human nature by affording to all entertainment of the highest and purest character, substituting this for the coarse, debasing, demoralizing amusements which would otherwise be sought and found. Further, it brings relief and strength to many a suffering body, and cheer and solace to many a sorrowing heart. It is instruction and inspiration to the young, comfort and consolation to the old, recreation and companionship to all ages and conditions.

"I close as I began.

"Education is the greatest concern of mankind; it is the foundation of all human progress. The library is an essential factor in all grades of education; and it is the agent plenipotentiary in the betterment of society and the culture and cheer of the human soul.

" "The highest gift of education is not the mastery of sciences, but noble living, generous character, the spiritual delight that comes from familiarity with the loftiest ideals of the human mind, the spiritual power that saves each generation from the intoxication of its own success." 


\title{
THE LIBRARY IN RELATION TO KNOWLEDGE AND LIFE
}

\author{
BY WILLIAM EDWARD ARMYTAGE AXON
}

[William Edward Armytage Axon, Member of the Literary Staff of the Manchester Guardian, Manchester, England, from 1874 until his retirement in 1905. b. Manchester, England, January, 1846. Self-educated. LL.D. Wilberforce, 1899. Deputy Chief Librarian, Manchester Public Libraries, 1874; one of the founders of the Library Association of the United Kingdom; Bibliographical Society; and Past President of Lancashire and Cheshire Antiquarian Society; Chairman of the Salford Museum and Libraries Committee. Author of many books and articles on the library, and also editor of several journals.]

If the most accomplished and most enthusiastic librarian in the world were possessed of Aladdin's power and summoned the Spirit of the Lamp, not to build a gorgeous palace for his beloved princess, but to erect an ideal library for the benefit of the world, what would it be likely to contain?

The dream library, standing in its fair pleasance, a structure beautiful and spacious, of ample proportions and conveniently arranged both for study and recreation, what would the Magician Librarian desire to place upon its myriad shelves? The library is an instrument of culture, of research, of moralization, and, as the record of human effort and aspiration, touches learning and life at every point. The ideal library would form a complete narrative of the past history of mankind, a record of all that men have found out or surmised about the physical facts of the universe, from the giant worlds that roll in space to the tiniest insect that can be detected by the strongest microscope; all that men have thought about that which has not material form; all that poet and sage, teacher and prophet, have said about ethics; all that men have invented and devised for the arts and pleasures of life; in short, all the documentary evidences of human activity since the advent of man upon the globe. Such a library never has existed and never can exist, but it is the ideal archetype to which all libraries, consciously or unconsciously, seek to approximate. Even in Utopia such a mass of literature, good, bad, or indifferent, would be impossible, for it would embrace all that human wisdom and human folly has ever intrusted to the recording word. Physical and financial considerations impose upon all existing libraries the necessity of selection, but the ideal library would be all-embracing and include all the literature of every land and of every science. Would the ideal library include "trash"? Must everything be preserved? Such inquiries are natural enough in an age when the printing-press vomits forth by day and night much that the sober-minded could easily spare. But everything that comes from the human brain is an evidence of what the mind of man 
can accomplish, if not for wisdom, then for folly. The most stupid production that ever flowed from a pen is at least a human document. And who shall decide what is and what is not "trash"? The legendary dictum attributed to Al Moumenin Omar, who declared that whatever was opposed to the Koran was noxious and whatever agreed with its teachings was unnecessary, a dictum at once practical and thorough, has not earned either the assent or the gratitude of posterity. Sir Thomas Bodley, the munificent founder of the Great Oxford Library, a learned man and a friend of learning, excluded plays and pamphlets from his great collection as mere " riff raff." He thus missed the opportunity of making a matchless collection of Elizabethan literature, and of furnishing to future ages the material for solving many of the problems that now perplex the student of the most glorious period of English literature. To Bodley the plays of Shakespeare as they came singly from the press were "trash," and he died before they were collected into the goodly "first folio." That the friends as well as the foes of learning can make such enormous blunders may give us pause in the effort to decide what is unworthy of preservation. "What," asked Panizzi, " is the book printed in the British dominions . . . utterly unworthy of the place in the National Library?" And he tells of a British library that was entitled to books under the copyright law and that solemnly rejected Scott's Antiquary, Shelley's Alastor, and Beethoven's musical compositions as unworthy of a place upon the shelves. Everything that has come from the human mind has a certain value. True, its value may be pathological, an evidence of mental or moral aberration, but pathology is an important department of science, and in the midst of its sadness, pathetic or grotesque, blossoms the flower of hope. The historian can usefully illuminate his annals by citations from the trivial and ephemeral literature of the period of which he writes. A ballad will express the feelings of the multitude, at least as clearly and as truthfully as a dispatch will exemplify the designs of ambassadors or kings. ${ }^{1}$ A volume valued as theology in the fifteenth century may now be highly treasured, not for its literary contents, but as the handiwork of an early printer. That which was once thought to be sober science may now be folklore, but it is still a matter for investigation.

The intimate nature of its relationship to the whole range of human knowledge and human conduct becomes evident when we realize fully that the essential note of the library is universality. All that relates to Man and the Universe in which he has his place it is the function of the library to remember. There we ought to find all

${ }^{1}$ An admirable paper on "The Idea of a Great Public Library" appears in the Library Association Record for April, 1903, from the pen of Mr. Thomas W. Lyster, M.A., of the National Library of Ireland. 
that successive scientific investigators have taught us of his bodily structure and of the complicated processes by which the mystery of life is sustained; all that has been ascertained of the changes that follow when the silver cord is loosed and the golden bowl is broken and the dust returns to the earth as it was. There we should be able to read the history of the races of men since the first dawn of human life upon the globe; the struggle of man in his efforts for the conquest of nature; the horror and the heroism, the mixture of grandeur and grotesque in the crimes of conquerors, in the struggles of the enslaved; the rise and fall of empires; the transformation of savage tribes into civilized nations. And the library must record the painful evidence of degeneration from higher to lower types not less than those documents which convince us that

. . . Thro' the ages, one increasing purpose runs,

And the thoughts of men are widened with the process of the suns.

If it is the function of the library to preserve the records of man acting in the corporate capacity of clan or nation, not less so is it to keep account of those members of the race who, by the force of their individuality, stand out, whether for praise or reproach, from the common mass. Apart from its fascination as a picture of human life and character, biography has a practical value both as warning and incentive in the conduct of life. The library should conserve for us all that the thinkers have formulated as to the conduct of life, the rules for the guidance of the individual in his duties to himself, in his relations to his fellows, in the contact of man with man, in the laws and tendencies to be seen in his industries and commerce, in the relation of nation to nation, of race to race, of class to class. Nor is it of less interest to us to know the marvels of industry, the wondrous processes by which the properties and forces of the earth and of the universe are utilized for the service of man. The relation of man to nature, the secrets of bird and beast, of flower and tree, of all the myriad creatures, past and present, that make up the sum of the life of our world, these are to be noted in our ideal library. There, too, we must look for the record of all that can be ascertained and surmised of the countless worlds, moving in empyreal space, worlds beyond the sight of man, yet known though unseen. The library is the temple of art as well as of science, and in its open volumes we may gaze upon the glowing visions seen by Phidias, by Raphael, by Michelangelo, by all those who in many lands and climes have interpieted to their fellows the strength and harmony of nature and the beauty of the human form. The power of the artist is immensely increased by the possibility of reproduction and by the popularization of art in the library. That such reproductions can never convey all the beauty of the originals may be quite true, but whatever may 
evaporate in the process of transfer enough remains for pleasure and inspiration. There is an illustration of this in the pathetic reference to Raphael's Madonna Della Seggiola in Mrs. Gaskell's Cranford. ${ }^{1}$ A soldier's wife in India, whose previous children have died, tramps with her baby to secure a passage to England that the child may have a chance to live. She tells her story:

"And when Phobe was coming, I said to my husband, "Sam, when the child is born, and I am strong, I shall leave you; it will cut my heart cruel; but if this baby dies too, I shall go mad; the madness is in me now; but if you let me go to Calcutta, carrying my baby step by step, it will, maybe, work itself off; and I will save, and I will hoard, and I will beg - and I will die, to get a passage home to England, where our baby may live.' God bless him! he said I might go; and he saved up his pay, and I saved every pice I could get for washing or any way; and when Phœbe came, and I grew strong again, I set off. It was very lonely; through the thick forests, dark again with their heavy trees - along by the river's side (but I had been brought up near the Avon in Warwickshire, so that flowing noise sounded like home) - from station to station, from Indian village to village, I went along, carrying my child. I had seen one of the officers' ladies with a little picture, ma'am, - done by a Catholic foreigner, ma'am, - of the Virgin and the little Saviour, ma'am. She had him on her arm, and her form was softly curled round him, and their cheeks touched. Well, when I went to bid good-bye to this lady, for whom I had washed, she cried sadly; for she, too, had lost her children, but she had not another to save, like me; and I was bold enough to ask her, would she give me that print. And she cried the more, and said her children were with that little blessed Jesus; and gave it me, and told me she had heard it had been painted on the bottom of a cask, which made it have that round shape. And when my body was very weary, and my heart was sick (for there were times when I misdoubted if I could ever reach my home, and there were times when I thought of my husband, and one time when I thought my baby was dying), I took out that picture and looked at it, till I could have thought the mother spoke to me, and comforted me."

The library should garner all that shows the development of the religious spirit. No manifestation of man's reaching out to the infinite, however ineffectual or however sordid, is to be despised. "Where others have prayed before to their God in their joy or in their agony is of itself a sacred place." 2 The speculations of philosophers as to the contents and methods of the human mind, its powers and its limitations, should find a place in the library. Nor should the song of the poet or the fiction of the story-teller be excluded.

${ }^{1}$ Gaskell's Cranford, chap. xI.

${ }^{2}$ Ibid. 
That fiction responds to a need of human nature may be safely inferred from its universal popularity. A great critic has styled poetry " a criticism of life," and the phrase may with at least equal justice be applied to nearly every variety of fiction, whether in verse or prose, and whether it take the form of novel, romance, drama, or apologue. For every work of fiction, great or small, shapeless or artistic, wise or foolish, is the author's solution of some problem of existence, presented to his mind as the result of experience or of vision. The hackneyed but beautiful Terentian phrase applies to the library, which aims at being the record of Man, and therefore finds nothing alien or out of place that relates to Man and the Universe which environs him. Well has Matthew Arnold said:

Look, the world tempts our eye,

And we would know it all!

We map the starry sky,

We mine this earthen ball,

We measure the sea-tides, we number the sea-sands;

We scrutinize the dates

Of long-past human things,

The bounds of effaced states,

The lines of deceased kings;

We search out dead men's words, and works of dead men's hands;

We shut our eyes and muse

How our own minds are made,

What springs of thought they use,

How righten'd, how betrayed -

And spend our wit to name what most employ unnamed.

But still, as we proceed,

The mass swells more and more

Of volumes yet to read,

Of secrets to explore.

Centuries ago, Michael the Bishop spoke with enthusiasm of the Book of the Wise Philosophers, a sort of miniature library in one volume." "In this book," he says, " are gathered together many discourses of exhortation and doctrine. This book gladdens the heart and increases the understanding of the intelligent. In it the wise philosophers have told of noble and of famous deeds. It contains the wisdom of the wise and the pronouncements of the learned. It is a light of inquiry and a lamp of understanding. There is in it a chain of profit, and it is to be preferred to gold and silver and to precious stones. It is fairer than the flowers of the garden. What garden can be compared to it in the fairness of its aspect and in the

${ }^{1}$ The book was a translation in Ethiopic from the Arabic. A German version by $\mathrm{Dr}$. C. H. Cornill appeared in 1875 and is described in The Library, October, 1903, by the present writer. 
fragrance of its scent? And this garden can be carried in the breast and sheltered in the heart. And this book can make thy understanding fruitful, and God the Almighty may enlarge thy understanding, and make thee to know many things, and make thy character noble, and give increase in all talents. . . . And it is an eloquent although a dumb and silent monitor. If thou have not gained aught else from its preference, has it not kept thee from sitting with fools and from communing with the wicked? This book is a great inheritance for thee, and a shining glory, and a beloved brother, and a faithful servant, and a joy-bringing messenger." If a small ethical manual thus impressed the wisdom-loving Michael, what would he have said to a great modern library with its storehouses of all that the human mind has wrought for instruction and delight?

" Knowledge grows from more to more," and in the midst of its immense and bewildering variety we are gradually feeling towards a sense of unity. There may be unity in diversity as there may be progression by antagonism. When the Royal Society was established in 1662, its aim was declared to be " the promotion of natural knowledge," the intention being, presumably, in the interests of peace, to exclude all that relates to the spiritual faculties as supernatural and beyond the scope of research. Some at least of the later academies wisely avoid such limitations and deal with all subjects that can be dealt with from the point of view of scholarship. The Smithsonian Institution, that remarkable gift from a son of the Old World to the sons of the New World for the benefit of both hemispheres, was founded for the "increase and diffusion of knowledge among men." Is there a better definition of the function of the library? The ideal collection of books knows no limitations of subject, but takes all knowledge for its province. It certainly does not exclude theology. A large library building would not hold all that has been written about the Bible alone. A small one might be filled with the printed material relating to Thomas à Kempis and his Imitation of Christ. The "Poet at the Breakfast-Table" supposed his neighbor to be an entomologist, but the man of science was too modest to claim that title. Often spoken of as a coleopterist, he was content to be a scarabæist. "If I can prove myself worthy of that name," he said, "my highest ambition will be more than satisfied." Every specialist knows how great his own subject is, how extensive its literature, how difficult, if not impossible, to bring together all the facts and speculations of those who have preceded him in the investigation of the little corner of chaos that he is striving to reduce to cosmic order.

If, then, the librarian could summon the Spirit of the Lamp to create the ideal library, its main characteristic as a collection of books would be its universality. The ideal library may have stood in one 
of Eden's happy vales, and since then the children of Eve, and especially those of them who are librarians or book-lovers, have sighed for this lost paradise of thought and knowledge. Certain it is that since the fall of man the Bibliotheca Universalis has never taken material form, and as the years widen the circle of knowledge it recedes further and further into the land of dreams and the speed at which it retires increases, so it would seem, with each new generation. The first edition of the Encyclopredia Britannica appeared in 1771, and filled three quarto volumes. In a century and a quarter the three have grown to thirty-six. It is a significant fact that this period wherein the boundaries of learning have been so widely enlarged is also the period in which libraries, great and small, have increased with marvelous rapidity. It used to be an article of undergraduate faith that the Bodleian contained a copy of every printed book, but no library now, not even the largest, dare claim completeness in every direction, and huge specialist libraries have been created. But happily there is a constant stream of literature in which this specialist learning, in a condensed and quintessential form, finds its way to the general library.

The nearest approach to the ideal library is in the attempt to supply, with generous liberality, the literature of all lands and subjects, to be seen in the great national collections provided mainly at the cost of the state, though often enriched by the munificence of individuals. The British Museum is the most familiar type of such an institution, and may probably, alike in extent and in freedom of access, claim the premier position. France might possibly, in some respects, challenge the claim, and other European nations are proud of their vast repositories of literary treasure. In the Library of Congress, America, though later in the race than some of her compeers, is, with amazing energy, building up a great national library, and, happily unfettered by conventions, is working with a skill and individuality that insures success. But in the nature of things the newer institutions are at a disadvantage. No modern library can duplicate the treasures of the Vatican. Every great library rejoices in the possession of gems that are unique. Happily in these latter days the arts of exact and faithful reproduction have made it possible to have trustworthy facsimiles prepared. These simulacra can never have the interest of the originals, but they suffice for the purposes of scholarship and they have a further value as a precaution against the loss to learning that would follow from the accidental destruction of the originals. It is much to be desired that all manuscripts of great importance should be facsimiled. In this direction we may commend the action of Italy in the magnificent publication of the manuscript of her mighty son Leonardo da Vinci, who combined the talents of painter, poet, and engineer; whose well-stored 
mind seems to have contained all the learning of his generation, and whose prescient genius anticipated, in part, some of the great ideas of later generations. There is another function of national libraries. Their catalogues, so far as they are printed, should form a standard of excellence and be an important contribution, not only to the bibliography of the nation to which they belong, but also to that universal catalogue which haunts the dreams of students and librarians who, in our time, have taken such mighty strides toward this unattained ideal. When the first International Library Congress was held in London in $1877 \mathrm{I}$ urged the printing of the British Museum Catalogue of Printed Books, which then filled two thousand volumes of manuscript and was estimated to contain three million entries. There were, of course, many other advocates of the printing scheme both earlier and later. The task was declared to be impossible of execution. Yet it has been accomplished. The British Museum Catalogue of Printed Books is the best bibliography of English literature and it is also the largest contribution that has ever been made to the Universal Catalogue. The publication of the British Museum Catalogue has facilitated research and has sensibly raised the standard of accuracy. In spite of the general opinion that every man, and nearly every woman, is able to drive a dogcart, edit a newspaper, and make a catalogue, the accurate description of books is not an easy art to be learned without apprenticeship or effort. The youngest of the national libraries, if I may so style the Library of Congress, has made a novel and praiseworthy departure in the supply of printed catalogue title-slips to other libraries. This is one of several examples of economy by coöperation.

The printed catalogue of the British Museum is, as I have said, a mighty contribution to the Universal Catalogue. ${ }^{1}$ Every library seems fully occupied with its own special work, but there awaits for some national library or international office the task, not indeed of completing, for in the nature of things it can never be complete, but of greatly advancing the preparation of the Universal Catalogue. This could be done by the simple process of reducing to cards the printed titles of the books in the British Museum, and of incorporating with them, as opportunity served, the "Catalogue of Scientific Papers," and such special bibliographical works as might be approved or be available. All these ought, in theory, to be editorially revised in accordance with a code of rules, and I know of none better than those of the British Museum, which have the additional advantage of having served as the standard in the largest undertaking of the kind that the world has yet seen. And if absolute uniformity was not attained there would still be an immense advantage in the bringing together and arrangement of the multitude of

${ }^{1}$ See Dr. Richard Garnett's paper in The Library, v, 1903. 
references that could thus be made available for personal inspection or dispatch through the post. What has been said refers to an alphabetical catalogue, but there are also many subject-entries awaiting consolidation. The labors of Poole and his continuators and imitators, British and foreign, and the excellent Subject Index of Mr. G. K. Fortescue should here be named. The Institut International de Bibliographie announces that it has in its possession six and a half million of bibliographical references and that it is daily adding to its store. Millionaires who desire to advance literature and learning might find a useful employment for their money and energies in the task of facilitating rational efforts towards a general catalogue of all literature.

"If we think of it," says Carlyle, " all that a university, or final highest school can do for us, is still but what the first school began doing - teach us to read. We learn to read, in various languages, in various sciences; we learn the alphabet and letters of all manner of books. But the place where we are to get knowledge, even theoretic knowledge, is the books themselves! It depends on what we read, after all manner of professors have done their best for us. The true university of these days is a collection of books."

In this illuminating passage is the justification for insisting that universality is the true note of the library. No science can prosper without its aid. He who would add to the sum of knowledge must, as a preliminary, learn what is already known. He who devises what he hopes is a new invention must investigate, in fear and trembling, lest he has been anticipated. Even the mistakes of predecessors may be turned to account. The comparison of discordant views may suggest omitted considerations that will bring them into fruitful harmony. There is happily no finality in science.

Classification, even the most elaborate, useful and necessary as it is, can often only be approximate, and that only in a rough and ready fashion. One book may serve several purposes and may be placed with equal propriety in more than one part of the library. Thus the celebrated Lunar Hoax of Richard Adams Locke, which describes "wonderful" - and quite imaginary - discoveries in the moon, has certainly no scientific value, yet it is an interesting document in the history of astronomy, as it shows the condition of education which caused its impossibilities to be greedily swallowed by multitudes both in Europe and America. The tract itself is an amusing piece of mystification, and it has a literary interest from the fact that Edgar Allan Poe noticed it in his Literati, and institutes a comparison between its incidents and those in the story of Hans Pfaal. Knowledge is not an island but a continent, and, however strictly defined the capital may be, each kingdom has vague borderlands where one science merges into another. Literature cannot be 
hemmed in by exclusive boundaries of nation or race. The arrogant Western world owes its most cherished book, the Bible, a volume of many books in one, to the East, to the patriarchs and prophets of a race that lives only in exile from its fatherland - a race that, wherever it may be, powerful or oppressed, wealthy or mendicant, turns in prayer to the Holy City that is the symbol of its faith and hope.

It used to be said that an educated man was one who knew something of everything and everything of something. With the everwidening field of knowledge and observation it is impossible that a man should know even something of everything, and even the most devoted specialist, however minute his specialty may be, finds a difficulty in learning all that can be known of his subject. Thus arise opposite dangers of superficiality and narrowness. The library, whilst it should aid the researches of the specialist, should also help him to take broad views and to see even his own special work in its right proportion and true relation to other studies. To see things, not in sections but as a whole, is not the easiest duty of the student, but it is real and essential. A great library impresses this thought on the mind. Are you an astronomer? Has it been yours to feel the awe and wonder when "a new planet swims into the ken"? Your science may have begun when Eve, on the night of the expulsion, saw shining above the lost Paradise a star of hope. Thousands of men have devoted their lives to your study since the days, thousands of years ago, of the shepherd star-gazers on the Babylonian plains. It has a rich and extensive literature, but in the greatest library its hall is but one of many. Mr. Dewey allows it ten places out of a thousand in his Decimal Classification. So it is with every other department of learning. I do not know of a more remarkable bibliography than that contained in Dr. J. S. Billings's Catalogue of the Surgeon-General's Library at Washington. Sixteen volumes of a first series, eight of a second series, and more to follow, all filled with titles of books and papers written on the healing art. Looking on this great effort, we are as ready as Socrates to pay tribute to Esculapius. Yet medicine, like astronomy, is but one of the many departments of a great library. Universality is, as we have seen, an ideal impossible of realization. Not the less is completeness the watchword for every library - a rational effort to provide the best that is possible under the environing circumstances. Every library, however small, may aim at completeness in some direction and every true microcosm is a contribution to the macrocosm. And the ideas of universality and completeness become nearer of fulfillment by that spirit of coöperation which is happily becoming more and more common amongst librarians and amongst the large and increasing class of persons who are engaged, to use the fine Smithsonian phrase, in "the increase and diffusion of knowledge among 
men." Much has already been done, but doubtless there are still many ways in which the relations of the library, the school, the university, and the individual student may be improved. The possibilities of coöperation and serviceable help are practically illimitable. In the morning of life, when the direction of the student's energies are still undetermined, the resort to a library, with its inviting panorama of human learning, will often give the impulse to fruitful endeavor. Reverence as well as the desire for knowledge is inspired in generous minds by the sight of a great collection of books. Pope's words have often been quoted:

A little learning is a dangerous thing,

Drink deep, or taste not the Pierian spring.

The doctrine, if not a fallacy, is a half-truth at the best. A little learning has some dangers, but a little less learning has more, and no learning is the most dangerous of all. And the wider our know- ledge grows the keener will be our sense of the limits of acquirement, our eagerness to profit by the labors of the students who have gone before, and the true humility of our desire to add to the sum of human knowledge or at least to make straight some part of the way of those who shall enlarge the boundaries of learning.

The library has relation to life as well as to learning. It can aid us in acquiring the practical wisdom for the management of daily affairs, for the right relationship to our fellow men. It can help us to moderation in prosperity, to humility in success, to courage in adversity, and to endurance and resignation in affliction.

"There is no God," the foolish saith,

But none, "There is no sorrow."

How many sorrowing hearts have found consolation in the companionship of books! How tender are the accents of Plutarch striving to allay the grief of his wife for the death of their beloved daughter! How many have been strengthened by the words of those who have been dust and ashes for centuries, men who belong to an empire that has past away, to a faith that has become extinct, to a race alien to our own, but whose message still lives and has power for consolation, for reproof, and for inspiration. Literature can give us rest as well as inspiration, nor is it only the great ones who are of service to us in the work of life. There are moments when the melody of the milkmaid's song is a better tonic than the pealing grandeur of a great cathedral's organ. How well has Longfellow expressed this feeling when he asks for 
Not from the grand old masters,

Not from the bards sublime,

Those distant footsteps echo

Through the corridors of Time.

For, like strains of martial music,

Their mighty thoughts suggest

Life's endless toil and endeavor, And to-night I long for rest.

Read from some humble poet,

Whose songs gushed from his heart,

As showers from the clouds of summer,

Or tears from the eyelids start. . . .

Such songs have power to quiet

The restless pulse of care,

And come like the benediction

That follows after prayer.

Wise, indeed, was the ancient Egyptian monarch who placed over the door of a library an inscription signifying that it contained " the medicine of the mind." From literature we may derive courage for the battle, fortitude in defeat, wisdom in victory, and an anodyne for grief. What Shelley has said of the drama may well be given a wider application. "The highest moral purpose," he says, " aimed at in the highest species of the drama, is the teaching of the human heart, through its sympathies and antipathies, the knowledge of itself; in proportion to the possession of which knowledge, every human being is wise, just, sincere, tolerant, and kind." 1 This is what Arnold means when he describes culture as "a study of perfection." This is that at which our schools, and colleges, and universities, and libraries, all the machinery great and small of education, should aim. In proportion as this is attained are they successful and their existence justified. No educational system has fulfilled its purpose that does not nourish the love of knowledge and the desire for righteousness.

The library has its lessons for nations as for individuals. It is a perpetual symbol of the brotherhood of man. It knows no distinction of Jew or Gentile, of bond or free, but welcomes genius from every quarter. The better part of Emerson the American, Homer the Greek, Kalidasa the Hindoo, Dumas the French mulatto, Shakespeare the Englishman, Dante the Italian, Omar the Persian, Goethe the German, Tolstoy the Russian, stand on the shelves of the library to warn us against arrogating preëminence to our own people, and to teach us that every nation may contribute to the common fund, and to lead us to hope that every race will bring some special gift to the common service of humanity. The American, newest born

${ }^{1}$ Preface to The Cenci. 
of time, with his self-reliant individuality; the ancient Greek with his sense of beauty; the Roman with his skill as lawgiver; the Japanese with his feeling for color; the Negro with his cheerful enclurance; the Englishman with his power of association; the Hebrew with his deep religious instinct, are familiar instances of special gifts and aptitudes. These are mirrored in the literature and history of the races of mankind as we may read them in the halls of a great library. Each race may have its own ideal, - the French love equality, the English love liberty, - and the interaction of all these influences upon each other modifies the thought of the world and makes for the progress of mankind.

The duty of the library in relation to learning is to garner with sedulous care all the fruits of knowledge, to record what is known, and to provide material from which future knowledge may be wrought. The mission of the library to the individual is to place before him for his use and benefit all the knowledge and all the wisdom and all the inspiration that the ages have accumulated. The summons of religion, the efforts of philosophy, the warnings and incitements of the moralist, the historian's long record of endeavor, of failure, and of success, the varied wonders that the physical sciences have to reveal, the investigations of the geographer, the narratives of the traveler, the inventions of men for the comfort and ease of existence, the pictures of life drawn by the novelist and the dramatist, the melody of the poet's song - all these the library places before the individual for delight, for instruction, and for guidance. The library has also its international mission. Paul's declaration that God " hath made of one blood all nations of men " finds its realization in the library to which East and West and North and South, the Old World and the New, have alike contributed all those things that they deem most precious and beautiful, the holiest and the wisest that they have been able to fashion and express. The library is the symbol of

$$
\text { ... Truth, }
$$

Knowledge and Duty, Virtue, Progress, Right, And Reason scattering hence delirious dreams. ${ }^{1}$

${ }^{1}$ Victor Hugo, translated by Mathilde Blind. 


\section{THE LIBRARY - ITS PAST AND FUTURE}

\section{BY GUIDO BIAGI}

[Guido Biagi, Director of the Laurentian and the Riccardi Libraries of Florence. b. Florence, Italy, 1855. Ph.D. 1878, Istituto di Studi Superiori Pratici e di Perfezionamento, Florence; granted fellowship by the Board of Education for Italian literature. Assistant Librarian in the Victor Emanuel, Rome, 1880; First Vice-Librarian, by competition, in the National Library of Florence, 1882; Librarian in the Victor Emanuel, 1883; Chief of the Cabinet of the Secretary of Education, 1884; Librarian of the Marucelliana Library in Florence, 1886; Prefect of the Laurentian Library of Florence, 1889; Chief of the Cabinet of the Minister of Education, 1892; General Inspector of Public Instruction, 1893; Director of the Laurentian Library, 1895; Vice-President of the International Library Conference, London, 1897; Director of the Riccardiana, annexed to the Laurentian Library, 1898; Hon. Professor of the Fine Arts Academy of Florence, 1897; Correspondent of the Royal Historical Society of Tuscany, 1887; Hon. Secretary of the Dante Society, 18871894; Hon. Treasurer of the Dante Society, 1899 until now; member of the Superior Jury, St. Louis Exposition, 1904. Author of The Novelle Antiche (Florence, 1878); The Mare Magnum of F. Marucelli (Florence, 1888); The Private Life of the Renaissance Florentines; The Last Days of P. B. Shelley; The Illustrations of Stradanus to the Divine Comedy; Aneddoti Litterari; several publications of bibliography and library economy. Editor of The Library Review (Rivista delle Bibliotiche e degli Archive).]

THE first founders of public libraries having been Italian, it will perhaps be neither strange nor unfitting that an Italian, the custodian of one of the most ancient and valued book-collections in the world, should speak to you of their past. He may, however, appear presumptuous in that he will speak to you also of their future, thus posing as an exponent of those anticipations which are now fashionable. It is in truth a curious desire that urges us and tempts us to guess at the future, to discover the signs of what it will bring us, in certain characteristics of the present moment. It answers to a want in human nature which knows not how to resign itself to the limitations of the present, but would look beyond it into time and space.

This looking forward toward the future is no selfish sentiment; it springs from the desire not to dissipate our powers in vain attempts, but to prepare new and useful material for the work of the future, so that those who come after us may move forward without hindrance or perturbation, without being obliged to overturn and destroy, before they can build up anew. Thus does it happen in nature: huge secular trunks flourish and grow green by luxuriant offshoots which add new vigor of life to the old and glorious stock.

We may perhaps discover the secret of the future of the library by looking back over its past, by attentively studying the varying phases through which it has passed in its upward path towards a splendid goal of wisdom and civilization. By thus doing we may 
prepare precious material for its future development and trace with security the line of its onward movement. It is of supreme importance that humanity in general, as the individual in particular, know whither its efforts must be directed, that there may be no straying from the straight path. We are sailors on a vast sea bound toward a shore we know not of; when we approach it it vanishes like a mirage from before our eyes. But we have as guides the stars which have already ruled our destinies, while before us flames, on the distant horizon, that light of the Idea toward which our ships and our hearts move eagerly. Let us stand firm at the helm and not despise the counsels of some old pilot who may perhaps seem fainthearted to young and eager souls. He who is hurried along by the excitement of the course, by the impetuosity of the motion, finds neither time nor place to look back and to meditate, which is necessary, that he may look forward with sharper and calmer gaze. Modern life among the younger and more venturesome peoples is a giddy race. They run, they annihilate the space before them, they press onward, ever onward, with irresistible impetus, but we cannot always say that this headlong course leads straight toward the goal. We are not sure, even, that it may not sometimes be running in a circle, a retracing of their steps. In mechanics a free wheel turning upon itself and moving no machinery is so much lost power. Let us beware of free wheels which consume without producing, which give the illusion of movement whilst they still remain stationary. Modern civilization bears within itself a great danger, the endeavor which loses the end by a misuse of the means, and which, though busy, is ever idle; idle, yet never at rest. It may be, therefore, that a momentary return to the past, with all that it can teach, will be useful to all of us.

Progress has rightly been compared to a continual ascent. Modern man sees before him ever vaster horizons; the eye of science discovers in the infinitely distant and in the infinitely small ever new worlds, whether of suns or of bacteria. In the same way do conceptions and ideas ever widen and tend to a more comprehensive generalization. All the march of civilization, both material and moral, consists in rising from a simple primordial idea to another more complex, and so on to the highest scientific abstractions. Woe to science if it stops short in the course of this evolution; its reputation would be injured beyond repair. In material things the fate of certain words shows us the great advance that has been made; the words are the same but the things they represent are very different. We still give the name of casa (capsa, that is, hut) to our splendid dwellings, which have here among you reached their highest point of development in your skyscrapers; we still give to the great transatlantic steamers, floating cities, the name of boats, which was once 
applied to the first rude canoes of the troglodytes. The first function of the casa and of the boat still remains, but how differently are the details carried out. So also the book, the liber, whose etymology is preserved in the word library, was anciently the inner part of the tree (liber) on which men used to write, and which is now unfortunately again used in the making of paper no longer obtained from rags but from woody pulp. The libraries of Assyria and Egypt, those for instance of Assur-Bani-Pal and of Rameses I, consisted of clay tablets of inscribed stones or of papyrus rolls; the libraries of Greece, those of the Ptolemies and of the kings of Pergamos, the libraries of Rome, first opened to public use by the efforts of Asinius Pollio; the Byzantine libraries, which arose within Christian churches or in monasteries; and lastly, the rich and splendid collections made at great expense by the patrons, by the builders, of the culture of the Renaissance; all these, compared with the modern libraries, of which the most perfect specimens may be found in this land, are like an ancient trireme beside a twin-screw steamer. And the essential difference between the ancient and the modern library, between the conception of library as it existed up to the times of Frederic, Duke of Urbino, and of Lorenzo il Magnifico, and that existing in the minds of Thomas Bodley, or Antonio Magliabecchi, is to be found in the different objects represented by the same word, liber.

A study of the fate of this word would lead us step by step through the varying forms of the library, from those containing clay tablets, from those filled with rolls covered with cuneiform characters, to the codices brilliant with the art of Oderisi da Gubbio, splendid with gold and miniatures, to the first block books, to the printed books of Faust and Schöffer and of Aldo Manuzio, of William Caxton, and of Christopher Plantin.

The invention of printing caused a great revolution in the world of books. The new art was, as we well know, received at first with scorn and indifference. The incunabula were but rough, vulgar things as compared with the beautiful manuscripts, clearly written on carefully prepared parchment, and glittering with brilliant colors. They were fit at most to be used by the masses - by women, by children, to be sold at fairs, to be put into the hands of clean-jacks and charlatans; but they were quite unfitted for the valuable collections guarded with so much care in perfumed cases carved from precious woods, in sculptured cabinets, on reading-desks covered with damask or with the softest of leathers, made from the skins of sucking animals. We can easily understand that fastidious art patrons such as the Duke of Urbino should scorn this new form of book, and should proclaim it unworthy of a place in a respectable library. But this tempest of scorn gradually subsided before the 
advantages which the new invention offered and before the marvelous progress it made. It sought, moreover, the favor of the miniaturists by leaving, in the margins of the new codices, sufficient space for ornamentations and for initials of burnished gold; it sought the favor and the help of the learned humanists by employing them to revise and correct the texts; it won the favor of the studious and of clerks, who have at all times been poor, by spreading abroad the texts of the classics, by offering for a few halfpence that which could at first be obtained only with gold or silver florins, by imparting to all that which had been the privilege of the few. And we must not forget the help given to typography by the invention of the minor arts, calcography and xylography, which added new value to the pages of the no longer despised book; so that printed codices (codices impressi) might stand side by side with the manuscript codices (codices manuscripti).

The word, the sign of the thought, first took on visible form with the invention of the alphabet. But other ways of revealing thought were to be discovered in the future. No one in the ancient world, no one before the very culminating point of the Renaissance, could have supposed it possible that a library might contain anything but manuscripts; just as we, to-day, are incapable of imagining a library containing anything but books. We have seen that the conception of the book underwent expansion when printed books were added to those written by hand; and in the same way the library underwent expansion, gradually rising, between the fifteenth and the twentieth centuries, from a simple collection of codices, to the vast and wonderful proportions it has at present reached, assuming the duty of receiving within itself any kind of graphic representation of human thought, from clay tablets and inscribed stones and papyrus rolls, to phototypes and monotype or linotype products, from books for the blind written in the Braille alphabet to the new manuscripts of the typewriters.

From this brief compendium of bibliographical history one essential feature emerges. As though directed by an unswerving law, by the law of reproduction, human thought feels the necessity of expanding and of multiplying and perpetuating itself; and it is ever searching for new means of carrying out this intent. Thus the copyist or the scribe is replaced by the compositor, the miniaturist by the engraver, the draftsman by the litlographer, the painter by the color-printer, the engraver by the photographer and zincographer; thus the machine replaces the hand of man, the machine which is only concerned with working quickly, with producing as many copies as possible with diminished effort, with snatching her secrets from Mother Nature herself. We have replaced the notae tironianae of the Roman scribes by the typewriter, the wax 
tablets by the pages of the stenographer; for drawing and painting we have substituted photography and three-color printing; wireless telegraphy has taken the place of messages sent by posthorses.

And not content with these singular and wondrous modes of reproducing graphically the thought and the word, we have found another means of reproduction still more stupendous in the immediateness of its action. Sound, the human voice, whose accents have hitherto been lost, may now be preserved and repeated and reproduced like other graphic signs of thought. When the graphophone was first invented we little thought that the cylinders upon which the vibrations of the voice had traced so slight and delicate an impression would ever be reproduced as simply as, by electrotyping, we reproduce a page of movable characters. Neither have we yet, or I am much mistaken, grasped the whole of the practical utility which the graphophone may have in its further applications and improvements. Up to the present time the graphophone has been kept as a plaything in drawing-rooms or in bars, to reproduce the last roulades of some well-known singer, the bangings of some military band, or the pretended uproar of some stormy meeting. At the present day the librarian would probably refuse to receive within his library this faithful reproducer of the human voice and thought, just as Frederic, Duke of Urbino, banished from his collection the first examples of printed books. But without posing as a prophet or the son of a prophet, we may surely assert that every library will, before long, contain a hall in which the disks of the graphophone may be heard (as already is the case at the Brera in Milan), and shelves for the preservation of the disks, just as the libraries of Assyria preserved the clay tablets inscribed with cuneiform characters. This is a new form of book, strange at first sight, but in reality simply a return to ancient precedents, yet a return which marks the upward movement of progress.

An Italian Jesuit, Saverio Bettinelli, undertook toward the middle of the eighteenth century to give laws to Italian writers. He produced certain letters which he assumed Virgil to have written from the Elysian Fields to the Arcadia at Rome. In two of these twelve tablets, which he put forth under the names of Homer, Pindar, Anachreon, Virgil, Horace, Propertius, Dante, Petrarch, and Ariosto, in the poetical meetings held in Elysium, he laid down as a rule: "Let there be written in large letters on the doors of all public libraries: "You will be ignorant of almost everything which is within these doors, or you will live three centuries to read the half of it;' and a little further on: 'Let a new city be made whose streets, squares, and houses shall contain only books. Let the man who wishes to study go and live there for as long as may be needful; 
otherwise printed matter will soon leave no place for the goods, for the food, of the inhabitants of our towns." "

This anticipation, which dates from 1758 , still seems an exaggeration, but I know not whether, a century and a half hence, posterity will think it so, so great is the development of the industries, the succession of ever new inventions for preserving any graphic representation of human thought. Not even the life of Methuselah would be long enough to read as much as the tenth part of all that a modern library contains; and I know not whether we could invent a more terrible punishment than to insist upon this for our criminals. How many repetitions of the same ideas, how much superfluity, how many scientific works canceled and rendered useless and condemned to perpetual oblivion by those which succeed them! By welcoming everything, without discrimination, the modern library has lost its ancient and true character. No longer can we inscribe over its entrance the ancient motto, "Medicine for souls;" few, indeed, of the books would have any salutary influence on body or on mind. Now that the conception of book and of library has been so enormously expanded, now that the library has become the city of paper, however printed, and of any other material fitted to receive the graphic representation of human thought, it will become more and more necessary to classify the enormous amount of material, to separate it into various categories. The laws of demography, whatever they may be, must be extended also to books; the dead must be divided from the living, the sick from the sound, the bad from the good, the rich from the poor; and cemeteries must be prepared for all those stereotyped editions of school-books, of catechisms, or railway time-tables, for all that endless luggage of stamped paper that has only the form of a book and has nothing to do with thought. Sanatoria must be provided for books condemned to uselessness because already infected with error or already eaten away with old age, and the most conspicuous places must be set apart for books worthy to be preserved from oblivion and from the ravages of time, either on account of the importance of their contents or of the beauty of their appearance. In this great republic of books the princes principes will stand high above the countless mass, and an aristocracy of the best will be formed which will be the true library within the library.

But even this will not have the exclusive character of the ancient library. It will receive divers and strange forms of books; next to a papyrus of Oxyrinchos, with an unknown fragment of Sappho, may be placed a parchment illuminated by Nestore Leoni or by Attilio Formilli, a graphophone disk containing Theodore Roosevelt's latest speech, or a scene from Othello given by Tommaso Salvini, the heliotype reproduction of the Medicean Virgil or some 
phrases written on palm-leaves by the last survivor of a band of cannibals. The great abundance of modern production will render ever more rare and more valuable ancient examples of the book, just as the progress of industrialism has enhanced the value of work produced by the hand of man.

Thought as it develops is undergoing the same transformation which has occurred in manual labor; mental work also has assumed a certain mechanical character visible in formalism, in imitation, in the influence of the school or of the surrounding. Industrialism has made its way into science, literature, and art, giving rise to work which is hybrid, mediocre, without any originality, and destined, therefore, soon to perish. The parasites of thought flourish at the expense of the greater talents, and they will constitute, alas, the larger part of future bibliographical production. The greatest difficulty of future librarians will be to recognize and classify these hybrid productions, in choosing from among the great mass the few books worthy of a place apart.

The appraisal of literature which has already been discussed in books and congresses will continue to increase in importance; and in this work of discrimination we shall need the aid of critics to read for other men and to light up the path for those who shall come after. "The records of the best that has been thought and done in the world," said George Iles, "grow in volume and value every hour. Speed the day when they may be hospitably proffered to every human soul, the chaff winnowed from the wheat, the gold divided from the clay."

One of the special characteristics of the library of the future will be coöperation and internationalism applied to the division of labor. We may already see premonitory symptoms of this in the Catalogue of Scientific Literature now being compiled by the Royal Society of London, in the Concilium Bibliographicum of Zürich, in the Institut de Bibliographie of Brussels, and in the Card Catalogue printed and distributed by the Library of Congress at Washington. This cooperation, however, will have to be more widely extended and must assert itself not only by exchanges of cards and of indices, but also by means of the lending of books and manuscripts, of the reproduction of codices or of rare and precious works. The government libraries of Italy are united under the same rules and correspond with all institutions of public instruction and with several town and provincial libraries, with free postage, so that books and manuscripts journey from one end to the other of the peninsula, from Palermo to Venice, without any expense to those who use them, and the different libraries of the state become, in this way, one single library. And so the day will come when the libraries of Europe and of America and of all the states in the Postal Union will form, as it were, one single collection, and the old books, printed when America 
was but a myth, will enter new worlds, bearing with them to far-off students the benefit of their ancient wisdom. The electric post or the air-ships will have then shortened distances, the telephone will make it possible to hear at Melbourne a graphophone disk asked for, a few minutes earlier, from the British Museum. There will be few reaclers, but an infinite number of hearers, who will listen from their own homes to the spoken paper, to the spoken book. University students will listen to their lectures while they lie in bed, and, as now with us, will not know their professors even by sight. Writing will be a lost art. Professors of paleography and keepers of manuscripts will, perhaps, have to learn to accustom their eye to the ancient alphabets. Autographs will be as rare as palimpsests are now. Books will no longer be read; they will be listened to; and then only will be fulfilled Mark Pattison's famous saying: "The librarian who reads is lost."

But even if the graphophone does not produce so profound a transformation as to cause the alphabet to become extinct and effect an injury to culture itself; even if, as we hope will be the case, the book retains its place of honor, and instructions through the eyes be not replaced by that through the ears (in which case printed books would be kept for the exclusive benefit of the deaf), still these disks, now so much derided, will form a very large part of the future library. The art of oratory, of drama, of music, and of poetry, the study of languages, the present pronunciation of languages and dialects, will find faithful means of reproduction in these humble disks. Imagine, if we could hear in this place to-day the voice of Lincoln or of Garibaldi, of Victor Hugo or of Shelley, just as you might hear the clear winged words of Gabriele d' Annunzio, the moving voice of Eleonore Duse, or the drawling words of Mark Twain. Imagine the miracle of being able to call up again the powerful eloquence of your political champions, or the heroes of our patriotic struggles; of being able to listen to the music of certain verses, the wailing of certain laments, the joy that breaks out in certain cries of the soul. The winged word would seem to raise itself once more into the air as at the instant when it came forth, living from the breast, to play upon our sensibilities, to stir up our hearts. It is not to be believed that men will willingly lose this benefit - the benefit of uniting to the words the actual voices of those who are, and will no longer be, and that they should not desire that those whose presence has left us should at least speak among us. ${ }^{1}$ We may also believe that certain forms of art, such as the novel and the drama, will prefer the phonetic to the graphic reproduction, or at least a union of the two. And the same may be said of poetry, which will find in modern

1 A Phonographic Pantheon has been founded in the Laurentian Library, according to this proposal. 
authors its surest reciters, its most eloquent interpreters. The oratory of the law-court and of the parliament, that of the pulpit and of the cathedra, will not be able to withstand the enticement of being preserved and handed on to posterity, to which their triumphs have hitherto sent down but a weak, uncertain echo. "I shall not die altogether" - Non omnis moriar - so will think the orator and the dramatic or lyric artist; and the libraries will cherish these witnesses to art and to life, as they now collect play-bills and lawyers' briefs.

But internationalism and coöperation will save the future library from the danger of losing altogether its true character by becoming, as it were, a deposit of memories or of embalmed residua of life, among which the librarian must walk like a bearer of the dead. The time will come when, if these mortuary cities of dead books are not to multiply indefinitely, we must invoke the authority of Fra Girolamo Savonarola, and proceed to a burning of vanities. A return to ancient methods will be a means of instruction, and those centenary libraries which have preserved their proper character, which have not undergone hurtful augmentations, which have reserved themselves for books and manuscripts alone, which have disdained all the ultra-modern rubbish which has neither the form nor the name of book, - these libraries will be saluted as monuments worthy of veneration. And then some patron who, from being a multimillionaire, as was his far-off ancestor, will have become at least a multi-billionaire, will provide here in America for the founding of libraries, not of manuscripts, which will no longer be for sale, but of reproductions of codices in black or in colors; and we shall have libraries of facsimiles most useful for the study of the classics, just as we now have museums of casts for the study of the plastic arts.

The application of photography and of photogravure to the reproduction of texts which are unique rather than rare, makes it possible for us not only to have several examples of a precious codex or manuscript, but to fix the invisible deterioration which began in it at a certain date, so that, as regards its state of preservation, the facsimile represents an interior stage to the future state of the original. By thus wonderfully forecasting the future, these reproductions render less disastrous the effects of a fire such as that which lately destroyed the library of Turin. They have, therefore, found great favor among students and have excited the attention of the most enlightened governments. If the means for carrying on what have hitherto been but isolated efforts do not fail, if generous donors and institutions and governments do not deny their aid, we might already begin a methodical work of reproduction, and come to an agreement concerning the method of fulfilling a vast design which should comprehend all the most precious archetypes of the various 
libraries in the world, those which are the documents of the history of human thought and which are the letters-patent of the nobility of an ancient greatness. This, I think, would, nay should, be the most serious and principal duty assumed by the library of the future: to preserve these treasures of the past while hoping that the present and the future may add to them new ones worthy of public veneration. Think how vast a field of work, to seek through all nations the autographs or archetypes to which have been intrusted the thought of great men of every age and of every race, and to reproduce them in the worthiest way and to explain them so as to render them accessible to modern readers. Thus should we form the true library of the nations which, with the facsimiles, would bring together the critical editions of their authors and the translations and the texts made for the explanation of the works. But the first and most urgent duty would be that of making an inventory, an index, of what should constitute this collection; and, first of all, we should know and search out such authors as may have influenced the history of the human race by their works in all times and among all peoples; and we should have to find the venerable codices which have handed on to us the light of their intellect, the beating of their hearts. Every nation which is careful of its own glory should begin this list, just as we are now beginning that of the monuments of marble or of stone which have value as works of art. We should thus begin to prepare the precious material to be reproduced, while at the same time it would be possible to calculate the expense needed for carrying out the magnificent design. The Belgian Government has appointed a congress to meet at Lieges next year for this purpose, but its programmes are too extended; for they take in also the documents in the archives and in the museums. More opportune and practical would be an inquiry affecting the libraries alone and beginning with oriental and classical authors, with those who represent the wisdom of the ancients. Thus the library of to-day would gradually prepare its work for the future library, which will surely want something more than the editions, however innumerable, supplied to it by the bibliographical production of the years to come.

Internationalism will also be able to render great services to science, in the field of photo-mechanic reproductions, if it find a way of directing them to some useful goal, and if it prevent them from taking a merely material advantage of the precious collections which every nation is justified in guarding with jealous care. Photography with the prism, which has no need of the plate or of the film, costs so little and is so easy of execution, especially if the process of the late Mlle. Pellechet be adopted, that one can, in a few hours, carry away from a library the facsimile of an entire manuscript. No doubt many learned men of the new style find it more convenient to 
have these collections at their own house instead of wandering from one library to another to collect them at the expense of their eyes, their patience, and their money. To be able to compare the various texts and to have the various readings of them under one's eye is an inestimable benefit; but the true philologist will never be contented with simply studying these facsimiles, however perfect they may be; he will want to examine for himself the ancient parchments, the time-yellowed papers, to study the slight differences between the inks, the varieties in the handwritings, the evanescent glosses in the margins. In the same way an art critic is not content with confining his study simply to the photographs of pictures, but he observes the pictures themselves, their patina, their coloring, their shadows, their least graduations of tones and half-tones. In the same way, too, a musician would not presume to the knowledge of an opera which he had only studied in a pianoforte arrangement. If this manner of shunning fatigue took root, our splendid collections of manuscripts would no longer be the goal of learned pilgrims, but would become the easy prey of the photographer, who would certainly embark upon a new speculation - that of retailing these collections to the manifest injury of the libraries and of the states, which would thus lose the exclusive literary and artistic possession of what is a national glory. Meanwhile a wise jurisdiction will avoid these dangers without injuring or hindering studies and culture. We shall adopt for manuscripts, which excite other people's desires, the proposition made by Aristophanes in the Ecclesiazuse (that charming satire on socialism) to bridle the excesses of free love. We shall permit a man to have a copy of a manuscript when he has first had one of another and older manuscript and when the latter, which is about equal in value to the first, has already been given up to the library, which will thus lose none of its property. "I give to make you give,"-Do ut des, - base and foundation of international treatises for customs duties must be applied also in a reasonable manner to the intellectual traffic that will be the characteristic of future civilization, which will never permit one nation to grow poor while another grows rich, and will insist that wealth be the bearer of equality and fruitful in good. A well-regulated metabolism, as it insures the health of our organic bodies, will also serve to maintain the health of that great social body which we all desire and foresee, notwithstanding political struggles and the wars which still stain the earth with blood. When the time comes in which we shall be able to use for ideal aims the millions which are now swallowed up by engines of war, of ruin, and of assault, the library will be looked upon as the temple of wisdom, and to it will be turned far more than at present the unceasing care of governments and of peoples. When that time comes, the book will be able to say to the cannon, with more truth than Quasimodo to Notre 
Dame de Paris, "This has killed that" - Ceci a tué cela - and it will have killed death with all her fatal instruments.

But another and a more important aspect of scientific internationalism which will preserve the library of the future from becoming a bazaar of social life, will be the importation of the most wholesome fruits of ancient wisdom collected with wonderful learning by the great scholars of the seventeenth and eighteenth centuries, the first founders of libraries, men who attempted an inventory of human knowledge. During the seventeenth and eighteenth centuries, hitherto looked upon by experimental science with disdain, was collected with laborious detail all the learning of past centuries,-that of the holy books of the oriental world, that which the fathers of the Church, and after them the Arabs, and later on the Encyclopedists of the Middle Ages, and then the astrologists, and the alchemists, and the natural philosophers, condensed into encyclopedias, into chronicles, into treatises, into all that congeries of writings which formed the libraries of the Middle Ages and of the Renaissance, into that infinite number of printed books which still fill the ancient and classical libraries of Europe with voluminous folios and quartos. The desire of classifying and bringing into line all human knowledge, of reading this immense amount of material and gaining a thorough knowledge of it, armed those first solemn scholars with patience, formed those legendary librarians who, like Antonio Magliabecchi or Francesco Marucelli themselves, were living libraries. The Latin anagram of the celebrated founder of the Florentine library, Antonio Magliabecchi, is well known: "This, one large library" - Is unus bibliotheca magna; but it may be, and at that time also could be, equally applied to the others. These devourers of books were the first inventors and asserters of the scientific importance of a card catalogue, because armed with cards they passed days and nights in pressing from the old books the juice of wisdom and of knowledge and in collecting and condensing it in their miscellany, in those vast bibliographical collections compared with which the catalogue of the British Museum is the work of a novice. They not only appraised the known literature of their time, but they classified it; not by such a classification as we make now, contenting ourselves with the title of the book, but by an internal and perfect classification, analyzing every page and keeping record of the volume, of the paragraph, of the line. The skeleton of the encyclopedia, of the scientific dictionary, which at the end of the eighteenth century underwent, in France, a literary development, may be found within these bibliographical collections now forgotten and banished to the highest shelves of our libraries. Any one who has looked through and studied one of these collections as I have done, has wondered at the 
treasures of information, of learning, of bibliographical exactitude, which are contained in those dusty volumes. Above all, the precision of the references, and of the quotations, the comprehensiveness of the subjects and of the headings, render them, rather than a precious catalogue, an enormous encyclopedia, to which we may have recourse not only for history, for geography, for literature, for all moral sciences, but also, impossible as it may seem, for natural sciences, for medicine, and for the exact sciences. Incredible is the number of quotations made for even the least important subject; incredible, too, is our ignorance, our stupid disdain for this emporium for out-of-the-way information. Were you to study the article "Fever," you might perhaps find a hint at its propagation by means of mosquitoes, just as I, studying the geography of Ethiopia, came across mention of those gold-mines which have just lately been found again in Erythrea. Modern science, less presumptuous than that of a short while ago, which had shut itself up in the dogmas of materialism, will not disdain to visit these springs, and to compile an encyclopedia of the knowledge of the ancients, with quotations drawn from these true wells of science.

In the library of the future, classified on the decimal system, or Cutter's expansive, every section should contain a shelf of cards on which should be collected, arranged, verified, and even translated this ancient material, which may throw light on new studies and on new experiments; for the empirical methods of our forefathers, like tradition and legend, have a basis of truth which is not to be despised. Meanwhile the modern library, which in this land prospers and exults in a youth strong and full of promise, should collect this material, and thus spare the students at your universities the long researches needed to assimilate the ancient literature of every subject. The modern library, the American library, would not need to acquire and accumulate with great expense all the ancient mass of human knowledge in order to make use of the work of past generations; it need only collect the extract of this work, opportunely chosen, sifted, classified, and translated. This would be an immense advantage to its scholars, and the internationalism of science, of whose certain advent I have spoken to you, would find in this first exchange, in this fertile importation, its immediate application. Why should students and specialists be sent to begin new researches in learned and dusty volumes, when this work already has been done by the great champions of erudition in their miscellany, in their bibliographical encyclopedias? Let us rather try to spread abroad a knowledge of this treasure, this well of science; let us publish information about it; let us draw largely from its pure and health-giving waters. You will not be without guides who will lead you to it, who can and will give you to drink of its fresh waters. 
Thus shall those noble and solitary spirits who worked unknown in the dark of the seventeenth century and in the wan eighteenth century, be joined, by an invisible chain, to the vigorous intellects which, in the last century and in that upon which we have just entered, are working, are toiling, in the diffused light of civilization, and will continue to work and will continue to toil for science, for humanity.

And the card, the humble card, the winged arrow of the librarian and of the student, will fly from continent to continent, a messenger of knowledge and of concord. 


\section{WORKS OF REFERENCE FOR THE DEPARTMENT OF EDUCATION}

\section{PSYCHOLOGY OF EDUCATION}

Adams, Herbartian Psychology Applied to Education.

BArr, Mental Defectives.

Bastian, The Brain as an Organ of Mind.

Binet, Psychology of Reasoning.

Binet et Henri, La Fatigue Intellectuelle.

Bradford, Heredity and Christian Problems.

Bryan, Eye and Ear Mindedness.

Colgrove, Memory.

Dewey, Studies in Logical Theory.

Interest as Related to Will.

School and Society.

Dexter and Garlick, Psychology in the School Room.

Dopp, The Place of Industries in Elementary Education.

DuBors, The Point of Contact.

Ferrier, Functions of the Brain.

Fiтch, Lectures on Teaching.

Art of Securing Attention.

Galton, Natural Inheritance.

Gross, The Play of Man.

HaLl, Adolescence.

HALLECK, Education of the Central Nervous System.

Harris, The Psychologic Foundations of Education.

Hinsdale, Art of Study.

HoвHOUSE, Mind in Evolution.

Holmes, Mechanism in Thought and Morals.

Huston, Education of the Imagination.

JAMES, Principles of Psychology, v. 1 \& 2.

Talks to T'eachers.

KaY, Memory, What it is and How to Improve it.

KInG, The Psychology of Child Development.

KIRKPATRICK, The Fundamentals of Child Study.

LANCAster, Psychology and Pedagogy of Adolescence.

LANGE, Apperception.

Morgan, Habit and Instinct.

OpPenheim, Mental Growth and Control.

Ostermann, Interest.

RADESTOCK, Habit in Education.

Riвот, Psychology of the Emotions.

Psychology of Attention.

Diseases of Memory.

Diseases of Personality.

Riddeld, Heredity and Pre-Natal Culture.

Smald, The Suggestibility of Children.

STEer, Imitation.

STREET, Adolescence.

Sully, Human Mind. 
Sully, Studies of Childhood.

Thorndike, Notes on Child Study.

Titchener, Outlines of Psychology.

Tuke, The Influence of Mind upon Body.

Welton, The Logical Basis of Education.

Wilson, Bibliography of Child Study.

\section{HISTORY OF EDUCATION}

Adams, Civilization in the Middle Ages.

Barnard, English Pedagogy.

Pestalozzi and Pestalozzianism.

Kindergarten and Child-Study Papers.

BEARD, Lectures on Reformation 16th Century.

Bosanquet, Education of the Young in Plato's Republic.

Bowen, Froebel and Education through Self-Activity.

Brown, The Making of our Middle Schools.

Browning, History of Educational Theories.

BurCKHARDT, The Renaissance in Italy.

Burnet, Aristotle on Education.

Burcher, Some Aspects of the Greek Genius.

Butler, Education in the United States.

CAPES, University Life in Ancient Athens.

ClaAkE, The Education of Children at Rome.

COMPAYRÉ, Abelard.

History of Pedagogy.

Cunningham, Western Civilization in its Economic Aspects.

Davidson, A History of Education.

Education of the Greek People.

Rousseau and Education according to Nature.

De Coulange, The Ancient City.

DE Garmo, Herbart and the Herbartians.

DEWEY, School and Society.

The Educational Situation.

Dexter, A History of Education in the United States.

Dill, Roman Society in the Last Century of the Western Empire.

Drane, Christian Schools and Scholars.

Draper, History of the Intellectual Development of Europe.

ELY, Studies in Evolution of Industrial Society.

Emerton, Desiderius Erasmus of Rotterdam.

Felkin, Herbart's Science of Education.

Fischer, Francis Bacon.

Froebel, Education of Man.

Hadlex, The Education of the American Citizen.

HaTCH, Influence of Greek Ideas on the Christian Church.

HerRICK, Commercial Education.

Hinsdale, Horace Mann and the Common School Revival in the United States.

HobHouse, Ancient Education.

Hughes, Loyola and the Jesuit System of Education.

The Making of Citizens.

JеBB, Humanism in Education.

Erasmus.

Laurie, John Amos Comenius.

Pre-Christian Education. 
LAURIE, Rise and Early Constitution of the Universities.

LECKX, History of European Morals.

LEgGe, The Chinese Classics.

Luввоск, The Origin of Civilization.

MAHAFFY, Greek Life and Thought.

Old Greek Education.

Martin, The Chinese.

Monroe, A Text Book in the History of Education.

Source Book.

Mullinger, Schools of Charles the Great.

Munroe, The Educational Ideal.

Newman, Historical Sketches.

Painter, A History of Education.

Luther on Education.

Pater, Plato and Platonism.

Paulsen, Character and Development of Universities of Germany.

Pestalozzi, Leonard and Gertrude.

Pinloche, Pestalozzi and the Modern Elementary School.

Quick, Educational Reformers.

Rashdall, The Universities of Europe in the Middle Ages.

Rousseau, Emile.

Russell, German Higher Schools.

Sеввонм, The Oxford Reformers.

Symonds, The Renaissance.

TAYLor, Ancient Ideals.

Classical Heritage of the Middle Ages.

Townsend, Great Schoolmen of the Middle Ages.

TyLor, Primitive Culture.

Vincent, The Social Mind and Education.

WARE, Educational Foundations of Trade and Industry.

WEST, Alcuin and the Rise of the Christian Schools.

Wilkins, National Education in Greece.

Williams, The Middle Kingdom.

Woodward, Vittorino da Feltre and Other Humanist Educators.

Erasmus Concerning Education.

\section{PRINCIPLES OF EDUCATION}

Baglex, The Educative Process.

BaLDwin, Mental Development.

Barnett, Teaching and Organization.

BRYANT, Educational Ends.

ButLER, The Meaning of Education.

Chancellor, Our Schools; Their Administration and Supervision.

Cot, Education in Religion and Morals.

Collar and Crook, School Management and Methods of Instruction.

DeGarmo, Interest and Education.

Dewey, The Child and the Curriculum.

Psychology and Social Practice.

Euiot, Educational Reform.

Findlay, Principles of Class Teaching.

Gilman, University Problems.

Gordy, A Broader Elementary Education.

HADLEY, The Education of the American Citizen. 


\section{BIBLIOGRAPHY : DEPARTMENT OF EDUCATION 233}

Hanus, Educational Aims.

Harris, Psychologic Foundations of Education.

Henderson, Social Elements.

Horne, The Philosophy of Education.

LAURIE, The Institutes of Education.

MacCunn, The Making of Character.

McMurry, General Method.

Method of the Recitation.

Muensterberg, Psychology and Life.

N. E. A. Reports:

(a) Report of Committee on College Entrance Requirements.

(b) Report of Committee of Fifteen.

(c) Report of Committee of Ten.

OpPenheim, The Development of the Child.

PARKer, Talks on Teaching.

Rein, Outlines of Pedagogics.

RoYCE, Is there a Science of Education?

Shaw, School Hygiene.

Sinclatr, The Possibility of a Science of Education.

Thorndike, Educational Psychology.

WALKER, Discussions in Education.

WARnER, The Study of Children. 


\title{
WORKS OF REFERENCE RELATING TO THE SECTION OF EDUCATIONAL THEORY
}

\author{
(Prepared by the courtesy of Professor Wilhelm Rein)
}

Herbart, John Fr., Ausgabe von Kehrbach, Langensalza-Beyer u. Mann, 1887.

Rein, Wilhelm, Encyklopädische Handbuch der Pädagogik, 8 vol., 2. Aufl., Langensalza-Beyer u. Mann, 1906.

Pädagogik in Systematischer Darstellung, Langensalza-Beyer u. Mann, 1904.

Schmid, Carl A.,Encyllopädie des Gesammten Erziehungs. 11 B., Gotha, 18591875.

Sтот, K. V., Encyklopädie Methodologie und Literatur der Pädagogik, Leipzig, 1861.

Struempell, L., Psychologische Pädagogik, 1880.

Wartz, Th., Allgemeine Pädagogik, 1880.

Willmann, Отто, Didaktik als. Bildungslehre nach ihren Beziehungen zur Sozialforschung $u$. zur Geschichte der Bildung, 2 vol.

ZILLER, T., Vorlesungen über Allgemeine Pädagogik, Leipzig, 1876. 


\section{WORKS OF REFERENCE REIATING TO THE SECTION OF THE SCHOOL}

(Prepared by the courtesy of Dr. Michael E. Sadler)

Dewer, John, The School and Society, University of Chicago Press, 1899.

Eliot, Charles W., The Function of Education in Democratic Society, Essays on Educational Reform.

LeGGe, J. G., and SAdLER, M. E., Notes on Children's Workshops in Sweden, Special Reports on Educational Subjects, vol. VIII, London, Wyman \& Co., for his Majesty's Stationery Office, 1901.

SADLER, M. E., National Education and Social Ideals, in Education in the Nineteenth Century, Cambridge University Press, 1901.

The Unrest in Secondary Education, chap. I, Special Reports on Educational Subjects, vol. Ix, 1902.

Wells, H. G., Mankind in the Making, London, Chapman \& Hall, 1904.

Report of the Interdepartmental Committee on Physical Deterioration, vol. I, Report and Appendix. Vol. II, Evidence. Vol. III, Index and Appendix, London, Wyman \& Co., for his Majesty's Stationery Office, 1904. 


\section{SPECIAL WORKS OF REFERENCE FOR THE SECTION OF THE SCHOOL}

(Prepared by the courtesy of Dr. William H. Maxwell)

Boone, R. G., Education in the United States.

Butler, N. M., Meaning of Education.

Committee of Fifteen, Report.

Dewey, John, Educational Situation.

School and Society.

The Child and the Curriculum.

Dutron, S. T., Social Phases of Education.

Filiot, C. W., Educational Reform.

Folks, Homer, Care of Destitute, Neglected, and Delinquent Children.

GoRdy, J. P., Broader Elementary Education.

HaNus, P. H., Modern School.

Horne, H. P., Philosophy of Education.

Hughes, R. E., Making of Citizens.

Hunter, Robert, Poverty.

Mosely Education Commission to the United States, Report.

Tenement House Department, New York City, Report 1902-1903.

Walker, Francis, Discussions in Education.

\section{MAGAZINE ARTICLES}

Harris, W. T., Reports of the Moseley Educational Commission, Educational Review, November, 1904.

Hoose, J. H., Educational Problem of Americanizing Immigrants, Education, January, 1905.

McMurry, F. M., Advisable Omissions from the Elementary Curriculum, Educational Review, May, 1904.

Moseley, Alfred, British View of American Schools, World's Work, February, 1904.

Percival, James, Educational Problems, Public Science Monthly, January, 1905.

Wrlliams, A. S., New York School Problem, Educational Review, April, 1904. 


\section{SPECIAL WORKS OF REFERENCE RELATING TO THE SECTION OF THE COLLEGE}

(Prepared by the courtesy of President William DeWitt Hyde)

Butler, Nicholas Murray, Education in the United States, Monograph No. 5.

Dexter, History of Education in the United States, chap. xv.

Thwing, Charles F., The American College in American Life.

College Administration.

West, ANDrew F., The American College.

Circulars of Information, issued by the United States Bureau of Education on education in the several states. 


\section{WORKS OF REFERENCE RELATING TO THE SECTION OF THE LIBRARY}

\section{(Prepared by the courtesy of Dr. Axon)}

The literature relating to the library in relation to knowledge and life is so extensive that only a few suggestive titles can be cited here.

Memoirs of Libraries, 1859; Free Town Libraries, 1869; Libraries and Founders of Libraries, 1865; Lives of the Founders of the British Museum, 1870, - all four by Edward Edwards, - are full of interesting and important matter.

The Life of Edwards by Thomas Greenwood, 1902, is an almost indispensable appendix.

The Report on Public Libraries in the United States, 1876, is important both for its historic information and as a contribution to library science.

The Bibliotheca Bibliographica, by Julius Petzhold, 1866, with the Manuel de Bibliographie Générale, by Henri Stein, 1897, form an enumeration of works relating to general and special bibliography, and if not complete, show that an immense amount of work has been done. To this class belong the Bibliographie des Bibliographies, of Léon Vallée, 1883-87, and the Register of National Bibliography, by W. P. Courtney, 1905.

Works such as the Clue to Latin Literature by Professor J. E. B. Mayor; the Bibliographie Biographique Universelle by E. M. Oettinger, 1866; and the Bibliographie des Ouvrages Arabes, by Victor Chauvin, may be named. The last is the most important contribution that has yet been made to the detailed study of comparative literature.

Much information as to libraries and catalogues is to be found in periodicals, such as, the Serapeum, Centralblatt für Bibliothekenwissenschaft, Library, Library Association Record, Library Journal, Petzhold's Anzeiger, Polybiblon.

The publications of the American Library Association, and of the Library Association of the United Kingdom, are especially important for modern developments of library work.

On municipal libraries, Freie öffentliche Bibliotheken, by E. Schulze,1900; and Public Libraries, 1890; British Library Year Book, 1900, by Thomas Greenwood, should be consulted.

On the problems of management may be named, Manual of Library Economy, by J. D. Brown, 1903; Handbuch der Bibliothekslehre, by Arnim Graesel (originally based on Petzholdt's Katechismus), 1902; Manuel Pratique du Bibliothécaire, by Albert Maire, 1896; and the Library Series, edited by Dr. Richard Garnett. The last named includes books on the Free Library by J. J. Ogle, 1897; Library Construction byF. J. Burgoyne, 1897; Library Administration by J. Macfarlane, 1898; Prices of Books by Henry B. Wheatley, 1898; Essays in Librarianship and Bibliography by Richard Garnett, 1899.

The largest contribution yet made to the Universal Catalogue is the Catalogue of Printed Books in the British Museum. The Catalogue of Scientific Papers and the publications and collections of the Concilium Bibliographicum at Zürich and of the Institut Bibliographique Universelle at Brussels are movements in the same directions. The last named has adopted the decimal classification of Melvil Dewey, a system which is finding increased acceptance and greatly facilitates the use of collections of books by students in search of information on specific topics. 
Mr. Thomas Greenwood has had the happy thought of founding a "Library for Librarians." This collection, now numbering some ten thousand volumes, is placed in the Manchester Free Library, but the works can be borrowed for use elsewhere. The books range over the whole domain of bibliography and library science. 

DEPARTMENT XXIV - RELIGION 



\title{
DEPARTMENT XXIV - RELIGION
}

\author{
(Hall 4, September 20, 4.15 p.m.)
}

Chairman: Bishop John H. Vincent, Chautauqua, N. Y. Speakers: President Henry C. King, Oberlin College.

Professor Francis G. Peabody, Harvard University.

\section{THE FUNDAMENTAL NATURE OF RELIGION}

\section{BY HENRY CHURCHILL KING}

[Henry Churchill King, President of Oberlin College, Professor of Theology and Philosophy. b. Hillsdale, Michigan, September 18, 1858 . A.B. Oberlin College, 1879 ; D.B. Oberlin Seminary, 1882; A.M. Harvard University, 1883; D.D. Oberlin College, 1897; Western Reserve University, 1901; Yale Úniversity, 1904. Associate Professor of Mathematics, Oberlin College, 1884-90; Associate Professor of Philosophy, Oberlin College, 1890-91; Dean of Oberlin College, 1901-02. Member of Council of Seventy of American Institute of Sacred Literature; Chairman of Executive Board and Council of Religious Education Association; member of Western Philosophical Association. Author of Reconstruction in Theology; Theology and the Social Consciousness; Rational Living; The A ppeul of the Child; Personal and Ideal Elements in Education.

Is religion of really fundamental importance, or can we easily dispense with it? Is the real trend of the scientific and educational and ethical life of the world away from religion, or toward a deeper recognition of it? Is religion something external, to be merely tacked or pasted on to life, or is it absolutely fundamental to life, touching every part of it? No questions can be more important than these questions; the answer to none concerns us more deeply.

But a satisfactory answer here must be thoroughgoing. No shallow investigation can suffice. And we can hardly expect to come to any profound conviction of the fundamental nature of religion without careful consideration of its relation to education, to ethics, and to life. If religion is of fundamental importance, such a consideration ought to make that clear.

\section{Religion and Education}

And if we ask first as to the relation of religion and education (so far as education is not merely technical or professional), we seem bound to say that the relation is here so intimate that we cannot separate either at its best from the essential spirit of the other. The modern world believes in education as it believes in almost nothing else. Let us see, then, the inevitable outcome of a comparison of religion and education as to aim, as to means and spirit, as to method, and to results. 
(1) In the first place, I think it must be said that the ultimate aims of religion and education are essentially the same. For, on the one hand, the best education seeks to call out the whole man in his highest harmonious development. That education often falls short of this highest aim must, of course, be granted; but to this ideal it must nevertheless be held, and any education must be regarded as defective in just the degree in which it fails to accomplish this aim.

Religion, too, at its highest, as looking always to the fulfillment of the supreme personal relation, involves everywhere the full personality in its highest possible response; and, just so far as it attains its aim, must touch and quicken every faculty, must call out the entire man, volitionally, emotionally, intellectually. In the concrete case, doubtless, religion also fails all too often to reach its final goal; but the power of the genuine religious experience to quicken to its best the entire personality of the man cannot be doubted. The ideal aims, therefore, both of education and religion, surely fall together.

(2) If one compares religion and education, in the second place, as to means and spirit, a similar result is obtained. For, on the one hand, true education must offer, as I have elsewhere said, "the opportunity to use one's full powers in a wisely chosen complex environment, in association with the best; and all this in an atmosphere catholic in its interests, objective in spirit and method, and finely reverent in its personal relations." That is, the great means in the truest education are broad environment, work calling out the whole man, and personal association. The spirit demanded is catholic, objective, and loving.

Now, if these means and this spirit are those properly demanded in true education, just these means and just this spirit, it must be said, in like manner hold throughout for religion also. That this is for the most part true would probably hardly be questioned by any; and it may be maintained that the parallel holds even as to the catholic and the objective spirit, where perhaps most question would arise.

For, as to the first, we are coming to see with increasing clearness that the true spirit of the life of religion, as of the life of culture, must be that of a broad catholicity. As Wundt says, "The dangers that come with civilization can be met only by the further advance of civilization." Psychological investigation, in its insistence upon the necessity of a wide range of interests for the large and free and sane life, is forcing upon us everywhere the conviction that no ideal interest has anything to gain by exclusiveness; that it is not in the true interest of the sacred to attempt to draw a sharp line between the sacred and the secular; that, in point of fact, the denial of legitimate worldly interests only limits the possible sphere of morality and 
religion. Every attempt to preserve something as especially sacred by setting it apart from all the rest of life results inevitably in leaving it apart - out of vital contact with the rest of life, in failing to permeate life with its power. This has happened, for example, again and again in false attempts to exalt the Bible. Religion must, rather, believe in itself so profoundly as to be certain that no part of the life and work of the world can come to its best except as it is permeated with the religious spirit. Religion, therefore, equally with education, must be catholic in its spirit.

Not less earnest must be the insistence that, equally with education, the spirit of religion must be predominantly objective. It is indeed true that men have very commonly believed that the sphere of religion was preëminently a sphere for introspection; but, unless the whole modern study of man is mistaken in its clear conviction that in body and mind we are made for action, the sphere of introspection, even in religion, must be decidedly limited, and much more limited than has often been conceived to be the case. There is no doubt a place for a certain amount of self-examination, and it can be clearly indicated just what that place is. There should be, namely, just so much introspection as may make a man certain that he is really putting himself in the presence of the great objective forces that make for character and godliness. Having determined that, the less a man's gaze is turned in upon himself, the better both for his character and for his religion. It is not less true, then, in religion than in education, that the prevailing mood must be everywhere the objective mood.

As to both means and spirit, then, we may unhesitatingly conclude that the ideals, both of religion and of education, are in agreement. An education, thoroughgoing in the use of these means and completely informed by such a spirit, cannot be really "godless." It is only shallow insight that can so see it. We need to insist only that the education shall be real education - education of the entire man. And religion, too, is so seen not to be some simply external thing that can be merely spliced on to life, but an essential factor, implying the greatest means and moved by the highest spirit.

(3) If, in the third place, we compare religion and education as to method, it must be said that the ruling method in both is the same, - staying persistently in the presence of the best in each sphere of value.

For education, conceived as culture, should give especially ability to enter into all values with appreciation and conviction,- - conviction strong enough to be ready to pass into act. We can hardly ask less than this in any well-rounded education. No man can be called fully cultured to whom are closed the doors of any of the great kingdoms of worth. 
And religion, in like manner, asks that men should become sufficiently cultured to be able to appreciate Christianity - religion at its best. For all values finally go back to the riches of some personal life. We cannot be too often reminded that the best the world has ever shown us in literature, or music, or art, is but a partial revelation of the inner riches of some personal life. So Kaftan is in the habit of saying in his lectures at the University of Berlin, that the greatest problem of life is the problem of appreciative understanding of the great personalities of history. The highest conceivable culture, therefore, would be the culture that should enable a man to enter with appreciation and conviction into the deepest and most significant personal life of history; and the world is eoming to see with greater clearness every day that that life is the life of Jesus Christ. The world of the beautiful and of art, therefore, one may properly hold with Browning, is but the ante-chamber of the temple of the full sharing of the life of God.

The wise who waited there could tell

By these, what royalties in store

Lay one step past the entrance door.

All partial beauty was a pledge

Of beauty in its plentitude.

And all thou dost enumerate

Of power and beauty in the world,

The mightiness of love was curled

Inextricably about.

Love lay within it and without,

To clasp thee.

All the world of the beautiful and of art is but a single rose thrown over the garden wall, as but a little hint of the infinite riches of the life of God.

It is no accident that, for the most part, the best in sculpture, in architecture, in painting, in literature, and in music has been most closely connected with religion, and has found its highest inspiration there. And, where this is not the case, it must still often force itself upon the feeling of the thoughtful man that in any one of the arts, indeed, but especially in music at its greatest, the medium is too great for small passions. I suspect that I only voice the inner feeling and conviction of many another when I say that the music of the best love songs, for example, manifestly goes far beyond themselves; the music tells far more than the sentiment itself will bear.

Nor can this seem strange to the man who can think as well as feel. For, after all, in the first place, in much we all live alone, a solitary life, shut up to ourselves and God. There is much, both of good and evil, in us that no other has ever known, that we could hardly con- 
ceivably reveal to any other. Only to God is the deepest in us " naked and laid open." And that means that only unto God can that complete revelation of ourselves be made that must underlie the deepest personal relation of which we are capable.

Moreover, men are mastered in different degrees by two great contrary instincts - the instinct, on the one hand, of self-devotion; the instinct, on the other, of an insatiate thirst for love; and there is only one relation in which a man can give himself with absolute devotion, only one in which the response can wholly satisfy, if a man is fully awake to the real and ultimate meaning of his experiences. And this means that we are helpless in the face of the deepest instincts in us apart from God. "I came from God," George MacDonald makes one of his characters say, "and I'm going back to God, and I won't have any gaps of death in the middle of my life."

It is natural, therefore, that only under the great motives of religion should the artistic medium be felt to be fully filled by the sentiment it carries. Even the esthetic power of our natures is swept in its full compass only by the undying religious appeal; because only a conviction essentially religious can assure us of the final and complete worthfulness of life. We need to be able to respond with some real conviction to the prophetic appeal: "Arise, shine; for thy light is come, and the glory of the Lord is risen upon thee." "Lift up your heads, O ye gates; and be ye lifted up, ye everlasting doors; and the King of glory shall come in."

(4) Once more, religion and education are most closely akin in the final results attained. The highest results of a true education are convictions and ideals. The danger, no doubt, of a shallow education is over-sophistication - the false tolerance that is essentially indifferentism, because the great fundamental convictions and ideals have lost their hold on the man. Nevertheless, if it is the business of a true education to fit for high and rational living, then it must still be true that the highest results to be demanded from such an education are convictions and ideals; and the deepest convictions and the highest ideals, it should be remembered, are those of religion. For no convictions go deeper, and none are more vital, than religion's great assertions of the love of God and the life of love; they are practically all-inclusive. And even education would have reached its highest conceivable result only in the establishment of these convictions and their implied ideals. The real forces in education are persons, even on the intellectual side. The greatest results of education are convictions and ideals. And the supreme persons, convictions, and ideals are those of religion - are Christian.

We may, then, reasonably conclude that in aim, in means and spirit, in method, and in results, religion and education may be said essentially to agree. And that is to say: It is not possible for us to 
stand strongly for education in its full modern sense, and not find ourselves driven to the recognition of essential religion.

\section{Religion and Ethics}

From this comparison, now, of religion and education, let us turn to the comparison of religion and ethics, and see here, too, how impossible it is to conceive either at its best apart from the other.

(1) For, on the one hand, if the true ethical life is the fulfillment of all personal relations, then an impartial and thoroughgoing ethics must involve religion. For the spirit of the life that means to throw itself with impartial loyalty into the fulfillment of all personal relations in which it finds itself, certainly cannot logically leave out the most fundamental and significant relation of all. And if there is a God at all, the relation in which we stand to him must be just that most fundamental and significant relation. Not to fulfill that relation is, then, not merely to have failed on the religious side, but to have failed in any consistent fulfillment of our acknowledged ethical aim. From this point of view ethics involves religion.

(2) Or if, on the other hand, we look at the matter from the point of view of religion, we have here, too, to recognize that religion is the fulfillment of exactly that personal relation which gives reality and meaning and value to all other relations. These owe the very fact of their existence to the purpose of God; they owe their meaning to what he has put into them; and they have the value that is theirs only because he has so established it. To the man of religious conviction, therefore, the religious position of one whom he loves becomes inevitably the most important of all matters; because he knows that, in very fact, this relation to God is the one essential relation which, itself set right, sets all others right. The religious man believes, not without full warrant, that the man who has come into a true relation to the God of character revealed in Jesus Christ must thereby have put himself, in just that degree, into absolutely right relations with other men. The first and second,commandments are indissoluble; and religion is here seen to involve ethics, as before ethics involved religion.

(3) Indeed, if we strive to take the ethical laws simply as laws of our own nature, even so we can hardly help connecting them with the great ongoing righteous trend of the universe, else we could not reverence them; and this is an essentially religious conviction. For we must take the laws of our own being as at least a partial manifestation of the essential nature of things. We have not conferred our nature upon ourselves, and the laws which we find revealed in it are not of our own creation. We cannot, therefore, recognize them as carrying in any degree the consent of our reason and conscience 
without thereby rendering the tribute of our deepest reverence to this essential nature of things in its highest revelation in ourselves. Here, too, then, a conviction essentially religious underlies the ethical.

Wundt's thoroughgoing study of The Facts of the Moral Life may be taken as confirming this result, in his insistence that " the whole development of human morality rests on the expression of these two fundamental impulses of human nature " - "the feelings of reverence and affection." Of these, one, at least, is distinctly religious. And how important the religious element is, Wundt bears witness when, in speaking earlier even of the development of the forms of human society, he says: "Here, again, it is the religious factors that constitute the most important of all aids to moral evolution, whether found within or without the sphere of morality itself." 1

(4) For us Americans, too, there is an historical reason why we can hardly separate the ethical and the religious without a denial of ourselves. For our national character has had a religious basis, and has been plainly glorified thereby. When William Stoughton, in 1688, in words that John Fiske asserts must be taken as literally true, said of our Puritan ancestors, "God sifted a whole nation that he might send choice grain into the wilderness," he reminds us how great these founders of our national life were, and how transcendent was their service. And their greatness lay in their convictions and their conscience. And any "new Puritanism" in life needs beneath it the old Puritan religious convictions in their seership, in their prophet's sense of God and the spiritual world as the realest of all realities, in their consequent sense of commission, vocation, divine calling - the apostle's sense of being called to an "imperishable work in the world "- and in their resulting conviction of responsibility and accountability. This tremendous sense of the significance and value of life in the doing of the will of God as co-partners with him, - this sense had power, and must ever have power, to lift men above the petty and the prejudiced and the partisan. Macaulay was certainly no eulogist of the Puritans, but Macaulay saw that their "coolness of judgment and immutability of purpose" were "the necessary effects of their religious zeal." And, if we are to be worthy successors of worthy sires, we must bind our ethical life up indissolubly with their great religious convictions.

In truth, from whatever point of view we choose to consider them, if we look deeply into both, we can hardly fail to find that, in Wundt's words, "religion and morality tend more and more to blend in an inseparable unity." Religion is the sharing of the life of God, and no man may share the life of the God of character without character.

${ }^{1}$ Pp. 226, 328. 


\section{Religion and Life}

If there is any one emphasis of our time more powerful than the emphases upon education and the ethical, it is the emphasis on life. The demand for life, real, full, and satisfying, is the deepest instinct of our time.

'T is life whereof our nerves are scant;

More life and fuller, that I want.

So far is this true, that Professor Leuba feels justified in saying, as the result of his study of the religious consciousness of the Protestant Anglo-Saxon: "The preservation and increase of life is the moving impulse as well of religion as of secular activity." In our search, then, for the fundamental nature of religion, let us turn from this comparison of religion and education, and of religion and ethics, to the comparison of religion and life, and let us see how surely a faith that is essentially religious logically underlies all our reasoning, all work worth doing, all strenuous moral endeavor, all earnest social service; how permeated with the religious, therefore, all life at its highest must be.

(1) For, in the first place, a faith essentially religious logically underlies all our reasoning. For every argument that we can possibly make, especially concerning any of the greater interests of life, must go forward upon the double assumption of the consistency and the worth of the world. We can reason at all, only so far as we have already virtually asserted that the world is a world in which we can rationally think; and our most significant arguments require, as well, that we should add the faith that the world is a world in which we can rationally live. That, in other words, there is the unity and consistency of one truth and of a unified reason in the world, and an essential love at its heart that makes life abundantly worth living. And these two fundamental assumptions of all our reasoning are essentially religious convictions.

That men often do not recognize these logical implications of their reasoning and may use with great complacency impersonal and irreligious language concerning their experience that will not bear thinking through - this is all too true; but this does not alter the fact of the ultimate logical implications of their deepest thinking and living. The mere report, therefore, of the psychological facts of a man's religious experience, as he conceives it, is by no means the final step in any fundamental religious inquiry.

(2) In the same way, a faith essentially religious underlies all work worth doing. For, as Paulsen says, speaking simply as a philosopher, "Whoever devotes his life to a cause believes in that cause; and this belief, be his creed what it may, has always something of 
the form of religion." "Hence," he adds, "faith infers that an inner connection exists between the real and the valuable within the domain of history, and believes that in history something like an immanent principle of reason or justice favors the right and the good and leads it to victory over all resisting forces." ${ }^{1}$ It is impossible, that is, for a man with full consciousness to throw himself enthusiastically into a work which he regards from the start as absolutely hopeless. When, then, he takes up the work of his life calling, or the cause to which he devotes himself, as work really worth while, in which he can lose himself with joy, whether consciously or not, he is virtually asserting his faith in a plan larger than his own plan, the all-embracing plan of the on-going providence of God, which shall catch up the little fragments of his work into a larger whole and make them contribute, thus, to a goal greater than any that the man himself may set. To believe in the final worth of one's own work, then, logically implies a real belief in God. For "principles" and "plans" and "laws," so far as I am able to see, have no real existence that will bear thorough thinking, and can do nothing apart from Being that must be conceived ultimately in essentially personal terms. A fully religious conviction logically underlies all enthusiastic work.

(3) In all strenuous moral endeavor, in the fight for character for one's self, a faith essentially religious is in like manner involved. So Martineau asserts: "Nothing less than the majesty of God, and the power of the world to come, can maintain the place and sanctity of our homes, the order and serenity of our minds, the spirit of patience and tender mercy in our hearts." For here, once more, we shall not earnestly attempt a hopeless task. And if, in the surrender to the highest in us, we cannot believe that we thereby at the same time link ourselves to the highest in the universe, we shall not be able to reach that courage which gives promise of any high attainment. Only the highest motives are finally sufficient here. If our faith in the ultimate ethical trend of the great power back of the universe really breaks down, we shall hardly be able to keep our faith even in our own ideals.

That this faith in the ethical trend of the universe is always consciously present, or even the need of it definitely felt in any recognized religious way, I am far from affirming. There may even be such a kind of intoxication with life itself, as should lead one, as in a recorded case, on the one hand, to deny any relation to God, and yet, on the other hand, to assert in the most varied and ardent ways, "I trust the laws that govern my destiny." ${ }^{2}$ And the emotional and general volitional state of such a one might conceivably be almost

${ }^{1}$ Introduction to Philosophy, pp. 8, 9.

${ }^{2}$ American Journal of Religious Psychology and Education, Vol. I, No. 1, p. 72. 
ideal, for she expresses so deep a faith in the universe as fairly to rival the old Calvinistic test of willingness to be damned for the glory of God. But her intellectual perception of the real implications of her "faith-state," I confess, does not seem to me all that is to be desired. That a successful business man should even report to Professor Leuba, "I have no religious need; I am devoid of religious feeling," - this is entirely conceivable. But the fact by no means proves that there is no such need, if the man is to be thoroughly and consistently rational in his thinking and living. There are great temperamental differences here, doubtless, and the very force of life in us may carry us over many thin places in our reasoning, without misgiving; but the fact remains that hopeful, courageous, moral endeavor logically requires the faith that we are not here at war with the ultimate purpose of things.

(4) And, once more, a faith essentially religious logically underlies, in like manner, all earnest social service. I do not forget that, in the inconsistency of our natures, men may often go on in forgetfulness of the real significance of their actions, and in the strength of motives which they have at least formally denied. Nor do I forget that it is possible for social service itself to become, for the time being, even a kind of fad, and for the phrases of the new social consciousness of our time to become only a new cant. Nor do I forget that men in such unselfish service may honestly think of themselves, for a time, as not needing in any degree either the convictions or the consolations of religion.

Nevertheless, when I try really to think the situation through, I am not able to doubt that Nash is right when he says: "Nothing save a settled and fervid conviction that the universe is on the side of the will . . . can give the will the force and edge suitable." For here, also, we shall not throw ourselves with all abandon into a task that we think either hopeless or worthless. And that means that we must have back of our social service the great religious convictions of the love of God and the worth of men. We shall not attempt to dip out the ocean with a cup, and we shall not enter on a boundless social task in which there is no hope of accomplishing any permanent and large result. We must believe here that we work with God, in line with his own purpose, and that the mighty will of the living God is pledged to our attempt.

So, too, must we believe that we ourselves and those for whom we work have a personality great enough to make the sacrifice rational. Let religious faith in the immortality of men be once thoroughly sapped, let men be once fully persuaded that man is not a creature of the endless life, that he is not capable of an absolutely endless development, and that there is in his constitution no pledge of the eternal years, and the immortal hope dies down not only in us, but the 
value of all those for whom we labor is essentially lowered. It is not merely that our lives have lost value; the life of the other, also, has become comparatively worthless, and our self-sacrificing, altruistic service becomes vain and irrational. We shall not ultimately be capable of acts of supreme self-sacrifice on behalf of a creature merely of a day. And faith essentially religious, therefore, is necessitated, and, whether consciously or not, logically implied in all earnest social service.

And when we have thus said that a religious faith logically underlies all our reasoning, all work worth doing, all strenuous moral endeavor, and all earnest social service, we have already asserted that religion is inseparable from life. Benjamin Kidd, in his study of social evolution, insists that " the evolution which is slowly proceeding in human society is not primarily intellectual, but religious in character." 1 And though he uses the term "religious" in the sense rather of the altruistic, his contention may surely be regarded as essentially correct; for, as we have just seen, this spirit of willing self-sacrifice for others builds on a faith really religious. Fairbairn's conclusion is, thus, thrust upon us: "Religion is the supreme factor in the organizing and regulating of our personal and collective life." We can hardly take a step in any direction that we can regard as really significant, without a virtual assertion of God, of the sanctity of his will, and of the worth of men.

It is but an illustration of this inevitableness of religion that, in an introduction to a recent edition of Wesley's Journal, Hugh Price Hughes should say: "He who desires to understand the real history of the English people during the seventeenth, eighteenth, and nineteenth centuries should read most carefully three books: George Fox's Journal, John Wesley's Journal, and John Henry Newman's Apologia pro Vita Sua. . . . The Religious Question cannot be ignored. It is the Question; in the deepest sense it is the only Question. It has always determined the course of history every where." To similar import, Brierley says, in the preface to his Problems of Living: "Spite of the modern assertion to the contrary, our problems of living are finally religious, and look to religion for their solution."

Nor can this seem to the thoughtful man strange, when he thinks that, if religion is really communion with God, the fulfillment of that personal relation most essential to man, then religion can hardly fail to give the ideal conditions of the richest life. It is the great claim and challenge of Christ that he is come that men " may have life, and may have it abundantly." He welcomes just this test, and is willing to abide the issue. He brings, he says, not limitation of life, but life itself, the fullest, richest, largest life.

${ }^{1}$ Social Evolution, p. 263. 
Or if, in harmony with the social consciousness of our time, we think of life as love, we have only struck the note of Christianity's most fundamental conviction. Or if, with Kaftan, we find the great problem and joy of life in the appreciative understanding of the great personalities of history, then in Christianity we are confronted again with the one great, central, supreme personality of Jesus Christ. Or, if we try to think of the highest conceivable goal of life, we can hardly set before ourselves anything greater than the possible sharing of the life of the infinite God. Compared with the infinity of the religious outlook, all other aims and goals are poor indeed.

Or if, once more, we ask from psychology a statement of those ideal conditions of the richest life, and get its answer, - Reverent association, and work in which one can forget himself, - we can then hardly fail to see that exactly these greatest means and greatest conditions are given in religion. For here alone are the most intimate and unobtrusive association with the Spirit of the Highest, and work for the Kingdom of God - God given and large enough for a man to lose himself in it with joy.

We are thus unavoidably brought to our conclusion, and to Christ's great insistence: Religion is life. "This is life eternal, that they should know thee, the only true God, and him whom thou didst send, even Jesus Christ."

No doubt, the depth of a man's religion must depend on the depth of his conviction as to the significance of life, and his felt need of religion on the claim he makes on life. The man who requires little from life will have little conscious need of religion. But in just the proportion in which he awakes to the real meaning of the life into which he is called and of the true greatness of his own nature, in just that degree must he awake to the need of more than the finite can give - to the need of religion and to its indispensable contribution to life. What religion requires, above all, is not credulity, but simply that a man should be really awake. "Man's unhappiness," Carlyle says, " as I construe, comes from his greatness; it is because there is an Infinite in him, which, with all his cunning, he cannot quite bury under the Finite." He cannot satisfy the infinite though unconscious thirst of his nature with finite things.

It is no new heresy, then, though it has been so called, to assert that in this sense religion grows out of the claim on life. For it is, after all, only a modern echo of that great sentence of Augustine that has voiced the heart of the Church through the centuries: "Thou hast made us for Thyself, and our hearts are restless until they find rest in Thee." In our deepest nature, then, we are religious, and we cannot escape it. We were never meant to come to our best in independence either of our neighbor or of God. Man is alone the religious animal, and he cannot escape the demand of religion until he escapes 
from his deepest self. No wonder that Sabatier should say: "Man is incurably religious." Or that Royce should give "the highest worth to religion among the interests of humanity." Or that Coe should affirm: "Worship is so wrought into the fiber of our minds that we need only come.to ourselves to find God." " Or that Granger should say, even in arguing for the right of free thought in matters of religion: "The religious sentiment needs no adventitious aids, for it is safe here to trust the unbiased instincts of mankind. So far as prophecy can reach, it seems certain that man will always worship and that the symbols of the Christian tradition will afford the ultimate vehicle of his devotion." 2 We can hardly do less, therefore, than to confess with George Macdonald: " Life and religion are one, or neither is anything. Religion is no way of life, no show of life, no observance of any sort. It is neither the food nor the medicine of being. It is life essential."

Is religion of really fundamental importance, or can we easily dispense with it?

No age ever believed more than our own in education, in the ethical, in life. No age ever demanded more imperiously the best that education, ethical living, and the richest experiences of life can give. And the truest thinking of our time indicates that into this best no age and no man may come without religion. We cannot dispense with religion; it is absolutely fundamental in its nature.

${ }^{1}$ The Religion of a Mature Mind, p. 250.

${ }^{2}$ International Journal of Ethics, October, 1903. 


\title{
THE EXPANSION OF RELIGION
}

\author{
BY FRANCIS GREENWOOD PEABODY
}

[Francis Greenwood Peabody, Plummer Professor of Christian Morals, since 1886, Harvard University, and Dean of the Divinity School. b. Boston, Massachusetts, December 4, 1847. A.B. Harvard, 1869; A.M. ibid. 1872; D.D. Yale, 1886. Pastor, First Parish Church, Cambridge, Massachusetts, 1874-80; Parkman Professor of Theology, Harvard Divinity School, 1880-86. Author of Mornings in the College Chapel; Afternoons in the College. Chapel; Jesus Christ and the Social Question; The Religion of an Educated Man ; Jesus Christ and the Christian Character.]

I Do not propose in this introductory paper to attempt any contribution to theological or philosophical science, or to discuss any specific application of religion. The first has been impressively accomplished by the paper of President King; the latter will be presented in many ways by the meetings which are to follow. I have in mind nothing more than a point of view, a cursory survey of the present horizon of religious opportunity, from which we may descend, with a sense of common understanding, to the consideration of the religious needs and problems of our own time. What is the message of the twentieth century to religion? What is the possible expansion which is offered to religion by the new conditions of a new age?

No sooner does one thus approach the general characteristics of modern religious progress than he is confronted by the besetting sin of religious people, which has always obstructed the expansion of religion and still blocks the way to its larger use. This sin of the saints is neither moral obliquity, nor doubt, nor heresy, nor schism. It is provincialism; the dealing with a great theme as though it were a small one, the magnifying of the local until it shuts out the universal, the exaggeration of the unimportant, the loss of perspective, the failure to appreciate the dimensions of the purposes of God. A person of cosmopolitan experience finds himself some day in a secluded village. He listens to the conversation - the gossip of the highway, the parish, and the cottage hearth - and what most impresses him is the meagerness of the interests which most occupy these rustic minds. The cold and the crops, the price of hay and the gossip of the rival churches, - these things which are near shut out the remoter concerns of the larger world; and the wars of nations and of industry, the achievements of science and art, excite less real emotion than the condition of the corn and the problems of the town-meeting. These interests are not fictitious or discreditable; they are simply provincial. This rural life is side-tracked from the main line of the world. The alert and energetic youth of this provincial village are drawn by the law of natural direction toward a larger centre where 
life may expand to diversity, comprehensiveness, richness, scope. Provincialism is not directed to the untrue, but to the unimportant. It is false perspective, like that which a Chinaman paints on a plate, where the man is larger than the bridge he crosses, and the bridge is larger than the castle it joins. The incorrect drawing of the picture of life crowds the foreground with details which are larger than the universe behind.

The same defect of disproportion, or, in the language of economics, the limitation of spiritual output, meets one as he traces the history of the Christian religion. A person unfamiliar with the mechanics of religion who should enter some Christian convocation and listen to the hot debates of Christian ministers, might well find himself astonished by the narrow range of topics which seemed to command attention. What is this organization, he might ask, whose interests are here considered? Is it a piece of machinery, to be adjusted and repaired; is it a court, assigning its discipline and penalties; is it an army, with its uniforms and drills; is it a theater, with its search for a new sensation? It is not that these discussions are wholly illegitimate or superfluous. Organization involves orderliness; worship must have form. When, however, the spiritual is subordinated to the mechanical, and a way of inspiration regarded as a way of organization, then there results provincialism, and religion is detached from the real interests of the modern world, as the small-talk of the village is detached from the great movements of the world. In the preface to the last edition of Professor Paulsen's Ethics he remarks that many controversies of theology recall to him a student's reply to an examiner's question concerning the occupations of the inhabitants of the Hebrides. "The people of the Hebrides," answered this youth, "obtain a meager subsistence by washing each other's clothes." A similar comment might be made on the issues which divide religious sects and claim the first place in conventions. The Christians, a looker-on might say, maintain a meager existence by washing, or soiling, or criticising each other's clothes.

Even the highest themes of religion may be provincially approached. The purposes of God and the destiny of man, though they are the subjects of contemplation which environ human life like an atmosphere, without which it is impossible to draw full breath or to hold one's soul erect, may become unreal, uninteresting, unrefreshing, provincial. The habit of mind induced by theology easily develops into a detached and specialized way of thought, unrelated to the common duty of the world; and the theologian may discourse of the highest concerns in a language quite unintelligible to the common work-a-day world. Even theology is but a province of life, though it be a province of lofty altitude and large horizon; and the air of 
these heights is to those who habitually dwell below not easy to breathe. Aerial navigation, though it fascinate its practitioner, has as yet but slight practical applicability to the plodding world below. It is not surprising that one of the leaders of American education was led not long ago to remark: "I am an attendant at church and a church member, but I very rarely hear anything in worship or preaching which appears to have any direct relation with the work I have to do." The provincialism of the Church had alienated this sympathetic mind. The busy world had swept him into its hurrying movement, and the methods of the Church had left her, as it were, on the banks of this swift stream, unmoved and orthodox perhaps, but high and dry upon the shore, while the new scenery of modern life unfolded itself to the modern man at every turn of the flowing river of time.

If, then, it is provincialism which limits the effectiveness and obstructs the progress of religion, what is the call of the present time which religion must hear if it would hold its place among the constructive forces of the world? It is the call to a larger interpretation of its own task, the call from provincialism to cosmopolitanism, from the limited to the universal, from religion for a part of life to religion for the whole of life, from a detached, specialized, guarded, esoteric faith to a faith which is the key of the world's work, its public concerns, and its private needs, its politics and industry, its education and art, its national, social, and domestic welfare, its real and contemporary needs and cares and sins. This is the opportunity which the conditions of the twentieth century appear to offer to religion and which is reinforced by the philosophy, the science, the political movements, and the industrial changes of the modern world. The nineteenth century was a period of extraordinary development in the mechanical, external, and physical efficiency of the world. It was the age of science, of invention, of machinery, of political consolidation, of industrial organization, the period which made of human society in an unprecedented degree a fighting, producing, governing, administering machine. Religion had its part in this great movement toward mechanical effectiveness. It was the period of institutional churches, parish houses, denominational work, associated enterprise, conventions, conferences, delegations, committees. Never before did the machinery of the Christian Church work as well as it does now. It is the natural order of progress, first, that which is natural; afterward, that which is spiritual. The development of natural science, the acceptance of natural law, the interpretation of human society in terms of biology, the conception of the social organism with its many members,- all this which has marked the philosophy of the past century has had its effect upon religion and has given it also the aspect of a physical, biological, material organization, with 
a mechanical and external work to do. Does not such a period, however, though it be essential in the history of religion, bear on its very face the mark of preparatoriness, as though it were confessedly preliminary to a new movement of a new time? Does not the mechanism of nature, which has been so impressively taught by the nineteenth century, begin to disclose within itself a spiritual movement of which natural law is the symbol and expression? Is not the key of modern thought to be found in the dictum of Lotze, that mechanism in the universe is everywhere essential, yet everywhere subordinate? Are not the vast organizations of politics and industry which have been devised within one generation now offering to the next generation a new possibility of industrial stability and peace? Is society a merely biological organism, as we were taught twenty years ago, or does the biological analogy, by its very insufficiency disclose the essentially ethical nature of social forms? These are the new aspects of the world and its affairs which meet us as the new century begins. A spiritual significance within the machinery of the world, a penetration of the mechanical by the ideal, a renaissance of ethical idealism, - these are the ways that now lie open to the philosophy and sociology of the time. The nineteenth century had for its theme the social body; the twentieth century has for its theme the social soul.

The same demand for the spiritualization and expansion of the task is now laid upon religion. I have spoken of this as the religious opportunity of the present time. I had almost said that it was the last opportunity of organized religion. If the churches remain ensnared in the mechanism of their work, if they live in the era of organization while philosophy and sociology are advancing to the era of spiritualization, if they remain a separate, detached, provincial group, when the whole secular life of the world is learning the lessons of solidarity, fraternity, organic unity, then they must expect to forfeit the right to primacy among the creative influences of the new world and to become simply the refuges of the disheartened and the sentimental. Religion in all ages has the same central reality, the communion of the individual soul with God. The teaching of Jesus was fundamentally for the individual. It sought the one sheep; it rejoiced over each one that was found. The first discovery of Jesus was the significance of the individual. The first duty of the Christian is to practice the presence of God. All this makes a religious heritage which no change of the centuries can alienate or supplant: Religion, if possessed at all, is a personal possession. "The kingdom of God is within you." Because the centre, however, is the same, the circumference is not unchangeable. Religion does not become less personal because it becomes more universal. Personal religion is not antiquated or outgrown because personal religion 
finds itself in a universe of hitherto unrecognized religious significance. Religion has not less to do in the new world, but finds a new range of interpretative power. The soul is not less because the world is more. It is like the transition from the Ptolemaic to the Copernican conception of the solar system. Instead of a personal centre round which the whole world of eircumstance revolves, the person finds himself to-day in an infinitely larger system, set in his own orbit within a universe of other souls; and the grandeur and sanctity of this comprehensive law holds him to his own place with a new authority. Such is the expansion of religion. The one sheep is not lost or overlooked because it is gathered into the one fold. The practice of the presence of God is no longer to be attained by retreat from the world, but by service of the world. Religion is to be rescued from provincialism. The kingdom of God is to be not only within but to come on earth as it has come in heaven. The Church has heard much of religion as apart from the world; it is called to the discovery of the religious significance of the world itself, from abandonment of the world to interpretation of the world, from what the older theologians called the "body of doctrine" to what is now designed as the soul of doctrine, from the provincialism of religion to the comprehensiveness of God. The religion of earlier centuries has found its mission in saving the soul from the world; the religious mission of the twentieth century is to be the salvation of the soul of the world.

Let us consider, then, some of the ways in which this expansion of religion in the twentieth century may occur.

The first and most obvious redemption from religious provincialism is by deliverance from sectarianism. During the last century many ways of uniting the fragments of the Christian Church have been devised which were consistent with an age of machinery. It has seemed as though, with a little yielding here and there, an arrangement of ordination, a phrasing of creed, a shifting of organization, a divided church might be reconstructed into a single machine. It had been a disheartening enterprise. The purpose of Jesus, it now seems plain, cannot be expressed in the language of the nineteenth century. He did not prescribe an organization; he communicated inspiration; his call was not to uniformity but to life. The sects which have issued from his influence have not been mechanical failures which should now be supplanted by more modern machines; they have been, for the most part, results of great spiritual awakenings, of new vistas of insight, of brave sacrifices for reality, simplicity, piety, and truth. Words like Methodism, Quakerism, Puritanism, do not recall historical events which should be forgotten or depreciated, but are memorials of lofty experiences, deep movements of the Spirit, genuine revivals of forgotten elements in the teaching of 
Jesus Christ. The evil of sectarianism is not, therefore, in the external divisions which it permits. It is no more to be anticipated that there shall be one form of religious expression than that there shall be one language, one nation, or one form of government. The evil of sectarianism is its provincialism, the assumptions and contentions which proceed from the shut-in life, the isolation of spirit which breeds ignorance or contempt of the larger purposes of God. The sects are not to be distinguished from each other as false and true. They are, as it were, cross sections through religion. Each is true when looked at as a section, yet each is but a fragment of the growing whole. "Nothing is diviner in the Christ," says one of the greatest of modern theologians, " than the impossibility of identifying him with any church, though he is in all." The deliverance from sectarianism is to be attained, not by patching and softening and compromising and reorganizing, but by the simple appreciation of the magnitude and many-sidedness of the revelation of God to men. It is not a matter of a better machine, but of the expansion of motive power within the machine. Christian unity is not to be attained by a consent to opinion, but by an ascent to a larger horizon. It is not the giving up of much, but the believing more. It is rescued from provincialism by discovering the comprehensiveness of God.

The expansion of religion is, further, the problem now confronting the Christian Church in its missionary activity. The audacious dream of a world made obedient to Christ has, during the nineteenth century, taken shape in a vast business enterprise, magnificently conceived, lavishly endowed, and sagaciously organized. Never before was missionary machinery so well devised or its operation so smooth. Yet together with the new mechanism for the conversion of the world has come a new respect for the world, and a new appreciation of other religions which have been long conceived of as forms of spiritual blindness. Refined and subtle philosophies, great historic personalities, and noble literature, have become a new possession of the western world. What is to be the effect of this new knowledge upon Christian missions? Does it make them superfluous and intrusive? Does the new recognition of the unity of the world extinguish missionary zeal? On the contrary, this expansion of religious appreciation is the essential preliminary of rational missionary progress. Many missionary undertakings, with all their heroism, have been provincial in spirit. They have assumed a contrast of absolute truth with unmixed error, of light with darkness, where are now known to have been sages, scholars, mystics, great literatures, and great traditions, sources of instruction as much as objects of missionary effort. What an expansion of opportunity, what a new demand for insight, appreciation, and comprehensiveness, is thus demanded of the message of Christianity! Other 
religions may be the technical possession of priests and adepts; the Christian religion recognizes the sanctity of the whole of life, and sends out not alone its preaching missionaries, but its medical missionaries, its teaching missionaries, yes, even its mercantile missionaries, who shall rescue trade from trickery and teach the religion of commercial life. Christian missions are called to stand among the traditions and resources of an unChristianized world, and to say of it what St. Paul said as he stood before the men of Athens: "I perceive that ye are exceedingly devoted to religion. Whom therefore ye worship at a single altar I declare unto you as the God who made the world and all things therein."

It is not, however, within the specialized activities of religion that its expansion is most clearly indicated by the signs of the time. Beyond the interior discipline and technical tasks of organized religion lies the great world of human life, stretching like concentric circles round the sphere of religion, as though the island of faith were set in a great and stormy sea. Nearest to the shore of religion lies the circle of the home, with its problems of domestic integrity and domestic instability; beyond stretches the circle of social classes, with its diverse conditions of luxury and want; still further on the horizon lie the problems of industry, the toil of the millions and the wealth of the few; and beyond all extends the scene of political agitation and the storms that threaten national life. What have all these to do with religion, or rather, what has religion to do with all these? They are the scene of the expansion of religion for which the times are ready. It is not a question of outgrowing personal religion. The message of life is still to the individual. It is not a change of the centre, but an extension of the radius of religion. Is religion applicable to those new issues of a new world; is it large enough to cover the whole of life? Must it remain a personal possession, to be hoarded and prized for its uses within the soul; or may it be applied as a form of power for the redemption of the world? Was the purpose of Jesus restricted to the individual, or, as he looked out upon his mission, did he say, "The field is the world"? Is religion to remain provincial, an island of security set in an unexplored sea; or, is that island life to breed brave navigators, so that not alone the island but the uttermost parts of the sea shall be colonized by faith? Shall we still draw a line between the secular and the sacred? Is there not a religious significance in social life, a religious interpretation of social problems? Here is this extraordinary force which has already proved sufficient to convert and recreate unnumbered separate souls. Must it be dissipated like escaping steam in pious utterances, or may it be applied within the mechanism of the world, and by its expansion give new momentum to the world's work? These are the questions which confront religion as the age of organi- 
zation and mechanism comes to its close and religion asks for a larger work to do.

It is interesting to observe that religion has already taken its first steps of expansion, and has annexed to its territory some outlying provinces of the modern world. It has recognized, for example, the religious significance of the family, and has ventured out into that first circle of social duty. It has proposed better laws, better comity between churches, more scrupulous administration, closer scrutiny of the teaching of Jesus. Yet in this consciousness of social peril there still exists the provincial impression that religion is proceeding beyond its own proper sphere, as into foreign territory which may be adjacent, but is not its own. Shall, then, the home be regarded as a product of law and custom, to be safeguarded and shattered by legislatures and courts; or is it a part of the field of religion, historically created by moral sacrifices and restraints, maintained by the ideals of faith and love, and in the hands of religion to secure or corrupt? The relation of religion to the home is not that of one institution patronizing another institution or crossing the boundary into a foreign land. On the contrary, the home is a religious institution, and behind all legislative questions which concern the home lies the religious problem of creating in the home a type of the Christian religion. The stability of modern marriage is not to be accomplished by mechanical devices of law, but by a return from ostentation to simplicity, from laxity to loyalty, from the thought of the home as a commercial venture to the thought of the home as a moral opportunity. The problem of religion in the twentieth century is to annex the province of the family, and the order of procedure in this expansion of religion is to be, not, first the adjustment of ritual and regulations to be applied to the family, but first the restoration of domestic integrity within the family as an essential part of a healthy, religious life.

A second circle of social activity has already felt the expansion of religion. It is the circle of philanthropy, the sense of responsibility for the weaker members of the social body, the supplementing of the survival of the fit by the revival of the unfit. In all the centuries of Christian history the instinct of compassion has accompanied the life of faith. "If a man love not his brother whom he hath seen, how can he love God whom he hath not seen?" Yet how provincial has been the mind of the Christian Church as it has considered this expansion of its mission! It is as though philanthropy were, after all, an accessory enterprise, which might be becoming for Christians to undertake, but which lay beyond the distinctive sphere and essential task of the Church. I stood one day in a Women's Settlement House, the most unimpeachable form of self-effacing service which modern philanthropy has devised, and a minister of the Christian 
religion, looking about him for some technical expression of ecclesiastical loyalty, remarked: "This is very touching, but I wish there were more of Christ in it." How could there be more of Christ, one asked himself, than in such a work, just as it was, without technical confession or provincial limitation. Would not the Master, were he to walk those streets, pass with indifference many a great temple built in his name, and laying his hands of blessing on these ministering women, say, "Inasmuch as ye have done it unto these least, ye have done it unto me"? Is modern charity, in other words, an enterprise into which persons being already religious may venture as into a foreign land where one meets new customs and new languages, or does it lie within the natural boundaries of religion, a home-country whose language is the language of faith, and which needs no apology, or symbol, or flag, to bring it within the kingdom of God?

These steps in the expansion of religion are, however, in large degree already taken, though not always recognized. It is otherwise with the further circles of modern life, the industrial and political problems of the new century. Here is the most stormy and least explored sea of the modern world, and the Christian Church still stands and looks out to the tumultuous waves and conflicting currents of this sea as though it stood on the shore of its little island and watched a vessel driving toward the rocks. Something, the Church knows, ought to be done by religion which may save, not single lives alone, but the ship itself; yet how shall faith and love venture into so dangerous a sea? What means of help, what skill in salvage have they, what training to take command of so large a venture?

Precisely at this point, however, the new opportunity is offered to religion to justify its claim to leadership. sacrifice, wisdom, and saving power. Here is precisely what religion in the modern world is meant to do, - not to sit securely on the shore of the time, but to learn the currents and perils of the surrounding sea, to rescue from its disasters, to pilot to its ports. The industrial life of the present age does not lie beyond the province of the Church. It is the Church which is provincial when it permits industry to regard itself as Godless, irredeemable, remote. When Jesus stood one day with his little company of friends by the Lake of Galilee the meager use of their great opportunity seems to have impressed his mind, and he used the language of their vocation as a parable of the work they had to do. "Launch forth," he bade them, "into the deep, and let down your nets for a draught." They had been fishing along the shores of their opportunity, and he called them to do business in great waters. They had been as those who caught minnows, and he meant them to be fishers of men. It is the call which comes again from the present age to a timid Church - Launch forth into the deep. 
The place of religion in the modern world is not along the shores, but among its vicissitudes and storms. The industrial agitations of the time are a summons to the courage and daring of the Church. What is the fundamental reason for our present industrial discontent? It is to be discovered in the obvious fact that neither party to the industrial conflict manifests the slightest intention of any application of religion to business affairs. Many such combatants are religious men, but the world of their business appears to lie quite beyond the sphere of their religion; and in this divided life it is inevitable that business should become a mere state of war, and religion should seem to an increasing number formal, technical, or fictitious. One of the most extraordinary aspects of modern industry is the passionate devotion with which thousands have given themselves to a programme of industrial revolution and the abolition of private capital. What is there in socialism which gives it this emotional quality? On its face it involves a mere change of ownership, a new distribution of production. Why is it that men willingly sacrifice themselves for such a cause? It is because it is the nearest substitute they have discovered for a religion. A religion of materialism it may be that they have reached, a pathetic substitute for Christian faith; yet so long as the Christian Church regards the world of industry as foreign territory, so long those who are inextricably involved in the industrial order will create a new religion for themselves. The growth of socialism is an indictment of religion. It is the working-man's answer to religious provincialism.

Finally, the same situation presents itself in the political conditions of the present time. In the most unanticipated and dramatic manner the movement toward organization, concentration, and efficiency, which has dominated industry, now controls national progress. The questions which confront the nations are questions of world-politics. Political expansion has become not so much a policy to debate as a condition from which it is impossible to retreat. But what does political expansion indicate as the task of religion? It is often affirmed that it opens the way for the Church to follow. When other agencies have done their work, religion may reap the harvest. Such a view of religion, as technical, specialized, detached from politics and business, is sheer provincialism. Religion cannot be carried to a foreign nation after the politicians and the traders have opened the way. It is in and through the spirit of conquest, and through the conduct of commercial life, that religion must express itself. Its missions will be viewed as mere hypocrisy and formalism unless its rulers, soldiers, and exploiters are honest, just, and merciful. It is not after the statesmen have finished that the Church begins, but it is in that which the statesmen do that the religion they represent is weighed. Politics is not extraneous to 
religion, a foreign invasion to be followed by international peace; it is itself a part of the religion. The detachment of political inexpediency from religious ideals is the gravest indictment which can be made, not so much against the politics as against the religion of a land. In beginning the biography of Gladstone, Mr. Morley calls attention to the essentially religious character of this great political career. "He steadfastly strove," says his biographer, "to apply the nobler moralities of his church to the affairs of his own nation and of the commonwealth of nations. ... Well was it said of him, 'You have so lived and wrought that you have kept.the soul alive in England.' " That is the expansion of religion for which modern politics waits. The highest problem of the statesman is to keep the soul alive in his own nation and in the commonwealth of nations; and this, which is political greatness, is at the same time the largest expression of religion.

Such, then, is the call of the twentieth century to the religious life. Other centuries have been preparing the way for this expansion. Never before could the world of industry and politics be surveyed as one world, or the movement of the ages invite religion so urgently to a new enlargement of its sphere. Yet shall we speak of this expansion of religion as a new ideal? On the contrary, this conception of the unity of the world and this spiritual interpretation of its affairs was precisely the vision which lay before the mind of Jesus Christ in his teaching concerning the kingdom of God. Involved in Oriental imagery as his thought inevitably was, and directed at one time toward present circumstances and at another toward an ideal future, the fundamental note of the teaching of Jesus was his faith in the possibility of a consecrated world, when the will of God should be done on earth as in heaven, and out through all the circles of human association should radiate the controlling power of the consciousness of God. How distorted and shrunken has been at times the thought of the Church concerning the kingdom of God! The largeness of the purpose of Jesus has made it inconceivable to a shut-in world. He has been thought to proclaim an ecclesiastical organization, or an internal experience, or a glorious future in heaven for the saints, and it is quite true that all these aspects of the kingdom issue legitimately from his teaching. It seems to have been reserved, however, for the present age to appreciate the dimension of the kingdom of God. The unity of the world is a prerequisite for the recognition of the scope of religion. Social organization, industrial combination, political concentration, - these great events of the last century prepare us to discern, as it has been disclosed to no other generation in Christian history, the vision which dominated the mind of Jesus of a whole world - its homes, its business, its politics, its personal hopes and fears - penetrated and spiritualized 
by the consciousness of God and the desire to do his will. "In those days," says the first record of his mission, "Jesus came into Galilee preaching the kingdom of God." The words which thus begin the gospels are words written for the present age. In these days also religion is called from its provincialism to preach the gospel of the kingdom of God.

And how is it, finally, that this expansion of religion is to proceed in this or in any age? What is to be the instrument of this enlargement, the dynamic of the kingdom of God? It has been sought in many ways consistent with the spirit of the last century, through instruction in doctrine, through ecclesiastical machinery, through the discipline and organization of the Church; and all these enterprises have their place as preparations for the kingdom. When, however, one recalls the teaching of Jesus, he is astonished to observe how slightly the Master concerned himself for the machinery of his mission. He did not organize or discipline or even instruct in a deliberate form. He communicated himself. He trusted everything to the contagion of personality. He left all else to those who had been touched by him, perfectly sure that the Holy Spirit which the Father would send in his name would lead them into all truth. It is the same to-day. The kingdom of God, the expansion of religion through all the circles of human need, is not to be a new achievement of mechanism, but a new experience of the Holy Spirit. Personal religion is the key to social religion. It inherits the past, but it creates the future. Other centuries have converted the soul of the individual; the problem of the present age is to apply the converted soul to the conversion of the soul of the world. "I sanctify myself," said Jesus, - it was the secret of his power, - but he goes on to say, "For their sakes I sanctify myself." The sanctified life becomes the serviceable life, and in that perfect service finds its perfect freedom. The religious life rises, like some secluded stream, in the quiet consciousness of the single soul; yet it hurries down toward the world of men, as though it asked what further work it had to do. It sanctifies itself for others' sakes, and as it flows it joins with many another stream hastening like itself. Below waits the great plain of the world, with its busy multitudes and their unsanctified toil, thirsty for some spiritual meaning in their flat, dull lives. Out into the plain of human life flows the expanding stream of religion. It is no foreign land which it thus waters, but the valley whither, by the law of its own motion, it was meant to run. Here is the work which it was meant to do. This is the end for which the springs in the wilderness pour forth their unpolluted life. The enlarging stream finds at last the purpose of its own creation, and as it flows sings to itself the Master's message, "I am coming that these may have my life and may have it abundantly." 



\section{SECTION A GENERAL RELIGIOUS EDUCATION}





\title{
SECTION A GENERAL RELIGIOUS EDUCATION
}

\author{
(Hall 11, September 24, 3 p.m.)
}

Chairman: Professor Edwin D. Starbuck, Earlham College, Richmond, Indiana.

Speakers: Professor George A. Coe, Northwestern University.

Dr. Waiter L. Hervey, Examiner, Board of Education, New York City.

\section{THE REASON AND THE FUNCTIONS OF GENERAL RELIGIOUS EDUCATION}

\section{BY GEORGE ALBERT COE}

[George Albert Coe, John Evans Professor of Moral and Intellectual Philosophy, Northwestern University. b. Mendon, New York, March 26, 1862. A.B. University of Rochester, 1884; A.M. ibid. 1888; S.T.B. Boston University, 1887 ; Graduate student, ibid. 1887-88; Jacob Sleeper Fellow, Boston University, studying at Berlin, 1890-91; Ph.D. Boston University, 1891. Professor of Philosophy, University of Southern California, 1888-90; Lecturer on Religious Education at Harvard University Summer School of Theology. Associate Editor of American Journal of Religious Psychology and Education. Member of American Psychological Association, American Philosophical Association. Author of The Spiritual Life; The Religion of a Mature Mind; Education in Religion and Morals.]

How education in religion can be provided for the whole people in the modern state is undoubtedly a problem of great practical difficulty. Yet the more serious and decisive question is whether we really wish to provide such education. That the people will find a way to it whenever they are convinced of its paramount importance cannot be doubted.

The most disturbing feature of our present situation, accordingly, is not so much practical obstacles like that presented by the separation of the Church from the state as confusion or inconclusiveness in current thinking about both religion and education. Our age has caught glimpses of inspiring religious ideas, but it has not effectually harnessed them to the car of human progress. We have wrought out truths of widest import regarding education and the teaching process; we have taken some pains to study the child, and we have not been wanting in zeal for improving the machinery of the schools; yet in only a limited and over-cautious way have we tried to unify the aims and processes of the school with our world-view and with the fundamental aims of life.

We shall not proceed far in the attempt to unify these factors in 
our thinking and our practice before we perceive that the relation between religion and education is so close that the problem of the nature and place of one includes the problem of the nature and place of the other also. Solve one problem and you solve the other with it. That "education" and "religious education" are treated on this programme and in our every-day thinking as different conceptions is due simply to historical incidents that have temporarily divided what is properly one and inseparable.

The secularization of education that has been in progress for the last century is not to be regarded as a wanton or deliberate violation of principle, either religious or educational. It is rather an unavoidable incident of the coming of the people to self-consciousness and self-government. From of old, civil authority, religion, and learning, all alike descended upon the people from sources above them. Then came modern democracy, according to the inner principle of which the whole of culture should be found springing up from within the free mind and heart of man. What had been determined for the people by external imposition was now to be determined by them through self-imposition. Yet this principle could not be practically applied at once to the whole circle of life, nor could its true limitations be clearly defined. The principle could be put into practice only by limiting its application. Then was repeated the old story of conquering by dividing. There was ready at hand in religious thought a conception of a divided world, the world of the sacred and the world of the secular. This conception was now to receive its widest application and its severest test. Undertaking to govern themselves in the sphere of the secular, the people continued to think of things sacred as something separate therefrom and as coming to them from a realm beyond rather than as arising, like secular interests, from the nature and circumstances of human life.

Both Catholicism and Protestantism took this view. However much they differed as to the nature and extent of spiritual authority, they agreed in placing the affairs of religion apart from the affairs of nature and the secular life. This distinction, though the thought of to-day declares it to be artificial rather than real, made possible the modern free state and the modern state school. The secularization of education, therefore, is so far from involving any radical departure from religion that it is, in fact, an application of what religion herself has taught.

Nor is the secularization of education so much a retrograde step as an, as yet, only partially accomplished forward movement. It is difficult to see how free schools for the whole people, supported by self-imposed taxation of the whole people, could ever have become a fact in our divided Christendom without belief in the existence of a 
neutral ground like the purely secular. Our progress here has been like that of a mountain-climber who goes forward now and then by stepping momentarily upon stones or sands that move under his feet; or that of a skater who glides over ice that is too thin to bear his weight. Such movement is not only possible but also safe provided one move fast enough. Just so the secularization of education may be wholesome, provided we proceed promptly beyond it without trying to rest in it.

That it offers no resting place is certain alike from the religious and the educational point of view. If we approach the matter from the standpoint of religion, our fundamental consideration will have to be the idea of God that has been achieved through reflection upon our human experiences and through the study of external nature. The old separation of the sacred from the secular reflected the then current notion of the Divine Being. There are two worlds, it was thought, - the world of nature, and the world of the divine presence or supernature. Two educations logically followed, one conducted by the natural man organized as the state, the other by the Church as the representative of God. But the religious as well as the scientific thought of our day recognizes only one world. Religion is proclaiming that we have not to ascend into the heavens or descend into the depths to reach God. His dwelling-place is all reality, all experience. He comes to the soul, as an American writer has said, "without bell." $\mathrm{He}$ is in immediate and essential relation to the whole of nature, the whole of history, the whole of each personality. This conception justifies the remark that "religion is life, and life is religion, or neither is anything."

The bearing of this conception upon education is perfectly direct. If in all that we see and handle, all that we do and think, all that we hope and aspire toward, we are dealing with God, then any education that is vital must involve in its inmost essence a growing realization of the divine side of life. This conception renders possible, too, a reconciliation between democracy and the principle of authority in religion. For now that which springs up from within man as an expression of his deepest desire and will can no longer be regarded as having its sole source in his merely individual impulses or arbitrary choices. In all the aspiring and choosing that express what we most really are, a divine principle, deeper than our merely particular selves, is at work. Democracy, therefore, cannot truly express the will of the people, unless it submits itself to the inbreathing of this Over-Soul, the authority of this Over-Will; and democratic education will surely defeat itself if it ignores this deeper and most real aspect of life.

The demand for religious education, therefore, is a demand for education as such; it is not a proposal to superimpose one kind of 
education upon another, or to graft anything foreign into the original stock; it is not a proposal to remove education a single step from the concrete, practical realities of life. Religion is the recognition of realities as against mere shows, and religious education is simply that which moves within realities and not within the system of abstractions that the world tends to become whenever-its one, ever-present ground is ignored.

To say that education as such is properly religious does not, however, deny the propriety of division of labor in teaching. Each of our three great educational institutions, the family, the church, and the state, has functions that cannot be transferred to either of the others. Religion comes to the home and the state, not to destroy, or to supplant, but to bring to full realization and fruitage. But religion does demand that there be real unity within this diversity, that we have, not two or three educations, but one education to which all three institutions contribute, each its special part, while all are inspired by the same ideals.

From the standpoint of religion, then, the reason for religious education is the real presence of the Divine Being in the child and in his whole environment, and this idea excludes purely secular education altogether.

From the point of view of educational philosophy the conclusion will be the same unless the idea of the secular be pushed on from the sense of " non-religious" to that of " anti-religious." Secularism that consents to be a merely partial point of view, that merely ignores religion without weighing its claims, is for that reason incompetent to meet the universally recognized requirement of unity in education. The ultimate aim of the school cannot be other than the ultimate aim of life. It is vain for a school system to ignore the question of what life means and what are the highest use and destiny of a child's. developing powers. The effort to evade this deepest aspect of life, while professing to prepare children for living, is really to confess that one does not know what education is or what it is for.

The problem of the ultimate aim confronts us from whatever theory of education we start out. Suppose that we take our departure from biology. We then define education in terms of adjustment to environment. We are now required to make clear what we mean by the environment to which we propose to adjust the plastic child. The moment that we pass on from the physical conditions of life to the cultural environment, to the products of human thought and feeling and aspiration, religion meets us as an ever-present, insistent fact. If education is adjustment to environment, it must surely seek to influence the attitude of the child toward his religious heritage. To be neutral with regard to it is no more reasonable than to be neutral toward good literature, or toward civil liberty. The attempt 
to be neutral toward the religious factor in civilization is, in fact, an equivalent of what we call philistinism in respect to the other elements of culture.

What constitutes our environment is to be considered, too, not merely from the historical viewpoint, but also from the philosophical outlook, which surveys the question of what is real and what merely appearance. What kind of reality is this which we call the environing world? The immediate form in which it presents itself is that of a succession of sense-objects, but neither the intellect nor the heart of man rests in this first aspect. In philosophy the intellect and in religion the heart go forward to discover a supposed something "far more deeply interfused," that is, the abiding reality of things. The search may lead to any one of several conceivable kinds of reality; the question itself may conceivably be unanswerable; but the problem that it undertakes to solve and the impulse out of which it springs, are inevitable. Until we have at least faced the question of ultimate realities, with its corollary of the ultimate destiny of man, our conscious life hangs in suspense, unable to take possession of itself or its environment.

Education, considered as adjustment to environment, accordingly, cannot have in view adjustment to the merely immediate aspect of our world, but rather to the reality of it as far as we can discover or divine what that reality is. Does or does not a divine presence environ every growing child? Is there, or is there not, a benevolent purpose in nature and history? Are our duties divine commands, or are they not? Is there, or is there not, a divine government of individuals and of nations that exalts righteousness and brings to naught all the counsels of the wicked? To attempt to adjust a human life to its environment, or a nation to its environment, without facing these questions, is to lack seriousness in the work of education. Adjustment worthy of the name of education must be supremely adjustment to the real world as we believe it to be.

No school system, in fact, does or can maintain complete neutrality with regard to these deepest aspects of life. Even though specific instruction regarding religion be avoided, some belief or disbelief, some hope or hopelessness on this point creeps into the school in the personality of the teacher. Drive nature out at the door, says an old proverb, and she comes flying back through the window. There is religion or irreligion in the schools, there is adjustment to some view of the real world, wherever a man or a woman supervises a child's development.

We ought to insist that this inevitable part of school influence be made intentional, deliberate, and amenable to our cherished faiths. The non-committal habit regarding religion which the exigencies of the time have begotten in us has served its purpose and it should now 
be cast off. It is true that our age questions much that our fathers regarded as beyond question; we have grown sensitive toward the right of each soul to its own free thoughts and aspirations; we have become more gracious toward parties and sects that oppose us; we are, perhaps, more modest in the presence of the mysteries of existence; but we are still human. We believe, we aspire, we find the support and reality of life where our fathers found them. Why, then, should we not turn the mind of the child toward that which is most real to us? Rather, how, unless we do so, can we imagine that we are adjusting the child to his environment?

Suppose that we look at education from the viewpoint of the child rather than from that of the environment. The educational process is then regarded as development of the individual, as the full bringing out of his germinal powers. As under the environmental view we asked what is the environment to which the plastic child is to be adjusted, so under the developmental conception we ask what is the self that is to be unfolded, and when may it be regarded as fully developed?

The history of man shows that religion is neither a phenomenon of decay nor an incident of the childhood of the race. The emergence of man from animality was an advance toward religion as well as toward morality. The progress of culture has included, practically everywhere, advance in religion. In the whole history of civilization there is nothing more alive than religion. It is "closer ... than breathing, and nearer than hands and feet" to the world's poetry, music, art, morality, and social progress. As far as history can show us, the development of man includes development in religion as well as in the other elements of culture.

Similar answer comes from the study of mental structure and growth. The place occupied by the religious impulse in the edifice of mind is at least as fundamental as that occupied by the social instinct or the moral, intellectual, and esthetic ideals. Toward some centre of ideal unity all acts of thought are directed; in all our practical strivings of the higher orders there is an upward push through a world of fragments and discords toward unity, and harmony, and perfect fellowship. It is as natural for a human being to develop these ideals, to feel these impulses and aspirations, to " call to what he feels is Lord of all," as to grow into patriotism or the appreciation of literature.

Viewing education as the development of the child's germinal powers, then, we conclude that education as such is necessarily religious, just as it is necessarily physical, ethical, and social.

Indeed, every serious effort to define education leads in the same direction. Education is preparation for complete living; but a being who is capable, as man is, of infinite aspiration, cannot live 
completely without some realization of eternity in his temporal existence. Education is the transfer to each new generation of the accumulated products of race-experience; but religion is the supreme and most commanding product of that experience. Education, finally, is society's method of self-purification and progress; but social existence has ever had one of its chief roots in a common worship; society has ever included not only fellowship of men with one another, but also with superior beings. It is a precarious hypothesis that the social sense, apart from the religious sense, can ever be self-sustaining, much more self-purifying.

The reason for religious education, then, is precisely the same as the reason for education, and also the same as the reason for religion. Religious education is religion taken in earnest, and it is education taken in earnest. It is education in the complete and proper sense. It develops the whole man, adjusts him to his real environment, transfers to him all the values of race-experience, prepares him for living a complete life, and transfigures the social sense with the ideal feelings and faiths whence perennially may spring new and ever purer social aspiration.

To give the reason for anything is also, by implication at least, to indicate its functions. Instead, therefore, of trying to show in detail how education fulfills the notion of it that has just been described, it will be sufficient to call attention to one or two possible misunderstandings of what is its essential process, and finally to its relation to certain characteristic needs of modern life.

In respect to the individual, the function of religious education is the gradual development of a realization of God. God in nature, in history; God in all truth and beauty and goodness; God in the depths of one's own personality - growingly to realize this Presence, and to order one's life in the light of it, is to be educated in religion.

This proposition is not to be understood in any merely mystical, or merely dogmatic, or merely ritualistic sense. Learning a system of dogmas, or performing set acts of worship, may enter into religious education as parts or agencies of it, but they are not identical with it. True education is not merely instruction, or learning about things, but rather living increasingly in the reality as opposed to the mere shows of life. It is not merely the performance of this or that act, or even the formation of certain habits; it is also the growing selfcontrol and self-guidance of a soul that is achieving its freedom. Religion, too, is not identical with any of these, or with the joys of mystical contemplation. Rather, as "God fulfills himself in many ways," so religion has many aspects. It is as many-sided as our nature, and hence education therein must be as broad as the whole man.

The function of religious education, moreover, is not to effect a 
mechanical transfer to the new generation of a set of ideas or habits that control the older generation. The deposit of truth that the ages have accumulated certifies itself less by the weight of tradition, less by the compulsion of logic, than by entering as a vitalizing factor into the whole of a free and growing life. The realities of life have to be found out, or at least verified, by each generation, and by each individual, through an original experience. Only that is the true light which is also the life of men. Only that is true education which, abjuring all methods of forcing or externally fastening beliefs upon the mind, relies in unwavering faith upon the innate capacity of men to assimilate the truth and even to discern the truth thereby. Christianity lays the basis for such faith in its declaration that to every man coming into the world is given the true light, which is also the life of men, so that, when truth comes to men it comes to its own.

Our time has characteristic spiritual needs which only religious education can supply. In earlier times religion was in larger measure a refuge from the poverty of life's resources. Men turned to eternal things as compensation for the lack of temporal goods. In God and heaven they found safety and freedom to offset the serfdoms, the oppressions, the arbitrariness and insecurity of earthly society. Here they found enlargement and relief from the hard conditions of industrial life. Through religion the whole horizon of a narrow existence was lifted, revealing the islands of the blessed.

But the peoples that have yielded themselves to the modern movement no longer suffer from any such cramped existence. Geographical, astronomical, and other discoveries; modern invention, with its transformation of industries; modern commerce and intercommunication between men; popular education and popular government, - these have so diversified life, and so enlarged its physical and mental resources, that to-day men are finding in their ordinary occupations the enlargement which once they fled to religion to obtain.

Yet the old need is here, though the point of its impact has changed. We have, indeed, more and larger things to occupy our attention, but now as ever the life of a man " consisteth not in the abundance of the things that he possesseth," whether these things be material goods or the wealth of the mind. We are, in fact, so occupied and so distracted with the multifarious means of living that we forget to live. We are rich in objects, in ideas, in projects, but because we do not relate them to any principle that has finality in it our lives are fragmentary and ununified. We are full of movement, but we know not how to arrive. We are so desirous of keeping "up to date" that we lose ourselves in the flow of time. Even our philanthropic and not.seldom our religious enterprises have something of this spirit of distraction and divided selfhood. 
Thus the soul of modern man builds many houses for itself, yet lacks a home. At such a time the function of religious education, as far as the merely individual life is concerned, is the firmer organization of personality through the revelation within it of a divine principle of unity and finality. We must be brought to realize that, just as the apparent restlessness of nature really expresses unvarying law, so within the active struggle of life the peace and calm of eternity may brood. We must learn that values have their only value through ministering to personality, and that personality, in order to realize itself, must take hold upon the Infinite.

Another pertinent characteristic of our time is the growth of social self-consciousness. Nothing in modern life is more striking or more heartening than the deepening of the sense of social obligation, and the increasing realization, among reflective souls everywhere, that the meaning of life is found, not in anything that an individual can possess or achieve for himself or have bestowed upon him, but in the maintenance of truly human relations among men.

The social movement, to an extent of which it is hardly aware, takes its rise and derives its power from religion. Though it has been made possible by the coming of modern means of acquaintance among men, yet the notion of brotherhood that is emerging within this new human intercourse has been learned most of all from the teacher of the two great commandments. "Deep-seated in our mystic frame," as the social ideal is, it has been made "current coin " by Jesus and his followers.

It is significant that Jesus recognized no possible separation of the social from the religious impulse. To him the fatherhood of God and the brotherhood of men were reverse sides of the same coin. His religion, as far as it is realized in the world, is a social fact, a kingdom that comprehends in its scope all the so-called secular interests of life, and yet relates them all to the Father who is in all and over all.

But the present social consciousness has not yet perceived that, in the nature of things, ideal society must be a divine as well as a human fellowship. As in our individual occupations, so in our social strivings, we are largely missing the sense of eternity and finality. The enthusiasm for humanity that ennobles many of our choicest souls has in it a note of pathos because it includes an unsatisfied religious aspiration. Seeking for something large enough to fill a human heart and command a human will, but falling upon the doubts of the age, these noble souls have fixed upon humanity as the worthiest object of their devotion.

Thus it is with many of the enlightened and the gifted. Among the masses of the people the same movement of the mind is taking place, though in less ethereal form. Here a rough-and-tumble struggle for the betterment of human relations largely takes the place 
of formal or ecclesiastical religion. Indeed, the social aspiration and the sense of social law that utter themselves in this struggle are being substituted by a large proportion of the populace for the sense of divine law and divine love.

Religious education for the whole people, and that alone, can bring the social movement to its own. It is necessary to raise up a generation conscious of the divine element in the social consciousness and instructed in the truth that all the real progress of society is progress toward and within the kingdom of God. It is idle to think that enthusiasm for humanity can be propagated through the generations under any theory that looks upon humanity as a succession of flashes of consciousness drawn from unconscious nature only to be extinguished in the darkness whence they come. To the human consciousness, with its inherent impulse for unity and completeness, the end of life cannot be found in humanity unless man contains within himself something more than mere process, something of finality. The only adequate basis for social progress that could be found for us men would be some kind of meeting together of humanity and divinity; or in other words, a society that already possesses the eternities and infinities. Therefore, a special and needed function of religious education in our day is to interpret the social consciousness to itself in terms of religion.

That such education is already an urgent practical necessity is evident from existing political, social, and industrial conditions. In this time of rapidly changing ideas and modes of life, a very unusual strain has been put upon the bonds that protect property, family relations, and personal rights. Now and then we are made to shudder at the discovery of how slender these bonds have here and there become. At such a juncture there is peculiar reason for asking what conception of life the rising generation is acquiring, and what will be the fruitage from to-day's seed-sowing. The conviction appears to be general that neither in quality nor in amount is the religious education of to-day adequate to meet the practical problems of our time. Not only the children of the neglected poor, but also those of the neglected rich; not only the children of emigrant parents, but also those of native stock; not only the children of the unchurched masses, but also the children of the church - all are suffering from neglect.

Practical considerations like these have had much to do with the starting of the present movement for religious education and the organization of the Religious Education Association. Yet the movement is not a passing expression of any alarmist sentiment; it does not proceed from utilitarian considerations alone; nor does it-aim to meet any merely temporary exigency. Its reason for existence is rather the eternal truth of religion. It is a call to look 
through and beyond the external aspects of life, the mere means of existence, to real existence itself. It arises not through zeal for any party or any sectarian ideal; it seeks neither that which is new because it is new, nor that which is old because it is old, but that which is eternally real. It proposes no fantastic theory or form of education, but simply education. 


\title{
HOW MAY THE TEACHING OF RELIGION BE MADE POTENT FOR MORALITY?
}

\author{
BY WALTER L. HERVEY
}

[Walter L. Hervey, Examiner Department of Education, New York City. b Mount Vernon, Ohio, 1862. A.B. Princeton, 1886; Ph.D., ibid., 1892; University of Jena, 1893; University of Berlin, 1897-98. Teacher in Secondary Schools, 1886-89; Dean and Professor of History and Institutes of Education, New York College for the Training of Teachers, 1889-91; Acting President, ibid., 1891-92; President Teachers' College, 1882-97; Dean of Chautauqua School of Pedagogy, 1893-98; Lecturer, Hartford Theological Seminary, 1900-04; Member of New York Board of Examiners, 1898. Member of National Council of Education; Sunday-School Commission Diocese of New York; Religious Education Association. Author of Picture Work, and other books of education.]

IT is characteristic of present ways of thinking and doing that men increasingly regard moral ends as attainable chiefly by moral means, and moral forms as of less moment than moral forces. To create a moral environment and to bring the individual into vital relation therewith,- - this is the way to produce abiding results in the moral realm. Now, the social institutions that together make up the moral environment - the family with its expansion into the school and the social settlement, the press and the public opinion it reflects and forms, the vocation, the civic community, and emphatically, the Church - are, as never before, alive to their moral vocation. The conscious aim of the school, for example, is not knowledge alone, but character; not intelligence merely, but moral enlightenment; not selfish individualism, but efficient social membership. Moreover - this I postulate - all these institutions have a common stake in religion; and this, whether or not they are aware of the fact.

That religion is one of the deepest and most potent of moral forces is sometimes overlooked, - just because, perhaps, it is so deep and so pervasive. But it may be confidently affirmed that without the stimulus and the sanctions of true religion, $i$. e., of the religion that makes for righteousness, no one of these social institutions can do its perfect work. How religion may, through education, be made to reinforce the agencies that make for righteousness, is my theme. In discussing it I shall undertake to show, first, what the conditions are under which religion may best perform its work for morality; and, second, what that work is.

That there exists, and always has existed, a certain gap or divorce between morality and certain forms of religion, is a matter of history as well as of ordinary experience. Religion per se is neither moral nor immoral. It is a powerful force either for good or for evil. 
Whether it work for good or for evil depends on its relationships with the totality of life. If religion is essentially related to the unity of complete living, then religion makes for morality; otherwise not.

This requirement of unity is violated whenever religion and morality are looked upon as having to do with different and mutually exclusive realms, with different and distinct actions, days, places, standards. It is violated whenever morality is limited to human relations and duties, religion being confined to such other matters as pertain to God, - as if I could ever owe a duty to my brother without owing it to God at the same time; and as if I could ever fully do my duty to my brother without seeing in him a child of our common Father. And it is violated whenever those upspringing: impulses of human nature, which when nourished and guided become priceless elements of strength and beauty and enrichment, are trampled on, starved, and spurned in the name of "religion;" whenever in the name of "religion" sacrifice is substituted for mercy; whenever the palpable fact of unrighteousness is looked upon as not so unrighteous if done by a pillar of the Church, as if there were something he might do in church or on Sunday, with reference to higher powers, to mitigate, in his case, the hard mandates of the moral law; and whenever there exists the practice of discounting the morality of the man who is undeniably upright in life, but who is not apparently " religious," - - instead of taking the equally consistent and more charitable ground that if (or since) this man is righteous, he must have some religion.

The idea is of slow growth that morality and religion are essentially at one, and that each applies to every department of life. One hears tell of "religious duties," and other duties not religious; of "working for yourself " part of the time, and - "Can you not spare one day in seven in which to work for God?"- as if a righteously religious man, whose God is conceived as " nearer than breathing," could ever be working purely for his own self or his own pocket any of the time.

The use of the word spiritual in a certain familiar restricted sense is a case in point. A person's spiritual welfare is sometimes spoken of as if it entirely concerned his future salvation, or his churchly life. A spiritual person is (or perhaps I should say, used to be) commonly thought to be a person in whom sentiment is more strongly developed than practicality. But the term spirit, and its derivatives, may properly be applied to the higher life of the human mind as a whole. To give a cup of cold water in the name of a disciple (in any one of the myriad ways possible in modern life) is not the less, but the more, spiritual because it is practical. It is a loss to morality to use a term like spirit as if its connotations were wholly religious; it is a gain to religion as well as to morality when a noble word is made to em- 
brace not merely the infinite reach but the finite application. In seeking to realize the essential unity of morality and religion it is indispensable that we look for the religious aspect, not merely of some, but of all objects, relations, and activities. It is cramping both to religion and morality to seek God chiefly or wholly in the "house of God," on the "Lord's Day," under the ministrations of the "man of God." It is a good thing for religion and morality to meet God in a bush and in a mountain, as did Moses; under the stars and by still waters, as did the Psalmist; in rocks and rills, woods and prairies, as every one of us may do. Every law of nature is a law of God. Every truth is an accent of the Holy Ghost. It was not without reason that men once worshiped the divinity they found in animals. I doubt if there be a single object ever used in worship by man, however degraded, that may not for us bear a true message to the spiritual life. And if dumb animals, still more fellow men. The person who is an adept in discovering and in evoking the divine principle that lurks in every man is he who, other things being equal, is the man of righteousness.

Thus far we have the general thesis that religion and morality must be conceived of as in harmony if they are to work together. Three special requirements may now be considered. There must, in the first place, be an adjustment between one's general view of the world and one's ideas of religion. For if one's ideas about life in general belong to the Copernican system, while one's religious notions suffer arrest at the Ptolemaic stage, it is difficult to see how either set can influence the other. The following conversation gives a hint of the problem which is much more easily stated than solved:

"Why don't you like to go to church?" was asked of a bright young fellow, studying to be a mining engineer, who had been called "worthless" by the minister of the church he stayed away from, for no other apparent reason than that he stayed away.

"Do you want the reason, or just a reason?"

"The reason, if you don't mind."

"Because what I hear in church, and what I study all during the rest of the week don't gee. The Sunday talk has to be put into a hermetically-sealed compartment; it won't mix with the week-day work."

Yet the week-day work, we are bound to believe, was good engineering; and if it was, it was so because it was in harmony with the laws of the universe. If it was in harmony with the laws of the universe, why was n't it in harmony with " religion "?

Another aspect of the same problem is presented by those whose ideas are still, broadly speaking, at the Ptolemaic stage, and who are no more able to apperceive the higher criticism and kindred views than their great grandmothers would have been. To such, 
any and every change appears ominous. "If you take away Jonah from the whale's belly, and Deuteronomy from the books of Moses, what assurance have we that you will not, as the next move, wipe out the moral law, or rob hell of its power to terrify men into being good"?

It would seem that the religious sanctions of morality, to be effective, must be adjusted to the individual's stage of development. But not at the sacrifice of sincerity. It has sometimes been thought necessary, in the supposed interests of adjustment, to teach what is not believed as if it were believed to children who, if the truth were known, are suspicious of the insincerity. It is not enough to plead in extenuation the "culture epochs theory," for that theory means that what is truth for the adult grows out of what is truth for the child; it does not mean that the child must be taught error as a preparation for truth.

Finally, in view of the very human tendency to express religion in language rather than in life, the unity of religion with morality must take the form of practicality: that which is believed in religion must be translatable into righteousness of life. It is difficult for most persons in these days to understand how many articles of belief for which men once fought and died, and to which some still hold, could ever have had, or can still have, power for righteousness; or how a faith that wholly centres on the world to come can be sufficient for the daily needs of this present world. It is a favorable sign for morality when men look to religion for help for this present moment and the next, thus identifying the field of religion with the field of morality.

Assuming, now, that the unity of religion with life has been, in a given case, established, what in general is the service religion may be expected to give to morality?

Religion and morality, as we have seen, occupy common ground. They both deal with conduct and character. Both build on the same facts. Both apply to the same actions. Each covers nothing less than the whole of life. They differ in their mode of conceiving life. Morality, as Professor George Herbert Palmer shows, faces toward the finite; religion toward the infinite. They are " inextricably involved," because every object, action, and relation has both its finite and its infinite aspect. It follows that while morality serves religion by giving actions their concrete and finite application, and translating love of God into terms of service to this brother, here and now, religion serves morality by helping us to see the finite in the light of the infinite, to see the infinite in the finite, to raise the petty task to the level of divine coöperation, and to exalt the circumscribed person to the level of a co-worker with God. In short, to endow men with the firmness and the courage that inevitably comes with the 
vision of the infinite God walking among finite men, and working in and with them.

Let us now consider three specific points at which religion may reinforce morality. And may I ask you to observe if it be not true that the help that religion is, or should be, best able to supply, is the very help that morality most urgently requires.

First, obedience and fidelity. Obedience, particularly in the sense of fidelity to the inner law, is the primal fact in morality. It is a weak point in current morals. It is also a primal fact in religion, and if I mistake not, a decidedly weak point in current religious life. The trouble seems to lie with that which is at the heart of obedience, namely, belief. For there is an intimate relation between obedience and belief as is thus set forth by Professor Giddings, ${ }^{1}$ "The whole development of personality presupposes certain beliefs and obediences. All of that wise determining power which is characteristic of personality implies certain beliefs in regard to the world wherein man finds himself, and certain obediences, corresponding to the beliefs."

How, in the modern world of scientific proofs, of shaken creeds, and of weakened authority, are we to cultivate the tender plants of obedience and faith? First, let us answer, by standing out of the way. Faith is a natural function. We are, as a rule, "born believing." And we keep on believing until something makes us cease believing. The teacher cannot create faith; but unfortunately he can obstruct it. When we see that floating away which we were taught was solid rock, we naturally ask, Will this float away, too? Is there any rock? The trouble is that, as Paulsen puts it, the demand has been made "in the name of religion, that men subject themselves, not to the commands of God, but to human dogmas." 2 It is necessary to make a distinction between those beliefs which are forever firm, and those doctrinal tenets which, while they possess value for us and have been held by many, continually require reinterpretation and adjustment. "I believe in God" is an example of the former"; " born of the Virgin Mary," of the latter. Ruthlessly to clear the decks and throw overboard what does not at the moment seem to have use or meaning is not less unwise and unwarranted than to confound shifting doctrines with perdurable certainties. "Teach nothing as essential that is not so," is another form of stating this important principle. "Leave the way open for adjustments and interpretations, while holding fast to the thing itself," is another. "Religion," says Paulsen in his rare way, " does not demand that we think what cannot be thought, but that we believe what satisfies the heart and the will, and does not contradict reason." 3

${ }^{1}$ Principles of Sociology, p. 395.

${ }^{2}$ Introduction to Philosophy, p. 334.

${ }^{3}$ Loc. cit. 
This dictum of Paulsen's leads to a second note regarding the kind of belief that will count for morality. For if belief is an affair primarily of the heart and the will; if, as Professor James says, "will and belief are two names for one and the same psychological phenomenon;" and if "belief consists in an emotional reaction of the entire man on an object; " it follows that to believe that which leaves us cold and unmoved is a psychological impossibility. Belief in that which we cannot act on - that which makes no practical demand upon us - is inconceivable. We have no use for a belief which we cannot use. Per contra, it is inconceivable that we should persistently act on something, or even be vitally interested in it, without finally believing in it.

It is the greatest of errors in religious education to suppose, and to act on the supposition, that belief is an affair primarily of the reason; that beliefs are to be reasoned out, reached through reason. No one ever believed because of proofs addressed to the understanding.

A child believes in God because he has from infancy been taught to pray to God at his mother's knee; because his home life is lived in practical recognition of a heavenly Father; because in church he joins in public worship, and learns and loves to say "I believe in God the Father," before he begins to know what belief is, or what his words fully imply; and because at far back as he can possibly remember, God, the loving heavenly Father, has formed the background of his life. The same is true of every other fundamental belief. Which of them all has been arrived at by argument? Which of them not by living in the presence of the fact?

Here, if anywhere, appears the weakness of Socrates' dictum, Virtue is knowledge; and the strength of Aristotle's saying, Virtue is practice and habit. Beliefs arrived at in any other way than through deed, use, and life, and the immediate certainty of the heart springing therefrom, are not only less firm and less practical, but they are not even beliefs. If we were to conceive of religious belief as a squaring of ideas by certain standards, as an acceptance of certain views of truth, as in the Quicunque vult, then the net result for morality of such religious belief would be such as is wont to spring from intellectual enlightenment, - or darkening. If seeing what ' $t$ were well to do were tantamount to doing it, it would suffice for purposes of morality to convince the intellect. But mere knowledge is not conduct. Morality must be met on its own ground, that is, in the sphere of action. If belief is to reach behavior, it must have its roots in behavior. It must be an experience which has arisen less when we were saying something than when we were doing something. In laying the foundations of faith, action should precede explanations; there should be first the service, and afterwards the answer to the question, "What mean ye by this service?" 
But in exalting the emotions and the will as springs of belief, have we sufficiently taken account of that other fact, also asserted by Paulsen, that reason must approve, even though it cannot prove, that which we believe? The time certainly comes, and it should come, when every intelligent person calls his belief to pass muster at the bar of his intellect. I should be sorry for any man who then could not find at least one solid belief. Let him hold fast to that. One is enough, if that is all he has, and if he is "one of those whose little is his own." Let him affirm that mightily and triumphantly; and then let him add to it as he can. In most instances his case will be like that of the college student who went to the consulting pastor in grief because he had so many doubts. "Will you do one thing for me?" said the pastor. "Go to your room and spend one hour in writing down, on one side of a sheet of paper, the things you really do believe." On his return the youth said: "I could have spent two hours and filled the other side. I believe more than I had any idea I did."

A word before leaving this point on authority, a quickened sense of which we undoubtedly need here in America and at the present time. There can be no obedience without it. But it makes a difference what kind of authority. There is the authority of reason, the authority of institutions, the authority of faith. These three may be at odds one with another, but not necessarily so. So far as they are pure they all spring from within, and are at one. The only obedience to authority which deserves the name of moral, is obedience to the authority that springs from within. The moral man obeys himself. But that is only another way of saying that the moral man obeys God. Religion will have performed its highest service for morality when it has helped us to discern the authoritative voice of God, not only in the individual reason, but in social institutions, and in every relation of life.

Next to belief and obedience, as the roots of morality, we must place the sentiment of reverence. Reverence has been truly called the mother of morality. Like belief and obedience it is the fruit of religion; and like them it is not to-day flourishing as it should flourish. "There are few persons," says Mr. Lecky, " who are not conscious that no character can attain a supreme degree of excellence in which a reverential spirit is wanting. Of all the forms of moral goodness, it is that to which the epithet ' beautiful' may be most emphatically applied. Yet the habits of advancing civilization are, if I mistake not, on the whole, inimical to its growth."

Why is it that the habits of advancing civilization are on the whole inimical to the growth of the sentiment of reverence? The answer to this question is suggested by such observations as these: Wonder

${ }^{1}$ History of European Morals, II, p. 141. 
and devout admiration, the springs of reverence, have been clouded by half-knowledge and ignorance. The fearful wonder of the superstitious savage, and the devout humility of the true scholar are both akin to religion. The savage worships because he fears the power which is external to him; the scholar worships because he sees and feels that the power that made the heavens is his own essence. But there are many halts and arrests between these extremes.

The conquest of nature by science, moreover, tends to destroy our reverent sense of dependence, and to breed self-sufficiency.

The separation from nature, which to-day exists to a degree unprecedented, is a fruitful cause of irreverence. The philosopher who found in the starry heavens the counterpart of the moral law, and the poet who escaped from the lecture room of the learned astronomer to gaze "in perfect silence at the stars," enjoyed a privilege missed by many in these days.

We are submerged by the common prose of life at second-hand. When one gets vegetables from the grocer, and not from the garden, one is disposed rather to complain of man than to thank God. A man who from one year's end to another never experiences palpable proof of God's bounty, poured into his lap by the hand of nature, will have difficulty in rounding out his religious life. Where one is condemned to live for the most part in the man-made towns, instead of in the God-made country, religion suffers along with the other spiritual powers. Men used to be aided in their worship by animals, fire, trees, and forests. There are worshipful elements in all these things still. Yet we are largely missing them.

Again, we in America are paying the penalty of having so radically cut loose from the past. The distinct education, value of custom, tradition, and form in family, in school, and in church, cannot safely be disregarded.

These causes suggest their own remedies. The spirit of reverence will be promoted by increase in depth of knowledge, by loving contact and communion with nature, by quickening the sense of social authority, by safeguarding that which is of worth in the heritage of custom.

But there is a further characteristic of our time, and for that matter of every time,- the lack of reverence of man for man. If men were reverently conscious of themselves and their fellows as persons, and treated them accordingly, the kingdom of heaven would have arrived. The specific for this condition is religion, which has been defined as " a deep and reverent consciousness of the transcendent relations of personality;" 1 and in particular the religion of Jesus Christ. Now, one fruitful cause, in my judgment, of the lack of

${ }^{1}$ Giddings, loc. cit. p. 396. 
reverence of man toward man is found in the tendency to place Jesus Christ quite apart from his fellow men, and to regard him as being a man in some special and, as it often seems, unreal sense. If Jesus Christ was a man in precisely the same sense as you and I are men, then that not only helps us to understand him better, but helps us better to understand each other and all mankind, and to reverence all men as brothers of Jesus Christ. It is essential to the development of reverence that we follow the order laid down by Frederick W. Robertson: that belief in the human character of Christ's humanity must be antecedent to belief in his divine origin.

Reverting now to the expression " the sentiment of reverence," let us this time place the emphasis upon the word sentiment. There is no other word in the teacher's vocabulary which can take its place. For the word sentiment does not signify feeling, and still less idea, but a happy and fruitful welding of the two. Sentiment is emotion permeated with insight; it is an ideal on fire with feeling. When you effectively appeal to a man's reason, you convince his reason; when you effectively appeal to his moral sentiments, you move him. "The world," as President. Eliot has said, "is still governed by sentiments, and not by observation, acquisition, and reasoning; and national greatness and righteousness depend more on the cultivation of right sentiments in the children than on anything else." If all this be true regarding sentiment, it becomes of the highest importance to know how to cultivate it in the young. I shall briefly enumerate some points which seem to me of value to this end, especially to the teacher of religion:

(1) Sentiment is produced by subject-matter of instruction that contains the elements of nobility, sublimity, greatness. The selection of Biblical passages for study should be governed by this principle. The palpable fact that all passages are not of equal value has sometimes been overlooked by the makers of lessons. The plagues of Egypt, the interesting but comparatively innutritious stories of the Judges, the spectacular splendor of Solomon's court, have too often crowded out the noble and elevated messages of Hosea, Amos, and the Isaiahs.

(2) Sentiment is engendered by methods of teaching which recognize the truth of Herbart's dictum: "Moral power is the result of masses of thought; in them only can an abiding and many-sided interest be aroused." What Herbart means by interest is something very like sentiment. Moral power comes from masses, - it would be well for lesson-makers to remember that.

(3) There can also be no sentiment without the sense of reality.

(4) Since sentiment is primarily emotion, and not definition or reasoning, the means of producing it are those which are adapted 
to generate emotion. Purely intellectual aims and methods have no place in the teaching of religion.

(5) But sentiment, like every other emotion, is catching. Let the teacher himself have seen the noble vision and have been thrilled by it. The laws of suggestion will take care of the class. Nothing in all the panoply of education can take the place of the teacher's sentiments.

(6) And, finally, perhaps the most powerful of all means for molding sentiment in the individual, is the sentiment-generating power which resides in institutions. I treat this more in detail under my next and last head.

The third of the special ways in which religion can serve morality (the first and the second being, as we have seen, to develop obedience and fidelity and to ereate the sentiment of reverence) is (to use Professor Palmer's words once more) to inculcate "in the child and the youth a responsive respect for institutions." This is not a different point from the other two I have given, but it beautifully sums them up and shows how they may be realized. To inculcate a responsive respect for institutions, - that means authority, belief, obedience, reverence; it means the creation of sentiment; it implies recognition of the transcendent relations of personality; and it denotes these raised to their highest efficiency.

Institutions have been called "organizations of conduct in which is exerted the unnoticed pressure of a moral world." From another point of view they are viewed as "the organs that conserve what is best in the past of the human race, while to the individual they offer fields of ever widening activity." Both of these views mean the same thing.

A youth who becomes a member of an institution finds himself placed in relation to certain organized lines of activity; he finds that he is played upon by motives impelling him to follow those lines; he is given tools with which to do his work; and he finds the light of the experience of past generations thrown upon his path.

We saw in sentiment a valuable combination of idea and motive. Here in institutions we have a like combination, only one of vastly multiplied efficiency. The institution perfectly satisfies the seeker after an efficient moralizing agency. An institution is like a highly organized machine: in both, that which enters as raw material comes out as finished product; in both, the work is not done chiefly by the individual volition of the subject undergoing treatment; what is required of him is simply a responsive respect for the machine. "You do your part, and I 'll do mine," the machine seems to say. The individual " joins;" and straightway potent forces begin to play upon him of which he is not the source, and of which he but dimly understands the nature. It is a false psychology that exalts the 
individual, lonely will at the expense of moral environment. "The mature man is molded into individuality not through deliberate exercise of mind and will, undertaken for their effects, but through the daily struggle to fulfill the duties that pertain to his position in an organized community." 1 And if the mature man, still more the immature child and youth.

The way to acquire a moral character is, then, to become an efficient and loyal member of the institutions of society - the family, the school, the church, the state, and an efficient and loyal member of the smaller groups that these severally contain.

The ways in which the teaching of religion may aid in the development of the individual through institutional membership are well known. I cannot enumerate them here. But there are certain matters which deeply concern the efficiency of the institutions most closely related to religion, of which I do wish to speak in conclusion.

First, the institution must speak with authority. But that authority must, as we have seen, be an inner authority. The institution makes for moral development only when it dimly, it may be, but progressively, finds response in the heart of its members, only when that which at first seemed an external thing is felt, by the individual, to be his greater self. An institution which is a mere external machine produces merely mechanical results. An institution that is powerless to require moral obedience is essentially demoralizing and immoral. Sunday-school superintendents might profitably ponder this.

Second, the institution must make membership real through participation in organized activities.

A highly developed church service, one with some form of liturgy, helps to satisfy the former requirement; such organization as is found in the Young Men's Christian Association satisfies the latter. Without division of labor or the fixing of responsibility, and without pride in classes, in committee work, and the like, there will be lacking much of the incentive and the loyalty that make up the motive power of institutions.

Third, institutions should adequately furnish what Theodore T. Munger calls the " outward drill of religious observance and spiritual habit." 2 "We can do nothing better for ourselves, for our families, for the faith, than secure for each a full, ministering environment of religious custom. A man should have for himself certain religious habits and usage, something of an external nature that shall speak back to him in confirmation of his belief; . . . it is a body holding together the soul and playing into it from the external world." I would if I could incorporate into this paper the whole of Dr. Munger's

\footnotetext{
${ }^{1}$ Giddings, loc. cit. p. 396.

${ }^{2}$ The Freedom of Faith, p. 208.
} 
chapter on Moral Environment, published twenty-one years ago. The words I have quoted apply as well to the family as to the Church.

In conclusion, let me reaffirm that the highest service which religion can perform for morality is in its own way to meet what President Butler has called the greatest educational need of our time, by giving " a fuller appreciation of what human institutions really mean and what tremendous moral issues and principles they involve." 


\section{SHORT PAPERS}

Professor Edwin D. Starbuck, of Earlham College, presented a short paper on "Religious Education without Doctrines or Scriptures."

Rev. Thomas E. Judge, editor of the Catholic Review of Reviews, presented the following paper on "The Divorce of Religion and Education as Opposed to the Principles of Historical Continuity."

THERE were two cities that would have an irresistible attraction for the Apostles divinely commissioned to establish Christianity as the world-power the eities of Rome and Alexandria. The former was the seat of world-wide empire. Every current of history had been tributary to its imperial supremacy. After several hundred years of Roman conquest the world had been marvelously unified by the diffusion of a common civilization. Christianity in the nation and in the world at large, as well as in the individual soul, raises the supernatural structure on the basis of the natural. It, therefore, commenced its superhuman task of establishing a world-wide kingdom of liberty, equality, and fraternity among the children of men, by appropriating all the advantages of Roman unification. What Rome had accomplished in the coördination of the influences which control the external lives of men, Alexandria had attempted to achieve with the deeper forces that govern their minds and hearts and consciences. The famous lighthouse of Pharos, which stood at the entrance of the main harbor of Alexandria, might be regarded as a symbol of the city's intellectual relationship to the world at the beginning of the Christian era. Athens had for centuries ceased to be the mother of arts and eloquence. Greek freedom had been extinguished at the battle of Chæronea, and science and philosophy could not flourish under a despotism. Athenian wisdom as well as Athenian chivalry followed Alexander in his expeditions, until he established a congenial home for it where the Nile mingles its waters with those of the Mediterranean Sea. There, too, came the Jews, in numbers sufficient to give a name to one of the principal quarters of the city, bringing with them the Scriptures of the Old Testament and their synagogue ritual. There came Orientals of every variety of race and religion, with their dark sense of sin and their gloomy gospel of despair. For the first time in history there was absolute freedom of thought.

\section{Christianity, the Great Synthesis}

It was in this arena that Christianity was to measure its strength with the combined intellectual forces of antiquity and to win a decisive victory. It was here that wise men of the East were again to offer their gifts of gold and frankincense and myrrh at the cradle of Christianity. It was here especially that the new religion, after a century of isolation, during which, like the infant on its mother's bosom, it drew its nourishment exclusively from its divine source, was now, like every vigorous organism, to appropriate and assimilate and organize into its own life every element of value in its intellectual environment.

Thus Christianity in Alexandria became a great synthesis, in which the Incarnate Word was the unifying principle that coördinated and perpetuated all the wisdom of antiquity. But in Alexandria there was a great school of literature and science as well as a great school of philosophy and religion. Its system of exegesis, to which we owe the preservation and integrity of the ancient classics, 
was as elaborate and as complex as the "Higher Criticism" of our own day. Mathematics, medicine, astronomy, and physical geography were cultivated and developed to a remarkable degree, and the epicyclical theory of the heavens, afterwards called the Ptolemaic system, was originated by an Alexandrian. Clement, Origen, Athanasius, and hundreds of other great Christian scholars of Alexandria, were the leading representatives of all its ancient learning as well as the personifications of the great philosophical and religious synthesis accomplished by Christianity. Consequently before the Christian church engaged in the enterprise of organizing education she had accumulated and made her own all the intellectual capital of the ancient world. She was heir to the practical genius of Rome, to the revelation and religious enthusiasm of the Jew, and to the sublime speculations and artistic sensibility of the Greek. To inspire and guide her in the administration of this vast inheritance, for the highest and holiest purposes of humanity, there was the example and the teaching of Him who had shed His blood in order that the light-giving and the life-giving truth might reach all who sit in darkness and in the shadow of death.

\section{The Genetic Method}

In the intellectual movement of our time there is nothing more remarkable than the eminent position assigned to historical studies. This is due to a profound conviction that to understand thoroughly what a thing is we must know its growth and development. The category of "becoming" is regarded as the key to the category of "being." In other words, it is held that every important stage of the development of an institution is successively organized into its system, so that its genesis gives the best insight into its genius and constitution. If we apply this genetic or historical method to the educational problem, the conclusion will be forced upon us that the Christian religion is the most efficient educational organization which on historical grounds could have appeared in the world. It combined and systematized every principle of enlightenment, every educational method of preceding ages, so that any careful student of history may trace a continuity between the municipal and other schools of the Greco-Roman world and the parochial, palatine, and cathedral schools of the Middle Ages.

\section{What is Modern Progress}

What, it may be asked, is meant by modern progress from which the Church's life and methods are said to be alienated? The term progress by itself is an abstraction, a mere formal expression that derives definite content from its aims and methods. Progress towards a certain goal and by certain methods can alone have any real signification. We all know what is meant by material progress. It consists in obtaining increasing control over the forces of nature that they may be made to minister to man's necessities and conveniences. In reference to this vaunted element of modern progress Dr. Harnack, in his well-known book, The Essence of Christianity, says: "When a man grows older and sees more deeply into life he does not find, if he possesses any inner world at all, that he is advanced by the external march of things." The entire basis of every distinctive element in modern progress is the inductive method, which, as an instrument of observation and experiment, has been most fruitful, but which has never yet been reduced to a satisfactory logical principle. Either every inductive argument of the modern type is admittedly an argument in a circle or the conclusion is wider than the premises. If we pass from the contemplation of one science to the sciences taken collectively, they are only disjecta membra; there is no synthetic or philosophic unity which embraces and coördinates them all. It is easier to read the signs of the times in the practical than in the speculative order. The philo- 
sophical principles of to-day become the labor programme or the political platform of to-morrow. Anarchy in the political sense has forced itself on public attention under every form of government, republican as well as monarchical, until it is universally regarded as one of the grave perils of the age. Anarchy in the economic sense, disintegration of the two great forces of production and distribution, namely, capital and labor, already reacts detrimentally upon the whole social organism. But these are only the outward, partial, and visible signs of the intellectual anarchy which lies like a canker at the root of modern life. They did not exist before the disintegration of thought that resulted from the acceptance of the anarchical principle of private judgment.

\section{Need of a Great Synthesis}

The need of a great philosophical synthesis that will unify, harmonize, and coördinate all human interests both speculative and practical, the need of the recognition of a common principle of cosmic order, of righteous living, of scientific harmony, and religious faith like the Christian Logos is indeed universally acknowledged, until there is not a single great thinker who has not attempted a synthesis similar in scope to the synthetic philosophy of Herbert Spencer. The very multiplicity of syntheses is itself the clearest evidence of the presence of the disease and of the empirical character of the remedies that are being applied to it. No great synthesis has ever been accomplished or ever will be accomplished except within the circle of Christian ideas, and modern progress is bound to pursue an ignis fatuus until it is ready to receive its orientation from Christianity. Every enterprise, ethical and philosophical as well as scientific, is now being conducted on purely experimental lines. Ask these' men who are opposed to religious education to characterize for you, in the briefest terms, the institutions whose spirit and methods they direct and control, and they will reply that they are, above all things, schools of purely experimental pedagogy. Now when our Christian system encounters hostility from quarters like this, not, be it observed, through any animus of religious bigotry, but solely in the interests of what is called "educational unity," are we not justified in maintaining that we have passed beyond the merely experimental stage? A system of education that produced a Clement, an Origen, an Athanasius, a Basil, a Chrysostom, a Dante, a Thomas of Aquin, a Bossuet, and in our own age a Leo XIII, men of full-orbed personality, moral and intellectual, amidst every variety of social and political ideals and conditions, cannot be destitute of structural elements of permanent value. The educational controversy is only a particular phase of the opposition that is being set up between the static and dynamic theories of life. If the church has appeared too static and conservative, the reason is that modern progress has been too radical. If she has abstained from a cordial alliance with the intellectual movement of our time, is it not because this movement has failed to unify itself, to comprehend its own inner spirit or to define its direction?

\section{Educational Movement of To-day}

But a great era of activity has already commenced.

Bliss is it in this dawn to be alive,

But to be young is very heaven.

Never before was the universal mass of the Christian people so moved by a common impulse in favor of the highest and best education as at the present moment. The finger of God is here and the impulse of his Holy Spirit. Our minds, as true children of the Church, inheriting her traditional spirit, are open 
to every scientific and philosophical movement of our age; but, alike as Christians, as students of history, psychology, and philosophy, we must repudiate the assumption that an institution which incorporated in its life the beauty and wisdom of Athens, the strength of the polity of Rome, which realized the sublime hopes of Zion, which initiated every truly progressive movement of modern history, does not possess in an eminent degree, now as in the past, positive and constructive genius for organizing the highest intellectual as well as the highest moral and religious interests of the human race. 



\section{SECTION B}

PROFESSIONAL RELIGIOUS EDUCATION 



\section{SECTION B}

\section{PROFESSIONAL RELIGIOUS EDUCATION}

(Hall 1, September 22, 3 p. m.)

Speakers: President Charles Cuthbert Hall, Union Theological Seminary. Professor Frank K. Sanders, Yale University.

Secretary: Professor Herbert L. Willett, Disciples Divinity House, Chicago, Illinois.

\section{THE TEACHING OF THEOLOGY}

\section{BY CHARLES CUTHBERT HALL}

[Charles Cuthbert Hall, President of the Union Theological Seminary, New York City. b. New York City, New York, September 3, 1852; A.B. Williams College, 1872; Union Theological Seminary, 1875; D.D. University of New York; Harvard and Yale Universities. Minister of Union Presbyterian Church, Newburgh, N. Y., 1875-77; First Presbyterian Church, Brooklyn, N. Y., 1877-91. Fellow of the State Geographical Society. Member of the National Geographic Society. Author of Into His Marvelous Light; Evangelical Hymnal; Does God Send Trouble? Barrows Lectures to India and the Far East.]

ONE of the purposes of the International Congress of Arts and Science is understood to be the promotion of closer relations between the several branches of human knowledge. Truth being the common possession of all men, homogeneous, without the possibility of self-contradiction, the sympathetic coördination of all lines of approach to truth is in conformity with reason and morality. The conflict of one science with others, the segregation of one science from others on grounds of prudence, reverence, prejudice, or pride, is contrary to intellectual and moral right. The elements of knowledge are every one members one of another. There can be no schism in the body of the truth without violation of its first law.

Touching many departments of knowledge there is no need to argue this thesis. Its reasonableness is self-evident. None would dream of placing the student of chemistry under restrictions not exacted from the student of astronomy; nor of protecting either discipline from the vicissitudes of opinion produced by a changing state of knowledge. On the open field of the university there must be no cloistered retreats of authority, where fallacy and error may take shelter from the searching judgments of reality. On that threshing-floor of intellectual honesty there must be no corners fenced from the winnowing fan. Only thus can the prestige of universities henceforth survive. It is not their antiquity nor their wealth that ennobles them; it is their love of truth and their fidelity to the facts of ascertained knowledge. 
The science of theology, to a marked degree hitherto, has afforded an example of a branch of knowledge affected, if not retarded, in its development, by artificial conditions. Among the most important of those conditions is ecclesiastical authority. The restrictive and complicating effects of ecclesiastical authority upon the science of theology present themselves to the view of the student of history. That authority, once asserted in connection with other sciences, which, one by one, have claimed and gained their freedom, still retains such force in the realm of theology that whosoever shall advocate a teaching of theology upon which churchly authority cannot impinge is thought by many to be revolutionary.

Nevertheless, it is the purpose of this paper to defend a plea for the recognition of theology as a university discipline rather than an ecclesiastical discipline. When our Lord presented himself upon the scene as a teacher of the truth of God, his manner of presentation smote with freshness on the jaded religious sense of Israel. In the highest degree our Lord's teaching of theology was authoritative, yet its spirit was unlike that which governed the teaching of the scribes. Theirs was the authority of a preimposed system, whose sanctions must be maintained by reiteration and by threatening. His, the authority of a Person in contact with the sources of knowledge and filled with the spirit of power, of love, of right judgment, of filial intercourse with the Father. He intended that that attitude toward the knowable truth of God should prevail forever among his followers. The guaranty of it in perpetuity was the Abiding Comforter, the Spirit of truth, who, said he, shall guide you into all the truth, who shall continue with you forever. Time passed. Christ vanished from human sight. The Christian society took on organic forms and functions. The ages of ecclesiasticism began. The rise of ecclesiasticism as an administrative system involved the growth of the idea that it is the duty of a church to control the beliefs of its members and of those seeking to enter its ministry by the imposition of fixed systematic interpretations of truth, in distinction from the idea that it is the duty of a church to encourage its members and its students of theology to seek truth for themselves, as the children of light, dwelling in the freedom of the Spirit.

Churchly authority, as exercised in the region of theological science, utters itself, from time to time, in the course of history, under three modes of expression: the authority of an imperialistic Catholicism; the authority of rival protesting sects; the authority of popular religious usage. Unequal in their powers of enforcement, diverse in their spheres of influence, these several modes of authority rest in common on their right to impose upon the individuals within their respective jurisdictions predetermined interpretations of theological ideas, together with the obligation to conform thereto in belief and in 
teaching. It is not the purpose of this paper to speak in a derogatory manner of any one of these modes of authority, nor to question that, in the evolution of the religious consciousness of Christianity, important benefits have come by means of each of them.

To the open-minded student of religious history those benefits are apparent. Catholic imperialism has made its peculiar contribution to the advancement of theological science. By ceremonial splendors, investing the primary data of Christianity with sensuous magnificence; by august paternalism, breaking the bread of knowledge, pouring the wine of mystery, feeding the mind of ignorance with food convenient for it, restraining with the rod of correction the undue ardors of the intellect; by spiritual legislation delimiting the boundaries of religious ideas and prescribing their order and content, Catholic imperialism has forced upon the attention of the world the facts and claims of the Christian religion.

The development of the protesting sects of Christendom represents, in the first instance, revolt from Catholic authority, resulting in the substitution therefor of the authority of dissent, often no less imperial and uncompromising in its temper; in the second instance it represents the multifarious lines of cleavage in the body of dissent, with the consequent multiplication of sectional and sporadic claims of authority.

However confusing this spectacle of multitudinous rival authorities may be to him who conceives of truth as one essence, homogeneous, incapable of self-contradiction, it is probable that hereby resulting evil has not been unmixed with good. The revolts from authority have occurred for cause. Suppression of truth, perversion of its meaning, contempt of its ethical sanctions, have been among the charges brought against authority to justify dissent; and if, as in the present Scotch Church case, the imperialism of an autocratic minority brings catastrophe for the time being to the cause of religion, we may not doubt that, upon the whole, the protesting sects of Christendom have brought greater protection than peril to the Church which, without the perpetual recrudescence of salutary dissent, might fall a victim to secular ambitions and corrupt beliefs.

The authority of popular religious usage is another mode of expression exercised by ecclesiasticism in the region of theological science. Sects develop their own religious vernaculars. Biblical words acquire fixed connotations, determined by a sectarian authority, which unconsciously reflects popular usage, and, in turn, seals that usage with official approval. The peril of this is obvious. The criteria of truth may become its local modes of verbal expression; a theory of interpretation may count for more than the fact to be interpreted. The authority of popular religious usage contains grave possibilities of intellectual oppression and moral injustice. 
Nevertheless, it has its values. The sectarian vernacular is a convenient lingua franca. If not pressed unduly, it is a valuable channel of devotion. It lends itself to sentiment and endearing association. It puts a song into the mouth of saints untroubled by the scientific aspects of theology. As an outpouring of the heart, popular religious phraseology is a means of grace; as a test of fidelity to truth it may be an instrument of tyranny and a goad to agnosticism.

Assuming the justice of these observations, it is apparent that ecclesiastical authority, whether in the form of imperialistic Catholicism, protesting sectarianism, or popular usage, involves a principle that has its bearing upon the teaching of theology. That principle is the right and duty of the Church to place the seal of official approval on predetermined, fixed, systematic interpretations of truth, and to demand conformity thereto, in belief and in teaching, on the part of individuals within the bounds of its jurisdiction. It is far from my present purpose to discuss this principle on its merits, or to question the efficiency of theological schools maintained under churchly authority. I am interested simply in pointing out that there is a place, apparently a large and desirable place, for the teaching of theology under conditions of emancipation from ecclesiastical control and of correlation with the other great disciplines of the university. The teaching of theology in an atmosphere exempt from ecclesiastical tests represents the treatment of a great science according to the canons most reverenced in modern university life. Its major interest is truth in the region dealt with by theology. It holds no brief on behalf of a certain point of view; it is under no anterior commitment to maintain a given system fixed by objective authority; it is under no temptation to forestall inquiry for the protection of consistency; it is not repelled by the manifoldness, nor limited by the dogmatic urgency, of sectarian opinion, but rather welcomes the same, believing that all honest efforts to apprehend truth contribute, whether by weakness or by strength, to the ultimate disclosure of its absoluteness.

Having this mind it takes delight in the increment of knowledge for truth's sake, becoming neither elated if ascertained fact shall substantiate prior theory, nor alarmed if opinion long held in honor be discredited thereby. It esteems truth to be the sole fountain of authority. It affirms that truth contains its own authority - the well of water springing up within itself unto everlasting life.

Hence, in the teaching of theology in an atmosphere exempt from ecclesiastical tests, there is reverent readiness to alter theory and to modify interpretation at the bidding of fact. This is held to be consistency and not inconsistency, inasmuch as to stand with the truth is the touchstone of a higher consistency than to stand with the earlier and less enlightened opinion, although that be sanctioned 
by authority. That which to the eye of the ecclesiastical court appears as the tortuous and variable path of the uncontrolled truthseeker, may, to that Eye which sees all things as they are, be as the path of the arrow to its mark.

It may be urged as a demurrer to what has been presented that theology cannot be reckoned among the exact sciences; and that it is, therefore, fallacious to set this accent upon truth and ascertained fact in connection therewith, the data of theology being largely matters of belief, properly regulated by the authority of the Church. It is, without doubt, to be granted that theology is not an exact science in the mathematical sense, its material being related to the Infinite and the Unseen. But, equally without doubt, there is a formidable basis for regarding theology as, relatively, an exact science. To ignore that basis might result in enthroning superstition in the seat of intellect. The theology of the Christian religion rests primarily upon documents that claim for themselves no immunity from the laws and tests establishing documentary evidence. To presume to exempt them from those tests may be an act of faith. But the peril of the act is great, and daily becoming greater. These documents, attested by critical research, have content which has relation to the history of thought, the data of experience, the data of ethics. In the ages of ecclesiasticism the continuous effort has been to impose upon the content of Holy Scripture systematic interpretations predetermined by authority and to bind the will and conscience thereto. They may have been true interpretations; in many respects they are true; but, being made the instruments of authority, they place between the minds committed to them and the original sources of theology a barrier to intellectual freedom, a temptation to intellectual insincerity. The teaching of theology in an atmosphere exempt from ecclesiastical tests means direct access to the content of the documentary basis of the Christian religion, with no compelling motive other than that of the quest of divine truth. The door of immediate entrance thereto is the comparatively new discipline of Biblical theology. Biblical theology may conceivably be employed in the interest of positions previously established by sectarian authority or popular usage. This might be done unconsciously and honestly, as in the blind fervor of a zeal without knowledge. Or it might be done of set purpose. The diplomatic manipulation of Scripture to buttress an ecclesiastical structure of dogma is not unknown in the annals of the Church. But, however done, unconsciously or with intention, its effect must be to impart to the discipline an unmerited aspect of weakness. Biblical theology, pursued in an atmosphere purged of ecclesiastical and secular animus, is, of necessity, a strong and great discipline. For it is essentially historical. It occupies itself with documents previously 
tested by the canons of criticism and found to rest on the rock of actuality. The historicity of the documents being proven, it follows that the arrangement and comparison of their contents in accordance with historical principles, the exhibition of permanent elements in distinction from transitional elements, the expression of religious values becomes the important and prolific function of those who are to develop this branch of theological learning in the future. It is apparent that upon the basis of Biblical material thus made ready the companion discipline of systematic theology may build a structure of noble proportions. Absolved from ecclesiastical restraints, committed to no sectarian programme, its function is to formulate and coördinate the essential ideas of the Christian religion, and to do this in a constructive and irenic spirit, having in view the cosmic bearing of those ideas, and seeking to present them to the attention of the world. In this effort the university teacher of systematic theology will be sustained by presuppositions of the highest order. $\mathrm{He}$ assumes the nature of religion as the universal perception of the Infinite, the yearning of the universal human soul after God. He assumes the unity of the human race as an actuality existing beneath all social, political, religious, ethnic distinctions. He assumes the all-pervading presence of God, the limitless operations of his Spirit, who "hateth nothing that he hath made," and "willeth that all men shall be saved and come to the knowledge of the truth." Systematic theology developing in such an atmosphere becomes, not the intricate dialectic of a school, but the charter and gospel of the world's redemption.

From this point of view it appears that, without discriminating against local and sectarian schools for ministerial training, it is desirable that there be also an adequate recognition of the teaching of theology in the circle of university scientific pursuits over which churchly authority has no jurisdiction." This may tend to remove obstructions from the path of truth and to advance the progress of unity and religion. It may restrain certain undesirable tendencies which, having attracted the attention of the thinking world, have induced a regrettable disinclination toward theological studies on the part of many able men. These undesirable tendencies are, in particular, a disposition to forestall inquiry in the interest of systems sanctioned by authority; a disposition to disparage the beliefs and motives of those who, bound by conviction, are unable to subscribe to the authorized systems; a disposition to coerce subscription at the expense of intellectual and moral sincerity. The offensiveness of these tendencies to large numbers of strong and excellent men is marked. The protest against them, especially during the last fifty years, has been resolute and has gathered volume with time. One recalls the rugged and uncivil words of Mr. Froude in his essay on the 
Oxford Counter-Reformation: "Cardinal Manning says that the intellect is naturally skeptical; that it destroyed the faith of the Old World; that it is destroying still more rapidly the faith of modern society, and that religion can only be saved by some power which can smite the intellect back and humble it. Is this true?" demands Froude. "Is it not rather true that the intellect is the enemy only of falsehood? The human intellect," he continues, "will never voluntarily part with truth which has been once communicated. It hates lies, lies especially which come to it armed with terror in the place of argument. Between men of intellect and priesthood there has seldom been good agreement. Each regards the other as intruding upon his special domain. Priests and prophets went on ill together under the old dispensation. The prophet denounced the priest as a ritualist. The priest murdered the prophet with the help of popular superstition." We have little sympathy with the temper of these rude words, the words of an aggrieved and angry man. Yet they point to a need, felt by many strong natures, of opportunity to study the problems of religion in a place beyond the jurisdiction of ecclesiastical courts and the limitation of sectarian subscription. It is not without advantage to religion and to themselves that young men, advancing toward the Christian ministry, shall find their theological self-consciousness first, and ascertain their ecclesiastical distribution afterward. Theology is greater than any and all churches. Froude's words on subscription (in his Plea for the Free Discussion of Theological Difficulties) are less objectionable and not less true: "If the popular theory of subscription be true, and the Articles are articles of belief, a reasonable human being, when little more than a boy, pledges himself to a long series of intricate and highly difficult propositions of abstract divinity. He undertakes never to waver or doubt; never to allow his mind to be shaken, whatever the weight of argument or evidence brought to bear upon him. That is to say, he promises to do what no man living has a right to promise to do. The clergy, who are set apart to study a particular subject, are to be the only persons unpermitted to have an independent opinion on it." Mr. Froude was protesting against conditions which, in England, have been greatly altered since the time at which these words were written and which, in this country, have no existence; namely, the embarrassments to theological science created by the commitment of universities to the opinions of the Established Church. It was against these embarrassments, as connected with the admission of dissenters to the university, that Sir William Hamilton delivered his ferocious attacks, arraigning not only the intellectual but the moral integrity of the great universities of England in language of extraordinary bitterness. From this time to the present there has been a steady advance toward con- 
ditions making possible that development of theological study in connection with the university, and that exemption of theological study from ecclesiastical control, for which the present paper is a plea. Yet much remains to be accomplished. Theological teaching in the English universities is understood to be theoretically free from ecclesiastical tests, but apparently Oxford, for example, is not living up to its own ideal, as is shown by recent votes of convocation having reference to theological examiners. The German universities are more nearly approaching this idea, yet are not altogether free, as a recent incident shows, from the interposition of imperial authority with a view to rebuking the free expression of scholarly opinion. It would appear that, in America, by reason of the absence of official relations between the state and many of the universities, an opportunity exists either by the incorporation or the affiliation of the great independent theological schools with free universities, to bring the teaching of theology upon a plane of intellectual liberty coordinate with the teaching of biology or the teaching of anthropology and to develop theological science and its attendant religious advantages in a region as far apart from ecclesiastical tests and denominational authority as from secular control.

Due consideration should be given to the alleged risks involved in the prosecution of theological study apart from the oversight and restraint of an ecclesiastical court. It is claimed that, if theological teaching be permitted to escape from ecclesiastical surveillance, it must eventuate in radicalism and the decline of the religious sense. It is pointed out that unless the theological field be previously delimited by the landmarks of a system constructed by authority, teacher and student alike must wander in the midst of vague speculations; that lack of precision in the statement of belief is equivalent to lack of belief; that variation from the formula implies alienation from the fact of which the formula is an official attempt at definition. The seriousness and weight of moral authority with which these allegations are made entitle them to the deepest respect of all lovers of religious truth, inasmuch as no catastrophe could be more formidable than the substitution of indeterminate speculations for vital belief. The importance and effectiveness of a settled and impregnable faith cannot be overestimated. The Godward movement of the race, as well as the salvation of individuals, is accomplished by faith alone. The most glorious incentive to holiness, service, and sacrifice is afforded by ideas conceived, assimilated, transmitted in the atmosphere of faith. The hope of the world before and since the incarnation of Christ has survived in the men of intense and lofty belief who, by faith, "subdued kingdoms, wrought righteousness, quenched the violence of fire, stopped the mouths of lions, put to flight the armies of the aliens; out of weakness were made strong." 
The responsibility resting upon all lovers of truth is to take measures for preservation of this spirit in our time and for the projection of its influence into the time to come. The question of procedure to this end evidently is one of high importance. It involves a theory of teaching those who are to be the professed religious leaders of the coming time. Shall the teaching of theology continue to be viewed chiefly as the communication to the candidate for a denominational ministry of the formulas of belief authorized by the ecclesiastical tribunal under whose jurisdiction he is to serve? Or shall the primary interest in the teaching of theology be the encouragement and direction of the student in research into the sources of knowledge and in the coördination and use of his findings in whatsoever part of the Church he can ultimately enter with moral sincerity and intellectual self-respect? The presentation of these alternatives is not for the purpose of discriminating against schools of denominational theology, but of pointing out that those schools, however excellent, the outgrowth of a distant past, cannot be held to have provided in advance for certain needs increasing in urgency at the present time. The growth of scientific knowledge and the reconstructions in philosophy have invested the major problems of religion with new and large interest on lines of thinking not followed, perhaps not anticipated, in the historic symbols of Catholic and sectarian Christianity. Veneration for those symbols does not offer an equivalent for the neglect of large regions extending beyond them. Many earnest men are growing restive under the effort to conform to the predetermined statement of doctrine, for the sake of ecclesiastical regularity, when mind and soul are filled with the glory of what seems a larger and richer vision of the truth of God. The conventions of ecclesiastical opinion discountenance variations from confessional uniformity. Meantime men think, think for themselves, and although their thinking may issue in results substantially identical with the standards of orthodoxy, it may be regarded as probable that the strongest minds in the future will prefer to reach those results by independent investigation and apart from a commitment in advance to conclusions defined by authority of the Church.

If this be so, a place must be found where such minds, the choice product of noble and liberal culture, can pursue research in the science of theology without disloyalty to their own sense of mental honesty and equally without the discomfort of living under ecclesiastical censure. It is contrary to reason that one should be made to feel, even by indirection, that it is reprehensible to be fearless and free in the study of the most sublime of all the sciences. The way out from this difficulty is in the more intimate alliance of theology with the university; in the alignment of theology with the other pursuits of the university; in the more general interchange of work, 
on the part of students, in the affiliated schools of the university. Thus may there develop a sympathetic theological culture, ripened and deepened by contact with other disciplines, in distinction from a segregated tenure of dogmatic opinion.

As to the alleged peril that, in such an atmosphere, vagueness and radicalism may take the place of faith, it is to be said that the ground of this allegation probably is the tendency to measure the extent and depth of a man's belief by his facility and accuracy in using the language prescribed by authority. An impression exists that the ecclesiastical court alone can give a satisfactory guaranty of fidelity to truth. Whereas, in fact, the ecclesiastical body, being involved in the obligation to maintain its own dogmatic consistency, is less certain to be loyal to the ever-unfolding truth than the body of unfettered scholars and the custodians of the non-ecclesiastical schools of theology who, as such, have nothing else to eonsider save loyalty to truth and obedience to the heavenly vision.

There is no conservatism of revealed religion more pronounced than that which comes through unrestricted liberty of research; there is no warmth of devotional life more constant than in those whose worship is not under the law of a churchly commandment, but in the liberty of the Spirit. Of the conservatism and devoutness of a truly liberal theological culture may one use Wordsworth's splendid characterization of the reverent truth-seeker in the visible world of nature:

\footnotetext{
Thus deeply drinking-in the soul of things

We shall be wise perforce; and, while inspired By choice, and conscious that the Will is free, Unswerving shall we move, as if impelled By strict necessity, along the path Of order and of good. Whate'er we see, Whate'er we feel, by agency direct Or indirect, shall tend to feed and nurse Our faculties, shall fix in calmer seats Of moral strength, and raise to loftier heights Of love divine, our intellectual soul.
}

Excursion, Book IV.

There are other considerations of importance pointing to the expediency of a closer affiliation of the teaching of theology with the non-sectarian life of the greater universities. Larger concentions of the structural unity of the Christian Church are emerging into the field of vision. It is probable that at no past time have the Christian forces of the world been organized more effectively than now upon sectarian lines. In strength of membership, in wealth, in precision of business management, in excellence of religious method, the contemporary divisions of Christendom represent probably the highest average attained at any point in their history. As such 
they bear witness to the reasonableness of dissent and the effectiveness of subdivided organization. But, while the utilitarian value of sectarianism is recognized as an aid to executive efficiency, the theological significance of sectarianism is distinctly a waning interest. The fires of theological animosity that burned freely in the fierce controversial wind of an earlier time require artificial fanning at the present to keep them alive. This occurs not because of a declining interest in truth, but because of the unifying and irenic effect of advancing knowledge. Without inquiring to what extent the control of theology by ecclesiasticism accounts for the ferocious sectarian conflicts of the past, it is evident that the struggle of theology for intellectual independence has found an answer in the common Christian heart, has projected a beneficent influence into many parts of the divided church of Jesus Christ. Larger problems have supplanted smaller issues. Reverent and fearless scholarship has effected a redistribution of theological interests, and has attracted toward aspects of truth that transcend all sectarian issues, forces of mind and heart once spent in rivalry and evil-speaking. It is to be admitted with joy that this relative supersession of sectarian bitterness by fraternal interest in the common truth is being recognized with more or less approval in many seats of ecclesiastical authority. In the councils and schools of Christendom in the west and its missions in the east there is some evidence of irenic readjustment and of movement toward theological consensus. But there is need of suitable non-ecclesiastical leadership of this movement; of university leadership, the intellectual sanity, moral seriousness, and religious strength of which are beyond question. Around every such university centre should gather those who would enter into the fundamental conceptions of our religion, not in a spirit hostile to ecclesiasticism, but in a spirit uninfluenced by ecclesiastical presuppositions, seeking only the impregnable rock on which Christ has built his Church. From every such centre should go forth apostles of a larger theological consensus, penetrating with their influence all sections of the divided Church, and advancing everywhere that unity which is according to knowledge, that charity which rejoiceth in the truth.

Many of the denominational schools of theology contain teachers in sympathy with this larger consensus, and more interested in promoting it than in defining the grounds of difference. Great are their services, even where impeded by the atmosphere of hereditary conservatism of the disciplinary hand of authority. The gracious influence of such lives, and, in particular, their appeal to young university graduates and to the educated laity at large, suggests the direction in which non-clerical thought is moving. Venerable as are the sectarian organizations, sacred and saintly as are the names that wrought, by life and by death, to achieve the divisions of the 
Christian society, necessary and final as have appeared to be those dividing lines between the denominational schools, it is impossible to prevent the waning of sectarian zeal or to arrest an age-movement that derives its momentum from larger and more ultimate considerations. That this age-movement may advance beyond an unorganized groping into complete theological self-realization, it must be directed from centres of religious thinking where the science of Christian theology is studied and taught in an atmosphere exempt from ecclesiastical tests.

Another consideration, yet more far-reaching than the last, must be advanced, to establish the expediency of a more intimate alliance of theology with the university. Modern philosophy and anthropology have brought about a new conception of the nature and significance of religion as a fact in the life of the human race. No longer is it possible to hold that the final fact in religion is " the acceptance of a system of truths, presented from some external source and duly sanctioned by appropriate manifestations of authority." By the analysis of the inner experience of the human mind the phenomenon of religion has taken on new content and opened new questions of the first magnitude. "It is not needful," if I may use the recent words of Professor Estlin Carpenter, "to rehearse the specific modifications successively suggested by the great teachers of Germany: Kant with his reconstruction of religion on an ethical basis; Hegel and his doctrine of the Absolute; Schleiermacher with his protest that religion is neither morals nor metaphysics, but lies in the feeling with which the soul contemplates the varied life revealed in nature and in man - these three names may stand as representatives of different aspects of the great inquiry and the solutions which it begot. However much they might differ in detail, or even in principle, they all agreed in this: the sources of religion were to be found in the mind itself. Religion, therefore, must be regarded as inseparably bound up with human nature. It had a universal character, and the study of it was justified by psychology." 1

The advance of thought to this position has invested with new meaning the total religious experience of the world, has brought every form of religion within the sphere of serious and sympathetic examination. It has done more. It has set the Christian religion in a new relation toward other faiths, a relation involving momentous historical, moral, and social considerations.

It is impossible to ignore the conclusion that issues from the philosophical reconstruction of the idea of religion. It involves by the logic of necessity the status and function of the Christian religion in the world, and its relation to the non-Christian faiths. The authoritative ecclesiastical interpretations of Christianity, Protestant

I The Place of Christianity among the Religions of the World, pp. 13, 14 . 
and Catholic, were made and imposed prior to the philosophical reconstruction of the idea of religion, and under a state of deficient knowledge of the non-Christian world. They rest upon a world-view now, in many important particulars, abandoned. They contain no adequate provision for elements in Oriental religious experience that have now become a part of ascertained knowledge. The East is opening its reserves of intellectual and material power before the eyes of an astonished West. It is unfolding a capacity for heroic devotion, a depth of religious insight undreamed of by those who constructed theological symbols founded on erroneous assumptions concerning the non-European races.

If truth be homogeneous, and incapable of self-contradiction, there must be an interpretation of Christianity as the absolute religion, made in the light of the ascertained religious experience of the world, if the function of Christianity in the world and its message to the ethnic faiths are to be conceived and stated adequately. To demand that this shall be done in schools controlled by ecclesiastical authority is to demand relatively an impossibility. Where the conscience of the ecclesiastical court is in honor bound to enforce the terms of a theological interpretation incompatible with later knowledge of psychology and history, the schools within its jurisdiction are in honor pledged to conformity in their teaching.

The pathway to relief points to the university affiliation of the teaching of theology. To those who, as the students and apologists of Christianity, have touched with. a mind in spiritual sympathy the higher religious thinking of India and the Far East, nothing is more impressive than the readiness with which the fundamental conceptions of the religion of Jesus Christ lend themselves to the thought-forms and commend themselves to the aspirations of the most lofty and prophetic spirits of the Orient. But it cannot be hoped, perhaps it need not be hoped, that the East, in order to become Christian, shall assimilate remote and alien theological formulas and bow to Western ecclesiastical authority. There is, indeed, a letter without the spirit, which is dead. Is there not also a spirit and essence of the absolute religion of Christ, which, if it be without the letter of the Western mode, nevertheless is life and peace for the common heart of the race? To interpret to the world the religion of the Son of God in terms of this spirit and essence, and, while honoring the sects, to rise above them into the undivided inheritance of Christian truth, this, and more than this, is involved in the teaching of theology in an atmosphere exempt from ecclesiastical tests. 


\title{
PROFESSIONAL RELIGIOUS EDUCATION: THE TRAINED LAYMAN
}

\author{
BY FRANK KNIGHT SANDERS
}

[Frank Knight Sanders, Dean of the Theological Faculty of Yale University, and Professor of Biblical History and Archæology. b. Batticotta, Jaffna, Ceylon, June 5, 1861. A.B. Ripon College, 1882; M.A. ibid. 1884; D.D. ibid. 1901; Wesleyan University, 1903. Professor of Philosophy and English, Jaffna College, Ceylon, 1882-86; Assistant in Semitic Languages, Yale University, 1889-91; Instructor, ibid. 1891-92; Woolsey Professor of Biblical Literature, ibid. 1892-1901; President of American Institute of Sacred Literature; President of Religious Education Association; Member of American Oriental Society; Society of Biblical Literature and Exegesis. Author of Messages of the Bible Series; Library of Ancient Inscriptions Series; Outlines of Biblical History and Literature; Messages of the Earlier Prophets; Messages of the Old Testament Sages; The Teacher's Life of Christ; The Teacher's Life of Paul.]

THE theme assigned to me for discussion is the importance of the trained layman in religious education to-day. So extended has already become the religious activity of an educational character expected from the laity and freely allotted to them, so diverse are the forms through which such activity finds expression, and to such an extent is it still in the experimental and unorganized stage of development, that while there can be no question in any rational mind regarding the promise, the present efficiency, or the wisdom of the general movement which has encouraged the layman to assume a constructive responsibility in religious education, it is none the less a difficult task to make an adequate presentation. I shall omit for the most part any extended discussion of the origin or history of the organizations for laymen which are active in religious education. Nor will it be profitable to introduce the detailed statistical information which necessarily underlies this discussion. I shall in large measure take an acquaintance with it for granted. If this survey seems superficial, one can only wish it were possible to do better. I have aimed to make clear the signifincace of a professionally trained laity, wholly apart from the ministry, and to offer some suggestions regarding its coördination with the ministry.

The trained layman is at least a noticeable factor in the religious life and religious leadership of to-day. Reliance is readily and customarily placed upon his services not alone as a participant in activities directed by others, but as an administrator of such work or as an originator. The value of his own contributions to religious progress is being recognized. The scope of his free participation enlarges year by year. It may even be fairly said that by reason of the high standards of achievement which have already become fixed along many lines of religious activity, commonly committed to lay- 
men, the respect of the world is being granted to successful religious leaders among the laity, to a degree which falls but little below that accorded to the trained minister.

There can be no questioning of the fact that this age is in a peculiar sense the age of the layman in religious development. Never before has he attained the full freedom and the complete recognition of the present day. It is not, however, the only era which has countenanced the layman. From earliest times among progressive nations, even where religion consisted largely in the practice of a ritual under the direction of a closely guarded caste, this caste was at least recruitable among those who were not born into it.

A priesthood, jealous of its privileges, has rarely despised the strength obtainable by the addition from the laity of those who should be trained for priestly service.

A wider opportunity in the remote past for the religious activity of those born as laymen was afforded by Hebrew prophecy. Whatever the restrictions placed about the introduction of a layman into priestly functions and privileges, there were next to none in the case of a prophet. Whoever, like Amos, felt in his heart the summons of God to deliver an appeal to his fellow men; whoever, like Elisha, was invited by one already recognized for his leadership to become a follower and disciple; whoever, like Ezekiel, was drawn into prophetic instruction by the sheer necessity of restoring the sanity and hopefulness of his neighbors, - these who gave visible proof in deed or word of their fitness to play an inspirational part in life were readily accepted both by the people and by the prophetic order as true prophets. In fact, the presence in the prophetic ranks of so many who were quite unworthy may be in part explained by the ease and freedom of entrance.

It would be instructive to show in considerable detail how every nation which has notably contributed to the religious progress of the world has found a way by which one born a layman could come by a natural channel into prominence as a religious genius. They have, of course, as a rule been given admittance to some recognized religious order through which they had in time their opportunity.

Christianity could not fail to honor the layman, since it recognizes personality, freedom of thought and action, and the responsibility of the individual in his working environment. Roman and Protestant Christianity alike have freely opened the way for the layman to share in the religious upbuilding of society. A striking example of the opportunities and the limitations of the layman in olden time is afforded by the history of that curious group of enthusiasts known as Lollards, in the days of Wycliffe. Himself a trained scholar and theologian, Wycliffe sought to strengthen the impulse toward religious freedom, already finding manifestation among the masses 
in England, by organizing bands of men who should go through all England, reading the Scriptures, commenting thereon, and teaching the simple truths of morality and religion. While under his immediate influence these pupils, who were, in the main, men of humble rank and meager education, accomplished a modest but salutary result. Relieved of supervision, stirred by the novel joy of leadership and unrestrained by education or experience, they developed truly dangerous tendencies which forced the religious authorities to a cruel and rigorous suppression.

Romanism has always been willing to employ the layman in the promotion of religious development, but under careful supervision. Her method, and a very successful one, has been that of the religious brotherhood, with or without monastic vows. Through such organizations a vast amount of valuable religious work may be achieved without danger.

Our last century, however, particularly its latter half, and our country, have given the layman his real opportunity. At no other time and in no other country, except the self-governing colonies of Great Britain, has the growth of truly democratic ideas and institutions been sufficiently advanced to give the layman a free initiative and an ungrudging distinction in matters religious. If we would take honor to ourselves in this respect above the mother country, it is only because the looser religious traditions of America and the continuously pressing demands for wise initiative have caused us to make smooth and open the pathway of any aggressive would-be teacher. Opportunities we offer with freedom, although our approval is none the less based upon wise achievement. It is a curious but indisputable fact that two of the notable religious movements of the last century, the Sunday-school and the Young Men's Christian Association, each originated in England, was borrowed by this country, but has found its broadest and best-balanced development on this side of the water. The Sunday-school is coming to be with us the church's department of religious education; the Young Men's Christian Association long ago became a representatively educational organization. The dignity thus won for each, because of its indispensable place in organized society, has no parallel elsewhere.

How the layman came to have his matchless opportunity as a free religious agent is an interesting question which cannot be decisively answered. The hospitality of our fathers and of ourselves toward all that makes for moral culture and religious conviction, and their confidence and ours in the unfettered expression of one's deepest and noblest ideals, has combined, no doubt, to create an environment singularly adapted to the encouragement and upbuilding of any institution which gives promise of educating the public for 
righteousness. It is to the result rather than toward the doer that we turn our critical gaze. The old Puritan layman was a religious thinker of no mean capacity. While professing a profound reverence for the clergy and confining his religious leadership to work directed by them, he was an associate of constructive genius and broad ability. His readiness to receive and carry responsibility set the fashion for all later generations. At the same time the rapid development of religious organizations, made necessary by the struggle to maintain national ideals of righteousness amidst a rapidly growing and widely spreading people, has forced us to utilize the layman and to accord him the right and duty of self-directed, whole-souled participation in the work assigned.

Within the past half century, the unexampled growth of Sundayschools, of Young Men's Christian Associations, and of church activity of every sort, has drawn largely upon the voluntary service of the laity, both men and women, and caused them to be given recognition as essential to the proper maintenance or development of such types of religious achievement. No one could for a moment contemplate an elimination from our available active religious forces of the laity.

The extent and the significance of the share which the layman takes to-day in religious achievement or instruction is made manifest by the consideration of the accepted religious movements which have come into being and attained their development through the initiative and the care of the layman.

It is beyond dispute that the Young Men's Christian Association movement, now a little beyond the half-century mark, was due to lay initiative. The unconscious founder of this potent factor in the well-being and religious growth of the young men of our and other lands was intent, of course, at the outset, upon forming no more than a grouping of his fellows for mutual benefit of a religious character. It developed with unexampled rapidity, because it met an actual and persistent need. It became and has continued to be a layman's movement. While affirming its unabated loyalty to the Church and its standards, it uses the clergy as advisers or admits them to membership on the same basis as other men. As between a board of direction, composed of clergymen, and a board made up from men of secular affairs, it would choose the latter. It has passed from one country to another around the globe because of the natural adaptation of this layman's work to the needs of the young men everywhere.

The Association movement of to-day is so complex that I may well allude independently to movements which have grown up within it. One of these is the federated religious work among the students of our land and now of all lands. It is not easy to over-estimate the solid value of this branch or offshoot of the parent organization. 
Such value is calculable not merely on the basis of the notable results accomplished in the past twenty years, but far more in view of the efficient and adaptable organization prepared to promote religious education among students in time to come. Both in its inception about 1884, as a special department of the Young Men's Christian Association, under the direct supervision of the International Committee, and in its extension, some ten years ago, to the students of foreign lands, this religious work for students has been the result of the prevision and of the aggressive ardor of laymen.

Another significant movement for a special class of people, which has grown out of the Association movement at large, is the work for soldier and sailors, created to meet the unexpected conditions of the Spanish-American war, and suggested in a measure by the famous Christian Commission of our Civil War. The latter organization, however, was temporary in character and quite different in scope, although based upon a similar desire to minister to the needs of our brave heroes. At the outbreak of hostilities with Spain the Young Men's Christian Association undertook to furnish for each regiment, as far as feasible, a trained secretary, who would occupy the same relation to the men on the field that such as he occupy to those of our large cities. These army secretaries performed many of the duties which would naturally fall upon army chaplains and have to a considerable degree supplanted them. Their comradeship with the enlisted men gives them a great advantage in influencing the soldiers, an opportunity of which they are not slow to take advantage. No less an authority than Major-General Shafter has put himself repeatediy on record as affirming the practical effectiveness for the religious leadership of the private, of the unordained but well-trained man. The army as a whole, and with few exceptions, welcomes their appearance and assists their work. So in the navy, the trained secretaries stationed in attractive buildings at the ports where our ships of war are accustomed to gather or to call with frequency, are exerting a marked and much appreciated influence upon the morale of the sailors. Such a work as this has been imperatively needed. The government does not maintain a force of chaplains large enough to give one to each of the large battleships now in commission. It is also questionable whether the best equipped of chaplains has as close an access to such men as the unordained religious leader. The traditional reserve of the enlisted man in the presence of an officer greatly hinders the chaplain. And in any case the meager supply of religious leaders available for both army and navy make this recent movement most welcome and full of promise.

The settlement idea, like that of the Salvation Army, was not wholly due to the constructive genius of a layman, yet, in case of each, the movement has become a distinctively laical enterprise. 
General Booth was for all practical purposes a layman when he organized the Army as an instrumentality for reaching and for educating in simple ways the religious instincts of the desperately poor. Arnold Toynbee sought, as far as possible, to divest his enterprise of clerical appearances, and the whole settlement movement has consistently aimed at religious and moral instruction through friendly fellowship with a neighborhood or through classes and clubs, rather than by preaching.

The settlement suggests the clubs of every description which minister to the religious, moral, and social education of various classes. Of these the boys' clubs and girls' clubs are representative. Adolescent life is being explored in our day. It would not be far amiss to say that boy nature is being discovered. The boy is no longer spiritually a sort of dark continent, an unexplored territory popularly supposed to be incapable of production. We are coming to understand his true capacity for religious impression and to realize that he is never too young to be religiously trained. The secret key to his heart has been discovered by various sorts of laymen, some of them as widely-known educators and scientific students of psychology as President G. Stanley Hall; others incited only by their loving sympathy for the boy himself. It has been essentially a scientific and a practical problem.

The various societies for the cultivation of the religious life of the young people in our churches were originated and have been in large measure developed by ministers. Nevertheless they offer an unlimited field for the religiously active laity, and much of that rapid growth and adaptedness to the religious needs of young people which has made them noteworthy is due to the efficient service of such leaders.

A similar remark might be made regarding the Brotherhoods, i.e., of St. Andrew, of Andrew and Philip, etc., which are assuming an important relation to the young men of our churches. To these the ministers of those churches sustain a close and important relation, yet the characteristics which make for their efficiency are largely due to the far-sightedness and organizing ability of Christian laymen.

The greatest of the movements which owe their inception and their development to the enterprise and inventiveness of clergy and laity alike, and yet would pitiably fail in efficiency if the latter class were to cease to participate, is that of the Sunday-school. It is easy to criticise the management and the standards of the average Sunday-school, and yet we cannot overrate it as a significant religious institution, full of promise and potency. Like every other useful instrumentality, the Sunday-school has been developed by experiment. It has accomplished, even though the methods may 
have been crude and the aims narrow, three great ends. It has introduced multitudes of the laity, both men and women, to their lifelong careers of useful and often constructive service; it has developed an army, huge in dimensions, of loyal disciples of Jesus; it has created and fostered a widespread interest in the study of the Bible. The Sunday-school has apparently reached a turning point in its development. It must in the future become the channel through which the manifold interests of the Church in the religious education of its whole membership shall find productive expression. Not until it ministers to the education of old as well as young, and to each in the way which his special need requires, will it fulfill its mission. And to accomplish this end it must make larger use than ever of the trained laity.

I cannot pass in review every kind of religious organization that depends upon the laity for its successful development. I would not wholly ignore the sisterhoods of the Roman and the Episcopal church, both such as minister to some form of need and those which devote themselves to instruction, the orders of deaconesses, and the movements for the redemption of special classes or races or for the reformation of society in some particular respect. Their name is legion, but they are at one in drawing upon the laity for their workers.

I have reviewed the foregoing lines of activity which call out the energies of the laity, because the data set forth introduce a series of significant assertions regarding the present status of trained leadership among laymen in the work of religious education. It may seem that I have called attention to much religious activity which could not fairly be classed as educational. This would be true if we used the term "educational" in a technical and limited sense. We must not forget that religious education is a training of the whole personality into religious responsiveness. It should strengthen the will while stimulating the intellect. What Professor Coe calls "expressive activity" is a normal and important element in religious development. A movement which gives itself solely to the promotion of personal religious activity of a devotional sort may have great educational value. If it has none, the fault will lie with those who are its promoters.

It is instructive to note, however, that almost without exception a movement which begins as an organization for the promotion of the religious sensibilities is sure, if successful, to develop a directly educational function.

The Young Men's Christian Association in its early aggressive days gave itself to rescue work almost as distinctively as the Salvation Army does to-day, After entering upon its more specialized field of young manhood, it was characterized by a policy of the anticipa- 
tion and prevention of crime, by the cultivation of active righteousness in daily life. To-day, of its own initiative, and with wonderful skill, the Association is emphasizing education and giving it definite religious value. Its usefulness is narrowed by the fact that its constituency is a changing one, the average duration of desirable membership being less than three years. Only a small fraction of its membership is permanent. But within the limits thus imposed the Association is achieving a marked success in religious education. The movement had last year over fifty thousand registered students of the Bible.

A similar showing can be made for the Young People's societies. Organized at the outset to promote habits of religious expression in devotional meetings, they have come to emphasize strongly the value of Bible study. President Charles Cuthbert Hall in his annual Survey of Progress in Religious Education, just published, eites the fact that within a trifle over one year the Epworth League secured among its membership over a thousand classes, with more than eighteen thousand members, for the study of a text-book on the life of Christ, to the value of which I can testify.

Equally significant is the fact that the Methodist order of deaconesses are given careful instruction, in order to fit them for wise and efficient educational service in connection with their ministration.

In the second place, not only do these lay movements develop educational functions, they thereby tend to produce a host of eager and intelligent students of the varied problems of religious education. In the Religious Education Association to-day, a large and valuable section of the membership is composed of men and women who have a practical reason for their great interest in religious education. They are primarily interested in young men or boys or some distinctive class of people.

Thirdly, the infusion of this lay element among those who look at the problems of religious education from a theoretical point of view is in last analysis truly and broadly valuable. The influence of the able and consecrated layman makes for economy and directness of effort, for effective organization, for supervisory provisions, and in particular for a continuing emphasis upon the education and the consecration of every normal function of life. There is in the mind of the average layman an impatience with the merely theoretical survey of life which is not unwholesome. His participation in the working out of religious problems tends also to a normalizing of experiences and duties once regarded as obtainable only in an unusual way. This may account for the decay of the revival as a means of religious stimulus and the substitution of contact with a religiously earnest friend. It is the social evangelism of the person that seems to tell in this generation. 
Again, through the growth of these movements, the field for a distinctive religious career has been greatly widened, while adding to the opportunities for specialization in religious leadership. Not a few young men of commanding ability are giving themselves to a work for boys, the problems of which are now in process of solution. A high quality of ability is essential also to the man who takes up the work of a traveling secretary for the colleges. In settlement work, in the direction of all kinds of philanthropic and educational activity, a trained man or woman is recognized as essential for strong and profitable service.

Lastly, we are forced to note that in no other way than by the acceptance and vast enlargement of lay leadership can the friends of religious education keep abreast of the demand for efficient direction. This does not imply any loss of influence on the part of the ministry. There is no such diminution in the case of a true minister. But the demand for trained leadership is too great for any one class of men to supply.

Let us notice briefly what is being done to train laymen for such professional service as they may helpfully render on the score of religious education.

I would mention in passing the very interesting fact that the Teachers' College of Columbia University has definitely included within its curriculum for would-be teachers thorough-going courses by Dr. Richard Hodge on the principles, methods, and literature of religious education, and on the historical and literary study of the Bible.

It is also important to note the rapidly increasing number of educational institutions of the first rank among our universities and colleges which furnish courses in the English Bible, the history of religion, and in ethics, sociology, and pedagogy, which tend directly to give the student confidence and power in religious leadership. I have had the opportunity of following the history of fifteen years of such work at Yale, to the conclusion that many are thereby led to use a portion of their time in later life in promoting religious and moral training.

Inasmuch as the whole system of training the laity for efficiency in religious leadership is a very recent development, we cannot expect any such well-ordered, historically-developed institution as the school of theology to have made its appearance. As an earnest, however, of what will soon be found in enlarged numbers, I instance a few of the institutions which are giving to the laity a more or less thorough training for leadership.

Sometime ago the Young Men's Christian Association discovered the need of training schools for secretaries and physical directors. Two such are established and in operation; one at 
Springfield, Mass., the other in Chicago. No school can create the ideal general secretary; he requires the education of experience; but a large proportion of the most enterprising and successful secretaries of to-day have received their strongest impressions at one of these excellent institutions. At each a thorough mastery of the Bible and a general introduction to the best working religious and educational methods is given emphasis. As a result of the tireless promotion of religious education in the Associations, there is being appointed in every large organization a secretary who is a Bible study specialist. He supplements and enforces the more general religious work of his colleagues.

Such a teacher finds his training to-day at one of the universities like Chicago, or Vanderbilt, or Yale, or at the colleges for men or women which are equipped to give thorough Biblical instruction, or in such a specialized institution as Dr. Wilbert W. White's Bible Teachers College in New York, recently given an adequate home by Miss Gould. At the latter institution the practical and experimental side of Bibie training is given prominence.

The extensive courses for lay students at the Union Theological Seminary, New York, exhibit more thoroughly than the arrangements made by any other theological institution the good results among the laity of the provision at such centres of religious education of opportunities for those who desire to become better able to meet their opportunities as lay workers. Whether it is better than the independent lay college it is hard to say.

For the important posts of pastor's assistant, Bible school superintendent, and the like, the Bible Training School of Chicago, and the Hartford School of Religious Pedagogy, particularly the latter, furnish needed instruction. The school at Hartford has been notably successful in developing able teachers and organizers. These schools will prosper, and others like them will arise.

The most productive school of all for the training of religious leaders will continue to be, as it always has been, the close association of a successful leader with a chosen pupil. A pastor's class of one will rarely fail to develop the qualities of initiative, resolution, and ability to direct the effort of others. It is the most sacred duty of the true religious leader to keep placing his hand on some available personality, who shall be trained for future independent service.

It will be fully apparent to one who has followed this discussion, that the rise of the laity as men and women of religious initiative does not mean the corresponding decline of the ministry. On the contrary, the greater the number of such qualified laymen and laywomen, the more need will there be for the still better trained minister. The layman will never displace the minister until the latter becomes satisfied with the relatively meager training which meets 
the layman's needs. In an ideal relationship the two types of trained religious educators will be always coördinated. The ministry must in the main be responsible for high and true standards of scholarship and for their bearing upon sound religious interpretation; the laity will find its constructive opportunity in the direct application of the principles thus made clear to the problems of every-day life, and in the efficient organization of the forces which make for righteousness and in their promotion. Each share is coming to be essentially important.

I have already remarked that these are the days when the place of the religiously minded and well-equipped laymen is realized. $\mathrm{He}$ is a factor of steadily growing significance because the legitimate objects of his educational effort are constantly on the increase, while the scope of his service never ceases to broaden. Yet with the rapid growth of lay responsibility the larger function of the educated ministry will keep pace. The soundest and most satisfying ends can alone be reached by the coöperation of educators of each type. This assures, in time, the thorough working out of every important religious problem. A case in point is the history of the Sundayschool. For more than a century it has aimed to promote the instruction of the young for religious ends by becoming a place for the gathering together of the young for direct, religious impression, and for incidental study of the Bible. In consequence of the conviction that the results of such a work were too vague and temporary and that a mastery of the Bible was the more fundamental object of the two, many Sunday-schools have become Bible schools, with the avowed purpose of making a careful and thorough study of the Bible, with the formation of sound character as the logical and assured accompaniment. Our recent investigations, however, into child nature and its proper nurture causes the thoughtful student to place the subject of the wise instruction of the young religiously in a still larger synthesis. The Sunday-school will not fulfill its proper function until it becomes in fact the medium through which the church seeks to promote scientifically the religious education of its whole membership, old and young, in ways closely adapted to the religious habits of each class.

The outlook for the rapid and salutary development of organized religious education is very bright, because we have at last obtained the factors which will promote it in their proper balance, have achieved for them great freedom of expression and of investigation, and have assigned to each its most effective lines of independent activity. It is not extravagant to say that never in history were being drawn into working harmony as large a body of earnest, wellequipped, broad-minded, varied, yet essentially unified investigators of religious problems and active promoters of religious activity 
as can be found in this country and abroad to-day. We have only to insist that investigations shall be thoroughgoing and rigidly scientific in method, that the leaders of religious education shall themselves be many-sided in their sympathies and responsive to all legitimate impressions, and that sound educational principles shall not be sacrificed for the sake of temporary results, in order to assure in the near future an important advance in all departments of the field of religious and moral education.

The significance of our adoption in this generation of the trained layman as a respected and welcomed factor in religious development is most clearly realized when we remember his absence of traditions, his executive capacity, his directness and precision of approach to an important problem, and his perfect sympathy with that same practical, comprehensive view of life which makes it all religious. His point of view is one which is distinctly complemental to that of the trained minister. Together they will reach wise working solutions of the problems which we have so long been struggling to solve. 


\section{SHORT PAPERS}

Rev. George B. Stewart, of Auburn, New York, presented a short paper to this Section on "Qualifications and Training for the Ministry."

Professor Herbert L. Willett, of Chicago, Illinois, presented a short paper on "Some Phases of Professional Religious Education." 
SECTION C-RELIGIOUS AGENCIES 



\section{SECTION C.-RELIGIOUS AGENCIES}

(Hall 15, September 23, 3 p.m.)

Chairman: President Edgar Y. Muluins, Southern Baptist Theological Seminary, Louisville, Kentucky.

Speakers: Rev. Washington Gladden, Columbus, Ohio.

Rev. James M. Buckuey, Editor The Christian Advocate, New York. Secretary: Dr. Ira Landrith, formerly General Secretary, Religious Education Association, Chicago, Illinois; now Regent, Belmont College, Nashville, Tennessee.

In opening the Section of Religious Agencies, President Edgar Y. Mullins, of Louisville, Kentucky, spoke as follows:

"One of the most irrepressible and insistent demands of the human mind is that for unity. The ambition of thinkers from the beginning of time has been to bind up all the elements of being into a comprehensive conception, or to find a single principle which would explain the universe. This tendency in the realm of philosophy is very marked in our day. Monistic forms of human speculation. accentuate the tendency strongly. In science, also, the underlying assumption in all investigation is the unity of nature. In sociology the unity of life, the solidarity of the race, are being recognized as never before.

"It was a splendid conception in the minds of the projectors of the Congress of Arts and Science to attempt to bring together in a common meeting-place representatives of all the callings and departments of human investigation. Such a conference among leaders must result in broadening the horizon of all the participants and of all those under whose notice the proceedings of these Congresses may come. Nothing could emphasize more strongly the common interests of the race than this struggle for unity of view and for the realization of the eommon intellectual and ethical ideals which underlie all the struggle of modern life. These Congresses must prove to be far-reaching in their influence. Doubtless, in future generations, men will look back upon these meetings as marking an important era in the history of human thought, and recognize in them the introduction of important elements for the solution of the great problems of science." 


\section{RELIGIOUS AGENCIES}

\section{BY WASHINGTON GLADDEN}

Washington Gladden, Pastor, First Congregational Church, Columbus, Ohio; Moderator, National Council of Congregational Churches. b. Pottsgrove, Pennsylvania, 1836. A.B. Williams, 1859; D.D. Roanoke College; LL.D. University of Wisconsin; LL.D. Notre Dame University of Indiana. Lyman Beecher Lectureship, Yale, 1887-1902; Adin Ballou Lectureship, Meadville Theological Seminary, 1892; E. A. Rand Lectureship, Iowa College, 1897; William Belden Noble Lectureship, Harvard University, 1903; Preacher to Harvard University, 1892, 1893, 1902. Member of American Social Science Association, American Academy of Political and Social Science, American Economic Society. Author of Plain Thoughts on the Art of Living; From the Hub to the Hudson; The Young Men and the Churches; Parish Problems; Art and Morality; Social Salvation; The Practice of Immortality; and many other works on religion.]

THE extent and the indefiniteness of the theme assigned to me will be evident to any one who attempts to give any meaning to these words. No limit of time is suggested; I do not know whether I am expected to speak of existing religious agencies, or of all which have been employed since the world began. No limitation of space is proposed; I do not know whether I am to confine myself to my own country, or to Christendom, or whether I am to deal with the religious agencies of all nations. I dare say that the architects of the programme which we are following in this Congress would have found it easy to include the whole of time and space in a neat and comprehensive statement, by which the religious agencies of all centuries, all kingdoms, all tribes, all faiths, should be succinctly and adequately described; they could have distanced Puck and put a girdle round, not the earth only, but also the heavens in forty minutes; but this approximate omniscience is not mine, and I must begin by some sharp delimitations.

What is a religious agency? The word has a wide connotation. It may denote the operation or the operator, the instrumentality or the power using it. It may signify a method, a cult, a ritual, or the employment of forms of activity by individuals or organizations. I shall exclude the theoretic meaning, and confine myself to the practical meaning of the term. By religious agencies I shall mean individuals or classes or organizations acting for the maintenance or propagation of religion.

It would be interesting to trace the evolution of such agencies from the primitive periods down to the present day. That there has never been an hour when man was destitute of religion is the increasing probability on which scientific investigation encourages us to lay hold. The hasty assumption that some tribes were unreligious has, in nearly every case, been overthrown by a more careful 
study of their life. "The fact is," says Mr. Brinton, "that there has not been a single tribe, no matter how rude, known in history or visited by travelers, which has been shown to be destitute of religion under some form." 1

All human beings have some notion of powers superhuman to which they are related, and there are always agencies, of some kind, by which they hope to influence or modify these relations. Perhaps what is called animism, by which is meant the attribution of conscious life to everything which manifests any kind of force, is the earliest form of religion. "The ascription," says one authority, " of life analogous to his own to trees, rivers, fire, and the like, is not necessarily religious in itself; but the transition from animism in theory to animism in cult seems to involve a recognition of their superhuman powers. If a river is endowed with life as is a man, it has power to benefit, as in irrigation, or to injure, as in flood; and it becomes necessary either to propitiate the river, that it may be bounteous in its waters, or to induce it to refrain from destructive floods."

The agency by which primitive men seek to control these forces, to avert their enmity or make them benign, is magic, — the practice of certain incantations by which evil powers are quelled and good powers made propitious. The medicine men and the priests in the African jungles and in our own American forests assume this function, and gain great influence through the use of it. Sometimes they are supposed to exert this superhuman power in the injury of their enemies; sometimes in warding off injuries caused by alien forces, human or superhuman; sometimes in securing the favor of unseen influences. "The sorcerer," says Tyler, "is described as being initiated by living in some wild spot till by fasting and torture he attains his supernatural craft, becoming able to see spirits, to consecrate bits of bone or of stone into powerful amulets, to make good or bad weather, to gain mystic power over familiar birds or beasts, to take omens from their cries or from the itching of his own skin. ... The medicine man's apparatus includes the sorcerer's usual music, the rattle and the drum, simple and primitive instruments whose constant association with the lower magic bears witness to the beginnings of music and magic having been associated together when civilization was yet in its low stages of development. The American sorcerer carries a 'medicine bag' made from the skin of his guardian animal, which protects him in fight, cures the bites of serpents, and strikes at a distance as a spiritual weapon. He knows magic chants of power over the elements; he can, by sucking and blowing, extract disease elements from the sick; he can make pictures and images, and pierce them with thorns so as to kill the men or animals they

${ }^{1}$ Religions of Primitive People, p. 30. 
represent; and he can compel love by practicing on the heart of the picture of the beloved one." All this he does by his acquaintance and alliance with superhuman powers. Such are the earliest and most crude of the religious agencies, - earliest, I mean, on the scale of civilization. Among the backward races they are in use to-day in many parts of the world.

As civilization advances magical arts of a more refined nature are practiced; and we read on the Egyptian papyri and the Babylonian monuments stories of divinations and charms and incantations exercised by those who are supposed to represent the gods. Even in Greece and Rome there are oracles and auguries, a vast machinery of prediction and propitiation. As life becomes more complex religion is more highly elaborated and its rites more refined; great hierarchies arise; the priestly function which, in the early periods, was apt to be combined with political and military functions, is separated and developed along parallel lines; sacerdotal powers are sometimes hereditary; religion becomes a chief prop of the social order and often dominates the state. Temples, churches, altars, shrines, are erected; vestments and sacred vessels are accumulated; rituals and ceremonials are fashioned; great numbers of men are educated and trained for the performance of religious offices.

This is a mere glance at the development of the religious agencies now existing throughout the world. All types of them are in use to-day; the rudest natural magic; the animistic cults, divinations, exorcisms and auguries; the Shamanism of Siberian Tunguses, the Lamaism of Tibet, the Hinduism and the Jainism of India, the Buddhism and the Taoism of China and Japan, the Mohammedanism of Turkey and Northern Africa, with the great organized ecclesiasticisms of Christianity, the Greek, the Roman, the Protestant. Merely to mention the principal types of religious agencies would be tedious; to attempt any sketch or criticism of them would be the task of a lifetime.

I must content myself with a mere conspectus of the principal religious agencies now in use in our own country. There may be some value in such a résumé, which shall bring before us, in a rapid sketch, the various forms of religious activity now existing in the United States of America.

At the foundation of the monogamous social order is the family, in which religion is domesticated. There was a time when the most and the best of the religious teaching in America was given in the family; it is probable that even to-day no other religious influences are so effective as those of the home. But the family is more than a religious agency; it is the primary social organism; it is the political unit; it is a great economic factor; and it has properly been set apart for separate consideration in another section of this Congress. It is 
not one of the specialized agencies for the maintenance and propagation of religion, and, therefore, I have not included it here.

The first of these specialized agencies is the church, some form of which may be found in nearly every neighborhood. I speak now of the local church, the religious congregation or assembly, organized for worship and for work, and usually possessing an edifice or edifices in which its work is carried on. Of all the agencies employed for the maintenance and propagation of religion, this is by far the most important. The local church, as it exists in America, is modeled after the Jewish synagogue, of which it is the natural successor. The parent organization is here, living side by side with its offspring; for we have in America perhaps 600 or 700 Jewish congregations, and it is easy for any of us to discover, by personal observation, to what extent we are indebted to the Hebrew race for this method of promoting religion.

Other forms of faith are found in local religious organizations; there are 1400 or 1500 congregations of Mormons; and there are 60 or 70 theosophical societies, between 40 and 50 Chinese temples, a dozen or more communities of Shakers, a few groups of Free Religionists, and several hundred societies of Spiritualists.

All these, however, form but an insignificant number of local organizations when compared with the Christian churches of all creeds and names. Adding together the congregations of all the other forms of faith, we could not reach a total of more than three thousand, while of local congregations representing the various forms of Christian faith, there must be, in America, about 190,000. Of these 11,186 are of the Roman Catholic communion, and nearly 180,000 are Protestant societies. The Roman Catholics count all their adherents, and they claim a population of nearly 12,000,000 connected with their congregations. The Protestant congregations count only their communicants, of whom there are not less than $18,000,000$. If their adherents, young and old, were added, the Protestant population would reach $35,000,000$. These are estimates for the present day, based on the latest and most trustworthy statistics.

It would thus appear that the Christian churches are at present reaching by ministration and influence not less than $47,000,000$ of the people of the United States.

Connected with nearly all of these 190,000 Christian churches of various names are Sunday-schools in which religious instruction is given. But there are also many Sunday-schools not connected with churches, planted and supported by undenominational agencies, and not included in the figures given above. How many of these religious agencies there may be I have no means of knowing.

Closely affiliated with these churches, and indeed, as a rule, vitally 
related with them, are the Young People's societies, which have played so large a part in recent years in the religious life of the churches. The Young People's Societies of Christian Endeavor, the Epworth Leagues, the Baptist Young People's Unions, and similar organizations of young people, are effective agencies for the promotion of religion. All these are, however, connected with churches, and their membership is mostly included in the figures given above. The same is true of several Brotherhoods which have sprung up in connection with the churches. Some of them are confined to certain denominations; others are interdenominational; but they are, for the most part, in working relations with the local churches. They coöperate outside the churches, for common purposes.

These local congregations have, however, other than local interests. Most of them are grouped in national denominational bodies, through which they coöperate for many purposes, - for the extension of those ideas and methods which they severally represent, and for the evangelization and enlightenment of the nation and of the world. Through these national bodies much of the life of the Christian people finds expression. Each of them includes some kind of home missionary organization through which Sunday-schools and churches are established in neighborhoods which are destitute, - either in an absolute sense or in a sectarian sense; through which feeble churches are assisted in erecting houses of worship and homes for ministers; through which educational and philanthropic institutions are maintained, and missions are planted in heathen lands.

These ecclesiastical groups are very numerous. Not less than 132 different kinds of Christians are included in the list published in the World Almanac. Many of these are, however, mere subdivisions of sects, whose only reasons for being is a constitutional inability to coöperate with other people, or the ambition of masterful men for leadership.

Through these denominational agencies the Christian people find the principal outlet not only for their zeal for propagandism, but also for their passion for service. It is their messengers who have pushed out to the frontiers and gathered the pioneers into log meetinghouses, and laid the foundations of the religious life of the new communities. No considerable assemblage of settlers has been permitted to gather in any portion of our rapidly expanding domain without being speedily greeted by the home missionary, who comes to share with them their hardships and help them bring down to earth the New Jerusalem. Upon the hearts of the Christians in the older and more prosperous churches the spiritual needs of their brethren in the new settlements have always been lying, and they have given freely of their substance for the planting of the institutions of religion in 
every newly occupied territory. In that impulse of Christian zeal was embodied a sound statesmanship. Nothing has contributed more to the peace, the thrift, the healthy development of this great region whose festival we are celebrating, than the promptness and thoroughness with which each new community has been supplied with religious institutions and influences.

Not only toward the frontier communities, but toward the needy classes and races in our own country, the same impulse of good-will has been reaching out. Several of the great denominations have been moved by the conviction that the people in this land, who through no fault of their own, are in the darkness of ignorance and in the depths of moral and social degradation, are entitled to their special sympathy and help; and they have organized methods by which the needs of these people may be supplied. In behalf of the Indians on the plains, of the Chinese on the Pacific coast, of the mountaineers in the Appalachian fastnesses, and, above all, of the nine millions of negroes not yet free from the burden and blight of their slave inheritance, the compassion of Christian men has been called forth, and strong efforts have been made to extend to all these hapless multitudes sympathy and succor. Surely it is not possible for the disciples of Jesus Christ to live on the same continent with these people, and know their destitution and their darkness, and not do what is possible for their enlightenment and salvation.

The chief responsibility for the elevation of these unfortunate people must rest, of course, upon the communities in the midst of which they live, and must be discharged through political or public agencies; but so far as the work has taken on a philanthropic character, and has been done, not through taxation, but through voluntary contribution, by far the largest part of it has been done by the Christian churches. Some important aid has been rendered, in recent years, by agencies not distinctly religious, but the great majority of those teachers and laborers among these needy people who have been supported by voluntary charity, have been sent forth and maintained by Christian churches.

More and more during the past century the emphasis of religious obligation has come to rest upon philanthropic work, and the churches, as religious agencies, have devoted themselves, with increasing purpose, to the relief of human suffering and the amelioration of human conditions. Hospitals, asylums, orphanages, homes for the aged, and institutions of all kinds for the sick, the infirm, the friendless, and the unfortunate, have been erected in great numbers in all parts of the land. I find a list of twenty-five hospitals in this country erected and endowed by the Methodist Episcopal Church. Several other denominations have made similar provision for the sick poor. In this work, however, our Roman Catholic brethren 
leave the rest of us far behind; their hospitals are numbered by hundreds, and their asylums and orphanages are legion.

Of the great number of Catholic religious orders which are represented upon the soil of this republic, not a few are devoted to the care of the sick and the unfortunate. Some good beginnings have also been made by other Christian bodies in the organization of deaconess homes and sisterhoods, through which the churches stretch forth the hand of compassion to the suffering and the sorrowful.

It would, however, be impossible, in the time at my disposal, to give even the slightest descriptive sketch of the manifold philanthropic enterprises, the crèches, the homes for children, the schools for nurses, the industrial schools, the medical missions, the social settlements, which are under the care either of the local churches or of the denominational organizations. All that I can do is to mention them as part of the fruitage of the religious life in its organized form.

The church, as the chief religious agency, has found expression for its life not only in philanthropic work, but also in educational work. From the earliest days of our colonial life education has been a chief care of the churches. In those days the church and the town were one; there was no separation between secular and religious agencies, and a careful training in Christian principles was a principal reason for the establishment of the public school system of New England. It was " in consideration of a religious care of posteritie" that the people of Roxbury voted to establish a school. The time has long gone by when the churches used the public schools for religious purposes, but the time has never come in which the churches have ceased to put forth their energy in behalf of Christian education.

The Roman Catholic church still maintains that religion is an essential part of all education, and through its parochial schools it is making vigorous efforts to give its children a thorough religious training. Many of its strongest religious orders are mainly devoted to the work of education. Not only in its parochial schools, but by means of a great array of colleges and conventual seminaries, it is devoting its resources to the work of educating the young.

The Lutherans to some extent sympathize with the Roman Catholics in their view of education, and, in some parts of the country, their parochial schools are maintained at a considerable sacrifice.

For the most part, however, the Protestant denominations have left to the state the work of primary education, and have devoted themselves to the business of providing the secondary and the higher education. Into this work the state has also entered of late with great vigor, and in many parts of the country the state universities and the public high schools now quite outrank the institutions under denominational control. But the churches are still very actively coöperating in this work. The academies and seminaries for both 
sexes which are under the patronage and direction of churches are still very numerous, and of the colleges and universities much the larger number are controlled by religious influences. Out of a list of 592 colleges for men and women which I find in the report of the United States Bureau of Education, all but 150 are assigned to the care and control of some religious denomination. And many of those labeled "non-sectarian," like Princeton and Amherst and Oberlin, are really the children of the churches and under their . constant care and influence. The colleges of this country are, to a very large extent, the expression of the zeal for learning of the Christian denominations, the provision which they have made that the youth of the country may be trained in Christian ways of thinking and living. To this high purpose hundreds of millions of dollars have been devoted, and tens of thousands of men and women have given their lives.

I can only allude, in the briefest way, to one of the great features of the life of the Christian denominations,- their missionary work in foreign lands. The fact that Christianity is a universal religion, that it recognizes the brotherhood of man and gives to the word "neighbor" the definition involved in the parable of the Good Samaritan, is most clearly brought to light in the history of the American churches during the last hundred years. The Christian denominations as religious agencies have more and more strongly felt that the debt of love was due from them not only to the needy in their own land, but to all men everywhere; and they have gone into all the world, and are seeking to preach the gospel to every creature.

These missionary operations are at present nearly all connected with the different Christian bodies, each of which has its own missionary board and its own fields of work in foreign lands. There are one or two undenominational organizations, but most of the work comes under the control of the different churches. It has not always been so. Our oldest foreign missionary society, as its name indicates, was at first unsectarian; the Congregationalists, the Dutch Reformed churches, and the Presbyterians all united in its support; but the Dutch and the Presbyterians withdrew, and the latter church divided, so that the contributions which formerly flowed into one missionary treasury are now divided among four. Each sect prosecutes its missionary work in its own way. A fair degree of comity has, however, been observed in foreign lands, and the scandals arising from the multiplication of missionary agencies, though sufficiently offensive, are less flagrant than might have been expected. I have a record of twenty-eight such foreign missionary organizations in this country, employing white missionaries, male and female, lay and clerical, to the number of 5740 ; and no less than 15,842 native helpers; occupying 9598 stations and outstations; numbering as com- 
municants in mission churches 432,765 , of whom 37,487 were added in 1903; enrolling in 7136 schools 267,007 scholars; counting, in addition to the communicants in the churches, not less than $1,000,000$ adherents, and expending, in the year 1903, $\$ 6,964,976$. There can be no doubt that such a force as this, occupying strategic points all over the globe, and steadily witnessing for the light, is destined to affect powerfully the future history of the world. Already its influence has been felt in many ways outside the mission stations. We need not claim everything for Christianity in the evolution of Japan; some elements mingle in that result of which it would not be judicious to boast, and due credit must be given to the strong initiative of Japanese intelligence; but it is safe to say that Christianity, as presented to that people, has had much to do with the renewing of their minds; that it has furnished them with a good share of the new sentiments and conceptions and ruling ideas by which their national life has been revolutionized. Furthermore, the transformation which seems to be taking place in Japanese Buddhism, the movement toward the cleansing of that faith from its foulness and the uplifting of its standards and ideals, is clearly the result of its contact with Christianity.

Such work as this will go on more rapidly in the future than in the past; and the fruits of Christian missions will be far larger than those reported in the columns of statistics.

Such is an outline sketch, hasty, crude, and incomplete, of the churches of America as religious agencies; of the churches as local centres of religious and social influence; of the churches as denominational groups coöperating for the purpose of home evangelization, of philanthropy, of Christian education, and of foreign missionary work.

Other religious agencies must claim a few moments of our attention.

The Young Men's Christian Association, with its branches for railway work and for college work, is a most effective religious agency. It is independent of the churches, though its active and governing members must be communicants in evangelical churches, and its work is nearly all done by the young men of the churches. The Association has a place of its own and has proved itself a valuable arm of the Christian service. Its foundation is in Christian faith and experience, and the religious features of its work are central, but it has undertaken to care in very practical ways for the young men of the cities and larger towns; it furnishes them with comfortable and attractive places of resort; it assists those who are away from home in finding homes and work; it gives them opportunities of healthful recreation; it arranges for them educational classes; it seeks to surround young men with salutary influences, and to enlist them in generous endeavors in behalf of one another. 
In North America there are 1815 of these Associations, only 1500 of which report their membership, aggregating 373,502 ; of these 475 have buildings of their own, valued at $\$ 26,260, \$ 70$; other property, mostly land held for athletic purposes, is estimated at $\$ 2,598,645$. These figures are an impressive testimony to the confidence which the young men of the Associations have inspired in the business men of the communities. The work of these Associations among railway men and college men has also been taking on new strength in recent years; and it is evident that we have in the Young Men's Christian Associations religious agencies of great breadth and efficiency.

The Young Women's Associations, though far less numerous, are of kindred aims, and their labors on behalf of the young women of the colleges and the cities are worthy of all honor.

A somewhat similar organization is that of the King's Daughters and Sons, who are gathered in small groups for practical Christian work, and who claim a membership of half a million.

Last and by no means least is the great military organization of the Salvation Army, with 735 corps, and 2700 officers in the United States; with its daily street services, and its widely scattered literature; with its cavalry brigades, outriders' circuits, maternity homes, labor bureaus, women's shelters, and an inquiry department which looks up missing friends and relatives. Down among the submerged tenth these Good Samaritans are always working, and their service could ill be spared. With them must also be linked the Volunteers of America, whose work of rescue and relief incarnates and manifests the life of the Nazarene.

Thus rapidly and dryly have I summarized the organized activities of religion in the United States of America. I have confined my view to my own country because I have not sufficient knowledge of the religious agencies of other countries to speak of them intelligently. If I had possessed the knowledge, the limitation of my time would not have admitted of any such extension of the study.

These religious agencies at which we have been glancing are all in the strictest sense voluntary; none of them is supported or subsidized from any public fund; they are maintained by the free-will offerings of their adherents. It will not be denied that voluntaryism has been able to provide, in the amplest manner, for the religious wants of the community. There are few people living in the United States of America who are not within easy reach of some place of worship, and the poorest cannot complain that the offices of religion are too costly for their enjoyment. There are congregations in the cities from which the indigent people might feel themselves excluded, but there are always others, not far away, in which they may know that they are welcome. 
The question may indeed be raised whether the provision of religious agencies in America has not been overdone. If there are 190,000 churches in this country, there must be one church for every 400 inhabitants, which is certainly a liberal allowance. Adding to the churches all the other agencies which we have named, it is clear that there can be no dearth of religious privileges in America; and there are indications of a wasteful oversupply. That is a very unpleasant fact which, in many communities, we are facing. In the better residence portions of the cities, and in most of the small villages, the population is grievously overchurched. This taxes too heavily the small constituencies of the rich city churches, and leads to neglect of the poor districts, and it is the cause of serious waste in home missionary funds. A great number of the churches supported by missionary contributions on the frontiers and in the small villages could easily be spared if sectarian zeal were not stronger than love for the Kingdom of God.

This excess of ecclesiastical machinery cannot, indeed, be attributed wholly to the freedom enjoyed by the churches, for other systems have developed much more burdensome conditions. In the ancient Hebrew commonwealth one tribe out of twelve was consecrated to religious service, and one tenth of all the product of the soil was demanded for the support of religion. In ancient Mexico, whose population could not have been more than a fraction of ours, we are told that there were $1,000,000$ priests, against the 146,000 ministers in our country. And in Peru there was generally a minister for every ten Indians or less. We must not, then, imagine that America is as badly priest-ridden as some other lands have been. Nevertheless, the unseemly competition and the needless waste caused by the multiplication of churches for sectarian purposes have become a scandal and a shame, and earnest movements are now on foot looking to the combination of several of these separated sects.

The most promising field for such rapprochement would seem to be among the subdivisions of the sects. There is no obvious demand for seventeen different kinds of Methodists, or thirteen distinct types of Baptists, or twelve varieties of Presbyterians, or twenty-one kinds of Lutherans, or twelve stripes of Mennonites; a great deal of mental energy must needs be expended in distinguishing each of these varieties from all the rest and in emphasizing the small peculiarity which entitles it to separate existence - energy which could surely be put to better uses. The truth is that the strongest reason. for the maintenance of these distinctions is found in the selfish interest of the men who get their living by running the denominational machinery. If that motive could be eliminated, many of these separated bodies would quickly coalesce.

We have witnessed, within the past few years, some notable illus- 
trations of unselfishness among these denominational leaders, who have been able to prefer the welfare of the Kingdom of God to their own personal interests, and who have shown a generous willingness to lead in the movement toward the union of similar denominations. Substantial gains in this direction have already been made, for the largest part of which the Presbyterians are to be credited. The union of the Old School and New School bodies in 1869, the absorption by this larger body of the Cumberland Presbyterians this year, and hopeful negotiations now pending for the union of the Southern Church with the Northern, are signs of the times. In Canada, the Methodists of all names have come together, and the force of their centripetal movement has now extended to the Presbyterians and the Congregationalists of the Dominion, who are negotiating with the Methodists to form one body.

In the United States the most hopeful union movement now in progress is drawing together the Methodist Protestants, the United Brethren, and the Congregationalists. The first step proposed is the formation of a General Council in which the three bodies shall be represented, by which their missionary work may be coördinated, and through which methods may be devised for bringing them into organic unity.

In the process of differentiation by which these sects have been formed, the main force at work has been theological opinion. Doctrinal differences have led to most of these divisions. But the enlargement of knowledge and the broadening of men's view of God and his universe have robbed most of these distinctions of their significance. The old dispute over foreordination and free will has ceased to agitate the thoughts of men; there are not many to whom the mode of baptism now seems to be a vital matter, and many other points of belief, once emphasized, are not now dwelt upon. In truth, the obstacles in the way of the union of Christian denominations are not now largely theological. The difficulty in most cases is purely a matter of polity. What these separated sects find it hardest to surrender or modify is their ecclesiastical machinery, their methods of organization and work. The fact that the machinery is purely their own fabrication, that it possesses no sacred or inspired character, but is a purely human product, is perhaps the reason why they stick to it so tenaciously. We are often more anxious that the work of our hands should be established than that God's Kingdom may come. There are, however, signs of sanity in this distracted realm, and we have reason to hope that in the ecclesiastical as in the industrial realm the principle of coöperation is destined, ere long, to prevail over the principle of competition.

The consideration which is brought home to us most forcibly as we take this hasty survey of existing religious agencies in this country 
is the great need of a more efficient and productive use of these organizations for Christian work. If all of these 190,000 Christian churches were thoroughly alive, the power which would exist in the communities where they stand would be simply irresistible. Nearly, if not quite, one third of the people of this country are communicants in Christian churches, and fully two thirds of them are on the rolls of Christian churches either as communicants or more or less closely attached adherents. But in most of the local churches a large proportion of the communicants are not much more than nominal members, and many of the adherents are hardly touched by the influence of the church. It would seem that the great problem of the local church lies right here, in its own parish. To arouse and quicken and invigorate its own membership, to strengthen and vitalize the bond that should unite to its fellowship the families now so slightly related to it,- - this is the task set before it. What the agriculturalists call intensive culture rather than extensive culture, - the patient and thorough care of small areas rather than a superficial husbandry of large possessions, - is surely indicated as the sound policy for all these churches. If all those forty-seven millions of people, old and young, who are now enumerated among the adherents of our Christian churches could become Christians indeed, disciples of the Nazarene, filled with his spirit, living his life, what a change would pass upon the face of our society; how quickly the Kingdom of God would come with power, not only to this nation, but to all the nations of the earth. These churches are not by any means to neglect or disregard the work that lies beyond their own bounds; it is in doing this work that their own life will be developed; what I mean is only this, that they are often more anxious to add to their nominal membership than to develop a genuine Christian life among those who are already on their rolls; while the most effectual way of increasing the power and influence of the local church is by improving the quality of its membership.

The critical question is, after all, whether these manifold religious agencies, now in operation in the United States, understand their business. Have they a definite idea of what they are in the world for, or what they are trying to do, and are they working intelligently toward the attainment of this end? It is not at all certain that their answers to this question would be clear or uniform. One hundred years ago there would have been more distinctness and more unanimity in the replies. There was then, in the minds of most men, a tolerably definite notion of the mission of the church. It was a somewhat inadequate notion; it was mainly concerned about the salvation of the individual. The business of the church was simply getting people from earth to heaven. It had very little concern for anything else. That notion has been considerably modified; 
the work of the church is now seen to be much broader than it was formerly supposed to be; the emphasis of its true appeal to men does not now rest where once it did, and there is a question whether its real message and mission are quite firmly grasped to-day by many of its leaders.

There seems, indeed, just now to be some slackening of its energies, some weakening of its influence. Does not this arise from the failure to realize the changed conditions and to speak the adequate word, the living word, to living men, to preach the Christ of to-day to the people of to-day?

Surely this failure cannot long be permitted to exist. The horologe of the ages never fails to strike the hour. The world never needed a gospel more than it needs it now, and there is a gospel for its need. The religious agencies are here, numerous, well organized, adequate; there are wheels and wheels within wheels, machinery enough and more than enough; all that is needed is the Spirit of the Living Creature in the wheels. 


\section{THE PRESS AS A RELIGIOUS AGENCY}

\section{JAMES MONROE BUCKLEY}

[]ames Monroe Buckley, Editor of The Christian Advocate, New York. b. Rahway, New Jersey, December 16, 1836. A.M., D.D., Wesleyan University; LL.D., Emory and Henry College. Clergyman; Pastorates in New Hampshire; Detroit, Michigan; Stamford, Connecticut, and Brooklyn, New York. Member of the Medico-Psychological Society of North America. Director of various Methodist and charitable institutions. Author of Supposed Miracles; Faith Healing, Christian Science, and Kindred Phenomena; A History of Methodism in the United States; The Midnight Sun; The Czar and the Nihilist; Travels in Three Continents; Extemporaneous Oratory for Professional and Amateur Speakers; The Fundamentals and their Contrasts.]

\section{Religion and the Use of Documents}

ALL the great religions of the world were founded before the art of printing was invented, but all of them made much use of written documents. Books and parchments were employed by the Jews for many hundreds of years before Christ. Daniel, when in Babylon, learned from books, and the author of the book of Ecclesiastes declares that in his time " of making many books there is no end; and much study is a weariness of the flesh." The Babylonians possessed the art of writing long before the time to which the life of Abraham is attributed. The sacred books of China are numerous, authentic, and the most important were produced several hundred years before the Christian era. Many of the sacred books of India originated in a still higher antiquity, and are referred by various experts to a period between 1500 and 2000 years before Christ. In Persia the books of the chief religion, especially those in a liturgical form, have been wonderfully preserved. The Avesta, lost or destroyed at the conquest by Alexander the Great, more than 300 years before Christ, is said to have extended to two hundred thousand lines, and at that time to have been in existence several centuries.

Such was the case with the religions of Greece and Rome. By the circulation of the manuscripts both unity and diversity with respect to religious doctrines and customs were promoted. Mohammedanism also in its early history made great use of written documents. The number of manuscripts existing to this day, copies of the ancient, and some originals older than the art of printing, constitute a monument not merely to the ability and learning of the noble minds of their time, but to their marvelous patience and industry.

When Christianity arose the books of the Old Testament were accessible and were the common treasury of the orthodox Jews, 
to which branch Christ and his apostles without exception belonged. The constant use of them by the Pharisees, and the familiarity with them of the Sadducees, are obvious from the reference to Timothy: "And that from a child thou hast known the holy scriptures, which are able to make thee wise unto salvation through faith which is in Christ Jesus. All scripture is given by inspiration of God, and is profitable for doctrine, for reproof, for correction, for instruction in righteousness." So long as Christianity did not spread so rapidly and widely as to render intercourse with authorized teachers impossible, and so long as those recognized as teachers taught the same things, there was small need for manuscripts; but this was the situation only for a brief period. Converts were made faster than they could be educated orally; standards were required; letters, dignified at the present day as "epistles," were sent hither and thither, being read in the assemblies and passed from one to another, and a sure inference from the apostolic writings is that they speedily began to be a main reliance. The number of manuscripts continually increased. They were highly valued, and copies of them were multiplied.

Religion, even under the most adverse circumstances, possesses more possibilities for perpetuating the documents essential to it than does mere literature. Incidentally Disraeli, in his Curiosities of Literature, made this clear. In the section devoted to ". Lost Books" he recounts that Manetho's History of Egypt and the History of the Chaldeans by Berosus are wholly lost. Of the History of Polybius, which once contained forty books, only five remain. Of the historical library of Diodorus Siculus only fifteen books remain out of forty. Half of the Roman Antiquities of Dionysius of Halicarnassus have perished. Of the eighty books of the History of Dion Cassius only twenty-five remain. Livy's history consisted of one hundred and forty books; we possess only thirty-five. Of the eighty books of Tacitus little more than four remain. Two precious works of ancient biography are gone: Varro's Life of Seven Hundred Romans, and Acts of the Great Men among the Romans, composed by Atticus, the friend of Cicero. "We have only a few fragments of Menander, a poet who would have entertained us more than Homer. Eschylus, Sophocles, and Euripides each wrote about one hundred dramas, of which there remain only seven each of Eschylus and Sophocles, and nineteen of Euripides. Of the one hundred and thirty comedies of Plautus there are but twenty, and these are imperfect. Pliny the Elder wrote a history in twenty volumes, which has wholly perished."

Since the five books of the Pentateuch were arranged in their present form more than 2500 years have elapsed. The latest in the Old Testament canon, the Book of Malachi, has existed for 
more than 2200 years. When the number of lost books written by authors of the greatest celebrity, in an age when history and poetry were highly esteemed, is taken into the account, the facts that, in spite of persecution from governments, philosophers, other religions, and the common people, and of the wholesale destruction of books, so many Christian documents have persisted, and that there is no reason to believe that any really important documents have been lost, support the proposition that religion, whether true or false, can be clepended upon to perpetuate the documents embodying its sacred beliefs. That vast collection known as the writings of the Anti-Nicene fathers is an illustration by wholesale of the tenacity of life of such compositions.

But at all times the circulation of manuscripts was necessarily limited. The art of printing at once multiplied by thousands the facilities for distributing information and preserving records and transmitting to later ages all the literary productions of human thought, whether sacred or secular.

\section{The Service of Printing to Christianity}

The press as a religious agency must be considered from several viewpoints. As intelligently and directly wielded by religious authorities it performs the following functions: It publishes the entire sacred books. The sacred books of the Christian religion, collected in the book known as the Bible, are published not only in the tongues of the people of so-called Christian nations, but in all the principal languages of the earth and in various dialects. The Bible may be published in parts, as in the former instance, without note or comment, admitting the use of it most effectively according to the particular purpose at any time of foe or friend. In addition to this the art of printing admits of the wide distribution of the Bible and parts thereof with explanatory notes known as commentaries, whereby counsel is illuminated by the explanation of otherwise dark sayings, and at other times darkened by "words without knowledge."

For the special purposes of teachers and parents the sacred book is sent forth, accompanied by helps, historic statements, maps, definitions, and marginal references. By this means, the value of which is enhanced by the perfection to which the art of bookbinding has been enriched, it is connected with the great festal days of domestic life, presented to youth on birthdays, and to those who are establishing families of their own. This ever wonderful art makes it possible to produce speedily in the required number religious books, paraphrasing or illuminating the Bible as a whole, or of particular parts thereof, or of any special doctrine 
taught therein; thus almost as soon as Christianity is attacked an answer may be prepared, put upon the market, and, if competently done, it furnishes the antidote speedily after the poison is introduced.

In a similar manner working materials are furnished for ministers, laymen, teachers in the Sunday-school and missionaries. Only by means of the press can books of discipline be placed in the hands of each communicant and hymnals in the hands of each worshiper.

Text-books of theology, critical and historical commentaries, all kinds of books, elicited by the circumstances in which the Bible is circulated or the Christian religion preached, and all the various controversies which it always has evoked and always must evoke, can be produced by thousands in a few weeks, and a supply constantly be held in readiness. A remarkable instance was the telegraphing from New York to Chicago of the Revised New Testament and its appearing in a daily paper a day or two later.

As the Christian Church is divided into different religious organizations, and these, while agreeing in the broad facts and foundation principles of the system, disagree with one another in doctrine, discipline, or ceremony, the uses of the art of printing are greatly extended. A comprehensive example is the difference between the Latin and Greek churches, between them both and the Armenian church, and the controversies wherever they meet between these three churches respectively and the different forms of Protestantism. In the United States there are twenty-five distinct families of Christians, making necessary practical repetitions of a large class of the publications required for sustaining a necessary and consistent propagandism. To these must be added the works essential to set forth the distinctive marks of the sects composing these families. To-day all forms of Christianity meet either in the distinct Christian nations or in foreign mission fields.

The constant study of the Bible causes differences of opinion as to the mode and time of its origin, and the contents of each and every book of the Bible. As the result of such studies, are formed many hypotheses, divergent from or antagonistic to each other. Intense curiosity is excited by publications upon these subjects, each one from a responsible source, written with vigor and learning sufficient to attract readers, speedily evoking several others.

In many nations the progress of religion is impeded and circumscribed either by the dominance of one denomination or by a general public indifference or hatred to religion. In the former case without the press it would be impossible to unify the opponents of oppression, impossible to terrify the oppressors, and consequently impossible to overthrow them. 
Again, it has been found that the spread of knowledge does not prevent the rise of fanatical or semi-lunatical forms of Christianity, or the origination of new religions. Without the aid of the press it would be impossible to reach those dominated by such abnormal and often fascinating ideas and practices.

To a proper estimate of the press as a religious agency, the art of printing must be considered as utilized in the leaflet, the tract, the pamphlet, the book, and the periodical.

\section{Leaflet}

The leaflet is useful in a score of ways; it diffuses items of information, spreads notices of coming events, directs attention to larger works, epigrammatically sows seeds of truth, and often stirs thought and emotion to the point of action. It is especially adapted to reach the young, the careless, the uneducated, and those willing to read a little if brought to them, but who shun books.

\section{Tracts}

The tract differs irom the pamphlet in size and form, but the line between them is hard to fix. The standard definition of a tract is " a short treatise, discourse, or dissertation, especially a brief printed treatise or discourse on some topic of practical religion;" and of the pamphlet, " a printed work consisting of a few sheets of paper stitched together, but not bound. In the restricted technical sense the pamphlet stands for eight or more pages of printed matter, not exceeding five sheets, stitched or sewed, with or without a thin paper wrapper or cover." But popularly it is " a short treatise or essay, generally controversial, especially one on some subject of temporary interest which excites public attention at the time of its appearance . . a writing intended to publish one's views on a particular question or to attack the views of another."

Yet there are tracts that consist of much more than eight pages of printed matter, and there are pamphlets which contain only a few pages. In the English reformation, according to Dean Swift, tracts are powerfully used against the claims of the Roman Catholic Church, and he distinguished between those written by the church clergy and those written by the Presbyterians, giving the former the palm in vigor, pertinacity, point, and effect.

An illustration of the word "tract," as well as of the power of the influence exerted by tracts, is found in the word "tractarian- 
ism," derived from a series of ninety pamphlets known as the Oxford Tracts, or Tracts for the Times, published at Oxford between 1833 and 1841. These tracts, written by Newman, Froude, Pusey, and Isaac Williams, " actually checked the liberalizing tendeney in ecclesiasticism and theology, and finally developed a system of religious opinion and practice that to this day divides the Church of England."

On one of those tracts, the last of the series, No. 90, an issue arose. The tract, which was written by Newman and taught that "the Articles of the Church of England could be so interpreted as not to collide with the doctrines of the Council of Trent, was condemned by a number of bishops and heads of colleges; whereupon Newman and others entered the Church of Rome, leaving the followers of Dr. Pusey to propagate the views held by them all up to that point in the Church of England." It cannot be doubted that the issuing of those ideas in tracts or pamphlets exerted a far greater influence than could have been attained by the issue of books. But after the leaven had worked, the tracts were collected in volumes and continue to this day to exert what may be called a posthumous influence.

\section{The Pamphlet}

Pamphlets have been the short swords in political, social, and religious duels. Two hundred years ago almost all the battles in England were fought with pamphlets, and Isaac Disraeli says of England: "Wherever pamphlets abound, there is freedom; and, therefore, have we been a nation of pamphleteers." It has been affirmed that the first French Revolution was promoted more by pamphleteers than by orators. In all times of unrest sentimentmaking has been more by pamphlets than by books of large size. Monographs in science usually contain the latest results; tomes comes later. Decisions of great judges appear first in this form.

The after influence of speeches and sermons is magnified a thousandfold by the use of the pamphlet. By its very nature it can be thrust into the pocket; it can be left here and there; and it would not be extravagant to say that in all critical periods of development since printing became general, pamphlets have been among the powers behind the throne.

McMaster's History of the United States includes many sidelights that never could have been discovered except by his painstaking investigation of pamphlets. Thomas Paine's Common Sense Pamphlets, prior to and in the Revolutionary War, were almost worth a brigade to the American cause. For these and 
other important reasons great libraries accept every pamphlet offered and religiously preserve them.

There is a particular aptitude in the tract and the pamphlet for the propagation of practical religion as distinguished from doctrinal. John Wesley extended the Methodist movement to such a degree by the use of the printing press, particularly in the circulation of sermons in tracts and pamphlets, that it is a matter of reasonable doubt whether without it he could have insured the permanency of the movement. When the issue arose between him and George Whitefield as to the truth of their respective positions, the one being Arminian and the other Calvinistic, both resorted to pamphlets. Whitefield, not skillful in composition, being supported by Toplady, Richard, and Roland Hill, and many others, was unable to cope with Wesley with respect to propagandism, because of the superior facilities early secured by the latter of producing and circulating tracts, and because of his supporting his doctrinal tracts by those on practical religion. By this means, both in the hearts and heads of his people, he incorporated their religious experiences with their doctrinal views more fully than perhaps any other religious reformer. He learned much upon this subject from the methods of Martin Luther, who not only produced an extraordinary number of pamphlets, but made use of illustration to a degree hardly surpassed by the illustrated papers of the present day.

It is well known that the pamphlet gave rise to the newspaper, and the more thorough treatises upon language have extracted corroborative passages from the literature current at the times prior to the rise of the periodical press. In the sixteenth century the pamphlets contained "news ballads" and were also known as news books. There is a proclamation of Charles I, which relates to the "suppressing the printing and publishing of unlicensed news books and pamphlets of news."

\section{The Book}

To comprehend fully the function of the book it must be noted that a book gives time for study, meditation, and review; it transmits knowledge from generation to generation, and thus makes it possible for the later born population to be better informed at ten years of age than they could be at eighty years of age if without books. Oral tradition, with the aid of monuments and tablets, did much, but little in comparison with what is accomplished by books.

As distinguished from the pamphlet the book conveys more knowledge, elaborates arguments, introduces details, and answers 
not only the questions most likely to arise in the reader's mind, but provides an answer to these which only the cultivated reader and astute thinker would originate.

This difference between the contents of books and those of speeches, sermons, or orations has a greater bearing upon religion than upon almost any other department of human influence dependent chiefly upon the use of words. The object of diffusiveness and repetition in public address and in conversation is to hold attention, move hearts, and fuse audiences into one mass, so that influences may be indefinitely multiplied.

In books the style of composition is different. Where facts generally unknown are to be given, and explanations of methods are required, the number of words used may, or may not, be large. But where principles, equities, and rules of action are to be communicated, condensation to the limits of clearness is a great merit; in this age, if, outside of the realms of fiction and travel, one would secure a reading constituency, condensation is a necessity.

\section{The Periodical}

The periodical press arose long after the invention of the art of printing. Its modifications and the method by which its amazing influence is reached make its relation to religion an intricate problem.

The ponderous monthly or weekly review is really a book, and from it issues the kind of influence which single books exert, the only difference being that a certain continuity and grasp upon the mind of the reader results from the regular arrival of such publications. If edited upon a fixed principle and their articles selected with respect to the promotion of that principle, they produce about the same effect that books written for a special purpose would accomplish. If they are simply reflectors of the public mind, and brilliancy of style, depth of argument, accuracy of knowledge, or the personal fame of the writer determines the acceptance of the article, there can be no continuity of influence. They may present side by side articles written by agnostics, Comtists, Spiritualists, Unitarians, or Trinitarians. Theists, pantheists, idealists, and materialists may express their views without let or hindrance. The monthly magazines, with greater variety and some degree of editorial comment, differ from such reviews as have just been mentioned to such an extent that some of them have a recognized political or religious representative character.

The function of the weekly paper is to present a combination of news, literature, and politics, and local or general gossip. The 
daily newspaper floats to the door of every house a miscellaneous cargo, including facts, fancies, and fabrications and more or less fragmentary discussions of every subject which will contribute to the interest of the paper and the increase of its circulation. All these classes of papers deal with morals and on that subject, except in those who approach the true ideal, there is sometimes a strong contrast between the editorial and other parts of the paper. In the latter all that is abominable can be found; yet, in the same number, high moral principles are advocated and all that is admirable is commended, sometimes most eloquently, in the editorial columns.

In the present age much attention is given by the press to religion. The difficulty in connection with the periodical press generally, relative to religion, is that it is governed by commercial conditions. Formerly books were expensive and the privilege of a few. At present they are sold at a low price, and the advertisements of them in the secular press and the editorial notices secured by the publishers often unite to spread the most dangerous sentiments in morals and religion. So powerful are the commercial interests involved that even the publication houses established by churches for the promotion of the doctrines on which those churches are founded are not always free from the charge of circulating doctrines entirely inimical on some points to the views held by the churches.

But, upon the whole, the best daily and weekly papers are entitled to the credit of promoting religion. They distribute a vast amount of authentic information concerning great religious movements, the erection of churches, and the statistics and methods of the allied benevolent institutions of Christianity. They admit discussions, and in their course sometimes, and usually in closing them, make remarks adapted to leave religion in a favorable position.

Papers of another class speak irreverently and contemptuously of religion; ignoring the consistent and faithful pastor, they magnify the eccentricities of pulpit clowns, and devote more attention to the occasional moral lapses of ministers than to any other subject except prize fights and divorce cases; have the largest circulation, and that among persons who most need moral and religious influences. Thus they promote vice, demoralize the'weaker type of young ministers and the congregations among whose members they circulate.

\section{The Church Press}

The church press may be roughly divided into three classes. Those entirely devoted to sectarian interests. These have little 
or no interest in any part of the Christian world or of any religious communion excepting their own. With the exception of a little general news clipped from secular papers, without comparison or authentication, and information about their own body, and feeble editorials upon general topics, and more hysterical than vigorous discussion in controversial issues, they cater to the tastes of the most near-sighted of their constituents. Many of this class of papers are unknown to the general public. Only a classified list of the newspapers of the United States will reveal the number of them, and when specimen copies are secured it would seem that the dates might safely be changed and the year 1804 substituted for 1904. The second class, the largest and best supported, are denominational papers that regard themselves as peculiarly representative of the communion to which the editors and publishers belong, but at the same time display a deep interest in Christianity and its progress. They are generally edited in the spirit of amity and comity. Only an attack upon their distinctive denominational beliefs or usages will arouse them to controversy. The total of the circulation of these papers is vast. Some of them are edited with ability which commands respect, with a versatility which perpetuates interest, and with a spirit which supports the work of every priest, parson, or minister and of every interested layman in the circle of their readers. While they have to compete with the daily press and with small sheets whose limited subscription price is perhaps an exaggerated equivalent for their value, they are well supported, and in some cases all their profits are devoted to the direct promotion of religion and philanthropy.

By their means the philanthropic enterprises of Christian churches are placed before those who are able to contribute to their support; by their means philanthropic institutions have been established; and especially do they aid in the initiation and promotion of great educational enterprises. Also they stimulate special religious awakenings. One of their most useful functions is the maintaining of denominational traditions in families.

They furnish a forum for discussion, and unless in sympathy with them they counter-work the machinations of ambitious hierarchs and false teachers.

The third class consists of undenominational religious papers, and this class also must be subdivided into those really devoted to the promotion of Christian primarily, and incidentally general purveyors of news and literary criticism; those which have only a flavor of religion and in other respects resemble literary magazines; and those which have rather less Christian aroma and savor than ordinary magazines. Some of the last named have undergone a change. Formerly they were intended for religious papers; but 
in the change of publishers, or because of the loss of patronage, they have reached a point where they should not be classified with religious papers; but tradition holds them to be still there, and they are not unwilling to receive the patronage of such as do not discern or rightly estimate the transition through which they have passed.

\section{Has the Religious Press Lost its Influence?}

The power of the religious press as such is affirmed to be less than it was forty years ago. At that time the celebrated Thurlow Weed publicly stated that a political party, aided by the secular press, could afford to ignore the opposition of the religious press when only a portion of it denounced the action of the party, or when some approved and some denounced; but when the whole religious press united against a party it could not survive the shock and would have to compromise. A judicious estimate of the situation is this: The religious press once had a monopoly of religious news; once many took nothing but their religious paper; once the clergy conducted themselves upon the average with much propriety, and, except when a great moral issue arose, did not participate actively in party politics; once denominational differences were accentuated to an undue degree. In all these respects there have been changes tending to diminish the relative influence of church papers. One may find some daily papers and several weekly papers far superior to the magazines of forty years ago.

But where the religious press is in the hands of men of moral and intellectual power, and is edited not in the spirit of the dim past, but in that of the present day, where that spirit is not inimical to the fundamental principles of Christianity, it may, and does, retain an amount of influence sufficient to make those who control it almost stagger under the responsibility they have to bear.

\section{Works of Fiction and Religion}

Works of fiction dealing with morals or religion have in all ages of the modern Christian church been helpful or otherwise to religion. The Pilgrim's Progress has been of incalculable value to the Christian church, though in some particulars and to persons of a certain type the morbid strain which appears here and there may have done harm.

It would be not difficult to prove that the almost countless references of Shakespeare to Christianity have been of value in maintaining a sense of the truth of Christianity. It is true that in the plays of Shakespeare the Scriptures are used for all purposes 
and in the mouths of all classes, but many quotations from the Bible are given in their original sense; many passages elaborate the root ideas of the Christian religion. These have become popular quotations. Hamlet's soliloquy and various other passages have reinforced the teachings' of the Bible, or obtained a hearing for them which might not otherwise have been granted.

But while many works of fiction have been systematically constructed to promote Christianity, more are pervaded with a skeptical spirit. Whether a judicial estimate of the dealings of fiction with religion will show a balance to its credit, is uncertain. Some great works have been pervaded with skepticism; others have been devoted to showing that Christian morals are impracticable; others to the irresponsibility of man. That the nambypamby stories, which have obtained a wide vogue because of their religious aim, have weakened the religious sense of their readers, cannot be reasonably doubted. The number of really great works of fiction written with a religious purpose, that is, the purpose to make men Christians or to uphold Christian doctrines or ethics, is small. Certain great works of fiction, modern in their origin, and containing situations, ideas, and words that should not be allowed to enter a Christian or a refined family, could never have done so, had they not assumed a Christian aspect, and deceived unwary persons into commending them.

\section{Has the Christian Church Made the Proper Use of the Press?}

Another question of considerable importance is this: Has the Christian church made the proper use of the press? In all strictly utilitarian aspects it may be said to have done so; but so much credit cannot be given to it of late years with respect to the production of special spiritual results. Much is to be desired, and no religious communion can claim marked preëminence in efficiency. Many works written for the promotion of practical religion consist of forceless platitudes. The use of cant words persists, though it is not carried to the same degree of excess as in former years. Many religious publications are flimsy. Platitudes without number are repeated, and characters almost weak-minded are held up for admiration. It is a debatable question whether the heroes are religious from principle or inability to resist the religious tendencies in which they were immersed; others teach religiosity rather than religion.

Sermons put forth for the promotion of religion are often forceless. This is liable to be the case where sermons have been delivered extemporaneously, without adequate preparation, and have been published practically verbatim. That which is spoken 
under the influence of powerful feeling may produce great effects, yet when reported and printed verbatim it may hardly please those who were in sympathy at the time, and often when printed in a book will be futile as a means of making religious impressions.

The ornamenting of tracts and the using of pictures now so common is of doubtful utility except as a kindergarten movement. The tract has lost its dignity; first because of so many being written which are only a paraphrase of the printed sermons of years ago, and because they lack a direct, fresh, vivid style. Tracts and pamphlets on spiritual religion must be written as though the writer's life, liberty, and living depended upon persuading or convineing the reader.

Some denominations show more skill than others in the preparation of works intended to promote religion. The tracts, pamphlets, and books put forth by the Paulist Fathers, an organization of the Roman Catholic Church, are models from the point of view of the object. The Swedenborgians, the Unitarians, and the Baptists have shown great skill in the use of the tract, the pamphlet, and the small book. Generally speaking, schismatics and heretics, - using these words, not opprobriously, but as indicating the opponents of that which is supposed to be established,have shown greater strength and skill in the onset than the defenders of the faith. Not until danger surround them on every hand do the orthodox awake to the necessity of vigorous defense, and in the history of the Christian church this not unnatural fact has often been reproduced. The heterodox, when they have set up a new religion or a new variety of an old, grow indolent, write without a degree of force comparable with the vigor of their former revolutionary manifestations, and are themselves again in turn counterworked by the fusillades and undermined by the subleties of a new generation begotten of themselves.

The following conclusions I deem warranted by a careful survey of the subject:

(1) Where general indifference to religion exists, so that the public assemblies in its interests are neglected, it is difficult to make any progress except through the agency of personal conversation, supported by published facts and arguments.

(2) To aid in estimating the force of the press as a religious agency these facts are valuable: The report of the British and Foreign Bible Society is just out. Since its foundation, one hundred years ago, it has issued 186,680,100 copies. The American Bible Society, eighty years old, will say in its report, to be issued next week, that it has issued 74,441,674 Bibles, Testaments, and selected portions. Carefully prepared estimates of all the other publications of Bibles support the probability that at least $450,000,000$ 
have been printed. These have been published in 100 languages, and 340 dialects, in 120 complete Bibles, 150 complete New Testaments, and the rest in Gospels or other portions.

(3) In the broad sense in the present age the press as a possible religious agency is not surpassed by the pulpit. Whether this should be so in any age or under any circumstances may be doubted. But in the comparison the press is entitled to what it does for the preparation of the minister for his work, by the publication of the Bible, the hymnal, and the different necessary publications of the Church for instruction, consolation, and defense. On the other hand, the press is often a foe of religion, which both the pulpit and that part of the press which favors Christianity can hardly counteract. In France this situation, possible anywhere, is reached. In Germany and Italy it moves in increasing volume in that direction. In the word "press," in these comparisons, all the work of printing is indicated, not merely the press as representing the periodical.

(4) As it is able to reach a vast number, both of the ministry, the laity, and the general public, and to do it immediately, upon the press largely depends the exposure of evil teachings and errors in practice.

(5) The tract and the pamphlet might be made as important as ever they were, and the aim should be to develop in every religious communion men capable of producing stirring appeals, convincing vindications, and clear expositions.

(6) Discord between the press and the pulpit introduces a divisive element into a Christian communion, which will be certain to nullify the efforts of one or both.

(7) A combination of the press generally and a living pulpit would be irresistible, making impossible the decline of Christianity, and possible and practically certain its rapid progress.

(8) The religious press will always be necessary to make a full presentation of the doctrines, regulations, and ceremonies of those who maintain them, in order to protect its constituents from the inadvertent errors of the general press, to serve as a forum for intra- and inter-denominational discussion, and to defend Christianity and public and private morality against the tendency of an age, whether it wear the livery of heaven, or without disguise drifts or rushes toward the rocks and eddies which have ruined churches and states. It will always be needed to exploit the philanthropies and educational enterprises of the Church, to keep alive the memory of the worthies of the elergy and laity, and as a purveyor of information to and from the ends of the sphere of Christianity, which is, according to its founder, "the whole world."

Finally, as civilization advances, the press as a religious agency 
must become more and more potent, and the pulpit, in order to compete with its influence, must increase, both in intellectual power, depth of conviction, and a fervor which will restore to pulpit oratory its normal influence. For the saying of Delsarte is of the truth: "The eye is the sense of the intellect; the ear is the sense of the soul." 


\section{SHORT PAPER}

Dr. Ira LANDrith, then of Chicago, Illinois, and General Secretary of the Religious Education Association, now Regent of Belmont College, Nashville, Tennessee, presented the following paper on "Religious Educational Agencies:"

"Our trinity of educational institutions, the home, the church, and the school," will be complete when these three shall work together intelligently, cordially, continuously, and always devoutly. It was with the hope of helping to bring about the intelligent, cordial, continuous, and devout coöperation of the home, the church, and the school in the training of the young that the Religious Education Association was organized. If these all-comprehending institutions are duly active, wholly harmonious, and mutually helpful, all of the other agencies of religious education can be trusted to work together without friction and without hindering competition.

The Religious Education Association is not, therefore, properly a religious educational agency as the church is, or the home, or the school; it would be rather that organization which stands to promote and to proclaim the close coöperation of the church, the home, and the school, together with all those subordinate educational agencies intimately related to these, the chief, even the parent ones. The Religious Education Association is not another church, nor is it a school, neither has it any other than a benediction to pronounce upon the home. It would speak none other than words of praise and love for the church, none but words of commendation and kindly counsel to the school, and none but inspirational and welcome advice to the true home. It seeks no authority in any of these institutions, desires none, needs none.

But it does scek, desire, and need opportunity to help the church to be more effective, the school more complete, and the home more righteous, an opportunity which will be given in embarrassing abundance when leaders in the church, and managers of the schools, and lovers of the home, all alike realize what most of them have already seen, that in a peculiar sense, with reference to these three agencies, no one liveth to itself, and that nothing is too good for either, and that for the good of each there must be a striving after the best for all.

There are national associations and conventions, secular and educational, political and financial. The various churches have each for itself such general organizations, as have such important interdenominational departments of religious education as the Sunday-school, the Young People's Society of Christian Endeavor, and the Christian Associations of young men and young women; but, singular as it is, and it must seem very singular to all who know that the central purpose of all religious work is the building of character for temporal and eternal uses, there has been no one association in whose activities and conventions the workers in all churches and in all schools and in all institutions and societies of religious education might profitably and appropriately participate, both contributing and receiving the benefits of successfully tried plans, and uniting their testimony and their influence for the weal of their common cause, the religious education of this generation.

The Religious Education Association would serve the cause of individual, national, and international righteousness in the capacity of that safe and sane confederation in which all churches, schools, and persons, willing to get and to give better things, can meet, without compromise of principle, neither demanding, nor offering the surrender of, any sacred conviction, and study together how each may best do that part of the work of world-betterment which each has found 
to do. The advantages resulting from such acquaintanceship and conference are too numerous and too evident for cataloguing here. Lack of information about each other has been responsible for most of the bitterness sometimes shown by good enterprises and people toward one another. All that is not good in both sectionalism and sectarianism is the unhappy result of living too far apart. The Religious Education Association, if it shall accomplish all it aims at, becoming at once a clearing house for correct religious educational ideas, a rallying centre for sincere seekers after the best ways for developing the religious and moral character of the young, a confederation sufficiently strong, safe, and sane to merit the partisanship of all who desire that religious and moral education shall become the best of all education, and a non-partisan but trustworthy and helpful friend of every deserving individual, church, Sunday-school Association, Young People's Society, or other organization in any way engaged in religious education - if, let it be repeated, the Religious Education Association accomplishes all of this, and if in ever increasing numbers the leaders in the religious and educational life of the United States and Canada continue to participate in its management and its conventions, as there is every reason to expect them to do, there will continue to be a correspondingly growing need for every existing agency of religious education, every church and association, society or institution of any kind that, without desiring the destruction of any other worthy agency of religious education, is doing the best it can its own duty.

With the help of all for the Religious Education Association, then, the Religious Education Association would be helpful to all; and with or without the help of all it would supplant none, but supplement the good influences of every one of the agencies at work in every part of the field of religious education. How it will undertake to do this cannot be explained in the compass of this brief communication, but by corresponding with the association's executive office, Association Building, Chicago, the interested can secure the desired information. 
SECTION D - RELIGIOUS WORK 



\title{
SECTION D - RELIGIOUS WORK
}

\author{
(Hall 1, September 24, 3 p.m.)
}

Chairman: The Right Rev. Thomas F. Gailor, Memphis.

Speakers: Rev. Floyd W. Tomkins, Church of the Holy Trinity, Philadelphia. Rev. Henry C. Mabie, Corresponding Secretary, American Baptist Missionary Union, Boston.

IN opening the proceedings of the Section of Religious Work, the Right Rev. Thomas F. Gailor, Bishop of Tennessee, and chairman of the section, introduced the speakers as follows:

"Ladies and Gentlemen: The subject before us this afternoon is ' Religious Work.' I think that it is most fitting that this Congress of Arts and Science, which affords us an unprecedented opportunity to hear the views of eminent specialists on the intellectual progress of the world, should include an estimate, on the broadest lines, of that great, transcendent force which, more than any other, has influenced and directed the course of our civilization. We are to listen to two representatives of American Christianity who, in separate spheres of work, have won a right to be heard on this most important theme.

"I have great pleasure in introducing to you the Rev. Floyd W. Tomkins, D.D., rector of the Church of the Holy Trinity, Philadelphia, who will speak to us about the aims and methods of Christian work, and the Rev. Dr. Mabie, of the Baptist Missionary Board, Boston, who will discuss the claims of Christianity in relation to the other religions of the world."

At the conclusion of the two addresses by Dr. Tomkins and Dr. Mabie, Bishop Gailor closed the meeting with the following remarks, viz.:

"I am sure that I speak for this audience when I express our profound appreciation of the very interesting and able papers which have just been read. They illustrate the fundamental unity of conviction and hope among Christian men. They have lifted us out of the tangled jungle of difference and contention over matters of less serious moment, and have directed our minds towards the larger day, when we shall all work together for the realization of the apostle's vision of the new man in Christ. For this is our supreme assurance, which inspires us now to service and sacrifice, and overshines all temporary discouragement, that human life shall be consummated in the ever widening revelation of the Christ 'that is to be;' when we shall all have come into the unity of the 
faith and knowledge of the Son of God, unto the measure of the stature of the fulfilled and universal Christ.

"Where is one that, born of woman, altogether can escape From the lower world within him, moods of tiger and of ape? Man as yet is being made, and ere the crowning Age of ages, Shall not eon after eon pass and touch him into shape?

"All about him shadow still, but, while races flower and fade, Prophet eyes may catch a glory slowly gaining on the shade, Till the peoples all are one, and all their voices blend in choric Hallelujah to the Maker. "It is finished. Man is made." " 


\section{RELIGIOUS WORK}

\section{FLOYD WILLIAAIS TOMKINS}

[Floyd Williams Tomkins, Rector of Holy Trinity Church, Philadelphia. b. New York City. A.B. Harvard, 1872; General Theological Seminary, New York City, 1875; S.T.D. University of Pennsylvania. Rector of Saint James Church, Chicago, 1891-95; Grace Church, Providence, Rhode Island, 1895-99. Member of Contemporary Club, American Academy Political and Social Science, Department of Archæology, University of Pennsylvania. Author of The Christian Life; Following Christ; My Best Friend, etc.]

There have been many changes and developments in connection with religion since humanity's first vital appearance on the scroll of history. Yet it remained for Christianity to bring a change so marked and almost revolutionary that it has affected the whole growth of civilization, and made religion a new thing. The successive stages of religious life are readily marked and lead up to this modern revelation of truth in a way so beautiful as to prove the ruling of God. Man in his crude state, differentiated from the brute only by the possession of brain and conscience, found his first ways opened by this brain and this conscience towards some superior power, recognized but unknown. God was ignorantly worshiped, but $\mathrm{He}$ was the unknown God and, therefore, feared and dreaded. Then as brain and conscience grew, and so a way was opened for a revelation, God spoke to man and became to human consciousness a Person. Power became an intelligent power. Finally, the growth was sufficiently advanced, "in the fullness of time," for the richer revelation of God as a Father to be loved rather than a power to be feared. God himself came to man, his glory veiled, that love might be planted in the human heart. In Jesus Christ there came the great demarcation line of history. God showed himself, and those who saw him clearly were born again. To serve, to worship, to believe God, were the essentials of religion and of life as taught by our Lord and Saviour. And yet in all this fullness of light men went astray. They began to make the test upon which religion was to stand or fall in the individual case a matter of philosophical interpretation rather than of loyal and personal affection. Who Jesus was, and what were the plan of his life and the meaning of his death, held men so closely that they forgot to follow the natural line of the new religion, marked in the example of the Christ and in his declaration of a new kingdom. Their reasoning about him, united to their worship of him, shadowed their service. And this has practically continued until within the memory of our present generation, when again a new stage of development was reached, and work for God 
and with God became as important a matter as exactness in creed. This did not come in a day; nor did it come without serious struggles which for a time tended to unbalance all truth, and make religion a mere matter of philanthropy. Even yet it has not mastered men sufficiently to make all Christians and all churches true to the light which has beamed forth. And yet it has become so largely recognized as to mark a new and happy era in the history of religion. Christian work and Christian faith have been married. The Paul and the James of the imperfect theologians have become one. To believe and to do have taken the lead in the world's advancement, and no human power can separate them or stay their progress.

If we had time it would be of great interest to trace the natural causes of this great reform, found in three particulars: (1) A reaction from a severe and one-sided statement of faith; (2) an advance in intelligence which refused to think of a God eruel and terrible, or, in other words, a rebellion against a return to the ignorant ideas of the past; and (3) a leaping up of pity and love, born of God out of the modern mingling of all elements of humanity in the democracy of common living. It would well repay a profound study also, to show how this era of religious activity has had a perfectly natural growth from the past, and can be traced by theological evolution as clearly as modern methods of living can be traced from the imperfect conditions of past ages. But we must confine ourselves to a few of the characteristics of this glorious flowering of Christianity which has shed its fragrance and its beauty in the darkest places of common and personal life. It has been shown how greatly the missionary zeal of this age has profited, and how the very spirit of missions has caught the glow resulting from a clear understanding of what Christianity has to say to the men of nations who have not been in the path of its progress. The purpose of this paper shall be to show how large and rich religious work has become in the personal experience of the Christian, and in the sphere where the Christian Church is called upon to minister.

\section{The Present Ideal of a Christian}

What is it to be a Christian? Evidently to follow Christ, and one cannot follow him unless he believes in him. Here at once we strike that broad conception of truth which, though Jesus taught it plainly enough, it has taken humanity - yes, and the Church - eighteen hundred years to grasp. From one side to the other men have swayed, with tangent variations in many directions, until conscience, personal as well as ecclesiastical, has become 
blunted. Now men have said that he only was a Christian who held to a certain form of words exactly and honestly. Now they have demanded a certain performance of duty as towards Christ, vaguely called ceremony, a kind of opus operatum, which assured a man of catholic orthodoxy because of his catholic practice. Again there has been brought strongly to bear upon the individual the necessity of exact obedience to " the church," that is, to a few rulers and leading men who, whether elected in democratic fashion, or holding office by appointment or inheritance, were supposed to excel the common people in authority and intelligence, having a right to interpret and to command. As a reaction from this daring assumption of authority we are forced to note the liberalism which despised all rule, all law, all tradition, all custom, sometimes even the Bible itself, and made each man his own judge and religion a purely personal belief. From the Church being everything she became nothing. From being a slave with his spiritual food placed in his mouth, and his hands lifted by command from a central seat of power, the man became a free lance, and sometimes defied even God himself in his right to rule, magnifying humanity's glory. It was but a step from this to leave God entirely out of the question, and make right a matter of human opinion. "Where and who is God? We cannot see him, and revelation is vague, often contradictory! But we know by intelligence, no matter whence intelligence came, that right is right. And he shall be counted good who does good and is good, whether he believe or no." How vividly all these varied opinions speak! We have met them all, for they are all here with us even in this century. But by their side, or rather out of their very midst as they jangled and fought together, came this great, beautiful flower of the truth, springing from the deep earth of Christ's long ago teaching, and nourished by man's hungry dissatisfaction with trying to eat stones instead of bread. And this flower, with its fragrance and beauty like the lily, and its strength like the cedar of Lebanon, took the good from all the partial contentions and became the eternal resultant of all the minor forces. We must not think of it as suddenly appearing. Here and there for eighteen hundred years it has blossomed in individual cases, but it has never been recognized in all its glory and divine might until of recent years, and it is only now becoming the ideal of a Christian which all accept whether they practice it or not. In other words, a Christian to-day is a man of deep personal faith in Christ and love for him, and a desire to serve him and follow him. He holds to the old creed in its spirit, but he finds life in that creed only as it is exercised. He is not contented to be a slave, he must be a son; not to assume unto himself authority, but to join in the Father's work and make the Father known. He can find no 
meaning in morality aside from the will of a perfect God; but he can never think of weakening the moral law by claiming human exemption from effort. He acknowledges failure, but he acknowledges also the power of love to turn failure into success and to heal the wounds of the fall. And with his right hand extended towards God, towards heaven, towards Christ, and with his left stretched over the world towards his fellows, he fights for God's righteousness, for God's love, for God's honesty and purity, with a power drawn from the throne of his King.

I have dwelt long upon the delineation of the ideal because I wish to make clear the character of the agent in all modern church work. Religion is measured in the absolute by the character of religious people or of the religious man. Work is what it is to-day because of the workers. And when you have an ideal of Christian manhood realized at least in desire and intent, then you have a power in religious work which tells. This standard must never be lowered. No one must dare to lessen in any way this fullness of Christian manhood. The glory of it is the active power which makes all men, like the man Christ, saviors of the world, giving themselves to the work of redemption because they are so lovingly loyal to the Head, so fully alive to the great truth of God's will and God's purpose.

\section{Present Ideal of a Christian Church}

What, then, is the Church to-day? It is simply a union of the Christians we have been describing. In one way it is inorganic and invisible after an earthly fashion. In another sense it is organic through the strength of tradition, or the exact adhesion of its parts. But there can be no Church real and vital in its union with the Head of all, unless there is a clear and determined effort to save the world now and here. The conception of the Church as a body of a few faithful folk who hold to a creed and accept a form of worship, and wait for death to exalt them, is so much of an anachronism that it cannot stand for a moment to-day. It is a poor survival of a time of ignorance at which the dear God winked, that is, which he graciously permitted for a season, but which he never sanctioned. The idea of the Church as exclusive, with high gates and difficult entrance, can hold no longer. Nor can the idea of an exact and calm worship of a few respectable people once a week endure. Nor yet can the holding to a future salvation, regardless of a present and glorious salvation from wrong and injustice and impurity and intemperance, stand as an identification of the Church. Creeds are not to be despised. A right belief is a great part, we may almost say an essential part, of right action, 
but it is not, it must not usurp the place of action. Heaven and entrance thereto through the redemption of Jesus Christ are glorious elements of faith never to be diminished; but the true Christian knows that it is only as a man seeks to bring heavenly light now and here while and where he lives that he can fit himself or be fitted to endure the radiance of heaven hereafter. Godet's great words are everlastingly true: "Ce n'est pas dans le ciel qu'on trouve Dieu, mais c'est en Dieu qu'on trouve le ciel." "It is not in heaven that God is found, but it is in God that heaven is found." With this great truth ringing its symphony about her, the Church finds her work clearly marked. She is to reveal God as a present God. She is to make him real. She is to prove him real. She is to show how he works, and demonstrate the power and method of his working. She is to prove that he is the Lord and Ruler of all living, and, therefore, she is to seek to bring all living, all experiences, all works under his control. Nothing in all existence can be without interest to her because all things are of interest to God. There can be no secular and religious things; all are religious. There can be no human interests separate from the divine interests. All are one because God is one, uniting and holding all things in himself. Hence the ideal of the Church is very clear and very beautiful. It is the union of all who are trying to make God known and to bring his Kingdom. In its organized forms it is a body seeking to reveal God, through creed, through worship, through service, through preaching, through reform, to a world partly or wholly ignorant of him. Its work is as infinite as God's world. It has no longer a single part to play, but a whole real drama to enact. The Church is not merely to hold a form of sound words, or to stand as a witness, or to utter warnings, or to rebuke vice. All these things she certainly has to do, but they are parts of the great catholic work of regeneration,- - of saving the world and bringing it to God. Every nation and every individual in all the world are hers because Christ's. Every great highway and every alley of the slums, every saint and every sinner, every truth and every work, thoughts and words, books and men, states and rulers the Church is the leader of them all to righteousness.

\section{Purpose of Religious Work}

This brings us clearly to an understanding of the purpose of all religious work; it is to bring the righteousness of God amongst men. There has been much haziness even amongst good people here. With some the purpose of church work has seemed to be the glorification of the church herself. "We are living," the leaders have cried, "for see what great works are here being done." 
With others the machinery has been its own great satisfaction. It has existed for itself and its own noise has been its glory. Doubtless we have known such churches and such religious work. Again, some have made the work simply a means of exercise for the Christian folk, a kind of gymnasium for the limbering up of Christian character, activity being counted necessary for the avoidance of decay and death. Doubtless if you went to twenty churches and as many leaders in religious work you would have very varied answers to the question, "Why?" But if we know that there is a God of righteousness whose is the world, and that we are here as his children to make the world fruitful in his goodness, then the tilling of humanity's soil must be followed, not from necessity, nor yet for some great exhibition of varied products, nor yet for the beauty of its cultivated fields, but to make each part and all parts glorious in the fulfillment of their purpose. That is just what the Church has to do. It is no question of her own glory either present or future. Epaulets and swords and bands and banners may have a purpose in keeping up flagging spirits, but they are only the tinsel of living. The heart beats underneath. The Church has to take everything under her care, not to manage it herself - alas, there we have the Tridentine error - nor yet to yoke herself thereto - there we have the error of Erastianism; but the Church has to take everything under her care to help and guide and bless and purify, that it may be as God would have it, beautiful and good. How finely the whole thing maps itself out in accord with Christ's parable. The field is the world. God's children, whether individually or united, are the laborers seeking to please and serve God, seeking to keep themselves healthy in morals and spirit, but, half-conscious only of these efforts, striving to make the garden grow as it ought in all beauty and fragrance and richness. Each detail is a part of the whole. The child pulling a weed in some little corner or the man sowing great acres of grain, they are one. The Christian speaking a word of eheer, and the reformer changing bad methods to good, and the teacher urging plans - all are one. Or we might change the illustration, and see men seeking to make the ideal real. They have their model, their plan, their copy, and with eye fixed upon it they seek here and there, in this particular or that, to make it the lasting power after which all life is to be formed. Religion thus understood becomes a magnificent thing. It is not merely an intellectual belief in God. It is not only a heart-reliance upon him. But it is a great oneness with him, working as he works, seeking as he seeks, loving as he loves, rebuking as he rebukes, building as he builds. The Church is here to teach and to practice. She need not worry much about her clothes. She has no 
reason to wear her pedigree exposed that men may believe in her; she can let her methods almost take care of themselves, so long as she is honest and sincere; but oh, she must make God's world good through the power of Jesus Christ, or she is no church at all!

\section{Scope of Religious Work}

It is time now that we should go a little more into particulars. What is the scope of religious work? That we are met here by obstacles and a variety of opinions need not oppress us. Humanity is so constituted that she does more talking about ways and means than she ought, but we can gently and respectfully brush all this aside, and come to the point. Every church to-day that has a right to exist is a working church. She must do everything. The parish house, or church house, or whatever it is ealled, is as important as the sanctuary where prayers are wont to be offered. And the whole world is hers to meet. What an inspiration it is, and how finely this generation is grasping it! Theological education is becoming a new thing to-day, for ministers are being taught how to practice as well as how to preach, slow though some institutions are in grasping the situation. And laymen and laywomen are being fitted too, that religion may assume its catholic character and engage all its forces. We have then (1) the distinctively church or parish work; (2) the community work, whether in town or country; (3) the general or national work; and (4) the world's work. Let us briefly consider these.

(1) The church or parish work consists in the putting forth of every effort not merely to train Christians, but to set them at real active service. Sunday-schools, the earliest forms of church work, are now known not as children's churches to gather little people apart from adults and interest them. They are Bible schools rather, to instruct in the great truths of Christianity and to make young people work. Out of them have come many of our largest bodies of trained workers, the Christian Endeavorers, the Brotherhoods of St. Andrew and of Andrew and Philip, the King's Daughters, and kindred societies which are rich in influence and power. No church can exist in healthy fashion without these companies. The minister who is afraid to lose any of his own assumed authority, or the old deacons who are timid of the enthusiasm of the young, can never stand in the press of the pulsing activities of to-day. For our children are smelling the battle, and as their personal religion grows they feel themselves called to help the cause of righteousness. Woe to the church which keeps its youthful forces bound, and presses back the divine enthusiasm of her children! 
So with the classes for instruction and service. The Gradgrind theory of facts has not half the reason that the Squeers method of practice has. You remember how Dickens makes the horrible Yorkshire schoolmaster teach his boys how to spell "Wash windows " and then send them to do the thing itself. He was a rough specimen, and yet he had a crude grasp of truthful method. "Everybody at work" is the marching order of a living church to-day. To inspire with hunger the minds and hearts of people is the best glory of preaching and ministering. Hence our innumerable agencies, our institutional churches, our actual forces doing real service in every parish. You can't press them back. They are done with the old-fashioned ways, and unless they are well taught, as they are ready to be, they will soon be done with the old-fashioned creeds. Fling out the folds of the forms of faith! Let the breezes of God's pure air drive away the dust, and bring each expression into the light of meaning, and there will be no danger of faith failing. But work men will, and if the Church cannot show how the creed sanctions and guides their work, then the Church has lost her inspiration!

(2) Community work has to do with all the advances and reforms of the neighborhood. The Church has to lead in education, in philanthropy, in slum elevation, in moral conflicts. She need not assume control, but she must enter the army of toilers. Why should men stand aloof and ignorant when the question of schools and colleges is concerned? Why should great philanthropic endeavors like the Young Men's Christian Association and Young Women's Christian Association, and the Charity Organization Society, be left, if not without support, at least without recognition often? Why are hospitals and homes so largely separate from any church interest, and frequently left without definite and regular spiritual ministration? And in a far greater degree must the morals of a community be the care of religion. The question of temperance and the saloon must engage the church, or else the church is doomed. Dishonesty and gambling must be fought wherever and whenever found, as vigorously as heresy or esteemed heresy was fought in the Middle Ages. If religion had always expressed its authority and acted thereon in connection with purity, we would have no divorce question to puzzle our minds with its problems and to break our hearts with its pagan ravages. Church work implies a full and large meeting of these questions and evils both intellectual and practical. Preaching and warning must unite with personal endeavor and redemption, and religion must show herself in the field. In fact, the divinely-given place as a leaven in the community which religion holds demands a zeal which no criticism, no ecclesiastical aristocracy, no dread of contamination 
can forbid. What a blessing college settlements have become in many places, and yet has not the church held aloof? What a power rescue missions are in districts where the saloon reigns, and yet has the church favored them? This era of new living cries "Awake!" It is a sifting that is coming, nay, which is now in progress, and only the fittest will survive.

(3) In general or national work there is a still stronger call and a still deeper hesitation. Churches are afraid to have anything to do with politics. Indeed, some conservatives forbid the banns which might at least unite them in a common service, namely, the welfare of the race. Political partisanship doubtless is as faulty in religious circles as in the personal life. But has Christianity nothing to say regarding the wrongs of false government, regarding bribery, regarding great issues like that of Mormonism, regarding labor problems and trusts, and a host of things which touch the life of men as closely as the atmosphere? Religious work in this era, as vehemently as in earlier eras the church arose to the issues touching doctrine, arises to cleanse the earth! Shame on us that with a church eighteen hundred years old, vice and wrong and abuse and ignorance stand and defy God's goodness and God's truth! Men have no faith (and they are right) in a religion which is so busy singing hymns and mumbling prayers that it has no time or power to rescue those perishing with hunger and vice, no fancy for telling men their duty, no force to right wrongs. And the only way we can hope for a larger knowledge of God is the way of universal service in the issues of humanity. Nations will become pure when the church does her duty, not earlier.

(4) And like a great atmosphere outside of personal and communal and national life rises the world's life. The great world so largely untouched by civilization is waiting for religion to do something. She has waited a long while. Religion has been decorating her garments and framing her pedigree and garnishing her vessels while the heathen died! That a new impulse is gaining ground but proves at last a realization of divine truth and divine duty. Henceforth that church only will live in the eyes of God and man alike that takes the nations as her care and does her part in telling of God to his waiting children. Henceforth religious work will seize people more vigorously than religious belief, important though belief is; for our eyes are opening and seeing sights before which the subtleties of theology shrink and become as dross. With the one great truth on her banner, "God is, and God loves," the Church is now going out to make men good and establish righteousness in the earth. Who follows? 


\section{What Religious Work Must Bring to the Individual and to the} Church

It remains for me to touch in a clear and terse way upon the effect which religious work is to have upon the individual Christian and upon the cause of Christianity in general. This is necessary because there are many doubting hearts, seeking, like Uzzah, to stay the ark as in their eyes it seems to totter; who fear that an unsettled or a flabby faith may result from strenuous religious living. Is it safe, say these doubting ones, for us to leave the Word of God and serve tables? Dare we cease to enforce sound doctrine and give ourselves to the enforcement of sound living? Is not truth the greatest thing, after all? Setting aside the fact that such has been the cry through the ages, with rather sickening consequences both for the faith and for human life, let us face the issue, and the issue is distinctly this, that no dogma can live in solitude, but it must be shaken into active service. Madame de la Guyon, that wonderful woman who lived in the time of Louis XIV, said, in writing to a young preacher: "Preach nothing but the gospel of the Kingdom of God. Preach it as a kingdom near at hand, as something not a great way off, but to be received and realized now." And her suggestion is timely to-day. We have been preaching the kingdom as a dream of some far away and unknown era, an ecclesiastical Utopia, a new republic of the air. Truth is for the present. It has its place not in the case for preservation, but in the dusty way where men are fighting. It is not a deposit to be held from decay, but a seed to bear fruit, a jewel to shine, a sunbeam to impart life. One must admit that there is danger of erratic and Godless activity; but there is, alas, much greater danger of atrophied faith, palsied dogma, mummified truth. And just as the healthy, active child has a healthy and active mind, so the religion which lives and works has a normal faith which commends itself by its beauty and sanity. We can claim, therefore, (1) that Christian work is to faith what an exercised reason is to the brain. Hence the individual who works for God learns of God as none other can. Two men seek for truth. One gives himself to books and isolated speculative reason; the other deals with men and human needs which he seeks to satisfy. Which finds the truth first? The soul of man cannot live on husks, and, therefore, he finds nourishment not in a God of theory, but in a God of present help and power. No man's Christianity is healthy which is not a working force in his daily living. (2) The faith long held becomes for the man a living faith only when exercised. It is a grave question whether there is any truth for the man who is not himself true. Action, while it may not create 
substance, certainly reveals it, and the substance of the faith is breathing only when it is thrown against human life and made to thrill in the conflict between right and wrong. And (3) since truth ever has to do with the relation of things or of men, if it is not allowed to exercise itself in such relation, it is practically nonexistent. Orthodox teaching is only known through right living. The individual, therefore, whose religion is active finds first of all that his faith is greatly strengthened. It needs no bulwarks of text or authority from the ancients. He knows because he has demonstrated. And his life, rich in service and glorious in testimony, is as a light to show the way and a sword to cut off error. We have had too much of the selfish in the personal religious life. Now that a better day is dawning let us enter the ranks and be soldiers. And so with the Church, or, if you please, with Christianity in the abstract. It is just finding itself. Its shut-up powers are breaking the shell and leaping into action, and it is the resurrection day for the Church! Instead of weakening herself by work, she is advaneing to more glorious strength. Her goodness is daring to assert itself. She is breaking the bonds and going out to meet the world which has been crying for centuries for a help which did not come. Her new grasp of truth is already comforting thousands who thought themselves alone. What if the old conventional dignity is thrown somewhat rudely aside! What if the rough world drops titles, and forgets to bow to official rank, and tears the gorgeous garments away that the real form of goodness may be seen! What are the trappings and the ancestral degrees in comparison with a world redeemed, shame ground underfoot, and righteousness exalted? The days of kingly magnificence and feudal power and blind adulation have flown. Democracy rules, and the Church has nothing to lose and everything to gain in the new era, for her work will glorify her better than any retinue of obsequious followers or any mighty testimony of stones and altars. Throw down the barriers and let the multitudes throng her as they thronged the Christ, that some may be healed. Let her suffer crucifixion if need be, that in risen power she may claim the world. But never let it be thought that service, constant, hard, wearying, can lessen the truth of her mission and blind human eyes to the good she preaches. Nay, come out, O religion, and work for men! Drop the scepter and the miter and the canon and the orderly confession of faith; leave the throne to care for itself. Come out and save men from degradation, and so gain a right to scepter and miter, to erown and glory. For the only church which the world will recognize to-day, and which God will recognize, is the church that works. 


\title{
ELEMENTS IN CHRISTIANITY WHICH ÅDAPT IT TO BE THE UNIVERSAL AND ABSOLUTE RELIGION
}

\author{
BY HENRY C. MABIE
}

[Rev. Henry C. Mabie, Corresponding Secretary, American Baptist Missionary Union. b. Belvidere, Illinois, June 20, 1847. B.A. University of Chicago, 1868; M.A., D.D. ibid. Pastor of State Street Baptist Church, Rockford, Illinois, 1869-73; Oak Park Baptist Church, Chicago, 1873-75; Brookline Baptist Church, Massachusetts, 1876-79; First Baptist Church, Indianapolis, 1880-85; Central Baptist Church, Minneapolis, 1888-90. Author of In Brightest Asia; Romanism in Four Chapters, etc.]

THE general department of thought under which I am asked to speak in my contribution to this Congress is "The Influence of Religion upon Civilization."

I was assured that I might have freedom to treat such aspect of the subject as appealed to me. Accordingly I shall confine myself to the ascertainment of the place of Christianity as the final religion.

This is a day of wide and varied study of comparative religion, a matter broad as mankind, enduring as time, and profound as the needs of man. The subject is homed in every country, inwoven in every epoch in history, and connected with every type of thought. "Religion is the one elemental and eternal thing in man;" indeed, man has been defined as " an animate being with religion."

Vain would be an attempt in any single paper to deal with more than one aspect of the broad theme. I am among those who would have ample justice done to any and every aspect of religion, in whatsoever form the religious instinct has expressed itself. Every form of religion, even the crudest fetichism, gives utterance to some deep hunger of the soul, and so hints a thought of God. Every religion has an element of value, and its phenomena deserve to be carefully registered and pondered; for example, animism even at its lowest, holds a belief in the existence of a human spirit, in the antagonism of spirits good and bad, in the possibility of some sort of communion of spirits, and in the future life of spirits. The savage idolater does not really worship the symbol before which he bows; he simply tries thus to realize and localize the spirit which he fears. The rude African who would not complete a bargain with the European trader until he should have time to go and bring his fetich which he had forgotten, is far more to be commended than the modern nominal Christian who essays to conduct his business apart from his profession of the most spiritual religion; nay, the African, in loyalty to his crude conscience, reads 
a needed lesson to all such as have forgotten that God has the most intimate relation to all business, and especially to the denial of personal responsibility for iniquitous corporate acts.

In the Rig-Veda of the Hindus are found evidences of the sovereignty and omnipresence of the deity, and the ancient doculment records many a cry after immortality. Brahmanism with all its grossness is essentially a spiritual religion. It seeks to fit the spirit by endless transmigrations for a future life. Buddhism represents a half-truth, viz., that the soul to find its true blessedness must lose its life. Its fundamental defect is that, unlike Christianity, it does not show how, through losing its lower life, it may find itself in the higher life which Christ makes possible. Confucianism deals nobly with the manward duties embraced in the second table of the Mosaic law. It teaches the reform of personal life, some sort of regulation of the family, and the correction of certain social and political abuses. Of course, it is agnostic as to God, and yet in the very effort to escape God it substitutes nature and ancestor worship. Zoroastrianism entertains a dualism of principles embracing the conflict between good and evil, but all ultimating in the conquest of the good over the evil.

There are, however, fatal defects in all these systems which render them insufficient to meet the deeper needs of man, while Christianity alone embraces all the good found in all these systems and has none of their evils.

What I am to present in this paper may be described as "a study preliminary to the justification of Christian missions." For, as Mr. Balfour says of theology, so may it be said of missions, that "the decisive battles are fought beyond its frontiers." It is not over matters purely missionary that the cause of missions is lost or won. The judgments we form upon the special problems of missions are commonly settled for us by our general mode of looking at Christianity itself. So, in our talk about missions, to use a phrase of Emerson, we "say what we ought to say," according as we are Christian, modo-Christian, or non-Christian. At bottom the problem of Christian missions is only the problem of the extension of Christianity. How aggressively, how rapidly, or in what forms we are to do it, are secondary matters. The human methods whereby Christianity is extended, always with more or less imperfectness, are the methods of missions. My object now is to point out in Christianity those characteristics which constitutionally and reasonably commend it to universal trial, and, therefore, to universal and aggressive propagation. By Christianity I mean, of course, Christianity as it is in itself, as it came uncorrupted from the hand of its author; Christianity as separated from all those perversions and exaggerations which have become 
affixed to it through the ignorance, narrowness, or perversity of its professors. I mean Christianity reduced to its lowest terms.

For such a Christianity we must go back of all historic forms, back of all existing creedal statements, to revelation itself. We now turn to an examination into those elements in this religion which adapt it to hold the controlling place which we have claimed for it.

The first characteristic in Christianity which we note is the emphasis it puts upon the essential oneness of man. The account of man's creation in Genesis, the implications involved in the act of the dispersion at Babel, the twofold Adamic race headship of mankind, the insistence on the duty of mutual love among all men, and the goal towards which renewed humanity moves in the glorified civic unity of the New Jerusalem, all testify to the divine conception of man as one. That this has been only partially believed and accepted is sadly true. Since the first act of unbelief, logically resulting in the slaying of Abel by his brother Cain, schism and strife have characterized the long story of man's relation to man. The tyranny of the elder over the younger, of the strong over the weak, of kings over subjects, and of caste over caste, has disastrously prevailed until this hour, and is at the root of all the wars and woes of society.

The great epochal reforms among men have always turned upon some aspect of man's brotherly duty to his fellow. The passing of the feudal system, the establishment of the Great Charter of England, the Reformation under Luther, the rise of the American Republic, the abolition of slavery, and the freeing of the western hemisphere from mediæval intolerance and bigotry, all were grounded in a return towards the Bible conception of the oneness of man. Jesus Christ set forth this deep oneness in this fashion. The Herodians and Pharisees had combined in a plot to ensnare him. They approached the Master with the subtle flattery: "Teacher, we know that thou art true, and teachest the way of God in truth, and carest not for any one; for thou regardest not the person of men. Tell us therefore, What thinkest thou? Is it lawful to give tribute unto Cæsar, or not?" In his answer to this cunning flattery Christ seized upon the initial suggestion, "Thou regardest not the person of men," literally, "Thou lookest not into the face of men." And so he replied: "Shew me the tribute money " -- the Roman denarius appointed for the tax. This coin had on one side the face of Tiberius Cæsar, suggestive of civic responsibility; and on the other side the figure of a priest, suggest- 
ing religious responsibility. Looking then full upon the face of Cresar, Jesus said: "You tell me I do not look upon the face of men. Whose face is this upon which I am now looking, and the superscription whose?" They say unto him, "Cæsar's." Then said Jesus, "Render therefore unto Cæsar the things which belong to Cæsar, and unto God the things which belong to God." Thus Christ looked upon man's face, not superficially, not one-sidedly, as did both the Herodians and the Pharisees: he pierced to the deep, divine, composite pattern for man; he looked not upon the mere accidents of color or race or artificial station by which we are wont to gauge and value men; he looked to man's fundamental constitution, and saw him as his Father saw him, not as Teuton, Mongolian, or African; but man as man, man as the offspring of God, man as the subject of eternal redemption. Looking upon the face of man, in such a sense Jesus sought to remint the coin, so as to bring out again into clearness the divine image, now defaced by $\sin$, which was originally there. Thus Jesus viewed man in his integral, ideal completeness; and thus we are slowly learning to view him. Thus all reform must view him, if it accomplishes its mission.

At this point, then, Christianity as cherishing the highest hope conceivable respecting the reunion of all personal, social, political, and national schisms of men into one society of brothers, has in it the highest claim to universal acceptance.

\section{II}

But again, Christianity is adapted to become the final religion through the accent it places upon the redemptive principle in its idea of God. Other religions have their idea of deity, as representing power, intelligence, will, moral character, and judgment; but Christianity alone has at the very heart of its conception of deity the principle of recovery from moral evil.

The Bible, indeed, on its first pages definitely records the sin and fall of man, and straight through to the end it accentuates its dread reality. Even without a Bible, men of all times and races are aware of their sad condition in this respect.

Let men philosophize as they may to explain away sin, yet after all they recognize at least "a continuous abnormality" in the life of man. At the best man's life is " an ever not-quite," a falling short, a missing of the mark. Christianity, however, presents this unparalleled characteristic that, while frankly recognizing the mystery of man's sin, yet behind it all it holds out hope of recovery from it.

This purpose to redeem is set forth in the Bible as anterior to 
the purpose even to create, and to permit the fall. Otherwise the risk of the fall would not have been incurred. The Atonement is never to be thought of as an after-thought; it is always in revelation God's forethought, in which all his relations to a race of created men started; it is the ground purpose of the universe. Christ is ever "the Lamb foreordained before the foundation of the world."

The creator himself purposed from the beginning to become responsible for man's foreseen sin, in such a way as to make possible his glorious recovery from it, and his permanent establishment in positive holiness. That there is such a thing as "original sin" is indeed true. But we are coming to see that, even back of the incipient sin, God provided an "original grace" also, a grace inchoate indeed, until man, by his own free will, should respond to it and make it his own, but still an original provision, adequate to more than cancel the effects of original sin. The fathers used to maintain the doctrine of "total depravity." There is certainly a sense in which man through sin has fallen into a sad bias toward evil. His power for good has been blighted at the root. Now, however, in the light of a better understanding of Christ as the eternal Logos, and his relation from-ever-of-old to our humanity, we are coming to see that if there was in some sense a "total depravity," this is not the whole fact. There is also revealed in the Scriptures in close relation to it, a total inchoate redemption also, stored up in Christ's person and work, a redemption deeper than the acknowledged depravity. There is in Christ a potential new heredity in grace, an heredity that goes into effect for all who die in infancy or in infantine conditions, and which will also become effective in all others, unless by an act of evil free self-will and pride (which, alas, is apparently well-nigh universal), they repudiate it. Such grace is entirely a conception of the Christian Scriptures, and men who are destitute of the Bible, or who reject it, are wholly without any such assurance in deity. The utmost the pagan mind can do is to eherish the hope that there may be somewhere, although as yet all unknown, some such being as we have described, some redeemer.

A Christian missionary in China was one day describing the character of the Christians' God as a loving being, as a God of tender compassion, to a company of Chinese women, when all at once one of the women turned to her neighbor and said, "Did n't I tell you that there ought to be a God like that!"

As opposed to this, how hopeless and cruel are all ideas of God to which we are shut up by the mere agnostic philosophy of the day. In the bald Darwinian doctrine of the survival of the fittest, for example, what hope is there for the unfit of our race? yet the 
unfit are in the majority. It is the nine tenths instead of the one tenth that are submerged. It is the glory of the Christian religion that "the Son of Man is come to seek and to save that which was lost." It is idle to talk of mercy in the Bible sense apart from the Bible idea of the redeeming God. Men who shut themselves up to the cold logic of unaided human philosophy cannot entertain mercy for themselves or others. Said the late Cecil Rhodes in his last hours: "So much to be done, and yet so little accomplished." And can one wonder that so despairing a note was upon his lips when the first and last article of his creed is said to have been this, "I believe in Force Almighty, the ruler of the universe, working scientifically, through natural selection, to bring about the survival of the fittest and the elimination of the unfittest?"

Such an one in the moral school has not advanced as far as the poor Chinese woman above quoted, who said,." There ought to be a God like that!" With all his colossal power Cecil Rhodes had not yet got into the class of that rare disciple of nature, Helen Keller, who, when Bishop Brooks was giving her the first definitive lesson about God, is said to have remarked, with a face aglow with wonder, "Is that God? I have always known him, but until now I did not know his name."

The scientific conception of the survival of the fittest can never be accepted as applying to the spiritual relations of man for the reason that it always conceives of man as on the animal level only. On the physical plane it is true that nature brings into being more creatures, as it does animals, than can be educated into permanent well-being. Thus conceived of the individual is of account as the mere natural progenitor of a better race - in order to improve the breed - and failing to do this mere nature tends to put an end to man as she does to the animalculæ. The race of man thus viewed as a kind has no original and everlasting relation to the Infinite One. Says Dr. George A. Gordon: "Such a view of election to life covers only the few finest specimens and reprobates the overwhelming majority among the lower races to death. This is the new Calvinism that is tempting thinkers. It is the Calvinism of nature, elaborated from the method of the universe with animal life, which, when applied to man, is the translation of the method of the brute world into the human world." Humanity is thus "an ideal which a few are born to compass, but which for men in general is a hopeless impossibility."

Dr. A. H. Bradford, in commenting on the severity of the Darwinian theory of the survival of the fittest, is reported lately to have said: "If I were given to choose being left in the hands of the law of the survival of the fittest, and being placed in the hands 
of the God even of Edwards' famous sermon entitled, Sinners in the Hands of an Angry God, I would infinitely prefer the latter." So pessimistic a view of human life as that represented by Darwin's law of the survival of the fittest, thank God, is not the view of Christianity; for Christianity regards humanity as not merely animal, but made in the image of God also, belonging to a commonwealth of moral worth, with the possibilities of redeemed spiritual being. Hence, all the unfit may pass into the fit stage of existence and so, as precious to God, survive.

It will be recalled that George J. Romanes, when he returned to Christian faith after a long period of agnostic doubt, acknowledged that at the earlier period of his scientific studies he "did not sufficiently appreciate the immense importance of human nature, as distinguished from physical nature, in any inquiry touching theism." He, himself, says, "But since that early time I have seriously studied anthropology, including the science of comparative religions, psychology, and metaphysics, with the result of clearly seeing that human nature is the most important part of nature as a whole, whereby to investigate the theory of theism." "This," Romanes says, "I ought to have anticipated on merely a priori grounds, and no doubt should have pereeived had I not been too much immersed in merely physical research."

It may be added that this eminent man, for so many years a close follower of Darwin, was led to this new appreciation of human nature as the chief part of nature as a whole through correspondence with a Christian missionary, who has also attained distinction in the realm of natural science, Dr. John T. Gulick, of Japan, and now laboring in the Hawaiian Islands. On far deeper principles than physical science even at its best has ever contemplated, cannibals of interior Africa, the South Seas, and the pariahs of India, counted by their tyrannical superiors as the offscouring of the earth, have survived by tens of thousands and are the glorious trophies of Christian missions, and so of Christ himself, who is the Saviour of the lost, the Redeemer of all types of human failure.

A religion which can produce such a saving reversal in human hopes and conditions is adapted to find welcome and prevalence on a universal scale.

\section{III}

But a third ground of confidence for believing that Christianity is adapted to become the universal and absolute religion is in the valuation it places upon the principle of loyalty to light, and the divine authentication in experience assured to it. This it 
is that enables the soul to make an instant beginning anywhere, and with whatever measure of truth it has, in the school of Christ. I freely grant that this idea has not always prevailed, and is even now far from universal among Christian religionists. True, there are those that hold that in order to salvation in any sense or degree, there must first exist in the mind a certain intellectual concept, or set of concepts, which, in themselves, must be dogmatically believed, before the soul can come into vital relation to Christ. Such a position assumes that faith is primarily and essentially an intellectual belief; belief in a doctrine about God, or Christ, or the Bible. But this is not the truth concerning Christian faith, and never was. There is a place for intellectual beliefs, but this in the school of method is not now, for the soul we have in mind.

Saving faith at its heart is a moral attitude of personality; it is the collective, executive act of the entire soul. As such, therefore, any soul, anywhere, whatever its degree of intelligence or light, is capable of exercising such faith in principle the moment it is appealed to. Christianity alone of all religions takes note of so elemental a thing as this. Christianity alone can afford thus to accommodate itself to man's present mental furnishing, irrespective of his own religious classification of himself. Christ in his school requires of no soul more than one step at a time, and that step a relative one, in view of all the conditions it faces. Doubtless at this point many Christians have sadly misunderstood their own religion, and so they still place the cart before the horse in their initiative appeals to men. This really embarrasses Christianity and makes it needlessly slow of acceptance.

It is always a tactical mistake to put religion as a philosophy over against any other form of religion as a philosophy, in a competitive way. Those who proceed as if Christianity were a competitive religion, always do so to the damage of Christianity; they misrepresent its spirit and distort its method. Christianity is not in the field to gain a partisan victory. Such victories as Christianity wins, it wins from intrinsic desert because it complements the limited or vitalizes the expiring hope in other systems. Christianity never seeks victory for its own selfish sake, but because of its genuine and exhaustless love for those whom it would win from error and short-sightedness; it came " not to destroy, but to fulfill." It comes as sunrise comes, not to obliterate the starlight, but to suffuse it with a more original glow.

What the seeker after God chiefly needs is to find the right clue leading to the truth absolute at the end of the search. No soul conditioned in this world as it is, really ever does much more than follow a clue, with some aberrations, to the solutions of the mys_ teries involved in its religion. Nor is it the first business of th 
Christian teacher to furnish a creedal religion ready-made with answers to numerous speculative queries, but rather to put and keep men on this clue, as we have called it. He is to point out the next step, and then the successive steps toward the experimental knowledge of Christ himself, rather than to a philosophy about Christ. There is a place for the philosophy about Christ, for theology, but this place is secondary. Christ is always within personal touch of every soul, even though the soul does not know it; and by pressing our opinions about Christ inopportunely, we may widen the breach when we should close it. This touch with Christ is realized through the adoption of the right personal attitude in the light one really has, toward his ideal. The Bible calls this ideal " the Word," or Jesus Christ, that " light which lighteth every man that cometh into the world," the omnipresent living Redeemer.

To assume this willing attitude to one's ideal is faith, a faith always morally rather than intellectually conditioned. Our will has no power of itself to realize the essential Christ to the soul. The will, however, can annul the practical living lie which controls the life in its sinfulness, and the moment this is done the Spirit of Christ rushes to the soul's confessed helplessness and effects faith in him. As nature abhors a vacuum, so Christ abhors it; the moment, in the light one has, the will causes a sin to vacate the heart's throne, - that moment the Holy Spirit of Christ with infinite pressure rushes in to fill the vacuum. God's interest in conferring blessing is infinitely greater than man's in accepting it.

Says Dr. Cremer: "The wondrous counter-effect of God against man's sin is indeed a supernatural thing, the absolutely inconceivable to human philosophy; it is different from anything which elsewhere or otherwise ever takes place or can take place." This is the interior, profound reality of the Christian religion.

Now, assuming that this initiative of Christian experience, which we have called the entrance on the clue to the experimental realization of the Christ, has taken place, Christianity depends for its deeper intellectual apprehension of what has occurred, upon the after-effect of such an experience, as the mind, like a waking dreamer, casts its eye backward on the track over which the soul has come. At this point, also, the Holy Scriptures, with indispensable value, come in to bring out into consciousness, to explain to the understanding, the profound realization which has occurred, as well as to afford a basis on which further subjective experiences may be wrought. Here is the true place for objective truth.

But, further, this loyalty to light which Christianity so values receives from its divine author a peculiar attestation. This attestation will come to him who follows the light of nature, although 
in a different degree, as really as to him who follows the light of revelation, because the God of nature and of revelation are one and the same being. Christ speaks as really in the voice of natural conscience as in his written word, because the conscience with all other created things is constructed according to Christ, the true norm in creation. The conscience, indeed, as well as other powers of the natural man, is fallen, and needs to be renewed by the influence of the written word. The voice of Christ, however, yet speaks in the conscience, however obscurely; and to follow that conscience is of the spirit of faith.

It is the misfortune of current Christianity that it is supposed by any that the realities of Christian faith and experience in themselves are coterminous with the limited diffusion of the Scriptures; that in themselves faith and experience cannot exist except where the knowledge of the Bible exists. To this extent Christianity has narrowly and mistakenly alienated from itself much territory which really belongs to it, a domain which is its birthright. Christian revelation brings to light what is, in the spiritual realm; for example, life and immortality, the love of God in Christ, the suspended judgment on sin, etc.; but the existence of all these was before revelation, and independent of their explanation of them, which revelation affords. It is of the realities, and not the theories about them, that we speak. "In the beginning was the word, and the word was with God, and the word was God."

Says Paul in his letter to the Romans, "But the righteousness which is of faith saith thus, Say not in thy heart, Who shall ascend into heaven? (that is, to bring Christ down:) or, Who shall descend into the abyss? (that is, to bring Christ up from the dead.) But what saith it? The word is nigh thee [that is, the ideal is nigh thee], in thy mouth, and in thy heart:, that is, the word of faith, which we preach." The word, or ideal, of faith which is, in itself, is such a thing as may be ignorantly held. The word of faith which we preach is the same reality receiving a Biblical explanation. This essential faith by the missionary is to be sought for, as possibly existent in however slight measure, immediately, everywhere and in all men, and always encouraged, explained, and fed with revealed truth. This is the missionary's true place of beginning with the pagan mind everywhere. He is to find the handle of the soul, to take, hold, and control for God.

It will be remembered that in the account of David Brainerd's work among the Delaware Indians, he speaks of a remarkable priest or reformer who had been "strangely moved to devote his life to an endeavor to restore the ancient religion of the Indians." He was grotesquely dressed in Indian fashion, but he was evidently 
devout. He lamented freely the degenerate condition of the Indians, and said that "their ignorance and wickedness has so troubled him sometimes that he had felt driven to the woods" in the solitariness of his distress for them. At length he said, "God comforted his heart and showed him what he should do," when he would return to his associates and love and labor for them as never before. While Brainerd was discussing with him at times, he would say, "Now that I like, so God taught me." This reformer had a doctrine that " departed souls all went southward, and that the difference between the good and bad was this, that the good were admitted into a beautiful town with spiritual walls, or walls agreeable to the nature of souls, and that the latter would forever hover near those walls, and in vain attempt to get in." Brainerd testifies that this man was sincere, honest, and conscientious, according to his own religious opinions, as no other pagan he had seen. He labored earnestly to banish the drinking habit from the Indians; but by his followers, for the most part, he was regarded as "a precise zealot," and his efforts were unwelcome. It would thus appear that in the heart of this nature-taught savage was the spirit of faith existing with most limited light. It needed further instruction to give it such form and power as would enable it to grasp the large concept of "salvation" - salvation for himself and others, but the germ in "the righteousness of faith" evidently was there, before the missionary with his message came. It was the function of the missionary to develop that germinal faith, that it might grow to intelligence and power. How far even Brainerd did this, we are not told. Doubtless multitudes of instances among so-called heathen peoples similar to this exist, if they were only known. If so, it is evidence of the at-homeness of Christianity among all men everywhere. Christianity, in fact, is a religion which cannot be apprehended by the intellect merely, but requires for its realization the right use of other faculties of the soul as well, such as the conscience, the feelings, the imagination, and, above all, the will. The entire composite soul must be open. Even the living God cannot vindicate himself to the mere fragment of a man, even though that fragment be his majestic reason. In the mere action of the understanding, the executive soul puts itself outside the truth, and simply speculates upon it from without. One needs to move by an act of will inside the truth, with all the love of the heart, and with all the moral sense of the conscience. He who does this touches reality. The agnosticism of the world is only the outcome of a mistaken intellectual self-sufficiency, a species of intellect worship. The biographer of Romanes tells us that as he drew near the end of life he reproached himself for what he called " sins of the intellect, mental arrogance, and undue 
regard for intellectual supremacy." Romanes then clearly saw the principle we have above enunciated, that faith in the Christian sense is essentially a right attitude of personality to the light one has, from whatever source derived. It could not be otherwise than that those who close so many avenues of the soul in the interest of "speculative supremacy" should thus blindly miss the way to God. It is such blindness of heart that our Lord had in mind when he said: "I thank thee, O Father ... because thou hast hid these things from the wise and prudent, and hast revealed them unto babes." The essential difference in habit of mind between a child and a mere creature of intellectual prudence is this, that a child allows its whole composite being to act and the philosopher does not.

Now, Christianity risks everything as to its acceptance or rejection with him who will put its proposals to the experimental test. The method of Christianity corresponds to the laboratory method of modern science; it puts the inquirer into the laboratory, and it says, "There are the chemicals, the test tubes, the crucibles, the dynamos, etc.; now by personal, executive acts, enter into relations with the author of these; use them and get your experienced results. Those results you will find to correspond with the really true and worthy dogmatic theorems of your text-books; and wherein they do not, you must revise your text-books." Thus Christianity shines in its own light; the attempt to illuminate it by an external artifice is like holding a candle before the sun; it casts a shadow.

Christianity as thus relying upon its self-evidencing power is adapted to appeal instantly and everywhere, in all conditions, to all types of earnest life, without fear of any rival. Its practical difficulty, indeed, is to get human nature into a state of such teachableness as will really test it. When, however, the test is applied, the divine attestation is always forthcoming, and the way is prepared for Christianity's acceptance.

\section{IV}

But again, Christianity is adapted to become universal in its prevalence, because it reveals a doctrine of Providence as able to tranquilize and bless human life, irrespective of outward or material conditions. This doctrine is posited on the assumption that the soul has but one final and absolute need, and that is God. By the Providence of God we mean the assurance, so emphatically given in the Scriptures, that all the circumstances and events of life, as subservient to the grace of God, are working together for good to the soul that is filial, that is trustful and submissive, 
in its attitude towards God. This is a reality as available, potentially, for the most poverty-stricken pariah in India, as it is for the most favored denizen of the civilized world. As this is a potential value, however, the heathen yet needs to be made aware that he is to coöperate with it to gain the blessing.

This doctrine of providence is grounded in two things; first, in the nature of the divine love which ever outreaches to impart to man God's own type of blessedness and God's plan for his life unfolding; and, second, in the fact that he who is en rapport with such a God need expect nothing inharmonious with his ultimate and highest welfare to occur to him. No other system than Christianity has such a doctrine; it cannot have, because no other system has such a conception of deity, nor such a conception of harmony with the deity. Doubtless such a doctrine of providence, even by most Christians, is but feebly believed; human nature resists it in its practical bearings. Probably more unrest and mental misery arise from distrust of and rebellion against God concerning untoward events in life, than from any other single cause. And yet this Christian doctrine stands elemental in the system of Christian truth.

Christianity puts no embargo on a man's bettering his material conditions, if he justly can; it encourages to this. Whenever, however, the circumstances of life impose limitations, sorrows, or affliction beyond man's power to remove, they are to be regarded as divinely imposed or permitted for divine though hidden reasons, and when trustfully submitted to, from that moment they become providential in their bearings and purpose, and have an entirely transformed value. There is, of course, a sovereign element in appointing to men their conditions. The Christian thing, then, to do when events are plainly beyond one's power of control, is devoutly to accept them, however trying and however mysterious. No Christian can be said to have passed beyond the infantile stage of Christian experience who has not learned that the richest blessings in the grace of Christ come through the school of trial. The exact form of outward circumstance in itself considered then, would seem to have little or nothing to do with the measure of the real satisfaction with life. Said the Apostle Paul: "I have learned, in whatsoever state I am, therein to be content." The reason of this was that he was confident that through the very pressure of the events of life, and under the guidance of that Spirit, which is also immanent within the wheels of all circumstance, he was finding his way into God's eternal plan for him.

Every man's life in its last analysis is a plan of God. By him the end is seen from the beginning; every disappointment is anticipated, every sorrow provided for, every hair of one's head 
counted, every tear put in God's bottle. For every deprivation and bereavement rightly received, there is provided a compensation in the grace of God, so that when life's programme is wrought out, it will appear that " the sufferings of this present time are not worthy to be compared with the glory that shall be revealed in us."

How adapted then is Christianity at once wherever it finds human life and under whatsoever conditions, to commend itself to all, with every assurance that the grace which it offers covers all the experiences and conditions of life. It undertakes not only to justify the soul from its sins, but to redeem the whole life also; to guide it into a course, a career, and to a divine goal. Surely, then, if the human soul anywhere, in any land, would find a religion which promises to take account of the hard and painful externals in its life and lot, and turn it all into present and eternal wellbeing, where can it find it so well as in Christianity?

Another element in Christianity which adapts it to become the universal and absolute religion is its ultimate aim. That aim is to create the Godlike in personal character. The confidence that such a goal may be reached is grounded in the fact that the work of Christ, as set forth in the Scriptures on its subjective side, is to form Christ himself within the soul as "the hope of glory." Through sin the human soul has been thrown off its centre. It is Christ's work by the divine spirit to recentre the soul in God, and by a progressive method to habituate the soul to live its life in God. Thus a new spontaneity of righteousness is begotten. By exercise in this new freedom it progressively becomes second nature to act as God wills, until in the end the whole being promises to be conformed to the likeness of Christ. Professor James concludes his remarkable book Varieties of Religious Experiences by saying: "We have business with God; and he who opens himself to that business, fulfills his destiny." Where did Professor James get that idea? Certainly not outside the Christian revelation? For there only is it to be found. There, indeed, it is gloriously found in the person of Jesus as the head of the new creation.

Look for a moment at the gospel picture of the transfigured Christ, and then at the contrasting picture which follows it. The first picture is that of Christ in his glory, his whole person, even his garments, shot through and through with his own inner light, and holding fellowship with the glorified personages of heaven. The voice comes from heaven, exclaiming, "This is my Son, my chosen: hear him;" "this is what I mean by Sonship," the Christ of the Incarnation, the second Adam, accepting his cross, refusing 
to evade it, declining to return to heavenly glory, except by way of crucifixion to his lower self, thus accepting the glory of resurrection as the Father's reward - sonship communicable also to all who by faith are new-created in him.

This was sonship of the highest type. The contrasting picture is in the scene at the foot of the mount. A broken-hearted father, surrounded by the impotent disciples, to whom the father had brought his ruined child, possessed with a demon. The condition of the child wretched in the extreme. He was "lunatic," he had a " dumb spirit." The affliction was from birth. He had often fallen helpless into the water and into the fire. Even as the father was bringing him, " the spirit tare him," and he fell at the Saviour's feet " as one dead," "foaming at the mouth." There he lay prostrate, a monstrosity of sin, a masterpiece of the devil. The acme of the expression of the parent's distress is heard in the appeal, "I beseech thee, look upon my son, for he is mine only-begotten." Observe the antithesis between those two types of "only begotten" sons, the one in the glory of the mount completely transfigured, the other on the borders of pandemonium, wallowing in the dust, demonized. Raphael in his much-criticised painting of the Transfiguration is true to this antithesis. The very task of the Christian Church, in view of the havoc which sin and Satan have wrought, is to take man even at his worst, in all the wretched conditions in which he writhes and suffers, the victim of sin, and to change him, convert him, transfigure him, until in the end he shall be like the Son of Man, in the glory of the mount, the adopted and owned of heaven. With such an aim then Christianity, even Christian missions, is chartered to go anywhere upon this planet, possessing the same right which the Redeemer himself had to come here, and to lay hold of the poor Indian fakir, the wretched, superstitious Chinese Boxer, the bestial South Sea Island cannibal, and every other type of wretchedness peculiar to "Satan's castaways," and to set itself to the task of changing them into the image of the Lord. It is the right to love where others hate; the right to bless where others curse; the right to offer heaven in this world and the world to come, where others consign only to present and future doom. A charter thus attested has in it limitless power of self-commendation, and may well seek universal welcome for its renewing message.

Now, granting that Christianity is a religion possessing the qualities I have named, can it justify itself in undertaking anything less than the presentation of these values, these potentialities, to the whole world? Until recent times no system of religion, oriental or occidental, as practically held, has allowed itself to make universal effort for others. The West has been 
arrayed against the East, and the East against the West, in a mutual exclusiveness of suspicion, that one or the other must wholly triumph, or wholly succumb to the triumph of the other. As evidence of this, recall the noteworthy book of Meredith Townsend on Asia and Europe. The whole argument in this book is to show that Europe is not likely to conquer Asia. The deeper question to which Mr. Townsend does scant justice is this: Has Europe, has Christendom, the power to bless the world in such a way that neither Europe nor Asia will need any conquest, but one of love and grace?

If the positions laid down in the preceding pages are sound, the matter of mere physical or national conquest, as between any two races or peoples, is wholly irrelevant. The question lying at the bottom of everything else, is this: Has any people anywhere on the globe a message of such benignity, that if it were communicated to all the races of the world, it would result in a federation of mankind, a federation deeper than the mere "brotherhood of man;" such a federation as would shortly pass into the communion of saints? If Christianity, nay. if Christ himself, be not that message, then as yet there is none upon earth.

The work of foreign missions up to this time, and especially during the past century, has been that of blazing the path to the discovery of ways and means whereby humanity can get together and find its real salvation, salvation in every sense. Grant that in the efforts made many blunders have occurred; that the means employed have been very inadequate, even that little more than the sowing of the seed of the coming Kingdom of God has been accomplished. Yet the effort has been an earnest one, a sincere one, and, on the whole, an effective one. The humblest inquirers in this realm are those who have labored hardest and sacrificed most to get their message understood among the agnostic and idolatrous races. Our contention, however, is that nothing less than has been done could have been done, and the Christian Church have remained decently Christian, and particularly in the face of the great providential changes that have occurred in the interrelations of the occident and the orient within the past half century. The reason why Christianity could not have done less is precisely this: that Christianity when understood has in it such elements as we have noted, elements in themselves of untold value, and universally applicable to humankind.

To recapitulate these: Christianity holds the only adequate conception of human unity; it alone cherishes an idea of a glorious redemption at the heart of its God. It only places a premium upon loyalty to present light, with its corresponding divine attestation. It alone guarantees human blessedness in providence utterly irre- 
spective of outward conditions, and it alone affords practical hope of character recentred in God, to be ultimately transfigured into the likeness of the glorified Christ.

There is, then, a divine right of missions; and, of course, if so, a human right also.

In an address given by ex-Secretary Foster, repeated widely on his return from a round-the-world tour a few years since, he substantially said that if he were asked by what right Christian America had gone out into the various lands of Asia to disturb and reconstruct institutions and systems in those lands known as heathen, his reply would be: "The right to communicate to others benefits too good to keep; " and the answer cannot be gainsaid. In the argument we would make for the legitimacy of foreign missions as the profoundest agency in the ongoing civilization of the world, we are not pleading for a mere partisan crusade of one religious system against another; but rather we are seeking for the basis on which we may impart to all men potencies of so renewing and constructive a sort, that if rightly used, they would bring blessing, and blessing only to the world. Our contention in this paper has been that Christianity has in it elements of such transcendent value as are adapted to every one on earth; and, if so, the conclusion is irresistible that by the same intelligence and will that brought them into being, they are intended for every one on earth. He who discerns this adaptation must himself share in executing the intention, or himself must suffer inestimable loss. 


\section{SECTION E \\ RELIGIOUS INFLUENCE: PERSONAL}





\title{
SECTION E \\ RELIGIOUS INFLUENCE: PERSONAL
}

\author{
(Festival Hall, September 25, 10 a. m.)
}

Chatrman: Chancellor J. H. Kirkland, Vanderbilt University.

Speakers: Rev. Hugh Black, Edinburgh, Scotland.

Professor John E. McFadyen, Knox College, Toronto.

Rev. Samuel A. Elrot, Boston, Massachusetts.

Rev. Edward B. Pollard, Georgetown, Kentucky.

Secretary: Profressor Clyde W. Votaw, University of Chicago.

In opening the Section of Religious Influence: Personal, at the general meeting held in Festival Hall, Sunday morning, September 25, Chancellor J. H. Kirkland, of Vanderbilt University, spoke as follows:

"Some objects in nature are so large that one must view them from a great distance to appreciate their magnitude. So some events are so important, so far-reaching in their consequences, that it is only as they are seen in the perspective of history that their true value and significance $c$ an be appreciated. This, I am persuaded, is true of this International Congress of Arts and Science. You, gentlemen, have been laying the foundation on which others, coming after you, shall build. You have doubtless seen, with prophetic vision, the bold outlines of the fair superstructure, but it remains for your distant successors to see its magnificent scope, symmetry, and perfect unity.

"The growing unity of the world, which has been so marked a feature of these later years, is fitly supplemented by the growing consciousness of the unity of all knowledge. The wisest scientist and the greatest master of art must say, with the greatest theologian of the first century, "We know in part and we prophesy in part.' Each of us, toiling in his own separate field of investigation, sees only an arc, a very small arc, of the infinite eircle of truth. But it is a great thing to realize that whatever truth any of us may make our own, while a part of this circle, is not the whole of it. The value of this truth in the realm of religion, in promoting freedom, charity, and coöperation, is apparent. So far as your present chairman knows, no previous programme of any congress has so fully recognized this principle of the unity of all departments of knowledge, nor assembled so many of the world's greatest thinkers in the widely-separated fields of human investigation. This is your peculiar honor, this the crown of glory, which the muse of history will place on your brow.

"We are now, in this closing session of the Congress, to deal 
with religion as a part of universal science, and with that phase of the subject which recognizes religion as a social factor working for the moral progress of mankind and seeking to minister to the manifold needs of the race. It is a distinct gain to religion and to the unity of all knowledge that religion is thus recognized as having its legitimate place in the circle of knowledge, as a normal development of one part, the highest part, of man's nature. We are happy in having with us some eminent speakers who will present this subject for our consideration." 


\section{RELIGIOUS INFLUENCE: PERSONAL}

\section{BY HUGH BLACK}

[Hugh Black, Professor of Practical Theology, Union Theological Seminary, New York, 1906. b. Rothesay, Scotland, March 26, 1868 . M.A. Glasgow University; Post-graduate, Free Church College, Glasgow. First Minister of Sherwood Church, Paisley, 1891-96; Minister of St. George's United Free Church, Edinburgh, 1896-1906. Author of Friendship; Culture and Restraint; Work; The Practice of Self-Culture; Edinburgh Sermons.]

THE title of this section of the great department of religion is somewhat ambiguous, as it might mean a discussion of the influence of the individual on religion, on religious development and organization, and might also mean the influence of religion on the individual, its effects on personal character and its special impact on the single soul. Fortunately these two subjects are cognate and are only different sides of the one preëminent subject of personal religion. From whichever side we enter, we come close to the heart of religion. The real subject of this section is the place of the individual in this great matter of religion, the relation of the human soul to God.

Our subject is the climax of all the sections in this department of the Congress. All that has gone before of religious education and agencies and work leads up to this transcendent culmination, in which the soul is at home with God; and the section that follows, dealing with the social influence of religion, can have meaning only in so far as religion is a living power in the hearts and lives of individuals. Indeed, this whole wonderful Congress, attempting to cover or at least to touch upon every branch of universal knowledge, is a mighty illustration of one aspect of our subject, reminding us of all the inspiration that has come to the hearts of men and all the glory of truth that has broken upon their sight, part of the light that lighteth every man that cometh into the world. And still more, I make bold to say that the magnificent triumphs of human knowledge of which this Congress is a record, all the arts and sciences represented in such profusion here, would lose all their joy, and lose all essential meaning, if we were compelled to abandon the sphere of this humble section of personal religion. The only unity of knowledge and life and nature and the universe is God, and if we can never enter into a relation of personal communion we are only fumbling at the fringe of things and can never get further than the fringe. All our attainments and achievements turn to dust and ashes, with no true meaning and no clear future for them, if we are shut out from any hope of spiritual fellowship. My purpose, therefore, in this lecture, is not to treat of details of 
what religion can do for a man or what a man can do for religion, but to impress ourselves anew with the fact that religion means the impact of God on the human soul, and the communion of the human soul with God.

This simple fact, which might be taken as an axiomatic definition of religion, needs to be enforced on our generation. In our thinking to-day, which is inevitably sociological, there is the equally inevitable danger of the individual being submerged in the mass. In practice also our social organization is becoming ever more complex, so that we are compelled to lay less and less stress on the individual. We see that man can never be considered in isolation, that he has become what he is through society, that the social reactions are responsible for every stage of his progress. The family, the industrial conditions, the civic relation, the state, are not merely the different spheres in which man's abilities and energies are employed, but they have conditioned these very abilities and energies. We are what the social forces have made us. Development and environment are the great watchwords of our day, and the mighty truth in them can bear constant repetition. It carries with it much hope for the future in improved conditions and in practical efforts for the betterment of all classes. So full are we of this thought that we attempt to explain all life and the history of all thought and progress in broad lines of cosmic development. The individual drops out of our calculations. We make less of personal initiative and more of the environment that molds men. We are tempted to look upon the single life as merely a plastic material on which society works. And, perhaps, there never was more necessity for a protest, and for some reassertion of the place of the individual. The current of modern thought runs so strongly in one direction that most of our systems would have no place for this section of the Congress, a section entitled, "Personal Religious Influence," even when much would be made of the following section on Social Religious Influence. All who know the thought of our time will admit the existence of this tendency. We find it not only in the material sciences, but even more strongly in sociology and in all the branches of history which deal with man and his progress. The modern school of history itself boldly preaches and practices this doctrine, and the importance of it for us in our present connection is simply this, that if they are right, then there is no room for the consideration of our subject at all.

We see the tendency very marked in the protest against such a doctrine as that of Carlyle's doctrine of heroes, a protest made so strongly by Lord Acton, who more than any other man of our time has influenced the study of history in England. With him the 
great purpose in history is to get behind men and grasp thoughts. History is the growth and development of ideas, and this is true of every kind of history, political, religious, literary, or scientific. In the Letters of Lord Acton, recently published since his death, this is incessantly and vigorously asserted. "The vividness and force with which we trace the motion of history depends on the degree to which we look beyond persons and fix our gaze on things." This represents a useful protest against the picturesque scenery of an older school of historians, and is, perhaps, a necessary revolt from Carlyle's teaching: Our new historians are interested in doctrines, in principles which push things toward certain consequences, not in the passions and follies and wishes of persons. They are interested in what Lord Acton called " the impersonal forces which rule the world, such as predestination, equality, divine right, secularism, congregationalism, nationality, and whatever other religious ideas have grouped and propelled associations of men." But surely the protest has been carried too far. An impersonal idea, after all, is unthinkable. It is right in history to get past the men who played their part on the stage, but never to leave them so far out of account as to forget their real connection with the ideas. Acton's plan for his projected History of Liberty would seem to assume that there is an impersonal force called liberty, which somehow ground itself out and developed spontaneously. After all, as there could be no society without the individual with his contribution to make to the whole, so there could be no idea without an idealist, and no religion nor religious influence without the single soul. In the great scheme of modern history projected by Lord Acton, and being so worthily carried out by scholars in the Cambridge History, he reckoned modern history as beginning with the close of the fifteenth century "when Columbus subverted the notions of the world and reversed the conditions of productive wealth and power; Machiavelli released government from the restraint of law; Erasmus diverted the current of ancient learning from profane into Christian channels; Luther broke the chain of authority and tradition at the strongest link; and Copernicus erected an invincible power that set forever the mark of progress upon the time that was to come." Surely the very mention of the names is enough to suggest doubts as to the rigor and vigor of the theory.

The history of the world may not be what it has been called and treated, merely, the biography of great men; but at any rate the history of the world would be different if the influence of even a few of its great men had been left out. We sometimes think we can explain a great man by our common phrase that he was the creature of his time, and there is usually much truth in the use 
of the phrase. The leader gets as well as gives. He cannot be put in a separate category as a thing apart, as if he were a peculiar creation, unrelated to the past and independent of the present. No man could affect his age if he were not in the fullest sense the fruit of the age, entering into its thought, knowing its problems, feeling the pulse of its life. The great world-movements do not owe their origin to one man's thought, like Minerva sprung fullgrown from the brain of Jove. They grow from the needs of the time, the slowly gathering vital forces that must find outlet. The Reformation, for example, was greater than the reformers, greater than Luther, or Calvin, or Knox. In its political aspect it was the breaking of bonds in Western Europe that had become intolerable. In its inner aspect it was the movement of the soul of man towards liberty of mind and conscience, towards a fuller knowledge, a truer faith, a purer worship. But the acknowledged truth of all this gives us no warrant for imagining that we have explained the great man by calling him the creature of his time. If he brought no free and individual force to the situation, the situation would only be where it was. Granted that the Reformation would have been without Luther, there would need to be some other sort of Luther somewhere else, or, if you prefer it, some score of pigmy Luthers to do his work. There could be no Reformation without at least some kind of reformers.

This modern tendency to ascribe historical events to vague causes as opposed to personal influence needs to be checked by the absolute truth that nothing has ever been or can ever be accomplished in the way of progress without a distinct and definite personal agency. As Dr. Harnack, the great church historian, whose presence at this Congress gives even such a gathering distinction, says, "History tells us that no aspiration and no progress have ever existed without the miraculous exertion of an individual will, of a person. It was not what the person said that was new and strange - he came when the time was fulfilled and spoke what the time required - but how he said it; how it became in him the strength and power of a new life; how he transmitted it to his disciples. That was his secret, and that was what was new in him." 1

It is a foolish way to treat history as if it were in a vacuum, the whirl of impersonal forces without father or mother or any definite connection. We have gotten so scientific to-day with our tendencies and streams of influence and movements of thought, though it is not easy to see how there can be spiritual tendencies without spiritual beings, and moral influence without moral life, and movements of thought without thinkers. As if there were in the world

${ }^{2}$ Christianity and History, p. 35. 
man, but not men, the generic man without the individual! It is of a piece with so many arguments of political economists about human life in terms of $x$ and $y$, and their talk of the masses, as if the masses were not composed of units, each with his own heart's bitterness and his heart's joy. We play with words when we talk of tendencies and movements, as if we were really accounting for anything by the use of words like these; and our preference of such general terms to acknowledging the ereative influence of individuals is part of the latent infidelity which dislikes to admit creation in any sphere, the launching of a force straight from the hand and the heart of God.

It is thus we find room for revelation and a place for personal religion, a place for communion with God, and the influence of all that religion stands for on the single human soul, and thus also we find room for the unique place an inspired and consecrated soul can have in his generation, influencing others and lifting life to a higher level. If a generation has any distinctive character at all, it is, and must be, the fruit of personal character. And it is here in this region that religion does its permanent work. In its ultimate issue religion consists of a relation of the soul to God. Religion is communion, entering into and living in a relationship of love and service and obedience to God. The abiding power of our Christian faith is that Christ brings us into this relation of simple trust and loving dependence on our Heavenly Father. Religious influence, then, is personal before it can be social. It brings the individual into the presence of God. There is a moment, which came to the prophets and to men called to exceptional work, a moment when the world is dissolved, when earth has faded and heaven has opened and reveals the eternal, a moment when in all the universe there seems nothing but God and the human soul. That moment altered the perspective of everything afterwards to the Hebrew prophets; they read everything in the light of that moment, and when in the future they were brought up against seemingly impassable difficulties and things that seemed irreconcilable with their faith, they simply fell back upon God; for they knew that whatever else might be false that great experience must be true.

To most of us our religious assurance does not come in that direct fashion; it is mediated to us, so to speak. It is brought to us by human hands. From soul to soul the flame leaps and spreads. The fire is kindled from the living glow in another's heart. But we are here in the same mysterious region of personality, the Holy of holies of the human spirit, where God meets with man and man tastes the power of endless life. The unique work of Christ is that he proves himself to be the way of access to God. To see him 
is to see the Father. All that is implied in the Christian faith originated in a life, the life of the Master; and its perfect work is done when other lives are moved by the same spirit. The heart of religion lies not in adherence to an abstract system of thought, not acceptance of certain great truths, nor even reverence of great moral principles, but adherence to that thought and truth and morality as they are revealed in a great personality, as they are incarnated in a life. The dynamic of religion is personal love; the driving power is found in the devotion of the disciple to his Lord. Every great religion has had this personal note; and Christianity has it in a preëminent degree. It asks for discipleship, demands submission to the authority of Christ, and can be satisfied with nothing less than personal spiritual relations with him. This is why the faith can be universal, since it asks not for intellectual assent to propositions, but personal loyalty to a matchless personality; and is not an idle sentiment, but a power in actual life, presenting an ideal to every man that sees the vision. It is not a system of teaching merely, but a new principle of life, which takes root and assimilates elements of its environment, transforming them into new forms of life. The beginning of this process is when a man becomes a Christian, when he opens heart and life to the influence of Jesus; but that is only the beginning of a process, the goal of which is that he is a man in whom Christ lives. It is a spiritual transformation after the image of Christ. No part of the being of man is to be left out of this great scheme; the body and its members are to be the body and members of Christ and to be treated as such; the mind is to be the mind of Christ; the heart is to be the seat and throne and sanctuary of Christ. What a magnificent ideal this New Testament conception is of the Christbirth in a man till he becomes a veritable reincarnation, until he is no longer he, but Christ, reclothed in flesh and human attributes by him, so that he can say with some measure of truth, as Paul could say, "I live, yet not I, but Christ liveth in me."

The psychology of it is, that we bring every thought into subjection to the obedience of Christ, superimposing Christ's will and mind over ours, desiring to serve and please him and not ourselves, making him in all things our conscience, and bringing everything to the test of that conscience. We let him color opinion and thought and judgment and desire and ambition and hope, transforming them all into his glorious purpose. The bond of personal attachment is the deepest thing in religion. And, as a matter of historical fact, Christ's personality has been the dominating power in the Christian religion. The Christian character is modeled on his character. The Christian mind is the same mind as was in Jesus Christ. Only this personal element can give the 
necessary motive for true living. We know in practice that to be aware of the truth of a thing is quite different from possessing its power. We know what moral inability is. A man may know the right and desire the right and sincerely will the right, and yet cannot do the thing he would. He needs to be infused by a personal power that will carry him over the things that stand in the way of his will. He needs a larger and higher love that will give him the victory. This Christ gives, so that His lover can say, "I can do all things through Christ which strengtheneth me." Faith is needed before moral effort can be successful, a faith that runs up into a personal love. Christ, the Teacher, is also the Saviour; the Revealer is also the Redeemer. He redeems by revealing; he reveals by redeeming. Thus the Christian life is the imitation of Christ; and this is the power of his teaching, that it is himself and not merely his sayings we follow. Christ never says to us, "Go," without also saying "Come." He goes with us. To go to any duty, any command, any cross even, means to follow him. This personal touch, personal communion, personal love, is the unique power of Christian ethics. He who gives us the victory stands in our battle.

I do not speak of the details of this mighty personal influence, the practical effects of this communion. I do not speak of the peace and rest of heart which faith produces, the way in which the character is made strong and true. The important thing after all is to get to the source, the living fountain of strength and beauty of life. All effective social work of religion to be treated in the next section this afternoon depends on our being right here. It is personal religion which can give equipment for social service. If our life is poor within and our character is weak, our religious work will effect little. The ultimate value of a man's work is what he is. That is primarily of more importance than what he does. His power of real service is conditioned by his personal worth, his character. True religion deepens and enriches the quality of the life.

We need to have the personal note back into our confession if our religious testimony is to be effective, moving men's hearts with the pang of desire, convincing the world of God. We were born for the love of God. It is written in the needs of our nature, in the wants of our heart. Until we submit and enter into the blessed fellowship we are orphaned and desolate. "Thou has made us for Thyself, and our hearts are restless until they find rest in Thee." That word of the great Augustine sums up our life, and points to what personal religion may be to us when the heart is fixed on God. 


\title{
PERSONAL RELIGIOUS INFLUENCE
}

\author{
BY JOHN EDGAR M'FADYEN
}

[John Edgar McFadyen, Professor of Old Testament Literature, Knox College, Toronto, Canada, since 1898. b. Glasgow, Scotland, 1870. B.A. Oxford University; M.A. Glasgow University. Snell Exhibitioner, Balliol, Oxford, 1890-94; George A. Clark Fellow in Classics, Glasgow University, 1893-97; Lecturer in Hebrew, Free Church College, Glasgow, 1897-98. Member of Society of Biblical Literature and Exegesis. Author of The Messages of the Prophetic and Priestly Historians; The Messages of the Psalmists; The Divine Pursuit; Thoughts for Silent Hours; Old Testament Criticism and the Christian Church; Introduction to the Old Testament; The Prayers of the Bible.]

THE special theme which I have selected to discuss is the relation of religion to character. Who is the religious man, and what is it to be such a man? What is religion? Religion is the link that binds man to God; and the religious man is the man who is always very sure of God. He is the man who, wherever he may be, and whatever he may be called upon to do or to bear, can say with a high heart, "Nevertheless I am continually with thee." $\mathrm{He}$ is the man who counts God the great reality, and who knows himself to be the friend of God.

Now, if God be, indeed, the great reality, if he be the creator and sustainer of all the worlds, if he be the lord of all, high and lifted up above the chances and changes of mortality, and if he loves men, surely that man must be happy and secure whose soul is stayed on such a God. For if he can believe and has reason to believe that such a presence as this can come into his life, that his God is not merely in the heavens above or on the earth beneath, the high and holy one who inhabiteth eternity, but that he is very nigh, will all this mean nothing to him? Rather, will it not mean everything? Will it not rather transfigure his life, and touch it to the finest and the best that it can be? For by his side there is a friend, not a force, but a friend, strong, and wise, and tender; not a force that makes for righteousness, but a living God, whose love will not let him go, whose light follows all his way, and by whose law he must live. To such a man life will, indeed, be a solemn and mysterious thing. He will feel himself to be standing on the shores of infinity and eternity. But the mystery is one which he does not fear, for it is the mystery of love. "I am continually with thee. Thou dost hold me by the right hand. Thou dost guide me by thy counsel; and when the journey of life is over, thou wilt afterward receive me to glory." To lose this faith is to let the light go out of life. One who had lost it for a time has told us that with this virtual negation of God, the universe to him had lost its soul 
of loveliness; " and although," he wrote, "from henceforth the precept to 'work while it is day' will doubtless but gain an intensified force from the terribly intensified meaning of the words that ' the night cometh when no man can work,' yet when, at times, I think, as think at times I must, of the appalling contrast between the hallowed glory of that creed which once was mine, and the lonely mystery of existence, as now I find it, at such times I shall ever feel it impossible to avoid the sharpest pang of which my nature is susceptible." These pathetic words of George Romanes are proof enough that the loss of the sense of God can cast a blight over the human spirit.

I wish to consider what religion does for a man in relation (1) to the world of nature, (2) to his inner life, (3) to the men and women about him. (1) I shall not say much of his relation to nature, and yet something has to be said; for perhaps most religious people are too little impressed by this aspect of religion. They call in the help of God to support them when the shadows come, but they forget to contemplate the glory and the love which shine through all the works which he has made - the sea and the earth and "the splendid breadth of the open sky." There is much in nature that seems hard and eruel; in some of her moods she seems like a very monster, "red in tooth and claw." But to the man who has learned to look out upon the world with the eyes of Jesus, it is one of the many mansions of the Father's beautiful house. He sees the Father wherever he turns his eyes. It is the Father who causes the sun to shine upon the just and upon the unjust, and who sends the seedtime and harvest, the summer and winter, the cold and heat, the day and night. To such a man it is never very far to God; for the earth is the Lord's and the fullness of it, and on any spot of it the religious man will find him. He lifts up his eyes to the starlit heavens, and he sees in them "the wide and shining house of God." He feels at home in the universe; for the universe is his Father's house, and he is his Father's son. He

\section{"Can be calm and free from care}

On any shore, since God is there.'

He is not alone, never alone, for the Father is with him; and the abiding presence of the Father transfigures for him the whole world. Wherever I am, in the loneliness of a strange land, or in the silences of the night, " nevertheless I am still with thee."

(2) Now if this faith in God is able to transfigure the world, to reveal it to me as the Father's house, and to light it up with the Father's love, still more is it able to transfigure my life. Think for one moment of the difference that it makes to the inner life of a man as soon as he believes with all his soul that God is. If 
God is, then he has to be reckoned with; he knows my downsitting and mine uprising. There is not a word on my tongue or a thought in my heart, but, behold! he knows it altogether. And if he knows, what a power this thought should be to purify the heart, and to touch the motives and purposes of life to sincerity. "Search me and try me," said one to God. There are few who would care, few who would dare, thus boldly to challenge Almighty God; few who could fling their lives open to the scrutiny of his eyes; and none who could do it with any success at all, but one who all the time was saying to his heart, "Nevertheless I am continually with thee."

Besides securing inner sincerity, this sense of the presence of God is fitted to impart peace and steadfastness to the life; for the God who is evermore present is a God who cares, - not a force, but a Father. When the clouds begin to sweep across our sky, it is not enough to believe that God is; if the heart would be at peace we must believe that he is love, and that the rushing of the storm is but the mighty voice of that love. Now this peace amid the blows and buffets of fortune, this power to sleep quietly in the boat when the storm is raging, belongs truly to no one but the man who has faith in God. The man who has none is tossed about by every wind; he is vexed by fears and misgivings. He looks out into the dark future; and as he stands on the verge of the unknown, he trembles, if he thinks at all. He does not know what the days will bring; but he knows very well that they are sure to bring pain and sorrow and surprise and death. He knows that he will one day have to leave those whom he loves: he will leave them, or they will leave him, and go away to the silent land. His heart is disquieted by fear, fear of the coming days, fear of the coming night, when he shall work no more.

Now, how will these doubts and fears be met by the man who believes in God? When they smite him, as smite him they will, they will not be able to hurl him to the ground; for, in the profoundly personal language of the Bible, he knows that the Lord will hold him up. He says to his heart, "Nevertheless I am continually with thee; nevertheless thou art continually with me." $\mathrm{He}$ is content with God, and he knows that in some mysterious way his God is working all things together for his good. In the same night in which he is betrayed he is able to give thanks, because he knows his life is always in the hands of his Father. "Peace I leave with you," said Jesus, - with you who believe in God, and who believe also in me. And this was no vain word. $\mathrm{He}$ who spoke of this peace knew well whereof he spoke. When cruel mobs were thirsting for his blood, when he was confronted with all the majesty of imperial Rome, when certain death on the 
cruel cross was staring him in the face, he was always quiet and sure of himself, because he was sure of the Father. The only truly steadfast character is that which is rooted in God. It is one thing for a man to steel himself against the assaults of what he calls fate; a very different thing it is to accept the discipline that comes with the belief that it works out a gracious purpose. Then whatever be the experience through which he may have to pass, he will believe that it is good for him to be there, that that place is to him a house of God and a gate of heaven.

The sense that God is with us can make the life pure and keep the heart calm; but further, it endows the life with power, and inspires, as nothing else, with strength for the work which is given us to do. For we have a work to do, which is nothing else than the great work which God is himself doing. "My Father worketh hitherto," and in that work the religious man feels that he has his share. Now that work is simply the setting up of the kingdom of God in the world, and it is the privilege and joy of every religious man to contribute, as far as in him lies, to further its interests and ends. No doubt there are times not a few when the individual may well think his life to be lost, and his work to be vain, "cast as rubbish to the void." As he thinks of the myriads who have been before him and whose work is now forgotten, as he reflects upon the insignificant place which he occupies in the economy of the universe, he is apt to be depressed by the seeming futility of the best that he can do. But not surely if he remember, "Nevertheless I am continually with thee." He may well say, "Who am I that I should go to Pharaoh?" But "Go," says the voice, "and I will be with thee." When a man is striving to work out the purpose of God, he is not alone; he is the "co-worker of God." And this he may be, whatever his station in life; for the Kingdom is more than the Church. It covers the whole range of human activities - its trade and commerce, its literature and law, its art and seience. Now what an inspiration it must be to the lonely worker to feel that he is permitted to share in this mighty work of God - the transfiguration of the world by the spirit of God. Whatever the man is doing, he is a co-worker with God, and the minutest details of his life are steeped in the light of the eternal world. He is a mystic, but he is no recluse; and the thought that he works with God and God with him will nerve his hand and lead him to grasp his tools, whatever they be, and work with all his might, not so much because the night is coming, as because it is to him an unspeakable joy to coöperate with God. The very power of God will enter into his soul, and his strength will be as the strength of ten, because he is fighting the battles of the Lord. 
What hope, too, must be his! for he knows that the issue must be victory. The purpose of Almighty God must be fulfilled, and those who coöperate in that purpose will share in the triumph. Thus the strength that comes from the certainty of victory will pass into the heart of the lowliest worker, and in his eyes there will be the light of those who see visions and dream dreams.

(3) The sense of God, then, can make life pure and peaceful and strong. What will be its effect upon the relation of the individual to other men? Just because he believes that God is continually with him, so he must believe that God is, in some very real sense, continually with them; for in God we all live and move and are. Then is it not plain, to begin with, that he is bound to respect each man, if not for what he is, at least for what he might be? He looks upon men with the eyes of hope, for he believes that the purpose of God in the long march of history is the redemption of humanity. He will, therefore, hope and bear and believe all things for the men who are bound, like himself, to God, by the chains of a common humanity; and he will not only hope and bear and believe, for them, but he will work for them - not for himself, but for them; for he knows that he only finds his true life by losing it in the service of men. Though it is true that the man who believes in God will see visions, though his heart will be in the heavenly places, though he will remember that he is a citizen of the city which hath the foundations, he will never allow himself to forget that he is also a eitizen of some earthly city, and that his love for God must translate itself into some good work for the men and women who need him. There is no part of the teaching of Jesus so recurrent or so plain as this, that love of God has to show itself as love of man. There were only two commandments, he said: the first, Thou shalt love the Lord thy God with heart and soul, strength and mind; and the second, Thou shalt love thy neighbor as thyself - and these two are one and the same. Not ten commandments, but two; not two, but one-Love. The ultimate, though not always the acknowledged, basis for the love of humanity is the common relation of humanity to God. Why should I love my neighbor? There may be much in him that is unlovely; why should I be willing to forget all this and to look upon him as my friend and brother? There is no reason but this, that the brotherhood of humanity, if it is to be more than a loud-sounding phrase, must rest upon the fatherhood of God. Or, as Jesus said, the second commandment is, Thou shalt love thy neighbor; and this is to be reached through the first, Thou shalt love the Lord thy God. It would be absurd, of course, to deny that love of humanity may exist where there is no conscious love of God; but such a love has not adequately realized its implications.

It follows that one of the ways in which the religious man will 
express his religion will be in the work he will do for society. It is true that many of those who have loved Jesus well have led the cloistered life, and sought to save their own souls by fleeing from the busy world; but they have not learned well the lesson of the Master. There is a time to sit, like Mary, at Jesus' feet; but there is also a time to rise and do some brave and beneficent thing in Jesus' name. Once and again did he emphasize this truth so plainly and powerfully that it is passing strange that it should so often have been missed by those who have sought to live in his spirit. You will remember how he describes the great surprises of the judgment. "Lord, when saw we thee an hungered and thirsty and naked and did not minister to thee?" They had supposed that they were religious men, and that they would safely stand the last great test; yet the judge condemns them, because they had done nothing. They had supposed that they were willing to serve God; Jesus shows that the service of God is the service of men, especially of the needy, and these they had refused to serve. In other words, true love for God is bound to express itself in love for the men and women who know the hardships of life and have drunk very deep of its sorrow. "What must I do," said one who was very earnest, "that I may inherit eternal life?" "Go and sell and give to the poor." In a flash Jesus shows him the quality of his religion. If he really cares about his spiritual life, then he must also care for the poor. The religion which Jesus taught and lived is a religion which touches the lives of men, which takes them by the hand and lifts them up and sets them on their feet. If a man thinks he loves the God whom he has not seen, he can very easily put himself to the test. How much is he doing for humanity? Or rather, how much is he doing for some man, for the man who needs him and whom he can in some way help? What is he doing to relieve the ignorance, the poverty, the vice, the pain, the sorrow, the misery, of which the city streets 'are so full? Does he pass by on the other side? If he does, then Jesus would say he has no real love for God and, in other words, no religion worthy of the name. It is the duty, and it ought to be the joy of the religious man, to love men, to pity their misery, to do what he can to set at liberty those that are bruised, whether by misfortune or sin. It is the business of his life to work out his own salvation; but he does this most effectively by doing what in him lies to work out theirs. And this he will do because the God and Father in whom he lives is the God and Father of all men, in whose sight the soul of each one of his children is very precious. We are not our own. We belong to God, we belong to society, we belong especially to those whom we can help.

Thus life with God will be a life of purity, of peace, and of power, a life spent in the service of God, which is the service of man. 


\section{RELIGIOUS INFLUENCE}

\section{BY SAMUEL ATKINS ELIOT}

Samuel Atkins Eliot, President of the American Unitarian Association, Boston, Massachusetts. b. Cambridge, Massachusetts, August 24, 1862 . A.B. Harvard, 1884; A.M. Harvard, 1889; D.D. Bowdoin, 1900. Minister, Denver, Colorado, 1889-93; Minister, First Unitarian Church, Brooklyn, New York, 1893-98.]

I wish, in this address, to consider what is the present attitude of the normal man toward religion, what the wholesome nurture of his religious sensibility involves, and what it may be expected to produce.

The common attitude of the average man toward religion in these days is one of neutrality. In the lives of the great majority of people, the interests of daily occupation, of home and school, business and amusement, all precede the interests of what is commonly understood as religion. We need not deny the obvious fact that there are, on the one hand, men and women who are sincerely religious, and on the other hand there are people who indulge themselves in open and conscious hostility to all religion. Nevertheless, the average man is in an attitude toward religion which can best be defined as " mental reserve." I think it can be justly said that the majority of intelligent Americans, whether connected with Christian institutions or not, are " reverent agnostics."

It does not concern me here to inquire into the causes of this situation. In part it may be an outcome of the overwhelming interest of our age in material affairs and the insatiable search for new resources of luxury and power. In part it may be due to some misinterpretation of the scientific discoveries of the last century. We may only observe the fact that the present'spiritual condition of Christendom is not altogether unlike that of the old Athenians in the time of the Apostle Paul, when all the outward observances of religion went forward unobstructed, but when men were critically dissatisfied and in their inmost hearts worshiped at the lonely altar of an unknown God.

I do not, indeed, perceive that our age is characterized by any widespread atheism, but rather by restlessness and uncertainty. The conclusions of materialistic atheism are as much of an affront to reason as were the superstitions of childish credulity. Some men through hard experience or temperamental gloom may come to believe that the affairs of the universe are controlled by evil powers; some may come to believe in a dualistic system wherein the powers of good and evil contend for the mastery; but intelligent 
people do not attempt to set a mere mechanism on the vacant throne of mind. They know that no superstition is more degrading than that which idolizes negations, and that to accustom the mind to denials is to rob it of constructive power. They readily assent to the truth that " the laws of the universe cannot account for their own origin." They recognize with Carlyle that "it is flatly inconceivable that intellect and moral emotion should have been put into us by an entity having none of its own." They seem to hold with Martineau that while " all our belief and speech about God is untrue, it is truer than non-belief or silence." Sometimes such souls yield themselves, in the want of something better, to extravagant substitutes for rational religious faith; but, for the most part, without earnest conviction on the one hand or any open hostility on the other, they go about their daily work and play as best they can without the impulse of profound conviction or of confident hope. An impatient neutrality or a somewhat contemptuous indifference characterizes the religious condition of Christendom to-day.

What then, I ask, are the conditions of a rebirth of spiritual vitality, what new visions may bring to this apathy a new dynamic of progress? How is the average man to realize and achieve the peace and joy of religious faith? In the first place, we must recognize certain primary conditions of religious influence. It does not flow in any single channel. The joys and sorrows of domestic life, healthy amusements, the exercise of business industry and integrity, all upbuild character and faith. The beauty of the outward universe is often a silent teacher which prepares the human spirit for the indwelling of the infinite spirit. Music has strange power to calm or to invigorate, to open the mind and heart to gentle pleadings and sweet memories; it is often a better medium of sympathy than speech. Art and architecture are equal handmaids of spiritual influence. Save only prayer, poetry is the highest expression of emotion. When feeling reaches a certain point, it drops the slow processes of argument and takes the wings of song. This great variety of teachers, the endless production of different forms and expressions of thought and feeling, enriches life and speaks of the infinite inventiveness of creative love.

In the second place, we must note that the normal influence of 'religion on the human soul is gradual and evolutionary. According to certain still surviving traditions, religion is primarily a process of revolution; not a growth, but a surprise. It delays its approach; it is inaccessible to the natural man; it comes upon one abruptly to transform a character and change the purpose and direction of a life. It is unquestionably true that the experience of religion is often thus sudden and decisive. I cannot, however, but believe that the accidental incidents only make more impressive the orderliness and 
continuity which mark the normal condition of the growth of the spiritual life. Religious influence is not, as a rule, capricious and spasmodic, but a silent process of evolution and expansion. It may have its crises, its sudden awakenings, as (if I may borrow a figure) a river has its rapids and its sudden falls, its backward turns and whirling eddies; but through the surge and foam the underlying current makes its way, and the occasional agitations are but incidents of its steady movement toward the sea.

In the third place, I note that freedom is essential to genuine spiritual growth. No hand of outward constraint can wisely guide the nurture of the human spirit. The individual soul must be free to obey its own volitions, and have power to select, to discriminate, to accept or deny. It must have freedom to choose not merely what is right, but what is wrong, - freedom to sin as well as to follow righteousness. By no coercion can a soul develop vitality, by no dictation can it learn to govern justly the little republic of the inner life.

Accepting then these conditions of vital religious influence, its diversity, its continuity, its liberty, - I turn to consider how it may operate on the minds and hearts of a generation waiting in the attitude of neutrality and mental reserve, an attitude which surely is not one to be rebuked or despised, but which is essentially unsatisfactory and provisional. The first thing to note in that spiritual vitality is something transmitted rather than created. This transmission is something more than verbal communication. Truth requires the medium of personality. Religious influence is the contact of life with life, of spirit with spirit. It is well-nigh impossible for an abstract truth to promote activity or form character, or create fervor of heart. Ask yourself what nobility of character means to you, and you will find that you have learned it not from books, but from example, not from definitions, but from deeds.

Said Phillips Brooks, whose characteristic message I am in this paragraph repeating: "We often hear the cry, 'Principles, not men.' But to send out principles without men is to send an army of ghosts abroad who would make all virtue and manliness as shadowy as themselves. It is principle brought to bear through the medium of manhood that draws and inspires." Let us recognize that spiritual . life is not a matter of spontaneous generation. It is kindled by a spark from the burning heart of another. Knowledge is transmitted from teacher to scholar, love glows from mother to child, ideals are caught from seer and poet. Feeling acts on feeling and mind on mind. Courage passes from strong to weak, enthusiasm springs from eye to eye. We cannot explain just how these influences work, we cannot locate the wires of this invisible telegraphy, but of the 
fact of such communication and transmission there is not the slightest doubt. All the great religious faiths have had a personal origin. None of them was born of an abstraction. Every one was an incarnation. It is when we see a soul manifestly sustained of God that we are sure that God lives.

I note next that the idealism thus caught from inspiring personalities is to be developed through the ordinary relations of man to man. Its guides must be the landmarks of an every-day morality. The foundations of the Holy City are in the normal labors and loves of humanity, in the discipline which shows its results in the strengthening of the qualities of manhood which all people recognize and honor. I know that this again is a conception that stands apart from the more familiar conceptions of the promotion of the spiritual life. It is generally held that admission to the domain of faith is through conformity to the dictates of dogmatic authority, or through meditation and prayer, or through certain rites and ceremonies. These all have their legitimate place in spiritual nurture, but in no one of these methods inheres the secret of power. The theory that religious influence is primarily the gaining of an intellectual assent, and that religion has been taught and learned when certain truths have been imparted, is surely so partial that it cannot long endure. The stoutest assertion of a borrowed opinion cannot be faith. The theory that religious influence enters only in quietude and through the gate of abstract thought is jostled by the confusion of rival philosophies, premature and incoherent. The theory that religious influence is transmitted only in sacred usages and by ecclesiastical drill distorts the fair completeness of religion and cramps and imprisons the spirit. There is certainly place, I repeat, for all these theories and methods. Without definite convictions religion may be a mere invertebrate mush of sentimentality. Without meditation it may be purely superficial. Without worship it is stifled and inexpressive, without the charm of beauty, without a door of utterance. Sound doctrine and quiet contemplation and beloved rituals are all aids to the maintenance of religion, but they are not religion.

The supply of religious influence through the channels of the natural duties and relationships of human life alone satisfies, I ask you to note, all the primary requirements of which I have spoken. It alone convinces men of reality. There is nothing speculative or visionary about it. It assures men of freedom. Their spiritual nurture proceeds under no law of outward constraint, but in control of the law of liberty. It is diverse and varied in its operations. The pietist's devotions, the dogmatist's rules, and the ceremonialist's rites are apt to be the same from day to day and in all men. They lose the value of the rich personal distinctions of mankind. Freedom, reality, variety, and continuity are the conditions of education, 
secular or religious. To grow spasmodic or monotonous or unreal or dogmatic, is not that the death of any vital religious influence?

The method of religious nurture through moral experience takes then the imperfect, unformed, elementary facts of the spiritual life, and draws out their significance. It does not bid men bury their heads in the sands of tradition or lead them to suppose that they can escape from the restlessness of the modern world by the cobweb ladders of metaphysical subtleties or by the shallow creeks of pietistic sentimentalism. It takes men just where they are. It pleads with Robertson: "If there be no God and no future life, yet even then it is better to be generous than selfish, better to be chaste than licentious, better to be true than false, better to be brave than to be a coward." It lays on the soul no conventional consents, no formal initiations. It asks no abrupt acceptance, no ascetic devotion. It says to each individual: "Here is your life with its perplexities, its doubts and fears, its ambitions and regrets, its obligations and opportunities. Take hold of the problems of life at the small end. Do the duty that lies nearest you. It is by doing the will that. we learn of the doctrine. Pursue the best you can perceive, and by degrees, unconsciously perhaps, your true spiritual nurture will proceed, from criticism, through obedience, into reverence; from neutrality, through service, into sonship."

Let us have done with the idea that religious experience is something different from ordinary human experience. A genuine religious influence is that which bids man put the undeveloped power for unselfish action into situations where it must act and speak. It bids men use for their delight and upbuilding the common things of earth and air, the universal things of human experience, the multitudinous interchanges of work and sympathy and helpfulness. These are opportunities which all men and women possess, but too often they are thought to be so common that they are not recognized as the natural and inevitable teachers of faith. When a mother is faithfully tending her children, keeping her hearthstone clean, and making her fire burn bright, we seldom think of her as religiously employed. When a man works hard all day and comes home to make his family happy with cheerful voice and tender helpfulness, the world does not think that there is religion in anything so common as that. Religion is supposed to stand aloof from such familiar scenes. It is something reserved for the serious moments of life, for the great disasters, for the approach of death, or it is something connected with certain sacraments, certain beliefs, or with churchgoing. God help the weary world if that separation between religious experience and every-day experience is to be long continued. I plead not indeed for the secularizing of religion, but for the sanctifying of the things too generally regarded as secular. Through use 
of the simple and the familiar we find the sublime. The higher ardors grow out of the lower as naturally as the branches of a tree from its root and stem. The branches take from the light and air of heaven new energy, and the roots strike more deeply and firmly.

When doctrine and meditation and worship and conduct are all valued, not for themselves, but as channels through which the power of the infinite and eternal energy may enter the soul it seeks to renew, then each is rightly understood in itself, and is set in its right relation with the others. Each is endowed with higher majesty when it is recognized as one of the bonds by which human life is connected with the source of life. A man may indeed think clearly or worship devoutly or live honorably without any consciousness of high descent and destiny, without any thought as to what these things mean in their universal relations. But, when to such a man the consciousness comes that through his fidelity and energy the eternal purpose of the universe presses to accomplish its ends, then he becomes religious. Then there dawns upon his mind the wondrous truth that religion is more than his effort to find God; it is God finding him, the universal mind calling to the individual mind, the father claiming his child. He discovers that "it is not the sheep who look for the shepherd, but the shepherd who calls the sheep."

The gospel for this age of material prosperity and ambitions, this age of threatening evils and many noble aspirations, is the proclamation of the present and veritable incarnation of the eternal power, the presence and life of God in the human soul, not by exceptional inspiration, but inherently and organically. All enthusiasm for righteousness, all desire for knowledge, every impulse of disinterested loyalty, every throb of delight in beauty and in the sweetness of domestic love, every capacity to overcome difficulties and rise above sorrow, - these are not merely channels through which the Divine Life flows, but they themselves are the energies of the living God dynamic in the substance of man's being.

Religion is nothing less than "the affirmation of God in human nature." It is in our recognition of the vital bond that unites the Father God and his children. It is in the realization that God's quickening life within us is the pledge of our immortal being, that through purity of heart we see him, by truth we know him, by love we dwell in him. All our work, therefore, becomes the Father's business, and, whatever may be the nature of our daily toil, it is sanctified and ennobled through these high associations. To thus claim our kinship to God, to live by it, to recognize that it is eternal, - that is personal religion.

If, then, a man commits himself in modest confidence to this natural and human method of religious development, he finds in his possession the key to the regions where his mysterious existence 
is interpreted and sustained. He learns to tread these dim and wondrous ways of human experience with assurance that they are ways of reality, ways of order and of ordered meaning, not blind imaginings of a land of dreams. He is led by healthy processes out of the region of critical indifference, wherein he can never grasp the reality of religion at all, into the realm of moral adventure, where he tests the uncertainties and solves the perplexities of life by bringing them into contact with every-day obligations, and then he gathers up the results of his inquiries and the broadening experience of his mind and heart into a confident sense of relationship to an infinite life. In realized sonship he finds constraining evidence of fatherhood. Thus it is that religion meets the normal man of this generation. It takes us in the attitude of mental reserve, and leads us through moral experience into spiritual life, to where we acknowledge that, though clouds and darkness are still around the Infinite Source of all, yet righteousness and judgment are the habitation of his throne and underneath are the everlasting arms. When a life has come into realization of this deepest meaning of its being, it has entered into the secrets of power, into "the privileges of the immeasurable mind." 


\section{RELIGION AND PERSONALITY}

\section{BY EDWARD BAGBY POLLARD}

[Edward Bagby Pollard, Professor in Crozer Theological Seminary, Chester, Pennsylvania, since 1906. b. Stevensville, Virginia, 1864. Student, University of Berlin, 1896 ; B.A. Richmond College, Virginia, 1884; M.A. ibid. 1886; Ph.D. Yale University, 1893; D.D. Richmond College, 1901. Pastor, New Haven, Connecticut, 1890-93; Pastor, Roanoke, Virginia, 1893-96; Professor of Biblical Literature and Semitic Languages, Columbian University, District of Columbia, 1897-1902; Professor of Biblical Literature in Georgetown College, Georgetown, Kentucky, 1902-06. Author of Oriental W'omen; Paul Judson; and other works.]

"Look out for a people entirely devoid of religion," said Hume, " and if you find them at all, be assured they are but a few degrees removed from the brutes." But the truth is, such people are not found. Some races, like marble, are capable of much polish; others, like granite, possess a high resistance to crushing; yet others, like sandstone, are readily shaped by external agencies. Some races are intellectual, some emotional, some progressive, and some conservative; but all are religious.

Religions are many, as there are "gods many and lords many." But beneath all religions lies religion. It is not an incident nor an accident; it is not the invention of priestcraft nor of policy, but the very outgoing of human nature itself. Religion is the most persistent and universal fact of human life.

It is impossible to deal with elements more vital than those brought before us in the subject assigned me; for religion is universal and imperishable, and personality is the fundamental fact of all existence; it is the ultimate reality.

The leading types of religion have already been discussed before this Congress. The varieties and the vagaries of religion do not fall in our purview. I am told that certain persons have facetiously dubbed Professor James's stimulating and informing volume upon Varieties of Religious Experience with the title "Wild Religions I Have Known." In dealing with the influence of religion upon personal life, it is not the extraordinary and exceptional, but the general and universal features of the religion that will claim our attention.

In primitive conditions of community life an irreligious man did not exist. As Robertson Smith says, in his Religion of the Semites: "Individual men were more or less religious, as men now are more or less patriotic, but there was no such thing as an absolutely irreligious man." This may be said of primitive peoples generally. Religion was largely a matter of tribal import rather than of personal life and individual choice. After a while, however, the individual emerges; 
partially, at least, disengaging himself from the society of which he was but a particle. Now he becomes truly conscious of himself, of his individual powers and privileges. God is his own God, and religious obligations and practices become at length individualized. New responsibilities are born to him, and from Deity he cannot flee, though he "take the wings of the morning."

Whether religion be viewed subjectively, as thoughts concerning the spirit world, or objectively, as the practices and organizations that have grown out of the religious sense, - that is, whether as creed or as cult, - its influence upon personal life has been incalculable. Mr. Benjamin Kidd, in his Social Evolution, finds religion to be the central feature in the development of human society. With yet greater force may it be claimed that religion has been the most influential factor in the development of the individual life. The problem of society must always be the problem of the individual.

First allow me to say that religion is the great unifying and harmonizing force in the personal life.

Speaking teleologically, it is the business of religion to bring a man en rapport with deity. Religion, as " the life of God in the soul of man," removes the individual from what would otherwise be an isolated and self-centred life into one which is Deo-centric. The spirit world and the spirit life become to him intense realities. God becomes the common denominator in all his relations. Religion can never be adequately conceived of as a single department of human interest. It is the underlying and unifying fact in all the departments of life. The lowest savage eats, dresses, hunts, kindles his fire, marries his wife, wages his wars - does everything in the name of his god; and one of the most enlightened of religious teachers enjoins " whether, therefore, ye eat, or drink, or whatsoever ye do, do all to the glory of God." Here we have from widely separated sources a recognition of the fundamental and unifying fact of religion. It is in man's God-consciousness alone that he can find the ultimate harmonizing of all his thoughts, powers, and strivings. Atheism and irreligion can furnish no rational basis for the fundamental unity of things.

\footnotetext{
"Though truths in manhood darkly join,

Deep-seated in our mystic frame,

We yield all blessings to the name

Of Him who made them current coin."
}

Religion has always involved belief in a certain solidarity of God with his worshipers. It makes no difference whether this sense of solidarity arose from the belief in blood kinship between the god and his people or in more ethical conceptions, religion always implies the bringing of God and man into proper relations with each other.

It is in this belief that there is an unseen one with which man has 
to do and to whom he is accountable, that the sense of obligation, so important in shaping human life and conduct, is both forgotten and kept alive. A sense of responsibility forever steadies man. $\mathrm{He}$ has about him a constant observer, or observers, to whom he must give account. The force of this statement is felt when one remembers that, in the lower forms of religious development, no obligation was felt which lay outside the realm presided over by the god or gods to whom the worshiper owed allegiance. When every deity had his own land, a crossing of the boundary line took one from the sphere of obligation. Even in medieval times the heathen and the infidel had no rights which the zealous, but misguided, Christian needed to respect. It is only as God is recognized as one, and his kingdom as ruling over all, that universal obligation is felt in the human breast. Take this religious sense of obligation away from the world and the earth is peopled with Ishmaelites and Philistines.

Religion in bringing man en rapport with deity, ipso facto brings about between himself and nature a relationship peculiarly true and vital. In the last analysis it is man's religious nature which enables him to interpret nature outside of himself in terms of his own life; for underneath all phenomena he recognizes a common source with his own. Such interpretations have at times been exceedingly crass. The savage believes in the personeity of everything about him. In the fetich is a spirit, of which the stick or stone is but the outward representative; trees and mountains, the running brooks, and starry heavens are peopled with unseen spirits not unlike his own. What Tylor named animism, - that is, the belief that everything is somebody, - is but the rude effort of the untutored mind at feeling after the religious truth that behind all phenomena there is spirit, that all move and have their being in God.

It is in the religious consciousness that man first recognizes the mysterious kinship between himself and nature. The North American Indian believing in his kinship with his tribal totem, and communing with a kin-divinity through the sacrifice of a kindred animal, is expressing in his crude way the same deep-seated truth set forth by the Christian apostle to the Gentiles: "For the earnest expectation of the creature waiteth for the revealing of the sons of God; . . . that the creation itself also shall be delivered from the bondage of corruption into the liberty of the glory of the children of God." Man and nature are discovered to be one in origin, and in a certain sense one in end and destiny. So to the religious spirit all nature speaks of God. "The heavens declare his glory and the firmament sheweth his handywork." All things about us speak of the bowed knee:

"The clouds like hooded friars Tell their beads in drops of rain." 
Through religious promptings the little cosmos of man's own soul has responded to the greater cosmos of the wide, wide world. Thus it comes about that religion is ancestress of the sciences. Chemistry springs from alchemy, the child of early religion; astronomy from astrology; pharmacy and the healing art from sorcery. Religion, standing before the mysteries of nature with an inquiring heart, opened the way for all knowledge of nature. So far, then, from there being an antagonism between the true religious spirit and the true scientific spirit, these are identical. It is the attitude of responsiveness, of obedience, the willingness that the message nature brings may speak what it wishes. Religion without inquiry has lost the primal religious spirit, and science without belief in the unity of things is without a rational basis; and while religionists have sometimes persecuted the spirit of inquiry as hostile to that of faith, and scientists have ridiculed religionists as hostile to the spirit of investigation, it still remains true that the uniform and irresistible influence of religion has been upon the side of the advancement of human knowledge. It says, with one of the richest religious spirits of the age:

"Let knowledge grow from more to more,
But more of reverence in us dwell,
That mind and soul, according well,
May make one music as before,
"But vaster. We are fools and slight.
We mock thee when we do not fear,
Help thy foolish ones to bear,
Help thy vain worlds to bear thy light."

Religion has also done more than all other agencies to disclose man's proper relation to his fellow men. The sense of the dignity and importance of man, his significance as an immortal being, the sense of obligation toward him as man - all this has been the fruitage of religion, more especially of the Christian religion, which, it may be said, was first in discovering the individual in the deepest and richest sense, as of infinite value in himself, as the religious unit, as deserving and demanding to be free. Christianity achieved this, however, not by discovering a new religious principle, but by universalizing and unfolding that which was in germ in the religious nature first implanted in the human soul. From the lowest forms of blood brotherhood through a totem, or a kindred animal, up to the very highest conceptions of brotherly love as taught by Jesus and his apostles, religion has kept alive the sense of man's responsibility to man. The application of this principle has often been exceedingly narrow; malice and bloodshed have been born of religious devotion, and yet this only proves the truth of the claim, for brotherhood and obligation always ceased where the sense of religious solidarity ended. A man was a brother if he worshiped the same God, and he 
was therefore, his brother's keeper. Fearful punishment followed a violation of this law. When religious development reveals the one God and Lord of all, the sense of universal brotherhood, through a universal paternity, was sure to follow. So at length love is recognized as the law of spiritual gravitation which regulates the universe of spirit. D. G. Brinton, in The Religious Sentiment, has strongly set forth the place of love in religion, affirming that love is the emotion above all others which " reveals the character of the religious sentiment." If this be the conclusion of a scientific study of religion, a truth with which every student of Christianity is perfectly familiar, then religion must have the credit of giving to man the fundamental working principle of personal life, a love which not only "worketh no ill to his neighbor" and "seeketh not its own," but which gives its very life for the world, revealing that the immortality of life is the immortality of love.

It is love that has given the world all that is best, truest, sweetest in human life and character. It is love that has stimulated the loftiest purposes and dictated the noblest achievements. It is love alone that has made life worth the living and brought ebbing hopes into being again.

And so religion has cared for the helpless and broken, buried the dead, built schools and asylums. It has elevated womanhood, as men have recognized that "the eternal womanly leads us on," advancing man from the sterner virtues of courage, strength, and endurance to the tenderer graces of humility, self-surrender, mercy, love.

All this means that religion has been the prime factor in enabling man to find his true place in the universe, so that God, man, and nature work out their perfect harmony.

This leads to the statement that religion has been the great energizing and enriching agency in the development of the personal character. "Religion," said Bacon, "is the spice which is meant to keep life from corruption." But it is more than an aseptic and moral sterilizer. It has energized and fertilized the will of man, elevated his sentiments, and enkindled his intellectual life.

What has religion done for the human will? Many, with Kant, would find the seat of religion here, in a " categorical imperative," which speaks the final "thou must." We shall not undertake to show how much cannot be accounted for upon this theory of religion. That the will is powerfully concerned all will admit. In those features of the religious life summed up in cult and in conduct the will is potent. Indeed, here we stumble upon the anomaly that the excessive ritualist and the preacher of an ethical culture, at the very opposite poles in spirit and practice, are at one in their root idea, namely, that religion is largely a performance of the will, manifesting 
itself, therefore, objectively, the one in ceremonies, the other in moral conduct.

Some religions, conspicuously Buddhism, have suppressed and enervated the will by exaggerating the doctrine of self-effacement, and teaching the utter loss of self as the highest blessedness. But this is exceptional. Even the very idea of self-abnegation has been a powerful educator of the will, enabling men without flinching to give themselves for their religious ideals, and count it joy! Certainly it is true that, as with every step of religion toward purer and more rational ideals, the more elevated it has grown, the purer the conduct has become, the saner the cult.

Once holiness was but a name for a ceremonial condition. In the development of the religious ideals holiness at length comes to mean wholeness, symmetry of character, purity of soul, to have an intensely ethical meaning. A perpetual problem of religion has been to disclose and to maintain morality in its rightful place in human life. Aside from the underlying principles of religion, morality has no fundamental justification. It is religion alone that speaks of an ideal standard and can furnish a rational ground for obligation in moral conduct.

Consider the value to personal life of some of the most universal expressions of the religious consciousness, such as the rites of purification, of sacrifice, and of prayer.

Some form of purification is almost as widespread as religion itself. From the lower ideals of bodily cleanliness to the higher spiritual conception, such as that of the Hebrew poet when he exclaimed:

\footnotetext{
"Who shall ascend unto the hill of the Lord? Or who shall stand in his holy place?

He that hath clean hands and a pure heart; Who hath not lifted up his soul unto vanity, Nor sworn deceitfully,"
}

this determination to have fellowship with God has made quick the conscience of men, fostered the sense of sin and the need of being reconciled to the Infinite One. The value of this prompting to personal life and conduct has been incalculable.

Some form of sacrifice is coextensive with religion itself. The sense of obligation to Deity, of gratitude for past blessings, of desire for present fellowship and future happiness, have thus been led out to their own best meaning; by this the springs of generosity and unselfishness have been opened. Take the sacrificial idea out of human life and human history, and the world would be poor indeed. Without it the best in mother-love, in patriotic devotion, as well as in religious achievement, is stricken down. This idea finds widest and best expression in the familiar words "God so loved the world 
that he gave his only begotten Son, that whosoever believeth in him should not perish, but have everlasting life." That is, self-giving in a world of sin and suffering is divine. Man's response to divine love is religion.

So, too, the value of the prayer-life, which, in some form, is characteristic of all religion, has made for unmeasured enrichment, for it has been keeping man's soul sensitive to the voice of the Infinite in myriad modulations about him, and man at length discovers with the Mariner:

\footnotetext{
"He prayeth best who loveth best All things, both great and small;

For the dear God who loveth us, He made and loveth all."
}

Religion, energizing the will, has made men stronger to dare and to do. No cause has so long a list of real martyrs. It has made men undertake and achieve the impossible, to hurl themselves against adamant only to see it crumble before them. What gave to the Crusaders, misguided though they were, their superhuman endurance? The belief "God wills it!" Cromwell and his Ironsides made the armies of Charles melt before them. The one party cried, "God with us!" The other had only the tocsin, "Ho! for the Cavaliers!" and the Royalists went down before the Roundheads. England dominates India, and the West dictates the policies of the East, because the more vital the religion, the more potent will be the will of the worshiper. The God motive is the most potential of all incentives. Let the human will be once thoroughly dedicated to the Divine, and at once you have a force that must be reckoned with. Every Hannibal who devotes himself at the altar will make Rome tremble. Man's will, no less his own than before, becomes God's; and this is the goal of religion, as the great laureate says:

"Our wills are ours, we know not how;

Our wills are ours to make them Thine."

This at once suggests the influence of religion upon the motives, upon the emotional nature of man. Among primitive peoples a religious motive seems to be present in almost all their doings. Some have found the seat of religion in the emotions. Long ago the Latin poet-philosopher held that "fear makes the gods." Schleiermacher finds religion's origin in the feeling of dependence. Mill makes religion "emotions and desires toward an ideal object." Huxley calls it " reverence and love for an ethical ideal." That we find in these statements, and in all others that find the rise of religion in the emotional life, important truth, cannot be questioned. It is because of this truth that religion has played so important a part in the shaping of human sentiments. There is deep seated in man the 
longing for divine fellowship, the desire for communion with a power not ourselves. In the presence of this power man "takes off his shoes." Aristotle held that all education may be summed up in teaching men how to fear rightly. Take away from human life the feeling of reverence for the sacred, awe for the sublime and the allpowerful, the sense of human dependence, the feeling of need for divine fellowship, and you have cut the nerve of all that has proved best and richest in human character and achievement. There has been a tendency to undervalue the emotional life and to crown Reason as king of the human powers. A rebellion has broken out, both among the psychologists and the theologians, that the emotions may enter into their rightful heritage. While religion is more than fear, or wonder, or dependence, - more than any one desire or emotion, - yet all these, so common to religion, have made greatly for the enrichment of life. Without the emotional nature, religion could not exist, and without religion there can be no emotional life worth the having.

Take the single fact of wonder, or what the author of Revealed Religion calls " habitual and permanent admiration" - which he gives as a definition of religion, at least in its elementary state. By keeping alive the sense of wonder, religion has greatly contributed to human life. The savage stands puzzled before the moving leaf; the little child gazes at the twinkling stars and wonders what they are so high above him; and the man of science cannot banish this awe-inspiring admiration; for with every advance of knowledge wonder gives place to a widening circle of mystery. This has ever led the untutored to better things and allured the man of science to newer conquests.

There are certain ideals which religion has always fostered, without which human life would be flat and arid. Religion is normative. The soul of man has, from the earliest times, been haunted by intimations or inspired by belief in an ideal life.

There are no more universal facts in the history of religion than faith in human perfectibility and the belief in personal immortality. To say that these two ideals have inspired human life, elevated and energized their undertakings, is to pronounce a truism. These two, coupled with the doctrine of the perfection of human society, may be termed cardinal beliefs, so general and radical are they. Leave the idea of immortality out of life, whether it move on the low plane of the Amerind, who would take his earthly trappings to the spirit world, or on the higher plane of Him who " brought life and immortality to life in the gospel ;" leave the desire for and striving after the perfect out of human emotions, and human undertakings languish. It is this ideal that has ever beckoned man onward and upward; it is because of this we find: 
"Progress man's distinctive mark alone, Not Goid's, not beasts'. He is; they are; Man partly is and wholly hopes to be."

Religion is optimistic. In so far as it is pessimistic it is irreligion. Even Buddhism looks forward in hope, though that hope be in the loss of personality. Religion looks forward to a Golden Age before as well as a Golden Age behind, a restored humanity, a redeemed society. Surely "we are saved by hope."

This reaching after perfection has its correlative feeling in the sense of divine sonship on the one hand and the widespread belief in a divine incarnation on the other. In all religions a certain sense of sonship is present - crude and narrow in primitive clan life; present in the patriarchal system of the Chinese; present in Plato's divine man who should bring order out of human conflicts; and best of all in the revelation of Jesus, whose preëminent emotion was the feeling of filial relation with God.

Without the aspirations for immortality and perfection which religion enkindles, personal life must ever move upon a low plane of hopelessness, helplessness, and blight.

The contribution of religion to the esthetic nature need only to be mentioned to be recognized. Imagination, twin sister to faith, imagination enkindled by religious motives, has given us all that is best in art. From the rude but rhythmic motion of the religious dance, all through the higher development of the drama; from the beginnings of architecture, painting, sculpture, up to the highest forms of poetry and eloquence, and music in all the stages of development, art owes its origin, its patronage, and its power to the religious motive. This is because religion has always touched the deepest and truest emotions of the heart.

As has already been intimated, religion has been foremost in stimulating the intellectual pursuits of men, fostering inquiry, being a patron of learning. Religion is, in fact, the progenitor of the sciences. The rich religious nature of many of the world's greatest scientists, statesmen, philosophers, educators, thinkers in all branches of intellectual pursuits, is a testimony to religion's contribution to the enrichment of personal life. Scientists from Copernicus and Tycho Brahe to Silliman, Agassiz, and Le Conte; Newton, Faraday, Dalton, Davy, the Herschels, Maury, Clerk-Maxwell, Pascal, Priestley, Joseph Henry, and a great host of others bear this testimony.

It is truly an encouraging sign of the coming unification of all knowledge, that the scientists, like James Starbuck and Stanley Hall, as well as the theologians, are carefully studying the facts of religious experience and giving them their rightful and indisputable place. A harmonizing of the facts of nature outside of man and nature within 
him can come only through patient and sympathetic study of all the facts, for

"Truth is one

And in all laws beneath the sun

Whoso hath eyes to see may see

The tokens of its unity."

That which the religious consciousness has known from the beginning is being disclosed by every advance of science and philosophy, namely, the essential unity of all things. The religionist is recognizing in the scientist a friend and co-worker; and the scientist would do well to remember that it is the attitude of reverence, of submission, of obedience, as Bacon, the father of the modern scientific research, well pointed out, that unlocks nature's secrets to the human mind.

We need all three of the galleries seen in the palace in Wilhelm Meister - reverence for things that are beneath us, reverence for things that are about us, and reverence for things that are above us - if we are to possess the universe of Truth.

"When I found him in the bosom,

Then I found him everywhere, -

In the bud and in the blossom,

In the earth and in the air;

And he spake to me with clearness

Thro' the silent stars that say,

As ye find him in the nearness

Ye shall find him far away." 
SECTION F

RELIGIOUS INFLUENCE : SOCIAL 



\title{
SECTION F
}

\section{RELIGIOUS INFLUENCE : SOCIAL}

\author{
(Festival Hall, September 25, 3 p. m.)
}

Chairman: Dr. J. H. Garrison, St. Louis, Missouri.

Speakers: President Joseph Swain, Swarthmore College.

Dr. EmIl G. Hirsch, Chicago, Illinois.

Professor Edward C. Moore, Harvard University.

Dr. Josiah Strong, American Institute of Social Service, New York.

Secretary: Professor Clyde W. Votaw, University of Chicago.

IN opening the Section of Religious Influence: Social, at the general meeting held in Festival Hall, Sunday afternoon, September 25, Dr. James H. Garrison, of St. Louis, spoke as follows:

"The subject assigned to this hour will be discussed by each speaker according to his own views as to its meaning. No division of the topic has been made, no particular interpretation suggested. We feel sure, however, that the papers of the morning will open up one of the most important and interesting fields of thought and discussion. Christianity is the unfolding of a person, and Christian influence is the power of an individual life. The individual is the social unit, after all. All education, so far as it is vital and effective, is the influence of one personality over another. This influence has power, not simply to instruct, but to transmute the baser elements into the finer and change the very essence of being. Radio-activity has long been foreshadowed in the realm of mind and soul. This is one of the incidental rewards of noble being, that it shines like the stars, never dimmed; warms like the sun, never cooling; draws like the eternal pull of gravity." 


\section{THE EDUCATED MAN AND SOCIAL PROBLEMS}

\section{BY JOSEPH SWAIN}

[Joseph Swain, President of Swarthmore College since 1902. b. Pendleton, Indiana, June 16, 1857. B.S. University of Indiana; M.A. ibid.; Student, University of Edinburgh; LL.D. Wabash College. Instructor in Mathematics, University of Indiana, 1883-85; Associate Professor, ibid. 1885-86; Professor, ibid. 1886-91; Professor of Mathematics, Leland Stanford Jr. University, 1891-93; President of Indiana University, 1893-1902. Member of National Council of Education, American Society for the Advancement of Science. Author of scientific papers for publication by Smithsonian Institute and elsewhere.]

In this paper I desire to do two things: First, to set forth briefly a view of the educated man; second, to inquire what should be his attitude toward social problems; to state some of the principles and ideals on which this attitude is based, and to illustrate these.

I am fully aware that the topic is large enough for volumes rather than a brief address, but I shall not attempt to give more than a point of view from which it seems to me these questions must be examined. I am at least persuaded in my own mind that if this view is accepted and acted upon after a complete knowledge of the facts in any given question is ascertained, not only social religion, but religion itself will be vitalized, and will have a new meaning for the mass of mankind. I claim nothing new nor startling.

At the Boston meeting of the National Teachers' Association, President Eliot, of Harvard, spoke on the topic, "The New Definition of the Cultivated Man." He said:

"In this paper he is not to be a weak, critical, fastidious creature, vain of a little exclusive information or of an uncommon knack in Latin verse or mathematical logic; he is to be a man of quick perceptions, broad sympathies, and wide affinities, responsive but independent, self-reliant but deferential, loving truth and candor, but also moderation and proportion; courageous but gentle, not finished but perfecting. All authorities agree that true culture is not exclusive, but the very opposite; that it is not to be attained in solitude, but in society; and that the best atmosphere for culture is that of a school, university, academy, or church, where many pursue together the ideals of truth, righteousness, and love."

Assuming the correctness of this definition of the educated man, I would emphasize only the last part of it, which concerns us especially at this time. "The cultivated man is not finished but perfecting." No one should ever think of having a "finished" education. Education is a growth. The attainment of to-day is not sufficient for to-morrow. 
All authorities agree that true culture is not exclusive but the very opposite. The man or woman who has special opportunity for the training of his powers can neither satisfy the highest possibility of attainment through living away from people, nor fill his obligation to society. By giving to others of his knowledge and wisdom, the cultivated man enlarges his own possessions and helps contribute to the happiness and welfare of others. True culture is not aristocratic, but democratic.

True culture is not attained in solitude, but in society. There was a time in the history of learning when the opinion prevailed that he who would be a scholar must live as monks live. This view, no doubt, had its virtues, but the finer qualities of the human heart cannot be touched and cultivated without an intimate contact with people. The cultivated man should keep in the stream of life and be a part of it. If he allows himself to feel that he is set apart from others by his training, he is not truly educated, and often becomes critical and unsympathetic with the best things in life.

And finally, the best atmosphere for culture is that of a school, college, university, academy, or church, where many pursue together the ideals of truth, righteousness, and love. These are the flowers and fruit of life, whether they come through college or church. These ideals should be fostered seven days in the week. Each one should think for himself and follow his own religious convictions. The cultivated man will continue to grow in the knowledge of truth, righteousness, and love, that he may gain "that kind of culture which means intelligence, knowledge, and character - the culture described by Matthew Arnold, which aims to learn, in short, the will of God, and to make it prevail."

If we apply each part of this definition to the life of Jesus, we find that in every respect he fulfills it. We also find no other leader who so completely fills it. We find, therefore, the right attitude of the cultivated man toward social problems to be that of the man of Nazareth. Let us then inquire what is the key to the teaching of Jesus, to what extent is this religion social, and how far the best modern practice in the treatment of social questions lies in the direction of the religion of Jesus. He says: "Thou shalt love the Lord thy God with all thy heart and with all thy soul, and with all thy mind. This is the first and great commandment, and the second is like unto it: Thou shalt love thy neighbor as thyself. On these two commandments hang all the law and the prophets." Thus it is clear that the first duty of man is to find out God by all the avenues open to him. It is only as we come to realize that, back of all the matter and forces of the visible universe, there is an invisible spirit of God, and that we come in touch with him, that we can love him. 
We live our highest lives when we turn all our cultivated powers and gifts in the direction of thinking and doing God's will. We may know more and more of him, as we grow older, by the study of his work, and the history and thoughts of his children. The true scientist is working on and on, in the belief that while he may never see the relation of this fact and that, in the fullness of time, through the patient labors of a multitude of workers through the ages, ultimate truths and laws will be discovered as they exist in the thoughts of God. In other words, he believes that everything in the universe is under a great, well-ordered, and harmonious plan, and the maker of it we call God. We may know something of him through the studies and thoughts of the greatest and best men of the world, the sages of profane and sacred history; but, most of all, those who receive and obey will find in their own hearts and minds the power of knowing what is that perfect good for them. "The kingdom of God is within you." By prayer, by divine patience and endless watchfulness, and by consecration, we may hear and know what is our pathway, and realize the spirit of God, and love him with all the power of heart, and mind, and soul which he has given us. This commandment is personal, not social. It is addressed to the needs and desires of the individual soul.

The second commandment, "Love thy neighbor as thyself," is social. It is only as we come more and more to follow the law of the second commandment that we grow in knowledge and fulfill the first.

The capitalist who fails to remember who is his neighbor in dealing with labor lays up trouble for himself and others, because he violates a law of life. The second commandment, which is like unto the first, means that in every act and thought and purpose in our lives, and in their administration; in all public as well as private affairs, we should seek to confer true benefits upon our fellow men. It means that the man who professes to love God and attempts to deceive men in regard to the real value of railroad stock or any other property, that he may coax their money into his pocket, is a hypocrite and a liar. It means that the man who oppresses the hireling in his wages is no Christian, whatever may be his declaration to the contrary.

I believe most of our social evils would be much alleviated if first we better understood the second commandment, and second, acted on the knowledge which we possess.

Washington Gladden says: "The fact that one man can no more be a Christian alone than one man can sing an oratorio alone is a fact that men have not clearly apprehended. The failure to realize this truth results in the highly unsocial conduct on the part of many whose piety is unquestioned. Their defective conduct comes from 
their failure to apprehend their individual relation to their fellow men. That the essence of religion is righteousness they would not deny, but the social nature of righteousness they do not understand. Breadth and comprehensiveness of the law of love has not been brought home to them.

"When we realize that the essence of $\sin$ is a defect of love, there is a new standard by which to measure human character, and there are many who fall before it. Social injustice, disorder, discontent, are due to a failure to recognize that the law of love applies to the whole of human life. It defines the relation of man, not only in the home and church, but in industry, commerce, and politics."

When we apply the second commandment to the conditions of capital and labor we find signs of improvement, but still conditions are far from ideal.

Ideal relationship does not mean industrial war, such as we now have to confront. Instead of a perfect union of all interested men, we have to-day a union of capital and a union of labor. Jevons has stated a law of political economy which seems also to be a true application of Christianity. The following of the law would give us a peaceful and unified society instead of warring factions. He says that the present doctrine is that the workmen's interests are linked to those of other workmen, and the employers' interests are linked to those of other employers. Eventually it will be seen that industrial lines should be perpendicular, not horizontal. The workman's interest should be bound up in his employer's and should be pitted in fair competition against those of other workmen and employers. There would be then no arbitrary rate of wages in organized contracts, no long disputes, rendering business necessarily hazardous. The best workman should seek out the best master, and the best master the best workman. Zeal to produce the best and cheapest and most abundant goods would take the place of zeal in obstructive organizations. The faithful workman would not only receive a share of any additional profits which such zeal created, but he would become a shareholder on a small scale in the firm, and a partaker in the insurance, superannuation benefits, which the firm would hold out to him with approximate certainty of solvency. This, I believe, is both Christian and scientific. But trouble will come. What then? Lyman Abbott, in the spirit of Jesus, replies: Conciliation, arbitration, law. These ideas are gaining ground and all have practical application.

This illustration from Carroll D. Wright will point out a method in favor of conciliation:

"Sometime ago the employees of the Southern Railroad (a combination then having about 6000 employees and 4500 miles of track) demanded of the management a restoration of the wages paid them 
two years before. They sent their committee to Washington, the headquarters of the system, and laid their demands before the manager. Their demands were made in a dignified and gentlemanly manner. The men were told they would be carefully considered and every interest canvassed and a decision given them at such a time. When the time arrived for the decision, the management laid before the men, through their committee, an itemized statement of the expense of the road for the past few years, the loss which it had sustained in freight and loss in passenger traffic, - in fact, all the financial and industrial conditions of the whole system. This statement was drawn up in a fair, just, and dignified manner and submitted to the committee of the employees. After many conferences, to which the officers of the different brotherhoods of the railway employees were admitted, the whole matter was peaceably and amicably settled to the satisfaction of all parties. And the men went home to work with a new dignity added to their characters the dignity of men who had been treated honorably, justly, and fairly. And the manager who had conducted the whole affair went to his home that night with a new dignity added to his character a dignity which results from manly action."

Not all questions of labor are to be settled by conferences and conciliation. Arbitration comes next.

This is a method growing in favor. It has been practiced successfully for many years in England, and it is growing in favor in the United States. The great coal strike in the anthracite coal region of Pennsylvania is a case in point, where infinitely worse possible damages were prevented by arbitration. Some things cannot be arbitrated. No employer should demand that a man leave his organization. No laborer should demand that only union men be employed. When arbitration fails we should invoke the majesty of the law. If there is no adequate law, then appeal to legislation. We must look to these: "Conciliation, the recognition by employer and employed that they are partners in a common enterprise; arbitration, the adjustment of all questions of self-interest, that cannot be adjusted through conciliation, by reference to a properly chosen tribunal; and the intervention of law when public rights are infringed upon by controversy between labor and capital.

"This seems to me to be the method of Jesus for the solution of the labor war until we come to the recognition of the fact that workmen and capitalists are partners in a common enterprise, and the very motive of war ceases to exist." (Abbott.)

Again we find the best modern charity is in the direction of the teaching of Jesus. In the Old Testament there are numerous passages showing the teaching of the Jewish nation concerning the poor. In the Psalms: "Blessed is he that considereth the poor." 
In Proverbs: "He that hath pity on the poor, happy is he." In Deuteronomy: "Thou shalt open thy hand wide unto thy brother, to thy poor, and to thy needy in thy land." In Isaiah: "Is not this the fast that I have chosen; to deal thy bread to the hungry, and that thou bring the poor that are cast out, to thy house?"

These expressions of the principles of the Old Testament many pious men have followed with the consciousness of duty performed, and yet these men have been guilty of pauperizing many. This has also been done in later days. We must look to a truer charity, by a broader interpretation of Christianity and a better understanding of sociology.

In Matthew we have: "Give to him that asketh thee, and from him that would borrow of thee, turn not thou away." A narrow and too literal interpretation of this statement may have been responsible for much unwise charity. "The letter killeth, but the spirit maketh alive."

Saint James says: "I by my works will show thee my faith." If we consider the works of Jesus with his words, we can give a better interpretation. Jesus says, "Give him that asketh thee." Whatever may have been the meaning of Jesus at that time, the present day interpretation should not be to give the suppliant what he asks, and all he asks, but give. Alms may be the last thing which the suppliant needs. One who asks usually does have need of something. It may be very different from the thing he asks. He may ask for bread, when he needs work. He may ask for money, when he needs sympathy. He may ask for some material aid, when he needs a friend.

Jesus did not place a high appreciation on almsgiving. "Let not thy right hand know what thy left hand doeth." Jesus places more value on the spirit and the sacrifice. "Of a truth I say unto you, this poor widow cast in more than they all." Jesus says to the Pharisees: "But rather give alms of such things as ye have, and behold all things are clean unto you."

These teachings give the true note of modern charity. "Not alms, but a friend."

Professor Peabody, in speaking of the story of the Good Samaritan, says: "Nothing can describe with more precision the exact programme which scientific charity has, by degrees, worked out to guide the visitation of the poor. First, friendly compassion, then the relief of temporary necessity, then a transfer of the case to restorative conditions. Finally, money; not as alms for the helpless, but to maintain continuity of relief. It was to the host, not to the ' case' that the neighbor gave his money, saying: 'Take care of him; and whatsoever thou spendest more, when I come again, I will repay thee.' " 
The chief obstacle to Christian charity now, as then, is the preoccupation of the individual with his own affairs, and the consequent dependence upon impersonal methods of relief; and the reform of method now proposed, in the name of scientific charity, is in reality nothing else than a return to the principles of the Good Samaritan.

This is what Alfred T. White, a practical charity worker of Brooklyn, says: "It may appear a slow process to eliminate poverty piece by piece from our great cities, and it is natural to long for some quicker way. But there is no way which does not reach to and touch the character of the individual poor." The following words from the statement of the Brooklyn Bureau of Charity shows the spirit of modern charity: "It shall be the duty of a friendly visitor to visit the poor and distressed, as a friend; to examine in the spirit of kindness the cause of their trouble; to do what can be done to remove the cause of their trouble; to become acquainted with the ability which each may have, and to aid in developing it, and in finding ways in which it may be developed in self-help; through friendly intercourse, sympathy, and direction, to encourage selfdependence, industry, and thrift; to recommend whatever may be possible and wise to alleviate the suffering of those whose infirmities cannot be cured or removed; if material aid be necessary, to obtain it from existing organizations, and, as far as possible, in every case, to promote in practical ways the physical and moral improvement of the families in the visitor's charge."

Practically, this method is being pursued in several cities and states. The churches in Buffalo have undertaken to divide the entire city among themselves, and to assign to each church a district, for the poor families of which it shall hold itself responsible. Each family has a visitor, whose business it is to search out the true need of each individual, and as a friend, give each help as is needed. Churches and other organizations are doing much to aid the state in making charity effective.

It seems safe to say that in assisting those who, for any reason, need help, the following principles are both in accord with Christianity and scientific charity:

First, the ideal to be attained is to offer to every human being all opportunities of education, and every other elevating influence which the age affords that is within the power of the individual under favorable conditions to secure. With nothing short of the best attainable under all conditions should we be content. For the masses, the aim should be to improve their condition in the work in which they are now engaged; not to encourage them to aspire to conditions which, in the nature of the case, they cannot reach.

Any assistance which does not have in mind helping the individual to help himself and to help others is in the direction of pauperism. 
It is here that much that has been done with the best of intentions has failed.

Of all charitable and philanthropic efforts, that which aims to prevent misery and degradation is most successful. "An ounce of prevention is worth a pound of cure."

Charity must have, above all, the consecration of heart and soul of those who would help others. Added to this there must be a knowledge of human nature and a certain intellectual insight.

Finally, charity, whether administered by the state, or through organization, or by the individual, must depend for its effectiveness at last on enlightened friendship, spiritualized by divine love.

Another illustration of the application of these same principles is to be found in the method of treatment of criminals. It is the duty of the educated man to give to this class the opportunity to reach, as nearly as possible, the ideal which he sets for himself. They are our brothers and our neighbors. Every member of society affects it for good or evil. There is much that is bad in our treatment of criminals. Yet there is a right way, and we are beginning to find out some things that we have done badly, and to correct them. Our whole theory, on which the great body of our prison laws are based, is faulty. We have placed too much confidence in the police system. We have asked our courts to solve problems which are insoluble under all the conditions, and we have more faith in prisons than the facts will justify.

Our law contemplates administering distributive justice. There is an effort throughout to assign to every malefactor that particular degree of suffering or privation which he has deserved, to proportion the punishment, so-called, to the offense; to make the criminal who has done a deed of but slight injury to society, or indicative of but a slight degree of malice, suffer a slight punishment, and, on the other hand, when the criminal has perpetrated a great outrage upon his fellows, to inflict on him such punishment as will appear proportional to his offense.

That justice can be reached in this way has been disproved by the great difference in the law governing offenses in the various states. In New Jersey there is a provision that a certain offense shall be fined $\$ 10$; in several states for the same offense the punishment is imprisonment for twenty-one years. In Texas the offense is punished by capital punishment. When we consider again the way in which the courts interpret the law, we find still wider divergence. So much depends, not alone on the judge, but on the time and attention given by the judge, and his knowledge of, and attitude toward a given case. Society is coming gradually to see that this method does not reach the end of justice. Criminals serve out their sentences to return to society, often worse hardened 
criminals than before. Too often neither the criminal nor society is benefited. Neither is it longer tenable to continue this system, on the theory that severe punishment is a preventive of crime. It is stated on good authority that crime has flourished most in civilized countries where the terrors proclaimed by the law and inflicted by its administration were most severe. Crime flourished most in Great Britain when she had the longest list of offenses punishable by death. There has been no increase in the number of murders in the United States in those states where capital punishment has been abolished.

What should be the method of dealing with criminals? Here is the answer of Charlton T. Lewis. He says he would introduce a sound philosophy of social science and broad Christian principles into our methods of dealing with men. In order that these principles may be introduced into the administration of the penal law, into its constitution, it is necessary that our thoughts be transferred from the act of crime to the person who commits the crime. The eriminal's character must be understood, and the conduct which we assume and adopt toward him must be that which is best adapted to promote at once the interest of society as a whole and the interest of the man to whom your efforts are directed. The prison does not serve its purpose either to punish crime or to prevent it. It has its use to protect society as long as it is not safe for the perpetrator of crime to have his freedom, and no longer. When protection to society is secured, then the whole emphasis needs to be placed on the reformation of the criminal. Progress is being made in this direction. The indeterminate sentence practiced in some states is in this direction; the probation officer in Massachusetts; and, beginning in New York and some other states, the separation of prisoners into as many classes as possible, so the more debased will not drag the others down; the Reform School for the Young, - all are in the direction of Christian beneficence and the science of humanity.

All the improvements of prisons and reforms that are abiding are in the direction of the ideal of the educated man. Nothing that criminals have done, nothing that they can do, conceals the fact that they are the children of our Father in Heaven, and that each one of us owes to these a brother's love. "Jesus said: "I was a prisoner, and ye came unto me.' By these words he bids us discern, with the eye of faith, the elements of Christlikeness in every prisoner. In every prisoner there are divine possibilities. This is his doctrine, and it reveals our duty." (Gladden.)

In conclusion, it is the duty of every human being, first of all, to form such habits of life, through the home, the school, the church, the state, and all the complex social relations of men, that he will 
acquire as completely as possible, in the providence of God, the full fruition of the educated man. This he cannot gain, neither should he if he could, unless he recognizes that the rich and the poor, the capitalist and the laborer, the law-abiding and the criminal, and all the working classes of society, are his brothers. These are his neighbors, whom he is to love as himself. He cannot in the highest form succeed in his search for truth, righteousness, and love, unless he, in the spirit of Jesus, recognize all those defective degenerates and unfortunate classes as an integral part of society, who are to be given by society, as far as enlightened Christian principles and practice can devise, all those opportunities which civilization can offer, so that they too may go as far as possible in the direction of the attainment of the educated man.

While social religion embraces the whole field of the relations of humanity, I have chosen to illustrate my point of view from the three great problems above briefly treated. If this view is correct, the educated man should not be content until he has done all in his power to give to every human being all the opportunities which he himself enjoys. 


\section{THE SOCIAL ASPECT OF RELIGION}

\section{BY EMIL G. HIRSCH}

[Emil G. Hirsch, Rabbi of Chicago Sinai Temple; Professor of Rabbinical Philosophy and Jewish History, University of Chicago. b. Luxemburg, Europe, May 22, 1852. A.B. University of Pennsylvania, 1875 ; A.M. ibid.; Berlin University, 1872-76; Leipzig, 1876; High School for Jewish Science, Berlin, 1872-79 (Rabbi and Ph.D.). Rabbi, Baltimore, 1877-78; Louisville, 1878-80; Chicago, 1880- ; Editor of Jewish Encyclopedia, 1900. President of Public Library, Chicago, 1886-97; Elector at large (for McKinley) of the State of Illinois, 1896. Member of the State Board of Charities, 1900. Author of New Tamid (1896); The Crucifixion; Biblical Department of Jewish Encyclopedia.]

THE character and influence of religion as a social force are attested on every page of human history. On the one hand, innumerable and important social institutions have been found to be rooted in religious conceits, while, on the other, profound religious doctrines, dealing with the deepest mysteries of the soul and its yearnings and trepidations, have come to be better understood as reflecting social institutions and practices. Without straying far afield into the domain of folklore, in quest for illustrations, the student cannot but stumble upon examples when consulting his Bible. That brother or next of kin shall marry the widow of the deceased brother or kinsman seems, at first glance, an arbitrary, if peculiar, provision of Biblical legislation. The root notion, however, from which it developed, is religious. It is antecedent to Israel's prophetic monotheism. Basic to it is the conception, emphasized in primitive animism under whatever zone it may have arisen, that unless filial honor be shown the deceased, no rest will be found by his hapless soul. To assure the departed of an heir in whom his name shall be revived, and through whose filial piety his own final peace shall be brought to pass, the institution of the Levirate marriage, rendered even poetic in the idyl of Ruth, sprang up. Affecting personal rights and property inheritance, this social institution rests on religious conceits. Closely akin to the conception underlying the Levirate, is that which is fundamental to the practice and obligation of avenging the blood of one come to his death by violence. That the clan is responsible for the deeds of every one of its component members is the assumption on which the social institution of the sacred Vendetta rests. Among the Semites this doctrine is universally entertained. The sins of the fathers are visited on the sons in never interrupted succession of vicarious responsibility. In it is operative the rudimentary thought of crude animism, that the spirit of the murdered and slain will not enter into rest unless blood be spilled in requitement for blood previously shed. The terrible law of talia- 
tion, the sharp phraseology of which sounds even in Biblical statute, is involved in primary religious constructions which, as will recur to mind, have also affected the language of the Decalogue, while, what is not as readily recognized, the social institutions developed from them are reflected in the formulation of the mystery of transmitted sin and subsequent salvation, as devised in Paul's theology. The thought that for the death of one Adam that of another was able and required to atone could not have occurred to thinker or believer, unless the Semitic practice which held clansman accountable for fellow clansman's or ancestor's act had previously formed part of his mental equipment. These instances may suffice. They suggest the intimate relations of social institution and religious dogma. In viewing religion then as a social force, modern thought ranges over familiar ground. It is neither revolutionary nor even original.

The viewpoint of the religionist is perhaps different from that of the sociologist. But the insistences of the one complement those of the other. The conceptions of him who would introduce religious considerations among the factors of the social equation may justly be claimed to be necessary in order to confer stability and effectiveness on the contentions of those that approach the questions affecting man's relation to fellow man from the direction exclusively of social impacts and interactions.

Socially analyzed, the humankind as now existent constitutes an aggregate of producers and consumers. Hunger is the impelling force. Greed, appetite, ambition, self-interest, instinct of selfpreservation and self-perpetuation through procreation - all these and many more familiar shibboleths are, upon close inspection, detected to be but variations of the first and formidable and fundamental fact that men are under the dominion and lash of insatiable hunger. Social action and interaction aim at minimizing the danger that hunger might exceed at any one time the means at hand to appease it temporarily. They are, in fact, the outcome of long and weary ages of experimentation, which at last forced upon men the dim recognition that hunger is more effectively combated through coöperation than through individual effort.

Still this very struggle with hunger reveals the inequality of the equipment for the fray in the component factors of society. Hence the human family divides into masters and leaders on the one hand, and slaves and followers on the other, the greater proportion of the booty going to the former. To bring about a more even distribution, combinations of men are formed on the part of the less well-equipped, which in turn suggest the formation of similar combinations on the part of the better armored in defense of their greater share of the prizes of this battle with hunger. Without the technicalities 
of the jargon of the school, the foregoing is a succinct sketch of the explanations advanced by the science of society of the motive and measure of social interaction and interdependence of men. While statically correct, the theory is dynamically false. It weighs facts as they are, but neglects forces that might be and ought to be vitalized. In other words, the merely economic conception should be supplemented by a mightily religious construction of man's nature and destiny and duty.

Religion reckons with the fundamental fact of hunger no less earnestly than does economics. But it will not permit the equipment for this struggle with hunger to determine the value or affect the equality of men. To subdue nature is the part assigned in the economy of the universe to the humankind. Hunger is the divinely planned goad that man might not neglect his task. But while struggling with nature under the lash of hunger, men are not meant to struggle against one another. They are to know and feel that they are brothers, destined to help one another. This is the basic note in religion's construction of the nature and position of man. It introduces a new element into the reasoning of the economist. It makes for consecrated coöperation where, without it, chaotic self-assertion, with the resultant lordship of the few and the slavery of the many, must appear as the inevitable issue of the battle against hunger.

The economic theories of our day are, like all modern thinkings, under the spell of the natural sciences. The watchwords that echo the hypotheses, by the aid of which the secrets of the heavens and oceans, of eons of creative energies, were seemingly unraveled, are also invoked as determinants in the domain of the humanities. The survival of the fittest, the elimination of the unfit through a process of natural selection, are a few of the pet dogmas by which social injustices are attempting to prove their naturalness and thereby stay the meddling hand of the reformer. The mechanics of a natural process of selection, religion replaces by the morals of a conscious effort at changing conditions and revolutionizing character. It conceives of men as under a common consecration and, therefore, of essential, though, of course, not externally absolute, equality. Opportunity spells obligation, better equipment greater responsibility. Possession is conceived of as while conferring power, conferring it as a trust to be utilized for the benefit of all, never for the gratification of self at the cost of others.

Invoking impressively the essential unity, though not uniformity, the functional and fundamental equality of all men, religion's sociology tends to neutralize racial and national, as well as class antipathies, by lifting natural differentiations into ideal potencies, where the non-religious anthropology inclines to declare them 
permanent titles to aristocratic distinctions and arrogated privileges. Racial superiority as inherent in the blood is, indeed, one of the fetiches at whose shrine many of the children of this century burn incense. If this superiority exist at all, it is to be energized in behalf of the whole human family, and not, as it is, alas, currently believed, to justify, in narrow bigotry of pride, as a title to the prerogative to despise and humiliate the inferior races. Noblesse oblige is the recurrent admonition of religion's interpretation of the differentiating distinctions among men.

The fundamental and original equality of all human beings is the solemn message of religion. It is its profound contribution to the science of society. The very opening chapter of Genesis, - and this is independent of our views concerning the date of its composition and the scientific accuracy of its contents, - at the threshold of religion's sanctuary, proclaims that all men are descended from one pair; that, therefore, as the rabbis apply the conception, none of the now living men and women has the right to arrogate to himself or herself superiority of racial composition. Contrast with this the implications of the naturalistic dogma, which one tempted to put in adaptation of a well-known Biblical query, as follows: "Have we not all one ancestral monkey? Hath not one ape procreated us all? Why, then, should one man carry his tail higher than another?" The religious conception, which will not allow that men are predestined to slavery to other men, makes for social peace. For whatever congenital differences there be among men, and whatever accidental variations in fortune and capacity there may obtain among them, the religious outlook and uplook will present them in the light of opportunities and obligations. Central to religion's preoccupation is the individual man only in so far as he is an agent in the life of all men, a factor in society. The non-religious conception regards society as a stepping-stone for individual man. The religious inverts the proposition. Man is individualized to enrich society.

This solves the vexatious problem of how far altruism shall absorb egotism - a problem that has kept thinkers busy in our day as it has distracted would-be saints in other days. Self-extinction and self-elimination have been proposed as the highest. But every self quenched and eliminated impoverishes society. On the other hand, the aristocratic and anarchistic philosophy of Nietzsche and others makes self-assertion but at the cost of others, the motif of healthful action. But this will necessarily lead to the disintegration of society. Religion is a social force just for the reason that it urges self-development to the furthest possible limit in order that the developed individual may render all the larger and richer service to society.

In penetrating with its spirit certain social institutions, religion 
has rendered them more efficient and through them influenced individuals to more beneficial social service. Two of the many social institutions which religion has endowed with deeper vitality may demonstrate in fuller detail the thesis of the social value of religion.

Law as exponential of custom but also as solicitous for the permanency of social basic relations, looks upon marriage as a contract, but at the same time assigns it a peculiar rank among contracts in so far as the dissolving and ending of this contract-relation is removed from the decision of the parties of the contract. The law alone is competent to dissolve and terminate this contract. Religion pleads the sacredness of this relation. It is concerned about its permanent abiding character. It assumes that marriage is a union and merging of souls. It lifts the family into a higher potency by attributing to it the atlas function, to pillar the whole of the moral and material universe of organic society. Polygamy and other more or less permanent forms of sexual unions might be justified on the ground of the social function of procreation. But on that of the moral values of human dignity and duty, monogamy, and that under strictest safeguards of the permanency of the relation, alone has credentials of nobility. Laxity of family constitution endangers social prosperity. By placing this central cell of social activity under special restrictions and investing it with deeper sanctity, religion exerts an influence on the social organism which is of farreaching consequences.

Exploitation of fellow man is one form of anti-social selfishness. Human life, which should be the dearest of all values, has often been deemed the cheapest. For while tools and machineries do not replace themselves automatically, the human tool or " hand " provides its own substitute. This one-sided view of the value of human " hands" has found echo in many a learned dissertation concerning the unalterable law of supply and demand as the regulator of prices. Religion has perpetuated a device which, almost from the very day of its first inception, has stood forth as a protest against such exploitation of men, and has become the bulwark of effective defense of the manhood of the weak against the iniquitous raids of the selfish and strong. The Jewish Sabbath, the seventh day of rest after six days of toil, has done more to maintain the independence and strength and dignity of the laboring classes than any institution known to man. It is the proclamation of man's freedom, of the essential worthiness of all men alike. In this country the Sabbath has protected the grand army of wage-earners against degradation to peonage. Without it, - who will doubt it? - they would have been condemned to work seven days at six days' wages. The maintenance of this day as a day of rest is one of the most urgent duties of American patriotism. If in factory and mill, and mine men and women 
are toiling that are proud of their patrimony of freedom and alive to its obligations, the Sabbath has been the most blessed influence and institution to bring this about. Perhaps it is no exaggeration to say that the Sabbath has made American workmen the superiors of all others. It has enabled this nation to forge ahead, to reclaim a continent to the uses of man, without lapsing altogether into commercial and industrial greed and egotism. As the Jewish Sabbath saved the persecuted Jews from annihilation and moral decrepitude, so its American copy, if on another of the seven days, still no less beneficially has affected the destiny of our young nation.

These instances tell the story. The merely economical interpretation of social possibilities neglects vital factors. These are energized by religion's message. If hunger drives man toward ever higher levels, it must not rob him of that which is more precious than gold and silver. Religion reminds us that man cannot live by bread alone. The struggle for bread would turn men into beasts of prey were it not that religion urges by teaching and institution upon the strugglers the consciousness of their essential unity and equality. It evokes in them the assurance of their brotherly destiny and duty. It converts competition into coöperation, the strength of one into a blessing for all. 


\title{
THE SECULAR LIFE AS THE EXPRESSION OF THE RELIGIOUS SPIRIT
}

\author{
BY EDWARD CALDWELL MOORE
}

[Edward Caldwell Moore, Parkman Professor of Theology, Harvard University, since 1902. b. West Chester, Pennsylvania, September 1, 1857. A.B. Marietta College, Ohio, 1877; A.M. ibid. 1880; graduated Union Seminary, New York City, 1884; Fellow for two years studying in Giessen, Göttingen, and Berlin, Germany, also 1894 in Oxford; Ph.D. Brown University, 1891; D.D. Marietta College, 1893. Pastor of Westminster Presbyterian Church, Yonkers, New York, 1886-88; Pastor of Central Congregational Church, Providence, Rhode Island, 1888-1902. Member of American Historical Society; Society of Biblical Literature and Exegesis. Author of The New Testament in the Christian Church.]

Wrien one reflects upon the strifes of which religions have been the occasion, when one recalls the divisive influence in human society which the religiously minded have often exerted, it may sound strange to say that the very gist of religion is its uniting and reconciling quality. In religion, so only that it be deeply and truly apprehended, all sides of life find their harmony and all kinds of men the basis of mutual regard and of coöperation. Yet surely that was a thought to which the greatest of the Hebrew prophets had risen. It is an idea to which the most exalted spirits under the ethnic religions attained. And however much Christians may, at times, by their harsh bearing towards the rest of mankind, and by their antagonism to much of life, have promoted narrowness and contention, yet surely they did not gather that spirit from the Nazarene.

The intent of his gospel for all mankind was plain. The joy with which he greeted truth and goodness in any man was obvious. $\mathrm{He}$ expected all men everywhere who any way followed truth and goodness to feel his fellowship with themselves. His attitude toward men of other races and of other faiths was the very thing which alienated him from the magnates of his own. He had absolutely no sympathy with ecclesiastics. He spoke scathingly of their conventionalities and exclusiveness. Devout Jew that he was, and never losing his sense for the meaning of the services of religion for the spiritual life, he yet never worked for the propagation of the synagogue dogma or for the triumph of the temple worship. And still less did he work, as some Christians have dreamed, for a dogma and ritual which were to bear his own name and to take the place of these. His serene and natural attitude toward men's business and their pleasures, toward things not deemed religious, shocked and amazed the professedly religious among his contemporaries. They 
could not endure him, because he found so much religion where they found none, and because he found so little where they found all.

Paul, sharing at first to the full the prejudices of a Pharisee, yet came to conceive as the very marrow of Christianity this, its universal intent, its all-embracing quality, its conciliatory attitude. The earliest church never wearied of repeating how Greeks and barbarians, Jews and Gentiles, slaves and freemen, sinners of deepest dye and seekers after God of every sort, all found in the spirit of Jesus a new bond of cohesion, and in this new enthusiasm for humanity the common ground for all who in any way were trying to be good. The secretly cherished ideals of men were greeted with joy by their brethren. The good was everywhere recognized and appropriated. Men in whom differences of race, of custom and of occupation, of intellectual training and horizon, had bred an alienation which seemed almost like a law of nature, knelt at the same devotions, listened together to the reminiscences of the simple life of Jesus, and partook of a common meal in token of their brotherhood.

But everybody knows how soon the Christian body lost this, its original projection. Every one knows how soon the sense began to fade, that the Church had been sent forth into the world to seek out in faith, to embrace in love, and to appropriate with joy anything that anywhere was good; to brood over all things in hope; to proclaim to every man the divine expectancy and trust, to recognize as the children of God even those who did not at all recognize themselves as such, and to assert as the service of God the lives and works of many men who might have feared or even scorned to say of themselves that they served God.

The simple brotherhood gradually became the most complex and dictatorial organization. This organization set itself about the most elaborate and positive definitions of what was true and good, and the exclusion of all those who could not agree with those definitions. It put forth a form of dogma as the infallible statement of the pure revelation of God, not realizing how much of the philosophy and science of the age and of the religious experience of the race had been taken up into that statement. It established a form of worship which alone was to be accredited. It preached an ideal of life which was often alien to the natural life of men, hostile to culture, and inimical to civilization. It denounced nature for the sake of that which it called grace. It set the church against the world. It sharply distinguished things sacred from things secular. It put the power of the interpretation of things divine in the hands of a single class of men, instead of appealing to every man's reason and conscience in the sight of God.

In doing all this the Christians indeed only followed an impulse which may be illustrated from the history of almost every other 
religion. Christianity, indeed, took up into itself large elements from other religions. It deified that which was passing and forgot that which was permanent. Disdaining other religions, it yet became like them in their least worthy qualities. And claiming to be universal, it yet abandoned that simple, ethical, and spiritual quality wherein alone its universality could consist.

As we look back over the history of humanity in these nineteen centuries of the Christian era, as we review the progress of the race under other religions before and apart from our own, we have thankfully to acknowledge that much has been accomplished. The sense of brotherhood in the human race asserts itself ever more and more strikingly. The dignity of man as man is acknowledged. Slavery is all but done away with. Wars are conducted with an underlying sense of the race unity and of the sacredness of the humanity. And though some things are worse than war, yet all men have a sense that war is a thing which is going to be done away. Commerce and business are seeking still further to embody the principle of fraternity. And all men have a sense that competition within this realm is a thing which is going to be modified without the sacrificing of any of those sterling benefits to character which competition has conferred. Struggles and conquests which once were looked down upon as purely secular are now admitted to have been glorious triumphs, moral and spiritual. Some of the struggles which have been made in the name of religion are now clearly seen to have had their origin in the lowest human propensities and to have been conducted in the basest human passion. And often what have been deemed conquests of religion have been catastrophes to the race, while the defeat of a contention made in the name of religion is seen to have been a liberation and a blessing to mankind.

The struggle for civil liberty has at times taken up into itself a large part of the moral and spiritual vitality of a given age. And in so far as it has been the expression of the idealism and of the altruism of that age, it has been the religion of the age. We understand the phrase of some in the time of the French Revolution that the Revolution was their religion. But how often has the conventional and the official religion of an age stood with the opponents of civil liberty, and seemed to be interested in the perpetuation of political tyranny.

Take, again, the struggle for social equality, on behalf of economic justice, for the righting of wrongs and the doing away of unjust advantages. The effort for the creation of the outward conditions of a nobler social life, - who can deny that this effort has taken up into itself no small part of the idealisn and of the altruism of our own age. And in so far they are a direct expression of the deep religious spirit of the age. And yet many of those most ardently 
engaged in this struggle would, because of their associations with the word religion, perhaps scorn to call themselves religious men. No one who knows the temper of our age will deny that these efforts are the sphere of a consecration upon the part of many which rises, for them and for the world, far toward the worth of the purest religious consecration. And that the religious institutions and the conscious and professed religious experience of our age is so often indifferent or even hostile to these efforts is a fact which is full of peril to religious institutions and of humiliation to the more truly religious mind.

Some things have been accomplished. But how slowly have they come to pass. How imperfect are they at best. How many misunderstandings still prove obstinate. How many senseless antagonisms still remain usnubdued. And how often has this progress, such as it is, been made, not by fearless proclamation of truth through the recognized channels of religion, but in opposition to religious authority, and by means against which some of those professedly religious have set themselves with all their strength. How often, in particular, has that pursuit of scientific truth which within the last two centuries has been the expression of the idealism and the altruism of so many minds, yet involved the seekers after that truth in embittered conflict with that which was proclaimed as divine revelation. How often have the most devoted scientific spirits been deemed to have no religion, and, in turn, how often have they deemed those given to religion to be incapable of manifesting the scientific spirit.

The theory of knowledge which has come to us with the idealist philosophy sets us over against nature with much of the same feeling toward nature which men had for that to which they ascribed the quality of revelation. It puts before us history and the human consciousness, that we may inquire of these as oracles, much as men once inquired only of a sacred book. But we have been so used to hearing the ideal and the moral, the divine meaning of human life associated with assumptions which are hard to bring into consonance with our genetic explanations, we have been so zealous in controverting those assumptions, that we have not always seen that human life has a meaning which, even after we have refused to phrase it in the old way, still clamors to phrase itself in its own new way. And then we come face to face with a man like Huxley - and I take him only as a type of the great class to which he belongs; - if ever there was a man who revered nature and looked to nature with expectancy, set his whole heart on obedience to nature, dedicated himself to the effort to increase the happiness of others by bringing them into obedience to nature, that man was Huxley. And we ask ourselves, in what respect does the reverence and expectancy and 
obedience and consecration which he felt toward nature differ from that which a man offers to God? Is it not a part of that which the most truly religious man offers to God? It is, indeed, the reverence of the child of light. But then, true religion is also the reverence of children of the light. And God is light, and in him is no darkness at all. It is a reverence without fear. But in true religion perfect love casteth out fear. It is a reverence for law, for intelligible sequence, an inviolable ground of confidence that nothing in the universe can ever be capricious or arbitrary. But for true religion also, with God there is no variableness, neither shadow of turning. The religious man would say that he was devoted to the truth. But did this man falter in his devotion to the truth? The religious man would serve others with his truth. But did not this man also wish to ameliorate men's lot and to exalt their lives by bringing them into unwavering obedience to the truth? One has a feeling that the difference between such a man as this and the traditional moralist and man of religion is that the latter calls by different names things which are just as real to the former under the names which he has coined for them. If the one does not go quite so far as the other, yet, so far as he does go, every step is real, and every advance solid and secure.

The very best aspect of much of religious thought in our own day is its willingness to own how much there is that we do not know. It seems strange that that very department of life and thought which you would suppose brought men closest to the sense of the unfathomed mystery which surrounds our being, should have been so ready to assert that for religion there was little or no mystery. It is sad that the professedly religious should have been the very men who, touching things immortal and eternal, have sometimes allowed themselves the greatest license of affirmation. No one can deny that it is a gain for religion that the humble confession of much ignorance goes halfway to meet the confession of the limits of knowledge on the part of those who have sometimes been rated as irreligious. But if the sense for mystery and the loving trust that at the depth of that mystery is nothing arbitrary, if the confidence that the Eternal will not put us to confusion is religion, then it cannot be denied that some of the foremost of our men of science have showed that religion. If devotion to the pursuit of truth, and allegiance to it when discovered, is the criterion, then it cannot be said that the theologians have had a monopoly of this kind of religion. If the zeal to spread the truth and the joy of bringing others into its allegiance, and so into peace and harmony and blessedness, is the essence of missions, then it cannot be said that the only missionaries of the truth are those who get called by that name. And if the life of discipline and of responsibility is the witness to morals, then 
it cannot be said that these are achieved only by those who have studied moral philosophy. If altruism is a good part of Christianity, then there are more people in the world who have that part than those who call them by the name of Christian. If to do justice and love mercy and walk humbly are still the requirements of God, then there are more people who follow God's requirements than those who realize that it is God's requirement which they follow.

It would not be true to say that these truths have gained recognition and these principles found application in spite of religion. On the contrary, Christianity, at its simplest, in its original, which is also its most permanent form, would seem to have full place for that recognition. And these achievements of the spirit of humanity are but the witness of the presence of God ever with us, of the working of God ever through us, and of that life for the good and the true which religion is. But of this essential Christianity, of this fundamental religion, the current forms, whether of thought or of life, which call themselves by those names, are often only the dead tradition or the caricature.

How often have men sincerely but narrowly religious made war upon things which are really indifferent, as if they were evil in themselves, and on behalf of things which are of absolutely no consequence, as if the salvation of the world depended on those things. How often have they regarded religion as but a corner of life religion as one thing, life as another. Deeming themselves sure of the divine favor and of another life, they have set at naught standards of rectitude in this life - standards which obtain among those who profess no religion. They have sometimes apprehended their mission as only that of the propagation of certain so-called religious truths, often at variance with many other things which men know to be true. They have acted as if their aim was to build churches and get men to come to them. Whereas the real aim of religion is to build up men into places of the indwelling of a holier spirit and the whole world into a kingdom of the living God in this nobler sense. In the midst of this world, with all of its manifold interests and energetic life, the particular institution which calls itself a church stands simply as focus and burning-point, hearthstone and centre of radiation, and of an inspiration which reaches out into all the departments of life. Men have acted as if the kingdom of God would then have come when all the people in the world should have been brought to do the particular things which people in churches do. Whereas in reality the kingdom of God will have come when men do all that they do, - business, politics, the pursuit of learning, of pleasure, of anything whatsoever, - according to that truth and goodness which obtains for those things, and in a beautiful spirit like that which Jesus showed. And the Church with its ministry of teaching 
and worship exists to help men up to that clear and exalted spirit and to keep ever before them a touching and inspiring example of him who incarnated the genius of such a life.

In one of the most extraordinary passages in the Fourth Gospel Jesus is made to say to the woman of Samaria: "Woman, believe me, the hour cometh, when neither in this mountain, nor in Jerusalem, shall ye worship the Father." The woman had asked about worship in the conventional sense, as to the place and time of it. Were her fathers or the Jews' fathers right in this old dispute? How familiar it all sounds - this puzzle of one whose notion of religion is largely a reminiscence of past greatness and a prejudice against present facts. And how great is Jesus' reply! You are both right in so far as he who worships in sincerity and in truth may worship in any place and in any way. But yet, more deeply than that, you are both wrong in supposing that religion is something which finds all of its expression in such acts of worship as those of which we speak. The time is coming and now is when there will not be any temple, church, or sacred mount in this exclusive sense; no one manner of worship alone acceptable, no peculiar religious works, no specific sacred ideas. There will be ideas, sacred if true, but not otherwise. And all true ideas will be.alike sacred, and only the false ones will be profane. And of all, the most profane will be the false ideas which have been put forth concerning God and man's highest interests. Works will be good works if they are good, but not otherwise. And if they are good, they will be good works, religion, holiness, the service of God, no matter where done, or when, or how, or by whom. And all special acts of worship which men call such will be only the kindling and sustaining of men's minds to this true and good and beautiful life which is the great act of worship.

Religion is that which is illustrated in the tenderness of parental and of filial affection, in the purity and happiness of marriage, in the steadfastness of friendship, in the honesty of trade, in the loyalty of citizenship, in the righteousness of political rule, in the prosecution of reforms, in the furtherance of every kind of social good. Where these are, God is, and the service of God is being performed. Where these are not, God is not. A worship which does not aim at these is an hallucination or an hypocrisy. A teaching which does not sustain these is false and injurious. A life which is set upon these things is the life in God, whether it knows itself by that name or not. It would more frequently and more willingly call itself by that name did it not so often hear that name applied to a type of life which, while pursuing some remote ideal of its own, neglects these fundamental things.

And if the Church seems to set before men only things artificial, 
instead of these great realities; if in the name of religion it appear to draw off men from these things which are actual, - then it is not difficult to understand how men intent on these primary matters may say they see no great need of the Church. And yet the whole history of humanity has shown that there is need. Men do not do those outward and practical things at their highest level without some feeding of their inward life, some nourishment of their spiritual strength, some ministry of humbling and of uplifting, of grace and peace and power, such as that for which the Church with its opportunity of worship and instruction was designed to stand. In the tremendous pressure of modern life, and just because of that which is sometimes decried as its secularizing tendency, while yet men know that in the deeper sense which we have described this great modern life of ours is not all secular, but much of it is very sacred, - just because of the idealization of every relation in which they stand, men are seeking the point of rest, the centre of unity, the place of power and of impulse. They need these things as never before, and if they turn from the Church, it is sometimes because in their need they have sought and have not found in the institution of religion that light and power, that ministry of grace and peace which before all other things they feel that it is the function of the institution of religion to afford to them.

There never was a time in the history of the world when a bold, far-seeing, and enlightened instruction in matters pertaining to man's moral life and his spiritual interests was more needful than just now, in the midst of the pressure and temptations, and of the limitless expansion of the life of our time. There never was an age when a worship which will deliver us from the tyranny of that which is ontward, which will lift us above the sordid and the commonplace, which will quicken us to that which is beautiful and great, was more necessary than it is at present. There never was a time when the Church, as institution, had a greater work to do, - so only that it knows how to do that work.

But its real task is always, like that of the Master, to lose its life that it may find it. The real task is always to lose itself as institution in order that it may become merely the soul of the great human society, and to find itself again in having made that society truly and freely, broadly and humanely, religious. It has no real aim but to make the men who will then make the world. It has no real aim but to nourish the inward life of the men who then are to see to it that laws are made and executed in the spirit of perfect justice, that business is transacted in faithfulness and honor, that personal relations are regulated in wisdom and love, and that in all things reason and the will of God prevail. In other words, the Church may well maintain worship and specific religious instruction as one 
of the grand supports of a righteous public and private life. But it must always maintain that the true religion, the supreme Christianity, is that life. The whole social spirit of our time reënforces the Church as an association for the furtherance among men of common ends, and for the meeting in public services of worship of men who feel a common spiritual need. And men quickly recognize and heartily sustain, as a means to an end, that of which they cannot any longer concede the validity as an end in itself.

We hear it deplored in some quarters that the present is a time of the decadence of religion among us. And with the narrower sense of those words there are not a few who are prepared to say that it is a good thing that religion should be decadent. In so far as the devotion to it led men away from that which is actual and practical, in so far as it made men concerned each man only for his own individual welfare, in so far as it ignored the problem of this life and praised only an unearthly experience, religion may be decadent among us. But surely with that parody of religion we have little to do. In the wider sense in which we have been using the word it would be more true to say that we are in the midst of one of the greatest revivals of religion which the world has ever seen. There has never been a time when men more widely acknowledged the moral and spiritual element in every phase of their lives or made more earnest effort to do justice to that element. There never was a time when they were more grateful for real help received from those whom they recognize as their fellows in their sincere endeavors or turned with more of aspiration to the God who is manifest in nature, in all the life of mankind, and in the spirit of Jesus Christ.

The kingdom of God, - what is it but the reign of truth and goodness in exactly the sense in which plainest men have aways understood those words and striven for those things, many of them not daring and many others perhaps not wishing to call their work the service of God when they thus strove. It is justice, mercy, and humility which God now, as in Micah's day, requires. It is plain trust of men and love for them which Jesus would inspire. It is a better state, a worthier church, a more helpful and fearless school, a more equitable court, more honorable trades, a less shallow, envious, and perverse social life. It is purer homes and loftier relations every way. It is civilization at its best, and better than the best we know. It is art, refinement, comfort. It is public virtue, private character in every manifestation. These will be the kingdom of God when that shall come. These are the kingdom of God in so far as they are now come. And who will say that they are not all abroad among us? It is for the fullness and perfection of these that we pray. It is toward their fullness and perfection that we would make our contribution, each one of us in the sphere in which 
he is set. We acknowledge to the full Jesus' contention for the inward nature, the spiritual character of that kingdom. The real genius of the kingdom of God is a nobler and holier spirit in man, primarily in the individual man. The gist of it is an attitude of the individual mind and heart. The germ of it is a passion for rightness, the struggle after truth in the individual life. But where that passion and struggle exist they work themselves out. That spirit cannot be, even in one man, without its effect upon the world. And that spirit even in one man will mightily influence other men. The work of numbers of such men will, in the end, modify customs, create institutions, transform societies. Never more forcibly than in our own great civilization was the lesson brought home to us that men never will be happy, nor the world good, save by a happier and better spirit within men themselves. But that is not what has ordinarily been understood by the contention for the inwardness and spiritual character of the kingdom.

When, therefore, we pray "Thy kingdom come," it is true that our thoughts rest first upon certain individuals whose spirits we could help, and whose lives we could bless. It is true, also, that our thoughts pause for a moment on that which is so inexpressibly dear to us, the Church, whatever be its name, the Church in this nobler sense which I have described. And that is because we deeply feel that there is something of infinite importance which the Church may confer upon the great life of mankind. But when we pray "Thy kingdom come," we mean the hallowing and glorifying of the great life of mankind in every way. If men only understood how wide and large a thing the kingdom is, how little is artificial in it, where men have made it so artificial and arbitrary, they would see how much religion is behind the daily doing of the world's work, and that on the part of men who might be very much surprised to hear themselves called religious. The phrase "kingdom of God "would not sound to them like a word in an unknown tongue. It would not describe a thing for which they felt no sympathy and toward which they had no desire. Something of the kingdom of God has come every time the truth underlying any one of all our manifold human relations has been discovered. Something of the kingdom of God has come every time men and women have set out with brave and faithful hearts to obey the truth which they have discovered. Something of the kingdom of God has come in every school in which children and youth are being trained in insight and character. Something of it comes in every home where, in the atmosphere of duty and responsibility, a love which hallows all prevails. Something of the kingdom of God comes in every advance of government toward being really good government. Something of the kingdom of God has come with every enlargement of human liberty. Some- 
thing of the kingdom of God comes in every business worthily administered for the advantage of all concerned. Something of it comes in every adjustment of the relations of employer and employed. Something of it comes in every adornment of life, in every enlargement of worthy comfort. Something of it comes in every proper charity, in every wise philanthropy, in every just and generous struggle after reform. Something of it comes to every man and every woman, every child, who is faithful in his place, and who views that place and work as part of the great and sacred whole.

And when we have said all this we look about us and say, "But the kingdom of God has already come." It is all abroad among us. Religion is everywhere manifest. We give thanks that there are so many millions of men who are to-day working for its manifestation, although they do not call their working by that name. We take up our own little tasks with a solemn sense that they are part of the great whole, and we lift up our hearts to God, asking that he will help us with moreopen eyes, with more generous hearts, and with more entire consecration to give ourselves to the furtherance of his kingdom and the manifestation of his religion. 


\section{SOCIAL RELIGIOUS INFLUENCE}

\section{BY JOSIAH STRONG}

[Josiah Strong, President of American Institute of Social Service. b. Naperville, Du Page County, Illinois, 1847. B.A. Western Reserve College, 1869; S.T.D. ibid.; Post-graduate, Theology, Lanes Seminary, 1869-71. Chaplain and Instructor, Natural Theology, Western Reserve College; Pastor, Sandusky, Ohio; General Secretary, Evangelical Alliance for the United States, 1886-98. Author of Our Country; The New Era; The Twentieth Century City; Religious Movements for Social Betterment; Expansion; The Next Great Awakening; and many others, some of which have been translated into foreign languages.]

"Gop and one man," says Dr. Parkhurst, " could make any other religion, but it takes God and two men to make Christianity." This characterization justly emphasizes social relations as constituting an essential part of the Christian religion, but overlooks the fact that Judaism also has its social aspects. As Christianity, however, includes all the social teaching of Judaism, adds others, and vitalizes the whole, we may confine our discussion to the social influence of Christianity, or more exactly, to the influence of the social teachings of Jesus.

It becomes necessary to define what is meant by the social teachings of Jesus. They are embodied in his doctrine of the kingdom of God, which was the great burden of his teaching. Until recently this doctrine has been generally misunderstood. Many have supposed that the "kingdom of heaven" was the home of the blessed dead. Others have confounded it with the visible Church, while still others have thought it was identical with the invisible Church. But it is an error, and a very mischievous one, to make the kingdom of God synonymous with any one of these, for it is more comprehensive than any one or all of them.

Speaking exactly, God's kingdom is, of course, as wide as his dominion, but in Scriptural usage the expression "kingdom of God" is generally employed to designate a redeemed world. The matured prophetic conception of that kingdom fully come in the earth was that of a world-wide society in which universal obedience to the divine law, administered by the Lord's Anointed, would bring universal blessings, spiritual and temporal; or, in one word, the kingdom of God realized would be an ideal world.

It is to be observed that while this kingdom was spiritual, was a kingdom of righteousness, it was also, in the conception of the Hebrew prophets, a kingdom of physical well-being. It distinctly included nature. All natural phenomena are constantly represented in the Old Testament as expressions of the divine will. Of course modern science was unknown to the ancient Israelites, and our 
conception of natural law was utterly foreign to their minds, but had natural laws been known to them, they surely would have been considered laws of the kingdom of God. It is good theology, and good philosophy, and not bad science, to regard all natural laws as expressions of the divine will; God's will, therefore, cannot be perfectly done in the earth until all natural laws are perfectly obeyed.

Modern science has revealed the intimate connection of mind and body. We are beginning to see that there are physical conditions of moral progress, so that to aim at an ideal moral and spiritual world while ignoring physical causes and conditions would be mere quackery.

If any one declines to accept this comprehensive conception of the kingdom of God, and objects to our including natural laws among the laws of that kingdom on the ground that this teaching is extraScriptural, he should object to all interpretation of Bible truth in the light of modern knowledge. The Scriptures teach that God is the Creator, but the creation which Scriptural writers had in mind was only an infinitesimal part of the universe which has been made known by science. Are we then bound to interpret the Scriptures as teaching that God created only an infinitesimal part of the universe?

Let us bear in mind, then, that the kingdom of God which the Hebrew prophets foresaw included the physical as well as the moral and spiritual redemption of the world, and all that is necessarily contained in that conception.

Now Jesus, like his forerunner, John, began his preaching by declaring that this kingdom was already at hand. He nowhere defined the expression, for the obvious reason that it was entirely familiar to all Jewish ears. He allowed his hearers to understand that he meant by it what they had always understood by it. Instead of setting aside the ancient teaching, he took care to say that he came not to destroy the prophets but to fulfill. Like them he recognized God in nature, and declared that not even a sparrow falls to the ground without our Father. He also asserted his own dominion over nature, commanding the winds and the waves. Like the prophets he included physical as well as spiritual well-being in his aim, and showed the keenest sympathy with bodily want and sickness, feeding the multitude, making the blind to see and the lame to walk, and healing all manner of diseases.

Jesus made it perfectly clear that he came to set up in the earth this kingdom of God which the prophets of Israel had foretold, and this redeemed world which was the principal subject of his discourse was his social ideal.

For the realization of this social ideal and for the government of this heavenly kingdom he inculcated and perfectly exemplified three fundamental social laws, viz., the law of service, the law of 
sacrifice, and the law of love, the latter being the most vital of the three, because it makes possible of fulfillment, and glorifies, the other two.

Now the influence of these social teachings of Jesus can scarcely be treated historically, because the recognition of them is so recent that their influence can hardly be said to have a history. A few choice spirits in earlier generations perceived the social aspects of Christianity, but an individualistic civilization led naturally to an individualistic interpretation of teachings which we, wrestling with the problems of our new, collective civilization, as naturally see to have been social in their intention and in their application.

We are to inquire, then, what influence might reasonably be expected to attend the common acceptance of the social teachings of Jesus.

Professor Alfred Marshall, in his well-known work, Principles of Economics, remarks that "the two great forming agencies of the world's history have been the religious and the economic," a statement which few in this audience probably would care to controvert. If, then, it can be shown what effect the common acceptance of the social teachings of Jesus would naturally have on these two great formative agencies, we may anticipate with some confidence what would be their effect on civilization.

I. Let us turn, first, to the religious forces.

The acceptance of the social teachings of Jesus would have a marked effect on the religious aim.

It is popularly supposed among Christians that the divine aim in the work of redemption was to increase the census of heaven, to multiply the number of saved souls.

If we share this belief, then as faithful disciples of Christ we must, of course, make it our supreme object in life, first, to save our own soul, and then to save other souls. This conception of religion naturally fixes attention on that part of man which alone can enter a spiritual heaven, and, therefore, depreciates the body. The world is a wilderness through which we must needs pass as pilgrims to gain the heavenly Canaan. Life is a probation, an opportunity to prepare for death. The discipline of life is to wean us from the follies of time and sense, and to prepare us for eternity. If the world seems to us very beautiful, appealing to every sense, if the natural relations of the family are very sweet and give to us unspeakable delights, we must be on our guard not to enjoy these beauties and delights overnuch, lest they become temptations of the Devil to wean us from the heavenly glory and to satisfy us with earthly good. If we are truly spiritually minded we shall have only a limited and rather questionable interest in art and science, in invention and the progress of civilization, in politics and social reform, 
in business and in recreation, because all these are of the world and worldly.

I would not imply that every one who fails to apprehend and to accept the social teachings of Jesus holds so narrow a conception of the Christian religion, for many a man's common sense saves him from his logic, but I maintain that this conception logically and commonly follows a misapprehension of the teaching of Jesus concerning the kingdom of heaven. If by that kingdom we understand the home of the blessed dead, then the injunction to seek first the kingdom of God must be understood to make the gaining of heaven at last the supreme object of life. It fixes attention on the other world rather than this, and lays the great emphasis on individual salvation. Failure to perceive the social character of Christianity leads to an individualistic interpretation of it. This interpretation has been, and still is, the commonly accepted one. It was this conception which the genius of Bunyan clothed with the imagery of the Pilgrim's Progress, and which has heretofore been accepted by all Protestant Christians as true beyond question.

But when we perceive that by "the kingdom of God" Jesus meant an ideal world, our interpretation of Christianity undergoes a radical change, and becomes social. We now discover that the great business of life is not to escape from the City of Destruction and to gain a place of personal safety, but to save the city; and with the broadening of our aim comes the broadening of our sympathies, of our ideas, and of our life.

Accepting the kingdom of God as our social ideal, we attach new importance to society. We perceive its solidarity, and learn that its members are members one of another, and that no one of them can live unto himself or die unto himself. We rediscover a truth which pagan Romans knew and which Christians ought never to have lost, Unus homo, nullus homo. The brotherhood of man now gains new meaning, and we perceive that love to our neighbor is as real a part of the religion of Jesus as is love to God. We no longer divide religion and philanthropy into two separate spheres, as if love to God and love to man were two essentially different things and implied two different kinds of character. Genuine love, that is, disinterested love, whatever its object, is divine. " $\mathrm{He}$ that loveth knoweth God." Cardinal Manning said to Henry George, "I love men because Jesus loved them;" to which Mr. George replied, "And I love Jesus because he loved men." It matters little which way round the circle we move, provided only we are within it; in that happy case we shall, in due time, complete the circle of love which embraces both God and man.

Accepting the teaching of Jesus that the kingdom of God is the world redeemed, we see that the kingdom cannot fully come until 
all kindreds and peoples and tribes are included in it. That kingdom cannot come in its fullness to the most favored land until it has fully come to the darkest corner of the earth; hence a new impulse to Christian missions. And our sympathies and endeavors reach not only outward to other nations, but also forward to other generations. We become interested in all that works the improvement or deterioration of the human stock, and it becomes as easy to make sacrifices for those who are to live five hundred years hence as for those who live ten thousand niles away. Many men, calling themselves Christians, are as little concerned for future generations as was Sir Boyle Roche when he asked the Irish Parliament: "Why should we put ourselves out of the way for posterity? What has posterity done for us?" But we see that the kingdom which Jesus preached cannot fully come in the world, that the humanity for which he lived and died cannot be fully saved, until the heredity of every member of every generation gives to him the highest possibilities of the noblest manhood, nor until the environment of every child born into the world enables him to realize those possibilities; for the long lines of descent which run through the ages are the warp in the great loom of time, while ceaseless intercommunication is the swift shuttle flying back and forth throughout the earth and weaving in the woof of common interest, thus drawing close the countless individual threads into one vast web of humanity.

Furthermore, accepting the teaching of Jesus, that the kingdom of God is the world redeemed, makes a new place in our religion for the physical world. It is no longer regarded as a sort of necessary evil, utterly foreign to the great spiritual realities, if not actually hostile to them. It is now seen to be a component part of the kingdom of God. We discover that spirit and matter are, in this world, intimately related, and that each conditions the other. We gain new respect for the human body, and perceive how noble and necessary an object of endeavor is the physical perfection of the race. We now find ourselves toiling to save not souls, but men. Our ideal for the individual is not the highest spirituality, nor the greatest intellectuality, nor the finest corporality, but all of these united into the noblest manhood.

With our new apprehension of the physical world as a part of the kingdom of God, we accept the laws of nature as laws of that kingdom. Science, therefore, which discovers those laws to us, becomes another revelation from God, the teachings of which are to be eagerly studied and conscientiously obeyed.

Thus religion, under the influence of the social teachings of Jesus, is expanded from interest and effort in behalf of a fraction of the individual until it embraces all the interests of the whole world; and instead of loosening its grip by fixing attention on "a land that is 
very far off," it gains reality and power by dealing with all phases of actual and everyday life. With such a religion God becomes real; not the Great Perhaps, but the great $I \mathrm{Am}$; not what Carlyle calls an "absentee" God, not the God of a remote past or of a dim future, but the God of to-day; the greatest reality in the world; active in all human affairs, turning and overturning among the nations, and out of the dispord and chaos of conflicting selfish interests slowly but infallibly evolving the harmony and beauty of his kingdom of loving obedience - heaven on earth.

Let us consider further what influence the acceptance of the social teachings of Jesus will naturally exert on theology. Changes in our conception of religion are sure to be reflected in our theological views. Heretofore theology has been a circle drawn around the individual as the centre; hereafter it must be an ellipse drawn around the individual and society as the two foci.

Of course it is impracticable to attempt on this occasion even an. outline of the modifications which will naturally result from a new point of view in theology, but we may note, by way of illustration, the new aspects of the doctrines of service, sacrifice, and love, when viewed in the light of the social teachings of Jesus.

The old theology, still current, gives to these doctrines or laws an individualistic interpretation, thus perverting them, and robbing them of their essential character. If I were the only being in the universe, it would clearly be impossible for me to observe any one of these three laws, which shows that they are social in their nature. If God and I were alone in the universe, I cannot imagine anything that I could do for him; though I might love him, I could neither serve him nor sacrifice for him, " as though he needed anything." The only way to serve him that I know of is to help him lift this poor blundering, sinning, and suffering world up into the light and blessedness of his knowledge and his love. I can serve God only in the person of his children, because it is only in their person that he is in need.

The attempt to serve God without serving man is the explanation of ritualism, which serves neither, and which is hateful to the one and hurtful to the other. Forgetting that service, if real, is necessarily sccial, we, by a misnomer, call divine worship " divine service;" thus our services are "held" instead of being rendered.

Failing to see that sacrifice is a social law, men have tried to sacrifice to God without sacrificing for men; and this blunder has shed rivers of blood of both man and beast, and has cost incalculable self-inflicted and wasted suffering. Sacrifice for the sake of others is divinely beautiful, but sacrifice for the sake of sacrifice is suffering for the sake of suffering, in which only a fiend could take delight.

Unless sacrifice is made for the love of another, it is made for the 
love of self. Men have sacrificed everything dear in this life in the hope of gaining the divine favor and the life to come. But this is not self-sacrifice; it is sacrificing present good for future good, and for the sake of self. This is investment, not sacrifice; it is commercialism, not Christianity. "Other-worldliness" is no more unselfish than this-worldliness; it is only longer headed. Self-suffering which I inflict to please my God is no more Christian than the selfsuffering inflicted by a Hindu to please his God, and reduces the two gods to the same moral level.

Again, love to God which is not love to man seeks to lose the consciousness of earthly things in the contemplation and the enjoyment of God, sometimes rising into ecstasy. But such pious rapture is not Christian love, because it is selfish. It is good-feeling, not good-willing. The only genuine love to God is that which longs and labors that all men may know the blessedness of sharing it.

Thus the social interpretation of the three fundamental laws of Jesus substitutes the service of humanity for the hollow and puerile forms of ritualism; it substitutes the beauty and helpfulness of genuine sacrifice for the wasted suffering of asceticism; and it substitutes benevolence and beneficence for a morbid and selfish mysticism.

This is not what some would call humanitarianism substituted for religion. It is love to God expressing itself in loving and sacrificial service to man. "Lovest thou me? Feed my sheep." "Inasmuch as ye did it unto one of the least of these, ye did it unto me."

Jesus' doctrine of the kingdom of God is not only destructive of the old individualistic theologies, it is reconstructive. It affords a new germinal principle capable of assimilating all the elements of truth in the disintegrated systems of the past, and of producing a vital and progressive theology. We expect all other sciences to grow, but there is a widespread impression (or conviction) that a system of theology is final, if true, because it is based on a closed revelation; hence the reluctance of theologians to modify their views, and the consequent odium theologicum. But when we recognize an immanent God, organizing the world into his kingdom, then all things animate and inanimate are seen, like the Scriptures, to contain a revelation of him, and all natural laws are seen to be God's laws; so that a discovery in natural science may as reasonably call for a revision of our doctrine of God as for a revision of our doctrine of matter. Thus theology, being based on a progressive revelation, would itself become progressive. Instead of being like a cast-iron case fastened about the trunk of the tree of knowledge, and either preventing growth or being shattered by that growth, it would be rather like the bark of the tree, itself partaking of the growth to which it ministers. 
A man who is afraid of new truth is not quite sure that his old truths are true. A theologian who believes in a progressive revelation of God will be as eager for new light as is a biologist or an astronomer, for he knows that all truths are one and holy, because all are a revelation of the Holy One.

Consider further what influence the acceptance of the social teachings of Jesus will naturally exert on the pulpit.

The ministry of to-day lacks enthusiasm, and the reason is because it lacks a message. The scientific method applied to Biblical criticism has destroyed many time-honored beliefs. During the present period of transition the pulpit is placed on the defensive. It has lost the power of the affirmative. Many a preacher speals, not because he has something to say, but because he has to say something. Few of them feel a fire in their bones which compels them to cry out, "Woe is me, if I preach not this gospel!"

A Connecticut pastor tells me that he was talking some months since with four other pastors of the same state, each of whom said that if he had his life to live over, he would not enter the ministry; nor would he let his son enter it, if he could prevent it. It is not strange that under such circumstances there is much restlessness on the part of both pastors and churches. It is probable that a majority of all the churches and pastors in the United States are at this moment desiring a change.

If now the preachers should accept the social teaching of Jesus in all its fullness, a large proportion of them would make the startling discovery that they have not been preaching Christ's gospel: They would probably first have a new and deeper religious experience, and then they would find themselves in possession of a new message which they would be eager to give, and the people would be eager to hear, for that message would apply the teachings of Jesus to the actual problems of present-day life, both of the individual and of the community.

Within the past few weeks there have come to my attention a number of instances of pastors who are preaching this gospel of the kingdom. They all report large audiences, and each one of them significantly adds that a majority of his hearers are men.

Not all will hear the new, old gospel gladly, by any means, for it will be dead against their selfish lives. A very prominent and very rich church member said to me, "We don't want too much of the Sermon on the Mount." The social teachings of Jesus would make trouble for the pulpit, precisely because they would vitalize the pulpit. In all the ages when the prophet has cried aloud and spared not, it has made trouble until the people have brought forth fruits meet for repentance.

Enough has been said to show that the acceptance of the Gospel of 
the Kingdom would work such changes in the religious aim, in theology, and in the pulpit as must needs vitalize the church and make it a power in every community, the avowed and organized enemy of everything that obstructs the full coming of the kingdom of God.

The great object of church activity, so far as churches are at all active, is to build up the local church or to multiply churches of the same order in home missionary, or foreign missionary, fields; that is, the church or the denomination is made an end in itself. Unlike her master, the typical church seeks not to minister, but to be ministered unto.

The acceptance of the Gospel of the Kingdom on the part of pastor and people would make the Church what it was intended to be, not an end in itself, but a means to the Kingdom as an end.

Such a readjustment would radically change the relations of the churches to each other. Now there exist the petty jealousies and strifes of sectarianism, which wound Christ in the house of his friends. But if the churches were laboring, not each for itself, but all for the Kingdom, they would find coöperation naturally taking the place of competition. The social mission of the churches is so vast that they cannot hope to accomplish it without coöperation; and this field where their coöperation is supremely needed is the one field where they have no historic differences.

When the religious aim has been corrected, when theology has been re-reasoned and made spherical instead of hemispherical, when the pulpit has gained a message, and really preaches Christ's Gospel of the Kingdom, with its social laws of service, sacrifice, and love, thus quickening and deepening the spiritual life of the Church, and when the Church perceives that her mission is not to get individual souls into heaven, but to create an ideal world, then religion will gain her rightful place, and power to mold and Christianize the new civilization.

II. Turning to the great economic forces to inquire what effect the acceptance of the social teachings of Jesus would have on them, we find ourselves at once confronted with the industrial revolution and the great social organism which it is creating.

As Herbert Spencer has reminded us, the fundamental laws which govern society are vital; and it goes without saying that the only way to establish and maintain social health is through obedience to these laws. What are they? An organism must have organs, and the function of every organ is to serve. Accordingly, throughout the vegetable world, we find the law of service.

The higher the kingdom, the greater is the number and variety of laws which obtain, and when in the scale of being we rise to animate life, we find that to the law of service there has been added another. 
As something cannot be obtained from nothing, in order to sustain the activities of animal life countless living cells are constantly consumed, the loss of which is supplied by new cells constantly formed. Thus, in the animal kingdom, we find not only the law of service, but also that of sacrifice.

When we rise to the social organism, we find the laws of service and of sacrifice in fullest operation: if they were suspended, society would perish; but their operation at the present stage of social evolution is not normal and healthy, hence social restlessness, soreness, and disease. In the individual organism, organ and cell have no power to refuse service and sacrifice, but in the social organism, man the social cell is endowed with will, and hence may obey or disobey the vital social laws of service and sacrifice. We have service, but much of it is that of the slave, we have sacrifice, but much of it is that of the victim; hence social discontent; and hence the added social law of love, which makes service a joy and sacrifice a privilege. Love transforms the slave into a freeman and the victim into the hero.

But these three vital laws of the social organism are precisely the three social laws which Jesus revealed for the government of the kingdom of God. Social health, therefore, will come through the acceptance of the social teachings of Jesus, and only through their acceptance.

Increasing wealth, which is now an increasing peril, would then become, not the means of luxury, but the instrument of service, thus saving the rich from the corruption of wealth and the poor from the envy of it.

It would solve the municipal problem by substituting the official possessed by the spirit of service and intelligence to serve for the boss who, to use the brutally frank confession of one of the class, "is in politics to fill his own pocket, every time." It would transform the duel between capital and labor into a duet, and organize them together for the service of society.

The world industry which is rapidly being organized is creating a new world life, a new world consciousness, and a new world conscience to which the accepted social teachings of Jesus would give new world ethics, and a new world diplomacy, which would substitute the Golden Rule for that of Machiavelli, "Not to depart from good if the ruler can help it, but to know how to do evil if he must."

We are in an age of transition. There have been other transitional aegs, but never before was the revolution in the world of thought accompanied by a radical revolution in the physical world. The coincidence of the application of the scientific method to the investigation of truth and of the application of steam and electricity to the physical world has precipitated a double disturbance, which 
has not only unsettled old beliefs, but has revolutionized the conditions of life and transformed civilization.

There has arisen the necessity of reconstruction, not only in religion and ethics and philosophy, but also in industry, in politics, and in society. In each of these great divisions of thought and life more or less reconstruction has already taken place; and enough progress has been made to reveal a tendency toward larger generalization a feeling after some synthesis vast enough to coördinate all into one comprehending whole. That something after which many are groping to-day is the kingdom of heaven, which John Bascom says is " the true synthesis of the universe of God, physical and spiritual." This is the

"... one far-off divine event,

To which the whole creation moves ;"

and its final consummation will be the new heavens and the new earth wherein dwelleth righteousness. 


\section{WORKS OF REFERENCE FOR THE DEPARTMENT OF REIIGION}

(Prepared by President Henry C. King, of Oberlin)

On the Strictly Philosophical Side

Bowne, Theism.

CAIRd, John, Philosophy of Religion.

CaIrd, Edward, Evolution of Religion.

Fiske, John, The Idea of God.

Through Nature to God.

The Destiny of Man.

Life Everlasting.

Lotze, Outlines of a Philosophy of Religion.

Pfleiderer, Philosophy of Religion.

Sabatier, Outlines of a Philosophy of Religion.

Sмутн, The Religious Feeling.

Wund, The Facts of the Moral Life.

On the Psychological Side

Com, The Spiritual Life.

Granger, The Soul of a Christian.

James, The Varieties of Religious Experience.

Starbuck, Psychology of Religion.

\section{On the More Theological Side}

Clarke, An Outline of Christian Theology.

Farrbairn, The Place of Christ in Modern Theology.

Harnack, What is Christianity?

Herrmann, Communion of the Christian with God.

Martineav, The Seat of Authority in Religion, 2 vols.

Pfleidirer, Philosophy and Development of Religion.

\section{General Literature}

Royce, The World and the Individual.

Nature, Man, and the Moral Order.

WARD, JAMES, Naturalism and Agnosticism. 
WORKS OF REFERENCE FOR THE SECTION OF GENERAL RELIGIOUS EDUCATION

(Prepared by Dr. Walter L. Hervey)

CaIrd, Evolution of Religion.

Giddings, Principles of Sociology.

HöfFding, Outlines of Psychology.

James, Principles of Psychology.

The Will to Believe.

Kant, Critique of Pure Reason.

The Practical Reason.

LECKY, History of European Morals.

LoDGE, Microcosmus.

PaLMIER, The Field of Ethics.

The Nature of Goodness.

Paulsen, Introduction to Philosophy.

System of Ethics.

Royce, Religious Aspect of Philosophy.

Spirit of Modern Philosophy.

Wundt, Facts of the Moral Life. 
ADDITIONAL WORKS OF REFERENCE FOR THE SECTION OF GENERAL RELIGIOUS EDUCATION

(Prepared by Professor George A. Coe)

Butler, Nicholas Murray, The Meaning of Education, chap. I. New York, 1898.

Principles of Religious Education, Lecture I. New York, 1900.

Coe, George A., Education in Religion and Morals. New York, 1904.

Dewer, John, My Pedagogic Creed. New York, E. L. Kellogg \& Co. A small pamphlet, but it contains the gist of a whole theory of education.

Horne, H. H., The Philosophy of Education, especially chap. vir. New York, 1904.

King, Henry C., The Fundamental Nature of Religion. An address delivered before the Congress of Arts and Science.

McMurry, Charles A., The Elements of General Method. Chap. I, "The Chief Aim of Education." New York, 1903.

Proceedings of the Religious Education Association. 153 La Salle St., Chicago. Spalding, Rt. Rev. J. L., Means and Ends of Education. Chicago, 1901.

Education and the Future of Religion. Pamphlet The Ave Maria, Notre Dame, Indiana. 


\title{
WORKS OF REFERENCE FOR THE SECTION OF RELIGIOUS WORK
}

\author{
(Prepared by Rev. Floyd W. Tomkins)
}

Gotт, Right Rev. John, The Parish Priest of the Town.

Johnson, Rev. Theo., The Parish Guide. London, Wells, Gardner \& Darton Co.

Peabody, Rev. F. G., Jesus Christ and the Social Question.

Strong, Dr. Josiah, Our Country.

The New Era.

Expansion.

Social Progress.

Thwing, Charles F., The Working Church. 


\section{ADDITIONAL WORKS OF REFERENCE FOR THE SEC- TION OF RELIGIOUS WORK}

(Prepared by Rev. Henry C. Mabie, D.D.)

Burrell, David James, Religions of the World. Presbyterian Board of Publication, Philadelphia.

Clarke, Janies Freeman, Ten Great Religions. Houghton, Mifflin \& Co., Boston.

David, T. H. Rhys, Buddhism.

Eldinwood, Frank E., Oriental Religions and Christianity. Charles Scribner's Sons, 1896.

Griffis, W. E., The Mikado's Empire. New York, 1896.

The Religions of Japan. New York, 1895.

Hunter, Sir William, Hinduism.

Mahan, Asa T., The Problem of Asia.

Mozoomdar, P. C., The Oriental Christ. Unitarian Association, Boston.

Perry, R. B., The Gist of Japan. New York, 1898.

Romanes, George J., Thoughts on Religion.

Townsend, Meredith, Asia and Europe. Putnam's Sons, London, 1901.

Welch, R. E., The Challenge to Christian Missions. London.

Willianis, M. Monier, Buddhism in its Connection with Brahmanism. Waddell, New York, 1889.

Religions of China. London, 1887.

Islam and Christianity. American Tract Society, New York, 1902.

Religious Systems of the World. Lectures delivered at South Place Institute, by various authors. Swan, Sonnenschein \& Co., London, 1890.

Reports of Numerous Addresses, World's Parliament of Religions. The Parliament Publishing Company, Chicago, 1893.

Report of the Centenary Conference on Foreign Missions. James Nisbet \& Co. 1898. 


\section{WORISS OF REFERENCE FOR THE SECTION OF RELIGIOUS INFLUENCE : PERSONAL}

(Prepared by Rev. John E. McFadyen)

$$
\text { Popular }
$$

Kempis, Thomas à, De Imitatione Christi.

Law, William, A Serious Call to a Devout and Holy Life. The Prophets of Israel.

The New Testament.

\section{Scientific}

Beet, Agar, The New Life in Christ Jesus.

Bovon, Morale Chrétienne.

Findlay, Christian Doctrine and Morals.

Forrest, The Christ of History and Experience.

Gretillat, La Morale Chrétienne.

Herrmans, Der Verkehr des Christen mit Gott.

Römische und Evangelische Sittlichkeit.

KIDD, Morality and Religion.

Martensen, Christian Ethies.

Pfleiderer, Grundriss der Glaubens- und Sittenlehre.

Rothe, Stille Stunden.

Schleiermacher, Die Christliche Sitte.

Sмyтн, Newman, Christian Ethics.

Strong, Christian Ethics. 

INDEX 



\section{INDEX}

Abnormal psychology, 5: 737-75; Biblio- Analysis, Algebra and, 1: 497-531; Developgraphy, 5:780-1; Relations of, Janet, ment and relation of mathematical analysis 5 : 737-53; Some of the present problems of, to some other sciences, Picard, 1 ; 497-517. Prince, $5: 754-74$.

Abbe, Cleveland, tr., Penck, Relations of physiography to the other sciences, $4: 607-26$; tr., Zirkel, Relations between petrography and related sciences, $4: 591-603$.

Abbott, Nathan, Characteristics of the common law, $2: 271-87$.

Abdominal aorta, Pathology and diagnosis of Tessier, $6: 149$.

Adams, George B., Present problems of medieval history, $2: 125-38$.

Henry C., Relation of the science of finance to allied sciences, $7: 179-89$.

Samuel S., Pediatrics, Sec'y, $6: 475$.

Thomas S., Industrial group, Sec'y, $7: 791$.

W. S., Astrophysics, Sec'y, $4: 429$.

Addams, Jane, Problems of municipal administration, $7:$ : 434-50.

Adler, Felix, Relations of ethics to social science, $7: 663-81$.

Administration, Colonial, see Colonial administration; Municipal, see Municipal administration; National, see National administration.

Administrative Board of the Congress, $1: 4$.

Esthetics, 1 : 417-46; Bibliography, 1 : 447 , 452; Fundamental questions of, Dessoir, 1: 434-46; Relation to psychology and philosophy, Marshall, 1 : 417-33.

Agricultural chemistry, Application of physical chemistry, Cameron, $4: 324$

Agriculture, 6 : 715-38; Bibliography, 6 : 741; Relations to other sciences, Dabney, $6: 715$ 26; Some present problems, Bailey, $6: 727-$ 38.

Ahasver in der Fiunstdichtung, Heller, 3 : 508.

Aitken, R. G. on double stars, $4: 426$.

Alcoholism, Relation to other forms of poisoning, Hunt, 6 : 185.

Alexander, James W., Do governments and lawmakers regard life assurance from the right point of view? 7 : 252 .

Alexandrianism, Its contribution to $\mathrm{New}$ Testament thought, Sheldon, $2: 649$.

Algebra and analysis, 1: 497-531; Present problems, Maschke, $1: 518-30$.

Allbutt, Thomas C., Historical relations of medicine and surgery, 6 : 189-209.

Almy, Frederic, George Junior republic, 7 : 847.

Alphabet, universal, Proposed universal conference, Stein, $3: 66$

Alsberg, C. L.. Physiological chemistry, Sec'y, $4: 327$.

America, History of, 2: 171-95; Bibliography of history of, $2: 237-38$.

American history, Problems, Turner, 2 : 18394; Relations to other fields of historical study, Bourne, 2 : 172-82.

Anatony, Comparative, see Comparative anatomy; Human, see Human anatomy.

Ancient history, Bibliography of, $2: 229-31$.

Andrews, E. Benjamin, Tendencies of the world's politics during the nineteenth century, $8: 293-306$.

Animal morphology, 5 : 243-84; Bibliography, 5 : 438; Contributions of, to education, Needham, 5:283-84; Relation to other sciences, Davenport, 5: 244-57 ; Present tendencies, and its relations to the other sciences, Giard, 5 : 258-82.

Anthropology, 5: 449-573; Bibliography, 5 : 572-23; History, Boas, 5 : 468-82; Individuality of, Manouvrier, $5: 485-97$; Larger problems, McGee, 5 : 449-67.

Applied mathematics, 1:591-622; Bibliography, 1 : 625-26; Principles of mathematical physics, Poincaré, 1 : 604-22; Relations of, Boltzmann, 1 : 591-603.

Apponyi, Count Albert, Juridical nature of the relations between Austria and Hungary, 7 : 529-49.

Aqueous salt solutions, Physical properties in relation to the ionic theory, Noyes, $4: 311$ 23.

Arabia, Bibliography of history of, $2: 229$ Bibliography of history of religion of, 2: 655; Poetry of Arabia and the ballad problem, Mardonald, 3 : 95-96.

Archeology, 5: 513-42; Problems, Seler, 5: 527-41; Relations to other branches of science, Chavero, 5 : 513-26.

Architecture, modern, 3: 621-49; Bibliography, 3:681; Relations to the study of other periods of the art, Enlart, 3 : 622-37; Problems, Hamlin, $3: 638-49$.

Aristotle's Poetics, á $\mu \alpha \rho \tau i ́ a$ of, Milner, 3 : 398.

Armstrong, A. C., Metaphysics, Chairman, $1: 227$.

Arrhenius, Svante A., Relation of meteorology to the other sciences, $4: 733-40$.

Art, History of, 3: 565-681; Bibliography, 3: 679-81; Development, Van Dyke, 3 : 577-88; Fundamental conceptions and methods in the study of, Richardson, 3 : 565-76.

Arthur, Joseph C., History and scope of plant pathology, 5 : 149-64.

Artificial and natural selection, Comparison, Vries, $5: 28-40$.

Ashmore, Sidney G., Classics in our schools, 3: 202 .

Asia, General survey of the history of, Cordier, $2: 86-108$.

Assyria, Bibliography of history of, $2: 229$; Bibliography of history of religion of, $2: 654$. Astrometry, 4 : 387-426.

American influences in the Slavic literatures, Astronomical ritual of Peru, Hagar, $5: 571$. Wiener, $3: 511-19$.

American literature, German impulse in, before 1800 , Learned, $3: 507-08$; Influence on German literature, Sauer, $3: 477-97$.

Ames, James B., Private law, Chairman, 7 : 619.

Astronomical science, Fundamental conceptions and methods, Boss, $4: 360-73$.

Astronomy, 4: 359-474; Bibliography, 4 : $471-4$; stellar, Statistical methods in, Kapteyn, $4:$ :396-425.

Astrophysics, 4 : 429-70; Problems, Campbell, 
4 : 446-69; Relations of photography to, Turner, $4: 429-45$.

Atmosphere, Circulation of, Clayton, 4: 756.

Atwater, Wilbur O., Physiological chemistry, Chairman, $4: 327$.

Austria, Bibliography of history of, 2 : 234-35; Juridical nature of relations with Hungary, Apponyi, 7 : 529-49.

Axon. William A. E., Bibliography on library, 8 : 238; Library in relation to knowledge and life, $8:$ 203-15.

Babylonia and Assyria, Bibliography of history of, $2: 229$.

Backlund, Oskar, Development of celestial mechanics during the nineteenth century, $4: 387-95$.

Bacon, Benjamin W., Bibliography on the New Testament, $2: 659-61$; Relation of New Testament science to kindred sciences, 2 : 569-84.

Bacteria, Production of light by, Gorham, 5 : 239.

Bacteriology, 5 : 207-39; Bibliography, 5 : 437-38, 443; Relations to other sciences Jordan, 5 : 207-18.

Bailey, Liberty H., Bibliography on agriculture, $6: 741$; Some present problems in agriculture. $6: 727-38$.

Baird, J. W., tr., Janet, Relations of abnormal psychology, 5 : 737-53.

Baldwin, James M., History of psychology, 5: $605-23$.

- Simeon E., Bibliography on the history of law, $2: 427$; History of the common law, 2: 331-49.

Bancroft, Wilder D., Physical chemistry, Chairman, $4: 303$.

Banquet, Official, of the Congress, $1: 34-40$.

Barge canals of New York, Symonds, 6 : 590.

Barker, Llewellyn F., Neurology, Chairman, $6: 225$.

Barnes, Charles R., Plant physiology, Chair$\operatorname{man}, 5: 101-02$.

Bartlett, John R., Oceanography, Chairman, 4: 683 .

Barus, Carl, Progress of physies in the nineteenth century, $4: 29-65$.

Bauer, Louis A., Present problems of terrestrial magnetism, 4: 750-56.

Baur, P., Classical art, Sec'y, 3 : 591.

Beale, Joseph H., Jurisprudence: its development during the past century, $4: 470-81$.

Beauvais, Early commune and the local secular law at, Dow, 2 : 138.

Beck, Carl, On the technic of urethral dislocation in hypospadias, 6 : 382; Surgery, Chairman, 6 : 307.

Becker, George F., Present problems of geophysics, $4: 508-22$.

Belgium, Bibliography of history of, $2: 236$.

Belles-lettres, 3: 531-57; Present problems, Matthews, 3 : 545-57; Relations of, Schofield, $3: 531-44$.

Benjamin, Marcus, Historical development of technical chemistry in the U. S., 6 : 701-12; Technical chemistry, Sec'y, $6: 671$.

Bessey, Charles E., Plant pathology, Chairman, $5: 147-48$.

Biagi, Guido, The library: its past and future, $8: 216-29$.

Billings, Frank, Development of modern medicine, $6: 41-50$.

Binnie, J. F., Surgery, Sec'y, $6: 307$.
Biology, 5 : 3-24; Bibliography, 5 : 435-46; Recent development, Loeb, 5 : 13-24.

Black, Hugh, Religious influences: personal, $8: 397-403$.

Blackmar, Frank W., Bibliography on sociology, 5 : 884-85; Sociology, Chairman, 5 : 785-86.

Blichfeldt, H. T., Concerning some geometrical properties of surfaces of revolution, 1 : 587.

Bliss, G. A., Algebra and analysis, Sec'y, 1: 497; Concerning calcidus of variations, $1: 587$.

Bloomfield, Maurice, Brahmanical riddles and the origin of theosophy, $2: 481-92$; IndoIranian literature, Chairman, $3: 357$.

Boas, Franz, History of anthropology, 5 : 46882.

Bôcher, Maxime, Fundamental conceptions and methods of mathematics, $1: 456-73$.

Bode, Mabel, tr., Lévi, Transformation of Sanskrit studies in the nineteenth century, $3: 99-$ 110.

Boltzmann, Ludwig, Bibliography of mathematics, 1: 623-26; Relations of applied mathematics, $1: 591-603$.

Boss, Lewis, Fundamental conceptions and methods in astronomical science, $4: 360-73$.

Bourne, Edward G., Relation of American history to other fields of historical study, $2: 172-$ 82.

Bovey, Henry T., Fundamental conceptions which enter into technology, 6 : 535-51.

Bower, Frederick O., Plant morphology, 5:6180.

Bowne, Borden P., Philosophical outlook, 1 : 171-72.

Boyer, Paul, Russia and studies in Russian, 3 : 520-28.

Brace, De Witt B., Ether and moving matter, $4:$ : 105-17.

Bracken, H. M., Public health, Sec'y, $6: 53$.

Brahmanical riddles and the origin of theosophy, Bloomfield, 2 : 481-92.

Brahmanism and Buddhism, 2 : 467-93; Bibliography, 2 : 653, 657-58.

Brandon, E. E., Romance languages, Sec'y, $3: 237$.

Bread, Digestibility of, Snyder, 4 : 324.

Brewer, David J., History of law, Chairman, 2: 241.

Brooks, William K., Individual development and ancestral development, 5 : 308-19.

Brown, Elmer E., Present problems in the theory of education, $8: 64-82$.

- Ernest W., On the completion of the solution of the main problems in the new lunar theory, $4: 426$.

Brunialti, Attilio, Constitutional Iaw, 7 : 55473.

Bruns, Henry D., Elements of improvement in municipal government, $7: 450$.

Brunton, Sir Lauder, Problems of therapeutics, $6: 170-84$.

Bryce, James, National administration, 7 : 339-52.

Buck, Carl D., Bibliography on Indo-European comparative philology, 3 : 303-5; Relations of comparative grammar, $3: 32-52$.

Buckler, William H., Relations of Roman law to the other historical sciences, 2 : 291-314.

Buckley, James M., The press as a religious agency, $8: 344-58$.

Budde, Karl F. R., Relations of Old Testament science to the allied departments and to science iu general, 2 : 551-63. 
Buddhism, 2 : 467-93; Bibliography, 2: 653, Chronological order of proceedings, 1:77657-58; Is it nihilistic? Suzuki, 2: 493.

Burgess, John W., Present problems of constitutional law, 7 : 574-601.

Burr, William H., Civil engineering, Chairman, 6: 555 .

Burton, Ernest DeW., Bibliography on the New Testament, 2: 659-61; Present problems of New Testament study, $2: 585-615$.

Bury, John B. Place of modern history in the perspective of knowledge, $2: 141-52$.

Butler, Nicholas Murray, Chairman Administrative Board, $1: 4 ; 1: 31$.

Butterfield, Tienyon L., Social problems of American farmers, $7:$ 747-60.

Cabot, R. C., Internal medicine, Sec'y, 6 : 189.

Calcidus of variations, Bliss, 1 : 587.

Calkins, Mary W., Limits of genetic and comparative psychology, $5: 712-34$.

Cameron, Frank K., Application of physical chemistry to agricultural chemistry, $4: 324$.

Campbell, William W., Problems of astrophysics, $4: 446-69$.

Canada, Bibliography of history of, $2: 238$.

Cancer, Morphology of, and the parasitic etiology, Orth, 6:382-86; of the uterus, Importance of an early diagnosis, Sampson, 6 : 408.

Capps, Edward, History of Greece, Rome and Asia, Sec'y, 2: 55 .

Carbon, Fundamental conceptions underlying its chemistry, Nef, $4: 195-220$.

Cattell, James McK., Conceptions and methods of psychology, 5: 593-604.

Causal law, Content and validity of, Erdmann, 1: 353-88.

Celestial mechanics in astronomy, Moulton, 4: 426; In the nineteenth century, Backlund, 4: 387-95.

Celtic language, Bibliography, 3 : 305.

Chabot, C., Professional training of teachers in France, $8: 176-91$.

Chaddock, C. G., Psychiatry, Sec'y, 6 : 243.

Chairmen, List of, 1 : 54-76.

Chamberlin, Thomas C., Geology, Chairman, 4: 525; Methods of the earth sciences, 4: 477-87.

Chaplin, Winfield S., Bibliography on engineering, 6: 739-40; The college, Chairman, 8: 119; Technology, Chairman, $6: 535$.

Chavero, Alfredo, Archeology and its relations to other branches of science, $5: 513-26$.

Chemistry, 4 : 193-355; Bibliography, 4 : 35255 ; Inorganic, see Inorganic chemistry; Organic, see Organic chemistry; Physical, see Physical chemistry; Progress and development in the nineteenth century, Clarke, 4: 221-40; Technical, see Technical chemistry.

Chester, C. M., Naval observatory in Tutuila, 4: 426 .

Child-saving work, Distinctive features of American, Folks, $7: 847$.

Chittenden, Russell H., Present problems of physiological chemistry, 4 : 335-50.

China, Bibliography of the history of, 2 : 229. Bibliography of the history of religion of, $2: 652$; and the Far East, Cordier, 2: 86108.

Christian church, History of, 2 : 621-49.

Christianity, Bibliography, 2: 654-55; Elements which adapt it to be the universal and absolute religion, Mabie, $8: 368-84$.

Christy, Samuel B., Present problems in the training of mining engineers, 6 : 644-68.

80.

Cicero, Rhythm in his philosophical works, 3 : 398.

Cipriani, L., tr., Rajna, Study of Romance medieval literature, $3: 435-57$.

Circulation of the atmosphere, Clayton, 4: 756.

Civil engineering, 6:555-90; Bibliography, 6: 739-40; Relations to other sciences, Waddell, 6 : 555-70.

Clark, John B., Economic theory in a new character and relation, $7: 47-56$.

Clarke, Frank W., Bibliography on chemistry, 4 : 354; Progress and development of chemistry during the nineteenth century, 4: 22140.

Clarke, John M., Paleontology, Sec'y, 4 : 551; Physiography, Sec'y, 4:607.

Classical archeology and its relations to allied sciences, 3 : 591-604.

Classical art, $3: 591-617$

Classical literature, $3: 369-98$; Present problems of the history of, Wright, $3: 386-98$; Relations to other branches of learning, Shorey, $3: 370-85$.

Classics in our schools, Ashmore, $3: 202$.

Classification of the sciences, Münsterberg, 1 : 99-127.

Clayton, H. H., Circulation of the atmosphere, 4. $: 756$.

Clements, F. E., Ecology, Sec'y, 5 : 177.

Coe, George A., Bibliography on general religious education, 8 : 470; Reasons and functions of general religious education, $8: 271$ 81.

Coffin, Charles H., Some considerations of our system of instruction in painting, $3: 678$.

Cohn, Adolphe, Romance literature, Chairman, 3: 435 .

Cohnheim, Otto, Bibliography on physiological chemistry, 4:355; Problems in nutrition, 4:327-34.

Colby, Charles W., Historical synthesis, 2 : 15368.

College. 8: 119-65; Bibliography, $8: 232$; College, Hyde, 8: 119-32; Education, Primacy of the person in, King, $8: 151-55$; Place of, in the great educational movement, Woolley, $8: 155-56$; Thomas, $8: 133-50$.

Collineation, Reduction to a product of perspective collineations, Haskell, $1: 531$.

Collins, E. Bagster-, tr., Minor, Problems and methods of modern history of literature, 3: 498-506; tr., Oldenberg, Relation of the religions of ancient India to the science of religion, $2: 467-80$.

Collitz, Hermann, Problems in comparative Germanic philology, $3: 286-302$.

Colonial administration, 7 : 385-416; Bibliography, 7 : 454-56; Control of dependencies, Moses, 7 : 387-98; Problems of, Reinsch, 7 : 399-416; Value of the study of colonies from a sociological standpoint, $7: 416$.

Colonial politics at the beginning of the eighteenth century, Greene, $2: 195$.

Comfort, Dr., Romance literature, Sec'y, 3: 435.

Commerce and discovery, Snow, 2 : 195.

Commerce and exchange, $7: 115-47$; Bibliography, $7: 257$.

Committee on Plan and Scope of the Congress, $1: 7$.

Committee on Reception in New York, 1 : 21.

Committee on Reception in St. Louis, 1 : 22.

Common law, Characteristics of, Abbott, 2 : 
271-87; History of, 2 : 331-64; History of, Baldwin, $2: 331-49$; Problems of to-day for the history of, Wigmore, $2: 350-64$.

Commune and the local secular law at Beauvais, Dow, $2: 138$.

Comparative anatomy, $5: 323-56$; Bibliography, 5 : 439-40, 445-46; Foundations of morphology and, Delage, 5 : 336-55; Place in general biology, Ritter, 5 : 323-35.

Comparative and genetic psychology, 5 : 693734; Bibliography, 5 : 778-79; Limits of, Calkins, 5: 712-34; Relations of, to other branches of science, Morgan, $5:$ 696-711.

Comparative jurisprudence, New Japanese code as material for its study, Hozumi, 2 367-416.

Comparative language, 3:31-66; Bibliography, 3 : 303-05; Relations of comparative grammar to other branches of learning, Buck, $3: 32-52$; Some present problems and tendencies in comparative philology, Oertel, $3: 53-65$.

Comparative law, $2: 367-425$.

Comparative psychology, Suggested methods in, Watson, $5: 775$.

Comstock, George C., Astronomy, Chairman, $4: 359$.

Congress, History of, Rogers, 1 : 1-44; Scientific plan of, Münsterberg, $1:$ :5-134.

Conrad, Johannes E., Economic history in relation to kindred sciences, 2 : 199-214.

Constitutional law, 7 : 551-615; Bibliography, $7: 653,657$; Brunialti, 7 : 554-73; Present problems, Burgess, 7 : 574-601; Separation of powers and the judiciary in France and the United States, $7: 602-15$.

Content and validity of the causal law, Erdmann, $1: 353-88$.

Cordier, Henri, General survey of the history of Asia, with reference to China and the Far East, 2 : 86-108.

Coromilas, George, Healing properties of sulfite of carbon, $6: 149$.

Cosmical physics, $4: 733-56$.

Cotchett, James Green, Secretary Department of Congresses, 1 : 43.

Coulter, John M., Development of morphological conceptions, $5: 3-12$.

Councilman, William T., Modern conceptions and methods of medieval science, $6: 23-40$.

Cowles, Edward, Abnormal psychology, Chairman, 5 : 737; Problems of psychiatry in the functional psychoses, $6: 262-304$.

Crafts. James M., Bibliography on chemistry, 4 : 352-53; Chemistry, Chairman, $4:$ 193-94.

Craig, James A., Relation of Semitics to religion, $3: 69-86$.

Crane, Charles, Slavic literature, Chairman, $3: 511$.

Credit, see Money and credit.

Creighton, James E., Methodology of science, Chairman, 1: 333 .

Crew, Henry, Bibliography on physies, $4: 188-$ 89; Physics, Chairman, 4: 17; Physies of ether, Chairman, $4: 105$.

Criminal group, $7: 849-68$

Criminology, New, Wines, 7 : 851-68.

Crunden, Frederick M., Library, Chairman, 8 195-202.

Culture, Social, see Social culture.

Cummings, John, Money and credit, Sec'y, $7: 151$.

Currier, Augustus S., Old Testament, Chairman, $2: 537$.

Curves, Certain universal, Dowling, $1: 587$.
Dabney, Charles W., Relations of agriculture to other sciences, $6: 715-26$.

Dana, Charles L., Psychiatry in its relations to other sciences, $6: 243-61$.

Darboux, Jean G., Study of the development of geometric methods, $1: 535-58$.

Davenport, Charles B., Animal morphology in its relation to other sciences, $5: 244-57$.

Davis, Bergen, tr., Langevin, Relations of physics of electrons to other branches of science, 4 : 121-56. 627.

William M., Relations of the earth-sciences in view of their progress in the nineteenth century, $4: 488-503$.

De Forest, Robert W., Dependent group, Chairman, $7: 817$

De Garmo, Charles, Educational theory, Chairman, $8: 49$.

Delage, Yves, Comparative anatomy and the foundations of morphology, $5: 336-55$.

Dennis, Frederick S., Bibliography on surgery, 6: $530-31$; History and development of surgery during the past century, 6: 307-81. W. C., International law, Sec'y, $7: 485$.

Denton, James E., Best economy of the piston steam engine at the advent of the steam turbine, 6: 602; Mechanical engineering, Chair$\operatorname{man}, 6: 593$.

Dependent group, $7: 815-47$; Bibliography, 7 : 875-76; Definition of a social policy relating to, Henderson, $7: 817-32$; Problems of poverty, Münsterberg, 7 : 833-47.

Dessoir, Mlax, Fundamental questions of contemporary ethics, $1:$ 434-46.

Development, Individual and ancestral, Brooks $5: 308-19$.

Dickinson, Jacob M., Comparative law, Chairman, $2: 367$.

Diet, Physical condition and mental performance of certain students in Harvard University, Mallinckrodt, $4: 351$.

Digestibility of bread, Snyder, $4: 324$.

Dike, Samuel W., Bibliography on the family, 7 : 873; Problems of the family, 7 : 709-22.

Dinkel, George, Mechanical engineering, Sec'y, 6: 593 .

Diplomacy, 7: 353-83; Biblingraphy on, 7 : 452-53; Contemporary development of, Hill, 7 : 369-83; Proper grade of diplomatic representatives, Foster, 7 : 355-68.

Discovery, Commerce and, Snow, 2 : 195.

Donaldson, Henry H., Problems in human anatomy, $5: 378-91$.

D'Ooge, Martin L., Greek language, Chairman, $3: 129-30$.

Dorsey, George A., Problems of somatology, 5 : 498-509.

Double stars, Aitken, $4: 426$.

Dow, Earl W, Early commune and the local secular law at Beauvais, 2: 138; Medieval history, Sec'y, 2 : 111.

Dowd, Jerome, Social structure, Sec'y, $5: 815$.

Dowling, L. W., Certain univ่ersal curves, 1: 587 .

Drude, Oscar, Bibliography on ecology, 5 : 43536 ; Position of ecology in modern science, $5: 177-90$.

Dudley, William L., Inorganic chemistry, Sec'y, $4: 243$.

Duggar, Benjamin M., Plant physiology Present problems, 5: 125-44.

Duncan, George M., Logic, Chairman, 1 : 295. 
Dunning, William A., Fundamental conceptions and methods of politics, 7 : 279-92.

Dust, Hurty, 6 : 85 .

Earth, Sciences of, $4: 477-764$; Bibliography, 4: 757-64; Methods, Chamberlin, 4: 47187: Relations in view of their progress in the nineteenth century, Davis, 4 : 488-503.

Ecclesiastical history, Progress of, in the nineteenth century, Réville, $2: 636-48$; Relations with general history, Harnack, 2 : 62135.

Ecology, 5 : 177-203; Bibliography, 5 : 435-36; Position of, in modern science, Drude, 5 : 177-90; Problems of, Robinson, 5 : 191-203.

Economic history, 2: 23-238; Relation to kindred sciences, Conrad, 2 : 199-214.

Economic institutions, History of, 2 : 199-228.

Economic interpretation of history, Present problems, Patten, $2: 215-28$.

Economic science in the nineteenth century, Miller, 7 : 21-44.

Economic theory, 7 : 47-67; in a new character and relation, Clark, 7:47-56; Scope and method of political economy, Hollander, $7: 57-67$.

Economics, 7 : 5-258; Bibliography, 7 : 253-59; Fundamental conceptions and methods, Fetter, 7: 7-20.

Eddy, Henry T., Applied mathematics, Sec'y, 1: 591; Electro-magnetic theory and the velocity of light, $1: 622$.

Educated man and the social problem, Swain, 8: $422-31$.

Education, 8 : 19-233: Bibliography, 8 : 23033; Religious, see Religious education; Science of, Horne, $8: 83-85$; Social culture in the form of, Harris, $8: 1-16$.

Educational ideas in the nineteenth century, Spalding, $8: 27-46$.

Educational methods and principles of the nineteenth century, Hadley, $8: 19-26$.

Educational theory, 8: 49-85; Bibliography, $8: 230-31$; Place and office of pedagogy in the university, Rein, 8:49-63; Present problems, Brown, $8: 64-82$.

Egypt, Bibliography of history of, $z: 229$; Bibliography of history of religion of, $2: 655$.

Eichelberger, W. S., Astrometry, Sec'y, $4: 387$.

Eleatic philosophy, Significance of the ipeocov, Heidel, 3 : 173.

Electrical engineering, 6 : 605-30; Problems of the time, Pupin, 6:617-30; Relation to other branches of science, Kennelly, $6: 605-$ 16.

Electro-magnetic theory and the velocity of light, Eddy, 1: 622

Electrons, Physics of, see Physics of Electrons.

Eliot, Samuel A., Religious influence, 8 : $110-16$.

Ellwood, Charles A., Social psychology, Chairman, 5 : 859.

Elmer, H. C., Some questionable tendencies of modern textual criticism, 3: 202 .

Ely, Richard T., Bibliography' on the industrial group, 7: 874; Certain psychological phases of industrial evolution, $7: 800-13$.

Embryology, 5 : 287-319; Bibliography, 5: 438-39, 444.

Emch, Arnold, Configuration of the points of inflection of a plane cubic and their harmonic polars, 1 : 587.

Engineering, Civil, see Civil engineering; Electrical, seeElectrical engineering ; Mechanical, see Mechanical engineering; Mining, see Mining engineering.
England, Bibliography of history of, $2: 232$.

English language, 3 : 205-33; Its history considered in its relation to other subjects, Jespersen, $3: 205-19$; Present problems in the study of, Kittredge, $3: 220-33$.

English literary history, Present problems, Hoops, 3 : 415-32.

English literature, 3:401-32; Relation to other sciences, Gummere, $3: 401-14$.

English monastic towns, Trenholme, $2: 138$.

Enlart, Camille, Relations of modern architecture to the study of other periods of the art, $3: 622-37$.

Epsteen, S., tr., Boltzmann, Relations of applied mathematics, 1 : 591-603.

Erdmann, Benno, Content and validity of the causal law, $1: 353-88$

Ernst, Harold C., Bacteriology, Chairman, $5: 207$.

Escherich, Theodore v., Foundations and aims of modern pediatrics, $6: 477-97$.

Ether and moving matter, Brace, 4 : 105-17; Physics of, see Physies of ether.

Ethics, 1: 391-414; Bibliography, 1: 452; Problems of Hensele, 1 : 403-14; Relation to social science, Adler, 7 : 663-81; Relations of, Sorley, 1; 391-402.

Ethnology, 5: 545-71; Relations to other branches of anthropology, Starr, 5 : 545-48; Scope and problems, Haddon, 5 : 549-70.

Europe, Modern history of, 2 : 141-68.

Evolution of the scientific investigator, Newcomb, $1: 135-47$.

Exchange, see Commerce and exchange.

Experimental psychology, 5: 655-90; Bibliography, 5 : 777-78; Problems of, Titchener, 5: 674-90; Relations to other branches of science, MacDougall, $5: 655-73$.

Exponential notation in vector analysis, Macfarlane, $1: 622$

Fairclough, H. R., Virgil's relation to GrecoRoman art, $3: 398$.

Fairlie, John A., Municipal administration, Sec'y, $7: 419$

Family, 7 : 695-722; Bibliography, 7 : 871-73; Civic ideal in, Sewall, $7: 722$; Problem of, Dike, 7: 709-22; Social control and the function of, Howard, $7: 699-708$.

Farlow, William G., Biology, Chairman, 5 : 3.

Farmers, Social problem of, Butterfield, $\boldsymbol{\gamma}$ : $747-60$.

Farrington, Oliver C., Petrology and mineralogy, Chairman, $4: 589-90$.

Favill, H. B., Therapeuties and pharmacology, Sec'y, $6: 153$.

Fay, E. W., Comparative language, Sec'y, $3: 31$.

Ferguson, W. S., Plutarch as a comparative biographer, 2: 108.

Fetter, Frank A., Fundamental conceptions and methods of economics, $7: 7-20$; History of economic institutions, Chairman, 2: 199.

Finance. Public, see Public finance.

Finlay, Carlos T., Ieucocytes, 6 : 149.

Fiske, Charles E., Township government in Indiana, $2: 195$.

Flameless wood, Sadtler, 6: 700 .

Fletcher, Alice C., Ethnology, Chairman, 5 : 545.

Flexner, Simon, Pathology, Chairman, $6: 105$.

Folks, Homer, Distinctive features of American child-saving work, $7: 847$.

Foreign markets, Plehn, 7 : 133-47. 
Fortier, Alcée, Bibliography on French literature, 3:558-60; Present problems in the field of Romance literatures, $3: 458-73$.

Foster, John W., Proper grade of diplomatic representatives, 7 : 355-68.

France, Bibliography of history of, 2 : 233-34.

Francis, David R., President, $1: 4$; Addresses, $1: 25-26 ; 1: 35$.

Francke, Kuno, Germanic literature, Chairman, $3: 477$.

French, F. C., Bearing of certain aspects of the newer psychology on the philosophy of religion, 1 : 290-91.

French hiterature, Bibliography on, 3 : 558-60.

Freund, Ernst, Jurisprudence and legislation, $7: 619-35$.

Frost, E. B., Comparative study of stellar spectra, $4: 470$.

Funetions defined by an infinite series of analytic functions of a complex variable, Porter, 1: 531; Generalization of the analytic functions of a complex variable, Hedrick, 1 : 531 ; Uniformizing of algebraic, Hutchinson, 1 : 531 .

Furtwaengler, Adolf, Classical archeology and its relation to the allied sciences, 3 : 591-604.

Gage, Simon H., Embryology, Chairman, 5: 287.

Gailor, Thomas F., Religious work, Chairman, $8: 363-64$

Gannett, H., Physiography, Chairman, 4 : 607.

Gantt, H. L., Application of scientific methods to the economic utilization of labor, $6: 602$.

Garrison, J. H., Religious influence: social, Chairman, 8 : 429.

Gayley, Charles M., Development of hiterary studies during the nineteenth century, $3: 323-$ 53; English language, Chairman, 3 : 205.

Gehörschärfe, Verstimmung mittelst Flüstersprache, Zwaardemaker, 6: 472

General psychology, 5: 627-52; Bibliography, $5: 776-7$; Present problems, Ward, $5: 637-52$.

Generation and inheritance, Advances and problems in their study, Hertwig, 5 : 288307.

Geodetic astronomy, On the accuracy attained in, Tittmann, $4: 426$.

Geographical position, Relative value of, Oldham, $4: 671-80$.

Geography, 4 : 653-80; Bibliography, 4 : 762; Present problems, Mill, 4 : 653-70.

Geology, 4: 525-48; Bibliography, 4: 757-59; Problems of, Van Hise, 4: 525-48.

Geometric methods, Study of the development of, Darboux, 1 : 535-58.

Geometry, 1 : 535-87; Present problems, Kasner, $1: 559-86$.

Geophysics, 4: 507-22; Present problems, Becker, 4 : 508-22.

George Junior republic, Almy, 7 : 847.

German impulse in American literature before 1800, Learned, $3:$ 507-08.

German linguisties, Relation to Indo-Germanic linguisties and to German philology, Sievers, $3: 273-85$.

Germanic languages, 3 : 273-302 ; Bibliography, $3: 305$.

Germanic literature, 3:477-508; Bibliography of history of, 3:560-62; Influence of American biterature on, Sauer, 3 : 477-97; Problems and methods of modern history of literature, Minor, 3: 498-506.

Germanic philology, comparative, Problems in, Collitz, $3: 286-302$.
Germany, Bibliography of history of, 2 : 234-5. Giard, Alfred M., Present tendencies of morphology and its relation to the other sciences, $5: 258-82$.

Giddinos, Franklin H., Concepts and methods of sociology, 5 : 787-99.

Gilbert, G. K., Sciences of the earth, Chairman, 4: 477 .

Githens, Thomas S., tr., Hertwig, Advances and problems in the study of generation and inheritance, 5 : 288-307; tr., Verworn, Relation of physiology to other sciences, 5 : 40315 ; tr., Waldeyer, Relations of anatomy to other sciences, $3: 361-77$.

Gladden, Washington, Religious agencies, 8 : $330-43$.

Glasgow, William C., Otology and laryngology, Chairman, 6 : 449.

Goebel, Karl F., Fundamental problems of present-day plant morphology, 5 : 81-98.

Goethe, More light on the text of, Hatfield, $3: 507$.

Goldziher, Ignaz, Progress of Islamic science in the last three decades, $2: 497-517$.

Goold, Charles B, tr., Chabot, Professional training of teachers in France, 8 : 176-91.

Gorham, Frederick P., Production of light by bacteria, $5: 239$.

Gould, George M., New ophthalmology and its relatiou to general medicine, biology and sociology, $6: 422-45$.

Grammar, comparative, Relations to other branches of learning, Buck, $3: 32-52$.

Greece, ancient, Bibliography of history of, 2: 230; Bibliography of history of religion of, 2 : 655-56; History of, 2 : 55-108; $\bmod -$ ern, Bibliography of history of, $2: 237$.

Greek, Problems of, Humphreys, 3 : 162-72.

Greek art, see Classical art.

Greek history, Expansion of, Mahaffy, 2 : 56-88.

Greek language, 3: 129-74; Bibliography, 3: 304, 308-09; Relation to the psychology of the ancient Greeks, Smyth, 3: 131-61.

Greek literature, see Classical literature.

Greek sculpture, Some present problems in the history of, Tarbell, 3: 605-17.

Greene, Evarts B., History of America, Sec'y, 2: 171; Some aspects of colonial polities at the beginning of the eighteenth century, 2: 195 .

Gregory, Charles N., Some problems of international law, $7:$ 509-28.

Griffis, William E., History of religion, Chairman, $2: 431$.

Group theory, Bearing of several recent theorems, Miller, 1: 531 .

Gummere, Francis B., Relation of English literature to other sciences, $3: 401-14$.

Gynecology, 6: 389-408; Some fundamental problems, Webster, 6 : 389-407.

Haddon, Alfred C., Ethnology: its scope and problems, 5 : 549-67.

Hadley, Arthur T., Educational methods and principles in the nineteenth century, 8:19-26.

Hagar, Stansbury, Astronomical ritual of Peru, $5: 571$.

Hague, James D., Mining engineering and mining law, $6: 668$.

Hale, George E., Astrophysics, Chairman, 4 : 429.

- William G., Century of metaphysical syn$\operatorname{tax}, 3: 191-202$.

Hall, Charles C., Teaching of theology, 8 : 30113. 
Hall, Christopher W., Geophysics, Chairman, Hering, Carl, Electrical engineering, Sec'y, 4: 507.

G. Stanley, Unity of mental science, 5 : $577-89$.

- Thomas C., Philosophy of religion, Chair$\operatorname{man}, 1: 263$.

Halsted, George B., Bibliography of mathematics, 1: 623-26; Non-Euclidean spherics, 1: 587 ; tr., Darboux, Study of the development of geometric methods, $1: 535-58$; tr., Picard, On the development of mathematical analysis, 1 : 497-517; tr., Poincaré, Principles of mathematical physics, $1: 604-22$.

Hamlin, Alfred D. F., Bibliography on modern architecture, $3: 681$; Problems of modern architecture, $3: 638-49$; Sources of savage conventional patterns, $1: 448$.

Hammond, John H., Mining engineering, Chair$\operatorname{man}, 6: 633$.

- William A., Relations of logic to other disciplines, 1 : 296-312.

Hancock, Harris, Algebraic minimal surfaces, 1: 587 .

Hare, Hobart A., Bibliography on medicine, 6 : 527-28; Therapeutics and pharmacology, Chairman, $6: 153$.

Harlan, George C., Ophthalmology, Chairman, $6: 411$.

Harnack, Karl G. A., Relation between ecclesiastical and general history, 2 : 621-35.

Harness mound, Exploration of, Mills, 5 : 542.

Harper, Samuel N., Slavic literature, Sec'y, 3: 511; tr., Boyer, Russian and studies in Russian, $3: 520-28$.

Harper, Wm. R., Administrative Board, 1 : 4; Address, 1 : 31-33.

Harris, J. Arthur, Importance of investigation of seedling stages, $5: 98$.

- William T., Social culture in the form of education and religion, $8: 1-16$.

Harrison, James A., Iiterary vitalities, 3 : 31522.

Harry, J. E., Greek language, Sec'y, 3 : 129.

Hartmann, I., New method of measuring the stellar spectra, 4: 470 .

Haskell, M. W., Geometry, Chairman, 1 : 535; Reduction of any collineation to a product of perspective collineations, $1: 531$.

Haskins, Charles H., Medieval history, Chairman, $2: 111$.

Hatfield, James T., More light on the text of Goethe, $3: 507$.

Haupt, Lewis M., Present problems of technology, 6 : 571-90.

Hayes, E. L., Social psychology, Sec'y, 5 : 859.

Edward C., Human experiences and activities as natural phenomena, $5: 883$.

Health, Public, see Public health.

Hebbel as a literary critic, Hohlfeld, 3 : 507.

Hedrick, E. R., Generalization of the analytic functions of a complex variable, $1: 531$.

Heidel, William A., Significance' of the ópeocov in the Eleatic philosophy, $3: 173$.

Hektoen, Ludvig, Relations of pathology, 6 : 105-22.

Hellenism, Hutton, 3 : 173-74.

Heller, Otto, Ahasver in der Kunstdichtung, 3: 508; Germanic languages, Sec'y, 3: 273 .

Hempl, George, History of language, Chairman, $3: 3$.

Henderson, Charles R., Bibliography on the dependent group, $7: 876$; Definition of a social policy relating to the dependent group, 7: : 817-32

Hensel, Paul, Problems of ethics, 1 : 403-14.

$6: 605$.

Hernia, Treatment of 300 cases of, Pfister, $6: 386$.

Herrick, C. H., Animal morphology, Sec'y, $5: 243$; Dynamic character of morphology, $5: 283$.

C. L., Comparative method in psychology particularly in its physiological and anatomical relations, $6: 240$.

Robert, Belles-lettres, Chairman, 3 : 531.

Hertwig, Oskar, Advances and problems in the study of generation and inheritance, $5: 288$ 307; Bibliography on embryology, $5: 444$.

Hervey, Walter L., Bibliography on general religious education, 8: 469 ; How may the teaching of religion be made potent for morality? 8 : 282-93.

Hill, David J., Bibliography on diplomacy, 7; 452-53; Contemporary developmentof diplomacy, 7 : 369-83.

William, Agriculture, Sec'y, 6:715; Rural community, Sec'y, 7 : 725.

Hirsch, Emil G., Social aspects of religion, 8 : 440-4.5.

Hiss, P. H., Bacteriology, Sec'y, 5 : 207.

Historical science, 2:1-3: 681; Historical development and present character, Lamprecht, 2 : 111-24.

Historical synthesis, Colby, 2 : 153-68.

History, Bibliography, 2:229-38; Conceptions and methods of, Robinson, $2: 40-51$; Medieval, see Medieval history; Modern, see Modern bistory; Variety and unity of, Wilson, 2:3-20; Science of, in the nineteenth century, Sloane, 2 : 23-39.

History of religion, 2 : 431-661; Bibliography, 2:650-61; Fundamental conceptions and methods, Schmidt, $2: 443-64$; in the nineteenth century, Moore, $2: 432-42$.

Hobbs, William H., Suggestions regarding a petrographic nomenclature based on a quantitative classification, $4: 604$.

Höffding, Harald, Present state of psychology and its relations to neighboring sciences, $5: 627-36$.

Hoff, Jacobus H. Van't, Relations of physical chemistry to physics and chemistry, $4: 304-$ 10.

Hoffman, Frederick L., Life insurance as a science, $7: 207-35$.

Hohlfeld, A. R., Hebbel as a literary critic. $3: 507$.

Holgate, Thomas J., Geometry, Sec'y, 1 : 535.

Hollander, Jacob H., Scope and method of political economy, 8 : 57-67.

Holls, Fred'k W., Administrative Board, 1 : 4; Death of, $1: 18$.

Hoops, Johannes, Present problems of English literary history, $3: 415-32$.

Horne, H. H., The college, Sec'y, 8:119; Science of education, 8: 83-85.

Howard. George E., Bibliography on the family, 7: 871-72; Social control and the functions of the family, $\boldsymbol{\gamma}: 699-708$. Leland, O., Executive Secretary of the Congress, 1 : 23; Animal morphology, Chairman, $5: 243$.

Howell, William H., Problems of physiology of the present time, 5: 416-34.

Howison, George H., Philosophy: its fundamental conceptions and its methods, $1: 173-$ 94.

Hozumi, Nobushige, New Japanese civil code 
as material for the study of comparative jurisprudence, 2 : 367-416.

Huberich, C. H., History of common law, Sec'y, 2: 331 .

Hughes, Percy, tr., Rein, Place and office of pedagogy in the university, $8: 49-64$.

Hulbert, Eri B., History of the Christian church, Chairman, 2 : 621.

Human anatomy, $5: 359-91$; Bibliography, 5 : 440-41; Problems in, Donaldson, 5 : 37891; Relations of anatomy, Waldeyer, 5 : 36177.

Humphreys, W. J., Physics of the electron, Sec'y, $4: 121$.

- Milton W., Problems of Greek, 3 : 162-72.

Hunt, Reid, Physiology, Sec'y, 5 : 395; Relation of acute and chronic alcoholism to some other forms of poisoning, $6: 185$.

Huntington, F. V., Set of postulates for real algebra comprising postulates for a one dimensional continuum and for the theory of groups, 1 : 531.

Hurty, J. N., Dust, 6: 86; Preventive medicine, Sec'y, $6: 89$

Hutehinson, J. I., Uniformizing of algebraic functions, 1 : 531.

Hutton, Maurice. Hellenism, 3 : 173-74; Latin language, Chairman, $3: 17 \%$.

Hyde, William De W., Bibliography on the college, $8: 237$; The college, $8: 119-32$.

Hydrocarbons, Study of the sesquiterpene class, Schreiner, 4: 299.

India, Bibliography of history of, 2 : 230; Bibliography of history of religion of, $2: 653$; Relation of its religions to the science of religion, Oldenberg, 2 : 467-80.

Indian languages, Main problems in the field of, Macdonell, 3 : 111-25.

Indiana, Township govermment in, Fiske, 2 : 195.

Individualism vs. law, Thomas, $7: 653$.

Indo-European comparative philology, Bibliography, 3 : 302-05.

Indo-Iranian languages, 3 : 99-125; Bibliography, 3 : 303-04, 307.

Indo-Iranian literature, 3 : 357-66.

Industrial evolution, Certain psycholorical phases of, Ely, 7 : 800-13.

Industrial group, 7 : 789-813; Bibliography, 7 : 874; Sombart, 7 : 791-99.

Industrial revolution, Social tendencies, Taylor, $7: 682-94$

Inorganic chemistry, 4: 243-71; Bibliography, 4 : 352; Present problems, Ramsay, 4 : 25871; Relations with the other sciences, Moissan, $4: 243-57$.

Insurance, 7:203-52; Do governments regard life assurance from the right point of view? Alexander, 7: 252; Life insurance as a science, Hoffman, $7: 207-35$; Present problems, Meyer, $7: 236-52$.

Internal medicine, 6: 189-222; Problems, Thayer, $6: 210-22$.

International advisory congress, Trueblood $7: 549$.

International law, 7 : 483-549; Bibliography, $7: 654$; Legal nature of, Scott, 7: 485-93; Present and future state, La Fontaine, 7 : 494-508; Relations between Austria and Hungary, Apponyi, 7: 529-49; Some problems, Gregory, 7 : 509-28.

Introductory address, Newcomb, 1 : 135-47.

Investigator, Evolution of the scientific, Newcomb, 1 : 135-47.
Ionic theory, Physical properties of aqueous salt solutions in relation to, Noyes, $4: 311-$ 23

Islamic science in the last three decades, Goldziher, 2 : 497-517.

Italy, Bibliography of history of, $\boldsymbol{z}: 235-36$.

Ives, Halsey C., Bibliography on the history of art, 3: 679-80; History of art, Chairman, $3: 565$.

Jackson, Abraham V. W., Our interest in Persia and the study of her history, language, and literature, $3: 357-66$.

Edward, Relations of ophthalmology to other departments of science, 6 : 411-21.

Jacobi, Abraham, History of pediatries and its relation to other sciences and arts, $6: 498$ 526.

Janet, Pierre, Relations of abnormal psycho$\log y, 5: 737-53$.

Japan, Bibliography of history of, $2: 229$. Bibliography of history of religion of, 2 : 653 Cultivation of marine and fresh-water animals, Mitsukuri, 4: 694-729.

Japanese cattle in regard to tuberculosis, Kitasato, $7: 137-48$.

Japanese civil code as material for the study of comparative jurisprudence, Hozumi, 2 : $367-416$.

Jastrow, J., Relations of the urban community to other branches of social science, $7: 763$ 74.

Jefferson, Territory of, Paxson, 2 : 195.

Jenkins, T. A., tr., Meyer, Beginnings and progress of Romance philology, $3: 237-55$.

Jespersen, Otto, History of the English language, considered in its relation to other subjects, $3: 205-19$.

Jesse, R. H., Administrative Board, 1 : 4.

Jessen, K. D., Bibliography on the history of German literature, 3: 560-62; Germanic literature, Sec'y, $3: 477$.

Jewett, James R., Mohammedism, Chairman, 2 : 497 .

Jews, Bibliography of history of, $2: 230$.

Johnson, Emory R., Bibliography on economics, 7 : 253-56; Economics, Chairman, 7: 5-6.

Jones, Aaron, Rural community, Chairman, $7: 725$. - Breckenridge, member Committee on Congresses, $1: 4$.

- Edward D., Bibliography on commerce and exchange, 7 : 257; Manufacturer and the domestic market, 7 : 115-32.

Jordan, David S., Utilitarian sciences, 6 : 3-20. - Edwin O., Bibliography on bacteriology, 5 : 443; Relations of bacteriology to other sciences, 5 : 207-18.

Judaism, Bibliography of the history of, 2 : 654 . Judge, Thomas F., Divorce of religion and education as opposed to the principles of historical continuity, $8: 294-97$.

Judson, Harry P., Colonial administration, Sec'y, $7: 387$.

Jurisprudence, 7 : 457-657; Bibliography, 7 : 654-56; Development during the past century, Beale, 7 : 470-81; Fundamental ideas and conceptions, Needham, $7: 459-69$; Legislation and, Freund, $7: 619-35$.

Kahlenberg, Louis, On the relation between the processes of solution, chemical action and osmosis, $4: 324$.

Kakuzo, Okakuro, Modern problems in painting, $3: 663-78$. 
Kapteyn, Jacobus C., Statistical methods in stellar astronomy, 4 : 396-425.

Karsten, Gustav E., Germanic languares, Chairman, $3: 273$.

Kasner, Edward, Present problems in geometry, $1: 559-86$.

Keller, Albert G., Value of the study of colonies from a sociological standpoint, $7: 416$.

Kelly, Howard A., Gynecology, Chairman, $6: 389$.

Kelso, James A., Old Testament, Sec'y, 2 : 537.

Kennelly, Arthur E., Relations of electrical engineering to other branches of engineering, 6 : $605-16$.

Keppel, F. P., tr., Enlart, Relations of modern architecture to the study of other periods of the art, $3: 622-37$.

Kimball. Arthur L., Relations of the science of physics of matter to other branches of learning, 4 : 69-86.

King, Henry C., Bibliography on religion, 8 : 468; Fundamental nature of religion, 8: 243-55; Primacy of the person in college education, 8 : 151-55.

Kirchwey, George W., Bibliography on jurisprudence, $7: 654-56$; Jurisprudence, Chairman, $7: 459$.

Kirkland. J. H., Religious influence: personal, Chairman, 8: 395-96.

Kitasato, Shibasaburo, Behavior of native Japanese cattle in regard to tuberculosis, 6 : $137-48$.

Kittredge, George I., Present problems in the study of the English language, $3: 220-33$.

Knapp, Charles W., member Committee on Congresses, $1: 4$.

Kriehn, George, tr., Muther, Problems of the study of modern painting, 3: 653-62; tr., Seler, Problems of archeology, 5 : 527-41.

Labor, Application of scientific methods to its economic utilization, Gantt, 6: 602 .

I.add, George T., Development of philosophy in the nineteenth century, 1: 194-223.

La Fontaine, Henri, Present and future state of international law, $z$ : 494-508.

Lamprecht, Karl G., Historical development and present character of the science of history, 2 : $111-24$

Landrith, Ira,Religious agencies,Sec'y, 8 : 329; Religious educational agencies, $8: 359-60$.

Langevin, Paul, Relations of the physies of electrons to the other branches of science, 4: $121-56$.

Langsdorf, A. S., The school, Sec'y, 8: 89.

Language, Bibliography of history of, $3: 303-$ 11; Comparative, see Comparative language; Fundamental conceptions and methods of its history, Lounsbury, 3:3-16; History of, 3:1-311; Progress of its history during the last century, Wheeler, $3: 17-28$.

Larnaude, Ferdinand, Bibliography on constitutional law, $7: 657$; Separation of powers and judiciary in France and the United States, $7: 602-15$.

Laryngology, $6: 449-72$; Relations of laryngology, rhinology and otology with other arts and sciences, Semon, $6: 449-72$.

Latin, Relations of, Sonnenschein, 3: 177-90.

Latin language, 3 : 177-202; Bibliography, 3: 304-05, 310; Century of metaphysical syntax, Hale, 3 : 191-202.

Latin literature, see Classical literature.

Laughlin, James L., Present monetary pro- blems, 7 : 161-75; Transportation, Chairman, $7: 71$.

Law, see also Jurisprudence; Bibliograplyy of history of, 2 : 426-27; Common, see Common law; Comparative, see Comparative law; Constitutional, see Constitutional law; History of, 2 : 241-427; History of, McClain, 2 : 241-70; Individualism vs. law, Thomas 7 : 653; International, see International law; Private, see Private law; Roman, see Roman law.

Lawson, John D. History of common, law, Chairman, 2 : 331 .

Layman, The trained, Sanders, 8: 306-17.

Learned, M. D., German impulse in American literature before $1800,3: 507-08$.

Lederle, Ernst J., Public health; its present problems, 6 : 68-85.

Lee, T. G., Embryology, Sec'y, $5: 287$.

Lefevre, George, Artificial parthenogenesis in Thalassema mellita, $5: 356$.

Legislation, Jurisprudence and, Freund, 7 : 619-35.

Lehmann, Fred'k W.. Chairman Committee on Congresses, $1: 4$; Address, $1: 39$.

Lehnerts, E. M., Geophysics, Sec'y, 4 : 507.

Leon, Maurice, tr., La Fontaine, Present and future state of international law, 7 : 494-508; tr. Larnaude, Separation of powers and judiciary in France and the United States, 7: 602-15.

Leucocytes, Finlay, $6: 149$.

Leuschner, A. O., On the general applicability of the short method of determining orbits from three observations, $4: 426$.

Lévi, Sylvain, Transformation of Sanskrit studies in the course of the nineteenth century, $3: 99-110$.

Lewis, William D., Private law, Sec'y, y: 619.

Library, The, 8: 195-229; Bibliography, 8 : 232-3; Its past and future, Biagi, 8 : 216-29; The library, Crunden, 8: 195-202; Relations to knowledge and life, Axon, 8 : 203-15.

Liebreich, Oscar, Relation of therapeutics to other sciences in the nineteenth century, 6 : 153-69.

Light, Production of, by bacteria, Gorham, 5: 239 .

Light of the stars, Pickering, 4 : 374-84.

Linear associative algebra, Shaw, $1: 531$.

Literary studies during the nineteenth century, Development, Gayley, $3: 323-53$.

Literary vitalities, Harrison, 3 : 315-22.

Literature, Bibliography of hist.ory of, 3 : 55862; History of, $3: 315-562$.

Lloyd, Francis E., Plant morphology, Sec'y, 5: 61 ; tr., Goebel, Fundamental problems of present-day plant morphology, 5 : 81-98; tr., Wiesner, Plant physiology under the influence of the other sciences, $5:$ 103-24.

Loeb, Jacques, Recent developments of biology, 5 : 13-24.

Logic, 1: 295-330; Bibliography, 1: 451; Field of, Woodbridge, 1 : 313-30; Relations to other disciplines, Hammond, 1 : 296-312.

Lounsbury, Thomas R., Fundamental conceptions and methods of the history of language, 3 : 3-16.

Lovejoy, A. O., Metaphysics, Sec'y, 1 : 227.

Lowell, Abbott L., Social regulation, 7 : 26375.

621

Lunar theory, On the completion of the solution of the main problems, Brown, 4:426 
Lyon, E. P., On the theory of rheotropism in free swimming animals, $5: 434$.

Mabie, Henry C., Bibliography on religious work, 8: 472; Elements in Christianity which adapt it to be the universal and absolute religion, $8: 376-92$.

MeClain, Emlin, Bibliography on the history of law, 2 : 426; History of law, 2 : 241-70.

MeClintock, Emory, Insurance, Chairman, 7: 203-06.

McCurdy, James F., Old Testament science, 2: $537-50$.

MacdonaId, Duncan B., Poetry of Arabia and the ballad problem, 3: 95-96; Problems of Muhammadanism, 2 : 518-34.

Macdonell, Arthur A., Bibliography on IndoIranian languages, 3: 307; Main problems in the field of Indian languages, 3:11125 .

MacDougall, Robert, Relations of experimental psychology to other branches of science, $5: 655-73$.

MeFadyen, John E., Bibliography on personal religious influence, 8 : 473 ; Personal religious influence, 8 : 404-09.

Macfarlane, Alexander, On the exponential notation in vector analysis, $1: 622$.

McGee, W J, Anthropology and its larger problems, 5 : 449-67.

McKim, Charles F., Modern architecture, Chairman, $3: 621$.

IcMahon, James, On the use of $\mathrm{N}$-fold Rieman spaces in applied mathematics, $1: 622$.

McMurrich, James P., Comparative anatomy, Chairman, $5: 323$.

Mahaffy, John P., Expansion of Greek history, 2: 56-68.

Mallet, John W., Inorganic chemistry, Chairman, $4: 243$.

Mallinckrodt, Edward, Diet, physical condition and mental performance of certain students in Harvard university, $4: 351$.

Manning, H. P., Representation of complex variables in space of four dimensions, $1: 587$.

Manouvrier, Léonce, Individuality of anthropology, 5: 485-97.

Manufacturer and the domestic market, Jones, z: 115-32.

March, Francis A., Comparative language, Chairman, $3: 31$.

Marine and fresh-water animals in Japan, Cultivation of, Mitsukuri, 4 : 694-729.

Market, Manufacturer and the domestic market, Jones, 7 : 115-32.

Markets, Foreign, Plehn, 7 : 133-47.

Marshall, Heury R., Relation of æsthetics to psychology and philosophy, 1: 417-33.

Marvin, Walter T., tr., Erdmann, Content and validity of the causal law, $1: 353-88$.

Maschke, Heinrich, On the present problems of algebra and analysis, $1: 518-30$.

Mathematical physics, Principles of, Poincaré, 1: $604-22$

Mathematics, 1 : 455-626; Applied, see Applied mathematics; Bibliography, 1 : 623-6; Fundamental conceptions and methods, Bôcher, 1: 456-63; in the nineteenth century, Pierpont, 1: 474-93.

Mathews, Joseph M., Preventive medicine, Chairman, $6: 89$.

Matter, Physies of, see Physics of matter.

Matthews, Brander, Present problems of belleslettres, $3: 545-57$.

Maxwell, William H., Bibliography on the school, 8:236; Present problems of the school, $8: 102-15$.

Maya rites in Yucatan and Chiapas, Tozzer, $5: 571$.

Mechanical engineering, 6 : 593-602; Relations to other branches of science, Smith, 6 : $593-602$.

Medical science, Modern conceptions and methods, Councilman, $6: 23-40$.

Medicine, 6 : 23-50; Bibliography, 6 : 527-31; Development of modern, Billings, $6: 41-50$; Historical relations with surgery, Allbutt, 6 : 189-209; Internal, see Internal medicine; Preventive, see Preventive medicine.

Medieval history, 2 : 111-38; Bibliography, 2 : 231; Present problems, Adams, $2: 125-38$.

Mental science, 5: 577-888; Unity of, Hall, $5: 577-89$.

Merriam, Charles E., Political theory and national administration, $\operatorname{Sec}^{\prime} y, 7: 309$.

Metaphysics, 1 : 227-60; Bibliography, 1: 450; Present problems of, Ormond, 1: 246-58; Relations with the other sciences, Taylor, 1 : $227-45$

Meteorology, Bibliography, 4: 764; Present problems, Rotch, 4: 741-49; Relations to other sciences, Arrhenius, 4: 733-40.

Methodology of science, 1:333-88; Bibliography of, $1: 451$.

Metzer, S. J., Physiology, Chairman, 5 : 395402 .

Mexico, Bibliography of history of, $2: 238$.

Meyer, Adolf, Abnormal psychology, Sec'y, $5: 737$.

- Balthasar H., Present problems in insurance, 7 : 236-52.

Max, Esthetics, Sec'y, $1: 417$.

- Paul, Beginnings and progress of Romance philology, 3 : 237-55.

Micro-organisms, pathogenic, Some problems in their life-history, Smith, $5: 219-38$.

Milk, Plea for twelve-hour, Reynolds, $6: 86$. Mill, Hugh R., Present problems of geography, 4: $653-70$.

Miller, Adolph C., Economic science in the nineteenth century, 7: 21-44.

- G. A., Bearing of several recent theorems on the group theory, $1: 531$.

W. MeN., Pathology, Sec'y, 6 : 105

Millikan, R. A., Physics of matter, Sec'y, 4:69; Relations between radio-activity and the uranium content of certain minerals, $4: 187$.

Mills, William C., Archeology, Sec'y, 5: 513; Explorations of the Harness mound, 5 : 542.

Milner, W. S., The á $\mu \alpha \rho \tau i \alpha$ of Aristotle's Poeties, $3: 398$.

Mineralogy, 4:589-604; Bibliography, 4: $760-61$.

Minimal surfaces, Algebraic, Hancock, 1 : 587. Mining engineering, 6: 633-68; and mining law, Hague, 6: 668; Relations to other fields, Richards, 6 : 633-43.

Mining engineers, Present problems in the training of, Christy, $6:$ : 644-68.

Mining law, Mining engineering and, Hague, $6: 668$.

Ministry, Qualifications and training for, Stewart, 8: 317.

Minor, Jacob, Problems and methods of modern history of literature, $3: 498-506$.

Mitsukuri, $K$., Cultivation of marine and freshwater animals in Japan, 4:694-729.

Modern history, Bibliography, 2: 232-38; in the perspective of knowledge, Bury, 2 : 141-52. 
Modern history of Europe, 2 : 141-68.

Mohammedism, 2: 497-534; Problems, Macdonald, 2 : 518-34.

Moissan, Henri, Inorganic chemistry: its relations with the other sciences, 4 : 243-57.

Monastic towns, Communication relative to, Trenholme, $2: 138$.

Money and credit, $7:$ 151-75; Bibliography, 7: 254, 258; Our monetary equilibrium, White $7:$ : 151-60; Present monetary problems, Laughlin, 7 : 161-75.

Montague, W. P., Philosophy of religion, Sec'y, 1 : 263; Physical reality of secondary qualities, $1: 259-60$.

Moore, Clarence B., Aboriginal urn-burial within the limits of the United States, 5: 542 .

E. H., Algebra and analysis, Chairman, 1: 497 .

- Edward C., Secular life as the expression of the religious spirit, $8: 446-56$.

F. G., Classical literature, Sec'y, $3: 369$; Rhythm in the philosophical works of Cicero, 3 : 398 .

- Frederick W., Social structure, Chairman, 5: 815 .

- George F., member Committee on Plan and Scope, 1: 7; History of religions in the nineteenth century, $2: 432-42$; Semitic languages, Chairman, 3: 69 .

- John Basset, member Committee on Plan and Scope, $1: 7$.

Morgan, Conway L., Relations of comparative and genetic psychology to other branches of science, $5: 696-711$.

Morgan, J. L. R., tr., Cohnheim, Problems in nutrition, $4: 327-34$.

Thomas H., Phylogeny, Chairman, $5: 27$.

Morphological conceptions, Development of, Coulter, 5 : 3-12.

Morphology, Animal, see Animal morphology; Dynamic character of, Herrick, 5:283; Plant, see Plant morphology.

Moses, Bernard, Bibliography on colonial administration, 7 : 456; Control of dependencies inhabited by the less developed races, $7: 387-98$.

Mosquito reduction, Logical basis of the sanitary policy, Ross, $6: 89-102$.

Moulton, F. R., Role of celestial mechanics in astronomy, $4: 426$.

Münsterberg, Emil, Bibliography on the dependent group, 7: 875; Problem of poverty, $7: 833-47$.

- Hugo, member Committee on Plan and Scope, 1: 7; First Vice-President of Congress, 1: 12; Scientific plan of the Congress, 1 : 85-134.

Muhammadanism, see Mohammedism.

Mullins, Edgar Y., Religious agencies, Chairman, $8: 329$.

Municipal administration, 7: 417-50;. Problems of, Addams, 7 : 434-50; Relations of, Shaw, 7: 419-33.

Municipal government, Elements of improvement in, Bruns, $7: 450$.

Munroe, Charles E., Relations of technical chemistry to other sciences, $6: 671-85$.

Murray, Sir John, Bibliography on oceanography, 4: 763; Relation of oceanography to the other sciences, $4: 683-93$.

Muther, Richard, Problems of the study of modern painting, 3 : 653-62.

National administration, Bryce, 7 : 339-52.

Naval observatory in Tutuila, Chester, $4: 426$.
Nazorean (Nazarene), Meaning of the epithet, Smith, 2: 616-17.

Needham, Charles W., Fundamental ideas and conception of jurisprudence, 7 : 459-69.

-J. G., Contribution of animal morphology to education, $5: 283-84$.

Nef, J. Ulric, On the fundamental conceptions underlying the chemistry of the element carbon, $4:$ : 195-220.

Nerincx, Alfred, Latest organization of popular sufirage, $2: 417-25$.

Netherlands, Bibliography of history of, $\mathbf{z}$ : 236.

Neurology, 6:225-40; Value of the physiological principle in the study of, Putnam, 6: 225-40.

New Testament, 2: 567-617; Bibliography, 2: 659-61; N. T. science, Relations to kindred sciences, Bacon, 2: 569-84; N. T. study, Present problems, Burton, 2 : 585615; N. T. thought, Contributions of Alexandrianism to, Sheldon, 2:649.

Newcomb, F. C., Plant physiology, Sec'y, $5: 101$. - Simon, member Committee on Plan and Scope, 1: 7; President of Congress, 1 : 12; Evolution of the scientific investigator, 1: 135-47.

$\mathrm{N}$-fold Rieman spaces in applied mathematics, McMahon, 1: 622 .

Nichols, Edward L., Fundamental conceptions of physical science, $4: 18-28$.

Nipher, Francis E., Cosmical physics, Chairman, 4: 733; Present problems in the physics of matter, $4: 87-101$.

Noble, G. H., Gynecology, Sec'y, 6 : 389.

Normative science, Royce, $1: 151-68$.

Norton, J. P., History of economic institutions, Sec'y, z: 199.

Noyes, Arthur A., Physical properties of aqueous salt solutions in relation to the ionic theory, $4: 311-23$.

William A., Present problems of organic chemistry, 4 : 285-99.

Nutrition, Problems in, Cohnheim, $4: 327-34$.

Obstetrics and gynecology, Some fundamental problems, Webster, $6: 389-407$.

Oceanography, 4: 683-729; Bibliography, 4:763; Relations to the other sciences, Murray, 4 : 683-93.

Oertel, Hanns, Some present problems and tendencies in comparative philology, $3: 53-65$.

old Testament, 2 : 537-63; Old Testament science, McCurdy, 2 : 537-50; Relations to the allied departments and to science in general, Budde, 2 : 551-63.

Oldenberg. Hermann, Bibliography on Brahmanism and Buddhism, 2:657; Relations of the religions of ancient India to the science of religion, $2: 467-80$.

Oldham, Henry Y., Relative value of geographical position, 4:671-80.

Opening Ceremonies of the Congress, 1 :2533.

Ophthalmology, 6: 411-45; Relation to general medicine, biology and sociology, Gould, 6: $422-45$; Relations to other departments of science, Jackson, 6 : 411-21.

Orbits, Applicability of the short method for determining from three observations, Leuschner, $4: 426$.

Organic chemistry, 4:275-99; Bibliography 4: 353 ; Present problems, Noyes, $4: 285-$ 99; Relations to other sciences, Stieglitz, 4 : 276-84. 
Origin of species, Problem of, Whitman, 5:| Petrography and its related sciences, Relations 41-58.

between, Zirkel, $4: 591-603$.

Ormond, Alexander T., Present problems of Petrology and mineralogy, 4: 589-604; Bibliometaphysics, 1: 246-58; Some roots and factors of religion, $1: 289-90$.

Orth, Johannes, Morphology of cancer and the parasitic etiology, 6: 382-86; Relation of pathology to other sciences, $6: 123-36$.

Osborn, Henry F., Present problems of paleontology, $4: 566-85$.

Osler, William, Medicine, Chairman, $6: 23$.

Osmosis, On the relation between the processes of solution, chemical action and, Kahlenberg, $4: 324$.

Ostwald, Wilhelm, On the theory of science, 1: $333-52$.

Otology and laryngology, $6: 449-72$; Relations with other arts and sciences, Semon, $6: 441$ 72.

Oxyrhynchus sayings, Votaw, $2: 616$.

Pace, Edward A., Experimental psychology, Chairnian, $5: 655$.

Painting, Modern, 3 : 653-78; Problems in, Kakuzo, 3:663-78; Problems of the study of, Muther, $3: 653-62$; Some consideration of one system of instruction, Coffin, $3: 678$.

Pais, Ettore, Problems in Roman history, $2: 69-85$.

Paleontology, 4: 551-85; Present problems, Osborn, 4: 566-85; Relations to other branches of science, Woodward, $4: 551-65$.

Palmer, George H., Ethics, Chairman, 1 : 391.

Parthenogenesis, artificial, in Thalassema mellita, Lefevre, 5 : 356.

Pathogenic micro-organisms, Some problems in their life-history, Smith, $5: 219-38$.

Pathology, 6 : 105-49; Bibliography, $6: 122$; Plant, see Plant pathology; Relations of, Hektoen, 6: 105-22; Relation to other sciences, Orth, 6: 123-36; Vegetable pathology an economic science, Waite, $5: 165-73$.

Patten, Jane, tr., Drude, Position of ecology in modern science, $5:$ 177-90.

- Simon N., Present problems in the economic interpretation of history, $2: 215-28$.

Patterns, Sources of savage conventional, Hamlin, 1 : 448.

Paxson, Frederic L:, Territory of Jefferson: a spontaneous commonwealth, 2: 195.

Peabody, Francis G., Expansion of religion, $8: 256-67$.

Pedagogy, see Educational theory; Place and office of in the university, Rein, 8:49-63.

Pediatrics, 6 : 475-526; Foundations and aims, Escherich, 6 : 477-97; History of and its relations to other sciences and arts, Jacobi, 6 : 498-526.

Penck, Albrecht, Relation of physiography to the other sciences, $4: 607-26$.

Perkins, James B., Modern history of Europe, Chairman, 2 : 141

Perrine, Charles D., Some total solar eclipse problems, $4: 470$.

Perry, Edward D., Present problems of the university, $8: 159-75$.

- R. B., Bibliography of philosophy, 1: 449-52; Methodology of science, Sec'y, 1: 333 .

Persia, Bibliography of the history of religion of, 2 : 653; Study of her history, language, and literature, Jackson, $3: 357-66$.

Peru, Astronomical ritual of, Hagar, 5 : 571.

Petrographic nomenclature based on the quantitative rlassification, Hobbs, $4: 604$.

Pfister, Carl, Treatment of 300 cases for hernia, 6 : 386.

Pfleiderer, Otto, Relation of the philosophy of religion to the other sciences, $1: 263-74$.

Pharmacology, 6 : 153-85.

Philippovich, Eugen V., Transportation, 7 : 7194

Philology, comparative, Some present problems and tendencies. Oertel, $3: 53-65$

Philosophical outlook, Bowne, 1: 171-72.

Philosophy, 1: 171-452 ; Bibliography, 1 : 449-52; Development in the nineteenth century, Ladd, 1 : 194-223; Fundamental conceptions and methods, Howison, 1 : 173-94.

Philosophy of religion, 1 : 263-91; Bearing of certain aspects of the newer psychology, French, 1: 290-91; Bibliography, 1: 451; Main problems, Troeltsch, 1 : 275-88; Relation to the other sciences, Pfleiderer, 1 : 263-74.

Phonetic conference to adopt a universal alphabet, Stein, $3: 66$.

Photography, Relations to astrophysics, Turner, $4: 429-45$.

Phylogeny, $5: 27-58$.

Physical chemistry, 4:303-24; Application to agricultural chemistry, Cameron, $4: 324$; Bibliography, 4: 352; Relations to physics and chemistry, Van't Hoff, 4: 304-10.

Physical reality of secondary qualities, Montague, $1: 259-60$.

Physical science, 4: 1-5: 573 ; Fundamental concepts, Nichols, 4:18-28; Unity of, Woodward, $4: 3-14$.

Physics, $4:$ 17-189; Bibliography, 4 : 188-89; Cosmical, see Cosmical physics; Principles of mathematical physics, Poincaré, 1 : 60422; Progress in the nineteenth century, Barus, $4: 29-65$.

Physics of ether, $4: 105-117$.

Physics of matter, 4: 69-101; Present problems, Nipher, 4: 87-101; Relations to other branches of learning, Kimball, $4: 69-86$.

Physics of the electron, $4: 121-87$; Relations to other branches of science, Langevin, 4: $121-56$

Physiographic problems of to-day, Russell, $4: 627-49$.

Physiography, 4:607-49; Bibliography, 4 : 626, 762; Relations to the other sciences, Penck, 4 : 607-26.

Physiological chemistry, 4:327-51; Bibliography, 4:355; Present problems, Chittenden, $4: 335-50$.

Physiology, 5 : 395-434; Bibliography, 5 : 441-42; Domain and relation to medicine. Metzer, 5 : 395-402; Plant, see Plant physiology; Problems of the present time, Howell, 5 : 416-34; Relation to other sciences, Verworn, 5 : 403-15.

Picard, Charles E., On the development of mathematical analysis and its relations to some other sciences, 1 : 497-517.

Pickering, Edward C., Light of the stars, 4: 374-84.

Pierpont, James P., History of mathematics in the nineteenth century, $1: 474-93$.

Piersol, George A., Human anatomy, Chairman, 5 : 359-60.

Plant pathology, 5 : 147-73; History and scope, Arthur, 5 : 149-64. 
Plant physiology, 5: 101-44; Development under the influence of the other sciences, Wiesner, 5: 103-24; Present problems, Duggar, 5 : 125-44.

Plant morphology, 4:61-98; Bower, 5:6180; Problems of the present day, Goebel, $5: 81-98$.

Plehn, Carl C., Foreign markets, 7 : 133-47.

Plutarch as a comparative biographer, Ferguson, $2: 108$.

Poincaré, Jules H., Principles of mathematical physics, $1: 604-22$.

Points of inflection of a plane cubic and their harmonic polars, Emch, 1:587.

Political and economic history, 2 : 23-238.

Political economy, Scope and method of, Hollander, $7:$ : 57-67.

Political theory and national administration, 7 : 307-52; Political philosophy, Willoughby, 7 : 309-25; Problems of political theory, Wilson, 7 : $326-38$.

Politics, 7 : 277-306; Bibliography, 7 : 451; Fundamental conceptions and methods of, Dunning, 7\% : 279-92; Tendencies of the world's politics during the nineteenth century, Andrews, $7:$ : 293-306.

Pollard, Edward B., Religion and personality, 8: 417-26.

Pope, Jesse E., Economic theory, $7: 47$.

Popular suffrage, Latest organization Nerincx, 2 : 417-25.

Porter, M. B., On the functions defined by an infinite series of analytic functions of a complex variable, $1: 531$.

Poverty, Problem of, Münsterberg, 7 : 833-47.

Prescott, Albert B., Organic chemistry, Chairman, $4: 275$.

Press as a religious agency, Buckley, $8: 336-$ 50.

Preventive medicine, $6: 89-102$.

Price, W. H., tr., Sombart, Industrial group, $7: 791-99$

Primacy of the person in college education, King, 8 : 151-55.

Prince, Morton, Bibliography on abnormal psychology, $5: 780-81$; Some of the present problems of abnormal psychology, $5: 754$ 74.

Pritchett, Henry S., Administrative Board, $1: 4$.

Private law, $7: 617-53$; Bibliography, 7 : 655-56; Doctrine of stare decisis, Whitney, 7:636-53; Jurisprudence and legislation, Freund, $7: 619-35$.

Programme and list of speakers, 1 : 45-84.

Psychiatry, 6 : 243-304; Bibliography, 6 : 529; Problems in its functional psychoses, Cowles, 6 : 262-304; Relations to other sciences, Dana, $6: 243-61$.

Psychology, 5, 593-781; Abnormal, see Abnormal psychology; Bibliography, 5 : 623 , 776-81; Bearing of certain aspects on the philosophy of religion, 1 : 290-91; Comparative and genetic, see Comparative and genetic psychology; Comparative method in its physiological and anatomical relation, Herrick, 6 : 240; Conceptions and methods of, Cattell, 5 : 593-604; Experimental, see Experimental psychology; General, see General psychology; Genetic, see Comparative and genetic psychology; Greek language in its relation to the psychology of the ancient Greeks, Smyth, $3: 131-61$; History of, Baldwin, 5:605-23; Present state and its relations to neighboring sciences, Höffding, 5:
627-36; Psychology and the theory of knowledge in the science of religion, Troeltsch, 1 : 275-88; Social, see Social psychology.

Public finance, 7 : 179-200; Pending problems, Seligman, 7 : 190-200; Relation to allied sciences, Adams, $7:$ 179-89.

Public health, 6 : 53-86; Its present problems, Lederle, 6 : 68-85; Relation to other sciences, Sedgwick, $6: 55-67$.

Puffer, Ethel D., tr., Dessoir, Fundamental questions of contemporary asthetics, 1 : 43446 ; tr., Furtwaengler, Classical archeology and its relations to the allied sciences, 3 : 591-604.

Pupin, Michael I., Electrical engineering problems of the time, $6: 617-30$.

Putnam, Herbert, Administrative Board, 1 : 4. - James J., Value of the physiological principle in the study of neurology, $6: 225$ 40.

- Frederic W., Anthropology, Chairman, 5 : 449; Bibliography on anthropology, 5 : $572-73$.

Radio-activity, Present problems, Rutherford, 4:157-86; Relation to the uranium content of certain minerals, Millikan, $4: 187$.

Rajna, Pio, Evolution of Romance medieval literature in the nineteenth century, $3: 435-$ 57.

Ramsay, Sir William, Present problems of inorganie chernistry, $4: 258-71$.

Ratzenhofer, Gustav, Problems of sociology, $5: 815-24$

Rein, Wilhelm, Bibliography on educational theory, $8: 234$; Place and office of pedagogy in the university, 8:49-63.

Reinsch, Paul S., Bibliography on colonial administration, 7 : 454-55; Problems of colonial administration, 7 : 399-416.

Religion, $8: 240-473$; ancient, Bibliography of history of, $2: 651-56$; Bibliography, 8 : 468-73; Divorce of religion and education as opposed to the principles of historical continuity, Judge, 8: 294-97; Expansion of, Peabody, 8: 256-67; Fundamental nature of, King, $8: 243-55$; History of, see History of religion; Philosophy of, see Philosophy of religion; Relations of the religions of ancient India to the science of religion, Oldenberg, 2 : 467-80; Religion and personality, Pollard, 8:417-26; Social aspect, Hirsch, $8: 440-45$; Social culture in the form of, Harris, 8: 1-16; Some roots and factors of, Ormond, 1 : 289-90.

Religious agencies, 8:328-60; Gladden, 8 : 330-43.

Religious education, general, 8 : 271-97; Bibliography, $8: 468-73$; How may the teaching of religion be made potent for morality? Hervey, 8 : 282-93; Reasons and functions, Coe, $8: 271-81$; Religious education without doctrines and scriptures, Starbuck, $8: 294$.

Religious education, professional, 8 : 299-326; Some phases of, Willett, $8: 326$; Teaching of theology, Hall, 8:301-13; the trained layman, Sanders, 8 : 314-25.

Religious educational agencies, Itandrith, 8: 359-60.

Religious influence, personal, $8: 394-426$; Bibliography, 8 : 469; Black, 8: 397-403; Eliot, 8 : 410-16; McFadyen, 8 : 404-09.

Religious influence, social, $8: 427-67$; Strong, 8: 457-67; Secular life as the expression of the religious spirit, Moore, $8: 446-56$. 
Religious work, 8:362-92; Bibliography, 8: 469; Tomkins, $8: 365-75$.

Réville, Jean, Progress of ecclesiastical history during the nineteenth century, 2 : 636-48.

Reynolds, Arthur R., Plea for twelve-hour milk, $6: 86$.

Rheotropism, Theory of, in free swimming animals, Lyon, 5 : 434.

Rhinology, otology, and laryngology, Relation with other arts and sciences, Semon, $6: 449-$ 72.

Ricco, A., On the distribution of the solar phenomena, $4: 470$.

Richards, Robert H., Relation of mining engineering to other fields, $6: \mathbf{6 3 3}-43$.

Richardson, Rufus B., Classical art, Chairman, 3:591; Fundamental conceptions and methods in the study of the history of art, 3: $565-76$.

Rieman spaces, $\mathrm{N}$-fold, in applied mathematics, McMahon, $1: 622$.

Ripley, William Z., Problems of transportation, 7 : 95-112.

Ritter, William E., Bibliography of comparative anatomy, $5: 445-46$; Place of comparative anatomy in general biology, $5: 323-$ 35.

Robbins, Reginald C.. Brahmanism and Buddhism, Sec'y, $2: 467$.

Robinson, Benjamin L., Problems of ecology, $5:$ 191-203.

- James H., Conceptions and methods of history, 2 : $40-51$.

Rogers, Howard J., Director of Congresses, 1 : 4; Editor of the Proceedings, 1: 40; History of the congress, $1: 1-44$.

Roman history, Problems in, Pais, 2 : 69-85.

Roman law, History of, 2 : 291-328; Relations to other historical sciences, Buckler, 2: 291-314.

Roman legal history, Smith, 2 : 315-28.

Romance languages, $3: 237-70$.

Romance literature, 3 : 435-73; Evolution of the study of Romance medieval literature in the nineteenth century, Rajna, $3: 435-57$; Present problems, Fortier, 3: 458-73.

Romance philology, Beginnings and progress, Meyer, 3 : 237-55; Bibliography, $3: 311$; Present problems, Todd, $3: 256-70$.

Rome. Bibliography of history of, $2: 230-31$; Bibliography of history of religion of, $2: 656$.

Ross, Edward A., Bibliography on social psychology, 5: 887 ; ' Present problems of social psychology, 5 : 869-82.

Ross, Ronald, Logical basis of the sanitary policy of mosquito reduction, 6 : 89-102.

Rotch, Abbott L., Bibliography on meteoro$\operatorname{logy}, 4: 764$; Present problems of meteorology, $4: 741-49$.

Thomas M., Pediatrics, Chairman, 6 : 47576.

Royce, Josiah, General psychology, Chairman, 5: 627; Sciences of the ideal, 1 : 151-68.

Rural community, 8: 723-60; Present problems in social science, Stahl, $7: 760$; Relations to other branches of social science, Weber, 7 : 725-46; Social problems of American farmers, Butterfield, $7: 747-60$.

Russell, Israel C., Geography, Chairman, 4 : 653; Physiographic problems of to-day, $4: 627-49$.

Russia, Bibliography of history of, $2: 236$.

Russian and studies in Russian, Boyer, 3: 520-8.

Rutherford, Ernest, Present problems of radioactivity, 4 : 157-86.
Sadler, Michael E., Bibliography on the school, $8: 235$; The school in its relation to social organization and to national life, $8: 89-101$. Sadtler, Samuel P., Flameless wood, $6: 700$.

Salisbury, R. D:, Geography, Sec'y, 4 : 653; Geology, Sec'y, 4 : 525:

Sampson, John A., Importance of an early diagnosis in cancer of the uterus, $6: 408$.

Sanders, Frank K., Professional religious education: the trained layman, $8: 314-25$.

Sanford, Edmund D., Comparative and genetic psychology, Chairman, 5 : 693-95.

Sanskrit studies in the nineteenth century. Lévi, 3 : 99-110.

Sauer, August, Influence of American literature on German literature, 3: 477-97.

Saunders, T. B., tr., Harnack, Relation between ecclesiastical and general history, 2 : 621-35.

Saville, Marshall H., Archeology, Chairman, $5: 513$.

Scandinavia, Bibliography of history of, 2 : 236.

Schmidt, Nathaniel, Bibliography of history of religion, $2: 650-56$; Fundamental conceptions and methods of the history of religion, 2 : 443-64.

Schofield, William H., Relations of belleslettres, $3: 531-44$.

Sehool, 8 : 89-115; Bibliography, 8 : 230-31; Present problems, Maxwell, 8: 102-15; Relation to social organization and to national life, Sadler, 8 : 89-101.

Schouler, James, History of America, Chairman, 2 : 171.

Schreiner, Oswald, Study of the sesquiterpene class of hydrocarbons, $4: 299$.

Schroers, John, member Committee on Congresses, $1: 4$

Schwill, Ferdinand, Modern history of Europe, Sec'y, 2 : 141.

Science, Methodology of, 1:333-88; On the theory of, Ostwald, $1: 333-52$

Sciences, Classification of, Münsterberg, 1 : 99-127.

Sciences of the earth, $4: 477-764$.

Sciences of the ideal, Royce, 1 : 151-68.

Scott, James B., International law, Chairman, $7: 485$; Legal nature of international law, $7: 485-93$.

Scott, William B., Paleontology, Chairman, $4: 551$.

Secondary qualities, Physical reality of, Montague, $1: 259-60$.

Sedgwick, William T. Relations of public health science to other sciences, $6: 55-67$.

Seedling stages, Importance of the investigation of, Harris, 5 : 98.

Seidenadel, Charles W., tr., Jastrow, Relations of the urban community to other branches of social science, 7 : 763-74; tr., Weber, Relations of the rural community to other branches of social science, $7: 725-46$.

Selection, Comparison between artificial and natural, de Vries, 5 : 28-40.

Seler, George E., Problems of archeology, 5 : $527-41$.

Seligman, Edwin R. A., Pending problems in public finance, $\boldsymbol{\gamma}:$ : $190-200$.

Semitic languages, 3:69-96; Bibliography, $3: 306$; Relation of Semitics to religion, Craig, 3:69-86; Two Semitic problems, Toy, $3: 87-94$.

Semon, Sir Felix, Relations of laryngology, rhinology, and otology with other arts and sciences, 6 : 449-72. 
Sesquiterpene class of hydrocarbons, Schreiner, 4: 299 .

Sewall, Frank, Civic ideal in the family, 7 : 722 .

Seymour, Thomas D., History of Greece, Rome and Asia, Chairman, $2: 55$.

Shapleigh, A. F., member Committee on Congresses, $1: 4$.

Sharp, F. C., Ethics, Sec'y, 1 : 391.

Shattuck, Frederick C., Internal medicine, Chairman, 6 : 189.

Shaw, Albert, Relations of municipal administration, $7:$ : 419-33.

James B., Linear associative algebra, 1: 531 .

Shear, C. S., Plant pathology, Sec'y, 5 : 147.

Sheldon, Henry C., Contribution of Alexandrianism to New Testament thought, $2: 649$. W. H., Logic, Sec'y, 1: 295.

- Walter L., Bibliography on the social sciences, 7 : 869-70; Social sciences, Chairman, 7 : $661-62$.

Shipley, F. W., Ethnology, Sec'y, 5: 545; Latin language, Sec'y, $3: 177$.

Shorey, Paul, Relations of classical literature to other branches of learning, $3: 370-85$.

Sievers, Eduard, Relation of German linguistics to Indo-German linguistics and to German philology, 3 : 273-85.

Skiff, F. J. V., Administrative Board, 1: 4; Address, $1: 27-28$

Slavic languages, Bibliography, 3 : 305.

Slavic literature, 3 : 511-28; American influences on Slavic literatures, Wiener, $3: 511-19$.

Sloane, William M., Science of history in the nineteenth century, $2: 23-39$.

Small, Albion W., member Committee on Plan and Scope, 1:7; Second Vice-President of the Congress, 1: 12; tr., Ratzenhofer, Problems of sociology, 5 : 815-24.

Smith, Albert W., Relations of mechanical engineering to other branches of engineering, 6: $593-602$.

Munroe, Problems of Roman legal history, $2: 315-28$.

_- Samuel G., The family, Chairman, 7 : 697-98.

- Theobald, Some problems in the life-history of pathogenic micro-organisms, 5 : 21938.

William B., Meaning of the epithet Nazorean (Nazarene), 2 : 616-17.

Smyth, Herbert W., Bibliography on the Greek language, 3 : 308-09; Greek language in its relation to the psychology of the ancient Greeks, 3 : 131-61.

Snow, Marshall S., Commerce and discovery, 2: 195 .

Snyder, Henry, Digestibility of bread, $4: 324$.

Social culture, 8 : $1-462$; in the form of education and religion, Harris, 8 : 1-16.

Social problems, The educated man and the social problems, Swain, $8: 422-31$.

Social psychology, 5: 859-83; Bibliography, 5: 778, 887; Present problems, Ross, 5: 869-82; Province of, Thomas, 5 : 860-68.

Social regulation, 7 : 261-876; Lowell, 7 : 26375.

Social science, 7 : 661-876; Bibliography, 7 : 869-76; Relation of ethics to, Adler, 7 : 66381; Relation of rural community to, Weber, $\boldsymbol{\gamma}:$ 725-46; Relations of the urban community, Jastrow, 7 : 761-74.

Social structure, 5:815-55; Bibliography, 5 : 886, 888; Evolution of social structures,
Ward, 5:842-55; Present problems, Tönnies, $5: 825-41$.

Social tendencies of the industrial revolution, Taylor, 7 : 682-94.

Sociology, 5 : 785-888; Bibliography, 5 : 884888; Concepts and methods, Giddings. 5 : 787-99; Development of, Vincent, 5:80012: Problems of, Ratzenhofer, 5 : 815-24.

Solar eclipse problems, Perrine, $4: 470$.

Solar phenomena, On the distribution of, Ricco, 4: 470 .

Soldan, F. I., The school, Chairman, $8: 89$

Somatology, 5 : 485-509; Individuality of anthropology, Manouvrier, 5 : 485-97; Problems of, Dorsey, 5 : 498-509.

Sombart, Werner, Industrial group, 7 : 791-99. Sonnenschein, Edward A., Bibliography on the Latin language, $3: 310$; Relations of Latin, 3 : 177-90.

Sorley, William R., Relations of ethics, 1 : 391402 .

South America, Bibliography of the history of, $2: 238$.

Spain, Bibliography of the history of, $2: 237$.

Spalding, John L., Development of educational ideas in the nineteenth century, $8: 27-46$.

Speakers and chairmen, 1 : 54-76, 82-84.

Spectra, New method of measuring stellar spectra, Hartmann, 4: 470 .

Spencer, S., Otology and laryngology, $6: 449$

Spheries, Non-Euelidean, Halsted, $1: 587$.

Spitzka, E. C., Somatology, Chairman, 5 : 485. — Edward A., Somatology, Sec'y, 5 : 485 ; tr., Manouvrier, Individuality of anthropo$\log y, 5: 485-97$.

Stahl, John M., Present problems in social science affecting the rural community, 7 : 760.

Starbuck, Edwin D., General religious education, Chairman, 8:271; Religious education without doctrines and seriptures, $8: 294$.

Stare decisis, Doctrine of. Whitney, $7: 636-53$.

Starr, Frederick, Ethnology and its relations to other branches of anthropology, 5 : $545-48$.

Stars, Light of, Pickering, 4: 374-84; On double stars, Aitken, $4: 426$.

Steam engine, Best economy of the piston type at the advent of the steam turbine, Denton, $6: 602$.

Stein, Robert, Proposer international phonetic conference to adopt a universal alphabet, $3: 66$.

Stellar astronomy, Statistical methods in, Kapteyn, 4 : 396-425.

Stellar spectra, Comparative study of, Frost, 4: 470; New method of measuring, Hartmann, $4: 470$.

Stewart, George B., Qualifications and training for the ministry, $8: 326$.

Stieglitz, Julius, Relations of organic chemistry to other sciences, $4: 276-84$.

Stone, Ormond, Astrometry, Chairman, 4: 387; Bibliography on astronomy, $4: 471-74$. Stratton, Samuel W., Physics of matter, 4: 69. Strong, Josiah, Social religious influence, 8 : $457-67$.

Struthers, Joseph, Mining engineering, Sec'y, $6: 633$.

Sulfite of carbon, Healing properties, Coromilas, 6 : 149.

Surfaces of revolution, Some geometrical properties of, Blichfeldt, 1:587.

Surgery, 6 : 307-86; Bibliography, 6 : 530-31; 
Historical relations to medicine, Allbutt, $6: 189-209$; History and development in the past century, Dennis, $6: 307-81$.

Suzuki, Teitaro, Is Buddhism nihilistic ? 2 : 493.

Swain, Joseph, Educated man and social problems, $8: 430-39$.

Sweet, William M., Ophthalmology, Sec'y, $6: 411$.

Switzerland, Bibliography of history of, $2: 237$. Symonds, Thomas W., New barge canals of New York, $6: 590$.

Syria, Bibliography of history of religion of, 2: 654 .

Tarbel], Frank B., Some present problems in the history of Greek sculpture, $3: 605-17$.

Taylor, Alfred E., Relations between metaphysics and the other sciences, $1: 227-45$.

Graham, Social tendencies of the industrial revolution, $7: 682-94$.

Teacher, Professional training of, in France, Chabot, 8 : 176-91.

Technical chemistry, $6: 671-712$; Historical development of, in the United States, Benjamin, 6:701-12: Relation to human progress, Wiley, 6 : 700-01; Relations to other sciences, Munroe, 6 : 671-85; Some present problems, Walker, $6:$ 686-99.

Technology, 6 : 533-741; Bibliography, 6 : 739-41; Fundamental conceptions, Bovey, 6 : 535-51; Present problems, Haupt, 6 : 571-90.

Terrestrial magnetism, Present problems, Bauer, 4 : 750-56.

Terry, R. J., Human anatomy, Sec'y, 5 : 359.

Tessier, Prof., Some new studies of the pathology, diagnosis, and special complications of the abdominal aorta, $6: 149$.

Testament, New, see New Testament; Old, see Old Testament.

Textual criticism, Some questionable tendencies, Elmer, 3 : 202.

Thalassema mellita, Artificial parthogenesis, Lefevre, $5: 356$.

Thayer, William S., Problems of internal medicine, $6: 210-22$.

Theology, Teaching of, Hall, $8: 293-305$.

Theory of education, Present problems, Brown, $8: 64-82$.

Theosophy, Brahmanical riddles and its origin, Bloomfield, 2 : 481-92.

Therapeutics and pharmacology, $6: 153-85$; Problems of, Brunton, 6:170-84; Relations to other sciences in the nineteenth century, Liebreich, $6: 153-69$.

Thomas, M. C., The college, $8: 133-50$.

William $\ddot{H}$., Individualism vs. law, $7: 653$.

- William I., Province of social psychology, 5 : 860-68.

Thomson, Elihu, member Committee on Plan and Scope, $1: 7$.

Titchener, Edward B., Problems of experimental psychology, $5:$ 674-90.

Tittman, O. H., On the accuracy obtained in geodetic astronomy, $4: 426$.

Todd, Henry A., Bibliography on Romance philology, 3:311; Present problems of Romance philology. $3: 256-70$.

Tönnies, Ferdinand, Bibliography of social culture, $5: 886$; Present problems of social structure, 5 : 825-41.

Tombo, Rudolph, tr., Sievers, Relations of German linguistics, $3: 273-85$.

Tomkins, Floyd W., Bibliography on religious work, 8: 471; Religious work, 8 : 365-75.
Township government in Indiana, Fiske, 2 : 195.

Toy, Crawford H., Bibliography on Semitic languages, 3 : 306; Two Semitic problems, $3: 87-94$.

Tozzer, A. M., A few survivals of ancient Maya rites in Yucatan and Chiapas, $5: 571$.

Transportation, 7 : 71-112; Bibliography, 7 : 256; Philippovich, 7 : 71-94 ; Problems of, Ripley, 7 : 95-112.

Treleare, William, Plant morphology, Chairman, $5: 61$.

Trenholme, N. M., Communication relative to the English monastic towns, $2: 138$.

Troeltsch, Ernst, Main problems of the philosophy of religion : psychology and the theory of knowledge in the science of religion, 1: 275-88.

Trowbridge, Augustus, Physics of ether, Sec'y, $4: 105$.

Trueblood, Benjamin F., An international advisory congress, $7: 549$.

Tuberculosis, Behavior of native Japanese cattle in regard to, Kitasato, $6: 137-48$.

Tucker, Henry S., Constitutional law, Chair$\operatorname{man}, 7: 551$

Tufts, James H., Esthetics, Chairman, 1 : 417.

Tummel, George F., Transportation, Sec'y, $7: 71$.

Turbine, Best economy of the piston steam engine at its advent, Denton, $6: 602$.

Turkey, Bibliography of history of, $2: 237$.

Turner, Frederick J., Problems in American history, 2 : 183-94.

- Herbert H., Relations of photography to astrophysics, $4: 429-45$.

Tutuila, Naval observatory in, Chester, $4: 426$.

United States, Bibliography of history of, 2 : $237-38$.

University, $8:$ 159-91; Present problems, Perry, $8: 159-75$.

Urban community, $7: 761-88$; Problems, Wuarin, 7:775-88; Relations to other branches of social science, Jastrow, $7: 763-$ 74.

Urethral dislocation in hypospadias, Beck, $6: 382$.

Urn-burial within the limits of the United States, Moore, $5: 542$.

Uterus, Importance of an early diagnosis in cancer of, Sampson, $6: 408$.

Utilitarian sciences, 6:1-7:258; Utilitarian science, Jordan, 6 : 3-20.

Van Dyke, John C.. Development of the history of art, $3: 577-88$.

Van Hise, Charles R., Problems of geology, 4 : 525-48.

Van't Hoff, J. H., see Hoff, J. H. Van't.

Variables, complex, in space of four dimensions, Manning, 1 : 587.

Variations, Calcidus of, Bliss, 1 : 587.

Vector analysis, Exponential notation in, Macfarlane, 1: 622 .

Vegetable pathology an economic science, Waite, $5: 165-73$.

Velocity of light, Electromagnetic theory and, Eddy, $1: 622$.

Verworn, Max, Relation of physiology to other sciences, $5: 403-15$

Vincent, George E., Development of sociology, $5: 800-12$.

J John H., Religion, Chairman, 8 : 243. 
Virgil's relation to Græco-Roman art, Fairclough, $3: 398$.

Votaw, Clyde W., New Testament, Sec'y, 2 : 567; Oxyrhynchus sayings in relation to the gospel-making movements of the first and second centurjes, 2: 616; Religious influence, personal, Sec'y, 8: 396; Religious influence, social, Sec'y, $8: 429$.

Vries, Hugo de, Comparison between artificial and natural selection, $5: 28-40$.

Waddell, John A. I.., Relations of civil engineering to other branches of science, 6 : $555-70$.

Waite, Merton B., Vegetable pathology an economic science, 5 : 165-73.

Waldeyer, Wilhelm, Relations of anatomy to other sciences, $5: 361-77$.

Walker, B. E., Money and credit, Chairman, 7 : 151 .

- William H., Some present problems in technical chemistry, 6:686-99.

Wandering Jew: Ahasver in der Kunstdichtung, Heller, 3 : 508.

Ward, Henry B., Bibliography on bacteriology, animal morphology, embryology, comparative anatomy, human anatomy, and physiology, 5 : 437-42 ; Comparative anatomy, Sec'y, $5: 323$.

- James. Present problems of general psychology, $5: 637-52$.

Lester F., Bibliography on social science, 5 : 888; Evolution of the social structure, $5: 842-55$

Watson, John B., Suggested method in comparative psychology, $5: 775$.

Weber, Max, Relations of the rural community to other branches of social science, 7: 725-46.

Webster, Arthur G., Applied mathematics, Chairman, 1: 591; Physics of the electron, Chairman, $4: 121$.

John C., Some fundamental problems in obstetrics and gynecology, $6: 389-407$.

Welch, Wm. H., member Committee on Plan and Scope, 1: 7 .

West, Andrew F., Classical literature, $3: 369$

Wheeler, Benjamin I., Progress of the history of language during the last century, 3 : 17-28.

- H. J., Agriculture, Chairman, $6: 715$.

Whitlock, Herbert P., Bibliography on geology and paleontology, 4: 757-59.

White, Henry S., Mathematics, Chairman, $1: 455$.

1- Horace, Bibliography on money and credit, $7: 258$; Our monetary equilibrium, $7: 151-60$

-William A., Psychiatry, Chairman, 6 : 243.

Whitman, Charles O., Problem of the origin of species, $5: 41-58$.

Whitney, Edward B., Doctrine of stare decisis, $7: 636-53$

-W. R., Physical chemistry, Sec'y, 4 : 303.
Whittle, G. M., Educational theory, 8: 49.

Wiener, Leo, American influences in the Slavic litcratures, 3 : 511-19.

Wiesner, Julius, Development of plant morphology under the influence of the other sciences, 5 : 103-24.

Wigmore, John H., Problems of to-day for the history of the common law, $2: 350-64$.

Wiley, Harvey W., Relation of technical chemistry to human progress, 6:700-01; Technical chemistry, Chairman, $6: 671$.

Willett, Herbert L., Professional religious education, Sec'y, 8: 301; Some phases of professional religious education, $8: 326$.

Williams, R. D., Bibliography on psychology, $5: 776-79$

Willoughby, W. W., Bibliography on political philosophy, $7: 451$; Political philosophy, $7: 309-25$

Wilson, George G., Problems of political theory, $7:$ 326-38.

Woodrow, Variety and unity of history, 2 : 3-20.

Wines, Frederick H., New criminology, $\boldsymbol{y}$ : 851-68.

Wood, Flameless, Sadtler, 6: 700.

Woodbridge, Frederick J. E., Field of logic, 1 : $313-30$.

Woods, J. H., tr., Hensel, Problems of ethics, 1: 403-14; tr., Troeltsch, Main problems of the philosophy of religion, $1: 275-88$.

Woodward, Arthur S., Relations of paleontology to other branches of science, $4: 551-65$. - Robert S., Unity of physical science, 4: 3-14.

Woodworth, R. S., Experimental psychology, Sec'y, $5: 655$; tr., Moissan, Inorganic chemistry: its relations with the other sciences, 4 : 243-57; tr., Sauer, Influence of American literature on German literature, $3: 477-97$.

Woolley, Mary E., Place of the college in the great educational movement, $8: 155-56$.

Wright, John H., Present problems of the history of classical literature, $3: 386-98$.

Wuarin, Louis, Problems of the urban community. $7: 775-88$.

Wyman, Walter, Public health, Chairman, 6 : 53-54.

Yerkes, R. M., Comparative and genetic psychology, Sec'y, 5 : 693; tr., Delage. Comparative anatomy and the foundations of morphology, 5: 336-55; tr., Giard, Present tendencies of morphology and its relation to other sciences, 5 : 158-82; tr., Ostwald, On the theory of science, $1: 333-52$.

Zenos, Andrew C., New Testament, Chairman, 2: 567-68.

Zirkel, Ferdinand, Bibliography on petrology and mineralogy, $4: 760-61$; Relations existing between petrography and its related sciences, $4: 591-603$.

Zwaardemaker, H., Vestimmung der Gehörschärfe mittelst Flüstersprache, $6: 472$. 



\section{CONTENTS OF THE SERIES}

Volume I. History of the Congress; The Scientific Plan of the Congress; Introductory Address; Department of Philosophy (6 sections); Department of Mathematics (3 sections).

Volume II. Department of Political and Economic History (6 sections); Department of History of Law (3 sections); Department of History of Religion (5 sections).

Volume III. Department of History of Language (8 sections); Department of History of Literature (7 sections); Department of History of Art (3 sections).

Volume IV. Department of Physics (3 sections); Department of Chemistry (4 sections); Department of Astronomy (2 sections); Department of Sciences of the Earth (8 sections).

Volume V. Department of Biology (11 sections); Department of Anthropology (3 sections); Department of Psychology (4 sections); Department of Sociology (2 sections).

Volume VI. Department of Medicine (12 sections); Department of Technology (6 sections).

Volume VII. Department of Economics (6 sections); Department of Politics (5 sections); Department of Jurisprudence (3 sections); Department of Social Science (6 sections).

Volume VIII. Department of Education (5 sections); Department of Religion (6 sections). 




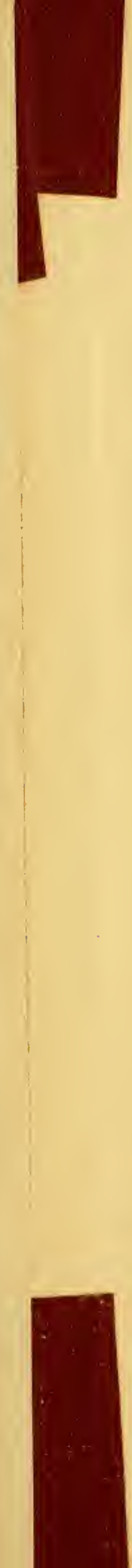
